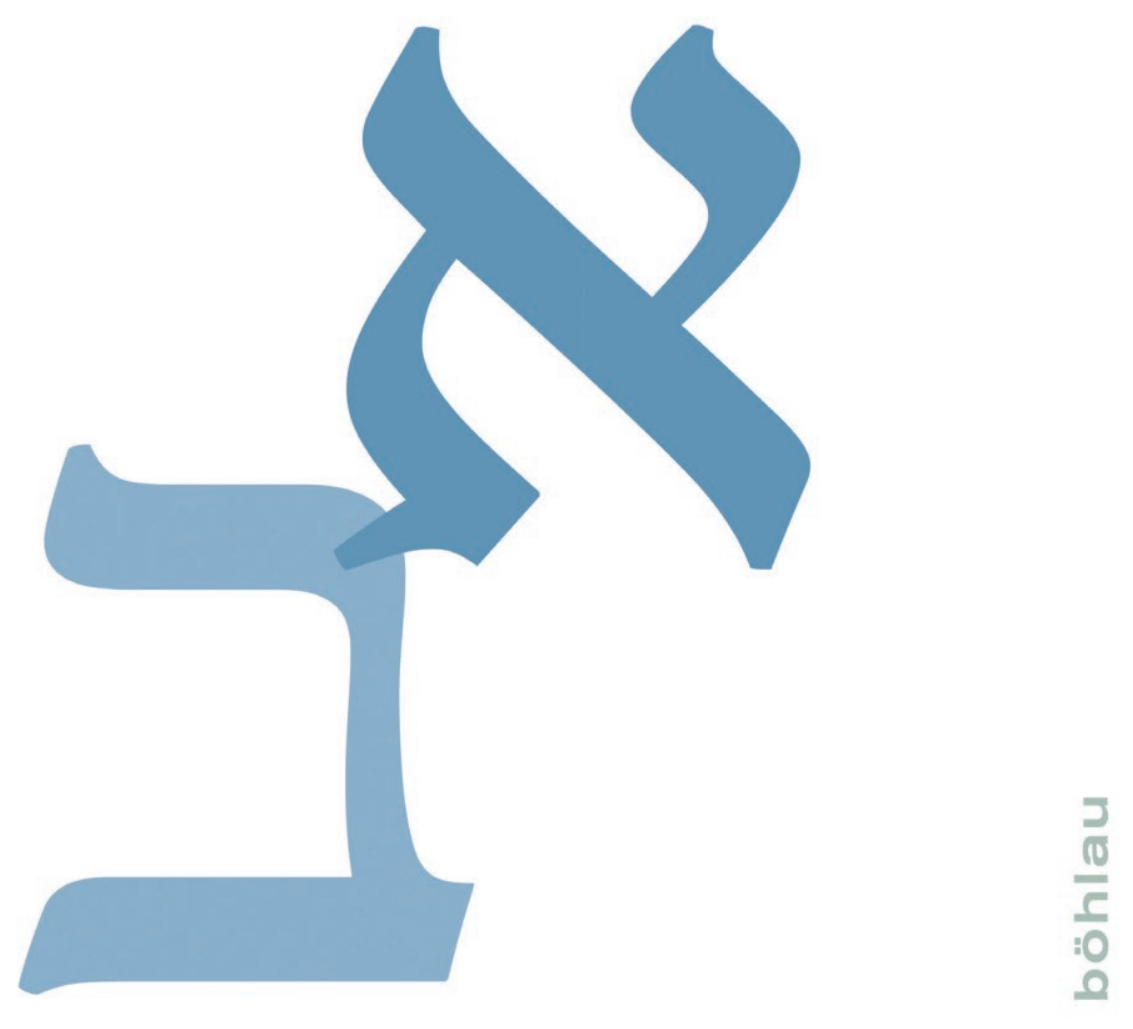

\title{
DER „JÜDISCH-CHRISTLICHE“ DIALOG VERÄNDERTE DIE THEOLOGIE
}

EIN PARADIGMENWECHSEL AUS EXPERTINNENSICHT 
böhlau 

Edith Petschnigg / Irmtraud Fischer (Hg.)

\section{Der ,jüdisch-christliche“ Dialog veränderte die Theologie}

Ein Paradigmenwechsel aus ExpertInnensicht

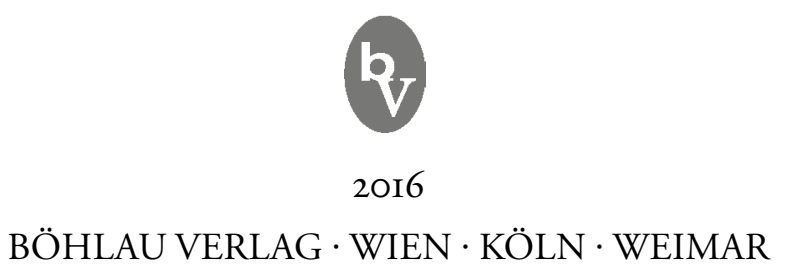




\section{Veröffentlicht mit Unterstützung des \\ Austrian Science Fund (FWF) (PUB 293-V24)

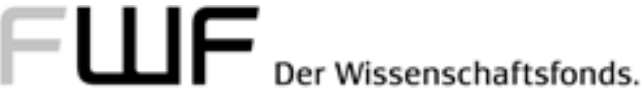

Ein Forschungskolloquium im Rahmen des FWF-Projektes „Die Hebräische Bibel im ,jüdisch-christlichen` Dialog in Österreich und Deutschland nach $1945^{\prime \prime}$

Bibliografische Information der Deutschen Nationalbibliothek:

Die Deutsche Nationalbibliothek verzeichnet diese Publikation in der Deutschen Nationalbibliografie; detaillierte bibliografische Daten sind im Internet über http://portal.dnb.de abrufbar.

Umschlagabbildung: Simone Lindner, Universität Graz

(C) 2016 by Böhlau Verlag GesmbH \& Co.KG, Wien Köln Weimar

Wiesingerstraße I, A-ıoıo Wien, www.boehlau-verlag.com

Alle Rechte vorbehalten. Dieses Werk ist urheberrechtlich geschützt.

Jede Verwertung außerhalb der engen Grenzen des Urheberrechtsgesetzes ist unzulässig.

Korrektorat: Wolfgang Fink, Graz

Einbandgestaltung: Michael Haderer, Wien

Satz: Bettina Waringer, Wien

Druck und Bindung: Dimograf, Bielsko Biala

Gedruckt auf chlor- und säurefreiem Papier

Printed in the EU

ISBN 978-3-205-7967I-8 
Für Prof. Dr. Erika Horn

Gründerin und Motor

der Grazer „jüdisch-christlichen“ Bibelwochen

im Bildungshaus Mariatrost 



\section{Inhalt}

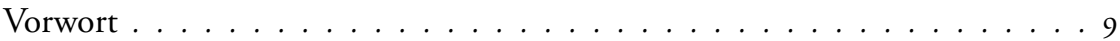

Hinführung zum Thema.

Der ,jüdisch-christliche“ Dialog veränderte die Theologie

Edith Petschnigg und Irmtraud Fischer . . . . . . . . . . . . . . . . . . . . . . II

Historische Aspekte einer Dialogkultur zwischen

Judentum und Christentum

Günter Stemberger. . . . . . . . . . . . . . . . . . . . . . I8

Notizen zur jüdisch-christlichen Begegnung im

Kontext judaistischer Forschung

Gerhard Langer . . . . . . . . . . . . . . . . . . . . . . . . . . 29

Das AT im christlich-jüdischen Dialog aus judaistischer Sicht

Johann Maier . . . . . . . . . . . . . . . . . . . . . . . . .45

Das Vorverständnis hinterfragen

Veränderungen alttestamentlich-exegetischer Zugänge aus der

lebensweltlichen Begegnung mit dem Judentum

Erhard Blum . . . . . . . . . . . . . . . . . . . . . . . . . . . . .58

Theologische und hermeneutische Inspirationen durch den

jüdisch-christlichen Dialog

Ein persönlicher Blick

Gerlinde Baumann . . . . . . . . . . . . . . . . . . . . I I

Vom „Alten Testament“ zu einem Buch mit Eigenwert.

Stationen von Erfahrungen mit Leseweisen der Bibel Israels

Johannes Marböck . . . . . . . . . . . . . . . . . . . . . . . . . . . . . . . . .8I 
Von der Wurzel getragen.

Feministische Exegese und Jüdisch-Christliches

Gespräch in biographischer Brechung

Marie-Theres Wacker

Nicht im Kontrast zum Judentum, sondern in seinem Kontext:

zum Verstehen des Neuen Testaments

Klaus Wengst . . . . . . . . . . . . . . . . . . . . . . . . . . II2

Erfahrungen im jüdisch-christlichen Dialog

Hubert Frankemölle . . . . . . . . . . . . . . . . . . . . . . . . . . I24

Der eine Gott der Bibel als Subjekt und Adressat christlicher Liturgie.

Zur Neuformatierung der Feiern des Glaubens und ihrer Theologie

durch den jüdisch-christlichen Dialog

Peter Ebenbauer. . . . . . . . . . . . . . . . . . . . . . . . . . . . . . . . . I48

Das neue „Gotteslob“ (2013) und die Hebräische Bibel.

Ein kritischer Durchblick

Albert Gerhards . . . . . . . . . . . . . . . . . . . . . . . . . . . . . . . . . 164

Hat infolge des Christlich-Jüdischen Dialogs ein Paradigmenwechsel in Kirche und Theologie stattgefunden?

Bertold Klappert. . . . . . . . . . . . . . . . . . . . . . . . . . . . . . . . I73

Kirche ohne Judentum?

Eine Vergewisserung zur Präsenz des Jüdischen in der ökumenischen

Theologie

Hans Hermann Henrix . . . . . . . . . . . . . . . . . . . . . . . . . . . . . 202

Von Julius Wellhausen bis Joseph Ratzinger

Simon Lauer . . . . . . . . . . . . . . . . . . . . . . . . . . . . . . . . . . . . . 225

Kirche und Judentum

Von Papst Benedikt XVI. zu Papst Franziskus

Josef Wohlmuth . . . . . . . . . . . . . . . . . . . . . . . . . . . . . . . . . 239

Verzeichnis der Autorinnen und Autoren . . . . . . . . . . . . . . . 256

Literaturverzeichnis. . . . . . . . . . . . . . . . . . . . . . 258 


\section{Vorwort}

Wir haben eine Behauptung als Titel unserer Tagung gesetzt: Der ,jüdisch-christliche" Dialog hat die Nachkriegs-Theologie bis in die Neunzigerjahre verändert, davon sind wir überzeugt. Ob er heute auch noch die Kraft dazu hat, sind wir nicht mehr so gewiss. Die christliche Theologie der zweiten Generation nach der Schoah befand die Begegnung mit dem Judentum als Notwendigkeit - heute wird eher der Dialog mit dem Islam als gesellschaftliches Postulat gesehen: Verständlich, in Anbetracht der Zusammensetzung unserer multiethnischen mitteleuropäischen Gesellschaften, aber unverständlich, dass damit der Dialog mit dem Judentum immer mehr ins Hintertreffen gelangt.

Die Grazer Bibelwoche wurde im Jahr 2007 ersatzlos abgeschafft. Zeitgeist? Sicher lag dies am - ohnedies im Lebenskontinuum sehr späten - Rückzug jener Frau, der wir diese Tagung gewidmet haben: Dr. Erika Horn. Sie ist die Nestorin des Dialogs des Christentums mit dem Judentum in der Steiermark, sie hat die „Österreichische Christlich-Jüdische Bibelwoche" in Mariatrost, wo während der Tagung der Vortrag von Hr. Henrix stattfand, gegründet und in der offenen Form am Leben gehalten. Ihre Persönlichkeit hat ein Zugehen aufeinander gerade deswegen ermöglicht, weil der Dialog nicht - wie an manch anderen Orten in deutschen Landen - auf Verdrängen oder Schönreden gegründet war, sondern von christlicher Seite auf offenes Bekenntnis. Auf offenes Bekenntnis zu einer Nazi-Jugend und zum Entsetzen darüber, was dieses Terrorregime bewirkt hat und man nichts oder zu wenig dagegensetzte. Dr. Erika Horn, der aufgrund ihrer Verdienste der Berufstitel Professor verliehen wurde, konnte leider an der Tagung nicht mehr teilnehmen. Sie ist in ihrem neunten Lebensjahrzehnt leider gesundheitlich derart angeschlagen, dass sie nur ihr großes Interesse daran bekunden konnte. Es war uns ein Bedürfnis, ihr die Tagung und den Tagungsband zu widmen, auch, um Frauenarbeit sichtbar werden zu lassen, wo meist nur von Verlautbarungen der Kirchenoberen die Rede ist.

Diese Publikation veröffentlicht eine hochkarätig besetzte Tagung, die im Kontext eines FWF-Projektes stattfand, das unter der Leitung von Irmtraud Fischer die „jüdisch-christlichen" Bibelwochen und den Einfluss des Dialogs auf die theologischen Wissenschaften erforscht. Es wird von Edith Petschnigg, einer Historikerin, die ein Theologiestudium nachgezogen hat und deren Diplomarbeiten beide publiziert sind, erarbeitet und wurde durch eine weitere Tagung zum Thema „Hat 
der ,jüdisch-christliche` Dialog Zukunft? Gegenwärtige Aspekte und zukünftige Perspektiven in Mitteleuropa", die in Kooperation mit Gerhard Langer am Institut für Judaistik im März 20I5 in Wien stattgefunden hat, abgeschlossen.

Die Tagung hätte ohne vielfältige finanzielle Unterstützung nicht stattfinden können: Wir bedanken uns beim Referat für Wissenschaft und Forschung des Landes Steiermark, beim Vizerektor für Forschung und Nachwuchsförderung der Karl-Franzens-Universität Graz, Univ.-Prof. Dr. Peter Scherrer, für die Förderung des Forschungskolloquiums sowie beim Österreichischen Wissenschaftsfonds (FWF), der die Durchführung des Forschungsprojektes inklusive der Projekttagung ermöglicht hat. Wir danken überdies dem Böhlau Verlag für die Aufnahme der Publikation in sein Verlagsprogramm, und last not least den Autorinnen und Autoren dieses Bandes sowie Elke Handl für die organisatorische Hilfe bei der Durchführung der Tagung.

Edith Petschnigg und Irmtraud Fischer 


\section{Hinführung zum Thema \\ Der ,jüdisch-christliche“ Dialog veränderte die Theologie \\ Edith Petschnigg und Irmtraud Fischer}

Die Geschichte von Judentum und Christentum war über weite Strecken eine Unheilsgeschichte, geprägt von einem jahrhundertelangen christlichen Antijudaismus mit oftmals gewalttätigen Auswüchsen. Die Hebräische Bibel wurde als „Altes Testament" christlicherseits vereinnahmt, das Judentum als Gottesvolk enteignet, Israel als durch die Kirche abgelöst betrachtet. Der Weg zur Rückbesinnung auf die jüdischen Wurzeln des christlichen Glaubens war ein langer, langsam beschrittener und für das Judentum immer wieder mit Verfolgung und Tod gepflasterter Weg. Eine Brücke über den „theologischen Rubikon “1 (Pinchas Lapide, 1922-1997) war lange Zeit nicht in Sicht.

Neunzehn Jahrhunderte sind Juden und Christen nebeneinander durch die Welt gegangen. An Seitenblicken hat es wahrlich nicht gefehlt, aber zu dialogischen Gesprächen ist es nicht gekommen - und hat es freilich auch nicht kommen können. ${ }^{2}$

Diese Bilanz zog der jüdische Religionshistoriker und -philosoph Hans Joachim Schoeps (1909-1980) in seinem 1937 unter Ausschluss der Öffentlichkeit in Deutschland erschienenen Werk ,Jüdisch-christliches Religionsgespräch in neunzehn Jahrhunderten". ${ }^{3}$ Erste Ansätze eines beginnenden gleichberechtigten Gesprächs zwischen jüdischen und christlichen Einzelpersönlichkeiten nahm Schoeps erst zu Beginn des 20. Jahrhunderts wahr, wie etwa zwischen Franz Rosenzweig und Eugen Rosenstock oder zwischen Martin Buber und Karl Ludwig Schmidt, um einige der namhaftesten Beispiele zu nennen. ${ }^{4}$ Die herausragende Novität dieser Begegnungen charakterisierte Schoeps folgendermaßen:

\footnotetext{
I Lapide, Pinchas: Juden und Christen. Verleitung zum Dialog, Zürich: Benziger 1976, 8I.

2 Schoeps, Hans Joachim: Jüdisch-christliches Religionsgespräch in neunzehn Jahrhunderten. Mit einem Nachwort von Edna Brocke, Königstein: Jüd. Verl. Athenäum 1984 [Nachdruck der 3. Aufl. München: Ner-Tamid-Verl. 1961; Erstauflage Berlin: Vortrupp-Verl. 1937], I47.

3 Vgl. dazu Lenzen, Verena: Der jüdisch-christliche Dialog heute, in: ZMR 97 (2013) 2032IO, 203.

4 Vgl. Schoeps: Religionsgespräch, I5O.
} 
Im wirklich neuen Gespräch der neuen Zeit, das wirklich etwas Neues ist, ist aus dem „Gegner" ein „Partner“, aus dem „Monolog“ ein „Dialog“ geworden, und die Lehrgehalte des Religionsbekenntnisses werden nicht vorgetragen, sondern müssen verantwortet werden - nämlich durch die Existenz des Sprechers. ${ }^{5}$

Diesen beginnenden Dialogbemühungen war jedoch nur eine kurze Lebensdauer beschieden: Sie wurden erstickt durch den nationalsozialistischen Antisemitismus und die Schoah, in der rund sechs Millionen europäischer Jüdinnen und Juden ermordet wurden. Erst die Tragödie der Schoah markierte für die christliche Theologie schließlich den entscheidenden Wendepunkt in der Definition ihrer Haltung zum Judentum und damit zum ersten Teil ihrer „Heiligen Schriften“, der Hebräischen Bibel.

Es dauerte auch nach 1945 lange, bis den Kirchen und den Theologen, den christlichen Politikern und den christlichen Gemeinden die Augen aufgingen. ${ }^{6}$

Dies stellt Erich Zenger (1939-20I0), einer der profiliertesten Wegbereiter des ,jüdisch-christlichen " Dialogs auf christlicher Seite, fest, denn theologische Neuansätze im Verhältnis von Kirche und Israel sollten erst ab den 1960er-Jahren erfolgen.

Diesen Neuansätzen folgen in dieser Kongresspublikation evangelische, katholische und jüdische Expertinnen und Experten aus unterschiedlichen theologischen Fachrichtungen wie der alt- und neutestamentlichen Bibelwissenschaft, der Liturgiewissenschaft, der feministischen und systematischen Theologie sowie der Judaistik und zeigen Stationen dieses theologischen Wandels auf, dem zweifelsohne die Qualität eines Paradigmenwechsels zukommt.

Eröffnet wird diese interdisziplinäre Publikation mit einem Beitrag aus judaistischer Perspektive. Günter Stemberger widmet sich den historischen Vorläufern einer „jüdisch-christlichen“ Begegnung, wie wir sie heute kennen. Beginnend in der patristischen Zeit zeichnet der Autor exemplarisch wichtige Stationen des „) jüdisch-christlichen“ Wissensaustausches durch die Jahrhunderte bis hin zur Neuzeit nach. In seinem mit „Historische Aspekte einer Dialogkultur zwischen Judentum und Christentum " überschriebenen Artikel zitiert Stemberger sowohl christliche als auch jüdische Autoren, deren Äußerungen einen regen interreligiösen Austausch dokumentieren. Freilich bleibe es eine Frage der Gewichtung, ob man viele dieser Ausführungen eher der antijüdischen christlichen oder, seltener,

5 Schoeps: Religionsgespräch, I49.

6 Zenger, Erich: Das Erste Testament. Die jüdische Bibel und die Christen, Düsseldorf I99I, I4. 
der antichristlichen jüdischen Polemik zurechne als einem auf gleichberechtigten Austausch hinzielenden Dialog. Neugier gegenüber der anderen Religion finde sich jedoch durch alle Jahrhunderte.

Der Beitrag „Notizen zur jüdisch-christlichen Begegnung im Kontext judaistischer Forschung" von Gerhard Langer wirft einige Blitzlichter auf jene Aspekte der „jüdisch-christlichen“ Interaktion, die im Kontext der quellenorientierten judaistischen Forschung diskutiert werden. Ausgehend von einer Würdigung der Verdienste der Wiener judaistischen Forschung unter Kurt Schubert und einem knappen Abriss über die Entwicklung der Disziplin Judaistik, die wie jedes Fach Veränderungen unterworfen ist, leitet der Autor zum Kernthema seines Artikels über, der Geschwisterlichkeit und der Geschwisterrivalität von Judentum und Christentum. Dabei betont er insbesondere unter Rückgriff auf Publikationen von Israel Yuval, Daniel Boyarin und Peter Schäfer, dass das Judentum ebenso vom Christentum beeinflusst worden sei wie umgekehrt.

Der Artikel des emeritierten Kölner Judaisten Johann Maier, „Das AT im christlich-jüdischen Dialog aus judaistischer Sicht“, beleuchtet das biblische Textkorpus im Lichte des jüdischen Verständnisses. Zunächst analysiert er das Offenbarungsverständnis im Judentum, insbesondere im Hinblick auf die drei Teile der jüdischen Bibel, Tora, Nebiim und Ketubim, um sodann exemplarisch auf die Pionierleistung der frühen Wiener Judaistik unter ihrem Begründer Kurt Schubert näher einzugehen. Abschließend bespricht Maier zwei konfliktträchtige Themen des ,jüdisch-christlichen“ Dialogs: die Landverheißungen und die Bundestheologie, Letztere verbunden mit der Schwierigkeit, eine angemessene Bezeichnung für den ersten Teil der christlichen Bibel zu finden.

Die vier folgenden Beiträge schildern aus alttestamentlicher Sichtweise und teilweise sehr persönlicher Perspektive Aspekte bibelwissenschaftlicher Neuansätze in Bezug auf Judentum und Hebräische Bibel. Erhard Blum geht in seinem Artikel „Das Vorverständnis hinterfragen - Veränderungen alttestamentlich-exegetischer Zugänge aus der lebensweltlichen Begegnung mit dem Judentum" exemplarisch drei Sachfragen nach, deren thematischer Zusammenhang darin besteht, dass sie drei Variationen christlich-exegetischer Konzeptionen eines postulierten Endes der Geschichte Israels darstellen. Daran schließt der Autor jeweils Neuformulierungen an: im Hinblick auf die Begriffsdebatte „Spätjudentum“ versus „Frühjudentum“, in Bezug auf Martin Noths Rede vom „Ende Israels“ sowie im Blick auf das Modell einer so genannten Jerusalemer Kultgemeinde in nachexilischer Zeit.

Unter dem Titel „Theologische und hermeneutische Inspirationen durch den jüdisch-christlichen Dialog. Ein persönlicher Blick" nähert sich die Alttestamentlerin Gerlinde Baumann der Thematik an. Sie stellt einen persönlichen Erfahrungs- 
bericht hinsichtlich ihrer Berührungen mit dem „jüdisch-christlichen“ Dialog, die insbesondere aus ihrer Auseinandersetzung mit feministischer Hermeneutik erwuchsen, an den Anfang ihrer Ausführungen und setzt sodann an zwei essentiellen Fragen des „jüdisch-christlichen "Verhältnisses vertiefende Analysen an: am Beispiel der Bibelhermeneutik sowie an der Frage nach Gott und den biblischen Gottesbildern.

Im Beitrag „Vom ,Alten Testament' zu einem Buch mit Eigenwert. Stationen von Erfahrungen mit Leseweisen der Bibel Israels" skizziert Johannes Marböck persönliche Erfahrungen seines Umgangs mit dem Alten Testament. Er zeichnet dabei die Etappen seines beruflichen Werdeganges vor und nach dem II. Vatikanum nach und gibt Einblick in seine Tätigkeit an den Universitäten Linz und Graz (1970 bis 2003), die auch durch sein Engagement in der „Österreichischen Christlich-Jüdischen Bibelwoche" des Bildungshauses Mariatrost gekennzeichnet waren. Schrittweise sei aus all diesen Erfahrungen die Erkenntnis des bleibenden Eigenwerts der Bibel Israels gewachsen.

Antijüdische Tendenzen in der feministischen Theologie und deren Überwindung reflektiert der Beitrag von Marie-Theres Wacker mit dem programmatischen Titel „Von der Wurzel getragen. Feministische Exegese und Jüdisch-Christliches Gespräch in biographischer Brechung ". Aus lebensgeschichtlicher Perspektive geht die Alttestamentlerin den Stationen ihrer Hinwendung zu ,jüdisch-christlichen“ Themen nach, die insbesondere in der Auseinandersetzung mit christlich-feministischem Antijudaismus in der Matriarchatsforschung und der Göttinnenfrage sowie im Bemühen um eine christlich-feministische Exegese im Respekt vor dem Judentum ihren Ausdruck fand. Exemplarisch stellt die Autorin die Lektüre des Esterbuches als zentralen Punkt christlich-feministischer Exegese jenseits allen Antijudaismus in den Mittelpunkt, bevor sie abschließend ihre Sichtweise der palästinensischen Bibelrezeption im Kontext des ,jüdisch-christlichen“ Dialogs erläutert.

In Bezug auf die Auslegung des Neues Testaments plädiert Klaus Wengst in seinem Beitrag „Nicht im Kontrast zum Judentum, sondern in seinem Kontext: zum Verstehen des Neuen Testaments" für eine uneingeschränkte Wahrnehmung der neutestamentlichen Schriften in ihrem jüdischen Entstehungszusammenhang. Fußend auf einem persönlichen, jahrzehntelangen Lernprozess, erwachsen aus dem Gespräch mit Jüdinnen und Juden, zeigt Wengst Anachronismen im Verständnis des Neuen Testaments auf und spricht deshalb konsequenterweise von den frühen Schriften der auf Jesus bezogenen Gemeinschaft. In seinem Beitrag macht er an ausgewählten Punkten beispielhaft deutlich, was die Aufgabe neutestamentlicher Exegese sei: den jüdischen Kontext jener Texte, die später zum Neuen Testament zusammengestellt wurden, aufzuspüren, ihr jüdisches Profil klar herauszustellen 
und dabei zu fragen, wo ihr Ort innerhalb des Judentums war und welche Auseinandersetzungen sie widerspiegeln.

Die „Erfahrungen im jüdisch-christlichen Dialog“ des Neutestamentlers $H u$ bert Frankemölle bereichern die vorliegende Publikation um einen Beitrag, der aus persönlichen Gründen nicht im Rahmen des Forschungskolloquiums präsentiert werden konnte. Der Autor rekapituliert in seinem Artikel ein vielfältiges Ineinander verschiedener Erfahrungsebenen aus fünf Jahrzehnten, die geprägt sind von wissenschaftlicher Theologie, von amtlichen Erklärungen und im Besonderen von theologischen Gesprächen mit Juden, sowohl auf Ortsebene als auch auf nationalem Niveau. Als Auftrag für die Zukunft plädiert Frankemölle dafür, das glaubensmäßig einzigartige Verhältnis des Christentums zum Judentum nicht in Vergessenheit geraten zu lassen.

Aus liturgiewissenschaftlicher Perspektive erweisen zwei Beiträge den postulierten Paradigmenwechsel der christlichen Theologie: Peter Ebenbauer geht in seinem Artikel „Der eine Gott der Bibel als Subjekt und Adressat christlicher Liturgie. Zur Neuformatierung der Feiern des Glaubens und ihrer Theologie durch den jüdisch-christlichen Dialog" den liturgischen Reformen im Gefolge des II. Vatikanums, vor allem in der Rezeption der Konzilserklärung Nostra Aetate, nach. Er rückt explizit drei Fragenkreise, die sich für die Neupositionierung christlicher Liturgie und ihrer Theologie angesichts der fundamentalen Neubesinnung auf den bleibenden Bund Gottes mit seinem Volk Israel als bedeutsam erweisen, in den Mittelpunkt seiner Ausführungen: die Überwindung liturgischer Substitutionstheologie, den liturgischen Umgang mit dem Namen und der Einzigkeit/Einheit Gottes sowie die Vertiefung des dialogischen Grundprinzips christlicher Liturgie durch das Studium jüdischer Liturgie.

Der jüngst erschienenen Neuausgabe des katholischen Gebets- und Gesangsbuchs „Gotteslob“ widmet sich der Beitrag von Albert Gerhards. Ziel dieses Artikels ist es, exemplarisch zu überprüfen, ob die Neugestaltung dem in der theologischen Forschung und in kirchlichen Dokumenten erreichten Standard entspricht. In seinem Beitrag mit dem Titel „Das neue ,Gotteslob“ (2013) und die Hebräische Bibel. Ein kritischer Durchblick“ nimmt der Autor das Gesamtwerk mittels drei Stichproben in den Blick: in Bezug auf Einführungstexte, auf biblische Texte sowie auf Gebete und Gesänge. Dabei stößt er jeweils auf schwerwiegende Mängel. Beispielhaft sei etwa die Feststellung in den Einleitungstexten des Gotteslobs genannt, der zufolge die Hebräische Bibel lediglich Vorläufer und Materiallieferant, das Judentum nur Vorspiel des Christentums offenkundig ohne Gegenwartsrelevanz sei. Wenngleich es auch insgesamt gesehen manche Verbesserung gebe, sei auf eine abermalige Revision des Buches zu hoffen. 
Bertold Klappert wirft mit seinem Artikel „Hat infolge des Christlich-Jüdischen Dialogs ein Paradigmenwechsel in Kirche und Theologie stattgefunden?“ die Frage auf, ob und in welcher Weise sich in der Systematischen Theologie eine tief greifende Veränderung im Sinne einer ökumenisch-theologischen Neupositionierung gegenüber Israel vollzogen habe. Die Beantwortung dieser Frage liefert Klapperts detaillierte Auflistung vor allem protestantischer dogmatischer Entwürfe im Geiste des Respekts vor dem Judentum. Als deren Kennzeichen führt der Autor - um nur einige Aspekte des theologischen Neuanfangs zu nennen - die Absage gegenüber dem traditionellen heidenchristlichen Konzept der "Judenmission“ und die Umkehr von einem inklusiven, ekklesiologisch-christologisch enggeführten dogmatischen Denken an.

Der Suche nach dem Vorkommen des Judentums in Äußerungen der ökumenischen Theologie widmet sich der Beitrag „Kirche ohne Judentum? Eine Vergewisserung zur Präsenz des Jüdischen in der ökumenischen Theologie“ von Hans Hermann Henrix. Unter der Prämisse, dass wahre Ökumene ohne Israel nicht möglich sei, nimmt der Autor, dessen Lebenswerk dem ,jüdisch-christlichen“ Dialog gewidmet ist, Stationen der Integration des Jüdischen in die ökumenische Theologie in den Blick und expliziert Positionen bedeutender Exponenten dieses Paradigmenwechsels. Henrix verweist sowohl auf die Nähe als auch auf die bleibende Differenz der beiden Schwesternreligionen: Während für die zwischenkirchliche Ökumene von „Gemeinschaft“, von koinonia, zu sprechen sei, müsse in der ,jüdisch-christlichen“ Ökumene zurückhaltender vom Ziel einer „Mitgemeinschaft", einer synkoinonia, gesprochen werden.

Simon Lauer spannt unter dem Titel von „Von Julius Wellhausen bis Joseph Ratzinger" einen weiten zeitlichen und inhaltlichen Bogen von der christlichen, insbesondere protestantischen Exegese des 19. Jahrhunderts über die päpstliche Enzyklika Divino afflante Spiritu Pius XII. bis hin zum Nachsynodalen Apostolischen Schreiben Verbum Domini Papst Benedikt XVI. Lauer führt durch mehr als einhundert Jahre christlicher Verhältnisbestimmung zu Judentum und Altem Testament und lässt auch zeitgenössische jüdische Reaktionen exemplarisch zu Wort kommen.

Den jüngsten dogmatischen Entwicklungen in der Katholischen Kirche ist der Beitrag von Josef Wohlmuth gewidmet. Unter dem Titel „Kirche und Judentum von Papst Benedikt XVI. zu Papst Franziskus" geht er den Fragen nach, ob die Weichenstellungen des II. Vatikanums in Nostra Aetate bei Papst Benedikt XVI. ihre entschiedene Weiterführung gefunden haben und ob sich bereits abzeichnet, in welche Richtung Papst Franziskus die Beziehung von Kirche und Judentum vertiefen will. Zunächst beleuchtet Wohlmuth die beiden Jesus-Bücher Joseph 
Ratzingers und geht dabei insbesondere dessen Interpretation des Letzten Abendmahles und des neuen Kultes der Jesusgemeinden als Feier der Versöhnung nach. Wohlmuth stellt sich auch dem Problem der umstrittenen Neuformulierung der Karfreitagsfürbitte für den außerordentlichen Ritus von 2008. Weichenstellende Äußerungen im Geiste des II. Vatikanums von Papst Franziskus zum Verhältnis von Judentum und Christentum führen den Beitrag in die Gegenwart.

Alle in dieser Publikation versammelten Artikel belegen: Der theologische Rubikon ist überschritten. Ein neues ,jüdisch-christliches“ Miteinander ist erwachsen - der Dialog bewirkte Veränderungen in allen Disziplinen der christlichen Theologie. Der vorliegende Band gibt damit Einsichten in die Problemfelder und Entwicklungen des ,jüdisch-christlichen “ Dialogs seit der Nachkriegszeit und erhellt, wie diese die biografische Entwicklung der involvierten Forschenden geprägt haben. Er bietet damit wertvolle Zeitzeugendokumente und ist gleichzeitig ein Stück reflektierter Theologiegeschichte, die den Paradigmenwechsel von antijüdischer Polemik zu respektvollem Dialog nachzeichnet. Freilich wird auch deutlich, dass dieser Wandel der christlichen Sicht des Judentums, dem es entstammt, noch keineswegs flächendeckend in den Disziplinen und schon gar nicht in kirchlicher Praxis vollzogen ist. Ein Stillstand im Dialog zum jetzigen Zeitpunkt würde also einen klaren Rückschritt bedeuten. 


\title{
Historische Aspekte einer Dialogkultur zwischen Judentum und Christentum
}

\author{
Günter Stemberger
}

Um die Frage nach historischen Vorläufern des heutigen Dialogs zwischen Judentum und Christentum sinnvoll behandeln zu können, ist im Voraus zu klären, was wir unter „Dialog“ zu verstehen haben. Wenn man darunter mit Clemens Thoma nur das Gespräch unter Gleichberechtigten und auf selber Augenhöhe versteht, „in bewußter Abgrenzung von den Disputationen, deren Form das christlich-jüdische Gespräch während fast zweier Jahrtausende bestimmte “, ${ }^{1}$ wird man in der jüdisch-christlichen Geschichte nur wenige Situationen finden, in denen wir den Begriff anwenden können. Doch mahnt Thoma selbst an: „Der Dialog leidet an mangelnder Geschichtlichkeit und Freiheit. Aus schlechtem christlichen Gewissen heraus wird die äußerst tragische und vielschichtige jüdisch-christliche Entzweiungsgeschichte oft einspurig nur noch als Drama zwischen christlichen Mördern und jüdischen Opfern gesehen. Die sich durch große Perioden der Geschichte ebenfalls hindurchziehende geistig-religiöse und kulturell-soziale Auseinandersetzung zwischen Juden und Christen wird übersehen". ${ }^{2}$

Wenn wir weniger hohe Idealforderungen an einen Dialog stellen, als Dialog gelten lassen, wo immer beide Seiten bereit sind, dem anderen respektvoll zuzuhören, Informationen anzunehmen und voneinander zu lernen, auch wenn gewöhnlich die Hoffnung mitschwingt, den anderen von den eigenen Auffassungen zu überzeugen, ihn in gewissem Sinn zu bekehren, dann finden wir im Lauf der jüdisch-christlichen Geschichte doch eine Fülle von Situationen, die man als Dialog bezeichnen darf oder die einem solchen zumindest nahekommen. Es geht dabei meist um den Austausch Einzelner in religiösen Fragen, zuweilen (v. a. auf christlicher Seite) bekannter Namen, meist aber um anonyme Personen, von deren Existenz wir nur wissen, weil wir auf der jeweils anderen Seite Kenntnisse von religiösen Positionen oder Schriftauslegungen der Gegenseite feststellen können. Im Einzelfall muss es dabei oft offen bleiben, ob solche parallele Auslegungen auf die je andere Seite reagieren oder unabhängig voneinander zustande gekommen

I Thoma, Clemens: Art. Dialog, in: Petuchowski, Jakob. J. / Thoma, Clemens: Lexikon der jüdisch-christlichen Begegnung, Freiburg: Herder 1989, 69-76, 69.

2 Thoma: Dialog, 74. 
sind, wie dies v. a. Johann Maier für viele rabbinische Texte vermeintlich jüdischer Reaktionen auf christliche Auslegungen argumentiert hat. ${ }^{3}$ Der jüdisch-christliche Austausch von religiösem Wissen setzt auf jeden Fall eine gewisse Interaktion voraus; diese impliziert, solange man nicht einfach auf schriftliche Texte der Gegenseite zurückgreifen kann bzw. auch nicht deren Positionen aufgezwungen bekommt (wie das ab dem Mittelalter v. a. in Spanien immer wieder mit dem Zwang zum Anhören christlicher Predigten geschieht), einen wie auch immer gearteten Dialog. Ein kurzer Gang durch die Geschichte soll im Folgenden einige wichtige Punkte dieses Dialogs aufzeigen, wobei in den meisten Fällen man sehr wohl darüber diskutieren mag, wieweit man hier tatsächlich von Dialog sprechen darf.

\section{Vorislamische Zeit}

Viele der christlichen Schriften aus der patristischen Literatur werden als Adversus Judaeos-Literatur zusammengefasst. ${ }^{4}$ Doch zumindest einzelne dieser Schriften setzen sehr wohl einen wirklichen Dialog voraus, so an erster Stelle Justins Dialog mit dem Juden Tryphon. Auch wenn es ein fiktiver Dialog und Tryphon eine literarische Gestalt ist (die Gleichsetzung mit R. Tarfon ist seit Langem aufgegeben), setzt das Werk doch eine gute Kenntnis jüdischer Bibelauslegung voraus. Zwar meint man vielfach, der Dialog sei gar nicht an Juden, sondern an Heiden gerichtet, doch ist der freundliche Ton auffällig, mit dem Justin durchgehend Tryphon als „mein Freund" anredet und auch Judenchristen, die noch immer an den Gesetzen festhalten, nicht verurteilt, solange sie nicht auch Heidenchristen zu ihrer Auffassung verpflichten wollen. Juden sind ,a real audience and so too must their representative be; they cannot simply be the projection of the ,dark side' or the ,negative' of Christian struggles to establish a secure identity". 5

3 Maier, Johann: Jesus von Nazareth in der talmudischen Überlieferung (EdF 82), Darmstadt: Wissenschaftliche Buchgesellschaft ${ }^{2}$ 1992; ders.: Jüdische Auseinandersetzung mit dem Christentum in der Antike (EdF 177), Darmstadt: Wissenschaftliche Buchgesellschaft 1982.

4 Schreckenberg, Heinz: Die christlichen Adversus-Judaeos-Texte und ihr literarisches und historisches Umfeld (I.-II. Jh.) (EHS.T I72), Frankfurt: Lang ${ }^{3}$ I995; ders.: Die christlichen Adversus-Judaeos-Texte und ihr literarisches und historisches Umfeld (II.-I3. Jh.) mit einer Ikonographie des Judenthemas bis zum 4. Laterankonzil (EHS.T 335), Frankfurt: Lang ${ }^{3}$ 1997; ders.: Die christlichen Adversus-Judaeos-Texte und ihr literarisches und historisches Umfeld (13.-20. Jh.) (EHS.T 497), Frankfurt: Lang I994.

5 Lieu, Judith: Image and Reality: The Jews in the World of the Christians in the Second Century, Edinburg: T \& T Clark 1996, I06, zitiert bei Rokéah, David: Justin Martyr and the Jews (JCP 5), Leiden: Brill 2002, II. 
Origenes hatte während seiner langen Jahre in Caesarea vielfach Gelegenheit und Interesse, mit gebildeten Juden über biblische Texte zu diskutieren. Kontakte waren schon im Rahmen seiner Arbeit an der Hexapla notwendig. Manchmal bringt man R. Hoschaja Rabba direkt in Verbindung mit diesem Projekt (so Dominique Barthélemy) ${ }^{6}$, andere betonen den „virtuellen Dialog " zwischen Origenes und den Rabbinen etwa in der Kommentierung des Hohenlieds (so Ephraim Urbach) ${ }^{7}$. Tatsache ist, dass Origenes selbst wiederholt von Gesprächen mit Juden über biblische Texte spricht; so habe er sich z. B. „mit dem Patriarchen Ioullos und einem von jenen, die bei den Juden den Titel, Weise tragen, über einige Prophezeiungen Gottes beraten " und bei der Gelegenheit erfahren, dass Psalmen ohne Überschrift oder ohne Autorangabe in der Überschrift dem zuzuschreiben seien, der in einem vorausgehenden Psalm als Autor genannt sei. „Und während er davon redete, sagte er zuerst, dreizehn Psalmen seien Mose zuzuschreiben; später erfuhr ich, es seien elf“ ${ }^{\text {‘ }} 8$ Hier bespricht also Origenes ganz sachlich und ohne jede Polemik mit jüdischen Gelehrten biblische Einleitungsfragen und bekommt auch die von ihm gewünschten Informationen.

Eusebius von Caesarea, Zeitgenosse des R. Abbahu, des bedeutendsten rabbinischen Lehrers im frühen 4. Jahrhundert in Caesarea, hat genügend Gelegenheit zu Gesprächen mit Juden gehabt, auch wenn sich das in seinen Schriften nur indirekt durch seine guten Kenntnisse jüdischer Traditionen zeigt, die weit über das aus Origenes rezipierte Wissen hinausgehen. Er wird gemeinhin als Judenfeind bezeichnet. Dagegen hat Jörg Ulrich eine viel differenziertere Beurteilung begründet: „Euseb ist [...] den Juden keineswegs feindlich gesonnen. Er betrachtet sie allerdings als theologische Gegner. Diesen bringt er, anders als bei fast allen anderen seiner theologischen Gegner, hohen Respekt entgegen [...] Euseb kritisiert die Juden theologisch: Immer von neuem und in beinah ermüdenden Argumentationsgängen betont er ihnen gegenüber den christlichen Standpunkt und [...] das

6 Barthélemy, Dominique: Est-ce Hoshaya Rabba qui censura le "commentaire allégorique"? in: Colloques Nationaux du CNRS: "Philon d'Alexandrie", Lyon 1966, Paris: Centre National de la Recherche Scientifique 1967, 45-78; Nachdruck in: Ders.: Études d'histoire du texte de l'Ancien Testament (OBO 2I), Fribourg: Universitätsverlag 1978, I40-I73.

7 Urbach, Ephraim Elimelech: Rabbinic Exegesis and Origenes. Commentaries on the Song of Songs and Jewish-Christian Polemics, in: Studia Hierosolymitana 22 (197I) 247-275; Nachdruck in: Ders.: Collected Writings in Jewish Studies, hg. v. Raphael Brody und Moshe David Herr, Jerusalem: The Hebrew University Magnes Press 1999, 318-345.

8 Origenes: Selecta in Psalmos [Dub.]: fragmenta e catenis, PG I2, I056. Ausführlich zur Thematik Lange, Nicholas R. M. de: Origen and the Jews. Studies in Jewish-Christian Relations in Third-Century Palestine, Cambridge: Cambridge University Press, 1976, 89-IO2. 
christologische Verständnis der jüdischen Heiligen Schriften. Kompromißlos tritt er für den eigenen Wahrheitsanspruch ein. Die Klarheit des eigenen Standpunktes führt bei ihm aber nicht zu einer Mißachtung seiner jüdischen Gegnerschaft".? Auch bei ihm darf man demnach sehr wohl von einem Dialog mit Juden sprechen.

Hieronymus ist in diesem Zusammenhang eher nicht zu nennen; seine Kenntnisse des Judentums sind weithin sekundär, kaum aus direktem Kontakt mit Juden, sondern meist literarisch, aus den Schriften seiner Vorgänger, oder über judenchristliche Informanten vermittelt. ${ }^{10}$

Auf einer breiteren Ebene ist ein verstärkter Austausch zwischen Judentum und Christentum ab Konstantin festzustellen. Die Annahme jüdischer Führer christlicher PilgerInnen lässt sich zwar nicht belegen; doch gibt es viele informelle Gespräche, die einen Austausch von Wissen bewirken, durch den auch ursprünglich jüdische Traditionen, die in Flavius Josephus oder der pseudepigraphen Literatur belegt sind, wieder in das Judentum zurückfließen (das belegen rabbinische Texte ab dem frühen 5. Jahrhundert, die auf einmal früher rabbinisch nie bezeugte Kenntnisse zeigen). In diesem Rahmen befasst man sich natürlich auch mit dem Schriftverständnis der jeweils anderen Seite. Zum Teil wird dieser Wissensaustausch auch durch ChristInnen vermittelt, die immer noch gerne die Synagoge besuchen, wie Kirchenväter wiederholt beklagen.

Auf rabbinischer Seite finden wir eine Vielzahl von Belegen, wo einzelne Rabbinen im Austausch mit Minim stehen, die man im Palästina des 4. Jahrhunderts wohl meist als Christen verstehen kann, und über verschiedene biblische Texte diskutieren, etwa die Schöpfungserzählungen der Genesis, die fortdauernde Geltung biblischer Gebote wie Sabbat, Beschneidung, Reinheits- oder Speisegesetze oder aber auch die Erwählung Israels. Man kann hier natürlich den polemischen Aspekt hervorheben, doch Tatsache ist, dass man miteinander redet und dabei die jeweils eigenen Positionen schärft und besser zu begründen gezwungen ist. ${ }^{11}$ Eine Erzählung im babylonischen Talmud bringt das schön zum Ausdruck:

9 Ulrich, Jörg: Euseb von Caesarea und die Juden. Studien zur Rolle der Juden in der Theologie des Eusebius von Caesarea (PTS 49), Berlin: de Gruyter, 1999, 238.

IO Stemberger, Günter: Hieronymus und die Juden seiner Zeit, in: Ders.: Judaica Minora II. Geschichte und Literatur des rabbinischen Judentums (TSAJ I38), Tübingen: Mohr Siebeck 20I0, 66-8I.

II Die Literatur dazu ist umfangreich. Drei neuere Titel: Teppler, Yaakov Y.: Birkat haMinim. Jews and Christians in Conflict in the Ancient World (TSAJ I2O), Tübingen: Mohr Siebeck 2007; Schremer, Adiel: Brothers Estranged. Heresy, Christianity, and Jewish Identity in Late Antiquity, Oxford: Oxford University Press 2oro; Labendz, Jenny R.: Socratic Torah. Non-Jews in Rabbinic Intellectual Culture, Oxford: Oxford University Press 2013. 
R. Abbahu lobte R. Safra gegenüber den Minim, er sei ein großer Mann. Da erließen sie ihm für dreizehn Jahre die Steuer.

Eines Tages trafen sie ihn an und sagten zu ihm: Es steht geschrieben: „Nur euch habe ich erkannt unter allen Stämmen der Erde; darum ziehe ich euch zur Rechenschaft für all eure Vergehen“ (Am 3,2). Wenn jemand zornig ist, lässt er das an seinem Freund aus?

Er schwieg und konnte nichts antworten. Da banden sie ihm ein Tuch um den Hals und quälten ihn. Es kam R. Abbahu und traf sie an. Er sagte zu ihnen: Warum quält ihr ihn? Sie entgegneten ihm: Hast du uns nicht gesagt, dass er ein großer Mann ist? Dabei kennt er nicht einmal diesen Vers!

Er antwortete ihnen: Was ich euch sagte, bezieht sich auf die mündliche Tradition. Von Schrift(kenntnis) habe ich nichts gesagt.

(Sie fragten:) Und was macht den Unterschied, dass ihr sie kennt? Er sagte ihnen: Wir sind häufig mit euch beisammen. Daher haben wir es auf uns genommen und studieren die Schrift; jene aber, die nicht oft mit euch zusammenkommen, studieren sie nicht.

Da sagten sie ihm: Dann sag du uns (die Antwort)!

Er antwortete ihnen: Ich möchte euch ein Gleichnis erzählen. Wem gleicht die Sache? Einem Mann, der zwei Menschen Geld leiht. Einer ist sein Freund, der andere sein Feind. Von seinem Freund fordert er es nach und nach zurück, von seinem Feind alles auf einmal. So auch der Heilige, gepriesen sei er (bab. Talmud, Avoda Zara 4a).

Man hat diese Stelle oft zu Unrecht so verstanden, dass es in Babylonien, anders als in Palästina, keine (oder fast keine) jüdisch-christlichen Begegnungen gab, bei denen man über die Auslegung von Schriftversen diskutierte. Dabei unterschätzt man die Ausbreitung des Christentums auch im jüdischen Siedlungsbereich Babyloniens und den jüdisch-christlichen Wettstreit v. a. auch um die persische Winterhauptstadt Ktesiphon und das angrenzende Machoza. Geoffrey Herman hat deutlich gemacht, wie sehr sich die Einrichtungen des jüdischen Exilarchats und des christlichen Katholikats weithin parallel entwickelten, ${ }^{12}$ Shai Secunda den von der persischen Regierung geförderten Austausch religiöser Schriften und religiösen Wissens im be abedan (cf. bShabbat iı6a u. ö.) analysiert. ${ }^{13}$ Von daher betont

I2 Herman, Geoffrey: A Prince without a Kingdom. The Exilarch in the Sasanian Era (TSAJ I50), Tübingen: Mohr Siebeck 2012.

I3 Secunda, Shai: The Iranian Talmud. Reading the Bavli in Its Sasanian Context (Divinations: Rereading Late Ancient Religion), Philadelphia: University of Pennsylvania Press 20I4, 5I-63. 
Michal Bar-Asher Siegal, ${ }^{14}$ es habe sehr wohl einen regen Austausch auch in Babylonien gegeben, wenn auch nicht unbedingt in der Diskussion von Bibeltexten, sondern allgemeiner zu religiösen Fragen, v. a. in der Begegnung mit dem blühenden syrisch-persischen Mönchtum, das zum Teil dem Studium der biblischen Schriften eher kritisch gegenüberstand, deren Apophthegmata Patrum aber eine Fülle von Parallelen zum babylonischen Talmud, im Einzelfall vielleicht sogar literarische Querbeziehungen aufweisen.

\section{Islamisch-gaonäische Periode}

Für die frühe islamische Periode möchte ich nur auf zwei Punkte verweisen. Die Regierungszeit von Harun al-Rashid im frühen 9. Jahrhundert gilt allgemein als eine Phase regen kulturellen und religiösen Austausches, in der man in Bagdad die verschiedensten religiösen Traditionen kennenlernen konnte, vieles aus fremden Traditionen auch übernahm und für eigene Interessen verarbeitete. Interessant sind in diesem Zusammenhang vielfältige Übernahmen christlicher Traditionen im Judentum - bekannt etwa Pesiqta Rabbati 34-37 über den leidenden Messias, im selben Werk auch die Verarbeitung von Traditionen aus der Offenbarung des Neuen Testaments, ${ }^{15}$ eine Parodie auf die christliche Lehre der Jungfrauengeburt im Alphabet des Ben Sira (vermischt mit der Erzählung von der Zeugung des Buddha), ${ }^{16}$ oder allgemeiner die Wiederaufnahme vieler Motive aus der pseudepigraphen Literatur und Apokalyptik in den Pirqe de-Rabbi Eliezer. ${ }^{17}$ Auch die Ich-Erzählungen im Seder Eliyahu, einer Schrift aus derselben Zeit, belegen, natürlich literarisch eingekleidet, die Begegnung mit anderen Religionen und das Gespräch mit deren Vertretern.

Das Neue Testament, besonders das Mt-Evangelium, wird in dieser Zeit aber auch direkt jüdisch rezipiert, gegen christliche Ansprüche etwa zur Göttlichkeit

I4 Bar-Asher Siegal, Michal: Early Christian Monastic Literature and the Babylonian Talmud, Cambridge: Cambridge University Press 2013.

I5 Ulmer, Rivka: Psalm 22 in Pesiqta Rabbati: The Suffering of the Jewish Messiah and Jesus, in: Garber, Zev (Hg.): The Jewish Jesus. Revelation, Reflection, Reclamation, West Lafayette: Purdue University Press 2011, I06-I28; dies.: The Contours of the Messiah in "Pesiqta Rabbati", in: HThR Io6 (2013) II5-I44; dies.: The Culture of Apocalypticism. Is the Rabbinic Work "Pesiqta Rabbati” Intertextually Related to the New Testament Book "The Revelation to John"?, in: RRJ I4 (20II) 37-70.

I6 Stern, David: The "Alphabet of Ben Sira" and the Early History of Parody in Jewish Literature, in: Najman, Hindy / Newman, Judith H. (Hg.): The Idea of Biblical Interpretation. Essays in Honor of James L. Kugel (JSJ.S 83), Leiden: Brill 2004, 423-448.

17 Adelman, Rachel: The Return of the Repressed. Pirqe de-Rabbi Eliezer and the Pseudepigrapha (JSJ.S I4O), Leiden: Brill 2009. 
Jesu oder der Geburt Jesu aus einer Jungfrau gelesen und mit biblischen Stellen umfangreich konfrontiert. Dies ist eine jüdische Beschäftigung mit christlichen Schriften, um Kerngedanken des Christentums aus dessen eigenen Quellen zu widerlegen. ${ }^{18}$ Diese Tradition ist zuerst im arabischen „Bericht über die Disputation des Priesters" (Qișșat Mujādalat al-Usquf) bezeugt, wovon es mehrere Redaktionen gibt; die ab II7o bezeugte hebräische Übersetzung Sefer Nestor ha-Komer belegt eine Zwischenform; in ihr sind viele lateinische Zitate des NT hebräisch transkribiert. Früheste Vorformen der Schrift sind schon im 6. Jahrhundert anzusetzen; der Text ist sicher über die Jahrhunderte gewachsen. Da der Verfasser nicht nur das Mt-Evangelium und andere Texte des Neuen Testaments, sondern auch eine Reihe apokrypher christlicher Texte wie z. B. das Protoevangelium Jacobi kennt, ist die Angabe, der Verfasser sei ein zum Judentum konvertierter Christ, plausibel. Die Schrift sammelt v. a. Texte aus den Evangelien, die die Menschheit Jesu betonen, um gegen Jesu Gottheit zu argumentieren, und versucht, christliche Lehren aus dem NT zu widerlegen.

\section{Europäisches Mittelalter}

Der „Bericht über die Disputation des Priesters“ wurde in der hebräischen Version „Sefer Nestor ha-Komer" schnell auch in Europa bekannt. Er wird schon im „Buch der Gotteskriege“" (Sefer Milhamot ha-Shem) zitiert, das um II70 in Südfrankreich oder Spanien geschrieben wurde; über seinen Autor Jacob ben Ruben ist wenig bekannt. Er diskutierte wohl mehrfach mit einem Priester Glaubensfragen; diese Erfahrungen mag der größere Teil des Buches spiegeln, eine Diskussion zwischen dem „Leugner“ und dem „Bejaher der Einheit (Gottes)“. Teile des Mt-Evangeliums übersetzte er aus dem Lateinischen (gesammelt in Kapitel II), um damit systematisch den christlichen Glauben zu kritisieren, und dies wurde eine wichtige Vorlage für spätere polemische Werke.

Aus Frankreich stammt Rabbi Josef ben Nathan (mit Beinamen Official), dessen kurz nach 1260 verfasstes „Sefer Yosef ha-Meqanne“, das „Buch Josefs des Eiferers“, v. a. wegen des Berichts über die Pariser Talmuddisputation von I240 bekannt ist. Der Verfasser hatte mehrfach Gelegenheit zu Diskussionen mit christlichen Theologen und Bischöfen; er konnte Latein und kannte viele kirchliche Texte. Sein Buch polemisiert gegen die christliche Auslegung biblischer Texte, zeigt aber auch

I8 Ochs, Christoph: Matthaeus Adversus Christianos. The Use of the Gospel of Matthew in Jewish Polemics Against the Divinity of Jesus (WUNT 2/350), Tübingen: Mohr Siebeck 2013. Ders. auch zum Folgenden. 
Widersprüche im Neuen Testament auf und argumentiert gegen die Gottheit Jesu, die Trinität und die bleibende Jungfräulichkeit Marias.

Even Bohan (der „Prüfstein“) ist ein polemisches Werk (Erstfassung wohl um 1384, Überarbeitungen 1385 und I405) des spanischen Rabbiners Shem Tov ben Isaak Ibn Shaprut, der mehrfach mit hochrangigen Kirchenmännern disputierte. Er übersetzte als Erster ganz Mt und fügte in die Übersetzung 58 kürzere oder längere Kommentare dazu ein; er betont das Jüdische an Jesus und seiner Lehre und versucht zu zeigen, dass Jesu Gottheit aus Matthäus nicht belegt werden könne.

Die arabische Fassung von „Nestor ha-Komer" ist etwa zeitgleich mit der Spätphase der Talmudredaktion entstanden - ein wichtiges Argument in der Frage, wieweit die Rabbinen des Talmud schon christliche Texte kennen konnten. Den Autoren ging es dabei nicht allein darum, christliche Lehren zurückzuweisen; wichtig war ihnen v. a., vom Christentum angezogenen, später auch zwangsweise zum Christentum bekehrten Glaubensgenossen einen kritischen Umgang mit den ihnen bekannt gewordenen, vielleicht auch attraktiven christlichen Texten zu ermöglichen. Reine Polemik hätte oft nur wenig überzeugt; viel mehr konnte eine weithin wohlwollende Lektüre des Neuen Testaments aus jüdischer Sicht beitragen. Damit haben die hier besprochenen Schriften viele Punkte moderner jüdischer Kommentierung des Neuen Testaments vorweggenommen, aber auch so manche Argumente der christlichen Evangelienkritik seit der Aufklärung.

Man könnte hier als christliches Gegenstück die Talmuddisputationen von Paris (I240) sowie von Barcelona (I263), ebenso die zweite Disputation von Paris (I269) anführen, in denen man die rabbinische Literatur in zunehmendem Maß zur Kenntnis nimmt. ${ }^{19}$ Man hat diese Disputationen wie auch die spätere von Tortosa (I4I3-I4I4) zu Recht als Zwangsdisputationen bezeichnet; von „Dialog“ auch im abgeschwächten Sinn kann hier keine Rede sein. Doch beginnt gerade hier eine umfassendere Wahrnehmung des Judentums, das man nun nicht mehr als bloßes Fossil der biblischen Religion missverstehen konnte. Das Gegenüber in seiner Eigenart besser zu kennen ist sicher eine wesentliche Voraussetzung für jeden weiteren Dialog.

Schon früher, im I2. Jahrhundert, haben die Gelehrten der Schule von St. Victor in Paris jüdische Bibelauslegung bewusst gesucht und geschätzt. Oft wird behaup-

I9 Dazu siehe Chazan, Robert: Barcelona and Beyond. The Disputation of I263 and its Aftermath, Berkeley, Calif.: Univ. of California Press 1992; ders. / Friedman, John / Hoff, Jean C.: The Trial of the Talmud: Paris, I240 (Mediaeval Sources in Translation 53), Toronto: Pontifical Institute of Mediaeval Studies 20I2. Ragacs, Ursula: Die zweite Talmuddisputation von Paris I269 (JudUm 7I), Frankfurt: Lang 200I. Allgemein Novikoff, Alex J.: The Medieval Culture of Disputation. Pedagogy, Practice, and Performance (The Middle Ages Series), Philadelphia: Univ. of Pennsylvania Press 2013, v. a. I72-22I. 
tet, dass Andreas von St. Victor in Troyes Rashbam, den Enkel Rashis, persönlich gekannt habe; doch ist das nicht zu sichern. Jedenfalls hat die Viktorinerschule alles getan, um die Kenntnis des Hebräischen und der zeitgenössischen jüdischen Bibelauslegung in die christliche Welt einzuführen, und damit eine (bei Hieronymus vorgezeichnete) Entwicklung für die eigene Zeit begründet, die über Nikolaus von Lyra dann direkt zu Reformation und Aufklärung führt. ${ }^{20}$

\section{Aufklärung und christliche Hebraisten}

Nur ganz knapp sei noch auf spätere Entwicklungen hingewiesen. Christliche Hebraisten haben seit dem 15 . Jahrhundert beträchtlich zu einer besseren Kenntnis des Judentums und dessen Verständnis beigetragen und waren für ihre Studien grundlegend auf enge Kontakte mit jüdischen Gelehrten oder zumindest Informanten angewiesen. Hier sei nur Giovanni Pico della Mirandola (I463-I494) genannt, der mit dem jüdischen Philosophen Elia del Medigo Hebräisch und Arabisch studierte und sich für seine kabbalistischen Interessen eine Reihe hebräischer Schriften von Flavius Mithridates, einem getauften Juden aus Sizilien, übersetzen ließ. ${ }^{21}$ Johannes Reuchlin (I455-I522) war der bedeutendste frühe christliche Hebraist in Deutschland; Hebräisch hatte er beim jüdischen Leibarzt von Friedrich III., Jacob ben Jechiel Loans, gelernt und sich später stark für die Verteidigung des Talmud eingesetzt.

Doch waren es nicht nur Christen, die sich für jüdische Traditionen interessierten. Auch manche gebildete Juden studierten christliche Schriften und eigneten sich manches daraus auch für ihre jüdischen Interessen an. Als charakteristisches Beispiel sei nur der Mantovaner Arzt Abraham ben David Portaleone (I542-I6I2) genannt, der in seinem enzyklopädischen, am salomonischen Tempel orientier-

20 Berndt, Rainer: The School of St. Victor in Paris, in: Sæbø, Magne (Hg.): Hebrew Bible / Old Testament. The History of its Interpretation. I: From the Beginnings to the Middle Ages (Until I300), Göttingen: Vandenhoeck \& Ruprecht 2000, 467-495; Bunte, Wolfgang: Rabbinische Traditionen bei Nikolaus von Lyra: Ein Beitrag zur Schriftauslegung des Spätmittelalters (JudUm 58), Frankfurt: Lang 1994.

2I The Kabbalistic Library of Giovanni Pico della Mirandola. I: Busi, Giulio / Bondoni, Simonetta M. / Campanini, Saverio (Hg.): The Great Parchment. Flavius Mithridates' Latin Translation, the Hebrew Text, and an English Version. 2: Campanini, Saverio (Hg.): The Book of Bahir. Flavius Mithridates' Latin Translation, the Hebrew Text, and an English Version. 3: Corazzol, Giacomo: Menahem Recanati, Commentary on the Daily Prayers. Flavius Mithridates' Latin Translation, the Hebrew Text, and an English Version. Turin: Aragno 2004; 2005; 2008. 
ten Werk „Heldenschilde“ auch zahlreiche christliche Quellen verwertete. ${ }^{22}$ Die Grenzen zwischen jüdischer und christlicher Welt waren schon länger durchlässig geworden.

Christliche Hebraisten des 17. Jahrhunderts erkannten gegen die traditionelle christliche Verurteilung des Talmud den Wert der rabbinischen Literatur für ein tieferes Verständnis des Neuen Testaments und intensivierten deren Studium, auch da wieder gewöhnlich mit jüdischen Lehrern. Hervorgehoben sei hier allein der Cambridger Theologe John Lightfoot (1602-1675), der das Neue Testament mit Texten aus dem Talmud zu erklären versuchte (Horae Hebraicae et Talmudicae, 6 Bände, Cambridge I658-1678) und damit zu einem wichtigen Vorläufer des bis heute benutzten Kommentars von Paul Billerbeck wurde. ${ }^{23}$ Erwähnt sei auch Johann Jacob Raabe (I710-1798), lange Jahre protestantischer Pfarrer in Ansbach, der die erste deutsche Übersetzung der Mischna veröffentlichte und für seine Arbeit in engen Kontakt zu Moses Mendelssohn trat und von diesem und anderen jüdischen Gelehrten wie etwa Leopold Zunz hoch geschätzt wurde. ${ }^{24}$ Schließlich muss auch Hermann L. Strack (I848-1922) genannt werden, noch heute durch seine Einleitung in Talmud und Midrasch bekannt, ${ }^{25}$ der schon während seines Studiums der Theologie mit dem jüdischen Gelehrten Moritz Steinschneider Kontakt aufnahm und auch noch als Professor für Altes Testament in Berlin immer wieder die Hochschule für die Wissenschaft des Judentums besuchte. Es mag verwundern, dass dieser Kenner der rabbinischen Literatur und unermüdliche Verteidiger des Talmud sowie schlechthin des Judentums gegen den Antisemitismus seiner Zeit seine Wurzeln in der pietistischen Judenmission hatte und diesen Wurzeln auch nie abschwor, auch wenn er sich nie aktiv in diesem Sinn betätigte. Mit dem von ihm begründeten Institutum Judaicum in Berlin stand er in der Tradition des pietistischen Theologen und Orientalisten Johann Heinrich Callenberg (I694-1760), der die

22 Miletto, Gianfranco (Hg.): Die Heldenschilde / Abraham ben David Portaleone (JudUm 74), Frankfurt: Lang 2002; ders.: Glauben und Wissen im Zeitalter der Reformation. Der salomonische Tempel bei Abraham ben David Portaleone (I542-I6I2) (SJ 27), Berlin: de Gruyter 2004.

23 (Strack, Hermann Leberecht /) Billerbeck, Paul: Kommentar zum Neuen Testament aus Talmud und Midrasch, 6 Bände, München: C. H. Beck 1922-196I.

24 Stemberger, Günter: Die Mischna-Übersetzung von Johann Jacob Rabe, in: ders.: Judaica Minora II, 676-689.

25 Strack, Hermann Leberecht: Einleitung in den Thalmud, in: Herzog, Johann Jakob / Hauck, Albert / Plitt, Gustav Leopold (Hg.): Real-Encyklopädie für protestantische Theologie und Kirche I8, Leipzig: Hinrichs ${ }^{2}$ I888, 297-368, im selben Jahr noch getrennt gedruckt: Berlin (Schriften des Institutum Judaicum 2), ab der vierten Auflage als Einleitung in Talmud und Midrasch, München: C. H. Beck 1908. 
Mission unter Angehörigen des Judentums (und des Islam) durch ein gründliches Studium von deren Traditionen befördern wollte und freundlichen Umgang mit Juden anstelle aggressiver Mission als wesentliche Voraussetzung sah. Das eigentliche Ziel der Mission trat dabei immer mehr zurück, auch wenn es offiziell erst nach Stracks Tod aufgegeben wurde. So wurde aus ursprünglich anderen Ansätzen im Lauf der Zeit doch immer mehr ein echter Dialog, der auch heutigen Ansprüchen genügen würde.

\section{Zum Schluss}

Am Ende dieser sehr knappen Skizze bleibt zu fragen, wieweit die genannten Personen und Ereignisse tatsächlich als geschichtliche Vorläufer einer heutigen Dialogkultur zwischen Judentum und Christentum gesehen werden dürfen. Manche würden einen großen Teil, wenn nicht alles vom hier Angeführten eher in den Bereich der antijüdischen Polemik, seltener der antichristlich jüdischen Polemik einordnen. Es ist eine Frage der Gewichtung, wie man diese Phänomene beurteilt. Ein absolut irenisches Gespräch, in dem jeder den anderen voll gelten lässt und auch nicht den geringsten Versuch unternimmt, ihn für seine eigenen Vorstellungen zu gewinnen, war im längsten Teil der Geschichte kaum zu finden. Doch worauf es ankommt und weshalb ich hier auch Personen nannte, die man auch anders bewerten könnte, ist die Neugier gegenüber anderen und deren Traditionen und Vorstellungen. Im Fall von Judentum und Christentum sollte schon die gemeinsame Vorgeschichte und biblische Tradition eine hinreichende Voraussetzung sein, um miteinander ins Gespräch zu kommen. Und tatsächlich finden wir diese Neugier quer durch die Geschichte immer wieder. Was mit dem so gewonnenen Wissen gemacht wird, ist höchst unterschiedlich; es kann Waffe gegen das Judentum sein (so etwa, um nur das bekannteste Beispiel zu nennen, Johann Andreas Eisenmengers „Entdecktes Judenthum“, zwei Bände, Frankfurt I700), bloße Wissensbereicherung, aber im positiven Fall auch der Anfang von Verständnis und Wohlwollen, ohne deshalb die Seite wechseln zu wollen. Doch bleibt echter Wissensdurst die Voraussetzung jeden Dialogs. 


\title{
Notizen zur jüdisch-christlichen Begegnung im Kontext judaistischer Forschung
}

\author{
Gerhard Langer
}

Der folgende Beitrag ist ein Versuch, in aller Kürze einige Schlaglichter auf jene Bereiche der jüdisch-christlichen Begegnung zu werfen, die im Kontext der quellenorientierten judaistischen Forschung diskutiert werden. Ich setze dabei den in diesem Band vorliegenden Beitrag von Günter Stemberger voraus, der deutlich macht, wie über die Jahrhunderte die Begegnung von Jüdinnen/Juden und Christinnen/Christen weder als friedlicher Dialog noch als beständige Kontroverse gesehen werden darf, sondern als spannende und durchaus komplexe Interaktion.

Von den Anfängen der Judaistik an der Universität Wien, die auf die Nachkriegszeit zurückgehen, an, war es unter der Leitung von Prof. Kurt Schubert ein zentrales Anliegen, die Kenntnis des Judentums aus seinen originalsprachlich gelesenen und kritisch ausgelegten Quellen heraus (im Rahmen) einer weitgehend christlich sozialisierten und vom Christentum dominierten Gesellschaft zu vermitteln, und das gerade nach der Schoah. Schuberts Bemühungen um den jüdisch-christlichen Dialog, über Initiativen wie dem Koordinierungsausschuss für christlich-jüdische Zusammenarbeit oder dem Katholischen Akademiker/innenverband, das jüdische Museum in Eisenstadt und natürlich das Institut für Judaistik als wissenschaftlicher Einrichtung wurden bereits vielfach gewürdigt und müssen hier nicht im Detail aufgezählt werden. In jedem Fall kann man die Gründung eines Instituts für Judaistik in Österreich nicht von der Aufgabe trennen, durch Forschung und Bildung ein Bewusstsein von einer reichen und faszinierenden jüdischen Kultur zu vermitteln und eine Haltung zu fördern, die klar gegen jede Form von Antijudaismus und Antisemitismus auftritt.

Der Blick auf das Judentum weitete sich in diesem Kontext von der starken Fokussierung auf das Umfeld des Neuen Testamentes - eine Fokussierung, die vor allem im Rahmen der theologischen Disziplinen gängig war - hin zu einer umfassenden Beschreibung des Judentums auch und vor allem nach der Zerstörung des Jerusalemer Tempels 70 n.Z. Es ist hier nicht zu entscheiden, ob die Bezeichnung „Frühjudentum“ in diesem Zusammenhang als radikaler Gegenpol zum früher weit verbreiteten Begriff „Spätjudentum“ auf Kurt Schubert zurückgeht, das Anliegen selbst ist jedoch zweifellos damit richtig getroffen. Die Judaistik machte u. a. deutlich, dass Judentum weder als Kontrastfolie zum Christentum, noch als mit 
dem Christentum an ihr Ende gekommen zu betrachten ist, sondern vor allem in der rabbinischen Zeit zwischen 70 und Iooo, im Mittelalter und in den verschiedenen Strömungen der Neuzeit bedeutsame Entwicklungen durchmacht, die man u. a. mit den Stichworten Kontinuität und Brüche erfassen kann.

Die Diskussion um Begriffe wie „Spätjudentum“ oder „Frühjudentum“, die Frage, ob man überhaupt von einem Judentum oder nicht von mehreren Judentümern sprechen müsste, die Unterscheidung von "Jüdischkeit“ - im Englischen „Jewishness" - gegenüber dem Begriff „Judentum“ bzw. im Englischen „Judaism“-, hinter diesen Themen verstecken sich mehr als nur Sprachregelungen, sondern die grundlegende Frage nach einer einheitlichen Beschreibbarkeit des Phänomens Judentum über die Jahrhunderte und im Angesicht vieler unterschiedlicher Strömungen.

Dies beginnt schon bei der Diskussion um die Frage, wann überhaupt Judentum beginnt. Wie auch in diesem Band etwa im Beitrag von Erhard Blum gezeigt wird, war die Diskussion über die Anfänge des Judentums z. B. in bibelwissenschaftlichen Publikationen nicht immer neutral, sondern begleitet von Wertungen und zum Teil Ressentiments. Judentum wird hier als jene religiöse und politische Größe wahrgenommen, die nach dem babylonischen Exil - verbunden mit den Namen Ezra und Nehemia - eine jüdische Identität auf der Basis der Mosetora und als ethnische Einheit definiert hat/hätte. Es ist hier nicht Raum, dieses überaus spannende Gebiet näher zu vermessen, es muss genügen, darauf hinzuweisen, dass eine intensive kritische Auseinandersetzung mit der Forschungsgeschichte zu diesem Thema notwendig ist, wie diese etwa Reinhard Gregor Kratz im Bereich der Kontroverse von Eduard Meyer und Julius Wellhausen geleistet hat. ${ }^{1}$ Vielleicht ist auch seine einführende Bemerkung mit gewisser Gültigkeit zu übernehmen:

Das Judentum ist aus dem alten Israel hervorgegangen, dessen Geschichte mit der Gründung der beiden Monarchien in Israel und Juda begann und mit ihrem Untergang, der Einnahme Samarias durch die Neuassyer und Jerusalems durch die Neubabylonier, endete. Trotz der klaren historischen Zäsuren läßt sich die Entstehung des Judentums aber nicht auf den Tag genau datieren. Die Grenzen zwischen dem alten Israel und dem Judentum sind fließend und zeichnen sich weniger in den historischen Zäsuren als vielmehr in der literarischen Überlieferung der biblischen und davon abhängigen parabiblischen Schriften ab. ${ }^{2}$

I Die Entstehung des Judentums, in: Kratz, Reinhard Gregor: Das Judentum im Zeitalter des Zweiten Tempels. Kleine Schriften I (FAT 42), Tübingen: Mohr Siebeck ²013, 6-22.

2 Ebd. 3. Empfehlenswert ist auch die gesammelte Studie von Cohen, Shaye J. D. zu den Anfängen des Judentums: The Beginnings of Jewishness: Boundaries, Varieties, Uncertainties, Berkeley: University of California Press 1999. 
Im Laufe der Zeit sind viele weitere Epochen und Perioden hinzugekommen, die an der Kontinuität des Phänomens Judentum, wenn nicht zweifeln ließen, so doch diese stark in Frage stellten. War das Judentum nach der Zerstörung des Tempels 70 n.Z. noch dasselbe wie vorher? Welche Zäsur bildete das Aufkommen der Aufklärung? Wie ist die Errichtung des Staates Israel einzuordnen?, um nur drei zentrale Einschnitte zu nennen, an die sich viele kontroverse Diskussionen anschließen.

Meine Antwort geht von der vorsichtig geäußerten Überzeugung aus, dass trotz verschiedener Einschnitte innerhalb des Judentums Kontinuität konstatiert werden kann, die in enger Verbindung mit einer erstaunlichen Anpassungsfähigkeit an geänderte Umstände steht. So blieb die Katastrophe der Tempelzerstörung im Grunde wesentlich weniger tragisch für den Fortbestand einer jüdischen kulturellen Identität, als dies zu erwarten gewesen wäre. ${ }^{3}$ Und so lassen sich Grundpfeiler jüdischer Kultur wie die Bedeutung der Tora über die Jahrhunderte beschreiben und selbst im „säkularen“ Kleid wiederentdecken. Eine umfassende und komplexe Studie zu diesem Thema wäre reizvoll und steht noch aus.

Judaistik unterliegt wie jedes Fach Veränderungen und Trends. War es etwa in den Anfängen der Wissenschaft des Judentums im 19. Jahrhundert ein zentrales Anliegen, durch die Beschreibung des eigenständigen Beitrages des Judentums zur Geschichte die Größe und Bedeutung des Judentums im Rahmen vor allem einer europäischen Kultur zu betonen und die Anliegen der jüdischen Emanzipation zu vertreten, so zeichnen sich heute andere Schwerpunkte ab, die vielleicht noch stärker auf die Integration des Judentums im Rahmen der verschiedenen Kulturen abheben, auf den regen kulturellen Austausch und auf das Verständnis des Judentums als Teil einer mehrdimensionalen Kultur, wie etwa der griechisch-römischen in der Spätantike. Judentum ist auf keinen Fall mehr losgelöst oder „unbeeindruckt“ von Strömungen, Lebens- und Bildungskonzepten der so genannten Umwelt zu betrachten. ${ }^{4}$ In diesem Zusammenhang hat sich auch der Blickwinkel auf das jü-

3 Vgl. z. B. den Sammelband von Schwartz, Daniel / Weiss, Zeev (Hg.): Was 70 CE a Watershed in Jewish History? On Jews and Judaism before and after the Destruction of the Second Temple (Ancient Judaism and Early Christianity 78). Leiden: Brill 20I2; Stemberger, Günter: Reaktionen auf die Tempelzerstörung in der rabbinischen Literatur, in: Hahn, Johannes (Hg.): Zerstörungen des Jerusalemer Tempels. Geschehen - Wahrnehmung - Bewältigung (WUNT 147), Tübingen: Mohr Siebeck 2002, 207-236 (= Judaica Minora II, 625-653).

4 Als eine herausragende Studie sei Hezser, Catherine (Hg.): The Oxford Handbook of Jewish Daily Life in Roman Palestine, Oxford: Oxford University Press 20Io, genannt. 
disch-christliche Verhältnis gewandelt. ${ }^{5}$ Einige wenige Beispiele dieser veränderten Blickrichtung sollen in der Folge kurz vorgestellt werden. ${ }^{6}$

\section{Geschwisterrivalität}

Im Juni 20I3 hielt Papst Franziskus seine erste größere Rede vor Vertretern des International Jewish Committee on Interreligious Consultations. Dabei sprach er Kathpress zufolge seine Gäste mit „liebe ältere Brüder"“ an. Diesen Ausdruck hatte Johannes Paul II. (1978 bis 2005) eingeführt. Franziskus nahm damit einen Faden auf, den sein Vorvorgänger geknüpft hatte, indem er die Geschwisterlichkeit von Judentum und Christentum betonte. Dabei stellte man klar, dass das Judentum als das ältere Familienmitglied vorausgesetzt war und mit Wertschätzung behandelt wurde.

Natürlich erinnern sich viele an die bahnbrechende Rede von Johannes Paul II. in der Synagoge von Rom am I3. April 1986, in der er sagte:

Der erste Punkt ist der, daß die Kirche Christi ihre „Bindung“ zum Judentum entdeckt, indem sie sich auf ihr eigenes Geheimnis besinnt (vgl. Nostra aetate, Nr. 4, Absatz I). Die jüdische Religion ist für uns nicht etwas „Äußerliches“, sondern gehört in gewisser Weise zum „Inneren“ unserer Religion. Zu ihr haben wir somit Beziehungen wie zu keiner anderen Religion. Ihr seid unsere bevorzugten Brüder und, so könnte man gewissermaßen sagen, unsere älteren Brüder.?

Die Geschwisterlichkeit stellte im christlich-jüdischen Dialog eine neue Sichtweise dar, und diese Metaphorik schien nun mehr und mehr die vorausgehende Eltern(Mutter-Tochter)- und Wurzelmetapher, die sich aus dem Römerbrief des Paulus ableiten ließ, zu verdrängen. Das Christentum und das Judentum teilen eine gemeinsame Basis und ein gemeinsames Elternhaus. Dieses findet sich zweifelsfrei in der Hebräischen Bibel.

5 Ich verweise auf nur eine einschlägige wichtige Publikation, die das wieder erstarkte Interesse am jüdisch-christlichen Gespräch zeigt: Carlebach, Elisheva / Schacter, Jacob J. (Hg.): New Perspectives on Jewish-Christian Relations: In Honor of David Berger (The Brill Reference Library of Judaism 33), Leiden: Brill 2012.

6 Vgl. auch die schöne Zusammenstellung neuerer Ansätze bei Rainer Kampling/Clemens Leonhard, Gegenwärtige Ansätze der Rekonstruktion der frühen Geschichte von Judentum und Christentum, in: Theologische Revue Io6/4 (2010), Sp. 267-286.

7 Text u. a. in: http://www.vatican.va/holy_father/john_paul_ii/speeches/1986/april/documents/hf_jp-ii_spe_I98604I3_sinagoga-roma_ge.html [abgerufen am 9.5.20I4]. 
Die Geschwistermetaphorik an sich ist jedoch nicht neu. Sie ist in der Bibel selbst verankert. In Gen 25,23 heißt es: „Zwei Völker sind in deinem Leib, zwei Stämme trennen sich schon in deinem Schoß. Ein Stamm ist dem andern überlegen, der ältere muss dem jüngeren dienen." Damit sind Jakob und Esau gemeint, die als Brüder im Leib der Rebekka schon ziemlich Rabatz machen.

Die biblische Völkergeschichte der Genesis ist eine große Familiengeschichte, deren semitisch-abrahamitischer Zweig sich mit dem ismaelitischen (später Synonym für muslimisch) und dem sich mit Edom und später Rom weitgehend identifizierten Esaustrang Konturen gibt. Esau wird in der maßgeblichen rabbinischen Tradition zwar nicht ausschließlich mit Rom identifiziert, erhält aber zusehends die Züge einer negativ geprägten Persönlichkeit, die vor allem durch ihr Verhalten mit Rom verbunden wird. ${ }^{8}$

Mitte der I990er Jahre - im deutschen Sprachraum erst um einiges später beachtet - hat der israelische Mittelalterhistoriker Israel Yuval die Jakob-Esau-Rivalität zur Grundlage seiner Forschung und eines Buches 9 gemacht, in dem er darlegt, dass jüdische Tradition und religiös-kulturelle Identität maßgeblich vom Christentum beeinflusst wurden. Christliche Theologie, Motivik, Typologie, Liturgie etc. hätten das Judentum auf nachhaltige Weise beeindruckt und herausgefordert. Natürlich war Yuval nicht der erste, der eine eindimensionale Linie von Judentum zu Christentum hinterfragte. Er selbst zitiert Arbeiten von Ivan G. Marcus ${ }^{10}$, Jeremy Cohen $^{11}$ oder Elliot Horowitz ${ }^{12}$. Diese und einige andere haben auch schon vor ihm die enge Verbindung von jüdischer und christlicher Gedankenwelt des frühen Mittelalters herausgestrichen.

Yuval sieht zahlreiche Anknüpfungen an christliche Themen bereits in rabbinischen Erzählungen, so in der Erwähnung von Neros Konversion, ${ }^{13}$ die er als Ge-

8 Vgl. dazu Langer, Gerhard (Hg.): Esau - Bruder und Feind, Göttingen: Vandenhoeck \& Ruprecht 2009 .

9 In deutscher Übersetzung: Yuval, Israel: Zwei Völker in deinem Leib. Gegenseitige Wahrnehmung von Juden und Christen in Spätantike und Mittelalter (Jüdische Religion, Geschichte und Kultur 4), Göttingen: Vandenhoeck \& Ruprecht 2007.

Io Marcus, Ivan G.: Rituals of Childhood. Jewish Acculturation in Medieval Europe, New Haven: Yale University Press 1996.

II Cohen, Jeremy: The "Persecutions of I096". From Martyrdom to Martyrology: The Sociocultural Context of the Hebrew Crusade Chronicles (Hebr.), in: Zion 59 (1994) I69-208.

I2 Horowitz, Elliot: Medieval Jews Facing the Cross (Hebr.), in: Assis, Yom Tov u. a. (Hg.): Facing the Cross. The Persecutions of 1096 in History and Historiography, Jerusalem: Hebrew University Magnes Press ${ }^{2}$ 200I (Hebr.), II8-I4O.

I3 Nach dem Talmud bGittin 56 a konvertiert Nero zum Judentum, nachdem er wundersame Ereignisse bei seinem Feldzug erlebt hat. 
genlegende zur christlichen Betrachtung der Tempelzerstörung als Gottes Rache ansieht, oder in der Gründung von Javne durch Jochanan ben Zakkai, ${ }^{14}$ die er als Replik auf die Silvesterlegende - Silvester erhält für die Heiligung von Aussatz ein Geschenk von Kaiser Konstantin - versteht und einige mehr, vor allem aber die Ausgestaltung der Pesachhaggada nach Vorbildern und als Dialog mit der Osterliturgie. ${ }^{15}$

Das Esau-Edom-Motiv tritt, wie schon gesagt, in der rabbinischen Tradition in Verbindung mit Rom auf. Edom erhält im Laufe der Zeit immer stärker die Züge des Christentums. Nach Yuval reichert sich die jüdische Polemik zusehends mit Rachefantasien gegen Edom an, vor allem im Zusammenhang mit den Martyrien während der Kreuzfahrerzeit; Rachefantasien, die ihrerseits wiederum christliche Polemik beeinflussen. Die radikale Bereitschaft, Familienmitglieder und selbst die eigenen Kinder zu opfern, habe auch dazu beigetragen, dass von christlicher Seite jüdische Menschen mit dem Vorwurf des Ritualmordes in Verbindung gebracht wurden.

Es ist hier nicht Raum, Yuvals Thesen zu analysieren, zumal sie bereits von anderer Seite kritisch gewürdigt wurden. ${ }^{16}$ Eine hervorragende Studie in diesem Kon-

I4 In der in mehreren Varianten erzählten Gründungslegende der rabbinischen Bewegung wird davon berichtet, dass Jochanan ben Zakkai sich als Leiche getarnt aus dem von römischen Truppen eingekesselten Jerusalem zum Feldherrn Vespasian bringen lässt. In der bekanntesten Version in bGittin 56b (in dessen Kontext auch die Konversion Neros erzählt wurde) begrüßt Jochanan Vespasian als König, worauf dieser ihm antwortet, dass der Rabbi sein Leben verwirkt habe, da Vespasian kein König sei. Jochanan entgegnet ihm mit Bibelworten, die beweisen, dass nur ein König Jerusalem erobern könne (Jes I0,34; Jer 30,21; Dtn 3,25). Wenig später überbringt ein Bote die Botschaft, dass Nero gestorben und Vespasian zum Kaiser akklamiert worden sei. In der Folge gibt Jochanan noch zweimal heilsame Erklärungen aus der Bibel. Als nämlich Vespasians Fuß anschwillt und er nicht in die Stiefel steigen kann, zitiert er Spr I5,30 („[Strahlende Augen erfreuen das Herz], frohe Kunde macht den Knochen dick“) und schließlich als „Heilung“ Spr 17,22 („ein bedrücktes Gemüt lässt die Glieder verdorren"), wobei er Vespasian den Rat gibt, eine ihm unliebsame Person an ihm vorbeigehen zu lassen. Als Dank für seine (wirksame) Weisheit erhält Jochanan unter anderem die Möglichkeit, mit seinen Getreuen in Javne einen Ort für die Lehre einzurichten.

I5 Zum Thema der Entwicklung von Pessach hat Clemens Leonhard wichtige Beobachtungen gemacht, die zu einem nicht geringen Teil manche Einschätzungen Yuvals vor allem für die frühe Tradition der Feier als historisch nicht haltbar erweisen. Prinzipiell bleibt aber die Beeinflussung von Pessach (und der Haggada) durch Ostern im Laufe der Zeit durchaus eine richtige Annahme. Vgl. Leonhard, Clemens: The Jewish Pesach and the Origins of the Christian Easter. Open Questions in Current Research, Berlin: de Gruyter 2006.

I6 Die Zeitschrift Zion 59 hat 1994 eine Doppelnummer (2-3) mit den Kritikern (vor allem Ezra Fleischer, Mordechai Breuer, Abraham Grossman, Mary Minty) und Yuvals Antwor- 
text stellt im Übrigen auch Simcha Goldins Arbeit mit dem Titel „The Ways of Jewish Martyrdom "17 dar. Festzuhalten ist, dass Yuval das Bewusstsein geschärft hat, dass Judentum und Christentum nicht nur historisch und gesellschaftlich, sondern auch religiös-kulturell in einer viel engeren Verflechtung eingebunden waren als normalerweise angenommen. Die Spannung von Nähe und Abgrenzung führt zu zahlreichen Gegengeschichten.

Noch stärker als Israel Yuval hat der amerikanische orthodoxe Judaist Daniel Boyarin in den letzten Jahr(zehnt)en die Beziehungen zwischen Judentum und Christentum in der Antike neu beleuchtet. 1994 erschien sein Buch „A Radical Jew: Paul and the Politics of Identity ${ }^{118}$, in dem Paulus als nach Universalismus strebender Jude vorgestellt wird. Damit traf Boyarin einen Nerv seiner Zeit, zumal - nachdem das Judentum Jesu in den letzten Jahrzehnten mehr und mehr zum Allgemeingut geworden ist - Paulus als Auslöser der Trennung von Judentum und Christentum gesehen wurde. Hier sei nur erwähnt, dass Alan F. Segal mit seinem Buch „Paul the Convert ${ }^{119} 1990$ ein ebenfalls wichtiges Buch zu Paulus herausgegeben hat, in dem er diesen als Juden ernst nimmt und seine - wie er es nennt Konversion (bei ihm ein wichtiges Thema) zu einem apokalyptisch-messianischen Judentum beschreibt und erläutert.

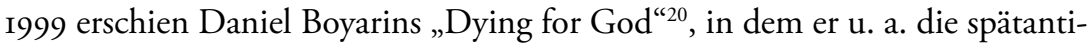
ken jüdischen Märtyrererzählungen in enge Beziehung zu christlichen Narrativen bringt. Grundsätzlicher noch argumentiert Boyarin, dass sich Jüdinnen/Juden und Christinnen/Christen in einer gemeinsamen religiösen Landschaft befinden, in der die theologischen Abgrenzungen beständig neu verhandelt werden. Judentum und Christentum ließen sich längere Zeit nicht streng trennen, seien vielmehr Entitäten im Fluss, die sich in dynamischer Dialektik befänden. Das Christentum erhielte seine betonte Eigenständigkeit erst durch die Einrichtung als Religion des Römischen Reiches.

ten publiziert, da Yuval ursprünglich in Zion 58 / I (1993) seinen Artikel zum jüdischen Märtyrertum veröffentlicht hatte, den er dann zu dem hebräischen Buch Schnej Gojim be-vitnekh („Zwei Völker in deinem Leib“) 2000 erweiterte.

I7 Goldin, Simcha: The Ways of Jewish Martyrdom, Turnhout: Brepols 2008 (Englisch). Das Original ist 2002 in Lod auf Hebräisch erschienen.

I8 Boyarin, Daniel: A Radical Jew: Paul and the Politics of Identity (Contraversions: Critical Studies in Jewish Literature, Culture and Society I), Berkeley: University of California Press 1994 .

I9 Segal, Alan F.: Paul the Convert. The Apostolate and Apostasy of Saul the Pharisee, New Haven: Yale University Press 1990.

20 Boyarin, Daniel: Dying for God. Martyrdom and the Making of Christianity and Judaism (Figurae: Reading Medieval Culture), Stanford: Stanford Univ. Press I999. 
Mit „Border Lines: The Partition of Judaeo-Christianity” (2004) ${ }^{21}$ setzt er dort fort. Hier greift Boyarin, der immer wieder seine Thesen mit literaturwissenschaftlichen Theorien untermauert, auf die linguistische Wellentheorie zurück, wonach Neuerungen durch Überlagerungen und Zusammenflüsse entstehen, im Unterschied von Stammbäumen, nach denen aus einer gemeinsamen Grundlage unterschiedliche Arten sich evolutionär entwickeln. Wie in der Sprachtheorie bestimmte über Sprachgrenzen hinausreichende sprachliche Phänomene sich mit der Wellentheorie besser erklären lassen, so auch der Bezug von Judentum und Christentum in den Anfängen. Demnach ist die sich langsam durchsetzende Unterscheidung nicht Ergebnis getrennter Wege, sondern gemeinsamer Geschichte. Das Judentum entwickelt seine Vorstellung von Orthodoxie erst in der Begegnung mit dem Christentum, indem es seine ethnische und religiöse Identität herausarbeitet. Anders als bei Yuval geschieht dies jedoch weniger in einem Klima der Abgrenzung und Gegennarrative, als in einer Bearbeitung von gemeinsamen Grundlagen und Thematiken. Boyarins Thesen radikalisieren sich zusehends, wenn er viele Entwicklungen des rabbinischen Judentums fast ausschließlich als Respons zum Christentum betrachtet. Die jüdische Rede von der Minut (Apostasie) ist dann Ergebnis der christlichen Häresiedebatte; die Erzählungen um die Gründung Javnes als neues rabbinisches Zentrum nach der Tempelzerstörung wären eine Reaktion auf die Beschreibung der mit dem Konzil von Nicäa verbundenen christlichen Selbstdefinition durch den Kirchenvater Athanasius. Nach Boyarin sind der in der rabbinischen Tradition so wichtige Gedanke einer mündlichen Tora und des "demokratischen“ Wettstreits unter den Rabbinen, eines undogmatischen Zugangs zu Texten, Ergebnis einer Abhebung von christlicher Dogmatik.

Selbst das Geschwisterbild, so deutlich dem Stammbaum und Eltern-Kind-Bild vorgezogen, trägt bei Boyarin letztlich nicht. Nicht selten erhält man den Eindruck, dass es eigentlich das Christentum gewesen wäre, das maßgeblich die Ausgestaltung des Judentums in rabbinischer Zeit verursacht bzw. in die Wege geleitet hätte.

So faszinierend dieser Ansatz und so bedenkenswert er in vielen Teilen ist, so sehr muss er jedoch im Detail befragt und hinterfragt werden. ${ }^{22}$

Ein zentrales Thema bei Boyarin (und nicht nur bei ihm) ist der Zugang zur Frage, ob es zwei Mächte im Himmel gäbe oder nicht. Hier würden sich die Grenz-

2I Boyarin, Daniel: Border Lines: The Partition of Judaeo-Christianity (Divinations), Philadelphia: University of Pennsylvania Press 2004. Deutsch: Abgrenzungen: Die Aufspaltung des Judäo-Christentums (ANTZ Io), Berlin: Institut Kirche und Judentum 2009.

22 Vgl. die Rezensionen von Stuart Miller in: AJS Review 3I / 2 (2007), 35I-362 oder von Ra’anan S. Boustan in: JQR 3 (2006) 44I-446. 
linien abzeichnen. Die Bedeutung, die diese Frage im rabbinischen Judentum hat, ist zwar ernst zu nehmen, auf der anderen Seite jedoch auch nicht zu überschätzen.

2012 erschien das vorläufig letzte Buch „The Jewish Gospels: The Story of the

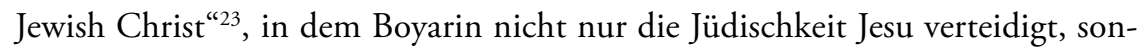
dern darüber hinaus argumentiert, dass die Vorstellung vom Messias und damit die Christologie, die von Jesus als Sohn Gottes spricht, tief in der jüdischen Tradition verankert gewesen seien. Damit schließt er wieder an das wichtige Thema "Zwei Mächte im Himmel“ bzw. „Binitarianismus“ an, das ihn schon lange beschäftigt. Jedoch nicht nur Binitarianismus, auch die Trinität seien Vorstellungen, die in der Zeit Jesu in jüdischen Kreisen zirkuliert wären, auch wenn Boyarin diese These nicht weiterführt.

Boyarin verweist vor allem auf die Menschensohnworte des biblischen Buches Daniel, in denen er einen wichtigen Vorläufer der messianischen Rede über Jesus erblickt (Dan 7,I3: „Immer noch hatte ich die nächtlichen Visionen: Da kam mit den Wolken des Himmels einer wie ein Menschensohn. Er gelangte bis zu dem Hochbetagten und wurde vor ihn geführt").

Dabei weist er anderslautende Auslegungen der Wissenschaft - wie etwa die Kollektivdeutung auf Israel oder die Identifikation des Menschensohnes mit dem Erzengel Gabriel, dem himmlischen Schutzengel Israels - zurück.

In einem abschließenden Teil widmet sich Boyarin dem leidenden Christus, den er als Midrasch zum Danielbuch - also nicht nur beeinflusst vom leidenden Gottesknecht des Buches Jesaja - sieht. Vom Leiden des Messias, so behauptet Boyarin, sei in rabbinischen Quellen des Öfteren die Rede. Dies stimmt nur bedingt, da nur selten, so in bSanhedrin 98b, wo sich der Messias bei den Leprakranken in der großen Stadt (Rom) befindet, dazu Andeutungen existieren. Wohl aber gibt es die expliziten Stellen zum leidenden Messias im Midrasch Pesiqta Rabbati 34-37 oder auch im Sefer Serubbabel, die man als Reaktion auf das Christentum verstehen muss.

Neben überbordendem Lob, etwa von Jack Miles, der auch ein Vorwort zum Buch verfasste, findet sich auch Kritik. Prominentester Kritiker ist wohl Peter Schäfer, zuletzt Professor in Princeton, der u. a. auch zu den Stellen um den leidenden Messias gearbeitet hat, stellt dem Buch ein schlechtes Zeugnis aus. Neben mangelnder Einarbeitung einschlägiger Literatur, fehlenden Eingehens auf wichtige Quellen wie die „Self-Glorification Hymn“ aus Qumran (zum leidenden Messias) oder zum Logos bei Philo oder dem Gebet des Josef, das bei Origenes zitiert

23 Boyarin, Daniel: The Jewish Gospels: The Story of the Jewish Christ, New York: The New Press 2012. 
wird, in dem ein Erzengel Jakob-Israel als präexistent dargestellt und als Erstgeborener allen Lebens bezeichnet wird, sieht Schäfer vor allem in der falschen Bezugnahme auf Daniel ein Problem.

Aber auch Schäfer bescheinigt Boyarin, dass er das Bewusstsein, dass zur Zeit Jesus ein kompetitiver Streit um Meinungen existierte und das Judentum prägte, geschärft habe.

Die Vorstellung von zwei göttlichen Figuren im Himmel hat das Judentum beschäftigt, wobei vor allem Henoch als höchster Engel Metatron dabei in gewissen, keineswegs randständigen Kreisen eine große Rolle spielt, eine Vorstellung, die im Kampf um ein Mainstream-Judentum stark angegriffen wurde.

Auch Schäfer gesteht ein, dass in den Anfängen Judentum und Christentum nicht durch eine klare Linie getrennt waren und dass auch die binitarische Idee für ihn keine Demarkation darstellt. Allerdings meint er, dass der Tod am Kreuz und die Trinität für den jüdischen Glauben eine Grenze darstellten.

Peter Schäfer hat selbst wichtige Beiträge zu einem besseren Verständnis der Bezüge von Judentum und Christentum in der Spätantike geliefert. Dazu zählt sein Buch "Jesus im Talmud“. ${ }^{24}$ Darin zeigt Schäfer, wie rabbinische Gelehrte auf Texte des Christentums reagieren, diese aufnehmen und oftmals auch umwandeln. Schäfer ortet eine ganze Reihe von Kontrasterzählungen, die mitunter christliche Vorstellungen und Ansprüche auch karikieren. Vor allem der babylonische Talmud war hier reicher, wohl, weil er in einem geschützteren Rahmen agieren konnte, als dies im christlich dominierten Palästina möglich gewesen wäre. Hier ist im Übrigen ein wichtiger Grundsatz vermerkt, wonach palästinische und babylonische Quellen nicht einfach vermischt werden dürfen.

Bei Schäfer finden sich die auch schon früher, unter anderem von Johann Maier ausführlich, damals vor allem historisch-kritisch unter die Lupe genommenen Texte, darunter die Tradition um Ben Stada und/oder den Sohn des Pandera/Panthera. ${ }^{25}$ Darin wird u. a. das griechische Wort für Jungfrau, parthenos, karikiert. Jesus wird als Sohn einer unsittlichen Frau geschildert und ihm selbst wird unsittliches Verhalten vorgeworfen, daneben Zauberei, Götzendienst und Blasphemie.

Für Schäfer spielt auch die Person des bekannten Rabbi Eliezer eine Rolle als eine Art Doppelgänger Jesu. Auf Eliezer ${ }^{26}$ einer überaus schillernden Figur in der rabbinischen Tradition, hat auch Boyarin mehrfach hingewiesen, um seine Nähe

24 Schäfer, Peter: Jesus im Talmud, Tübingen: Mohr Siebeck ${ }^{2} 2010$.

25 Vgl. tChullin; jAvoda Zara 2,2/7; jSchabbat I4,4/8, Qohelet Rabba I0.5.

26 Vgl. zu den Traditionen u. a. Neusner, Jacob: Eliezer ben Hyrcanus. The Tradition and the Man, Leiden: Brill 1973. 
zu christlichen Vorstellungen zu beschreiben. Hierzu ist zu sagen, dass die unterschiedlichen Auslegungen zu Eliezer nicht zweifelsfrei eine Nähe zum Christentum belegen, auch wenn manche seiner ihm zugeschriebenen Eigenschaften, so sein Beharren auf einer direkten Gottesbegegnung, auf die richtige Auslegung auch gegen die Mehrheit der Kollegen, seine Kenntnis der Magie u. a. Anklänge an christliche Sichtweisen möglich erscheinen lassen.

Die textliche Kenntnis des Neuen Testaments, die von Schäfer behauptet und mit vielen Beispielen illustriert wird, ist ungewöhnlich. Hierzu ist weiter zu forschen. Gab es Sammlungen, Zugänge durch syrische Übersetzungen wie das Diatessaron des Tatian oder die Peschitta (wie dies z. B. auch Holger Michael Zellentin vermutet $)^{27}$, vielleicht sogar Vorläufer der späteren polemischen Traditionen der Toldot Jeschu?

In seiner Aufsatzsammlung „Die Geburt des Christentums aus dem Geist des Judentums ${ }^{\text {“28 }}$, später massiv in englischer Sprache zu einem Buch mit dem Titel "The Jewish Jesus“ ${ }^{\text {"29 }}$ überarbeitet, geht Schäfer gekonnt auf einige Traditionen ein, in denen Judentum christliche Motive aufnimmt.

Der Band vereint fünf Vorlesungen, die Peter Schäfer 2009 in Jena gehalten hat. Er analysiert darin rabbinische Texte, die auf die eine oder andere Weise Bezüge zum Christentum nahelegen und dadurch zeigen, dass der Prozess der Selbstfindung des spätantiken Judentums nicht unabhängig vom parallel entstehenden Christentum gesehen werden darf. Die erste Einheit mit dem Titel „Warum verschwand das Messiasbaby?" bezieht sich auf einen Text in jBerakhot 2,4,I2-I4 bzw. Klagelieder Rabba I.I $6 \$ 5 \mathrm{I}$, in dem eine Mutter ihr Kind „beinahe“ tötet, weil es am Tag der Zerstörung des Tempels geboren wird. Doch das Kind wird vom Wind entrissen. Schäfer sieht darin einen Bezug zum christlichen Messias-Anspruch, der Ablehnung desselben durch das Judentum, die als „Mutter“ ihr Baby, das Christentum, töten möchte. Am Ende der Erzählung scheint das Kind von Gott entrückt (verbunden mit Elija-Traditionen). Schäfer ist es wichtig zu betonen, dass der Messias hier nicht als falsch abgelehnt wird, sondern vielleicht der christliche Messias Jesu übernommen worden ist, ,gewissermaßen übertrumpft von dem, wirklichen“ jüdischen Messias, dem Messias aus dem Hause Davids? Und sogar das Verschwin-

27 Zellentin, Holger Michael: Rabbinic Parodies of Jewish and Christian Literature (Texts and Studies in Ancient Judaism 139). Tübingen: Mohr Siebeck 20II, I42.

28 Schäfer, Peter: Die Geburt des Christentums aus dem Geist des Judentums. Fünf Vorlesungen zur Entstehung des rabbinischen Judentums (Tria Corda: Jenaer Vorlesungen zu Judentum, Antike und Christentum 6), Tübingen: Mohr Siebeck 20 Io.

29 Schäfer, Peter: The Jewish Jesus. How Judaism and Christianity Shaped Each Other, Princeton: Princeton University Press 2012. 
den des Messiasbabies in unserer Erzählung könnte eine ironische Übernahme der christlichen Unterscheidung zwischen dem ersten und zweiten Kommen des Messias $\operatorname{sein}^{\prime \prime}($ S. 30).

Die zweite Vorlesung ist mit „Rabbi Simlai und die Häretiker. Ein Gott oder mehrere Götter?" übertitelt. Rabbi Simlais Auseinandersetzung mit den so genannten Minim über die Deutung des Plurals im Gottesnamen Elohim stammt aus Genesis Rabba 8.9 mit Parallele in jBerakhot 9,I/9-IO,I2d. Simlais zweigeteilte Antworten - einmal an die Häretiker, einmal an die Jünger - betonen die Einheit Gottes gegen die binitarischen Entwürfe der Zeit.

Mit dem Titel „Der alte und der junge Gott" bezieht sich Schäfer auf eine Tradition in der Mekhilta Bachodesch 5/Schirata 4, einer Sammlung von Auslegungen zu Ex 20,2, in der Gott in unterschiedlicher und teilweise widersprüchlicher Form auftritt. Dieser Text wendet sich u. a. gegen die Vorstellung von zwei Mächten im Himmel. Hier zitiert der Autor auch weiterführende rabbinische und außerrabbinische Quellen, darunter bSanhedrin 38b. Hinter dieser babylonischen Variante ortet er eine Auseinandersetzung mit dem Christentum, aber auch den Umstand, dass ,jüdische Kreise in Babylonien [...] die Vorstellung eines neben Gott im Himmel inthronisierten Messias attraktiv gefunden “ (S. 96) hätten, womit sich die Rabbinen schließlich kritisch auseinandersetzen mussten.

„Rav Idit und die Häretiker. Gott und Metatron" benennt er seine vierte Vorlesung, die von der Textbasis direkt anschließt, da sie bSanhedrin 38b (Parallele Exodus Rabba 32.4) zur Grundlage hat. Schäfer diskutiert die Metatron-Traditionen hier und in 3 Henoch, in der er den - rabbinisch bekämpften - Niederschlag von Vorstellungen „gewisser Kreise“ (S. I32) vermutet, die christliche Zuschreibungen aufgenommen und gleichzeitig umgedeutet hätten. „Erlöser ist ein Mensch, der in ein göttliches Wesen verwandelt wurde, und als solcher richtet er nun, zusammen mit Gott [...] Himmel und Erde“ (ebd.).

Im Zusammenhang mit der Metatrontradition ist auch auf den in der rabbinischen Tradition mehrfach dokumentierten Abweichler Elischa ben Avuja einzugehen. Er ist ein herausragender rabbinischer Gelehrter, der jedoch als Häretiker gebrandmarkt und Acher (der Andere) genannt wird. In der vom babylonischen Talmud in bChagiga Isab überlieferten Variante der Erzählung von der Häresie Elischas werden deutliche Akzente gesetzt. Elischa ist mit drei anderen Weisen zu einer „Paradiesesreise“ aufgebrochen, die er nicht unbeschadet „überlebte“. Elischa habe nämlich den obersten Engel Metatron gesehen, der saß (und sitzen blieb, als Elischa kam) und die Verdienste der Israelit/inn/en in ein Buch schrieb. Elischa habe sich verleiten lassen, daraus zu schließen, dass es zwei Mächte im Himmel gäbe. Metatron wird mit 6o Schlägen gezüchtigt, weil er Elischa Anlass zum Irrtum gab, aber er erhält 
auch die Erlaubnis, diesen mit dem Edikt, nicht mehr von seinem falschen Weg umkehren zu können, zu bestrafen. Erst in der Folge beschließt Elischa, sich mangels einer Perspektive des Erreichens der kommenden Welt in der hiesigen auszuleben. Er besucht eine Prostituierte. Diese gibt ihm schließlich den Namen Acher, nachdem er am Schabbat einen Rettich ausreißt und ihr (als Bezahlung?) überreicht.

Der letzte und vielleicht beeindruckendste Teil der Ausführungen Schäfers ist eine Auseinandersetzung mit der Vorstellung des leidenden Messias Efraim, wie sie im Zuge der byzantinisch-persischen Auseinandersetzung zu Beginn des 7. Jahrhunderts auftraten, im Sefer Serubbabel etwa oder in Pesiqta Rabbati 34-37. Darin findet sich die wohl umfassendste Beschreibung einer leidenden Messiasfigur innerhalb der jüdischen Tradition. Präexistenz, Leid, Erlösung Israels durch das Sühneleiden, Inthronisation und Erhöhung werden ausführlich geschildert und liefern zahlreiche Parallelen zur christlichen Passionserzählung.

Schäfers Beschreibung ist auf hohem Niveau gut lesbar und legt den Finger auf wichtige Fragen und Themen, die lange Zeit in der judaistischen Forschung keinen Platz hatten, in den letzten Jahr(zehnt)en jedoch verstärkt wahrgenommen werden. Es geht um die Beziehung zum Christentum, die keine Einbahnstraße vom Judentum weg war, sondern vielmehr ein kritischer und lebendiger Austausch, der auch in den rabbinischen Schriften seinen Niederschlag gefunden hat. Freilich bleiben manche Schlussfolgerungen in ihrer Beweisbarkeit vage, dies tut jedoch der Analyse an sich keinen Abbruch. Das Buch (vor allem die erweiterte englische Fassung) ist in jedem Fall sehr zu empfehlen.

Israel Yuvals Analyse, die ihren Schwerpunkt im Mittelalter hat, und Peter Schäfers hervorragende Beschreibung der spätantiken Bezugspunkte, stimmen in der Überzeugung überein, dass Judentum nicht losgelöst vom Christentum zu betrachten ist und dieses immer wieder reagiert, sei es durch Gegengeschichten oder aber auch durch Übernahme von Vorstellungen und Ansichten, die ins Judentum integriert werden. Daniel Boyarins Arbeiten haben wohl die weiteste Verbreitung erlangt und damit vielleicht am stärksten dazu beigetragen, das Bild der Anfänge von Christentum und Judentum neu zu zeichnen. Ob und wieweit er dabei gelegentlich übers Ziel hinausschießt oder in manchen Bereichen seine Analysen zu einseitig sein mögen, bleibt im Detail zu erschließen.

Wichtige neue Erkenntnisse ergeben sich auch bei einem kritischen Befragen der Kirchenväterliteratur auf Begegnungen mit dem Judentum in realer, literarischer oder auch hermeneutischer Hinsicht. Zu den Bezügen zwischen den Rabbinen und den Kirchenvätern sind nicht zuletzt die Studien von Burton Visotzky ${ }^{30}$,

30 Visotzky, Burton L.: Fathers of the World: Essays in Rabbinic and Patristic Literature 
Judith Baskin ${ }^{31}$ oder Adam Kamesar ${ }^{32}$ zu nennen. Informativ ist die kleine Monografie von Marc Hirshman ${ }^{33}$. Darin widmet er sich den Kirchenvätern in Palästina zwischen dem 3. und 5. Jahrhundert im Vergleich mit rabbinischen Texten dieser Ära. Er analysiert Texte von Justin, Origenes und Hieronymus, stellt vorsichtige Vermutungen über mögliche Kenntnisse der jeweilig anderen Überlieferungen an und reflektiert über Polemik, aber auch über die Ähnlichkeiten und Unterschiede zwischen Midrasch und antiker Rhetorik. Hierzu sind weitere Arbeiten und Initiativen notwendig, wie sie etwa auch von Agnethe Siquans ${ }^{34}$ an der Universität Wien oder in interdisziplinären Arbeitskreisen (derzeit ebenfalls u. a. unter der Initiative von Susanne Plietzsch und Dorothea Weber ${ }^{35}$ ) erfolgen.

Neben den Bezügen zu den Kirchenvätern sind Arbeiten wie die von Alexei M. Sivertsev, ${ }^{36}$ in der überzeugend die Verbindungen zwischen byzantinischer imperialer Kultur und Ideologie und rabbinischen Gegentexten wie dem Sefer Serubbabel aufgearbeitet werden, von großer Bedeutung.

Die jüdisch-christlichen Bezüge sind auch dort, wo sie vordergründig im Rahmen von Kontroversen angesiedelt sind, auf komplexere Begegnungen hin zu befragen. Im Rahmen eines Forschungsprojektes erarbeitet derzeit Károly Dáni-

(WUNT 80), Tübingen: Mohr Siebeck 1995; ders.: Anti-Christian Polemic in Leviticus Rabbah, in: PAAJR 56 (1990), 83-I00; ders.: Jots and Tittles: On Scriptural Interpretation in Rabbinic and Patristic Literatures, in: Prooftexts 8 (1988), 257-269.

3I Baskin, Judith: Rabbinic-Patristic Exegetical Contacts in Late Antiquity: A Bibliographical Reappraisal, in: Green, William Scott (Hg.): Approaches to Ancient Judaism. 5. Studies in Judaism in Its Greco-Roman Context (Brown Judaic Studies 32), Chico: Scholars Press I985, 53-80.

32 Kamesar, Adam: The Church Fathers and Rabbinic Midrash, in: Neusner, Jacob / Avery Peck, Alan J. (Hg.): Encyclopedia of Midrash. Biblical Interpretation in Formative Judaism. I. Leiden: Brill 2005, 20-40; ders.: The Church Fathers and Rabbinic Midrash: A Supplementary Bibliography, 1985-2005, in: RRJ 9 (2006) 190-196.

33 Hirshman, Marc: Origen and the Rabbis on Leviticus, in: Adamantius II (2005), 93-I00; ders.: A Rivalry of Genius. Jewish and Christian Biblical Interpretation in Late Antiquity (SUNY Series in Judaica: Hermeneutics, Mysticism, and Religion), Albany: State University of New York Press 1996; ders.: The Greek Fathers and the Aggada on Ecclesiastes: Formats of Exegesis in Late Antiquity, in: HUCA 59 (1988), I37-165.

34 Vgl. u. a. Siquans, Agnethe: Die alttestamentlichen Prophetinnen in der patristischen Rezeption. Texte - Kontext - Hermeneutik (HBS 65), Freiburg i. B.: Herder 201 I.

35 Unter dem Titel: Salzburger Arbeitskreis „Rabbinen und Kirchenväter“, vgl. http://www. uni-salzburg.at/fileadmin/multimedia/Zentrum\%2ofuer\%20Juedische\%2oKulturgeschichte/documents/SalzburgerArbeitskreis2.pdf [abgerufen am 9.5.2014].

36 Sivertsev, Alexei M.: Judaism and Imperial Ideology in Late Antiquity, Cambridge: Cambridge University Press 20II. 
el Dobos eine Reihe von jüdischen „polemischen“ Texten aus dem I7. und I8. Jahrhundert. ${ }^{37}$ Darunter sind Texte von Jehuda Arje aus Modena oder Jona Rapas Pilpul al zeman, zemanim, zemanehem. Dabei stellte sich heraus, dass bei einigen Kompositionen die theologische oder auch philosophische Funktion gegenüber unterhaltender Absicht zurücktritt und die humorvollen Parodien und Überarbeitungen wichtiger Gebetstexte nicht nur als Polemiken gegen Christ/inn/en funktionieren, sondern auch einen verdeckten Angriff auf die eigene (jüdische) Tradition erkennen lassen.

Die Person Jesus ist über die Jahrhunderte nicht nur zu einer kontroverstheologischen Figur geworden, sondern dient vor allem in der Moderne vielen jüdischen Autoren und Künstlerinnen und Künstlern als Identifikationsfigur. Dies ist in den letzten Jahren verstärkt erforscht worden. ${ }^{38}$ An unzähligen Beispielen deutschsprachiger, jiddischer und hebräischer Literatur zeigt sich eine genuin jüdische Aneignung von Jesus vor allem im Kontext von Leid und Verfolgung, von nationaler Selbstfindung und künstlerischer Vergegenwärtigung. Nicht selten geschieht diese Aneignung in bewusster Abhebung von den Kirchen. Wichtig ist die Einordnung des Jesusphänomens in die innerjüdische Identitätenbildung und die Frage nach einer Abgrenzung vom Christentum in ihren vielfältigen kulturgeschichtlichen Verflechtungen.

Als Fazit kann gelten, dass sich im Rahmen judaistischer quellenorientierter Forschung zur Begegnung von Judentum und Christentum die Perspektive zusehends wandelt. Viele Entwicklungen innerhalb der jüdischen Geisteswelt werden als vom Christentum angeregt erklärt und erläutert, die Geschwister werfen sich sinnbildlich Bälle zu, manchmal freundschaftlich, manchmal leidenschaftlich, manchmal aggressiv.

Im Rahmen des jüdisch-christlichen Dialogs sind diese Studien wichtige Beiträge zu einem Mosaik der jüdisch-christlichen Begegnung, dem sich entscheidende Erkenntnisse im Rahmen der Liturgieforschung (hierzu auch einige Beiträge in diesem Band), der Geschichte, Soziologie, Archäologie etc. dazugesellen.

Der Theorie muss jedoch die Praxis folgen. Wie schon in den Anfängen der österreichischen Judaistik unter Kurt Schubert das Bekenntnis zum jüdisch-christlichen Dialog immer mit der realen Begegnung, dem Gespräch, der Solidarität mit

37 Insgesamt 48, davon sind 37 nur handschriftlich erhalten, erst elf sind bereits im Druck erschienen.

38 Vgl. dazu u. a. Wallas, Armin: Rabbi Jeschua ben Josseph. Jüdische Jesus-Interpretation im 20. Jahrhundert, in: Das jüdische Echo 46 (1997) 2I-38; Stahl, Neta (Hg.): Jesus Among the Jews. Representation and thought, London: Routledge 20I2; dies: Other and Brother. Jesus in the 2oth-Century Jewish Literary Landscape, Oxford: University Press 20I3. 
Jüdinnen und Juden in diesem Land und der Welt, vor allem auch in Israel, verbunden war, so wird heute eine gelingende Begegnung daran gemessen werden, wie sie gegenüber den aktuell oft bedrohten jüdischen Gemeinden auftritt und diesen zur Seite steht.

Für einen jüdisch-christlichen Dialog heißt dies konsequent, dass nicht von zwei getrennten Entitäten ausgegangen werden kann, die sich irgendwann einmal knapp nach Jesus oder Paulus getrennt hatten, sondern von einer Geschwistergeschichte, die aufs engste verbunden bleibt. 


\title{
Das AT im christlich-jüdischen Dialog aus judaistischer Sicht
}

\author{
Johann Maier
}

I. Das so genannte AT aus judaistischem Blickwinkel

Das so genannte Alte Testament ist entsprechend seiner nachhaltigen Bedeutung für die jüdische Religion und Kultur natürlich ein grundlegender Gegenstand der judaistischen Arbeit. Diese stützt sich dabei auf die alttestamentliche Wissenschaft der Theologie und unterscheidet sich von dieser nur in der Begründung und Zielsetzung. Die theologische Wissenschaft sucht zu erforschen, was in diesen Texten ursprünglich gesagt worden ist, fragt darüber hinaus danach, was sie für heute zu sagen haben, und wird mit der Frage des Verhältnisses von Altem und Neuen Testament konfrontiert. Der Judaist braucht sich darüber nicht den Kopf zu zerbrechen. Für ihn steht sogar weniger das in den Texten ursprünglich Gemeinte im Zentrum des Interesses, als deren Interpretation und Anwendung durch die Jahrhunderte hindurch, also wie die Texte Geschichte gemacht haben und wie sie verwendet worden sind. Auslegungs- und Wirkungsgeschichte gewähren ja auch wichtige Einblicke in den Verlauf der Geschichte der jüdischen Religion und Kultur. Das gilt nicht nur für den hebräischen/aramäischen Text. Der vielfältigen Geschichte des Judentums in der Diaspora entsprechend belegen die Bibelübersetzungen Art und Ausmaß der kulturellen Integration in den einzelnen Perioden und Regionen.

Mit der Entstehung des Christentums, das die griechische und später auch die lateinische Bibel als ihre Heilige Schrift betrachtete, aber weitgehend auf Christus hin deutete, ergab sich zwar ein gemeinsamer Bestand an Büchern, aber sprachlich verschieden und im Verständnis völlig konträr. Die Frage des richtigen Bibelverständnisses war darum in der jüdisch-christlichen Kontroversliteratur von entsprechender Bedeutung.

Der hebräische Text wurde in der Antike ja nur von wenigen Autoren wahrgenommen, erst im Mittelalter verdichtete sich das gelehrte Interesse daran. Mit dem Humanismus und der Reformation wurde dem hebräischen Text schließlich grundsätzlich der Vorrang eingeräumt, denn Hebräisch galt als Sprache der Schöpfung und Ursprache der Menschheit. Man lernte daher von jüdischen Gewährsleuten das Hebräische und Aramäische und übernahm die standardisierte Textform der Masoreten. Man ging dabei über den engeren Gelehrtenkreis hinaus sogar so 
weit, diese Textform als textus receptus anzuerkennen. Die Christen hatten von da an als „Altes Testament" bis in unsere Zeit die jüdische Bibel, wie sie textgeschichtlich durch die frühen Drucke festgeschrieben war.

Ungeachtet dieser gelehrten Kooperationen beherrschte die christozentrische Auslegung des Alten Testaments die kirchliche Wirklichkeit derart, dass dem gemeinsamen Text nur begrenzte positive Auswirkungen zukamen. In der Theologie wurde dieser die Judenfeindschaft fördernde Umstand erst relativ spät erkannt und eine Neubesinnung gefordert, so besonders energisch auf katholischer Seite etwa in einem Aufsatz von Josef M. Oesch ${ }^{1}$ im Jahr 2006, und auf evangelischer Seite 20II in einem vieldiskutierten Buch von Frank Crüsemann. ${ }^{2}$ Das ist aber nicht Gegenstand der Judaistik. Selbstverständlich ist das Neue Testament mit den anderen frühjüdischen Schriften, speziell den Werken des Flavius Josephus, für die Judaistik eine Quelle von besonderem Gewicht. Aber weniger wegen der Person des Jesu von Nazaret und seiner christlichen Wahrnehmung, sondern als Zeugnis einer (immer noch) jüdischen Richtung mit einer Fülle von Hinweisen auf Verhältnisse und Umstände, die in der sonstigen, stark durch die Bildungstraditionen am Tempel geprägten frühjüdischen Literatur kaum belegt werden. ${ }^{3}$

Die moderne Bibelwissenschaft hat ungeachtet bestimmter gruppenspezifischer Besonderheiten eine religiös neutrale Plattform geschaffen, auf der man die biblischen Texte ohne kontroverstheologische Zwänge unter Fachleuten diskutieren kann, für deren Arbeit die alten Antagonismen, seien es innerchristliche oder christlich-jüdische, keine maßgebliche Bedeutung mehr haben. Ob und wie dies theologisch fruchtbar sein kann, ist eine Frage für sich. Aus judaistischer Sicht, aber auch aus der Sicht einer modernen Wissenschaft des Judentums, stellt dies einen grundlegenden Wandel im Verhältnis zueinander dar, nämlich die Ermöglichung persönlicher Kontakte und Kooperationen auf gleicher Ebene. Denn in den letzten fünfzig Jahren hat sich im modernen Judentum auch eine Bibelwissenschaft entfaltet, die mit der christlichen wissenschaftlich Schritt halten kann und auf Grund der besonderen eigenen Voraussetzungen imstande ist, neue Wege und Möglichkeiten aufzuzeigen, aber auch ein recht variables Eigenprofil entwi-

I Oesch, Josef M.: Die gemeinsame Bibel von Juden und Christen. Der steinige Ausstieg aus dem katholischen Antijudaismus, in: Guggenberger, Wilhelm / Steinmair-Pösel, Petra (Hg.): Religionen - Miteinander oder Gegeneinander? Vorträge der sechsten Innsbrucker Theologischen Sommertage, Frankfurt a. M.: Peter Lang 2006, 45-60.

2 Crüsemann, Frank: Das Alte Testament als Wahrheitsraum des Neuen. Die neue Sicht der christlichen Bibel, Gütersloh: Gütersloher Verlagshaus 20II.

3 Frey, Jörg: Neutestamentliche Wissenschaft und Antikes Judentum: Probleme - Wahrnehmungen - Perspektiven, in: ZThK IO9 (2OI2) 445-47I. 
ckelt hat. ${ }^{4}$ Dass auch religiöse und politische Impulse wirksam sein können, wie im Fall der Archäologie im Staat Israel, ist natürlich mit zu bedenken. In der Folge kann sich dergleichen jedenfalls auch auf das interreligiöse Verhältnis auswirken. Als spürbarste Auswirkung ist gleichwohl ein normal gelebtes Miteinander in Forschung und Lehre zu verzeichnen. Man darf das nicht unterschätzen, auch im Fall, dass der theologische Ertrag dürftig ausfällt. Die Normalität des zwischenmenschlichen Verhaltens ist ja angesichts der langen Zeit abwertender Duldung und scheuer Bewunderung auch heute keine Selbstverständlichkeit.

Die jüdische Orthodoxie lehnt allerdings die moderne jüdische Bibelwissenschaft ab, und auch in modernen jüdischen Richtungen werden Hemmschwellen wirksam, sobald der Pentateuch zum Gegenstand kritischer Forschung wird. Die Vertreter der jüdischen Orthodoxie haben im Gegensatz zur christlichen Theologie kein grundsätzliches, religiös begründetes Interesse an einer Auseinandersetzung mit dem Christentum. Was Nichtjuden religiös denken oder tun, ist für das traditionelle Judentum nur relevant, sofern es die eigene religiöse Praxis behindert oder die Existenz als Gruppe gefährdet. Dabei spielt der Staat Israel immer eine Rolle, auch für Nichtzionisten, weil im Land Israel eben so viele Juden leben. Von daher entstehen sogar zwanghafte Verhaltensweisen, die mit eigenen Grundsätzen, sowohl der modernen Richtungen wie orthodoxer Kreise, kollidieren. Und aus dieser zwanghaften, durch politische Agitationen noch verstärkten Verteidigungsattitude ergibt sich die Notwendigkeit, Verbündete zu suchen, wobei man auf der christlichen Seite am leichtesten fündig wird, vor allem in Kreisen, die ohnedies zu Konfrontationen neigen und die Weltbewohner in gute Fromme und böse Schurken einteilen.

In Europa wird weithin übersehen, welches weltpolitische Gewicht diese Verbindung zwischen jüdisch-fundamentalistischen bis ultranationalistischen Kreisen und christlichen, prozionistischen Fundamentalisten aktuell hat. Die Außenpolitik der USA wird in erheblichem Maß von Vorstellungen bestimmt, die auf eine endzeitliche Konfrontation zwischen Guten und Bösen abzielen, um nach der Schlacht

4 Siehe v. a. Berlin, Adele / Brettler, Marc Z. (Hg.): The Jewish Study Bible. Oxford: Oxford University Press 2004; Liss, Hanna, in Zusammenarbeit mit Annette M. Böckler und Bruno Landthaler: TANACH. Lehrbuch der jüdischen Bibel (Schriften der Hochschule für Jüdische Studien Heidelberg 8), Heidelberg: Universitätsverlag Winter ${ }^{3}$ 2oII; Shavit, Yaacov $/$ Eran, Mordechai: The Hebrew Bible Reborn: From Holy Scripture to the Book of Books. A History of Biblical Culture and the Battles over the Bible in Modern Judaism (Studia Judaica 38), Berlin: de Gruyter 2007; Kugel, James L.: How to Read the Bible. A Guide to Scripture, Then and Now, New York: Free Press 2008; Sommer, Benjamin D. (Hg.): Jewish Concepts of Scripture. A Comparative Introduction, New York: New York University Press 2012. 
von Harmagedon das endgültige Heilsziel zu erreichen. Diese wahnwitzigen Zielsetzungen machen sich der "military-industrial complex“, die Rüstungsindustrie und die mit ihr verbundenen Großunternehmen für ihre Absatzstrategie zunutze, was bereits Eisenhower in seiner Abschiedsrede als Präsident der USA als große Nachkriegsgefahr bezeichnet hat. Im Vergleich dazu stellt sich das christlich-jüdische Verhältnis in Europa als harmlose Spielwiese dar, obwohl man doch weiß, dass mit der NATO auch die EU in den Strudel der weltpolitischen Vorgänge eingebunden und drauf und dran ist, sich im Nahostkonflikt zu verheddern, weil man Zionismus und Judentum und schließlich sogar den Staat Israel und das Judentum gleichsetzt und dies oft mit Rekurs auf das Alte Testament zu untermauern sucht. Das Alte Testament wird als angeblich gemeinsame Heilige Schrift von Christen und Juden nämlich auch zur Rechtfertigung des Verhaltens gegenüber dem Islam verwendet. Dass der Islam den Text der biblischen Bücher nicht tradiert hat, wurde auf jüdischer wie christlicher Seite übel vermerkt. Der fehlende gemeinsame Text hat in diesem Rahmen den Vorwurf der Schriftfälschung provoziert, und daher sollte man nach jüdischer Ansicht mit Muslimen lieber nicht über biblische Texte und Themen diskutieren. Man anerkannte darum einerseits als positiv, dass die Christen den Bibeltext hatten, wenn auch in Übersetzungen, musste freilich darauf beharren, dass die christliche Auslegung des AT völlig willkürlich und nicht nachvollziehbar sei. Andererseits hielt das jüdische Recht mit weitreichenden kulturellen und sozialen Folgen fest, dass der Islam keinen Götzendienst darstellt, während man im Blick auf das Christentum diesbezüglich noch bis in die Neuzeit und teilweise bis heute nicht recht sicher war. Bis zur Aufklärung wusste man sich als Jude jedenfalls dem Islam näher als dem Christentum. Erst die Europäisierung des Judentums infolge der Emanzipation leitete eine Umkehrung der Wertung ein. Die Versuchung, unter Berufung auf die gemeinsame Bibel einen gemeinsame Frontstellung gegen den pauschal als Feindbild projizierten Islam zu fordern und zu konstruieren und die jüdische wie christliche Religion für politische Auseinandersetzungen zu instrumentalisieren, ist darum zur Zeit besonders akut und sollte in der Politik mit mehr Sorgfalt bedacht werden.

In solchen Kontexten wird die Bibel im Sinne des Alten Testaments als einheitliche Größe zitiert, ohne Rücksicht auf die tatsächliche Form und Rolle dieser Schriften im Judentum. Mit den modernen jüdischen Richtungen besteht diesbezüglich allerdings ein gewisser Konsens. Auch das Reformjudentum hat eine vergleichbare Auffassung von der Schrift. Es hat den Akzent ebenfalls von der Tora auf die Propheten und den Psalter verschoben und die Bedeutung des jüdischen Rechts durch ein pathetisch propagiertes biblisch-jüdisches Ethos ersetzt, das man v. a. den Prophetenbüchern unterlegt. 
2. Die biblischen Bücher und der Offenbarungsbegriff im Judentum

Der Judaist sieht die jüdische Bibel selbstverständlich im Licht der Vorgaben in der jüdischen Tradition. Es handelt sich um grundlegende Unterschiede in Bezug auf Einteilung und Wertung und damit verbunden auch der praktisch-religiösen Verwertung. Nur in modernen jüdischen Richtungen, also v. a. im Reformjudentum, haben diese Vorgaben so gut wie keine Bedeutung mehr.

Eines ist aber vorweg festzuhalten: Den Begriff „Kanon“ gibt es im Judentum nicht, er stammt aus der christlichen Dogmengeschichte. Zwar wird manchmal der Ausdruck miqra 'verwendet, also „(gelesene) Schrift“, aber konkret werden nach Offenbarungsautorität, liturgischer Schriftlesungspraxis und rabbinischen Schreibvorschriften drei klar abgegrenzte Korpora unterschieden, Tôra, Nebî îm (Propheten) und Ketûbìm (Schriften), abgekürzt $T N^{\prime \prime} K$.

Tôra bezeichnet in diesem Rahmen den Pentateuch, konkreter aber die so genannte „schriftliche Tora“ im Pentateuch, 6r3 Gebote und Verbote, dem Mose am Sinai diktiert. Ein großer Teil davon kann nur zur Zeit des Tempels und im Land Israel praktiziert werden, die schriftliche Tora reicht also keineswegs aus, um jüdisches Leben zu organisieren. Der Pentateuch hat aber einen hohen Symbolwert, repräsentiert die Gesamttora, wird daher auch liturgisch innerhalb eines Jahres kontinuierlich nach Sabbat-Perikopen feierlich und demonstrativ vorgelesen.

Zur Gesamttora, der verbindlichen Offenbarung, gehört die viel umfangreichere „mündliche Tora“, ebenfalls durch Mose am Sinai offenbart, aber mündlich tradiert, später im talmudischen Schrifttum niedergeschrieben, also außerhalb des (christlichen) Bibelkanons. Die so genannte "gemeinsame Schrift“ enthält also nur zum geringeren Teil das, was für jüdisches Leben als verbindliche Offenbarung gilt.

Schriftliche und mündliche Tora bilden die Grundlage des jüdischen Rechts, der Halacha, die alle Bereiche des jüdischen Lebens regelt. Folglich stehen das jüdische Recht und seine Geschichte systembedingt im Zentrum des judaistischen Interesses.

Leider sieht die Realität anders aus: Es gibt nur mehr wenige Judaisten, die in den Quellen des jüdischen Rechts bewandert sind, meist fehlen die philologischen, also hebraistischen und aramaistischen Voraussetzungen, und infolge der neueren Bildungspolitik werden diese philologischen Grundlagen immer weiter abgebaut. Es war nicht zuletzt die philologische Kompetenz, die uns in die Lage versetzt hat, auch Studierenden aus Israel noch etwas bieten zu können.

Die negativen Folgen treffen aber nicht nur das Fach selbst, sie vermindern auch die Kompetenz der christlichen Seite im christlich-jüdischen Dialog. Das Herzstück der jüdischen Tradition, das jüdische Recht, rückt in den Hintergrund, man 
begnügt sich mit eventuell vorhandenen Übersetzungen und ist selber auf Gewährsleute angewiesen, deren tatsächliche Fachkompetenz man nicht zu beurteilen imstande ist. Diese einseitige Entwicklung hat ihren Ursprung in einer berechtigten Kritik am Begriff des „Gesetzes“ und insbesondere der „Gesetzlichkeit“, mit der sich die Theologie im 19. und 20. Jahrhundert antisemitischen Vorurteilen ausgeliefert hatte. Dieses Missverständnis der Bedeutung der Tora verleitete im Zug der Korrektur dieser Vorstellungen aber dazu, das Kind mit dem Bade auszuschütten und die Bedeutung des jüdischen Rechts für die jüdische Tradition zu verkennen.

Das Prophetenkorpus besteht aus den Geschichtsbüchern und den Prophetenbüchern, sie enthalten keine Tora, haben aber heilsgeschichtstheologische Bedeutung, und aus diesem Grund werden zu den Toraperikopen auch Haftarot, Auswahlperikopen, aus diesem Korpus vorgelesen.

Aus den Ketûbîm Schriften erfolgt keine liturgische Lesung, ungeachtet der vielfältigen liturgischen Verwendung von Psalmen und Einzelversen. Als inspirierte Dichtungen Davids stehen die Psalmen aber den Prophetenschriften nahe und wurden darum exegetisch ähnlich behandelt.

Die Auslegungsgeschichte der biblischen Bücher ist ein faszinierender Teil der judaistischen Arbeit, nicht nur wegen der Bedeutung der Texte, sondern auch wegen der vielfältigen Informationen, die Bibelauslegungen darüber hinaus enthalten können. Auch in der Kontroversliteratur spielt die Exegese eine beträchtliche Rolle, folglich ist sie auch für das moderne christlich-jüdische Gespräch von Bedeutung. Die Interessenlage ist dabei freilich einseitig zugespitzt, vor allem auf Texte, die für die christliche Theologie von besonderer Bedeutung sind. Und da bei der christlichen christozentrischen Auslegung von jüdischer Seite meist auf den Wortsinn verwiesen wurde, also auf den rational nachvollziehbaren Sinn, entstand der Eindruck, dieser sei das Merkmal des jüdischen Bibelverständnisses überhaupt. Innerjüdisch sieht dies anders aus, der Wortsinn gilt zwar als so gut wie unaufhebbar, aber darüber hinaus setzte man wie im Christentum mehrere Schriftsinne voraus, und über allen steht der geheime Schriftsinn, für manche philosophischer, für andere esoterischer, kabbalistischer Natur.

Einzelne christliche Gelehrte, sogar hochrangige Kleriker, haben sich intensiv für diese kabbalistische Tradition und Exegese interessiert, aber mit der Aufklärung schrumpfte auch im Judentum selber die Bedeutung solcher Traditionen auf Restbestände in engeren, traditionalistischen Kreisen ein. So blieb der Wortsinn in nichtjüdischen Augen weithin als das für das Judentum kennzeichnende, rationalistische Bibelverständnis im nichtjüdischen Bewusstsein. Das verleitet manchmal zu Trugschlüssen, wenn jemand zur Korrektur des traditionellen christlichen Verständnisses in der jüdischen Exegese das Heilmittel sucht. 
Zurzeit hat Esoterik einen hohen populär-religiösen Marktwert. Manche suchen in der Kabbala das „genuin Jüdische", aber nur wenige sind in der Lage, die einschlägigen, u. a. auch bibelexegetischen Quellen im Original zu lesen. Man sucht also Übersetzungen und Gewährsleute. Und dieser Nachfrage wird entsprochen. Weltweit wird eine popularisierte Form der Kabbala in so genannten Kabbala-Centers angeboten und eine erstaunlich hohe Zahl von Juden wie Nichtjuden - inklusive Popstars - unterstützen leichtgläubig und freigebig diese florierenden Unternehmen. Solch eine „Kabbala light“ hat mit der wirklichen Kabbala nur mehr wenig gemein. Der eigentliche Zweck der Kabbala ist ja die spekulative und religiös-praktische Integration der Torafrömmigkeit in ein universales System der Welterklärung. Löst man die Tora aus diesem System heraus, kann man den Rest eigentlich nicht mehr Kabbala nennen, denn was bleibt, ist ein neuplatonisch fundiertes Weltbild in einer vulgär verwässerten Form, eine Wellness-Religiosität für die Bedürfnisse religiös frustrierter Kreise der Gesellschaft.

\section{Die frühe Wiener Judaistik, das AT und der christlich-jüdische Dialog}

Kurt Schubert hat sich an der Universität Wien und darüber hinaus hartnäckig und schließlich mit Erfolg bemüht, das Judentum als historisches, religionsgeschichtliches und kulturgeschichtliches Gesamtphänomen in den Fächerkatalog der philosophischen Fakultät einzuführen, um eine Lücke zu füllen, die sich in der Vergangenheit als äußerst verhängnisvoll erwiesen hatte. Zwei Voraussetzungen waren dabei grundlegend. Einmal die philologische Kompetenz, die sich aus der Verbindung mit der Semitistik ergab, und zum Zweiten die Verbindung von Gesamtüberblick über das Fachgebiet mit konkreter Einzelforschung.

Kurt Schubert ist es zu verdanken, dass der Ausdruck „Spätjudentum“ durch „Frühjudentum“ ersetzt wurde, was in der Erforschung des antiken Judentums den Blick auf die weitere Geschichte des Judentums öffnete und allein dadurch auch das Alte Testament in seiner jüdischen Bedeutung deutlicher ins Blickfeld brachte. Es ist daher auch kein Zufall, dass die Initiative für eine Institutionalisierung des christlich-jüdischen Gesprächs in Österreich von Kurt Schubert ausgegangen ist. Auf evangelischer Seite wirkte Wilhelm Dantine als Bahnbrecher für eine Neubesinnung über das Verhältnis zu AT und Judentum.

Die Gründung eines eigenen Instituts mit einer ordentlichen Professur für Judaistik wurde in hohem Maße durch eine forschungsgeschichtliche Sensation gefördert, nämlich durch Fund und Publikation der Qumrantexte. Kurt Schubert war auch auf diesem Gebiet einer der frühesten und gefragtesten Spezialisten. Für die alttestamentliche Wissenschaft war insbesondere der Fund biblischer Hand- 
schriften von Bedeutung, deren Alter die bis dahin bekannten um rund ein Jahrtausend übertraf. ${ }^{5}$ Die eigentümliche Ausdeutung prophetischer Texte im Sinne der Pešer-Methode belebte über die textgeschichtlichen Aspekte hinaus die auslegungsgeschichtliche Forschung. ${ }^{6}$ Besonders hervorzuheben ist in diesem Zusammenhang die Entwicklung einer immer stärker werdenden Kooperation zwischen jüdischen und nichtjüdischen Forschern, die sich allmählich über die Textgeschichte hinaus auf weitere Bereiche der Bibelwissenschaften erstreckte. ${ }^{7}$ Nicht zuletzt wurden in langwierigen Diskussionen einige Begriffe und Vorstellungen korrigiert, die aus einem vorgefassten christlichen Verständnis der Bibel und des „Kanons“ heraus das Verständnis der neuen Textfunde behindert haben. ${ }^{8}$

Als vergleichsweise spekulationsanfällig erwies sich das Interesse der neutestamentlichen Wissenschaft, vor allem wegen erhoffter Bezüge zu Jesus von Nazaret und wegen vermeintlicher, aber auch tatsächlicher Aufschlüsse hinsichtlich zahlreicher Begriffe und Vorstellungen im neutestamentlichen und frühkirchlichen Schrifttum. So ergab sich eine schier unübersehbare Flut von Publikationen, weithin nicht ernst zu nehmen, aber meist durch ein neues und intensives Interesse an der Hebräischen Bibel und an der Geschichte des antiken Judentums bestimmt. Auch der christlich-jüdische Dialog wurde durch diese Vorgänge und durch diese neue Situation auf nachhaltige Weise mitbestimmt.'

5 Lange, Armin: Handbuch der Textfunde vom Toten Meer. I. Die Handschriften biblischer Bücher von Qumran und den anderen Fundorten, Tübingen: Mohr Siebeck 2009.

6 Bernstein, Moshe J.: The Contribution of Qumran Discoveries to the History of Early Biblical Interpretation, in: Najman, Hindy / Newman, Judith H. (Hg.): The Idea of Biblical Interpretation: Essays in Honor of James L. Kugel (JSJ 83) Leiden: Brill 2004, 215-238; Lange, Armin / Dávid, Nóra (Hg.): Qumran and the Bible. Studying the Jewish and Christian Scriptures in Light of the Dead Sea Scrolls (Contributions to Biblical Exegesis \& Theology 57), Leuven: Peeters 2010.

7 Dávid, Nóra u. a. (Hg.): The Hebrew Bible in Light of the Dead Sea Scrolls (FRLANT 239), Göttingen: Vandenhoeck \& Ruprecht 2012.

8 Ulrich, Eugene C.: Clearer Insight into the Development of the Bible - A Gift of the Scrolls, in: Roitman, Adolfo D. / Schiffman, Lawrence H. / Tzoref, Shani (Hg.): The Dead Sea Scrolls and Contemporary Culture: Proceedings of the International Conference Held at the Israel Museum, Jerusalem (July 6-8, 2008) (STJD 93) Leiden: Brill 2011, II9-I37; Najman, Hindy: The Vitality of Scripture Within and Beyond the "Canon", in: JSJ 43 (2012) 497-518; Tov, Emanuel: Samkûtan šäl ha-meîillôt ha-miqra'ijôt ha-q'dûmôt. The Authority of Early Hebrew Scripture Scrolls, in: Meghillot io (2013) 57-7I.

9 Schuller, Eileen: The Dead Sea Scrolls and Jewish-Christian Dialogue, in: Walters, Patricia (Hg.): From Judaism to Christianity. Tradition and Transition. A Festschrift for Thomas H. Tobin, S.J., on the Occasion of His Sixty-Fifth Birthday (NT Supplements I36), Leiden: Brill 20I0, 43-58. 


\section{Zwei problematische Phänomene}

\section{I Die Landverheißungen}

Die Bedeutung und Verbindlichkeit der Landverheißungen an die Erzväter und folglich sowohl für jüdisches religiöses Bewusstsein und Handeln als auch für christliche Theologie und deren politische Orientierung sind heftig diskutierte Aspekte der Land-Theologie insgesamt und in ihren diversen jüdischen und christlichen Ausformungen. ${ }^{10}$

Da ein beträchtlicher Teil der einschlägigen Publikationen Parteinahmen darstellen, wird in der Regel eine passende, vereinfachte Vorstellung von der Bedeutung des „Heiligen Landes" unterstellt und dient als Basis für Schlussfolgerungen. ${ }^{11}$ Aber schon in der Antike gab es unterschiedliche Vorstellungen, doch stets tritt dabei das „Land Israel“ als eigentlicher Geltungsbereich der Tora ${ }^{12}$ in Erscheinung, und auch für die weitere Geschichte der jüdischen Religion bleibt diese Bindung des Landbesitzes an die Torapraxis bis zur Aufklärung und in der Orthodoxie bis heute maßgeblich. Moderne jüdische Richtungen haben damit ihre liebe Not. Grundsätzlich kann man die traditionelle Landtheologie nicht mehr teilen. ${ }^{13}$ Aber die Tatsache, dass rund die Hälfte der Judenheit heute im „Land Israel“ lebt, zwingt wohl oder übel zu einer gewissen Solidarisierung, ungeachtet dessen, dass am Zionismus auch profunde Kritik geübt wird. ${ }^{14}$

Io Goldman, Shalom: Zeal for Zion: Christians, Jews, and the Idea of the Promised Land, Chapel Hill: University of North Carolina Press 20Io; Munayer, Salim J. / Loden, Lisa (Hg.): The Land Cries Out. Theology of the Land in the Israeli-Palestinian Context, Eugene, OR: Cascade Books 2012.

II Zur besonderen Situation der evangelisch-theologischen Diskussion in Deutschland siehe v. a.: Marquardt, Friedrich Wilhelm: Die Bedeutung der biblischen Landverheißungen für die Christen, München: Kaiser 1964; Haacker, Klaus: Die biblischen Landverheißungen und der jüdisch-palästinensische Konflikt, in: ThBeitr 34 (2003) 294-305; Evangelische Kirche in Deutschland Kirchenamt (Hg.): Gelobtes Land? Land und Staat Israel in der Diskussion. Eine Orientierungshilfe, Gütersloh: Gütersloher Verlagshaus 2012.

I2 Dimant, Devorah: Je rûšat ha-'aräş ’al pî tefîsatah šäl ’adat mêîllôt Qûmra'n. The Inheritance of the Land of Israel According to the Ideology of the Qumran Community, in: Meghillot 8-9 (2010) II3-I33; de Vos, Cornelis Jacobus: Heiliges Land und Nähe Gottes. Wandlungen alttestamentlicher Landvorstellungen in frühjüdischen und neutestamentlichen Schriften. The Holy Land and Nearness to God. How Old Testament Concepts of Land Changed in Early Jewish and New Testaments Writings (FRLANT 244), Göttingen: Vandenhoeck \& Ruprecht 2012.

I3 Novak, David: Land and People, in: Walzer, Michael (Hg.): Law, Politics, and Morality in Judaism, Princeton, NJ: Princeton University Press 2006, 57-82.

I4 Rabkin, Yakov M.: A Threat from Within. A Century of Jewish Opposition to Zionism, 
Die Landverheißungen an die Erzväter werden in prozionistischen christlichen Kreisen gern wörtlich genommen und als unbedingte, für immer gültige Verheißungen aufgefasst. Die Propaganda der säkularen und teilweise religiös eingefärbten Richtungen des Zionismus macht davon in diesem Sinne Gebrauch und in der politischen Praxis werden die dabei formulierten Ziele konsequent realisiert. ${ }^{15}$ Soweit auf christlicher Seite Zionismus und Judentum identifiziert werden, geraten die diesbezüglichen schwerwiegenden innerjüdischen Differenzen aus dem Blickfeld.

In der jüdischen Tradition selbst gelten die Landverheißungen an die Erzväter mit der Landnahme unter Josua als erfüllt, das heißt: nach der Sinaioffenbarung. Von dieser an gibt es keine unbedingte Verheißung mehr, denn von nun an entscheidet sich Israels Geschick als Folge der Ausführung oder Vernachlässigung der Tora. Dies wird z. B. unter Verwendung liturgischer Segens- und Fluchformulare in Lev 26 und Dtn 28 und darüber hinaus in Dtn 29f. auf sehr drastische Weise formuliert. Der Besitz des Landes ist nach jüdischer Tradition selbstverständlich an den Toravollzug gebunden. ${ }^{16}$

Löst man die Landverheißungen von dieser Grundvoraussetzung, also von der Tora, schafft man etwas ganz anderes, etwas im Sinne der Tradition Un-jüdisches. Ausgerechnet so etwas zum Anknüpfungspunkt für eine christlich-theologische Stellungnahme zu machen, ist ein wohl fragwürdiges Unterfangen. Denn man unterstützt dabei vor allem eine Land-Ideologie, die in der Regel rechtsextrem unterfüttert ist. Doch auch der linkssozialistische Zionismus hat eine Landideologie entwickelt, die mit der rechtsextremen in der Zielsetzung weitgehend übereinstimmt. Nicht zufällig leitete ein linkssozialistischer Minister und ehemaliger General aus der Palmach-Elite mit dem „Alon-Plan“ jene Siedlungspolitik ein, die auf die Jordangrenze abzielt. Und da auch ein Teil der pionierzionistischen Sozialdemokratie davon beeinflusst wurde und für ihre zionistische Propaganda auch von Passagen

Winnipeg: Zed Books 2006; Brumlik, Micha: Kritik des Zionismus, Hamburg: Europ. Verlagsanstalt 2007; Aloni, Udi: What Does a Jew Want? On Binationalism and Other Specters, New York: Columbia University Press 20Ir. Neuerdings sehr exponiert: Butler, Judith: Parting Ways. Jewishness and the Critique of Zionism, New York: Columbia University Press 20I3. Die Verfasserin hat sich in der Genderforschung einen Namen gemacht und ethische Kriterien in Bezug auf Ausübungen von Gewalt in Staat und Gesellschaft entwickelt, die sie in dieser Publikation sehr dezidiert auf die Politik des Staates Israel anwendet.

I5 Cytrin, Yitzhak: Ha-pôlîțîqah ha-qarqa 'ît šäl ha-t'nû’ah ha-şijjônît bi-š elat ge' ûllat ha'aräş bi-šnôt ha-20, in: Shaanan 4 (1997/8) 155-170.

I6 Gesundheit, Shimon: Das Land Israels als Mitte einer jüdischen Theologie der Tora: Synchrone und diachrone Perspektiven, in: ZAW I23 (201I) 325-335. 
im AT Gebrauch machte, ergab sich die vertrackte Situation, dass es zur rechtsextremen, revisionistisch-zionistischen Landideologie keine politisch wirksame Alternative mehr gibt, zumal noch dazu ein starker Flügel der religiösen Zionisten eine messianisch motivierte Landtheologie verficht, die sich von der rechtsextremen Position in der Sache so gut wie nicht unterscheidet. Wenn in christlichen Kreisen eine prozionistische „Landtheologie“ vertreten wird, ist man sich kaum je im Klaren, in welchen ideologie- und religionsgeschichtlichen Kontexten man sich damit verheddert. Doch wer von sich behauptet, aus der Geschichte gelernt zu haben, sollte solchen Tendenzen gegenüber eigentlich immun sein.

\section{2 "Erstes" und "Zweites" Testament}

Die Hebräische Bibel kennt ja nicht bloß einen Bund, sie spricht von Bundesschlüssen im Zusammenhang mit Noah und der Sintflut, mit Abraham und der Beschneidung als Bundeszeichen, das Jubiläenbuch hebt einen Bund in Bethel hervor, in dem die Kultordnung und die Kultdienerschaft des Stammes Levi begründet werden. Der Bund am Sinai gilt als Bund Gottes mit dem Volk Israel schlechthin, doch gibt es noch den Bund, der den Nachfahren des Eiferers Pinchas das Priesteramt zusichert, den Bund im Lande Moab im Zusammenhang mit dem Deuteronomium, einen Bund mit David bzw. der davidischen Dynastie und einen „Neuen Bund“ in Jer 3r. Nicht zu vergessen die deuteronomistischen und chronistischen Darstellungen von Kultreformen judäischer Könige als Bundeserneuerungen. Die Vorstellung, ein Bund hebe einen anderen, früheren, auf, hat da keinen Platz, ein neuer Bund ergänzt Bestehendes und erneuert Versäumtes.

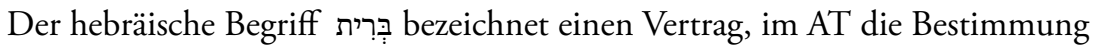
des Verhältnisses Gott - Israel nach dem Muster des Vasallenvertrags. Nie steht das Wort בִּרִ für „letztwillige Verfügung“. Die Formulierung „Tora des Mose“ bot freilich einen Ansatzpunkt für ein Verständnis als „hinterlassene Verfügung“. Im AT selbst und im hebräischen Schrifttum der Zeit des Zweiten Tempels wird mit „Mose“ jedoch die absolute Verbindlichkeit bzw. die Offenbarungsqualität einer Regelung signalisiert. In der LXX wird bis auf wenige Fälle $\delta\llcorner\alpha \theta \eta \dot{\kappa} \kappa \eta$ für בְּרִ verwendet, viermal auch für עִדוּת, ,Zeugnis“, ein juristischer Begriff für eine hinterlegte Urkunde. In hellenistisch-jüdischen Quellen wird Mose hellenistischem

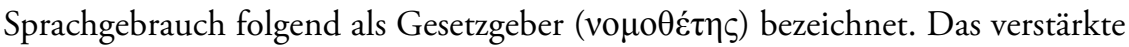
den Trend einer Auffassung von der Tora als Hinterlassenschaft des Mose.

Die lateinische Übersetzung von $\delta 1 \alpha \theta \eta \dot{\kappa \eta}$ mit testamentum verabsolutierte diesen Aspekt. Und infolge des allgemein verbreiteten Verständnisses von „Testament“ musste sich für das Verständnis des Titels „Altes Testament“ zwangsläufig ein Ver- 
ständnis ergeben, das der Substitutionstheorie in der christlichen Theologie entsprach: Das neue Testament hebt das alte auf.

Doch diese Deutung beherrschte keineswegs die gesamte Szenerie. Gerade das Attribut ,alt" bewahrte die Hebräische Bibel davor, als obsolet gewertet zu werden, denn im Gegensatz zur modernen Wertskala verband sich mit der Qualität des Alters die Vorstellung von Ehrwürdigkeit. Um Neues zu rechtfertigen, versuchte man folglich dafür nicht selten, einen Altersbeweis zu erbringen. Diese Hochschätzung übertrug sich zum Teil auch auf das Judentum als der Gruppe, die dieses ehrwürdige Erbe in Form seines hebräischen Textes überliefert und erhalten hat. Die Rede vom Ersten und Zweiten Testament setzt hingegen eine negative Wertung des Alters voraus, eine mentalitätsgeschichtlich bedeutsame Umpolung mit weitreichenden Folgen für den Umgang mit Altem, nicht zuletzt auch alten Menschen, kein Ruhmesblatt für die heutige jüngere Generation.

War also die Übersetzung mit testamentum schon ein Malheur, so die Rede vom Ersten und Zweiten Testament umso mehr, denn massiver konnte man die Substitutionstheorie nicht wiederbeleben: Ein zweites Testament hebt selbstverständlich jedes vorausgehende auf, macht es ungültig. Und als Buchtitel ist „Altes Testament" mit seinen Entsprechungen in allen Sprachen der Menschheit allein schon aus bibliographischen und bibliothekstechnischen Gründen unantastbar.

Es ist also nach wie vor sinnvoller, vom Alten und Neuen Bund zu reden, weil auf diese Weise nicht nur etwas Neues, sondern auch eine Kontinuität angezeigt werden kann, vorausgesetzt, man versteht „alt“ nicht als „abgetan“ und „neu“ im Sinne von Erneuerung und Ergänzung des Alten. Aber zweifellos geht es auch um Neues, andernfalls wäre das Christentum erst gar nicht zustande gekommen, und diesen Umstand kann man nur um den Preis einer kurzschlüssigen Anknüpfung ausklammern, auch wenn sich die Theologie sichtlich schwer tut, dieses „Neue“ zu definieren.

Es gibt von der Judaistik aus gesehen allerlei Möglichkeiten für neue theologische Ansätze. Doch gibt es heute weder ein "Christentum“ noch ein „Judentum“ als einheitliche, fest definierte Größe. Theologisch diskutieren miteinander immer Vertreter einzelner Gruppen oder Richtungen, und dabei kommt es darauf an, ob es sich um Vertreter vergleichbarer Größen handelt. Es ist nun einmal so, dass aus streng orthodoxer jüdischer Sicht kein Interesse an einem Dialog besteht bzw. bestehen kann. Wer dies beklagt, sollte bedenken, wie viele christliche Strömungen und Gemeinschaften es gibt, die in fundamentalistischer Selbstgenügsamkeit auch zu keinem Dialog bereit oder fähig sind. Und es liegt nun einmal im Bestreben der einzelnen Richtungen oder Gemeinschaften, das Ganze repräsentieren zu wollen, also die eigenen Standpunkte als allgemein-christlich bzw. allgemein-jüdische dar- 
zustellen. Die Folge ist, dass immer wieder etwas als allgemeingültig ,jüdisch“ oder „christlich“ dargestellt wird, das nur für Ausschnitte aus dem Gesamtphänomen gelten kann. In diesem Punkt kann die Judaistik, ob sie innerhalb oder außerhalb theologischer Institutionen betrieben wird, sinnvolle Dienste leisten, sofern sie die einzelnen jüdischen Richtungen von heute unparteiisch und umsichtig historisch verortet, in ihrem Anspruch sachgerecht beschreibt und in ihren Grenzen verständlich macht. 


\section{Das Vorverständnis hinterfragen}

\section{Veränderungen alttestamentlich-exegetischer Zugänge aus der lebensweltlichen Begegnung mit dem Judentum}

\section{Erhard Blum}

Der Titel meines Beitrags nimmt die in dem Tagungsthema vorgegebene These einer Veränderung der Theologie durch den jüdisch-christlichen Dialog affirmativ auf und stellt deren Exemplifizierung im Bereich der Exegese in Aussicht. Des Näheren wird es im Folgenden um Beobachtungen aus dem Bereich der alttestamentlichen Exegese gehen, also aus einem Fach, das zu den „historischen“ Disziplinen der Theologie gerechnet wird. Überdies wird der Fokus auf Fragen der historischen Forschung im engeren Sinne liegen. Vordergründig betrachtet mag es erstaunen, dass theologische Neuorientierungen unmittelbare Auswirkungen auf dezidiert historische Analysen haben sollen, deren Unabhängigkeit von spezifischen religiösen Vorgaben gemeinhin zu ihrem disziplinären Selbstverständnis gehört. Zwar fehlt in methodologischen Reflexionen nicht der Hinweis auf die unvermeidliche erkenntnisleitende Rolle eines allfälligen „Vorverständnisses“ welcher Art auch immer, doch ist kaum strittig, dass im historischen Kontext jegliche Vorgabe, sei sie noch so selbstverständlich, gegebenenfalls zur Disposition zu stehen hat. So jedenfalls die Theorie der akademischen Spielregeln. In der Praxis jedoch erweisen sich kritische Standpunktreflexionen als umso schwieriger, je elementarer es dabei um Fragen der eigenen Identität der forschenden Subjekte geht. Dementsprechend erwachsen wirksame Anstöße zu grundlegenden Neuorientierungen am ehesten aus Konfrontationen mit „fremden“ Identitäten; erfahrungsgemäß vollziehen sich diese besonders nachhaltig in persönlichen Begegnungen.

Vor diesem Hintergrund nehme ich die Anregung der Organisatorinnen der Tagung, so etwas wie eine Rückschau auf Auswirkungen des jüdisch-christlichen Dialogs zu unternehmen, in der Weise auf, dass ich Beispiele für Veränderungen der Wahrnehmung aufgrund "grenzüberschreitender" Begegnungen darstelle, und dies teilweise in einer persönlichen Perspektive. Dementsprechend sind die folgenden Überlegungen weder systematisch noch im Sinne einer allgemeinen Übersicht angelegt; exemplarisch konzentrieren sie sich vielmehr auf konkrete historische Sachfragen, deren thematischer Zusammenhang darin besteht, dass sie drei Variationen christlich-exegetischer Konzeptionen eines Abbruchs in der Geschichte Israels repräsentieren. 


\section{I. „Spätjudentum“ versus „Frühjudentum“}

Als ich Ende der 1960er-Jahre mein Studium der evangelischen Theologie in Heidelberg begann, gehörte das antike Judentum naturgemäß zu den wiederkehrenden Themen in exegetischen Veranstaltungen. Die gängige Bezeichnung dafür war „das Spätjudentum“. Gemeint war damit in der Hauptsache „die Religion des Judentums im neutestamentlichen Zeitalter“, wie ein bekannter Buchtitel von Wilhelm Bousset $^{1}$ lautete. Etwas präziser und zugleich großzügiger bestimmt ging es um das Judentum zwischen dem 2. Jahrhundert v. Chr. und dem 2. Jahrhundert n. Chr. (Bar Kochba), also in etwa um das, was heute als „Frühjudentum“ bezeichnet wird. Der Frage, wer den Terminus „Spätjudentum“ geprägt hat, brauchen wir hier nicht nachzugehen. ${ }^{2}$ Jedenfalls liegt die Problematik des Begriffs auf der Hand: Wenn das antike Judentum „spätjüdisch“ war, was ist dann mit dem mittelalterlichen oder dem gegenwärtigen Judentum? Offensichtlich blendet der Ausdruck die weitere Geschichte des Judentums aus. Aber auch die Frage, was dann eigentlich „Frühjudentum“ sein sollte, bleibt offen. M. a. W., der Begriff ist in historischer Perspektive unsinnig und offensichtlich allein wegen seiner evaluativen Implikationen und Konnotationen geprägt und gebraucht worden: Mit „Spätjudentum“ hat man Niedergang/Verfall konnotiert, näherhin so etwas wie eine degenerierte Spätform der alttestamentlichen israelitisch-jüdischen Religion. Und vor allem: Der Begriff impliziert semantisch ein darauf folgendes Ende. ${ }^{3}$ Ohne übertreibende Unterstellungen wird man die Intention in dem Sinne konkretisieren dürfen, dass das Judentum als Erbe des biblischen Israel durch das frühe Christentum ,abgelöst ${ }^{\star}$ worden sei. Kurzum: Das unhistorische Konzept des Spätjudentums brachte das in wesentlichen Elementen antijüdisch geprägte Judentumsbild der christlichen exegetischen Wissenschaften recht genau auf den Punkt. Als Teil der wissenschaftlichen Beschreibungssprache wurden aber zugleich seine evaluativen Implikationen unkontrolliert Teil des Vorverständnisses einer christlichen Wahrnehmung des

I Bousset, Wilhelm: Die Religion des Judentums im neutestamentlichen Zeitalter, Berlin: Reuther \& Reichard I903.

2 Möglicherweise war es Bousset selbst; vgl. die Angaben bei Valerio, Karolina de: Altes Testament und Judentum im Frühwerk Rudolf Bultmanns (BZNW 7I), Berlin: de Gruyter 1994, I2of. mit Hinweisen auf Vorläufer im Gebrauch des Adjektivs.

3 Ein von de Valerio, ebd., I20, mitgeteiltes Zitat Boussets (von I900) spricht für sich: „Ja man wird vielleicht zu dem Urteil kommen, daß das Spätjudentum eine Religion der Zersetzung und eines Aufösungsprozesses ist, durch den noch in ganz anderer Weise, als man bisher annahm, der schöpferischen Neubildung des Evangeliums der Boden vorbereitet ist." 
Judentums. Unbeschadet dessen war dieser Sprachgebrauch in der theologischen Fachliteratur bis in die beginnenden 1970er-Jahre hinein völlig selbstverständlich.

An der Heidelberger Fakultät gab es damals aber jedenfalls eine Stimme, die mit Verve solche Symptome eines christlichen Antijudaismus anprangerte: Es war die israelische Judaistin Pnina Navè (bzw. Navè-Levinson), die durch die Vermittlung von Rolf Rendtorff als Gastprofessorin nach Heidelberg gekommen war und dort kontinuierlich Seminare und Übungen anbot. Uns Studierenden leuchtete ihre Kritik zu diesem Punkt unmittelbar ein, und dies nicht zuletzt deswegen, weil sie mit ihrer Person ein lebendiges Judentum repräsentierte, das sich ausdrücklich in einer Kontinuität mit dem pharisäischen und rabbinischen Judentum der Antike sieht. Ein Insistieren auf dem Konzept „Spätjudentum“ hätte bedeutet, gegenwärtigen Jüdinnen und Juden ihre Identität abzusprechen.

Offenbar war Pnina Navè aber nicht die einzige und erste Jüdin, die diese Aufklärungsarbeit betrieb, und offenbar hatten sich christliche Theologen auch andernorts darauf eingelassen, das Judentum nicht nur als vergangene „historische“ Größe wahrzunehmen. Denn so selbstverständlich der Gebrauch von „Spätjudentum" noch in den 1960er-Jahren gewesen war, so zügig und nahezu komplett verschwand er im Laufe der I970er-Jahre aus den Lehrveranstaltungen und den neu publizierten Büchern. Stattdessen sprach man fortan von dem „Frühjudentum“ “4 oder von dem ,antiken Judentum“. Heute ist dies völlig selbstverständlich. Umgekehrt erscheint es schwer vorstellbar, dass eine wissenschaftliche Publikation mit „Spätjudentum“ im Titel oder im Text noch von einem seriösen Verlag angenommen würde.

\section{Das Ende der Geschichte Israels nach Martin Noth}

Im 20. Jahrhundert gab es eine Darstellung der Geschichte Israels in biblischer Zeit, die den Maßstab setzte, an dem sich alle orientierten: die Geschichte Israels von Martin Noth, publiziert im Jahr 1950. ${ }^{5}$

4 Laut dem Artikel „Frühjudentum“ (notabene!) in RGG 4. Aufl. war der Begriff schon in den 1930er-Jahren von dem amerikanischen Neutestamentler Frederick Clifton Grant als Alternative zu „Spätjudentum“ geprägt worden. Die älteste mir bekannte deutschsprachige Publikation mit „Frühjudentum“ im Titel ist die von Johann Maier und Josef Schreiner 1973 herausgegebene Einführung „Literatur und Religion des Frühjudentums“ (Würzburg / Gütersloh). Interessanterweise ist im Vorwort (anders als in den Beiträgen) „Frühjudentum" fast immer in Anführungszeichen gesetzt; offenbar sollen die Leser/innen auf den Terminus aufmerksam gemacht werden.

Um einer jüngeren Generation den forschungsgeschichtlichen Rang von Noths Werk zu 
Noths Standardwerk gilt in Fachkreisen bis heute als epochal, nicht zuletzt aufgrund seiner profilierten Bestimmung des Einsatzes seiner Geschichte Israels. ${ }^{6}$ Kaum weniger profiliert (wenn auch nicht so nachhaltig) war freilich seine Konzeption von einem „Ende Israels“. Rolf Rendtorff ist eine präzise Analyse der Voraussetzungen und Implikationen dieses Aspekts des Nothschen Werks zu verdanken. ${ }^{7}$ Sie dient den folgenden Ausführungen als Grundlage.

Im letzten Paragraphen ${ }^{8}$ seines Werks schildert Noth zunächst den ersten jüdischen Aufstand gegen Rom, der zur Zerstörung des Tempels führte. Er hebt hier insbesondere den Verlust Jerusalems als eines kollektiven Mittelpunkts hervor und kommentiert emphatisch: „Damit hörte Israel zu bestehen auf, und die Geschichte Israels fand ihr Ende. ${ }^{\text {" }}$ Konsequenterweise kann Noth in dem späteren gescheiterten Aufstand unter der Führung von Bar-Kochba (bzw. Ben Kosiba) nur mehr „das schauerliche Nachspiel der Geschichte Israels" sehen. ${ }^{10}$

Eine solche Rede von einem „Ende Israels“ ist bei einem Historiker von der Konsequenz Martin Noths nur denkbar unter der Voraussetzung eines entsprechenden „Israel“-Begriffs. Nicht von ungefähr setzt denn auch die ganze Darstellung in $₫$ I mit der Frage ein, „(w)as ,Israel', der Gegenstand einer ,Geschichte Israels' gewesen sei“. Zwar könne die Frage ,erst in der Darstellung der ,Geschichte Israels" selbst eine begründete Antwort finden“, doch zeigt seine ausführliche Problemanzeige (\$ I) bereits die Richtung an. Dazu gehört eine Relativierung des

vermitteln, hat Rolf Rendtorff gern erzählt, wie Gerhard von Rad in den I95oer-Jahren seinen Schülern gegenüber bemerkte, die wesentlichen Fragen der Geschichte Israels seien durch Noth geklärt.

6 Noth, Martin: Geschichte Israels, Göttingen: Vandenhoeck \& Ruprecht ${ }^{6}$ I966, 55: „Geschichtlich wirklich erfaßbar ist die Gesamtheit ,Israel', nach der alttestamentlichen Überlieferung ein Verband von zwölf einzelnen Stämmen, erst als eine auf dem Boden des palästinischen Kulturlandes lebende Größe.“ Der Erzählstoff über die Erzväter, Exodus und Sinai gehört nach Noth nicht zur Geschichte Israels, sondern repräsentiert „Traditionen“ des von Noth angenommenen ,sakralen Zwölfstämmebundes“.

7 Rendtorff hat seine Überlegungen erstmals 1972 im Arbeitskreis des Neukirchener Biblischen Kommentars vorgetragen und dann in einer Aufsatzsammlung von 1975 veröffentlicht: Rendtorff, Rolf: Das „Ende“ der Geschichte Israels, in: Ders.: Gesammelte Studien zum Alten Testament (TB 57), München: Kaiser 1975, 267-276. Das Engagement des Heidelberger Alttestamentlers für eine Erneuerung der Beziehungen zwischen Christentum und Judentum im akademischen und im kirchlichen Bereich war vielgestaltig und durchweg herausragend. Er ist am I. April 20I4 wenige Tage vor dem Kolloquium in Graz verstorben.

8 Er ist programmatisch überschrieben mit „Die Aufstände gegen Rom und das Ende Israels".

9 Noth: Geschichte Israels, 400.

IO Ebd., 406 im letzten Satz. 
Begriffs „Volk“ in Bezug auf Israel: Auch wenn man darin „die immerhin noch sachgemäßeste Bezeichnung für diese geschichtliche Größe“ sehen mag, „so wird man doch von vornherein darüber klar sein müssen, daß hier nicht ganz in demselben Sinne von einem Volke die Rede sein kann, wie es sonst bei den Völkern der Geschichte der Fall ist ${ }^{\text {" }}{ }^{11}$ Stattdessen spricht Noth wiederholt von einer Stämmegruppe, wobei ihn primär die Frage umtreibt, was „die israelitischen Stämme miteinander vereinigte und zusammenhielt und damit das eigentliche Wesen dieses seltsamen ,Israel' ausmachte" ${ }^{12}$ Bezieht man seine weitere Darstellung ein, so geht es ihm dabei entscheidend um die von ihm angenommene Verfassung des Stämmeverbandes als „sakraler Zwölfstämmebund“, der nach dem Modell einer Amphiktyonie auf ein zentrales Heiligtum hin angelegt war. Nach Noth hätten tragende „Institutionen“ dieser Amphiktyonie nicht nur in vorstaatlicher Zeit, sondern auch in der Königszeit und sogar in der nachexilischen ,Jerusalemer Kultgemeinde " bestanden. ${ }^{13}$ Freilich wird diese Annahme an keiner Stelle konkretisiert ${ }^{14}$; in der weiteren Diskussion hat sich darüber hinaus schon die Amphiktyonie-Hypothese für die vorstaatliche Zeit als brüchig erwiesen. Im Kern handelte es sich um den Versuch, dieses „Israel“ als „eine einmalige Erscheinung im Kreise der geschichtlichen Völker" ${ }^{\text {", }}{ }^{15}$ und dies bedeutete in dem forschungsgeschichtlichen Kontext um 1950, als eine sakral-heilsgeschichtlich bestimmte Größe zu definieren.

II Ebd., I3. Bemerkenswert ist auch die Fortsetzung: „und man tut daher vielleicht überhaupt besser, von ,Israel' statt vom ,Volke Israel' zu sprechen. " Damit revoziert Noth immerhin seinen eigenen Sprachgebrauch in vorausgegangenen Publikationen (z. B. in: Die Gesetze im Pentateuch. Ihre Voraussetzungen und ihr Sinn [Halle: Niemeyer 1940], wiederabgedruckt in: Ders.: Gesammelte Studien zum AT (TB 6), München: Kaiser 1960, 9-I4I; Überlieferungsgeschichtliche Studien. Die sammelnden und bearbeitenden Geschichtswerke im Alten Testament [Halle: Niemeyer 1943], Tübingen: Niemeyer ${ }^{3}$ 1967), wie auch den seines Lehrers Albrecht Alt.

I2 Ebd.

I3 In Noths Arbeit über die „Gesetze im Pentateuch“ (1940) beruhte die Argumentation dagegen noch vollständig auf der Annahme, dass mit der Zerstörung des Jerusalemer Tempels und dem babylonischen Exil eine „Auflösung der alten Ordnung der Dinge“, mithin das Ende „Israels“ verbunden gewesen sei. Dies hätte wiederum die Voraussetzung dafür gebildet, dass „das Gesetz“ in der „Spätzeit“ „zu einer absoluten Größe von voraussetzungsloser, zeit- und geschichtsloser Gültigkeit, in sich selbst begründet, verbindlich einfach deswegen, weil als Gesetz existierend, weil göttlicher Herkunft und Autorität“ geworden sei (ebd. II4). Entsprechendes gilt für die „Überlieferungsgeschichtlichen Studien“ von 1943; vgl. dazu Rendtorff: „Ende“ 270.

I4 Dies nimmt nicht wunder. So gab es die längste Zeit des Königtums kein zentrales Heiligtum, die nachexilische Provinz Jehud wiederum verstand sich nicht als Stämmebund etc.

I5 Noth: Geschichte Israels, I3. 
Dazu gehört schon in der Einleitung ( $(\mathrm{I})$ die Vorschau auf den „Untergang“ dieser Größe im Zusammenhang der Aufstände gegen die römische Herrschaft, wobei die zeitliche Terminierung sich wesentlich mit einer Abgrenzung verbindet:

Was aus dem Untergang „Israels“ erwuchs, war jene Erscheinung, die wir als ,Judentum’ zu bezeichnen pflegen. Sie hatte zwar ihre Wurzeln in der Geschichte „Israels“ [...] sie hat auch immer den Namen „Israel“ auf sich selbst angewendet; aber sie war nach dem Wegfall des kultischen Mittelpunktes, mit dem Fehlen eines Heimatlandes und damit der Möglichkeit gemeinsamen geschichtlichen Handelns etwas wesenhaft Neues, so daß wir gut daran tun, für sie die eigene Bezeichnung „Judentum“ statt des Namens „Israel“ zu gebrauchen. ${ }^{16}$

Das hier in Anschlag gebrachte „wesenhaft (!) Neue“ der Zeit ab dem römischen Krieg hängt nun freilich an der skizzierten unscharfen und historisch problematischen Bestimmung des „eigentlichen Wesen(s)“ der Größe Israel. Darüber hinaus lässt sich der unterstellte geschichtliche Abbruch bei Noth als Historisierung einer theologischen Konzeption erweisen. Dies zeigt schon die Verbindung dieses „Bruchs" mit den Bezeichnungen „Israel“ bzw. „Judentum“, die deren sonstiger Verwendung keineswegs entspricht. ${ }^{17}$ Vor allem aber hat Noth selbst sein Verständnis von „Israel“ als einer religiös fundierten Größe in aller Klarheit verdeutlicht, nämlich in dem vorletzten Paragraph der Geschichte Israels $(\$ 34)$, der überschrieben ist: „Die Ablehnung des Christus“. In dessen Schlussabsatz heißt es:

Jesus selbst mit seinem Wort und Werk gehörte nicht mehr zur Geschichte Israels. An ihm fand die Geschichte Israels vielmehr ihr eigentliches Ende. Wohl aber gehörte zur Geschichte Israels der Vorgang seiner Ablehnung und Verurteilung durch die Jerusalemer Kultgemeinde. Sie hatte in ihm nicht das Ziel erkannt, auf das verborgen die Geschichte Israels hinführte; sie hatte in ihm den ihr verheißenen Messias von sich gewiesen. [...] Die Geschichte Israels eilte danach schnell ihrem Ende zu. ${ }^{18}$

\footnotetext{
I6 Ebd., I5.

I7 So wird „Judentum“, ,jüdisch“ etc. mit guten Gründen bereits für die persisch-hellenistische Zeit verwendet. Zugleich war und ist im jüdischen Kontext „Israel“ immer auch als emphatische Selbstbezeichnung möglich. Zu den terminologischen Differenzierungen vgl. im übrigen Rendtorff: „Ende“, $268 f$.

I8 Noth: Geschichte Israels, 386.
} 


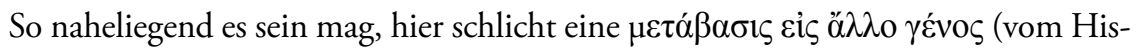
torischen zum Theologischen) zu konstatieren, ${ }^{19}$ wäre dies doch eine Verkürzung. Vielmehr expliziert Noth hier die biblisch-theologische Grundlegung seiner Israel-Konzeption, die von Anfang an in seinem historischen Modell angelegt war. Für diese Konzeption erweist sich nun die Rede vom „Ende Israels“ geradezu als essentiell, bildet sie doch eine notwendige Komponente einer bestimmten heilsgeschichtlichen Gesamtschau, dem Gleichnis von den bösen Winzern in den Synoptikern (Mt 2I; Mk I2) nicht unähnlich, hier freilich in einem historischen Lehrbuch.

Was war die Raison d'Etre dieser „historischen“ Konstruktion? Rolf Rendtorff dürfte den Finger auf den entscheidenden Punkt legen, wenn er formuliert: „Es geht letzten Endes um die Frage der legitimen theologischen Inanspruchnahme des Alten Testaments. Das Reden vom ,Ende' Israels ist im Grunde der Versuch, dem Judentum abzusprechen, daß es ein legitimes Recht auf diese Inanspruch-

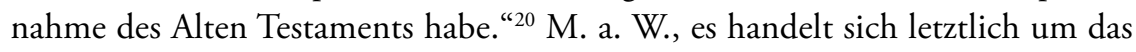
gleiche Interesse einer quasi-historischen, um nicht zu sagen pseudo-historischen Legitimierung des Christentums zulasten des antiken Judentums wie im Falle des Spätjudentumbegriffs.

Meines Wissens war Rolf Rendtorff bis dato der einzige Fachkollege, der sich analytisch mit dem Nothschen Konstrukt auseinandersetzte. Man darf m. E. fragen, ob sein sachliches Interesse an der Problemstellung und vor allem der klare Blick darauf möglich gewesen wären ohne den Diskurs des jüdisch-christlichen Dialogs, der in den 1960er-Jahren einsetzte, und insbesondere ohne seine intensiven Gespräche und Freundschaften mit Kollegen an der Hebräischen Universität in Jerusalem. ${ }^{21}$

Wie auch immer, die Veränderungen der Wahrnehmung von Israel/Judentum haben sich in den vergangenen Jahrzehnten - zumindest auf einer elementaren Ebene - in der alttestamentlichen Exegese weitgehend und mit zunehmender Selbstverständlichkeit durchgesetzt, so nicht nur in Bezug auf das so genannte Spätjudentum, sondern auch im Blick auf die diskutierte Fragestellung zur Ge-

I9 So Rendtorff: „Ende“.

20 Ebd., 273.

2I Vgl. dazu Rendtorff, Rolf: Kontinuität im Widerspruch. Autobiographische Reflexionen, Göttingen: Vandenhoeck \& Ruprecht 2007, 78-83. Im Zusammenhang seiner wiederholten Reisen nach Israel und der Begegnungen in Jerusalem seit 1963 nennt Rendtorff hier u. a. Isac L. Seeligmann, Shemaryahu Talmon und Moshe Greenberg. Nicht nur diese schriftlichen Erinnerungen, sondern auch mündliche Äußerungen deuten darauf hin, dass es erst die Begegnungen mit jüdischen Persönlichkeiten in Israel und den USA waren, die ihn in kirchliche Kontexte des christlich-jüdischen Gesprächs in Deutschland führten. 
schichte Israels: Deren „Ende“ im Nothschen Sinne scheint mir kein ernsthaftes Thema mehr zu sein. - Aus dieser Perspektive darf man den jüdisch-christlichen Dialog mithin als eine vielleicht ohne großes Aufsehen wirkende, aber doch nachhaltige „Erfolgsgeschichte" sehen.

Unbeschadet dessen ließe sich noch eine stattliche Reihe gewichtiger historisch-exegetischer Problemstellungen benennen, deren Diskussion von einer bewussten und differenzierten Wahrnehmung des gegenwärtigen Judentums und seiner Geschichte nur profitieren könnte. Dafür soll hier als letztes Beispiel eine weitere und in diesem Falle noch weithin selbstverständliche historische Israel-Konzeption thematisiert werden.

\section{Die so genannte Jerusalemer Kultgemeinde in nachexilischer Zeit}

Die meisten der Tagungsteilnehmer/innen wüssten vermutlich davon zu erzählen, wie schwierig es sein kann, interessierten Zeitgenoss/inn/en zu erklären, was das Judentum eigentlich ist: eine Religionsgemeinschaft oder ein Volk? Die in Abständen wiederkehrende Debatte in Israel um eine rechtliche Klärung der Frage mi hu' jehudi (wer ist ein Jude?) bestätigt darüber hinaus, dass das Problem in individuellen Fällen einigermaßen schwierig sein kann. Dabei ist die grundsätzliche Antwort für das traditionelle Judentum und für die gesamte Judenheit vor der neuzeitlichen Säkularisierung einfach: Beides trifft zu. Juden und Jüdinnen gehören zum 'am jisrael (Volk Israel), ob im Land Israel oder außerhalb, und sie leben entsprechend dem mosaischen Religionsgesetz. Dass man unter bestimmten Voraussetzungen dem Judentum beitreten kann, spricht nur auf den ersten Blick dagegen und für eine reine Konfessionsgemeinschaft, denn jüdische Proselyten und Proselytinnen treten nicht nur einer Religion bei, sondern sie werden zugleich, gleichsam per Adoption, in eine ethnische Gemeinschaft aufgenommen. In gewisser Weise entspricht dies dem Modell der Moabiterin Ruth, die zu ihrer Schwiegermutter aus Bethlehem sagt: „Dein Volk ist mein Volk, und dein Gott ist mein Gott.“ (Ruth I,I6) Das Judentum demonstriert damit ad oculos einen Sachverhalt, der für die Ethnologie und die Soziologie seit Längerem Allgemeingut ist, nämlich dass gemeinsame Herkunft und Verwandtschaft in Großgruppen wie Stämmen oder Völkern eine soziale Kategorie darstellen und keine biologische oder genetische. Schon deswegen wäre es ein Unding, jüdische Identität „rassisch“ begründen zu wollen. Andererseits konnte die zionistische Bewegung nur deshalb, weil die ethnische Zugehörigkeit in der Tradition so selbstverständlich war, dieses Selbstverständnis im Sinne einer modernen Nationalität re-formulieren und damit den Gedanken eines jüdischen Nationalstaates verbinden. 
Vor diesem Hintergrund soll noch eine dritte These zu einem historischen Bruch innerhalb der Geschichte Israels beleuchtet werden, dieses Mal aus dem Lehrbuch von Herbert Donner (1984/1986). Es ist (in der vierten Auflage) gegenwärtig das aktuelle Standardwerk zur Geschichte Israels in alttestamentlicher Zeit. ${ }^{22}$ Donner lehnt es ausdrücklich ab, „sich an der wenig fruchtbaren Debatte über das Ende der Geschichte des Volkes Israel zu beteiligen.“ Ihm gehe es „um nicht mehr als um einen vernünftigen Darstellungsabschluß, und der sollte dort liegen, wo die deutlichste und historisch wichtigste Zäsur zu erkennen ist: bei Alexander dem Großen, nach der Geschichte des alten Israel und der Formationsepoche des Judentums. “ ${ }^{23}$ Mit der zuletzt genannten „Formationsepoche“ ist offenbar die Perserzeit als eine Übergangsphase zwischen dem vorexilischen „alten Israel“ und dem „Judentum “ „im hellenistisch-römischen Zeitalter“ gemeint. Die tiefgreifende Transformation, die sich in diesem Zeitraum zugetragen hat, beschreibt Donner ebenso ,klassisch` wie pointiert in seinem Resümee zu der Zeit von Nehemia und Esra. Daraus einige Kernsätze:

Wir sind im Zeitalter der heiligen Schriften, in dem sich „Israel“ als theokratische Gemeinde unter dem Gesetz formierte. Diese Gemeinde verstand sich als eine Blutsgemeinschaft, obwohl sie das faktisch schon lange nicht mehr war [...]. Das wesentliche Merkmal der Zugehörigkeit zu „Israel“ war nicht mehr der Beweis oder die Behauptung der Abstammung von Menschengruppen, die das alte Israel gebildet hatten, sondern die Unterwerfung unter das "Gesetz“ als Willenskundgebung Jahwes. [...] Dieses neue Israel kann bei aller Kontinuität mit dem vorexilischen mit alten Maßstäben nicht mehr gemessen werden. Es ist mit dem ethnischen oder staatlichen oder religiösen Israel der I. Hälfte des I. Jahrtausends v. Chr. nur noch bedingt vergleichbar. Die Epoche der Restauration unter Nehemia und Esra war die Geburtsstunde des Judentums. ${ }^{24}$

22 Donner, Herbert: Geschichte des Volkes Israel und seiner Nachbarn in Grundzügen. Teil 2: Von der Königszeit bis zu Alexander dem Großen. Mit einem Ausblick auf die Geschichte des Judentums bis Bar Kochba, Grundrisse zum Alten Testament (ATD.E 4/2), Göttingen: Vandenhoeck \& Ruprecht 1986, ${ }^{4}$ 2008. Vgl. zum Folgenden bes. Crüsemann, Frank: Israel in der Perserzeit. Eine Skizze in Auseinandersetzung mit Max Weber, in: Schluchter, Wolfgang (Hg.): Max Webers Sicht des Christentums. Interpretation und Kritik (stw 548), Frankfurt a. M.: Suhrkamp 1985, 205-232 = in: Ders.: Kanon und Sozialgeschichte. Beiträge zum Alten Testament, Gütersloh: Kaiser 2003, 210-226; Blum, Erhard: Volk oder Kultgemeinde? Zum Bild des nachexilischen Judentums in der alttestamentlichen Wissenschaft, in: KuI io (1995) 24-42 und die unten in Anm. 28 und 29 genannte Literatur.

23 Alle vorstehenden Zitate aus Donner: Geschichte des Volkes Israel, 474f.

24 Ebd., 465 (erste Aufl. 43I). 
Donner begründet damit eine seit dem 19. Jahrhundert in der christlichen Forschung weithin geteilte Hypothese vom nachexilischen Juda als einer „Kultgemeinde“, die vor allem durch zurückgekehrte Exilierte gebildet worden sei. - Oder in der gern zitierten, zugespitzten Formulierung von Julius Wellhausen: „Aus dem Exil kehrte nicht die Nation zurück, sondern eine religiöse Sekte. " 25 Ob man dabei von „Gemeinde“, „Kirche“, „Bekenntnis-“ oder „Wahlgemeinschaft“ spricht, schlechthin konstitutiv bleibt die These, dass für die Zugehörigkeit zu „Israel“ wie Donner es formuliert - „nicht die Behauptung der Abstammung“ von entsprechenden „Menschengruppen“ ausschlaggebend gewesen sei, sondern „die Unterwerfung unter das Gesetz“. M. a. W., an die Stelle des Volkes wäre die religiöse Konfession getreten.

Angesichts des Quellenmaterials aus nachexilischer Zeit, über das wir in nicht geringem Umfang verfügen, sind die behaupteten Sachverhalte jedoch erstaunlich. Teilweise erscheinen die Gegebenheiten geradezu auf den Kopf gestellt. Frank Crüsemann hat hierzu u. a. bereits auf das in nachexilischen Texten virulente Problem der so genannten „Mischehen“ zwischen Judäern und Frauen anderer Volksgruppen verwiesen: „In keinem der darauf bezogenen Texte wird auch nur die Möglichkeit erwogen, die fremden Partner könnten für den Gottesglauben Israels gewonnen werden, also der angeblichen, Gemeinde' beitreten. An dieser Stelle wird deutlich, dass gerade nicht Gesetzestreue über die Zugehörigkeit entscheidet, sondern allein die Abstammungsverhältnisse. "26 Ebenso ist nicht zu übersehen, dass nirgendwo in der Hebräischen Bibel Stammbäume und verwandtschaftliche Zuordnungen so massiv belegt und so zentral sind wie in der nachexilischen Literatur; dazu gehören die P-Überlieferungen im Pentateuch sowie vor allem die Chronikbücher und Esra/Nehemia. ${ }^{27}$

Nun argumentiert Donner darüber hinaus vermeintlich historisch, dass die "Gemeinde“ in der perserzeitlichen Provinz Jehud „faktisch“ „schon lange“ keine „Blutsgemeinschaft“ mehr war. Eine solche Behauptung zu genetischen Verhältnissen (wie auch deren Bestreitung) bleibt jedoch pure Spekulation, weil hierzu jegliche Quellengrundlage fehlt. Noch wichtiger, die These verfehlt schon mit ihrer Präsupposition, es ginge um ein biologisches Faktum, die wesentliche Pointe: Wie

25 Wellhausen, Julius: Prolegomena zur Geschichte Israels, Berlin: de Gruyter (I878) ${ }^{6}$ I927, 28.

26 Crüsemann: Israel, $210=215$.

27 Dabei wird gelegentlich die Abstammung als Kriterium der Zugehörigkeit ausdrücklich thematisiert, so in Esr 2,59ff. in Bezug auf Familien, die aus Babylonien zurückkehrten, „ohne angeben zu können, ob sie nach Familie und Herkunft von Israel abstammten“ (2,59 NZB). Sie wurden nach 2,62f. vom Priestertum ausgeschlossen, „bis ein Priester für Urim und Tummim auftrete". 
bereits angesprochen, basiert Ethnizität traditioneller Gesellschaften nicht auf genetisch nachweisbarer Verwandtschaft, sondern auf dem ,Faktum' des Anspruchs bzw. der sozialen Anerkennung verwandtschaftlicher Beziehungen. Ob entsprechende Geschlechtsregister aus historischer Sicht „real“ oder fiktiv waren, ist für ihre gesellschaftliche Wirksamkeit irrelevant.

Die aktuellste und umfassendste Untersuchung zur sozialen Verfasstheit des nachexilischen Juda/Israel bietet die kürzlich publizierte Tübinger Dissertation von Kristin Weingart über die Verwendung des Israel-Namens in biblischer Zeit. ${ }^{28}$ Auf der Basis einer gründlichen Analyse des einschlägigen Materials wird darin der Nachweis geführt, dass sich die JudäerInnen der Perserzeit dezidiert als Ethnos und nicht als Wahlgemeinschaft verstanden haben. Komplementär dazu konnte Volker Haarmann ${ }^{29}$ zeigen, dass die so genannten Bekehrungsgeschichten in der Hebräischen Bibel (über Jethro, Rahab, Naeman etc.), die ausnahmslos in persischer Zeit formuliert wurden, zwar von der Zuwendung nicht-israelitischer Individuen zum Gott Israels erzählen, aber nicht von deren Integration in Israel als „Proselyten“(Jethro bleibt Midianiter, Naeman bleibt Aramäer etc.). Für Fachleute sei noch hinzugefügt: Auch die häufig in diesem Zusammenhang diskutierten Texte Esr 6,19-2 $\mathrm{I}^{30}$ und Jes $56, \mathrm{I}-8^{31}$ fügen sich in dieses Bild.

Wenn die Sachverhalte so eindeutig sind wie hier vertreten, wie konnte man dann im 19. Jahrhundert auf die Idee einer jüdischen konfessionellen Gemeinde nach dem babylonischen Exil verfallen und bis heute - weithin fraglos - daran

28 Weingart, Kristin: Stämmevolk - Staatsvolk - Gottesvolk? Studien zur Verwendung des Israel-Namens im Alten Testament (FAT II/68), Tübingen: Mohr Siebeck 2014.

29 Haarmann, Volker: JHWH-Verehrer der Völker. Die Hinwendung von Nichtisraeliten zum Gott Israels in alttestamentlichen Überlieferungen (AThANT 9I), Zürich: Theolog. Verl. 2008 .

30 Siehe dazu Blum: Volk, 29f.; Weingart: Stämmevolk, 299-302.

3I Siehe Blum: Volk, 30-33; Haarmann: JHWH-Verehrer, 206-245. Crüsemann: Israel 210 = 215, findet in diesem tritojesajanischen Wort zwar ähnlich wie Donner „die Vorstellung von Israel als einer, Gemeinde', die allein durch das Gesetz konstituiert und zusammengehalten wird“, sieht darin aber eine marginal gebliebene prophetische Position (darin vergleichbar der grundsätzlichen Kritik am Tempelbau in Jes 66,If.). In der Tat ist der Hinweis auf die innerjüdische Partikularität dieser Stimme wichtig. Gleichwohl bleibt zu beachten, dass die Verheißung für den Fremden (ben-hannēeär $)$, der sich am Gotteswillen ( $\left.b^{e} r i \bar{t} \bar{i}\right)$ orientiert, in dessen unbeschränkter Teilhabe am JHWH-Kult im Heiligtum bestehen soll $(56,6 \mathrm{f}$.); so werde das Heiligtum „Gebetshaus für alle Völker genannt werden“ $(56,7 \mathrm{~b})$. Dementsprechend ist auch die in V. 3 a zitierte Klage des Fremden über seine Absonderung auf die Frage der Kultgemeinschaft mit dem Gottesvolk und nicht auf eine Eingliederung in dieses zu beziehen. 
festhalten? Zum einen mag dabei das Selbstbild der christlichen Kirchen als Analogie eine Rolle gespielt haben. Zum anderen und vor allem gab es aber ein direktes „Vorbild“: Im Jahr I893 konstituierte sich in Berlin der „Central-Verein deutscher Staatsbürger jüdischen Glaubens e. V." In dessen Programm hieß es unter anderem: „Wir deutschen Staatsbürger jüdischen Glaubens stehen fest auf dem Boden der deutschen Nationalität. Unsere Gemeinschaft mit den Juden anderer Länder ist keine andere als die Gemeinschaft der Katholiken und Protestanten Deutschlands mit den Katholiken und Protestanten anderer Länder [...]." Unverkennbar artikulierte sich hier in der Tat so etwas wie eine ,jüdische Konfession" neben den etablierten christlichen Kirchen. Historisch bleibt aber zu bedenken, dass dies für das Judentum eine geschichtliche Sonderentwicklung in Mittel- und Westeuropa (mit Ausstrahlung nach Nordamerika) zwischen der bürgerlichen Emanzipation und der Schoah darstellte. Der Grundrahmen dafür war seit der Französischen Revolution vorgegeben, in der mit Blick auf die rechtliche Gleichstellung der Juden die Losung ausgegeben werden konnte: „Den Juden als Nation ist alles zu verweigern, den Juden als Individuen aber ist alles zu gewähren. ${ }^{\text {" } 22 ~ D e m ~ t r a d i t i o n e l l e n ~}$ jüdischen Selbstverständnis deutlich näher stand das Programm des ersten Zionistischen Kongresses, der vier Jahre nach der Gründung des „Central-Vereins“ in Basel die „Schaffung einer öffentlich-rechtlichen Heimstätte in Palästina“ „für das jüdische Volk" forderte. ${ }^{33}$

Nicht weniger vielfältig und komplex kann sich jüdische Identität in der Gegenwart, d. h. nach den Weltkriegen, der Schoah und seit der Gründung des Staates Israel darstellen. Auch von den für jüdische Menschen in besonderer Weise katastrophischen Verwerfungen des 20. Jahrhunderts einmal abgesehen, fallen hier die Wirkungen struktureller Verschiebungen zusammen, insbesondere des Auseinandertretens von familiärer Herkunft und religiöser Bindung und der weitgehenden Substitution des traditionellen Ethnos durch die moderne Nation. Unbeschadet dessen bleibt selbst in „säkular-jüdischen“ Kontexten die Kontinuität mit konstitutiven Traditionen klar ausgeprägt und wirksam präsent. Dementsprechend wird auch eine für das eigene christliche Denken selbstverständliche Dichotomie

32 „Il faut tout refuser aux juifs comme nation et tout accorder aux juifs comme individus.“ So die häufig zitierte Formulierung von Stanislas de Clermont-Tonnerre in einer Rede in der französischen Nationalversammlung (Dezember 1789).

$\mathrm{Zu}$ Entwicklungen im deutschen Judentum dieser Zeit s. den Sammelband Mosse, Werner E. (Hg.): Juden im Wilhelminischen Deutschland 1890-19I4. Ein Sammelband (Schriftenreihe wissenschaftlicher Abhandlungen des Leo Baeck Instituts 33), Tübingen: Mohr Siebeck ${ }^{2}$ I998, darin bes. Weltsch, Robert: Die schleichende Krise der jüdischen Identität - Ein Nachwort, 689-702. 
„Religionszugehörigkeit vs. Volkszugehörigkeit“ in jedem jüdischen Kontext sehr schnell in ihrer lebensweltlichen Partikularität wahrgenommen werden. ${ }^{34}$

Die epistemologische Bedeutung einer unverstellten Wahrnehmung des gegenwärtigen Judentums lässt sich gleichwohl nicht generalisieren. So können in historischen Fragen des alten Israel selbstverständlich auch Sichtweisen des so genannten normativen Judentums sich als Anachronismen erweisen, mehr noch: Dafür ließen sich mühelos Beispiele anführen. Gleichwohl erscheint mir die Frage nach dem jüdischen Selbstverständnis für die christliche Theologie essentiell, zuvörderst im Blick auf einen echten Dialog in der Gegenwart, aber auch da, wo es darum geht, die gemeinsame Ursprungsgeschichte zu verstehen. In dem eingangs skizzierten Sinne ist hier das Selbstverständnis des Anderen die verlässlichste Hilfe, um eigene Selbstverständlichkeiten zu hinterfragen.

34 Dies entspricht auch persönlicher Erfahrung: Die kritische Auseinandersetzung mit geläufigen Forschungspositionen, die erstmals 1995 publiziert (s. o. Anm. 22) und davor in meiner Augsburger Antrittsvorlesung vorgetragen worden war, beruht auf veränderten Wahrnehmungen infolge meiner Studienzeit an der Hebräischen Universität anfangs der I970er-Jahre. Des Weiteren kann in diesem Zusammenhang auf die Vorworte in den oben genannten Arbeiten von Kristin Weingart (Anm. 28) und Volker Haarmann (Anm. 29; vgl. auch die „Einleitung“!) verwiesen werden. 


\title{
Theologische und hermeneutische Inspirationen durch den jüdisch-christlichen Dialog
}

\author{
Ein persönlicher Blick
}

Gerlinde Baumann

\section{Erfahrungen}

Zunächst möchte ich dem Wunsch nach einem „Erfahrungsbericht“ hinsichtlich der Berührungen mit dem jüdisch-christlichen Dialog nachkommen, bevor Vertiefungen an zwei Punkten (2. und 3.) sowie ein kurzes Fazit (4.) folgen.

Exegetisch „in die Wiege gelegt“ war mir eine jüdisch-christliche Auslegungsperspektive nicht. Bei einer exegetisch eher konventionellen historisch-kritischen Ausbildung in den 1980er-Jahren an den evangelisch-theologischen Fakultäten in Tübingen und Hamburg haben jüdisch-christliche Fragen kaum eine Rolle gespielt. Erst während der Promotionsphase bin ich im Rahmen der Mitarbeit im Hedwig-Jahnow-Forschungsprojekt erstmals mit jüdisch-feministischer Hermeneutik in Berührung gekommen, und zwar in Gestalt des Entwurfs von Judith Plaskow. ${ }^{1}$ Eine weitere bestimmende Diskussion dieser Jahre war die Auseinandersetzung mit dem Vorwurf des Antijudaismus in der deutschen feministischen Theologie und Exegese. Diese Auseinandersetzung hat auch Spuren in der Arbeit des Hedwig-Jahnow-Forschungsprojekts hinterlassen. So hat sie ihren Niederschlag im programmatischen Einleitungsartikel des Forschungsprojekts im Band „Feministische Hermeneutik und Erstes Testament " gefunden. ${ }^{2}$ Es folgte eine Einladung, am Band „Von der Wurzel getragen“ mitzuwirken, den Marie-Theres Wacker und Luise Schottroff 1996 herausgegeben haben. ${ }^{3}$ Hierbei habe ich mich erstmalig als

I Plaskow, Judith: Und wieder stehen wir am Sinai. Eine jüdisch-feministische Theologie, Luzern: Exodus 1992.

2 Hedwig-Jahnow-Forschungsprojekt: Feministische Hermeneutik und Erstes Testament in: Hedwig Jahnow u. a.: Feministische Hermeneutik und Erstes Testament. Analysen und Interpretationen, Stuttgart: Kohlhammer 1994, 9-25, v. a. 20-22.

3 Marie-Theres Wacker / Luise Schottroff (Hg.): Von der Wurzel getragen. Christlich-feministische Exegese in Auseinandersetzung mit Antijudaismus (BIS I7), Leiden: Brill 1996; darin mein Beitrag: „Zukunft feministischer Spiritualität" oder „Werbefigur des Patriarchats“? Die Bedeutung der Weisheitsgestalt in Prov I-9 für die feministisch-theologische Diskussion, I35-I52. 
Exegetin begriffen, die sich eigenständig innerhalb eines von jüdisch-christlichen Überlegungen geprägten Diskussionskontexts bewegt.

Bei einer Tagung zu diesem Band bin ich wohl zum ersten Mal Athalya Brenner begegnet, die mich als Person und von ihren Positionen her sehr beeindruckt hat. Erneut habe ich sie 2004 auf der „Österreichischen Christlich-Jüdischen Bibelwoche“ in Graz zur „Frau Weisheit“ getroffen. Bei dieser Tagung haben auch andere persönliche Begegnungen bei mir einen tiefen Eindruck hinterlassen; so etwa mit der damals bekanntesten evangelischen feministischen Theologin Österreichs, Evi Krobath, sowie mit Richard Ames, dem Opernsänger und Kantor der jüdischen Gemeinde Graz, die leider beide bald danach viel zu früh verstorben sind.

Einen entscheidenden „Schub“ bekam meine Auseinandersetzung mit jüdisch-christlichen Themen durch die 2003 begonnene Arbeit an der „Bibel in gerechter Sprache“: In zahlreichen Gesprächen und Diskussionen wurde mir bereits Bekanntes vertieft, aber auch Neues angeschnitten. Eine wichtige Rolle spielte der Versuch, beim Gottesnamen oder der Benennung Gottes jüdisch-christliche und feministisch-theologisch inspirierte Gedanken miteinander zu vereinbaren. Auch die umfassendere Perspektive der „Gerechtigkeit im Hinblick auf den christlich-jüdischen Dialog “4 scheint mir für eine Bibelübersetzung nach wie vor sehr lohnend zu sein.

Durch diesen Lernprozess während der Arbeit an der „Bibel in gerechter Sprache“ ist bei mir ein Verständnis des Neuen Testaments als eines Textkorpus erwachsen, das vor allem einen Blick auf den Entstehungsprozess des frühen Christentums gewährt. In diesem historischen Rahmen sind wohl die hochproblematischen, antijudaistisch klingenden Texte wie z. B. Mt 27,25; Joh 8,44; I Thess 2,I4-I6 oder Offb 2,9 zunächst einmal als Ausdruck eines innerjüdischen Streits beziehungsweise des „Geschwisterstreits“ zu betrachten. Zum christlichen Umgang mit diesen Texten klingen mir auch noch die Worte Micha Brumliks auf einer der vorbereitenden Arbeitstagungen zur „Bibel in gerechter Sprache“ im Ohr: Auf die Frage, welche Vorschläge für eine nicht-antijudaistische Auslegung dieser neutestamentlichen Texte er denn von jüdischer Seite machen würde, reagierte er mit dem augenzwinkernden Abweis, dass es schon „unsere“ Aufgabe sei - also die der ChristInnen -, uns mit „unserem“ Antijudaismus auseinanderzusetzen.

In den Jahren vor und nach dem Erscheinen der „Bibel in gerechter Sprache“ im Jahr 2006 habe ich zahlreiche Vorträge zu diesem Projekt vor unterschiedlichem Publikum gehalten. Ich muss leider sagen, dass mir hierbei mit Ausnahme eini-

4 Bail, Ulrike u. a. (Hg.): Bibel in gerechter Sprache, Gütersloh: Gütersloher Verlagshaus 2006, Iof. 
ger weniger Male durchgängig antijudaistische Stereotype begegnet sind. Dadurch ist mir stärker zu Bewusstsein gekommen, dass ein Ansatzpunkt für eine Beschäftigung mit dem Antijudaismus in breiteren Kreisen - vor allem der kirchlichen Öffentlichkeit - wohl zunächst die Auseinandersetzung mit dem innerchristlichen Antijudaismus sein müsste, der auf einem bestimmten Verständnis des Neuen Testaments beruht - als eines Dokuments, in dem sich „die Christen“ „den Juden“ gegenübersehen, wobei die späteren historischen Konflikte in die Entstehungszeit des Neuen Testaments rückprojiziert werden. Hier bleibt meiner Wahrnehmung nach an der kirchlichen Basis noch viel zu tun.

Ähnliche Erfahrungen wie die gerade geschilderten habe ich in Vorträgen gemacht, in denen ich versucht habe, breitere Kreise mit meinen hermeneutischen Leitlinien zum Verstehen von Gottesbildern der Gewalt im Alten Testament vertraut zu machen: ${ }^{5}$ Auch hier gab und gibt es in den meisten Diskussionsrunden mindestens eine Person, die sich zu Wort meldet und kundtut, dass doch der gewalttätige Gott des Alten Testaments (gerne auch als ,jüdischer Gott des Alten Testaments“ bezeichnet) im Neuen Testament durch den Gott Jesu als den Gott der Liebe abgelöst und damit überwunden sei, und dass also „wir" ChristInnen mit diesem „alttestamentarischen " Gott kein Problem mehr hätten. Nicht erst dadurch ist mir bewusst geworden, dass beim christlichen Umgang mit problematischen Gottesbildern im Alten Testament sehr häufig Deutungsmuster greifen, die - vorsichtig gesagt - eine große Nähe zu antijudaistischen Denkweisen aufweisen (dazu siehe unten in Teil 3).

Die Erfahrungen aus diesen Vorträgen und Diskussionen mit „normalen“ GemeindechristInnen haben mich zunächst dazu bewogen, in einem populärwissenschaftlich gehaltenen Buch zur Bibel auch einen Schwerpunkt darauf zu legen, wie problematisch die gängigen christlichen Verstehensweisen des Neuen Testaments sind, und Wege aufzuzeigen, wie das Neue Testament anders als antijudaistisch ausgelegt werden kann. ${ }^{6}$ Dieses Buch habe ich mit auslegungsgeschichtlichem und hermeneutischem Schwerpunkt angelegt, wobei ich nicht nur christliche Auslegungsrichtungen mit ihren Fragen behandle, sondern auch jüdische; das Gespräch mit der Schwesterreligion sehe ich nach wie vor als Notwendigkeit und Bereicherung jeder christlichen Beschäftigung mit der Auslegung der Bibel an.?

Bei den Vorarbeiten zu diesem Buch habe ich die Parallelität und Unterschiedlichkeit der jüdischen und christlichen Auslegungsgeschichte und Hermeneutik als

5 Dazu siehe die Monographie: Baumann, Gerlinde: Gottesbilder der Gewalt im Alten Testament verstehen, Darmstadt: Wissenschaftliche Buchgesellschaft 2006.

6 Baumann, Gerlinde: Die Bibel. Wissen was stimmt (Herder spektrum 5955), Freiburg: Herder 2008, v. a. IO5-III.

7 Z. B. ebd., 48-50, 84-90. 
interessantes Arbeitsgebiet entdeckt. Daraus hervorgegangen ist meine Vorlesung über „Biblische Hermeneutik“ bzw. „Hermeneutik des Alten Testaments“, die ich an unterschiedlichen Orten in Deutschland und Österreich gehalten habe und halten werde.

Aus diesem „Bündel“ schriftlicher und mündlicher Auseinandersetzungen habe ich für meine Tätigkeit als Forscherin, Autorin, Dozentin und Referentin im Blick auf das Gespräch zwischen Christentum und Judentum folgende Schlüsse gezogen: Zunächst halte ich es für dringlich, Antijudaismus und antijudaistische Denkweisen schon im Bereich der Hermeneutik zu thematisieren und ihnen so bereits bei der Klärung des Verstehens und der Verstehensbedingungen der Bibel entgegenzutreten. Dabei scheint es mir wichtig, möglichst aufklärend und unter Rückgriff auf historische Informationen vorzugehen. Hierbei sollten meines Erachtens vor allem folgende zwei Punkte thematisiert werden:

- Bei der Auseinandersetzung mit der Bibelauslegung sollte der Ausgangspunkt beim TaNaK bzw. dem Alten Testament genommen werden, mit der innerbiblischen Auslegung als Beginn aller späteren Auslegung, und mit diesem Korpus als gemeinsamer und im weiteren Sinne autoritativer Schrift. Das Alte Testament erscheint so für den christlichen Blick als „die Bibel“ der sich herausbildenden frühen Kirche. Die Schriften, die später das Neue Testament bilden, gehören so zunächst einmal zur Gattung der Auslegungsliteratur. Dabei stellen jüdische und christliche Auslegungen zwei mögliche Bezüge auf ein in weiten Teilen übereinstimmendes Schriftkorpus dar.

- Essentiell ist der Hinweis auf historische Parallelentwicklungen und Begegnungen zwischen jüdischer und christlicher Auslegung seit den Anfängen, über die Jahrhunderte und bis heute (siehe unten Teil 2 im Anschluss). Dabei sollte das Potenzial betont werden, das den Begegnungen miteinander innewohnt, ohne die Auseinandersetzungen zu verschweigen, die eine maßgebliche Rolle bei der Entwicklung vor allem der christlichen Identität gespielt haben und spielen.

Diese Gedanken sollen nun noch einmal in zwei Punkten vertieft werden: erstens an der Schrifthermeneutik und zweitens am Thema des Gottesbildes.

\section{Schrifthermeneutik}

Wie sich die Früchte des christlich-jüdischen Dialogs und der entsprechenden Forschungen zur Schrifthermeneutik erschließen lassen, möchte ich am Beispiel einer überblickshaften Lehrveranstaltung zur Bibelauslegung oder zur Biblischen Hermeneutik erläutern. Neben hermeneutischen Positionen verschiedener christlicher 
Konfessionen sollte dabei selbstverständlich auch jüdische Schrifthermeneutik in Grundzügen behandelt werden. ${ }^{8}$

Wichtig erscheint mir der Hinweis auf die - bei aller Unterschiedlichkeit im Einzelnen - vorhandenen Parallelen zwischen der christlich-antiochenischen bzw. jüdisch-frührabbinischen Exegese einerseits (mit der Betonung des Literalsinns) und der christlich-alexandrinischen bzw. frühjüdisch-hellenistischen Exegese (mit dem Schwerpunkt auf der allegorischen Auslegung). Entsprechend zu betonen wäre für das Mittelalter die Parallelität zwischen (jüdischem) PaRDeS und (christlichem) vierfachem Schriftsinn. ${ }^{9}$

Illustrieren lässt sich die lange Geschichte des Austauschs zwischen JüdInnen und ChristInnen durch den Hinweis auf punktuelle Begegnungen, auf den Kontakt, die Gespräche und die Anregung zwischen den ExegetInnen. Ein Beispiel für das direkte Gespräch und die literarische Inspiration wäre etwa Origenes im 3. Jahrhundert, dessen Anlehnung an Philo ${ }^{10}$ oder sein Gespräch mit Rabbinen ${ }^{11}$; ein anderes Beispiel wäre die Schule von St. Viktor in Paris mit ihrer Kenntnis Abraham Ibn Esras oder Raschis im I2. Jahrhundert. ${ }^{12}$ Bei diesen Bezugnahmen dürfen allerdings die jeweiligen gesellschaftlichen oder religiösen Machtverhältnisse nicht unberücksichtigt bleiben, die den oft begrenzenden Rahmen für solche punktuellen Kontakte und „Dialoge“ gesetzt haben.

Seitdem die historisch-kritische Methode keine hegemoniale Position mehr im christlichen Methodendiskurs beanspruchen kann, ist nicht nur eine Pluralisierung im Bereich der Bibelauslegungsmethoden zu beobachten, sondern auch bei der Schrifthermeneutik. Dadurch werden Seitenblicke auf jüdische Auslegungen und Gespräche mit zeitgenössischen jüdischen AuslegerInnen leichter und produktiver

8 Beispielsweise unter Bezug auf Dohmen, Christoph / Stemberger, Günter: Hermeneutik der Jüdischen Bibel und des Alten Testaments, Stuttgart: Kohlhammer I996, v. a. 23-I32.

9 Hierzu vgl. ebd., I28f.

Io Siehe Signer, Michael A.: Auf der Suche nach der Schrift. Juden, Christen und das Buch, in: Ders.: Brücken bauen. Aufsätze und Vorträge zum jüdisch-christlichen Verhältnis, hg. von Rainer Kampling / Hans Hermann Henrix / Peter von der Osten-Sacken (SKI 29), Berlin: Institut Kirche und Judentum 2013, 13-27, v. a. 2If.

II Siehe Signer, Michael A.: Die gemeinsame Bibel lesen? Juden und Christen 25 Jahre nach der Erklärung der Rheinischen Synode von 1980. Auf dem Weg zu einem neuen Verhältnis zwischen Juden und Christen, in: ebd., 397-407, v. a. 403.

I2 Dazu siehe mehrere Beiträge von Michael A. Signer im eben genannten Band: Die Erneuerung der Erzählung. Jüdische und christliche Exegese im I2. Jahrhundert, 29-45; Polemik und Exegese. Spielarten der Hebraistik im I2. Jahrhundert, 47-59; Rabbi und Magister. Überschneidungen zwischen Denkmodellen in der „Renaissance des I2. Jahrhunderts“, 6I-85; sowie: Tröstung und Streit. Jüdische und christliche Auslegungen der Prophetenbücher, I27-I44. 
möglich. An dieser Stelle möchte ich zwei ForscherInnen nennen, die für mich prägend gewesen sind. Zum einen ist dies Athalya Brenner mit ihren vielfältigen feministisch-theologischen Inspirationen, auch und vor allem durch das Projekt des „Feminist Companion of the Bibel“, in dem sie und andere Forscherinnen sich alttestamentlichen Texten unter unterschiedlichsten methodischen und hermeneutischen Perspektiven genähert haben. ${ }^{13}$ Zum anderen ist dies Michael Fishbane mit seiner „innerbiblical exegesis"14. Eine solche Betrachtung der Texte kann einen Anstoß dazu geben, den hierzulande immer noch stark diachron geprägten Blick auf die Texte hinter sich zu lassen, der vor allem nach „Brüchen“ in den Texten sucht. Gerade für späte Texte ist häufig mit der Möglichkeit von Anspielungen, intertextuellen Verknüpfungen oder insgesamt mit innerbiblischer Exegese zu rechnen. Besonders gut verdeutlichen ließe sich das am Beispiel der „Gnadenformel“ in Ex 34,6f. und ihren zahlreichen alttestamentlichen Modifikationen. ${ }^{15}$

Eine Faszination geht von jüdischer Exegese aus, wenn hier die alttestamentlichen Texte als Quelle unerschöpflich vieler Auslegungen und „Weisheiten“ betrachtet werden. Diese Perspektive bildet einen anregenden Kontrast zum christlich-dogmatischen Bemühen, den biblischen Texten möglichst nur eine Bedeutung zuzuschreiben. Der jüdische Blick, der tendenziell eher eine Pluralität von Textbedeutungen zulässt, scheint den heutigen Erkenntnissen literaturwissenschaftlicher und philosophischer, poststrukturalistischer oder postmoderner Diskussionen eher zu entsprechen. ${ }^{16}$ Hier würde ich mir für den christlichen Kontext mehr Mut wün-

I3 Dazu siehe Brenner, Athalya (Hg.): A Feminist Companion to the Bible, Sheffield: Sheffield Academic Press bzw. T\&T Clark 1993-200I; insgesamt is Bände in zwei Reihen, davon drei Bände gemeinsam mit Carole R. Fontaine herausgegeben.

I4 Fishbane, Michael: Inner-Biblical Exegesis. Types and Strategies of Interpretation in Ancient Israel, in: Ders.: The Garments of Torah. Essays in Biblical Hermeneutics, Bloomington: Indiana University Press 1989, 3-18; von ihm dazu auch: Inner-Biblical Exegesis, in: Sæbø, Magne u. a. (Hg.): Hebrew Bible/Old Testament. The History of Its Interpretation. I: From the Beginnings to the Middle Ages (Until I300). Teil I: Antiquity, Göttingen: Vandenhoeck \& Ruprecht 1996, 33-48.

I5 So z. B. in: Fishbane, Michael: Biblical Interpretation in Ancient Israel, Oxford: Clarendon 1985, 335-350; sowie auch: Spieckermann, Hermann: „Barmherzig und gnädig ist der Herr ...", in: ZAW IO2 (1990) I-I8 (Nachdruck in: Ders.: Gottes Liebe zu Israel. Studien zur Theologie des Alten Testaments [FAT 33], Tübingen: Mohr Siebeck 200I, 3-19); sowie: Franz, Matthias: Der barmherzige und gnädige Gott. Die Gnadenrede vom Sinai (Exodus 34,6-7) und ihre Parallelen im Alten Testament und seiner Umwelt (BWANT I60), Stuttgart: Kohlhammer 2003.

I6 Dies führt Marianne Grohmann aus: Aneignung der Schrift. Wege einer christlichen Rezeption jüdischer Hermeneutik, Neukirchen-Vluyn: Neukirchener 2000, v. a. 23I-249. 
schen, auch dogmatisch unbequeme und plurale exegetische Ergebnisse zuzulassen, und mehr Zutrauen dazu, dass sich solche Ergebnisse auch systematisch-theologisch einholen ließen.

Natürlich gehört zu einer vom jüdisch-christlichen Dialog inspirierten Bibelhermeneutik auch eine Neubestimmung des Verhältnisses zwischen Altem und Neuem Testament beziehungsweise ein neuer Denkansatz im Hinblick auf das christliche Verständnis des Alten Testaments. Hier scheinen mir besonders drei Gedanken produktiv zu sein:

Erstens hat Jürgen Ebach bereits 2002 für den christlichen Blick auf das Alte Testament einen Wechsel der hermeneutischen Perspektive vorgeschlagen. Und zwar dergestalt, dass sich ChristInnen nicht mehr länger selbst (als „Kirche“) an die Stelle Israels setzen, sondern sich bei den Menschen außerhalb Israels in der Perspektive des Alten Testaments verorten. In Ebachs Worten lautet der Vorschlag, ,nach dem Ort [zu] fragen, der Menschen außerhalb Israels in der Perspektive der hebräischen Bibel selbst und ihrer jüdischen Lektüregeschichte eingeräumt wird" ${ }^{\text {"17 }}$. Auch hier wird die Frage der Identität angesprochen, die für das Verhältnis zwischen Christentum und Judentum so lange bedeutsam war und ist. Ebach beantwortet diese Frage eben nicht durch den bekannten wie unguten Modus des Ersetzens, sondern regt zu einer neuen Positionierung heutiger ChristInnen durch eine neue innertextliche Selbstverortung im Alten Testament als NichtisraelitInnen an.

Eine zweite hilfreiche Anregung für eine neue Verhältnisbestimmung zwischen Altem und Neuem Testament sehe ich in Frank Crüsemanns Verwendung der Metapher des „Wahrheitsraums“, den das Alte Testament für das Neue bildet. Dieser Raum könnte offen gehalten werden auch für jüdische Auslegungen des Textes, denen dann ein gleiches Recht zukommt wie den christlichen. ${ }^{18}$

Ein dritter Versuch könnte darin bestehen, neu damit Ernst zu machen, dass sich Judentum und Christentum sowie Altes und Neues Testament schwerpunktmäßig um das Handeln Gottes an der Welt und den Menschen drehen - nicht im Sinne einer Vereinheitlichung von jüdischer und christlichen Botschaft, sondern als gemeinsame Basis, auf die sich aufbauen ließe, und von der aus dann die unterschiedlichen Botschaften entfaltet werden könnten. In diese Richtung einer

I7 Ebach, Jürgen: Hören auf das, was Israel gesagt ist - hören auf das, was in Israel gesagt ist. Perspektiven einer „Theologie des Alten Testaments“ im Angesicht Israels, in: EvTh 62 (2002) 37-53, 43f.

I8 Crüsemann, Frank: Das Alte Testament als Wahrheitsraum des Neuen. Die neue Sicht der christlichen Bibel, Gütersloh: Gütersloher Verlagshaus 2011. 
stärkeren Theozentrik gehen beispielsweise Erich Zenger ${ }^{19}$ oder Bernhard Lang. ${ }^{20}$ Letzterer schlägt vor:

Will man dem AT gerecht werden, dann ist die theologische Voraussetzung zu ändern. An die Stelle der, Christus-allein-Theologie', die man als Christomonismus bezeichnet, muss die ,Gott-und-Christus-Theologie' treten. Diese würdigt die Geschichte Israels als Raum echter und vollgültiger Gotteserfahrung und entsagt jener einseitigen Betonung des NT, für die ich in Amerika den treffenden Ausdruck ,Neutestamentismus' gehört habe. Der neue Standpunkt erlaubt eine ungezwungene Auslegung des AT und verpflichtet den Theologen nicht, in alle Texte Christus , hineinzulegen' oder sie vom NT her abzuwerten. Er macht eine Lektüre des AT obne Christus nicht mehr zu einer Lektüre gegen ihn $[\ldots .]^{21}$

Diesem Problemkreis, der Frage nach Gott, soll nun im dritten Teil meiner Ausführungen die besondere Aufmerksamkeit gelten.

\section{Theologische Inspirationen, oder: die Frage nach Gott}

Wie schon erwähnt habe ich mich intensiver mit den „Gottesbildern der Gewalt im Alten Testament“ auseinandergesetzt. In meiner Monographie von 2006 habe ich mich darum bemüht, Verstehensmodelle für diese problematischen Gottesvorstellungen zu finden. ${ }^{22}$ Ich habe bereits angedeutet, dass mir in Vorträgen und auch stellenweise in der Literatur Deutungsmuster begegnet sind, die sich als antijudaistisch bezeichnen lassen. Das geläufigste Denkmuster lautet dabei: Als ChristInnen haben „wir“ doch mit solchen Gottesbildern kein großes Problem, weil „uns“ doch Jesus Christus die Botschaft von seinem Vater, dem Gott der Liebe, gebracht hat und damit den „alttestamentarischen“ Gott der Gewalt, des Zorns und der Rache überwunden hat. Dieses Denkmuster trägt deutliche Züge einer Überwindungs- ${ }^{23}$ oder Substitutionshermeneutik ${ }^{24}$. Erich Zenger beschreibt dieses Verstehensmodell

I9 Zenger, Erich: Einleitung in das Alte Testament, Stuttgart: Kohlhammer ${ }^{3}$ I995, 2I (spätere Auflagen passim).

20 Lang, Bernhard: Die Bibel. Eine kritische Einführung, Paderborn: Schöningh ²1994, 217.

2I Ebd.

22 Baumann: Gottesbilder der Gewalt.

23 Vgl. ebd., 74f.

24 So bei Zenger, Erich: Heilige Schrift der Juden und der Christen, in: Ders. u. a.: Einleitung in das Alte Testament, Stuttgart: Kohlhammer '2004, I2-35, I7f.; sowie bei Michel, Andreas: Gott und Gewalt gegen Kinder im Alten Testament (FAT 37), Tübingen: Mohr Siebeck 2003, 4 . 
des Alten Testaments so, dass es durch „den Atem jenes ,teaching of contempt' [gekennzeichnet ist], der ein Aspekt jener fatalen theologischen Judenfeindschaft ist, die einer der Auslöser des rassischen Antisemitismus war" ${ }^{\text {". }}{ }^{25}$ Denn der Verweis auf das Neue Testament als mögliche „Lösung" des Problems göttlicher Gewalttätigkeit im Alten Testament birgt die Gefahr, dass das Judentum aus christlicher Perspektive mit diesem Problem behaftet bleibt. ${ }^{26}$ Die Frage nach den gewalthaften Zügen Gottes in der Bibel wird durch die Ausgliederung bzw. „Judaisierung" des Alten Testaments quasi „entsorgt“. Das Problem mit den Gottesbildern der Gewalt im Alten Testament ist dann nicht mehr „unser“ christliches, sondern „deren“ ”üdisches Problem.

Varianten dieses Deutungsmodells finden sich öfter in christlichen Auslegungen von Texten, in denen Gott als Gewalttäter erscheint. Zur Vermeidung solcher Deutungsstrategien möchte ich an dieser Stelle zwei hermeneutische Strategien vorschlagen: Einmal eine Strategie der Ehrlichkeit, nach der zunächst auch einmal eine christliche Beschäftigung mit Gottesbildern der Gewalt im Neuen Testament einsetzt und Deutungsmöglichkeiten für diese Texte entwickelt werden. - Dies allerdings setzt entsprechende Forschungen im Bereich der neutestamentlichen Wissenschaft voraus, die ich als Alttestamentlerin nur anregen, nicht aber selbst erarbeiten kann. Auch aus diesem Grund habe ich mich in meiner Monographie von 2006 für eine zweite Strategie entschieden; ich möchte sie an dieser Stelle als Strategie der Selbstbeschränkung bezeichnen: Selbstbeschränkung in dem Sinne, dass die Gottesbilder der Gewalt im Alten Testament im christlichen Kontext zunächst einmal inneralttestamentlich erklärt und gedeutet werden sollten. So ließe sich der Gefahr einer Überwindungs- oder Substitutionshermeneutik mit dem Verweis auf das vermeintlich so andere Gottesbild des Neuen Testaments entgehen. Der christlichen Auslegung wäre so der Weg verbaut, sich von diesem theologischen Problem mit dem Verweis darauf zu dispensieren, dass es sich um ein jüdisches (und nicht um ein christliches) Problem handelt.

Zu guter Letzt möchte ich an dieser Stelle noch die Inspiration durch jüdische Schriftexegese nennen, die jener verwandt ist, die ich im Bereich des Schriftverständnisses schon angesprochen habe. Die Pluralität möglicher Bedeutungen biblischer Texte und die Auffaltung des Sinns in verschiedene Richtungen lassen sich natürlich auch für die zahlreichen Aspekte Gottes fruchtbar machen, die uns in der

25 Zenger: Heilige Schrift der Juden und der Christen, I8.

26 Dazu vgl. z. B. die Analyse von Beckmann, Klaus: Die fremde Wurzel. Altes Testament und Judentum in der evangelischen Theologie des I9. Jahrhunderts (FKDG 85), Göttingen: Vandenhoeck \& Ruprecht 2002. 
Bibel begegnen. Als evangelische Exegetin nehme ich das systematisch-theologische Bedürfnis nach dogmatischer Vereinheitlichung, nach Operationalisierbarkeit oder Tauglichkeit für die Ableitung normativer Aussagen in der Exegese auch im Bereich des Gottesbildes als sehr beschränkend wahr - und als im Konflikt mit dem Schriftprinzip stehend. Im Hinblick auf das Gottesbild könnte hier beispielsweise anregend sein, was Hanspeter Ernst in einem Artikel über rabbinische Traditionen über Gottes Nähe und Gottes Leid zusammengestellt hat - ein Blick auf Aspekte des biblischen Gottesbildes, die in christlicher Exegese häufig zu kurz kommen. ${ }^{27}$

\section{Schlussbemerkung}

Durch das christlich-jüdische Gespräch hat sicher nicht nur meine Forschungsperspektive eine erhebliche Weitung erfahren. Stärker in den Blick kommt durch jüdische Exegese die Vielfalt möglicher Sinne biblischer Texte. Die historischen Parallelen, Anregungen und gegenseitigen Beeinflussungen jüdischer und christlicher Exegese werfen ein neues Licht auf die Auslegungsgeschichte der Bibel. Natürlich geht dies mit einer Infragestellung der jeweils eigenen Position einher. Ich habe diese Infragestellung allerdings als konstruktiv erlebt, weil sie den Forschungsprozess und den wechselseitigen Austausch voranbringt - auch wenn mir an manchen Stellen noch nicht klar ist, wohin dieser Denkweg mich führen wird. Gewiss bin ich mir allerdings darin, dass ich sehr dankbar für diese Anregungen bin.

27 Ernst, Hanspeter: Rabbinische Traditionen über Gottes Nähe und Gottes Leid, in: Thoma, Clemens / Wyschogrod, Michael (Hg.): Das Reden vom einen Gott bei Juden und Christen (JudChr 7), Bern: Peter Lang 1984, I57-I77. 


\title{
Vom „Alten Testament“ zu einem Buch mit Eigenwert
}

Stationen von Erfahrungen mit Leseweisen der Bibel Israels

\author{
Johannes Marböck
}

Die Einladung zu diesem Forschungskolloquium mit der Herausforderung, eine Thematik für den eigenen Beitrag zu formulieren, war Impuls zu einem Nachdenken, in dem mir wie bisher noch nie in diesem Ausmaß überraschend bewusst wurde, wie sehr sich mein eigenes Denken zur Frage Altes Testament und Bibel Israels gewandelt hat. Ich möchte daher "ebenerdig“ einige Stationen und Erfahrungen meines persönlichen Weges im Umgang mit dem Alten Testament erinnernd skizzieren, die sehr viele Menschen heute wohl gar nicht mehr gemacht haben. Dies sind:

- Stationen aus der Zeit meiner eigenen theologischen Ausbildung und Praxis in Linz (Oberösterreich) vor dem II. Vatikanum;

- Johannes XXIII. und Nostra Aetate - Impulse der Zeit um das II. Vatikanum;

- Erfahrungen und Stationen von Lehre und Praxis meiner Tätigkeit in Linz und Graz zwischen 1970 und 2003;

- Der bleibende Eigenwert der Bibel Israels in einer christlich-jüdischen Hermeneutik.

I. Vorbemerkung: Stimmen für das Alte Testament in der Kirche von Linz zwischen 193I und 1938

Aus meinem näheren kirchlichen Umfeld der Diözese Linz, aus dem ich komme, scheinen mir im Kontext unserer Thematik drei Stimmen aus der Zeit vor der Machtergreifung des Nationalsozialismus bis heute der Erinnerung wert.

Im Jahr I93I veröffentlichte der an der Grazer Theologischen Fakultät 1922 mit dem Dr. h. c. ausgezeichnete damalige Linzer Domprediger Franz Stingeder ${ }^{1}(\dagger$ 1936) das für jene Epoche höchst bemerkenswerte Werk „Homiletischer Führer durch das Alte Testament", in dem er grundsätzlich und mit zahlreichen Beispielen

I Stingeder, Franz: Homiletischer Führer durch das Alte Testament. Mit einem Verzeichnis der wichtigsten exegetisch-homiletischen Literatur, der dogmatischen Stellen im A. T., einem Verwendungsregister nebst einem Anhang von Predigt-Dispositionen über alttestamentliche Texte, Linz an der Donau: Preßverein I93I. 
die Predigt über das damals von Christinnen und Christen kaum gekannte und vor allem wenig geschätzte Alte Testament als Pflicht (!) hinstellt. Gewiss trägt jener umfangreiche (396 + IX S.), aber in der homiletischen kirchlichen Literatur angesichts der damaligen Leseordnung völlig außergewöhnliche Versuch die Spuren und Grenzen zeitbedingten theologischen Denkens, wonach das Alte Testament Vorstufe, Vorhersage und Vorausdarstellung des Neuen ist, das jedoch ohne das Alte unverständlich bleibt. ${ }^{2}$ Bis heute aktuell aber bleiben seine damaligen Hinweise auf die reiche Fülle von Impulsen der Texte für die Verkündigung, aber auch auf die Notwendigkeit exegetischer Gewissenhaftigkeit des Homileten und die Kenntnis der wichtigsten alttestamentlichen Fragen. ${ }^{3}$

Neben diesem angesichts der damals schon feststellbaren Abwertung des Alten Testamentes in der Tat wegweisenden, leider weithin unbeachteten Werk ist auch eine zweite Stimme interessant. Gegenüber dem aus politisch-nationalistischen und antisemitischen Kreisen bereits zu hörenden unchristlichen Ruf „Fort mit dem Alten Testament", der an theologischen Fakultäten Deutschlands bereits Wirkung gezeigt hatte, etwa in Tübingen, erhebt der exegetisch äußerst traditionelle Alttestamentler Dr. Karl Fruhstorfer 1933 in der Linzer Theologisch-praktischen Quartalschrift seine Stimme zu einem leidenschaftlichen Plädoyer für das Alte Testament in Theologie, Religionsunterricht und Gottesdienst. ${ }^{4}$ Nach ihm liegt im Alten Testament nicht Rassenoffenbarung, sondern Offenbarung Gottes vor. Für Jesus war das Alte Testament Gottes Wort. Allerdings werden auch in seiner scharfen und mutigen Kritik an den ausdrücklich genannten Namen und Stimmen von Alfred Rosenberg und Adolf Hitler wiederum Grenzen spürbar, wenn das Alte Testament als lex imperfecta und lex timoris dem Neuen Testament als lex perfecta und lex amoris gegenüber gestellt wird und vor allem die Aufgabe hatte, auf Christus vorzubereiten, Christus durch Weissagungen voraus zu verkünden und durch Vorbilder anzudeuten. ${ }^{5}$

Eine dritte Äußerung mit diesem spannungsreichen Ineinander von persönlichem couragiertem Engagement zur Verteidigung des Alten Testamentes und damaligen theologischen Grenzen war die Antrittsvorlesung meines Vorgängers als Lehrer der alttestamentlichen Bibelwissenschaft in Linz, Professor Dr. Maximilian Hollnsteiner, der im Oktober 1938, nur einige Wochen vor dem Brand der in unmittelbarerer Nachbarschaft gelegenen Synagoge Religion und heilsgeschichtliche Bedeutung des Alten Testamentes gegen den schon begonnenen Vernichtungs-

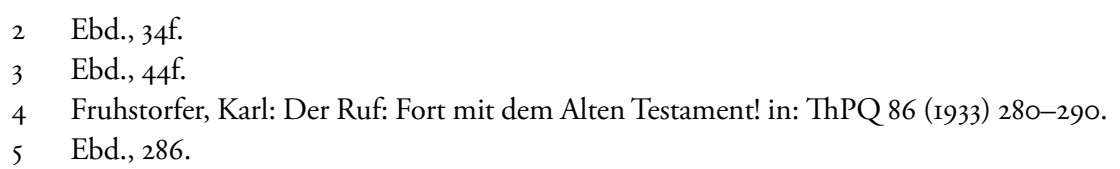


kampf verteidigte. Der Achtzigjährige verweist in einer Notiz zur persönlichen Übermittlung des Manuskriptes im Jahr 1984 ausdrücklich auf „den Antisemitismus teilweise auch bei der katholischen Jugend (Theologen)". Dennoch: Bei aller Gewichtung des Bekenntnisses zum Einen und Einzigen (Dtn 6,4) sowie des prophetischen Ideals von Recht tun und Güte lieben und achtsam umgehen mit Gott (Mi 6,8) bleibt auch bei ihm das größte der Güter im Alten Testament die Hinführung auf Christus und sein Reich, die Funktion des $\pi \alpha 1 \delta \alpha \gamma \omega \gamma o ́ \varsigma$ auf Christus hin (Gal 3,23f.). ${ }^{6}$ Neben der politischen Situation ließ die Betonung der Einheit der christlichen Bibel mit der Überzeugung vom großen Prozess des Sprechens Gottes nach Hebr I,I damals offenbar noch kaum Räume für Reflexionen über eine Eigenständigkeit des Alten Testamentes als Bibel Israels bzw. als Hebräische Bibel.

\section{Das Alte Testament in Theologiestudium und Pastoral I954-I965}

Dieser Zwiespalt und diese Spannung bestimmten im Wesentlichen auch noch mein Studium der Theologie in Linz 1954-1959. Der Enzyklika Divino afflante spiritu Pius XII. vom Jahr 1943, an der der Professor am Bibelinstitut Augustin Bea SJ wesentlichen Anteil hatte, war es ja um die damals zweifellos höchst wichtige dankenswerte Öffnung der katholischen Exegese für aktuelle historische und literarische Fragestellungen gegangen und noch keineswegs um exegetische und theologisch-systematische Auseinandersetzungen über den Stellenwert des Alten Testamentes in christlicher und jüdischer Sicht bzw. um das Verhältnis zwischen jüdischer und christlicher Bibel.

Dankbar bin ich aber immer noch, dass wir von unserem Lehrer des Alten Testamentes, Max Hollnsteiner, für die Auslegung der Genesis bereits damals auf den gewichtigen jüdischen Genesiskommentar von Benno Jacob (Berlin 1934) hingewiesen wurden. In der uns in jener Periode zur Verfügung stehenden bescheidenen zeitgenössischen exegetischen Literatur waren es vor allem Werke von Professor Claus Schedl CSsR in Wien, Mautern und Graz (1914-1986), die mich und gewiss auch viele andere mit ihrer suggestiven emotionalen Sprachkraft und ihrem Wissenshorizont für das Alte Testament zu interessieren vermochten, angefangen von seiner Antrittsvorlesung "Sieben Thesen wider des Alten Testaments Verächter" und dem Buch „Die Sehnsucht der ewigen Hügel. Christus im Alten Testament“. 8

6 Kopie des am 6.6.1984 von Maximilian Hollnsteiner erhaltenen Manuskriptes vom Oktober 1938: Zur Einleitung in das Alte Testament.

7 Schedl, Claus: Sieben Thesen wider des Alten Testaments Verächter, Wien: Herder 1947.

8 Ders.: Die Sehnsucht der ewigen Hügel. Christus im Alten Testament, Graz: Anton Pustet 1947. 
In diesem viel gelesenen, aus der Bildungsarbeit in der Erzdiözese Wien hervorgegangenem Werk, das Studierende und Prediger zweifellos für das Alte Testament begeistern konnte, war das Alte Testament noch notwendig „ein Christusbuch“, „Vorläufer für Christus wie der Täufer“, ${ }^{10} \mathrm{ja}$ „nichts anderes als eine einzige offene Wunde auf Christus hin" ${ }^{11}$ Auch für sein als Synthese von Geschichte, Einleitung und Theologie konzipiertes Studienbuch "Geschichte des Alten Testaments"12 galt: „Das Alte Testament ist ,der Erzieher auf Christus hin'. Sag mir daher, wie Du zu Christus stehst, und ich sage Dir, wie Du das Alte Testament liest. ${ }^{\text {"13 }}$ Zum Glück ließ die Behandlung konkreter Probleme von Geschichte, Texten und Theologie eine rein christologisch-neutestamentliche Sicht immer wieder zugunsten spezifischer Aussagen einzelner Schriften und Texte zurücktreten.

Anstöße für die Beschäftigung mit der theologischen Frage einer eigenständigen Hebräischen/Jüdischen Bibel unabhängig vom Neuen Testament waren für uns Studierende damals kaum präsent; fehlte doch das Alte Testament bis nach dem Konzil in den Texten unserer liturgisch-biblischen Leseordnung (ausgenommen in der Karwochenliturgie) und damit nahezu völlig auch für die Verkündigung. Es bedurfte offenbar selbst nach 1945 noch eines längeren mühevollen Prozesses, bis die katholische Kirche Israel und seine heiligen Schriften als schuldhaft vernachlässigte, vergessene eigene theologische Größe und Wirklichkeit wahrzunehmen und zu akzeptieren gelernt hat. Claus Schedl hatte dies 1947 in der sechsten seiner sieben Thesen zumindest theoretisch bereits zu formulieren versucht, wenn er dort für das Gespräch mit den Kindern Israels gefordert hat, „es müsste geschehen in der großen Demut einer Begegnung, die Gegensätze nicht verwischt, sondern über den Gegensätzen das Gemeinsame sieht, den Glauben an Gott und seinen Messias-Christus! “14 Als äußeres Zeichen dafür hatte er übrigens 1948 an der Katholisch-Theologischen Fakultät in Wien für drei Studierende, eine Moskauer Jüdin, einen katholischen Studenten aus Ungarn und einen evangelischen aus Österreich ein Semester lang eine „Einführung in den Talmud“ gehalten. Er hatte sich nämlich 1945 noch unter Beschuss der Roten Armee antiquarisch eine Ausgabe der Mischna besorgt und sichergestellt. ${ }^{15}$

\footnotetext{
9 Ebd., 305.

IO Ebd., 297.

II Ebd., 7.

I2 Schedl, Claus: Geschichte des Alten Testaments. I-5, Innsbruck: Tyrolia I952-I964.

I3 Ebd. I, XXIV.

I4 Schedl: Wider des Alten Testaments Verächter, 26.

I5 Ders.: Talmud. Evangelium. Synagoge, Innsbruck: Tyrolia I969, 7.
} 
Was damals für meine eigene Ausbildung und weithin wohl für die meisten katholischen Theologiestudierenden in Österreich galt, galt umso mehr für die pastoralen Konsequenzen biblischer Bildung in Pfarren und Gemeinden. Anfragen zum Alten Testament, das ja umfangmäßig und theologisch sehr begrenzt nur im Religionsunterricht in der Schule, aber nicht in Liturgie und Predigt vorkam, betrafen meist nur das Nachholbedürfnis zu aktuellen historischen und literarischen Fragen der Mosebücher (Urgeschichte, Erzelternerzählungen, Exodus), zu Wundergeschichten oder noch zu den so genannten messianischen Texten. Die theologische Dimension einer Bibel Israels, der Jüdischen Bibel als Bibel Jesu und der werdenden Kirche war kaum eine Frage, die katholische Christinnen und Christen berührte. Außerdem gab es ja in den Jahrzehnten nach der Schoah selbst in größeren Städten wie Linz kaum mehr größere jüdische Gemeinden; d. h. die Israelvergessenheit existierte leider auf mehreren Ebenen. - Die zehn Seelisberger Thesen von 1947 mit ihrer Weiterführung in Schwalbach $1950^{16}$ als erste Magna Charta für einen neuen, weiterführenden christlich-jüdischen Dialog blieben sowohl auf der Ebene der theologischen Ausbildung als auch der Verkündigung und Praxis in den Gemeinden, jedenfalls bei uns, leider weithin unbeachtet oder überhaupt unbekannt.

\section{Johannes XXIII. und Nostra Aetate Nr. 4 - Impulse um die Zeit des II. Vatikanischen Konzils}

Entscheidend für Theologie und Verkündigung der Bibel Israels als eigenständige Größe in der katholischen Kirche wurde zweifellos, auch für mich persönlich, die Gestalt Papst Johannes XXIII. (1958-1963), seine persönlichen charismatischen Impulse und vor allem der Anstoß zu Nostra Aetate. ${ }^{17}$

Dies gilt nach seinen Einsätzen für Jüdinnen und Juden schon als Apostolischer Delegat in der Türkei und in Griechenland (1934-1944) bereits für die Streichung der antijüdischen liturgischen Karfreitagsbitte „pro perfidis Judaeis“ bzw. der „Judaeorum perfidia“ im Jahr 1959 sowie für sein berührendes Wort „Ich bin Josef, euer Bruder" (Gen 45,4) vor einer Gruppe amerikanischer Juden im Oktober 1960. Vor allem aber war es sein vom Besuch des französischen jüdischen Historikers Jules Isaac inspirierter und Kardinal Bea anvertrauter Auftrag zu einer Erklärung über

I6 Rendtorff, Rolf / Henrix, Hans Hermann (Hg.): Die Kirchen und das Judentum. I. Dokumente von $1945-1985$, Paderborn: Bonifatius ${ }^{2} 1989$, 646-650.

I7 Henrix, Hans Hermann: „Die eigentliche Quelle ist das Herz Johannes' XXIII.“ Entstehung und Wirkung der Konzilskonstitution „Nostra Aetate“, in: ThPQ I6I(2013) 280-29I. 
die Beziehungen der Kirche zum jüdischen Volk, die als Artikel 4 zum Ursprung und Herzstück des in einem spannenden und schwierigen Prozess von 1960 bis 1965 gewachsenen Dokumentes Nostra Aetate, der Erklärung über die Haltung der Kirche zu den nichtchristlichen Religionen, geworden ist. Der ehemalige Lehrer am Bibelinstitut, Kardinal Bea (I89I-I968), hat, nach außen diskret, zurückhaltend und entsagungsvoll, aber zuletzt erfolgreich, alle Kräfte der Physis und des Glaubens seiner letzten Lebensjahre in dieses Dokument investiert. ${ }^{18}$ Es sind bis heute und auch für die Zukunft entscheidende Weichenstellungen für eine neue Sicht auch der alttestamentlichen Bibel in der katholischen Kirche, die da begegnen:

- Der Glaube Israels ist der gute Ölbaum (Röm II,I6ff.), dem sich auch die Kirche der Völker verdankt.

- Israel bleibt nach Paulus das erwählte Volk.

- Die jüdische Gemeinschaft ist entscheidend in die Suche nach dem christlichen und kirchlichen Selbstverständnis einzubinden.

- Das Evangelium ist ohne das zeitgenössische Judentum nicht zu verstehen.

Dies war bereits der weite und neue theologische Horizont, den uns am Ende des Konzils 1965 die Lehrer am Päpstlichen Bibelinstitut in Rom vermittelt haben, von denen ja selber 19 Professoren einen Vorschlag „De antisemitismo vitando“ an die Konzilsväter übermittelt hatten. Der Ansatz zum Ernstnehmen der Eigenständigkeit alttestamentlicher Texte der hebräischen oder auch der griechischen Gestalt der Bibel Israels zeigte sich neben der Exegese in Einladungen jüdischer Historiker, Archäologen und Exegeten nach Rom. So erinnere ich mich bis heute an das betroffen machende Schlusswort eines Vortrages von Yigael Yadin über seine Ausgrabungen in Masada: „It's a remind and a challenge.“

Solche Erfahrungen der Erinnerung und Herausforderung sowohl im Bereich der exegetischen Wissenschaft als auch in Begegnungen haben mich insbesondere durch ein anschließendes Studienjahr an der École Biblique der Dominikaner in Jerusalem nach dem Sechstagekrieg 1967/68 geprägt. Der bekannte Neutestamentler Pierre Benoit OP hatte auch selber an Nostra Aetate mitgearbeitet. Dazu kam dort die neue Möglichkeit, nicht bloß die historisch-archäologischen Gestalten der Stadt Jerusalem mit ihrer dramatischen Geschichte, sondern auch die Stationen und Spuren der ganzen Geschichte Israels und seiner Bibel im Land selber abzuschreiten und ausführlich kennen und schätzen zu lernen, von Tell Dan im

I8 Schmidt, Stjepan: Augustin Bea. Der Kardinal der Einheit, Graz: Styria 1989, 640-689; Siebenrock, Roman: Theologischer Kommentar zur Erklärung über die Haltung der Kirche zu den nichtchristlichen Religionen: Nostra Aetate, in: Hünermann, Peter / Hilberath, Bernd Jochen (Hg.): Herders Theologischer Kommentar zum Zweiten Vatikanischen Konzil. 3, Freiburg: Herder 2005, 591-693. 
Norden über die Siedlungen am Toten Meer mit dem Ausgräber Roland de Vaux bis in die Oasengegend von Kadesch Barnea im Gebiet des Sinai. Die in den biblischen Erzählungen überlieferten Zeugnisse des Glaubens haben durch so manche Spuren in den Schichten der Erde, in den Stätten des Landes für mich ein eigenes, neues Gewicht gewonnen, über bloße Vorstufen hinaus als Zeichen und Botschaft der spannenden Geschichte eines nicht mehr rückgängig zu machenden Wohnungnehmens Gottes in Israel, seines Ja zu konkreten Menschen mit ihrer Geschichte.

4. Wachsen der Neugewichtung des Alten Testamentes - Stationen und Erfahrungen in Österreich $1968-2003$

Dieses doppelte Fundament, die Konzilsbotschaft von Nostra Aetate Nr. 4 sowie die realen Zeichen einer nicht mehr zu löschenden eigenständigen Geschichte des erwählten Volkes Israel, haben die weiteren Stationen meines Umgangs mit dem Alten Testament mitbestimmt und geprägt.

4.I. Das war vorerst eine kurze Tätigkeit als Assistent in Graz (1968-1970) mit der Habilitation beim hoch verdienten damaligen Rektor des Österreichischen Pilgerhospizes in Jerusalem, Univ.-Prof. DDr. Franz Sauer (1906-1990). Die gewählte Thematik der Weisheitstheologie beim frühjüdischen Schriftgelehrten Jesus Sirach ${ }^{19}$ stellt ja mit Kapitel 24 als bedeutsame Interpretation von Spr 8,2236, so sehe ich es heute, einen bis zur Stunde zukunftsträchtigen Impuls für eine ganzheitliche, eigenständige Sicht der Bibel Israels dar, vielleicht auch für das jüdisch-christliche Gespräch überhaupt. Enthält doch Sir 24 die bis dahin umfassendste Synthese alttestamentlichen theologischen Denkens. Sie fasst ja Offenba-

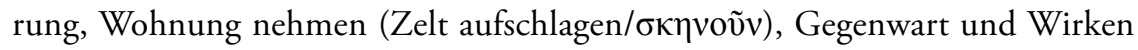
Gottes in Gestalt der Frau Weisheit in Kosmos und Geschichte Israels (Jerusalem, Kult, Land, Menschen) im Zeugnis der Weisung des Mose sowie schließlich in der Person des Weisen selber zusammen. Die Theologie der Schekina, der Einwohnung Gottes in Israel, erreicht in Sir 24 einen Höhepunkt. Der in sich geschlossene Text des Kapitels bleibt aber auch offen und wird zu einem Grenztext für jüdisches Denken, wenn wir fragen, ob und wie diese Einwohnung der Weisheit Gottes in Jerusalem und Israel nochmals weiter geführt werden kann und darf, wie es Joh I,I4 nach mehreren Stationen schließlich im Anklang an Sir 24 vom göttlichen Logos

I9 Marböck, Johann: Weisheit im Wandel. Untersuchungen zur Weisheitstheologie bei Ben Sira. Mit Nachwort und Bibliographie zur Neuauflage (BZAW 272), Berlin: de Gruyter 1999; Erstveröffentlichung in: BBB 37, Bonn: Peter Hanstein 197I. 
(Joh I,I) bekennt: „Und der Logos ist Fleisch geworden und hat unter uns das Zelt aufgeschlagen [...]. “20

4.2. Meine selbstständige Lehrtätigkeit in Linz (1970-1976), zum Teil auch in Graz, war Möglichkeit, aber auch Herausforderung, die Sicht des Alten Testamentes als Bibel Israels mit Eigenwert in der Auslegung von Pentateuch, Propheten und Schriften zu konkretisieren, zu vertiefen und zu vermitteln. Erfahrung und Einsicht, dass wir da Quellen kraftvoller und tiefer eigenständiger Geistigkeit begegnen, sind dabei Schritt für Schritt gewachsen. Die damals maßgebende exegetische Literatur der Kommentarwerke (Altes Testament Deutsch, Biblischer Kommentar Altes Testament) sowie zur Theologie des Alten Testamentes, durchwegs aus der evangelischen Wissenschaft, stellte dafür eine wichtige Orientierung dar. Die Frage der Beziehung zum Neuen Testament war dabei bereits gegenwärtig, wenn auch in sehr unterschiedlicher Weise. So sprach etwa Gerhard von Rad in seinem Genesiskommentar sehr zurückhaltend von der Möglichkeit einer Lektüre auch „zur Einübung auf die Selbstoffenbarung Gottes in Jesus Christus hin “. ${ }^{21}$ Er war aber auch überzeugt, die alttestamentliche Theologie „wird von ihrem Stoff selbst von einer Aktualisierung zur anderen getragen und schließlich wird sie bis an die Schwelle des Neuen Testamentes, ja über diese Schwelle geführt werden. "22

Von wegweisender Bedeutung in diesem Prozess wachsender eigenständiger Gewichtung des Alten Testamentes, in einer zweiten Line seiner Auslegung im Judentum, waren auf der einen Seite für mich vor allem frühe kollegiale, freundschaftliche Begegnungen mit Kurt Schubert († 2007). Seine Persönlichkeit, sein Engagement und sein literarisches Werk für die Umsetzung von Nostra Aetate und die Verankerung des Dialoges mit dem Judentum in der Kirche können zweifellos Kollegen und Nachfolger in der ganzen Tragweite kompetenter beurteilen. Der andere Impuls war selbstverständlich bestimmt von der Lektüre und vom Studium jüdischer Auslegung biblischer Texte, etwa dem Midrasch Tehillim sowie in den

20 Janowski, Bernd: Gottes Weisheit in Jerusalem. Sirach 24 und die biblische Schekina-Theologie, in: Lichtenberger, Hermann / Mittmann-Reichert, Ulrike (Hg.): Biblical Figures in Deuterocanonical and Cognate Literature (DCLY 2008), Berlin: de Gruyter 2009, I-29 verweist auf den gewichtigen Beitrag: Wyschogrod, Michael: Inkarnation aus jüdischer Sicht, in: EvTh 55 / I(1995) I3-28.

2I Rad, Gerhard von: Das erste Buch Mose. Genesis Kap. I-I2 (ATD 2/2), Göttingen: Vandenhoeck \& Ruprecht ${ }^{9}$ I972, 26.

22 Rad, Gerhard von: Theologie des Alten Testaments. 2. Die Theologie der prophetischen Überlieferungen Israels (Einführung in die evangelische Theologie I,2), München: Kaiser ${ }^{4} \mathrm{I} 965,447$. 
Schriften zur Bibel von Martin Buber ${ }^{23}$ oder etwa von Abraham J. Heschel ${ }^{24}$ sowie anderer jüdischer Kommentarwerke. Da wurde mir immer wieder beeindruckend bewusst, dass es ein exegetisch ernst zu nehmendes und zugleich tief religiöses gläubiges Verständnis von alttestamentlichen Texten durchaus auch ohne eine/ die christliche Weiterführung zum Neuen Testament gibt und geben kann.

4.3. Die Weitung dieses meines Zugangs zum Alten Testament hat sich während meiner Tätigkeit gerade in Graz (1976-2003) nach außen vielleicht eher unmerklich, aber doch wirksam mit mehreren neuen Akzenten in Wissenschaft, Bildungsarbeit und vor allem durch Begegnungen fortgesetzt. Lehrveranstaltungen von Kollegen der Judaistik aus Wien haben das Verständnis für das Judentum gefördert, jüdische Exegetinnen wie Chana Safrai oder Athalya Brenner und Exegeten haben in Gastvorträgen und Lehrveranstaltungen dazu beigetragen, ihre Auslegung und Sicht der Hebräischen Bibel näher kennenzulernen und ernst zu nehmen. Wichtige Impulse dazu kamen von meiner geschätzten Mitarbeiterin und Nachfolgerin Irmtraud Fischer. Herders Theologischer Kommentar zum Alten Testament, vom leider zu früh († 20IO) verstorbenen Erich Zenger initiiert, stellt mit einer Reihe jüdischer Autorinnen/Autoren wie Moshe Greenberg, Sara Japhet, Yair Zakovitch ebenfalls einen bedeutsamen Schritt in dieser Richtung dar.

Prägend und weiterführend wurden in Graz vor allem persönliche Begegnungen im Zusammenhang mit der von Professorin Dr. Erika Horn mit persönlichem Einsatz geförderten jüdisch-christlichen Bibelwochen in Graz-Mariatrost mit jüdischen Exegetinnen und Exegeten völlig verschiedener Richtungen (Zwi Weinberg, Athalya Brenner, Daniel Krochmalnik). Dabei ist z. B. auch meine persönliche Freundschaft mit dem großen Sänger und Kantor der Grazer Synagoge Richard Ames gewachsen, dessen Weihnachtsgrüße drei Monate vor seinem Tod 2005 mich immer noch berühren. Der Tag des Judentums war ebenfalls stets neu Anlass, christliche Gemeinden in Graz auf verschiedene Leseweisen des Alten Testamentes als kostbares Erbe Israels, als Bibel Jesu und als Fundament der Botschaft des Neuen Testamentes hinzuweisen. ${ }^{25}$

Diese Entwicklungen kirchlicher Bildungsarbeit und Pastoral waren bereits Früchte der von Johannes XXIII. und vom Konzilsdokument Nostra Aetate an-

23 Buber, Martin: Werke. 2. Schriften zur Bibel, München: Kösel 1964.

24 Heschel, Abraham J.: The Prophets. An Introduction. I, New York: Harper \& Row 1969; ders.: The Prophets. 2, Harper \& Row I975.

25 Marböck, Johannes: Die römisch-katholische Kirche und das Judentum. Perspektiven eines Neubeginns, in: Kogler, Franz / Fischer, Irmtraud / Hubmann, Franz (Hg.): Johannes Marböck: Faszination Bibel (Theologie im kulturellen Dialog 27), Innsbruck: Tyrolia 20I4, 239-258. 
gestoßenen Dynamik in Kirche und Theologie. Vor allem Papst Johannes Paul II. (1978-2005) hatte durch seine Gesten und sein Wort die Rezeption entscheidend mitbestimmt „und der Haltung der Kirche gegenüber dem jüdischen Volk und dem Judentum eine neue Qualität und Konsistenz gegeben ", ${ }^{26}$ an der vor allem die Exegese mit der Sicht des Alten Testamentes nicht mehr vorbeikonnte. Ich erinnere nur an die theologische Tragweite des Satzes in seiner Ansprache an den Zentralrat der Juden in Deutschland vom I7. November 1980 in Mainz: „Die erste Dimension dieses Dialoges, nämlich die Begegnung zwischen dem Gottesvolk des nie gekündigten Alten Bundes und dem des Neuen Bundes, ist zugleich ein Dialog innerhalb unserer Kirche, gleichsam zwischen dem ersten und zweiten Teil ihrer Bibel. ${ }^{\text {"27 }}$ Beim Besuch der Synagoge in Rom 1986 bestätigt er zentrale Aussagen von Nostra Aetate, wenn er feststellt, die jüdische Religion gehöre in gewisser Weise zum „Inneren“ unserer Religion, und wenn er dort die Juden als „unsere bevorzugten" bzw. „gewissermaßen unsere älteren Brüder" anredet und auf die Elemente des großen gemeinsamen geistigen Erbes verweist. ${ }^{28}$

Das umfangreiche Dokument der Päpstlichen Bibelkommission vom Jahr $200 \mathrm{I}$ „Das jüdische Volk und seine Heilige Schrift in der christlichen Bibel“ ${ }^{29}$ gehört ebenfalls in diesen Kontext. Ich erinnere nur an einige für unsere Fragestellung wegweisenden Aussagen: ${ }^{30}$ „Das Alte Testament besitzt aus sich heraus [en lui même] einen ungeheuren Wert als Wort Gottes" (Nr. 2I). Zugleich wird die Beziehung zwischen Text und Lesegemeinschaft neu gewichtet: „Christen können und müssen zugeben, dass die jüdische Leseweise [lecture] der Bibel eine mögliche Leseweise darstellt, die in Kontinuität zu den jüdischen Heiligen Schriften zur Zeit des zweiten Tempels steht, eine Leseweise analog zur christlichen Leseweise, die sich parallel entwickelt hat. Jede dieser beiden Leseweisen bleibt der Sicht des Glaubens treu, deren Frucht und Ausdruck sie ist. Sie sind konsequenterweise nicht die eine auf die andere zurückzuführen" (Nr. 22). Neben der Betonung der Fortdauer der Liebe Gottes zu Israel (Nr. 3I-33), der Treue der Erwählung (Nr.

26 Henrix: „Die eigentliche Quelle“, 287 (Anm. I7).

27 Rendtorff / Henrix (Hg.): Die Kirchen und das Judentum, 75.

28 Ebd., IO6-III.

29 Das jüdische Volk und seine Heilige Schrift in der christlichen Bibel. Verlautbarungen des Apostolischen Stuhls I52, Bonn: Sekretariat der Deutschen Bischofskonferenz 200I. - Französisches Original: Le peuple juif et ses Saintes Ecritures dans la Bible Chrétienne, Paris: Ed. Cerf 200I. Die folgenden Übersetzungen aus dem Französischen stammen vom Verfasser.

30 Henrix, Hans Hermann: Die jüdische Messiashoffnung ist nicht vergeblich. Ein theologischer Versuch von Gewicht, in: Dialog DuSiach 5I(2003) I7-30. 
33-36) sowie des nicht gekündigten Bundes (Nr. 42) ist vor allem die im französischen Original noch stärkere Feststellung in Nr. 2I zu beachten: „Die jüdische Messiaserwartung ist nicht vergeblich, grundlos, nichtig [n'est pas vaine] und für Christen Ansporn, die eschatologische Dimension lebendig zu erhalten." Der Messias stellt in der jüdischen Leseweise auch nicht den zentralen oder gar den einzigen Verständnisschlüssel für Überlieferungen des Judentums dar (Nr. 62). Benedikt XVI. hat bei seinem Besuch in der Synagoge in Rom 2010 sowie bei seiner Begegnung mit Vertretern des Zentralrates der Juden in Berlin 20Ir das Wort von Israel als „Volk des Bundes" mit Mose wieder bestätigt, ${ }^{31}$ ebenso Papst Franziskus in Nr. 247-249 seines Apostolischen Schreibens „Evangelii gaudium“ vom 24. November 20I3 ${ }^{32}$ Nach ihm erlaubt uns eine reiche Komplementarität sogar, „die Texte der hebräischen Bibel gemeinsam zu lesen und uns gegenseitig zu helfen, die Reichtümer des Wortes Gottes zu ergründen“"33 (Nr. 249).

\section{Eigenwert der Bibel - christlich-jüdische Hermeneutik}

Zusammenfassend wenigstens einige Hinweise auf konkrete Dimensionen des „Eigenwertes der Bibel Israels“ bzw. der Hebräischen/Jüdischen Bibel, wie sie für mich auf den skizzierten Ebenen und Stationen kirchlicher Stellungnahmen, exegetischer Wissenschaft und in persönlichen Begegnungen schrittweise und durchaus unsystematisch gewachsen sind und zugleich stets Impulse für einen Dialog zwischen jüdischem und christlichem Bibelverständnis gegeben haben und bis zur Stunde geben.

\section{I. Das Gottesbild der Bibel Israels als bleibender Eigenwert}

Was sich rückblickend in einem langen Prozess über nun schon mehr als sechs Jahrzehnte hin in vielen kleinen Schritten für mich als bleibender Eigenwert der Bibel Israels in ihren ursprünglich mehrfachen Gestalten, sowohl der hebräischen als auch der griechischen Fassung, herauskristallisiert hat, finde ich bei Odil Hannes Steck treffend als das zusammengefasst, was beide Testamente verbindet; er

3I Henrix: „Die eigentliche Quelle“, 289 (Anm. 17).

32 Papst Franziskus: Die Freude des Evangeliums. Das Apostolische Schreiben „Evangelii gaudium“ über die Verkündigung des Evangeliums in der Welt von heute, Freiburg: Herder 2013.

33 Zit. n. http://w2.vatican.va/content/francesco/de/apost_exhortations/documents/papa-francesco_esortazione-ap_20I3II24_evangelii-gaudium.html\#Die_Beziehungen_zum_ Judentum [abgerufen am 9.5.20I4]. 
schreibt: „,Das, was Christum treibet', wäre aus heutiger Sicht und Wissen allerdings eine sehr einseitige in der Gefahr der Engführung stehende Bestimmung. Die Auskunft auf die Frage, wovon in der Bibel die Rede ist, muss weiter greifen und deshalb anders lauten: Es ist, die genannte christologische Antwort einschließend, umgreifend und natürlich auf sie zulaufend, textnäher Gott, also nichts anderes als die zu bestimmter Zeit ergangene, Zeit und Leben zugewandte Kunde von Gott, die da in den biblischen Überlieferungen [...] weitergegeben wird. Gott und sein zugewandtes Wirken, das ist der tragende, durchgängige Inhalt der biblischen Überlieferung. " ${ }^{\text {34 }}$

Konkret ist das für mich neben den uneinholbaren bleibend gültigen Fragen Gottes vom Beginn der Bibel an in Gen 3,9 „Wo bist du?" und 4,9 „Wo ist dein Bruder?" vor allem in den Psalmen entfaltet und erfahrbar geworden und wird es ständig noch mehr. Dort wird die uns zugewandte Kunde von Gott, Gottes zugewandtes bleibendes Wirken als kostbare Botschaft mit eigenem, selbstständigem Gewicht für eine glaubende Gemeinschaft (Geschichtspsalmen, Königspsalmen, Zionspsalmen, Klagelieder des Volkes), aber auch für einzelne Beterinnen und Beter und Glaubende zu allen Situationen des Lebens Wirklichkeit, auch ohne (und vor aller) neutestamentlich-christologische(n) Interpretation. Wurden und werden diese Psalmen doch in allen und trotz aller schrecklichen Erfahrungen zu gleicher Zeit und auch in Zukunft in diesem Sinn von Menschen des nicht gekündigten Bundes, von gläubigen Jüdinnen und Juden gesprochen, ein Geschehen, vor dem wir als Christinnen und Christen nur mit Staunen, Ehrfurcht und großer Dankbarkeit stehen können. ${ }^{35}$ „Wir können nach Auschwitz beten, weil auch in Auschwitz gebetet wurde“ (Johann Baptist Metz).

Für Texte von Propheten wäre Ähnliches zu sagen: „Sie waren und sind das unkalkulierbare Einfallstor der Transzendenz Gottes, die den Status quo immer wieder in Frage stellen" ${ }^{36}$ Wenn nun dieser Bund und die Verheißungen Gottes für Israel ohne Reue sind und Gültigkeit haben (vgl. Röm II,29), dann ist das Israel des Alten Testamentes eine bleibende Wirklichkeit; dann gilt das wohl auch für

34 Steck, Odil Hannes: Gott in der Zeit entdecken. Die Prophetenbücher des Alten Testaments als Vorbild für Theologie und Kirche (BThSt 42), Neukirchen-Vluyn: Neukirchener Verlag 200I, 7of.

35 Siehe auch: Worthen, Jeremy: Praying the Psalms and the Challenges of Christian-Jewish Relations: Dietrich Bonhoeffer and Thomas Merton, in: Studies in Jewish-Christian Relations 9 (20I4) I-22.

36 Zenger, Erich: Eigenart und Bedeutung der Prophetie Israels, in: Zenger, Erich u. a.: Einleitung in das Alte Testament (Kohlhammer Studienbücher Theologie I,I), 8. Aufl. hg. v. Christian Frevel, Stuttgart: Kohlhammer ${ }^{8} 2012,509-520,520$. 
viele andere Namen und Orte der Bibel Israels, etwa für Zion/Jerusalem, das trotz der vielen visionären Elemente der großen prophetischen Verheißungen (vgl. etwa Visionen wie Jes 2,2-5; Mi 4,I-5; Jes 19,23-25; Jes 25,6-8; Jes 60) keine bloß spirituelle Wirklichkeit ferner Zukunft ist, sondern zugleich ein Stück Realität und Herausforderung der Gegenwart. Es bleibt eine sehr ernste Frage für die Christenheit und die Kirche, wie sie in ihrer Geschichte mit diesen Texten und Verheißungen umgegangen sind.

Ihre bleibende Bedeutung auch nach dem Kommen Jesu und unabhängig von der Christusoffenbarung behalten zweifellos ebenfalls die in den Weisheitsschriften begegnenden vielfältigen Impulse für konkrete Orientierungen aus der Welt menschlicher Erfahrungen. In besonderer Weise gilt dies von der unerhörten Freiheit und Leidenschaft des Fragens und Ringens mit Gott in Ijob und Kohelet.

Man sollte übrigens nicht vergessen bzw. überhaupt neu bedenken, dass und wie sehr die Bibel Israels, das Alte Testament in sich selber auch Literatur von Weltrang enthält und ist.

\subsection{Christlich-jüdische Bibelhermeneutik}

Der skizzierte vielgestaltige persönliche Weg zum inhaltlichen theologischen Eigenwert der Bibel Israels, des Alten Testamentes, bleibt allerdings nur Teil der Diskussion eines noch umfassenderen zentraleren Problems, der Hermeneutik dieses Teils im größeren Ganzen unserer zweigeteilten christlichen Bibel, die in den I980er-Jahren intensiver begonnen hat und bis zur Stunde lebendig ist. Gewichtige exegetische Positionen zu dieser Frage, die meine begrenzte Themenstellung bereits überschreitet, können hier nicht mehr entfaltet werden. Ich erinnere beispielsweise nur an Namen wie Norbert Lohfink, Erich Zenger, Christoph Dohmen, Thomas Söding und Frank Crüsemann; auch Alfons Deissler und Josef Schreiner wären hier zu nennen.

Norbert Lohfink, der seit mehr als fünf Jahrzehnten dazu engagiert ist und eigenständig seine Stimme erhebt, möchte die faktische Zweiheit von Judentum und Christentum seit Jesus nicht resignierend-statisch, sondern im Sinn von Röm II,II dramatisch als eine Situation auf Veränderung hin betrachten: „Die Christen müssen die Juden zur Eifersucht reizen, die Juden müssen die Christen zur Eifersucht reizen. “" ${ }^{37}$ Im Blick auf die Gesprächsbereitschaft der jüdischen Partner/innen empfiehlt er dabei statt Bund den für sie weitaus zentraleren Begriff der Tora.

37 Lohfink, Norbert: Der niemals gekündigte Bund: Exegetische Gedanken zum christlich-jüdischen Dialog, Freiburg: Herder I989, IO9 (IO8-IIO). 
Erich Zenger formuliert als ein maßgebender Dialogpartner seine Option für eine jüdische und eine christliche Leseweise der Bibel Israels, d. h. für eine Hermeneutik des kanonischen Diskurses der beiden Teile unserer christlichen Bibel, des Alten Testamentes und des Neuen Testamentes je in ihrem Eigenwert und ihren unterschiedlichen Stimmen. ${ }^{38}$ Christoph Dohmen hat dies ausführlich entfaltet. Er spricht von einer doppelten Leseweise des Alten Testaments in unserer christlichen Bibel. Das Alte Testament ist zuerst rein und unvermischt ohne christologische Bezüge als Bibel Israels zu lesen und erst danach von den Rückbezügen des Neuen Testamentes her nochmals als Fundament zum Verständnis der Christusoffenbarung (vgl. neben dem Matthäusevangelium eindrücklich u. a. Lk I6,3I sowie die Zeugnisse von der Auferstehung). Es geht, so Dohmen, um ein komplementäres und korrigierendes Nebeneinander der beiden Leseweisen: um das Korrektiv des Wachhaltens des Ursprungs in der Bibel Israels, im Alten Testament, aber auch um die Deutung des Christusereignisses von dieser Schrift her als Legitimation. Christinnen und Christen erkennen im ersten Teil ihrer Heiligen Schrift ihren Israelursprung, hören dort den Anspruch des einen Gottes, erkennen „Israel“ aber auch als Ziel, als Volk des ewigen Bundes Gottes. Hermeneutik des Alten Testamentes ist Israelerinnerung. ${ }^{39}$ Unser Weg in den Neuen Bund ist ein Weg an der Seite Israels. Er spiegelt sich in der Art, wie wir Christinnen und Christen die Bibel Israels als Altes Testament und damit als Ur-Kunde unseres eigenen Glaubens lesen und verstehen, um unsere Identität zu finden und zu beschreiben. ${ }^{40}$

Auch Thomas Söding zeichnet diese Spannung im Umgang mit dem Alten Testament in der Gestalt unserer zweigeteilten christlichen Bibel. ${ }^{41}$ Das Alte Testament, das aus sich selbst heraus betrachtet nicht notwendig auf eine Fortsetzung im Neuen Testament hin angelegt ist, müssen wir vorerst in seinem Eigenwert als Bibel Israels zu Wort kommen lassen, als Dokument der Erwählung Israels wie

38 Zenger, Erich: Heilige Schrift der Juden und der Christen, in: Zenger, Erich u. a.: Einleitung in das Alte Testament (Kohlhammer Studienbücher Theologie I,I), 8. Aufl. hg. v. Christian Frevel, Stuttgart: Kohlhammer ${ }^{8}$ 2OI2, II-36, 2 of.

Dohmen, Christoph / Stemberger, Günter: Hermeneutik der Jüdischen Bibel und des Alten Testaments, Stuttgart (Kohlhammer Studienbücher Theologie I,2), Stuttgart: Kohlhammer 1996, 203-209.

40 Dohmen, Christoph: „Nicht wegen deines Bundes...“ (Ez 16,6I). Warum es für Christen keinen Bund mit Gott ohne Israel gibt, in: Dohmen, Christoph / Frevel, Christian (Hg.): Für immer verbündet. Studien zur Bundestheologie der Bibel (SBS 2II), Stuttgart: Katholisches Bibelwerk 2007, 43-48.

4I Söding, Thomas: Einheit der Heiligen Schrift? Zur Theologie des biblischen Kanons (QD 2II), Freiburg: Herder 2005; s. vor allem Kapitel VIII: Der Anspruch des Kanons, 326-377 sowie Kapitel IX: Auswertung, 378-397. 
seiner Geschichte mit Gott, in der die Christenheit wurzelt (Röm II,I8), als Urkunde einer Hoffnung auf endgültiges Heil für Juden und Heiden, das die Grenzen von Raum und Zeit sprengt. Aber auch die interpretatio christiana im Neuen Testament ist ins Gespräch zu bringen, die soteriologische Äonenwende, die Gott mit dem Nahekommen der Basileia und der Sendung des Sohnes herbeiführt. Der Dialog mit dem Judentum schließlich soll und kann in der gemeinsamen Lektüre des „Alten Testamentes“ zu einem besseren Verständnis der gemeinsamen Wurzeln, der gemeinsamen Hoffnung und auch der Unterschiede im Glauben an den einen Gott verhelfen.

Anregend und herausfordernd für die hermeneutische Beziehung zwischen Altem Testament und Neuem Testament ist auch der jüngste umfangreiche Diskussionsbeitrag von Frank Crüsemann. ${ }^{42}$ Nach kritischen Anfragen zu den Positionen einer doppelten Leseweise der Bibel Israels bei Erich Zenger und Christoph Dohmen vertritt er in Nähe zu Gerd Theißen die Auffassung, dass das Neue Testament keinen grundsätzlichen Vorrang vor dem Alten Testament habe. Das Alte Testament ist „die Schrift der Schrift“. Das heißt: „Nur wenn das, was das Alte Testament über Gott und Gottes Macht über den Tod sagt, wahr ist, nur dann und nur in dem dadurch eröffneten Raum kann auch das wahr sein, was über die Auferstehung Jesu erfahren und gesagt wurde. “43

Als Abschluss möchte ich nochmals an Sir 24 als einen möglichen, denkbaren Impuls für einen offenen, weiterführenden Dialog zwischen jüdischer und christlicher Auslegung des Alten Testamentes erinnern, auch wenn es sich dabei um einen Text außerhalb bzw. am Rand der Bibel Israels handelt. Diese weit über Spr 8,22-36 hinausführende umfangreichste Ich-Rede der Frau Weisheit von ihrem Zeltaufschlagen in allen Bereichen und Dimensionen des Kosmos, der Menschen und Israels stellt den Höhepunkt einer Theologie der Einwohnung Gottes in Israel dar. Der jüdische Religionsphilosoph Michael Wyschogrod geht bereits sehr weit, wenn er sogar die Möglichkeit erwägt, dies wäre u. U. auch in Jesus als einem Glied des jüdischen Volkes denkbar, allerdings weniger konzentriert, d. h. nicht einzig und exklusiv. Denn die räumlich-körperliche exklusive Zuspitzung auf Jesus bleibt für jüdisches Denken unannehmbar. ${ }^{44}$

Mir scheint, Sir 24 wäre ein Text und die Gestalt der Weisheit eine Kategorie, die die Bibel Israels als jüdische Bibel und die christliche Bibel mit dem Alten Tes-

42 Crüsemann, Frank: Das Alte Testament als Wahrheitsraum des Neuen. Die neue Sicht der christlichen Bibel, Gütersloh: Gütersloher Verlagshaus 20 II.

43 Ebd., 287.

44 Wyschogrod: Inkarnation, 26f. 
tament wie wenig andere Texte aufeinander zuführen, einander entgegen zu führen vermöchten, bis hin zur kühnen, verwegenen Frage, wieweit Gottes Einwohnung gehen kann, vielleicht auch, ob und wieweit wir als Menschen dem Denken und Walten Gottes Grenzen setzen können und dürfen. Für Christinnen und Christen wird dies zweifellos vorerst zur Frage, ob Gottes Einwohnung unter uns glaubwürdig erfahrbar war, ist und wird.

Die Bibel Israels in ihrer ursprünglich mehrfachen Gestalt, vor allem jetzt in der Hebräischen Bibel, hat, jedenfalls für mich persönlich, theologisches Fragen und Denken entscheidend angestoßen, verändert und wird dies zweifellos noch weiter tun können und müssen. Was ich dabei in mehr als 60 Jahren an zum Teil unerwarteten Veränderungen erfahren durfte, bleibt Grund zur Hoffnung für die Zukunft, aber auch Herausforderung für Liturgie, Verkündigung und Leben. 


\section{Von der Wurzel getragen \\ Feministische Exegese und Jüdisch-Christliches \\ Gespräch in biographischer Brechung}

Marie-Theres Wacker

\section{Anfänge}

Vor genau vier Jahrzehnten, im Sommer 1974, bin ich erstmals intensiver und systematischer mit christlich-jüdischen Themen in Berührung gekommen, und zwar über einen Ferien-Ulpan am Institutum Iudaicum in Tübingen, wohin ich gerade aus Bonn gewechselt hatte, um mein Theologiestudium dort fortzusetzen. Im Frühjahr des gleichen Jahres war ich während einer Israelreise für das Land der Bibel begeistert worden und hätte mich auch gern für das damals eben eröffnete Theologische Studienjahr an der Dormitio in Jerusalem beworben, hatte in Tabgha aber von Abt Laurentius Klein OSB, dem Initiator und Leiter des Projektes, persönlich die Auskunft erhalten, er könne keine Damen aufnehmen, da man von der Deutschen Bischofskonferenz im Blick auf die Priesteramtskandidaten gefördert werde. Daraufhin schwor ich mir, ich würde einen Weg finden, doch noch in Jerusalem zu studieren. Dass die „Frauenklausel“ an der Dormitio vier Jahre später fallen musste, als man für Studierende auch der evangelischen Theologie die Tore öffnete, nutzte mir nichts mehr. Aber ein anderer Weg tat sich auf: Nach Abschluss meines theologischen Diploms konnte ich ein Studienjahr (1977/78) an der École Biblique verbringen.

Der Ulpan in Tübingen weckte existenzielle Neugier - unsere Dozentin Angela Kries war dabei, zum Judentum zu konvertieren - und Interesse an einer wissenschaftlichen Beschäftigung mit dem Judentum. In den folgenden Semestern besuchte ich ausgewählte Veranstaltungen am Institutum Iudaicum, so etwa auch die Vorlesung, die Schalom Ben-Chorin im Sommer 1975 als Gastprofessor über die dreizehn Middot des Maimonides hielt ${ }^{1}$. Diese judaistischen Studien blieben allerdings vorerst mit meiner Schwerpunktbildung in der alttestamentlichen Wissenschaft noch kaum verbunden. Für Herbert Haag, den katholischen Alttestamentler jener Jahre in Tübingen, stand die kritisch-exegetische Auseinandersetzung

I Vgl. Ben-Chorin, Schalom: Jüdischer Glaube. Strukturen einer Theologie des Judentums anhand des Maimonidischen Credo. Tübinger Vorlesungen, Tübingen: Mohr Siebeck 1975. 
mit einer verengten katholischen Dogmatik im Vordergrund des Interesses, und so schrieb ich meine theologische Diplomarbeit bei ihm über „Die Hölle (und ihre defizitären biblischen Grundlagen)“. In diesem Sinne verdanke ich es der evangelischen Theologie in Tübingen und neben Dafna Angela Kries namentlich Frowald Hüttenmeister, Reinhold Mayer und Hans-Peter Rüger, dass ich für Fragen des Judentums und des jüdisch-christlichen Gesprächs nachhaltig sensibilisiert wurde. Das Jahr an der École Biblique wiederum, die in unmittelbarer Nähe zum Damaskustor und damit im ehemals jordanischen Teil Jerusalems liegt, hat mir zu einer profunden Kenntnis von Geographie und Archäologie des Heiligen Landes verholfen, mir aber auch die Augen dafür geöffnet, dass der so genannte Nahostkonflikt noch einmal eine eigene, besondere Problemebene darstellt, und dass neben jüdisch-deutschen und jüdisch-israelischen die arabisch-palästinensischen Positionen und Perspektiven ihr eigenes ernstzunehmendes Gewicht haben.

\section{Feministischer Antijudaismus in der Matriarchatsforschung und die Göt- tinnenfrage in der feministischen Theologie}

Dezidiert in das jüdisch-christliche Gespräch in der Bundesrepublik habe ich mich erstmals, dann aber auch pointiert und dauerhaft, eingemischt im Rahmen der ab I986 beginnenden öffentlichen Auseinandersetzung mit antijüdischen Tendenzen in der feministischen Theologie. Inzwischen war ich promoviert und Hochschulassistentin an der Universität Paderborn, wo ich die feministische Theologie als einen für mich wichtigen und herausfordernden theologisch-politischen Ansatz kennengelernt hatte. Es war zugleich die Zeit des so genannten Historikerstreits, in dem es im Kern um das politische Problem einer Verharmlosung der Schoah über eine bestimmte Form ihrer wissenschaftlichen Rekonstruktion und vergleichenden Einordnung ging. Im Zentrum des feministischen Antijudaismusstreits standen zwei die Bibel betreffende Themenkreise, die Behauptung eines frauenfreundlichen Jesus am Beginn des Christentums im Bruch mit dem angeblich durch und durch frauenverachtenden Judentum seiner Zeit, und die matriarchatsfeministische Revision der Hebräischen Bibel als Dokument eines aggressiven, göttinnenmordenden Patriarchats. ${ }^{2}$

2 Vgl. die Problemskizzen in: Wacker, Marie-Theres: Die Wurzel trägt auch uns. Feministische Theologie angesichts des Antijudaismusvorwurfs, in: RU I8 / 3 (I988) II2-II7; dies.: Feministische Theologie und Antijudaismus. Diskussionsstand und Problemlage in der BRD, in: KuI $5 / 2$ (1990) I68-I76 (= Theologie féministe et anti-judaisme. Mise à jour et évaluation de la situation en R.F.A., in: Recherches féministes [Quebec, Canada] $3 / 2$ [1990] 155-165; Feminist Theology and Anti-Judaism: The Status of the Discussion and the Context of the Problem in the FRG, in: JFSR 7 / 2 [I99I] IO9-II7). 
Schon im Sommersemester 1985 hatten die damalige evangelische Studentenpfarrerin und spätere Oberkirchenrätin der Westfälischen Landeskirche, Antje Heider-Rottwilm, und ich ein Seminar an der Universität Paderborn durchgeführt, in dem wir die bis dahin vorliegenden matriarchalfeministischen Veröffentlichungen von Heide Göttner-Abendroth, Christa Mulack, Elga Sorge und Gerda Weiler sichteten und auch das Problem des Antijudaismus diskutierten. Beide verstanden wir uns als feministische Theologinnen, aber beide waren wir auch auf der Suche nach theologisch-feministischen Ausdrucksformen, die nicht selbst wieder neue Unterdrückungs- oder Ausschlussmechanismen produzierten. Ein Jahr später wurde ich von der damaligen Studienleiterin der Evangelischen Akademie Arnoldshain, Leonore Siegele-Wenschkewitz, engagiert für eine öffentliche Tagung, die sich erstmals dem Thema des Antijudaismus in der feministischen Theologie widmen wollte, und zwar aus einer selbst dezidiert feministischen Perspektive. ${ }^{3}$ Auf dieser Tagung hielt ich einen sehr kritischen Vortrag zum matriarchalfeministischen Umgang mit dem Alten Testament, ein Vortrag, der anschließend innerhalb der feministisch-theologischen Szene seinerseits heftige Kritik erfuhr. ${ }^{4}$ Dadurch wurde ich herausgefordert, selbst eine exegetisch und feministisch klarere Position zur Göttinnenfrage im Alten Testament zu entwickeln und auf dieser Basis meine Kritik genauer, fundierter und solidarisch mit feministischen Grundanliegen zu formulieren. ${ }^{5}$

Im folgenden Jahrzehnt rückte die religionsgeschichtliche Frage nach Göttinnen im Alten Israel ins Zentrum meiner exegetischen Aufmerksamkeit. ${ }^{6}$ Sie war auch schon von Matriarchalfeministinnen in den grundsätzlicheren Kontext der damals beginnenden neuen exegetisch-religionsgeschichtlichen Debatte um den biblischen Monotheismus und dessen Intoleranz gestellt worden. Damit waren die Notwendigkeiten, aber auch die Fallen benannt: Notwendig war eine feministisch sensi-

3 Aus der Tagung entstand der Band: Siegele-Wenschkewitz, Leonore (Hg.): Verdrängte Vergangenheit, die uns bedrängt. Feministische Theologie in der Verantwortung für die Geschichte (Kaiser Taschenbücher 29), München: Kaiser 1988.

4 Vgl. bes. die Hefte I7-I9 der feministisch-religiösen Zeitschrift „Schlangenbrut“ (Mai; August; November 1987); Wacker, Marie-Theres: Das Patriarchat in uns austreiben. Antijudaismus als Testfall, in: Schlangenbrut I8 (August 1987) 36-38.

5 Vgl. Wacker, Marie-Theres: Matriarchalische Bibelkritik - ein antijudaistisches Konzept?, in: Siegele-Wenschkewitz: Vergangenheit, I8I-242; dies.: Die Göttin kehrt zurück. Kritische Sichtung neuerer Entwürfe, in: dies. (Hg): Der Gott der Männer und die Frauen (Theologie zur Zeit 2), Düsseldorf: Patmos 1987, II-37 (= dies.: Von Göttinnen, Göttern und dem einzigen Gott. Studien zum biblischen Monotheismus aus feministisch-theologischer Sicht [Theologische Frauenforschung in Europa I4], Münster: LIT 2004, I3-32).

6 Vgl. die einschlägige Sammlung von Beiträgen in Wacker: Göttinnen. 
bilisierte Religionsgeschichte Israels, die die innerbiblisch nicht bestrittene, aber bekämpfte Verehrung weiblicher Gottheiten mit besonderer Aufmerksamkeit für die Frauengeschichte rekonstruiert. Notwendig war aber auch eine gegenüber Antijudaismen hellhörige Auseinandersetzung mit der christlichen Exegese und mit angrenzenden nichttheologischen Disziplinen, insbesondere der Profanhistoriographie, um als Feministinnen nicht in die Fahrwasser judenfeindlicher Paradigmen zu geraten. In der ab dem Ende der I99oer-Jahre sich zuspitzenden Debatte um die Gewalt des Monotheismus, wie sie Jan Assmann mit seinen Thesen provozierte, habe ich versucht, die über die feministische Theologie erworbenen Sensibilisierungen und Differenzierungen für eine kritisch-hermeneutische Sichtung der damals vorliegenden Paradigmen exegetisch-religionsgeschichtlicher Rekonstruktion der Geschichte des biblischen Monotheismus fruchtbar zu machen ${ }^{7}$. Grundlagenvergewisserungen solcher Art erscheinen mir auch weiterhin unabdingbar.

\section{Christlich-feministische Exegese im Respekt vor dem Judentum}

Die feministische Antijudaismusdebatte - Ausdruck einer großen Bereitschaft zu selbstkritischer Überprüfung ad intra - hat, so vermute ich, dazu beigetragen, dass in den Christlich-Jüdischen Gesellschaften ab Ende der 1980er-Jahre ein vermehrtes Interesse an Beiträgen von frauenbewegten christlichen und jüdischen Gesprächspartnerinnen entstand. Auf der Seite der jüdischen Gesprächspartner gab es bis dahin ausnahmslos Männer, und auch auf der christlichen Seite waren Frauen zwar manchmal Initiatorinnen einer Christlich-Jüdischen Gesellschaft, immer zahlreiche Hörerinnen, aber, soweit ich weiß, nicht als Expertinnen oder Referentinnen präsent. Dies wurde nun plötzlich ein Thema; meiner Wahrnehmung nach kamen erstmals im zeitlichen Umfeld des feministischen Antijudaismusstreits in sichtbaren Zahlen auch Frauen als Expertinnen ins jüdisch-christliche Gespräch, und zwar sowohl auf jüdischer als auch auf christlicher Seite.

Ich selbst bin mehrfach als christlich-feministische Partnerin zu jüdisch-christlichen Tagungen oder zu so genannten Doppelschriftauslegungen mit einer jüdischen Partnerin eingeladen worden, so mit Eveline Goodman-Thau zu einer Tagung über die Schöpfungsgeschichten der Genesis (Laurentiushof Salzkotten) und zu einer Doppelschriftauslegung über die Perikope Jer 31,3I-34 zum Neuen Bund

7 Vgl. bes. Wacker, Marie-Theres: „Monotheismus“ als Kategorie der alttestamentlichen Wissenschaft. Erkenntnisse und Interessen, in: Manemann, Jürgen (Hg.): Monotheismus (JPTh 4), Münster: LIT 2002, 50-67 (= Wacker: Göttinnen, I39-I55). 
(Dillenburg) ${ }^{8}$, mit Marianne Wallach-Faller für eine Tagung zu feministischen Ansätzen der Schriftauslegung in Judentum und Christentum (Eva Kleinewefers-Haus, Nettetal-Leuth) und zu einer Doppelschriftauslegung über die Gestalt der Mirjam9 (Kassel), mit Rachel Monika Herweg zu einer Doppelschriftauslegung über die Brudermordperikope Gen 4,I-I $6^{10}$ (Kassel). Meine Rolle als christliche Exegetin war dabei jeweils die, mich mit den christlichen Auslegungstraditionen auseinanderzusetzen, deren antijüdische Weichenstellungen aufzudecken und eine eigene Auslegung zu entwickeln, die zeigen konnte, dass die christliche Theologie und Bibelauslegung bereit war, vom Judentum zu lernen, wie es das Zweite Vatikanum in seiner Erklärung Nostra Aetate gefordert hatte. ${ }^{11}$ Gleichzeitig beschäftigte ich mich intensiver mit jüdischen und jüdisch-feministischen Zugängen zur Bibel und bekam mehr Gespür für Gemeinsamkeiten, aber auch signifikante Unterschiede in den Methoden und inhaltlichen Akzentsetzungen aus jüdischer bzw. christlicher Perspektive. ${ }^{12}$

8 Vgl. Wacker, Marie-Theres: Was ist neu am Neuen Bund? (Jer 31,3I-34), in: Junge Kirche 55 / 4 (1994) 224-226.

9 Vgl. Wacker, Marie-Theres: Miriam - Doppelschriftauslegung mit Marianne Wallach-Faller, in: Leicht, Irene / Rakel, Claudia / Rieger-Goertz, Stefanie (Hg.): Arbeitsbuch feministische Theologie. Inhalte, Methoden und Materialien für Hochschule, Erwachsenenbildung und Gemeinde, Gütersloh: Gütersloher Verlagshaus 2003, Seminareinheit 5.I: Mirjam und ihre Bedeutung für christliche und jüdische Frauen, II8-I2I (CD-ROM); Wallach-Faller, Marianne: Miriam - Schwester unter Brüdern, in: Brodbeck, Doris / Domhardt, Yvonne (Hg.): Marianne Wallach Faller: Die Frau im Tallit. Judentum feministisch gelesen, Zürich: Chronos 2000, I77-I9I sowie Wacker, Marie-Theres: „Jüdischer Feminismus ist eine Notwendigkeit!“ Zum Tode von Marianne Wallach-Faller, in: Schlangenbrut 57 (Mai 1997) 2 und in: Brodbeck / Domhardt (Hg.): Frau im Tallit, 13-15).

Io Vgl. Herweg, Rachel: Kain blick auf, damit es anders anfängt zwischen uns allen! Jüdisch-feministische Auslegung zu Genesis 4,I-I6, in: Schlangenbrut 77 (Mai 2002) 34-37. Meinen Anteil habe ich weiterentwickelt zu: Wacker, Marie-Theres: Kain und die Macht der Sünde. Eine feministisch-gendersensible Lektüre von Gen 4,I-I7, in: Weibel, Nadine (Hg.): Weiblicher Blick - Männerglaube / Religions d'hommes - regards de femmes. Beiträge zur Gender-Perspektive in den Religionen, Münster: Waxmann 2008, 45-54.

II Die derzeit neueste Studie ist die von Renz, Andreas: Die katholische Kirche und der interreligiöse Dialog. 50 Jahre „Nostra Aetate“ - Vorgeschichte, Kommentar, Rezeption, Stuttgart: Kohlhammer 20I4. Sie stellt die Erklärung mit ihrer Vorgeschichte, in den Etappen ihrer Kompilierung und Beratung sowie in ihren Positionierungen zu den großen Weltreligionen insgesamt, mit Schwerpunkt auf Judentum und Islam, vor.

I2 Vgl. etwa meine Sichtung von christlichen und jüdischen Auslegungen zu Gen I-3: Wacker, Marie-Theres: Der Fall Eva(s). Christlich-feministische Theologie und die Paradiesgeschichte, in: Schöning-Kalender, Claudia / Neusel, Aylâ / Jansen, Mechtild M. (Hg.): Feminismus-Islam-Nation. Frauenbewegungen im Maghreb, in Zentralasien und in der Türkei, Frankfurt: Campus 1997, 24I-247. 
Diese Praxis floss ein in ein Projekt, das Luise Schottroff und ich zusammen realisiert haben. In zwei Tagungen in Hofgeismar versammelten wir jeweils ca. 20 christliche Exegetinnen, die sich herausfordern lassen wollten von der Aufgabe, einen alt- oder neutestamentlichen Text, der für die feministische Theologie Bedeutung gewonnen hatte, so auszulegen, das traditionelle Antijudaismen im Umgang mit diesem Text aufgedeckt und überwunden würden. An Methoden solch neuen Umgangs wurden etwa andersartige Übersetzungen, Aufweise der Engführung des traditionell herangezogenen Vergleichsmaterials, sozialgeschichtliche Kontextualisierungen oder kulturgeschichtliche Redimensionierungen erprobt. Dem aus den Tagungen erwachsenen Band haben wir den Titel „Von der Wurzel getragen“13 gegeben, um damit die den Autorinnen gemeinsame Überzeugung auszudrücken, dass eine feministische Theologie es nicht nötig hat, sich auf Kosten des Judentums zu profilieren, sondern dass sie vielmehr sogar konstruktiv zu einer erneuerten Theologie im Respekt vor dem Judentum beitragen kann. ${ }^{14}$

Als wir einige Jahre später an die 60 Autorinnen zur Mitarbeit am „Kompendium feministische Bibelauslegung “ einluden, jenem einbändigen Kommentarwerk, in dem jedes biblische Buch und einige über den Kanon hinausgehende frühjüdische und frühchristliche Schriften ausgelegt werden, ${ }^{15}$ war es für die Frauen, die sich zur Mitarbeit bereit erklärten, selbstverständlich, sich auf eine Exegese ohne Antijudaismen zu verpflichten. Dass es aber in dieser Frage keinen Stillstand gibt, dass vor allem auch der Rezeptionskontext einer Position oder eines Buches eine entscheidende Rolle spielt, wurde mir im Herbst 2013 auf der Jahrestagung der „Society of Biblical Literature" in Baltimore noch einmal sehr deutlich bewusst, wo die amerikanische Übersetzung unseres Kompendiums auf einem Panel diskutiert wurde. Ich stellte selbstbewusst unser Bemühen um Vermeidung von Antijudaismen dar, aber die jüdische Exegetin Helen Lenemann hielt dagegen, dass sie unser Buch anstößig finde, weil es sich auf dem Titelblatt ohne Spezifizierung als Kompendium feministischer Bibelauslegung präsentiere, faktisch aber ein rein christliches

I3 Schottroff, Luise / Wacker, Marie-Theres (Hg.): Von der Wurzel getragen. Christliche feministische Exegese in Auseinandersetzung mit Antijudaismus (Biblical Interpretation Series 17), Leiden: Brill 1996.

I4 Vgl. in diesem Sinne auch Wacker, Marie-Theres: Feministische Theologie und das Judentum, in: Deutscher Koordinierungsrat der Gesellschaften für Christlich-Jüdische Zusammenarbeit (Hg.): 1949-2009: Soviel Aufbruch war nie. Themenheft 2009, Bad Nauheim 2009, 24-26.

I5 Schottroff, Luise / Wacker, Marie-Theres (Hg.): Kompendium feministische Bibelauslegung, Gütersloh: Gütersloher Verlagshaus 1998; ${ }^{2}$ I999; 32007 , amerikanische Übersetzung: Feminist Biblical Interpretation. A Compendium, Grand Rapids/MI: Eerdmans 2012. 
Werk sei. ${ }^{16}$ Eine derartige Kritik ist uns im deutschsprachigen Raum nie entgegengebracht worden, erklärt sich aber sofort im US-amerikanischen Kontext, in dem religiöse Differenzierung eine viel größere und selbstverständlichere Rolle spielt und Sensibilität gegenüber Vereinnahmungen entsprechend stärker ausgeprägt ist.

\section{Jüdisch-deutsche Geschichte „vor Ort“}

In die Zeit des feministischen Antijudaismusstreits fiel das Jahr I988 mit seiner Erinnerung an die Reichspogromnacht von 1938. In meinem damaligen Wohnort Salzkotten bei Paderborn befindet sich ein kleiner, aber eindrucksvoller jüdischer Friedhof, der mich Anfang 1988 dazu inspirierte, bei der Stadt anzufragen, ob eine Dokumentation der Grabsteine mit ihren von der Verwitterung bedrohten Inschriften, unter ihnen auch viele hebräische, anlässlich der bevorstehenden Gedenktage erwünscht sei. Für eine Alttestamentlerin erschien mir dies als sinnvoller, ja gebotener Beitrag zur Auseinandersetzung mit dem, was während des „Dritten Reiches" geschehen war. Daraus entwickelte sich ein viel weitergehendes Projekt: Die Stadt stellte umfassendes Archivmaterial zur Verfügung, sodass mein Mann Bernd Wacker und ich mit Unterstützung einer kleinen engagierten Gruppe vor Ort eine Geschichte der jüdischen Gemeinde Salzkotten von 1933 bis zu ihrer Auslöschung 1942 schreiben sowie die Dokumentation des jüdischen Friedhofs mit ca. 80 Grabsteinen (I854-1940) vorlegen konnten. ${ }^{17}$ Diese Auseinandersetzung mit der Stigmatisierung, Verfolgung, Vertreibung und Vernichtung der Frauen, Männer und Kinder jüdischen Glaubens in einer ganz normalen deutschen Kleinstadt hat mich persönlich sehr bewegt und meine Achtsamkeit für Formen des Antijudaismus und Antisemitismus noch einmal geschärft, zumal wir in einer erweiterten Neubearbeitung des Buches ${ }^{18}$ über die Aufarbeitung der so genannten Wiedergutmachungsakten rekonstruieren konnten, wie ungebrochen sich antisemitische Grundeinstellungen auch nach der Schoah in den bundesdeutschen Behörden wie an der Basis der Normalbürger und -bürgerinnen zu Wort meldeten.

I6 Dokumentation des Panels: Scholz, Susanne (Hg.): Feminist Commentary upon Feminist Commentary. A Report from the Feminist Biblical Trenches, in: Lectio difficilior I (2014), in: http://www.lectio.unibe.ch/I4_I/pdf/scholz_susanne.pdf [abgerufen am I.8.20I4].

I7 Wacker, Bernd / Wacker, Marie-Theres: ... verfolgt, verjagt, deportiert. Juden in Salzkotten 1933-1942. Eine Dokumentation aus Anlaß des 50. Jahrestages der „Reichskristallnacht“ vom 9./Io.II.I938, Salzkotten: Selbstverlag 1988.

I8 Wacker, Bernd / Wacker, Marie-Theres: Ausgelöscht. Erinnerung an die jüdische Gemeinde Salzkotten, Salzkotten: Selbstverlag 2002. 
In den Jahren 2012 bis 2015 habe ich in Abstimmung mit dem Vorstand der jüdischen Gemeinde Münster an meinem „Seminar für Exegese des Alten Testaments“ mit der Dokumentation der ca. 400 Grabsteine auf dem dortigen jüdischen Friedhof begonnen. Wir verstehen dies als Beitrag zur Erinnerungskultur in einer für die jüdische Geschichte des 19. und 20. Jahrhunderts nicht unbedeutenden Stadt. ${ }^{19} \mathrm{Ob}$ dieses Projekt für die jetzige jüdische Gemeinde vor Ort Bedeutung gewinnen kann, deren Mitglieder zum größten Teil nicht Nachfahren der dort Beigesetzten sind, sondern nach 1989 aus dem Gebiet der ehemaligen UdSSR nach Münster kamen, ist offen.

Dem spezifischen Aspekt jüdisch-katholischer Beziehungen vor Ort bin ich 2005 anlässlich des I200-jährigen Jubiläums des Bistums Münster nachgegangen. Das Motto des Bistumsjubiläums lautete „Eine Liebesgeschichte“ - und was konnte passender sein, als einige Reflexionen zu „Gottes erster Liebe“, wie der österreichische Historiker und Publizist Friedrich Heer schon 1967 das jüdische Volk genannt hatte $^{20}$, anzustellen? Ausgangspunkt war für mich eine wenig beachtete, aber unübersehbare Figurengruppe an der Münsteraner Stadtkirche St. Lamberti, die neben dem Schmerzensmann Jesus, gerahmt von Johannes dem Apostel und Johannes dem Evangelisten, die Gestalten der Ecclesia und der Synagoga umfasst. Diese Figurengruppe, das stellte sich bei eingehenden Archiv- und Literaturrecherchen, die mein Mann und ich durchgeführt haben, zu unserer eigenen Überraschung heraus, gehört keineswegs zum ursprünglichen Figurenschmuck der spätgotischen Kirche, sondern ist eine Neuerung, die erst Anfang des 20. Jahrhunderts, einige Jahre vor Ausbruch des Ersten Weltkrieges, geschaffen wurde - in einer Zeit, da es eine blühende jüdische Gemeinde in Münster gab, im katholischen Münsterland aber auch allen Ernstes noch Ritualmordvorwürfe erhoben und jüdische Menschen deswegen verfolgt und vertrieben wurden. Als gleichsam die theologische Rückseite dieses Befundes habe ich das wissenschaftliche Schrifttum meiner Vorgänger auf dem Lehrstuhl für die alttestamentliche Exegese von der Einrichtung dieses Lehrstuhls I834 an bis ins „Dritte Reich“ hinein auf ihre Einstellung zum Judentum hin gesichtet. Der Befund zeigt, wie selbstverständlich judenverachtend Professoren einer katholisch-theologischen Fakultät hier agiert haben und im Konsens mit der Lehre der Kirche agieren konnten. ${ }^{21}$

I9 Vgl. http://www.juedischer-friedhof-muenster.de/ [abgerufen am I.9.20I5].

20 Heer, Friedrich: Gottes erste Liebe. 2000 Jahre Judentum und Christentum. Genesis des österreichischen Katholiken Adolf Hitler, München: Bechtle 1967.

2I Wacker, Marie-Theres: Gottes erste Liebe. Christliche Wahrnehmungen des Judentums in Münster, in: Sattler, Dorothea (Hg.): Gedenken und gestalten. I200 Jahre Bistum Münster, Münster: Aschendorff 2005, 48-86. Vgl. auch: Wacker, Bernd / Wacker, Marie-Theres: Abschied von Ratisbonne. Ein Exkurs zum katholischen Antijudaismus, in: Faber, Richard 
Vom Ansatz her gehören diese Recherchen in den Bereich der Wirkungs- oder Rezeptionsgeschichte der Bibel, sind aber natürlich auch Beiträge zur Zeitgeschichte bzw. Fakultätsgeschichte. Ich bin der Überzeugung, dass Theologen und Theologinnen aller Fachdisziplinen solche Recherchen an ihren Einrichtungen unterstützen oder auch selbst durchführen sollten, weil sich so die Möglichkeit ergibt, Klärungs- und Bewusstseinsprozesse anzustoßen. In Köln hat es vor einigen Jahren ein Symposion in Zusammenarbeit mit dem Dombauarchiv gegeben, auf dem erstmals systematisch den jüdischen Spuren im Kölner Dom nachgegangen wurde, angefangen vom mittelalterlichen steinernen Judenprivileg bis hin zu den im 19. Jahrhundert von der Familie Oppenheim gestifteten Königsfenstern. ${ }^{22}$ Für Münster und seine katholisch-theologische Fakultät ist natürlich darauf hinzuweisen, dass mit Erich Zenger, Johann Baptist Metz und auch Herbert Vorgrimler die vom II. Vatikanum eingeleitete Neuorientierung im Blick auf das Judentum in Forschung und Lehre Einzug hielt. Gegenwärtig allerdings, so denke ich, bräuchten wir noch einmal neue Impulse: Die Studierenden, die jetzt an unsere Fakultäten und Institute kommen, müssen anders abgeholt werden als meine Generation in den 1970er- und I980er-Jahren. Ich benenne hier nur drei Koordinaten, die zu beachten wären: Die Kenntnis der Bibel, zumal der Hebräischen Bibel, tendiert gegen Null, so dass der Inhalt dieser Texte gegenwärtig ganz elementar vermittelt werden muss, aber dadurch auch neu und möglicherweise ohne antijüdische Vorbelastungen vermittelt werden kann. Das gesellschaftlich derzeit hohe Interesse am Islam macht es schwieriger, ein dezidiertes und spezifisches Interesse am Judentum zu wecken; besser angenommen werden Konzepte des so genannten Trialogs, die ihre eigenen Chancen bergen. Der Nahostkonflikt verstärkt ein womöglich latent ohnehin vorhandenes Negativbild des Judentums; man differenziert in der Wahrnehmung und in der Beurteilung zu wenig zwischen Judentum und Staat Israel, aber auch zu wenig zwischen Religion und Politik.

\section{Auslegungen des Esterbuches zwischen Judentum und Christentum, zwi- schen Israel und Palästina}

Bevor ich diesen zuletzt angesprochenen Gedanken weiterdenke, komme ich noch einmal auf den feministischen bzw. gendersensiblen Umgang mit der Bibel zu-

(Hg.): Katholizismus in Geschichte und Gegenwart, Würzburg: Königshausen \& Neumann 2005, 29-32.

22 Vgl. Wacker, Bernd / Lauer, Rolf (Hg.): Der Kölner Dom und „die Juden“. Fachtagung der Karl Rahner Akademie Köln in Zusammenarbeit mit der Dombauverwaltung Köln vom I8. bis zum 19. November 2006 (Kölner Domblatt 73), Köln: Verlag Kölner Dom 2008. 
rück. Das Übersetzungsprojekt der „Bibel in gerechter Sprache“, an dem ich beteiligt bin, sucht Geschlechter-Gerechtigkeit und die Neukonturierung des christlichen Verhältnisses zum Judentum miteinander zu verbinden und ist damit die erste deutschsprachige Bibelübersetzung, die sich in dieser doppelten Weise in die Pflicht genommen hat. ${ }^{23}$ Als ein Schwerpunkt meiner Forschung ist mir seit gut einem Jahrzehnt das Buch Ester zugewachsen, eine Schrift der Hebräischen Bibel, die die tödliche Bedrohung des gesamten jüdischen Volkes explizit thematisiert und damit von einer in Deutschland tätigen christlichen Alttestamentlerin meines Erachtens gar nicht anders als im Wissen um die Schoah und im Blick auf das Judentum gelesen und ausgelegt werden kann. Dass in diesem Buch eine Frauengestalt im Mittelpunkt steht, hat die feministische Exegese seit ihren Anfängen herausgefordert, ist doch Ester kein Prototyp einer auf Gleichstellung drängenden Frau, aber auch keine geheime Göttinnengestalt, trotz ihres an Ischtar anklingenden Namens. Unter einer breiter ansetzenden Genderperspektive aber enthält das biblische Buch, zumal in seinen unterschiedlichen Versionen, viel unvermutetes Potenzial, treten ja insgesamt drei Frauengestalten (Ester; Waschti; Seresch) neben sehr unterschiedlich profilierten männlichen Figuren auf und gibt es dezidiert ein drittes Geschlecht in der Gestalt der Eunuchen ${ }^{24}$.

Ich bin mit Vorträgen zum Esterbuch mehrfach im zeitlichen Kontext zu Purim unterwegs gewesen. Die größte Herausforderung in diesem Zusammenhang war für mich eine Vorlesungsreihe zum Esterbuch im Studienjahr 2003/04 an der

23 Bail, Ulrike u. a. (Hg.): Bibel in gerechter Sprache, Gütersloh: Gütersloher Verlagshaus 2006; ${ }^{2}$ 2OII; vgl. Wacker, Marie-Theres: Die „Bibel in gerechter Sprache“. Vorstellung und Würdigung eines Projektes, in: BiKi 62 / I (2007) 54-59; dies.: The New Inclusive Bible Translation in the Context of (Post)Modern Germany, in: SBL Forum 6.4. (2008); http:// www.sbl-site.org/publications/article.aspx?ArticleId=764 [abgerufen am 6.5.20I4].

24 Wacker, Marie-Theres: Mit Toratreue und Todesmut dem einen Gott anhangen. Zum Esther-Bild der Septuaginta, in: Crüsemann, Frank u. a. (Hg.): Dem Tod nicht glauben. Sozialgeschichte der Bibel. Festschrift für Luise Schottroff zum 70. Geburtstag, Gütersloh: Gütersloher Verlagshaus 2004, 312-332; dies.: Das Buch Ester, in: Zenger, Erich (Hg.): Stuttgarter Altes Testament. Einheitsübersetzung mit Kommentar und Lexikon, Stuttgart: Kath. Bibelanstalt 2004, 86I-882; dies.: Ester. Jüdin - Königin - Retterin (Kleine Frauen-Reihe), Stuttgart: Kath. Bibelwerk 2006; dies.: Seresch, in: Duncker, Christina / Keita, Katrin (Hg.): Lieblingsfrauen der Bibel und der Welt. Ausgewählt für Luise Metzler zum 6o. Geburtstag, Norderstedt: Books on Demand 2009, I4O-15I; dies.: Innensichten und Außensichten des Judentums im septuagintagriechischen Estherbuch (EstLXX), in: Reiterer, Friedrich u. a. (Hg.): Gesellschaft und Religion in der spätbiblischen und deuterokanonischen Literatur (Deuterocanonical and Cognate Literature Studies 20), Berlin: de Gruyter 20I4, 55-92. 
Dormitio (als Dozentin durfte ich schließlich doch kommen). Welche Perspektive aber sollte ich in Jerusalem für eine Auslegung des Esterbuches wählen? Erich Zenger hatte mir den Impuls vermittelt, das Buch im Wissen darum zu lesen, dass Christinnen und Christen in der Geschichte Europas oft genug auf der Seite Hamans gestanden und sich erst einmal äußerst selbstkritisch mit dieser Hypothek auseinanderzusetzen hätten. ${ }^{25}$ Dieser Impuls erschien mir unverzichtbar, wenn ich, als Deutsche, aus Deutschland kommend, in jenem Staat über das Esterbuch nachdenke, der, wie Johann Baptist Metz so treffend formuliert hat, als „Haus gegen den Tod" gegründet worden war. Aber konnte ich dabei stehen bleiben? War und ist Jerusalem nicht auch die Stadt, in der ich erleben musste, wie Palästinenser und Palästinenserinnen unter israelischem Recht nur als Bürger und Bürgerinnen zweiter Klasse gelten? Auf dem Hintergrund dieser Erfahrung und dieses Wissens wurde mir die Frage nach den Facetten der Gewalt in der Estererzählung wichtig, insbesondere die drei ineinander verschränkten Ebenen der strukturellen Gewalt der persischen Herrschaft, der mit staatlichen Mitteln legalisierten tödlichen Gewalt Hamans gegen das jüdische Volk und der von Juden ausgeübten Gewalt, wie sie der Schluss des Buches erzählt. ${ }^{26}$ Hier greife ich nur meine mich seinerzeit überraschende Entdeckung auf, dass der Vorwurf, am Schluss der Erzählung gehe es doch um nichts anderes als um jüdische Gegengewalt, nicht nur von übelwollenden Christen und Christinnen, sondern auch von manchen jüdischen Kommentatoren und Kommentatorinnen erhoben wird, die sich an dieser Frage abarbeiten. Hier wird dann zum einen der Hinweis auf den Kontext des Purimfestes relevant, in dem das Buch im synagogalen Rahmen rezitiert wird, begleitet von karnevalesken Riten, so dass der Text, auch seine Gewalt, auf die Ebene des Komischen gehoben wird und seine komischen bzw. ironischen Motive und Strukturen in den Vordergrund treten können. Zum anderen aber ist das Buch Ester ja auch im säkular-jüdischen Kontext präsent als Teil der jüdischen Nationalgeschichte. Auf die-

25 Vgl. Zenger, Erich: Das Buch Esther, in: Ders. u. a.: Einleitung in das Alte Testament, Stuttgart: Kohlhammer ${ }^{7}$ 2008, 302-3II, 3II.

26 Vgl. Wacker, Marie-Theres: Tödliche Gewalt des Judenhasses - mit tödlicher Gewalt gegen Judenhass? Hermeneutische Überlegungen zu Est 9, in: Hossfeld, Frank-Lothar $/$ Schwienhorst-Schönberger, Ludger (Hg.): Das Manna fällt auch heute noch. Beiträge zur Geschichte und Theologie des Alten, Ersten Testaments. Festschrift für Erich Zenger (HBS 44), Freiburg i. Br.: Herder 2004, 609-637; dies.: „... ein großes Blutbad“: Ester 8-9 und die Frage nach der Gewalt im Ester-Buch, in: Bibel heute 42 / I67 (2006) I4-I6; dies.: Widerstand - Rache - verkehrte Welt, in: Butting, Klara / Minnaard, Gerard / Wacker, Marie-Theres (Hg.): Ester. Mit Beiträgen aus Judentum, Christentum, Islam, Literatur, Kunst, Wittingen: Erev Rav 2005, 35-44. 
sem Hintergrund finde ich die Verfilmung des Esterbuches (von 1985) durch den israelischen Regisseur Amos Gitai bemerkenswert, stellt doch Gitai durch vielerlei dramaturgische Mittel die Botschaft des Esterbuches in den Kontext des aktuellen israelisch-palästinensischen Konfliktes. Er versteht seinen Film als eine Art Purimspiel, in dem Mordechai durch einen palästinensischen Schauspieler dargestellt wird und eindringlich über die drohende Vernichtung seines Volkes klagt, in dem am Ende aber auch Mordechai in den Kleidern des Haman erscheint, also gewissermaßen doppelt die Botschaft durchgespielt wird, die das Esterbuch für Gitai vermittelt: „It is about oppressed people who gradually turn into oppressors “27.

\section{Palästina und der jüdisch-christliche Dialog}

Zum Weltgebetstag der Frauen im Jahr 1994 hatten Frauen aus Palästina die Gebetstexte formuliert. In Deutschland gerieten diese Texte in eine heftige Kritik; man warf ihnen vor, hier werde im Medium des Gebets christlicher Antijudaismus verbreitet. Verena Lenzen, damals Studienleiterin an der Bischöflichen Akademie Aachen, hatte mich im Vorfeld des Weltgebetstags zu einem weitergespannten Thema feministischer Bibelauslegung eingeladen, aber mit ihrer Zustimmung konnte ich die Gelegenheit nutzen, auch zu den Gebeten aus Palästina einige Überlegungen zu äußern. Für mich war in dieser Debatte auf der einen Seite ganz klar, dass es darum gehen musste, jede Form von christlichem Antijudaismus zu benennen, auch den von christlichen palästinensischen Frauen, aber es war mir ebenso klar, dass man verstehen musste, warum bestimmte Denk- und Sprachfiguren in den Weltgebetstagstexten der Palästinenserinnen für uns unter den Antijudaismusverdacht fielen und für die palästinensischen Frauen selbst damit nichts zu tun hatten. Eine mögliche Erklärung dafür war die, dass die Frauen ihre Gebetstexte in Abstimmung mit ihren jeweiligen Kirchenoberen formuliert hatten und viele von diesen wiederum in ihrer Theologie ganz selbstverständlich von den traditionellen christlich-antijüdischen Denkfiguren der Enterbung oder Überbietung geprägt waren. Damals ging mir aber auch auf, dass der Kontext Deutschland mit seiner ganz besonderen Sensibilität für Judenfeindschaft und der Kontext Palästina mit seiner ganz besonderen Sensibilität für die Diskriminierungen palästinensischer Menschen unter der Besatzung durch den Staat Israel zwei sehr unterschiedliche

27 Vgl. Wacker, Marie-Theres: Das biblische Estherbuch zwischen Palästina und Israel. Zum Film „Esther“ von Amos Gitai (1985) und seiner Kontextualisierung, in: Zwick, Reinhold (Hg.): Religion und Gewalt im Bibelfilm (Film und Theologie 20), Marburg: Schüren 20I2, 39-59; Zitat 5 I und 58. 
Resonanzräume für die gleichen Texte darstellen mussten und dass das, was für uns nach Enterbungstheologie klingt, aus einer palästinensisch-christlichen Perspektive nichts anderes als eine produktive Übertragung der biblischen Inhalte auf die seit vielen Generationen im Land der Bibel lebenden Menschen darstellt. Die besondere Kontextualität palästinensischer Bibelrezeption wird meines Erachtens auch gegenwärtig hierzulande noch zu wenig gesehen.

Dies gilt $\mathrm{m}$. E. auch für das wohl brisanteste Thema im gegenwärtigen jüdisch-christlichen Dialog, dem Thema „Land“. Mitte der I990er-Jahre hatte ich Gelegenheit, mit der Ehrendoktorin unserer Münsteraner Fakultät, der palästinensischen Biologin an der Universität Bir Zeit und Friedensaktivistin Sumaya Farhat Naser, ein Seminar zum Thema „Heiliges Land - zerrissenes Land“ durchzuführen, in dem wir uns auch mit Ansätzen palästinensisch-christlicher Theologie auseinandersetzten. Das Thema "Land“ hat mich seitdem als akademisches und zugleich politisches nicht mehr losgelassen. ${ }^{28}$ Als Alttestamentlerin steht man mit diesem Thema insbesondere im Hinblick auf den Nahostkonflikt vor einer Fülle von exegetisch herausfordernden und wirkungsgeschichtlich aufgeladenen Texten, angesichts derer ähnlich und doch auch wieder anders als beim Esterbuch die hermeneutische Frage nach dem Standort und dem Standpunkt des Auslegers/ der Auslegerin gestellt und beantwortet werden muss. Um hier keiner vorschnellen Parteilichkeit zu erliegen, habe ich versucht, unterschiedliche Positionen in der westlich-christlichen Exegese und Theologie, aber auch aus Israel und aus Palästina wahrzunehmen.

Dabei hat mir meine Auseinandersetzung mit der Bibelrezeption durch den ersten Ministerpräsidenten des Staates Israel, David Ben-Gurion ${ }^{29}$, die Augen geöffnet für die beeindruckenden Stärken ebenso wie für die abgründigen Engführungen des Zionismus. Für Ben Gurion ist das jüdische Volk mit dem Land, von dem die Bibel spricht, unlösbar verbunden, wobei er diesen „Dreiklang“ aber selbst gerade nicht religiös oder gar theologisch begründet, sondern historisch-faktisch, in-

28 Vgl. über den Nahostkonflikt hinausgehend Wacker, Marie-Theres / Wainwright, Elaine (Hg.): Landkonflikte - Landutopien. Themenheft Concilium 43/ 2 (2007) und im engeren Sinn auf biblische Landtexte und ihre Rezeption konzentriert Koerrenz, Ralf / Wacker, Marie-Theres (Hg.): Heiliges Land (JBTh 23) Neukirchen-Vluyn: Neukirchener Verlag 2008; insbes.: Jörg Bremer im Gespräch mit Marie-Theres Wacker. Zeitdiagnose: Heiliges Land. Zum Umgang mit dem Land im heutigen Israel/Palästina, in: JBTh 23 (2008) 275-294.

29 Vgl. Wacker, Marie-Theres: Feldherr und Löwensohn. Das Buch Josua - angeeignet durch David Ben-Gurion, in: Noort, Ed (Hg.): The Book of Joshua (BETL 250), Leuven: Peeters 20I2, 609-647. 
sofern er, knapp auf den Punkt gebracht, die Hebräer und damit die Vorfahren der heutigen Juden zu den Ureinwohnern des Landes erklärt. Die Bibel ist für ihn ein Instrument der Einigung zwischen religiösem und säkularem Judentum, zwischen den vielen Gruppen von jüdischen Einwanderern aus unterschiedlichen Kulturräumen, die in den Monaten und Jahren nach der Staatsgründung ins Land kamen, für die aber, so glaubte er, die Bibel ein gemeinsames Band war. Die Bibel enthielt für ihn aber auch, bedingt durch die Ereignisse des Unabhängigkeitskrieges von 1948, eine Art prophetischer Vision der eigenen Gegenwart. Im Buch Josua sah er seine eigenen militärischen Siege vorabgebildet, aber auch etwa die Verachtung für die arabischen Gegner, die ihn ganz zweifellos prägte. ${ }^{30}$ Bei aller Wertschätzung der Bibel aber hätte sich Ben-Gurion als Politiker wohl nie der Autorität eines religiösen Textes für seine politischen Entscheidungen unterstellt; für ihn musste die Politik gegenüber der Religion autonom bleiben. Darin unterscheidet er sich von manchen jüdischen Siedlern und Siedlerinnen, aber auch von manchen christlichen Fundamentalisten und Fundamentalistinnen mit ihren unmittelbaren und unvermittelten Übertragungen religiöser Imperative in politisches Handeln.

Auf der anderen Seite versuche ich zu verstehen, warum Mitri Raheb, der führende christlich-palästinensische Theologe der Gegenwart, in seinen jüngsten Veröffentlichungen immer stärker dazu übergeht, den aktuellen Konflikt zwischen Israel und Palästina in Kategorien von (Post-)Kolonialismus und Imperialismus zu beschreiben und weiterzudenken. ${ }^{31}$ Mitri Raheb hat einen grundlegenden Blickwechsel vollzogen: Während die Bibel das Volk Israel fast durchweg als von Imperien beherrscht darstellt und in ihren Schriften im Namen der Unterdrückten und für sie spricht, kann, darf, muss für Raheb der moderne Staat Israel als imperiale Macht beschrieben werden, die das palästinensische Volk, zumal die immer kleiner werdende Gruppe der palästinensischen Christen und Christinnen, in ihrer Bewegung behindert, ihre Lebensressourcen beschneidet, ihr Land mit Siedlungen überzieht. Die Bibel spricht für Raheb in diesem Sinn direkt zum palästinensischen Volk. Das heißt aber gerade nicht, dass der palästinensische Theologe zu einer reinen Umkehrung der Rezeption aufruft, als seien die Palästinenser und Palästinenserinnen nun das wahre Israel, und das heißt auch nicht, dass er nun in fundamentalistischer Manier Handlungsimpulse direkt aus biblischen Texten ableitet. Vielmehr kämpft er auf der einen Seite dafür, dass seine Leserinnen und Leser, die palästinensischen Christen und Christinnen, das Alte Testament, das die Geschich-

30 Vgl. ebd.

3I Vgl. jetzt Raheb, Mitri: Faith in the Face of Empire. The Bible Through Palestinian Eyes, Maryknoll/NY: Orbis Books 2oI4. 
te Israels, die Geschichte ihrer heutigen Unterdrücker also erzählt, auch als ihre Heilige Schrift überhaupt akzeptieren können, und auf der anderen Seite will er beide, Israelis und Palästinenser/-innen, dazu aufrufen, motiviert von ihrem Glauben und ihrer Hoffnung nach „dritten“ Wegen zu suchen, auch und gerade für ein gemeinsames Leben im Land. Das biblische Land, die darüber zu klärende Bibelhermeneutik, das Verhältnis von Theologie und Politik im Umgang damit sind Themen, denen sich das christlich-jüdische Gespräch in Deutschland entschlossen zuwenden sollte, so komplex und schwierig sie auch sein mögen. 


\title{
Nicht im Kontrast zum Judentum, sondern in seinem Kontext: zum Verstehen des Neuen Testaments
}

\author{
Klaus Wengst
}

Mein Lernen als Neutestamentler ist in den letzten gut 25 Jahren wesentlich dadurch bestimmt worden, dass ich in kontinuierliche Gesprächszusammenhänge mit Jüdinnen und Juden gekommen bin. Das hatte vor allem die Auswirkung, dass ich mich seitdem anders und auch sehr viel intensiver mit antiken jüdischen Texten, besonders rabbinischen, beschäftigt habe. Die dabei gewonnene - mir am wichtigsten erscheinende - Einsicht lässt sich in folgender Weise beschreiben: Es trifft einerseits gewiss zu, dass das Neue Testament als Ganzes ein christliches Buch ist, als man es als zweiten Teil des Kanons der Kirche zusammenstellte, wodurch die jüdische Bibel als dessen erster Teil zum Alten Testament wurde. Aber andererseits gilt doch auch, dass die meisten und wichtigsten seiner Schriften, vielleicht sogar alle, zur Zeit ihrer Entstehung keine christlichen, sondern von ihrem Inhalt wie vom Selbstverständnis ihrer Verfasser und ersten Rezipientinnen und Rezipienten her jüdische Schriften waren. Es ist schlicht ein Anachronismus, wenn man Phänomene des I. Jahrhunderts mit den Begriffen „christlich“, „Christen“ oder „Christentum" beschreibt. Damit trägt man den geschichtlich gewordenen Unterschied bis Gegensatz zwischen Judentum und Christentum hinterrücks in die Interpretation von Texten ein, die diesen Unterschied nicht kennen, wodurch vor allem der jüdische Charakter dieser Texte verdeckt wird.

Was bedeutet diese Einsicht für die christliche Auslegung des Neuen Testaments? Es bedeutete für mich negativ, dass ich sie nicht mehr weiter so betreiben konnte und durfte, wie ich sie erlernt und dann auch als Lehrender betrieben hatte, nämlich im Modell einer Abgrenzung von Altem Testament und Judentum und deren Überbietung. Was die Wahrnahme neutestamentlicher Schriften als jüdische Schriften im Kontext des Judentums als positiven Gewinn für ihre Auslegung erbringt, will ich an vier Punkten erläutern.

I. Die Bedeutung der jüdischen Bibel für die frühen Schriften aus der auf Jesus bezogenen Gemeinschaft

Die Formulierung dieser Überschrift mag als umständlich befremden. Warum rede ich nicht einfach von der Bedeutung des Alten Testaments für das Neue? Ich tue 
es deshalb nicht, weil ich keine Anachronismen begehen möchte, indem ich mit später entstandenen Begriffen zugleich die mit ihnen verbundenen Vorstellungen zur Beschreibung von Phänomenen einer Zeit gebrauche, in denen es diese Vorstellungen noch gar nicht gab. Es ist die Binsenweisheit zu beachten: Als die Autoren der Schriften, die später zum Neuen Testament zusammengestellt wurden, diese verfassten, gab es noch kein Neues Testament. Sie schrieben auch nicht in dem Bewusstsein, damit an einer neuen oder auch nur zu ergänzenden Bibel zu arbeiten. Was es aber ganz selbstverständlich für sie gab, war die jüdische Bibel, waren die in ihrer Zeit als heilig geltenden Schriften. Dass sie in und mit ihrer Bibel lebten, zeigt sich implizit und explizit in ihren eigenen Werken, sodass diese gar nicht ohne ihre Bibel verstanden werden können. Das sei am Beispiel der Evangelien kurz skizziert. Immer wieder finden sich in ihnen Zitate aus der jüdischen Bibel und Anspielungen auf sie. Man wird geradezu sagen müssen: Die Evangelisten erzählen die Geschichte Jesu mit ihrer Bibel. Das geschieht in besonderer Dichte in den Passionsgeschichten. Die Synoptiker tun es mit Anspielungen, Halbzitaten und ganzen Zitaten, ohne sie als solche kenntlich zu machen, das Johannesevangelium führt darüber hinaus ausdrücklich gekennzeichnete Zitate an. Es ist vorauszusetzen, dass die Evangelisten wussten, was sie taten, dass also ihr Erzählen mit der Bibel ein bewusst eingesetztes Mittel literarischer Gestaltung ist, das einer theologischen Intention dient. Weiter ist vorauszusetzen, dass auch die intendierte Leser- und Hörerschaft - die Evangelien sind von vornherein als Lesetexte für die versammelte Gemeinde geschrieben worden - diese Bezüge erkannte und ihr dabei die eingespielten biblischen Kontexte vor Augen standen. Denn jüdisches Zitieren ist - in aller Regel - ein Anzitieren, das erwartet, dass die Lesenden und Hörenden den Text fortsetzen können. In diesem Erzählen mit der Bibel wird Gott ins Spiel gebracht, wird Gott in dieses schlimme Geschehen hineingezogen, Gott, der ein Gott des Lebens ist und deshalb Leiden und Tod Jesu nicht das Letzte sein lassen wird, von dem erzählt werden kann. Gegenüber den geschichtlich mit tödlicher Gewalt handelnden Subjekten wird hier behauptet, dass ein ganz anderer das entscheidende Subjekt sei, das seine Finger im Spiel habe und dem schlimmen Geschehen eine andere Wendung gebe. Wohlgemerkt: Es geht dabei nicht um das Schreiben eines Drehbuchs für eine vom Himmel gesteuerte Inszenierung; das wäre einfach nur schrecklich. Die Evangelisten schreiben im Nachhinein der geschehenen Hinrichtung Jesu. Ihnen geht es darum, der hier erfolgten faktischen Gewalt nicht den Triumph der End- und Letztgültigkeit zu lassen. Noch einmal anders gesagt: Ihr Schreiben mit der Bibel ist nicht himmlische Legitimierung schlimmen Geschehens, sondern im Gegenteil Protest gegen es. Als ein Beispiel sei das letzte Wort Jesu am Kreuz nach Mk 15,34 angeführt. Dort heißt es: „Und in der neunten Stun- 
de schrie Jesus mit lauter Stimme." Was Jesus schrie, gibt Markus in griechischer Transkription auf Aramäisch wieder: $\varepsilon \lambda \omega t \varepsilon \lambda \omega t \lambda \varepsilon \mu \alpha \sigma \alpha \beta \alpha \chi \theta \alpha v$. Das ist auch der Wortlaut des aramäischen Targums von Ps 22,2a, das dem hebräischen Text wörtlich entspricht: „Mein Gott, mein Gott, warum hast Du mich verlassen?“ Die von Markus gegebene griechische Übersetzung folgt exakt seinem aramäischen Zitat und nicht der Septuaginta, die gegenüber dem hebräischen Text eine leichte und eine kräftige Abweichung hat. Nach dieser Darstellung sagt Jesus also den Beginn von Ps 22. Ich hatte schon gesagt, dass im Judentum das Zitieren als Anzitieren erfolgt. Der Kontext des Zitats wird vom Zitierenden bei seiner Leser- und Hörerschaft als präsent vorausgesetzt. Jede Leserin, jeder Hörer des Markusevangeliums weiß - oder kann es wissen -, dass Ps 22,2a der Beginn eines Gebets des leidenden Gerechten ist: „Mein Gott, mein Gott, warum hast Du mich verlassen? Fern von jeder Hilfe verhallt mein Schreien. Mein Gott, ich rufe am Tag, aber Du antwortest nicht, in der Nacht, aber ich finde keine Ruhe" (V. 2f.). Der Beter blickt im weiteren Text zurück auf Gottes rettende Hilfe in der Geschichte seines Volkes, kontrastiert das mit der eigenen Not; Vertrauensaussagen wechseln mit bitterer Klage. „Ich kann alle meine Knochen zählen. Sie schauen zu und taxieren mich. Sie teilen meine Kleider unter sich, um mein Gewand werfen sie das Los" (V. I8f.). Es folgt eine dringliche Bitte um Rettung - und dann die Wende: „Du gibst mir Antwort“ (V. 22b). Daran schließt sich sofort der Lobpreis an: „Ich will meinen Brüdern und Schwestern von Deinem Namen erzählen, inmitten der Gemeinde will ich Dich preisen" (V. 23). Für das Bewusstsein einer in biblischer Tradition lebenden Leser- und Hörerschaft - und das waren die Gemeinden, für die die Evangelien geschrieben wurden - macht sich Jesus mit dem Verlassenheitsruf am Beginn von Ps 22 dieses Gebet zu eigen. Sie weiß, wie es weitergeht und zu welchem Ziel es führt. Mit dem Zitat des Anfangs ist das Ganze gegeben. Die Einspielung von Ps 22,2a an dieser dramatischsten Stelle in der Erzählung des Evangeliums bringt einmal mehr und betont Gott ins Spiel und reißt die Dimension der Hoffnung auf sein rettendes Handeln auf. Dementsprechend beenden die Evangelien ihre Erzählung nicht mit einem Satz, wie er am Schluss des Jesusbuches von David Flusser steht: „Schließlich schrie Jesus laut und starb“. ${ }^{1}$ Da Jesus tatsächlich gestorben ist, können sie nicht von Rettung vor dem Tod erzählen. Sie können sozusagen noch eins draufsetzen und bezeugen seine Rettung aus dem Tod.

Im Lukasevangelium leistet dasselbe - gewiss in anderer Tönung - der Bezug auf Ps 3I,6 in Lk 23,46: „Deinen Händen vertraue ich meinen Lebensatem an.“ His-

I Flusser, David: Jesus, Reinbek bei Hamburg: Rowohlt-Taschenbuch-Verl. ${ }^{22} 2000$ (I968), I40. 
torisch verwertbar ist hier nichts. Was Jesus tatsächlich am Kreuz historisch getan hat, ob er nach Lukas Ps 31,6 gebetet hat oder ob nach Markus Ps 22,2 und - wenn Letzteres zuträfe - ob er nur den Verlassenheitsschrei ausgestoßen oder den Psalm weiter bis zum Ende gebetet hat oder ob es noch einmal ganz anders war, weiß niemand von uns und kann niemand wissen. Es sind müßige Fragen; wir brauchen es auch nicht zu wissen. Wir haben die Erzählungen der Evangelien; auf die ist jeweils zu hören. Das bloße historische Faktum, dass Jesus an einem römischen Kreuz hingerichtet worden ist, wird von den Evangelisten vorausgesetzt und ja auch berichtet. Aber an allen weiteren historischen Details sind sie nicht interessiert. Sie interessiert, was Gott mit diesem Faktum zu tun hat, dass und wie er in ihm und gegen es zum Zuge kommt. Dafür erzählen sie mit ihrer Bibel. Dafür führen Markus und Matthäus als letztes Wort Jesu vor seinem Tod Ps 22,2 an und Lukas Ps 3I,6.

Das eben Ausgeführte gilt nicht nur für die Evangelien, sondern für neutestamentliches Reden und Erzählen überhaupt. Es ist ganz und gar von der jüdischen Bibel bestimmtes, geradezu mit ihr erfolgendes Reden und Erzählen. Nur so kann zum Ausdruck gebracht werden, dass in dem hier ins Auge gefassten Geschehen Gott zum Zuge kommt. Von dieser Einsicht her spreche ich von der Schrift, der jüdischen Bibel, als dem Raum des Evangeliums. Bei Frank Crüsemann findet sich das in zugespitzter Formulierung im Titel seines bisher letzten Buches: „Das Alte Testament als Wahrheitsraum des Neuen ". ${ }^{2}$

Von daher ist aber auch klar, dass die der auf Jesus bezogenen Gemeinschaft von vornherein als heilige Schrift vorgegebene jüdische Bibel solche Vor-Gabe blieb, als man - wahrscheinlich um die Mitte des 2. Jahrhunderts - Schriften aus der eigenen Anfangszeit zum Neuen Testament zusammenfasste, womit die Vor-Gabe zum Alten Testament wurde. Über dessen Beibehalten als ersten Teils des christlichen Kanons ist in der Kirche nie abgestimmt worden. Damit war aber schon im Vorhinein entschieden, wer für die Kirche Gott ist: der in der jüdischen Bibel, der im Alten Testament bezeugte Gott, Israels Gott, dem es gefallen hat, mit diesem Volk eine besondere Geschichte zu haben. Das jedoch hat die Kirche aus den Völkern, das im 2. Jahrhundert in Abgrenzung und im Gegensatz zum Judentum entstehende Christentum, verdeckt, indem sie sich selbst als „wahres Israel“ behauptete und damit das tatsächlich weiter existierende Judentum als falsches Israel, als von Gott verworfen behauptete. Dass der in der Bibel bezeugte Gott Israels Gott ist, musste erst wieder neu entdeckt werden. Er ist als der Schöpfer ganz gewiss auch der Gott aller Welt, aber eben kein Allerweltsgott, sondern in sehr spezifischer Weise Israels

2 Crüsemann, Frank: Das Alte Testament als Wahrheitsraum des Neuen. Die neue Sicht der jüdischen Bibel, Gütersloh: Gütersloher Verlagshaus 20II. 
Gott. Das unterscheidet ja biblisches Reden von Gott vom philosophischen, dass es zwar den einen Gott auf die ganze Wirklichkeit bezieht, ihn aber mit bestimmter, dazu noch höchst partikularer Geschichte in unlösbaren Zusammenhang bringt, in der jüdischen Bibel, im Alten Testament, mit der Geschichte des Volkes Israel, im Neuen noch einmal zugespitzt mit der Geschichte eines Menschen aus Israel, dem Juden Jesus aus Nazaret.

Von der Erkenntnis her, dass der im Neuen Testament bezeugte Gott kein anderer ist als der im Alten Testament, in der jüdischen Bibel bezeugte und also Israels Gott, bin ich als Christ und besonders auch als Neutestamentler auf das Hören des jüdischen Zeugnisses verwiesen. Denn Israels Gott gibt es nicht ohne sein Volk Israel, ohne das jüdische Volk. In Jesaja 43,I2 heißt es in Gottesrede an Israel: „Und ihr seid meine Zeugen, Spruch des Ewigen, und ich bin Gott." Rabbinische Auslegung nimmt das so auf: „Wenn ihr meine Zeugen seid, bin ich Gott; wenn ihr aber nicht meine Zeugen seid, bin ich gleichsam nicht Gott". ${ }^{3}$ Wir Christinnen und Christen machen gewiss - durch die Botschaft von Jesus vermittelt - unsere eigenen Glaubenserfahrungen. Wer aber Gott als Israels Gott ist, das zu beschreiben, ist Sache des jüdischen Zeugnisses - in der jüdischen Bibel und in der weitergehenden jüdischen Tradition. Will ich also festhalten, dass Gott, zu dem ich mit meinen Vorfahren durch Jesus in Beziehung gesetzt bin, Israels Gott ist und bleibt - und das festzuhalten, bin ich durch meine kanonischen Grundlagen angehalten -, bleibe ich auf jüdisches Zeugnis angewiesen. Wenn ich also als Neutestamentler auf jüdisches Zeugnis höre, ist das nicht nur eine historisch-religionsgeschichtlich naheliegende Pragmatik, sondern es ist zutiefst theologisch bedingt.

\section{Antijüdische Polemik im Neuen Testament oder innerjüdischer Streit?}

Die Erkenntnis, dass es sich bei den Schriften des Neuen Testaments um ursprünglich jüdische handelt, hat Konsequenzen für deren Auslegung. Für mich ergibt sich daraus - pauschal gesagt - die Aufgabe, ihren jüdischen Kontext aufzuspüren, ihr jüdisches Profil klar herauszustellen und dabei zu fragen, wo ihr Ort innerhalb des Judentums war und in welchen Auseinandersetzungen sie standen. Gegenüber einem möglichen rein literaturwissenschaftlichen Zugang zu den neutestamentlichen Schriften ist mir historische Arbeit unverzichtbar, um auf den Überlieferungsbruch

3 Sifrej Dvarim $\$ 346$ (Finkelstein, Louis [Hg.]: Siphre ad Deuteronomium, H. S. Horovitzii schedis usus cum variis lectionibus et adnotationibus (Corpus Tannaiticum), Berlin: Jüdischer Kulturbund in Deutschland E.V. 1939 / New York: Jewish Theological Seminary of America 1969, 403f.) 
aufmerksam zu machen, dass nämlich eine in jüdischem Kontext entstandene Tradition in einen nichtjüdischen Kontext übergegangen ist, dass die von Juden oder dem Judentum nahestehenden Menschen geschriebenen neutestamentlichen Schriften schließlich von einer nichtjüdischen Gemeinschaft rezipiert wurden, die ihre Identität in Antithese zum Judentum bestimmte. So muss heutige Auslegung die Unterschiedenheit der eigenen Situation von der Entstehungssituation der neutestamentlichen Schriften und deren Wirkungsgeschichte im Auslegungsvorgang mitreflektieren, will sie nicht traditionelle christliche Judenfeindschaft weiter transportieren. Natürlich ist die Rekonstruktion dieser Entstehungssituationen nur hypothetisch, nur in wahrscheinlichen Annäherungen möglich, wie das bei aller historischen Arbeit der Fall ist. Aber solche Rekonstruktionen haben einen m. E. unaufgebbaren heuristischen Wert.

Besonders wichtig ist das bei polemischen Texten, in denen sich Auseinandersetzungen widerspiegeln, wie das vor allem über weite Strecken im Johannes- und Matthäusevangelium der Fall ist. ${ }^{4}$ Das sich hier findende polemische Gegenüber ist dann nicht als Gegensatz von Judentum und Christentum zu identifizieren. Daher sind solche polemischen Passagen auch nicht als „Antijudaismen im Neuen Testament" zu bezeichnen - so wenig, wie man heftige Ausfälle gegen andere jüdische Gruppen in den Qumrantexten als „Antijudaismen“ ausmachen würde. Es handelt sich vielmehr um innerjüdische Auseinandersetzungen zwischen einer an Jesus als Messias glaubenden jüdischen Minderheit und der sich vom Lehrhaus in Javne her nach 70 unter pharisäisch-rabbinischer Führung neu konstituierenden jüdischen Mehrheit. Dabei zeigt sich einmal, dass die Evangelisten jüdische Sprachmöglichkeiten wahrnehmen. Zum anderen wäre bei der Auslegung die in den Evangelien nur in polemischer Verzerrung begegnende Gegenseite von ihren eigenen Texten her genauso stark zu machen wie die in den Evangelien manifeste. Dabei kommt gerade dem rabbinischen Schrifttum eine besondere Bedeutung zu. Mit Ausnahme der authentischen Paulusbriefe sind wahrscheinlich alle anderen Schriften des Neuen Testaments in der Zeit nach 70 geschrieben, der Gründungszeit des rabbinischen Judentums nach der Katastrophe des ersten jüdisch-römischen Krieges mit der Zerstörung des Tempels. Wie sollen die in diesem Kontext entstandenen neutestamentlichen Schriften angemessen verstanden werden können, wenn nicht in erster Linie dieser Kontext beachtet wird? Das rabbinische Schrifttum dürfte auch für die Pau-

4 Zu diesen beiden Evangelien vgl. meine Versuche: Wengst, Klaus: Das Johannesevangelium. I. Teilband: Kapitel I-IO (ThKNT 4,I), Stuttgart: Kohlhammer ${ }^{2} 2004$; 2. Teilband: Kapitel II-2I (ThKNT 4,2), Stuttgart: Kohlhammer ${ }^{2} 2007$; Wengst, Klaus: Das Regierungsprogramm des Himmelreichs. Eine Auslegung der Bergpredigt in ihrem jüdischen Kontext, Stuttgart: Kohlhammer 2010. 
lusexegese von größerer Bedeutung sein, als gemeinhin angenommen wird. Denn in dieses ist die pharisäische Tradition der Zeit vor 70 eingegangen, in der Paulus sich seinen eigenen Aussagen zufolge ausgezeichnet hatte, bevor er zum Glauben an Jesus als Messias kam. Auch als an Jesus als Messias Glaubender hörte Paulus nicht auf, Jude zu sein. Aus „Saulus“ wurde kein „Paulus“, aus dem Juden kein Christ.

\section{Die „neue Perspektive auf Paulus“}

Die Topoi paulinischer Rechtfertigungslehre findet man nicht nur in der jüdischen Bibel, sondern auch in der rabbinischen Literatur, natürlich nicht in Entgegensetzung zum Tun der Tora. Der spannungsvolle Zusammenhang von Recht und Erbarmen als den beiden wichtigsten Maßen Gottes, von Gericht und Gnade, ist gewahrt. Das sollte die Augen dafür öffnen, dass es sich damit bei Paulus nicht anders verhält. Es weist zugleich darauf hin, dass dessen Grundthema nicht die Rechtfertigung ist, gar im Rahmen der lutherischen Unterscheidung bis Entgegensetzung von Gesetz und Evangelium. Sein Grundthema ist vielmehr das Verhältnis von Israel und den Völkern. ${ }^{5}$ Das ist schon vor recht langer Zeit (I963!) programmatisch in großer Klarheit von Krister Stendahl herausgestellt worden, ${ }^{6}$ fand im angelsächsischen Bereich - als „neue Perspektive auf Paulus“ bezeichnet - eine gewisse Ausgestaltung, ${ }^{7}$ gewann aber im deutschen Sprachbereich kaum an Boden. Hier dominiert nach wie vor die lutherische Paulusinterpretation. Gegen sie sprechen zwei Gründe: Erstens ist sie ist bei ihrer Entstehung nichts als Projektion. Luther parallelisiert sich selbst mit Paulus. Wie er gegen die spätmittelalterliche katholische Kirche und damit gegen seine eigene Vergangenheit als Mönch kämpft, so Paulus gegen die Juden. Das ist am prägnantesten in der Wendung zusammengefasst: „gegen die Papisten, unsere Juden“ “ ${ }^{8}$ Zweitens trifft die in dieser Perspektive dem Judentum unterstellte Verdienst-Gerechtigkeit in keiner Weise zu. Es gilt sich klar zu machen: Hält man die Rechtfertigung für den Punkt, der sich

Vgl. Wengst, Klaus: „Freut euch, ihr Völker, mit Gottes Volk!“ Israel und die Völker als Thema des Paulus - ein Gang durch den Römerbrief, Stuttgart: Kohlhammer 2008.

6 Stendahl, Krister: The Apostle Paul and the Introspective Conscience of the West, in: Harvard Theological Review 56 (1963) 199-215; in deutscher Übersetzung in: KuI II (1996) 19-33.

7 Vgl. vor allem: Sanders, Ed P.: Paulus und das palästinische Judentum. Ein Vergleich zweier Religionsstrukturen, Göttingen: Vandenhoeck \& Ruprecht 1985 (amerikanisches Original: Paul and Palestinian Judaism. A Comparison of Patterns of Religion, London: SCM Press 1977); Dunn, James D. G.: The Theology of Paul the Apostle, Edinburgh: Clark 1998.

8 Vgl. dazu Wengst: Völker, 25-35. 
Paulus bei der für ihn grundlegenden Erfahrung in oder bei Damaskus ergeben hat, kommt man aus der antijüdischen Falle nicht heraus. Da für Paulus nach seinen eigenen Aussagen diese Erfahrung einen radikalen Wandel bedeutete, muss man - hat er hier die Rechtfertigung als entscheidenden Punkt erkannt - etwas dazu Gegensätzliches für die Zeit vorher als seine Überzeugung annehmen und also diese Überzeugung für das Judentum oder eine Gruppe in ihm postulieren, der Paulus angehörte, auch wenn es dafür keine Texte gibt. Nebenbei sei darauf hingewiesen, dass sich das von Luther in seiner Übersetzung von Röm 3,28 hinzugefügte „allein“ (,So halten wir nun dafür, dass der Mensch gerecht werde ohne des Gesetzes Werke allein durch den Glauben") in einem Zusammenhang in der Mechilta des Rabbi Jischmael, der das Hohelied des Glaubens singt, dreimal der Sache nach findet: „allein dank des Glaubens “. ${ }^{9}$ Paulus selbst charakterisiert sich für die Zeit vor Damaskus als „Eiferer“. Damit ist eine Tradition gekennzeichnet, die sich von den Makkabäern bis in die rabbinische Zeit verfolgen lässt. Ihr geht es um die strikte Herausstellung und Befolgung der besonderen jüdischen Lebensweise in Abgrenzung zur Völkerwelt, was mit gewaltsamen Übergriffen gegen Landsleute verbunden ist, die diese Grenze zu missachten scheinen. Paulus hat vor seiner Berufung nicht „Christen verfolgt“, sondern ist als „Eiferer“ gewalttätig gegen jüdische Landsleute vorgegangen, die sich in der auf Jesus bezogenen Gemeinschaft im Zusammenleben mit Menschen aus den Völkern nicht an die besondere jüdische Lebensweise hielten. ${ }^{10}$ Seine Erfahrung bei Damaskus setzte für ihn deren Verhalten ins Recht. Diese grundlegende Erfahrung beschreibt und deutet Paulus in Gal I,I5f. mit dem Sprachmuster prophetischer Berufungen seiner Bibel, und zwar gerade mit den beiden Berufungen, in denen die Völker in den Blick kommen (Jes 49,I; Jer I,5); und so versteht er sich von daher als „Apostel für die Völker“. Diese treten durch die messianische Verkündigung zu Israels Gott in Beziehung, ohne ins Volk Israel integriert werden zu müssen. Das ist im galatischen Konflikt wieder umstritten. Wenn in diesem Konflikt Paulus den Glauben und das Tun der ह̌ $p \gamma \alpha$ vó von Luther mit „Werke des Gesetzes“ übersetzt, einander entgegenstellt, ist klar, dass er damit nicht das von der Tora überhaupt Gebotene meint, sondern diejenigen Gebote, die sich auf die spezifisch jüdische Lebensweise beziehen, sodass man

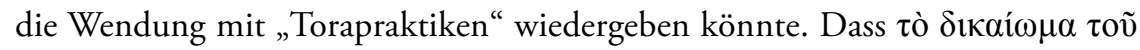
vónov, das von der Tora gebotene Rechte, von den zum Glaubenden kommenden Menschen aus den Völkern getan werde, ist nach Röm 8,4 geradezu Ziel der Sen-

9 MekhJ Beschallach (Wajehi) 6: Horovitz, H. S. / Rabin, Israel A. (Hg.): Mechilta d'Rabbi Ismael, Jerusalem: Wahrmann ${ }^{2}$ I970, II4.

Vgl. Wengst: Völker, 69-100. 
dung Jesu. Dem Paulus ist also von vornherein als zentrales Thema das Verhältnis von Israel und den Völkern vorgegeben. Das ist auch das den Römerbrief bestimmende und ihm Einheit gebende Thema. Dieses Thema führte Paulus als Jude aus, natürlich als an Jesus als Messias glaubender Jude, aber eben als Jude und nicht als "Christ". Seine in oder bei Damaskus gemachte Erfahrung als Bekehrung vom Juden zum Christen zu deuten, ist nichts als ein schrecklicher Anachronismus. Nach seinen eigenen Aussagen hatte Paulus bis zuletzt ein jüdisches Selbstverständnis. So formulierte schon Leo Baeck, dass Paulus Jude „war und nie aufhörte zu sein“."11

\section{Keine Vergottung Jesu}

Im ersten Abschnitt wurde ausgeführt, dass die Evangelisten die Geschichte Jesu mit ihrer Bibel erzählen und dass es ihnen so gelingt, das Mitsein Gottes in dieser Geschichte zum Ausdruck zu bringen. So wird deutlich: In dem, was Jesus sagt, tut und erleidet, kommt Gott zu Wort und Wirkung. Mit der Ausbildung der altkirchlichen Dogmatik haben die Kirchenväter des 3. bis 5. Jahrhunderts versucht, dieses neutestamentlich bezeugte "Gott in Jesus" in einem völlig anderen Kontext, nämlich dem griechisch-philosophischer Ontologie und Metaphysik, zum Zuge zu bringen. Dabei haben sie eine großartige Denkarbeit geleistet, der mit Gewinn nach-gedacht werden kann. Die hier entstandenen dogmatischen Bekenntnissätze steuerten dann aber ihrerseits die Auslegung des Neuen Testaments und tun es weiterhin, obwohl doch unser Kontext schon lange nicht mehr von griechisch-philosophischer Ontologie und Metaphysik bestimmt wird. Man räumt dann zwar ein, dass die neutestamentlichen Aussagen nicht in der Klarheit ausgebildet seien, wie es dann später in der Trinitäts- und Zwei-Naturen-Lehre der Fall ist, aber es sei in ihnen doch schon enthalten und angelegt, was dort dann entfaltet worden wäre. Meiner Einsicht nach wird hier hinsichtlich der christologischen Aussagen mit der dogmatischen Brille die zweite Person der Trinitätslehre in die neutestamentlichen Texte hineingelesen und nicht in ihnen gefunden. Setzt man diese Brille ab und nimmt die entsprechenden Aussagen in ihrem biblisch-jüdischen Kontext wahr, kann von einer Gottheit Jesu keine Rede sein, sehr wohl aber das Zeugnis vernommen werden, dass in diesem jüdischen Menschen kein Geringerer als Gott selbst zu Wort und Wirkung kommt. ${ }^{12}$

II Baeck, Leo: Der Glaube des Paulus, in: Friedlander, Albert H. / Klappert, Bertold (Hg.): Nach der Schoa - warum sind Juden in der Welt? Schriften aus der Nachkriegszeit (Leo Baeck Werke 5), Gütersloh: Gütersloher Verl.-Haus 2002, 420-466, 427.

I2 Vgl. dazu ausführlicher: Wengst, Klaus: Neues Testament und dreieiniger Gott. Trinitarisch von Gott reden im Angesicht Israels, in: Ders.: Christsein mit Tora und Evangelium. 
Das sei an einer Stelle des Johannesevangeliums gezeigt, die gerne für eine Wesenseinheit angeführt und üblicherweise so übersetzt wird: „Ich und der Vater sind eins" (Joh I0,30). Eine dem Sinn entsprechende Übersetzung müsste lauten: „Ich und der Vater wirken zusammen." Dieser Sinn ergibt sich einmal von einer sprachlich genau entsprechenden Parallele her. In I Kor 3,4-9 stellt Paulus sich und Apollos als Menschen nebeneinander, die in der korinthischen Gemeinde gewirkt haben: „Ich habe gepflanzt, Apollos hat begossen; Gott aber hat es wachsen lassen. Daher gilt weder, der pflanzt, etwas, noch der, der begießt, sondern der wachsen lässt: Gott“ (V. 6f.). Eine genau dem griechischen Wortlaut folgende Übersetzung des anschließenden ersten Satzes von V. 8 müsste lauten: „Wer pflanzt und wer begießt sind eins." So aber formuliert nur die an keiner Stelle Wörtlichkeit scheuende und darum manchmal Unsinn produzierende Elberfelder Übersetzung. Die Einheitsübersetzung etwa hat an dieser Stelle: „Wer pflanzt und wer begießt: beide arbeiten am gleichen Werk." Warum sie in Joh Io,30 nicht so übersetzt, liegt auf der Hand. Aber es handelt sich an beiden Stellen um die identische Formulierung. Auch der Kontext von Joh I0,30 verlangt den Sinn des gemeinsamen Wirkens. Im unmittelbar Vorangehenden hatte Jesus von den Seinen als solchen gesprochen, die auf seine Stimme hören und denen er Leben gibt, und fuhr dann fort: „Und sie gehen nie und nimmer verloren und niemand wird sie aus meiner Hand rauben. Was mein Vater mir gegeben hat, ist größer als alles, und niemand kann es aus der Hand des Vaters rauben" (Joh IO,28f.). Hier ist es geradezu terminologisch zum Ausdruck gebracht, dass Jesus und der Vater Hand in Hand zusammenarbeiten. Die danach ausgesprochene Einheit ist somit von vornherein als eine funktionale gekennzeichnet, eben als ein gemeinsames Wirken bzw. präziser, da mit der Aussage vom Vater, der Jesus gibt, dessen Vorordnung herausgestellt ist: als ein Wirken des Vaters durch Jesus. Der danach von Jesu Gegnern vorgebrachte Vorwurf, er mache sich Gott gleich, gilt als ein Missverständnis. Der Evangelist lässt es Jesus unter Berufung auf eine Bibelstelle zurückweisen. Er zitiert als „eure Tora“ die Aussage aus Ps 82,6: „Ich habe gesagt: Götter seid ihr“ und betont, dass „die Schrift doch nicht aufgelöst werden darf". Daran wird deutlich, dass die Formulierung „eure Tora" keine Distanzierung meinen kann. Aus der zitierten Psalmstelle folgert Jesus: „Wenn er jene Götter nannte, an die das Wort Gottes erging [...], dürft ihr dann dem, den der Vater geheiligt und in die Welt gesandt hat, sagen: Du lästerst, weil ich gesprochen habe: Sohn Gottes bin ich?“ (Joh I0,34-36). Das Verständnis von Ps 82,6 als eine den Israeliten gegebene Bezeichnung als Götter, weil Gott seine

Beiträge zum Umbau christlicher Theologie im Angesicht Israels, Stuttgart: Kohlhammer 20I4, 77-96. 
Worte an sie gerichtet hat, findet sich auch in der jüdischen Tradition in einem späten Midrasch. ${ }^{13}$ Johannes versucht hier also, die Bedeutung Jesu ,grundlegend auf derselben Ebene mit der Bedeutung Israels "verständlich zu machen. ${ }^{14}$ Es wird also argumentiert: Wenn schon alle vom Gotteswort Angeredeten "Götter" genannt werden, um wie viel weniger verdient dann Jesus aufgrund seines Anspruchs, Sohn Gottes zu sein, die Anklage der Lästerung, da er doch von Gott geheiligt und in die Welt gesandt worden ist. Dass jetzt für Jesus der Titel „Sohn Gottes“ gebraucht wird, könnte durch die nicht mitzitierte, aber doch mitgemeinte und mitgehörte Fortsetzung des Psalmverses bedingt sein: ,und Söhne des Höchsten ihr alle“. Zugleich liegt ein Rückbezug auf den zu Beginn des Abschnitts in V. 24 eingebrachten Messiastitel vor, mit dem er zusammengehört. Die Folgerichtigkeit des Schlusses hängt an der Aussage, dass Gott Jesus "geheiligt und in die Welt gesandt" habe. Das Sendungsmotiv unterstreicht wieder, dass Jesus in der Autorität des Sendenden auftritt. Heiligung von Gott her ist, biblisch verstanden, Beschlagnahme vonseiten Gottes, verbunden mit einer Beauftragung. Von daher versteht Johannes den für Jesus erhobenen Anspruch: In dem, was Jesus sagt und tut, begegnet Gott selbst. In dieser Weise gilt, dass er und der Vater zusammenarbeiten, „eins sind“, dass er „Sohn Gottes“ ist. Es geht nicht um die Vergötzung eines Menschen, sondern um die Präsenz Gottes in Jesus. Die Möglichkeit, so von Jesus zu reden, hat Johannes von der Schrift her aufgezeigt. Aber ob der in seinem Schluss für Jesus erhobene Anspruch, dass Gott selbst in ihm präsent ist, zu Recht besteht, lässt sich außerhalb des Glaubens nicht erweisen.

\section{Eine Schlussbemerkung}

Die christliche Kirche ist durch ihre kanonische Schriftgrundlage in ein einzigartiges Verhältnis zu Israel, zum Judentum gestellt. Sie geht auf eine jüdische Gruppe zurück, für die der Bezug auf Jesus als den von Gott auferweckten Gekreuzigten entscheidend war und die diesen Glauben mithilfe ihrer Bibel artikulierte. Als sich im 2. Jahrhundert die auf Jesus bezogene Gemeinschaft mehr und mehr im Gegenüber und im Gegensatz zum Judentum als christliche Kirche herausbildete, behielt

I3 TanB Waera 9: Buber, Salomon (Hg.): Midrasch Tanchuma. Ein aggadischer Commentar zum Pentateuch. Zum ersten Male nach Handschriften aus den Bibliotheken zu Oxford, Rom, Parma und München herausgegeben. 2, Wilna: Romm i885 (Nachdruck Jerusalem 1964), i3b.

I4 Kriener, Tobias: „Glauben an Jesus“ - ein Verstoß gegen das zweite Gebot? Die johanneische Christologie und der jüdische Vorwurf des Götzendienstes, Neukirchen-Vluyn: Neukirchener 200I, I44. 
sie die jüdische Bibel fraglos als ihre kanonische Grundlage bei. Sie erzählt von der besonderen Bundesgeschichte Gottes mit seinem Volk Israel und bezeugt somit den einen Gott, den Schöpfer und Gott aller Welt, als Israels Gott, der seinem Volk die Treue hält. Indem die Schriften des Neuen Testaments die jüdische Bibel als ihre Grundlage haben und sie von Jesus in deren Sprach- und Wahrheitsraum reden, bezeugen sie nicht einen Gott Jesu, der neu oder anders wäre, sondern machen den „Vater Jesu Christi“ als Gott Israels kenntlich. Wer aber Gott als Israels Gott ist und auch weiterhin bleibt, kann nur im jüdischen Zeugnis in Geschichte und Gegenwart vernommen werden. Auslegung des Neuen Testaments darf deshalb nicht als christliche Profilierung im Gegensatz zum Judentum, sondern kann nur im biblisch-jüdischen Kontext erfolgen. 


\title{
Erfahrungen im jüdisch-christlichen Dialog
}

\author{
Hubert Frankemölle
}

Das von den Herausgeberinnen gewünschte Thema impliziert bestimmte hermeneutisch-methodische Voraussetzungen meiner Theologie im christlich-jüdischen Kontext. Sie betreffen nicht nur meine Exegese biblischer Schriften, sondern auch den zwischenmenschlichen und theologischen Dialog zwischen Jüdinnen/Juden und Christinnen/Christen in Deutschland. Nur um diese lokale Begrenzung kann es aufgrund meiner Erfahrungen im Folgenden gehen. Dass der jüdisch-christliche Dialog trotz des fast vollständigen Genozids an Jüdinnen und Juden in Deutschland durch Deutsche in der NS-Zeit seit 1945 - dem Judentum sei Dank! - wieder geführt wurde und wird, erscheint mir immer noch als Wunder. Dass solche Gespräche und eine Zusammenarbeit wieder möglich sind, bedarf es Vorbedingungen, in die ich zum Teil involviert war, die den Interaktionen vorausliegen, sie aber prägen. Dies gilt es kurz zu bedenken. Meine einführenden Formulierungen mögen andeuten, dass der Begriff „Dialog“ zunächst unspezifisch verstanden wird, ebenso das Syntagma „christlich-jüdisch“, das auch - auf Ortsebene wohl ausschließlich - „deutsch-jüdische Kultur" meint. Vor allem: Nicht immer ist das, was vor allem von christlicher Seite „Dialog“ genannt wird, wirklich ein Gespräch unter gleichberechtigten Gesprächspartnerinnen und -partnern.

\section{Das hermeneutische Grundproblem}

Ging es in der wissenschaftlich reflektierten Theologie sowohl in der Bibelwissenschaft wie in der Kirchengeschichte, aber auch in der Dogmengeschichte um die Darstellung textlich vorgegebener Inhalte, die historisch-kritisch, kontextlos und geschichtslos - sozusagen objektiv (was nicht möglich ist) - zu erheben waren, so bringt das Stichwort „Erfahrung" das Subjekt im Prozess des Theologietreibens mit in den Blick. Es geht immer um ein Wechselspiel von vorgegebener Wirklichkeit (Schrift, Traditionen) oder pastoraler Wirklichkeit von Glaubensgemeinschaften (praktische Theologie) und erkennendem Subjekt. Dieses ist immer (schon von der Herkunft her per Geburt) zugleich Mitglied einer Glaubensgemeinschaft, etwa der römisch-katholischen Kirche oder einer der evangelischen Kirchen oder etwa der Orthodoxen Rabbinerkonferenz Deutschland (gegründet am 27.4.2003) oder der Allgemeinen Rabbinerkonferenz (gegründet am 3.2.2005); vorher gab es die Einheitsgemeinden, die sich nach dem Fall der Berliner Mauer 1989 ausdifferenzierten. 
Nicht zuletzt die Erkenntnis dieser religiösen Vielfalt war in den vergangenen Jahrzehnten prägend in meinen Erfahrungen im christlich-jüdischen Dialog, die als Wechselspiel von kirchlicher Sozialisation in der Jugendzeit, von kirchlichen Erklärungen, aber auch von eigenen exegetischen Forschungen und Reflexionen im Promotionsstudium bezeichnet werden kann. In dieser Verschränkung und Interaktion werden im Folgenden einzelne Aspekte benannt. Ein Beispiel: Im katholisch-evangelischen, später auch im christlich-jüdischen Miteinander wurde die religiöse Vielfalt virulent bei der Frage, ob man zusammen, nacheinander oder nebeneinander beten dürfe. Ich erinnere an die Auseinandersetzungen über das Friedensgebet von Assisi, 1986 von Johannes Paul II. initiiert, 1993 und leicht variiert 2002 wiederholt; 201 w wurden Texte und Ablauf unter Benedikt XVI. stark verändert, um eine „synkretistische oder relativistische Auslegung des Vorgangs unmöglich“ zu machen. ${ }^{1}$ Im Gesprächskreis „Juden und Christen“ beim Zentralkomitee der deutschen Katholiken, in dem ich von 1997 bis 2013 Mitglied war, brach der Konflikt nicht nur bei den Vorarbeiten zu den mit der „Arbeitsgemeinschaft Juden und Christen beim Deutschen Evangelischen Kirchentag" gemeinsam zu verantwortenden Veranstaltungen bei den Ökumenischen Kirchentagen auf (Protestant/ inn/en drängten von ihrem Glaubensverständnis her auf klare Trennungen), sondern auch zwischen orthodoxen und allgemeinen Rabbinern.

Meine Grundthese lautet: Die Wirklichkeit ist vielfältig, ebenso ist aber auch die Multiperspektivität der Wahrnehmung der Wirklichkeit hermeneutisch vom einzelnen Theologen und von Repräsentanten ihrer Glaubensgemeinschaft zu akzeptieren. Diese Erkenntnis wurde in den vergangenen Jahrzehnten auch in den theologischen Wissenschaften nur mühsam gewonnen, wenn sie auch nicht überall angewendet wird. Im Glaubenskontext bedeutet dies: Die Voraussetzung jeden Dialogs ,auf Augenhöhe“ lautet: Den Anderen in seiner Überzeugung wahrnehmen, seinen Glauben kennen - und als seine Glaubensüberzeugung akzeptieren. „Was mich unbedingt angeht" (so die bekannte, in der Religionspädagogik stark rezipierte Formulierung des Philosophen und Theologen Paul Tillich), kann keinen absoluten Anspruch für alle erheben. Absolutheit und Unbedingtheit sind hermeneutisch auf ihre Implikationen und Konsequenzen für den jüdisch-christlichen Dialog zu bedenken. Bekenntnis, Unbedingtheit ist etwas anderes als Absolutheit mit exklusivem Anspruch. „Absolute Wahrheit“ gibt es nur in der jeweiligen Ver-

I Zur Entwicklung vgl. Siebenrock, Roman / Tück, Jan-Heiner (Hg.): Selig, die Frieden stiften. Assisi - Zeichen gegen Gewalt (Theologie kontrovers), Freiburg: Herder 2or2; ebd. 70-IOI kritisiert mit Recht auch Söding, Thomas: Friedensliebe und Glaubenstreue. Das Assisi-Gebet im Licht des Neuen Testaments, dass „das Assisi-Treffen 2011 am unteren Ende der Möglichkeiten geblieben [...] ist“" (Iоo). 
sprachlichung unter den Bedingungen der Zeit in ihrer Unbedingtheit für den Bekennenden. Glaube steht gegen Glauben eines anderen, nicht Glaube gegen Unglauben. Auch in der Bibel finden sich „nur“ Bekenntnisse, Zeugnisse, die den unbedingten Glauben der Verfasser bezeugen, nicht Texte mit ungeschichtlichem, absolutistischem Wahrheitsanspruch.

Dieses hermeneutische Prinzip wurde vor allem im Pontifikat Benedikt XVI. nicht immer verbalisiert und bei Erklärungen praktiziert. Ein erhellendes Beispiel bietet der Katechismus der (lateinisch-römischen) katholischen Kirche von 1993. Offen, auch in Tageszeitungen, ausgetragen wurde die Diskussion anhand der vatikanischen Erklärung „Dominus Jesus“ aus dem Jahre 2000 und des Dokumentes „Zu einigen Aspekten bezüglich der Lehre der Kirche“ vom Juni 2007. Ihnen zufolge sind die Kirchen, die aus der Reformation des 16. Jahrhunderts hervorgingen, „nicht Kirchen im eigentlichen Sinn“. Diese Feststellung hat zu Recht viele evangelische Christinnen und Christen getroffen. Kardinal Walter Kasper, damals Präsident des Päpstlichen Rates zur Förderung der Einheit der Christen und zugleich Vorsitzender der Kommission für die religiösen Beziehungen zum Judentum, differenzierte im Kontext vielfacher Kritik - auch von katholischer Seite - und stellte klar, „dass das Dokument [von 2007] nicht sagt, die evangelischen Kirchen seien keine Kirchen, sondern sie seien keine Kirche im eigentlichen Sinn, d. h. sie sind nicht in dem Sinn Kirchen, wie die katholische Kirche sich als Kirche versteht. " Kirchenamtlich wurde diese zutreffende hermeneutische Überzeugung nicht. Diese und andere Texte wie die durch Papst Benedikt XVI. 2008 revidierte und heftig kritisierte Karfreitagsfürbitte ${ }^{3}$ werden nicht erneut revidiert, was zu bedauern ist (zumal Benedikt XVI. selbst das Recht in Anspruch nahm, die vorgegebenen Texte von Johannes XXIII. und Paul VI. und die seit 1976 für das deutsche Sprachgebiet verpflichtende Fassung zu revidieren). Er sprach weiter „absolut“, als ob es die Anderen nicht gab. - Die Beispiele mögen andeuten, wie mein Erfahrungsraum in den vergangenen fünf Jahrzehnten war: geprägt von wissenschaftlicher Theologie, von amtlichen Erklärungen und vor allem von theologischen Gesprächen mit Jüdinnen und Juden. Dabei ist deutlich, dass meine Wahrnehmungen nur im Ineinander der verschiedenen Erfahrungsebenen zu verstehen sind.

2 Zitiert nach ZENIT vom II.7.2007. - Auch der Absolutheitsanspruch im oft zitierten Satz „Außerhalb der Kirche kein Heil“ ist nach demselben Prinzip hermeneutisch zu bewerten.

3 Zur Debatte vgl. Homolka, Walter / Zenger, Erich (Hg.): „... damit sie Jesus Christus erkennen“. Die neue Karfreitagsfürbitte für die Juden, Freiburg: Herder 2008; ausführlich: Frankemölle, Hubert / Wohlmuth, Josef (Hg.): Das Heil der Anderen. Problemfeld „Judenmission“ (QD 238), Freiburg: Herder 2010. 


\section{Erfahrungen im Kontext der Wissenschaften}

Im Zuge der neuzeitlichen Entwicklung wurden von den Kirchen, von der römisch-katholischen Kirche offiziell in den Texten des Zweiten Vatikanischen Konzils (1962-1965), moderne Erkenntnismethoden anerkannt, auch wenn dies von konservativen Kreisen, deren Theologie in der Regel auch antijüdisch geprägt ist, bis heute bekämpft wird. Ohne das Dekret über den Ökumenismus, ohne die Erklärung über das Verhältnis der Kirche zu den nichtchristlichen Religionen Nostra Aetate (mit dem wichtigen Artikel 4 über die Haltung zum Judentum), ohne die dogmatische Konstitution über die göttliche Offenbarung Dei verbum (mit der Unterscheidung von Gottes- und Menschenwort und der Freiheit, die biblischen Texte nach allen Regeln exegetischer Kunst auszulegen) und ohne die Erklärung über die Religionsfreiheit Dignitatis humanae ist die Geschichte der theologischen Wissenschaften als Voraussetzung des offenen christlich-jüdischen Gespräches unter Wissenschaftlerinnen und Wissenschaftlern, unter Kirchenvertretern und in ökumenischen Gesprächs- und Arbeitskreisen nicht zu denken. Auch wenn es von evangelischer Seite frühere und zeitgleich ebenso wichtige Erklärungen etwa zum Verhältnis Christentum-Judentum gibt ${ }^{4}$ haben sie einen anderen lehramtlichen Stellenwert. Die römisch-katholische Hierarchie hat Vorteile, wie sich an der Wirkung der Päpste Johannes XXIII. und Johannes Paul II. auf das jüdisch-christliche Verhältnis belegen lässt, aber auch Nachteile, wie bereits die oben angesprochenen Entscheide von Papst Benedikt XVI. verdeutlichen. ${ }^{5}$ Grundsätzlich gilt: Solche

4 Vgl. das Standardwerk von Rendtorff, Rolf / Henrix, Hans Hermann (Hg.): Die Kirchen und das Judentum. Dokumente von 1945 bis 1985, Paderborn: Bonifatius 1988; Henrix, Hans Hermann / Kraus, Wolfgang (Hg.): Die Kirchen und das Judentum. Dokumente von 1986 bis 2000, Paderborn: Bonifatius 200I; seither weitergeführt von Henrix, Hans Hermann / Boschki, Reinhold (Hg.): Die Kirchen und das Judentum. Dokumente von 2000 bis heute (Band 3. Digitale Version), in: http://www.nostra-aetate.uni-bonn.de/ kirchliche-dokumente/online-publikation-die-kirchen-und-das-judentum/online-publikation-die-kirchen-und-das-judentum [abgerufen am 3.6.20I4].

5 Begründet sind sie im jeweiligen Vorverständnis von Theologie. Wenn es amtlich wird, zeigt es entsprechende Wirkungen. Meine Befürchtungen - aufgrund meiner Studien in systematischer Theologie in Münster bei den damaligen Professoren Walter Kasper und Josef Ratzinger - haben sich nach der Wahl Ratzingers zum Papst umfassend bestätigt; vgl. Quo vadis, Benedicte? Theologische Prinzipien des Papstes und ihre kirchlichen Folgen, in: Compass-Infodienst für christlich-jüdische und deutsch-israelische Tagesthemen im Web. Online-Extra Nr. 57 vom 28.9.2007, in: http://www.compass-infodienst.de/Hubert_Frankemölle_Quo_vadis_Benedicte.3872.o.html [abgerufen am 3.6.20I4]. Vgl. auch meine Aufsatzsammlung: Das Evangelium des Neuen Testaments als Evangelium aus den heiligen 
lehramtlichen Erklärungen sind der freien Verfügbarkeit der einzelnen Theologin/ des einzelnen Theologen entzogen; man kann ipso facto nur in diesem Kontext schreiben - selbst in dem Wissen, dass kirchliche Texte einen unterschiedlichen Stellenwert bei evangelischen und katholischen Christinnen und Christen haben. Dennoch bleibt nüchtern zu konstatieren: In der Regel arbeiten beispielsweise bis auf Ausnahmen auch Bibelwissenschaftler/innen historisch-kritisch (das ist ihre Aufgabe) als Text- und Religionswissenschaftler/innen.

Ich selbst hatte in meinem wissenschaftlichen Werdegang das Glück, dass sich die 1968 aktuelle Frage nach soziologischen Strukturen neutestamentlicher Gemeinden nach meiner Überzeugung als Altphilologe und an Exegese Interessierten am Matthäusevangelium nicht beantworten ließ. Bei der Suche nach dem theologischen Konzept dieses Textes erwiesen sich die damaligen heiligen Texte des Judentums in Hebräisch und Griechisch als elementar. Das Matthäusevangelium erwies sich als jüdisch geprägte Relektüre vorgegebener Bundeskonzepte des Mitseins Gottes in Jesus Christus (vgl. Mt I,23; 17,I7; I8,20; 26,29.38.40 und 28,20). Man kann das erste Evangelium einen Pescher und Midrasch nennen, der Gattung nach eine jüdische Form der aktualisierenden Auslegung der Schriften. Das Matthäusevangelium ist der am stärksten jüdisch geprägte Text im Neuen Testament, ${ }^{6}$ falls man bereit ist, ihn nicht aus der Perspektive späterer christologischer Entfaltungen, sondern im Kontext frühjüdischer Glaubensvielfalt als „Erfüllung“ zu lesen. Nicht nur die vielen Reflexionszitate belegen, dass der Verfasser als Jude im Dialog mit den biblischen Texten steht und in deren Licht die Geschichte Gottes in „Jesus (= Ja/JHWH hilft)“ gemäß I,2I, dem „Immanuel (Gott-mit-uns) “ gemäß I,23 - als Zitat von Jes 7,8.Io.I4 LXX - erzählt (zur Bedeutung der Septuaginta/LXX, der griechischen jüdischen Bibel, siehe unten).

Christlich-jüdischer Dialog kann in diesem Licht mit Papst Johannes Paul II. unter Berufung auf Röm II,29 bei seiner Ansprache in Mainz am 17. November I980 wie folgt verstanden werden: „Die erste Dimension dieses Dialoges, nämlich die Begegnung zwischen dem Gottesvolk des von Gott nie gekündigten Alten Bundes und dem des Neuen Bundes, ist zugleich ein Dialog innerhalb unserer Kirche,

Schriften der Juden (Forum Christen und Juden Io), Münster: LIT 20I3, 45-80, 8I-98, 275-302, 35I-372.

6 Frankemölle, Hubert: Jahwe-Bund und Kirche Christi. Studien zur Form- und Traditionsgeschichte des „Evangeliums “ nach Matthäus (NTA Io), Münster: Aschendorff I974, ${ }^{2}$ 1984; die „Diskontinuität“ beim Begriff „Volk Gottes“ (ebd. 77, 193-220) wird von mir heute stärker auf die innerjüdische Vielfalt bezogen, auch bei „sein Volk“ in I,2I oder bei „meiner Kirche“ in I6,I8; vgl. dazu ders.: Matthäus-Kommentar I-II, Düsseldorf: Patmos I I994, ${ }^{2}$ I999, II 1997. 
gleichsam zwischen dem ersten und zweiten Teil ihrer Bibel." Nur unter dieser Voraussetzung ist die „zweite Dimension unseres Dialoges - die eigentliche und zentrale - die Begegnung zwischen den heutigen christlichen Kirchen und dem heutigen Volk des mit Mose geschlossenen Bundes. " 7 In der Regel versteht man „Dialog" nur im letzteren Sinn. Vorauslaufend muss jedoch eine hermeneutische Besinnung und Klärung stehen.

Diese verstärkte sich noch durch die in den I970er-Jahren aufkommende, aus der allgemeinen Linguistik stammende Erkenntnis, dass die Auslegung biblischer Texte von einer reinen Textwissenschaft zur Kommunikationswissenschaft zu erweitern sei. Damit kam in der pragmatischen und rezeptionsorientierten Exegese der Adressat des jeweiligen Textes in den Blick, der eine sinnstiftende Funktion erhielt - mit der Folge, dass theologischer Sinn vielfältig, da nicht objektiv im Text vorgegeben ist. Folglich haben befreiungstheologische Lesarten ebenso ihr Recht wie feministische. Von nun an konnte man grundsätzlich zwischen Erst- und Zweitadressat/inn/en bzw. (jüdischen) Erst- und (christlichen) Zweitleser/innen unterscheiden ${ }^{8}$. Erst so wurde die Basis für eine doppelte historisch-kritische Auslegung der jüdisch-hebräischen Bibel durch Jüdinnen/Juden und christliche Alttestamentler/innen, ebenso die Auslegung der jüdisch-griechischen biblischen Texte für eine zweite Leseweise durch jüdische und nichtjüdische Jesus-Christus-Anhänger/ innen und durch christliche Neutestamentler/innen begründet möglich. In heutiger Rezeption gehört zudem für Christinnen und Christen die Besinnung auf „Auschwitz" hermeneutisch unabdingbar dazu, worauf hier nur stichwortartig hingewiesen werden kann. Es gibt nicht nur faktisch eine Vielfalt jüdischer und christlicher Glaubensrichtungen von Anfang an, sie ist auch hermeneutisch bedingt. ${ }^{9}$

Es gibt verschiedene Leseweisen biblischer Texte. Diese Erkenntnis ist Vorbedingung für einen christlich-jüdischen Dialog , auf Augenhöhe“. Mit Recht wird ein Satz aus der Erklärung der Päpstlichen Bibelkommission „Das jüdische Volk und

7 Rendtorff/ Henrix (Hg.): Die Kirchen und das Judentum, 76.

8 Zur Begründung vgl. Dohmen, Christoph: Das Alte Testament als Altes Testament verstehen, in: Dohmen, Christoph / Stemberger, Günter: Hermeneutik der Jüdischen Bibel und des Alten Testaments (Kohlhammer Studienbücher Theologie I,2), Stuttgart: Kohlhammer 1996, 192-209 mit Verweis auf meinen Sammelband: Biblische Handlungsanweisungen. Beispiele pragmatischer Exegese, Mainz: Matthias Grünewald I983 und auf meinen Kommentar zum Matthäusevangelium; zur Begründung rezeptionsgeschichtlicher Exegese vgl. ebd. I 34-76.

9 Vgl. Frankemölle, Hubert: Vielfalt von Anfang an. Option für den katholisch-evangelisch-jüdischen Dialog, in: Ders.: Das Evangelium des Neuen Testaments als Evangelium aus den heiligen Schriften der Juden (Forum Christen und Juden IO), Münster: LIT 20I3, 99-I2I. 
seine heilige Schrift in der christlichen Bibel“ vom 24. Mai 200 I viel zitiert. Er lautet: „Die Christen können und müssen zugeben, dass die jüdische Lesung der Bibel eine mögliche Leseweise darstellt, die sich organisch aus der jüdischen Heiligen Schrift der Zeit des Zweiten Tempels ergibt, in Analogie zur christlichen Leseweise, die sich parallel entwickelte. Jede dieser beiden Leseweisen bleibt der jeweiligen Glaubenssicht treu, deren Frucht und Ausdruck sie ist. So ist die eine nicht auf die andere rückführbar. “ ${ }^{10}$ Zur Begründung heißt es direkt vorher: „Wenn der christliche Leser wahrnimmt, dass die innere Dynamik des Alten Testaments in Jesus gipfelt, handelt es sich hier um eine rückschauende Wahrnehmung, deren Ausgangspunkt nicht in den Texten als solche liegt, sondern in den Ereignissen des Neuen Testaments, die von der apostolischen Predigt verkündigt worden sind. So darf man nicht sagen, der Jude sähe nicht, was in den Texten angekündigt worden sei.“ Wo christliche Theologinnen und Theologen diese Erkenntnisse im Hinblick auf den Glauben an Jesus Christus deutlich benennen, gibt es kirchenamtlich Kritik. So etwa zum Satz der Erklärung „Nein zur Judenmission - Ja zum Dialog zwischen Juden und Christen“ des Gesprächskreises „Juden und Christen“ beim Zentralkomitee der deutschen Katholiken (s. u. 4.I) aus dem Jahre 2009: „Weil Gottes Bund Israel bereits das Heil erschlossen hat, braucht die Kirche nicht um das Heil Israels besorgt zu sein, die Juden nicht zum christlichen Glauben zu bekehren und sie nicht um ihres Heiles willen zur Taufe zu veranlassen. "Mit Erich Zenger, dem allzu früh verstorbenen (1939-20I0), wohl engagiertesten katholischen Theologen auf allen Ebenen, nicht zuletzt in der Wissenschaft, lässt sich zu Recht noch deutlicher formulieren: „Aus dieser lehramtlichen Position ergibt sich unweigerlich die Feststellung: Das verweigerte Ja Israels zu Jesus von Nazaret kann von Christen als Treue der Juden zu ihrer ureigenen Tradition verstanden werden. ${ }^{\text {11 }}$

Io Das jüdische Volk und seine Heilige Schrift in der christlichen Bibel: 24. Mai 200I / Päpstliche Bibelkommission (Verlautbarungen des Apostolischen Stuhls 152), hg. v. Sekretariat der Deutschen Bischofskonferenz, Bonn: Sekretariat der Deutschen Bischofskonferenz 200I, 44. - Die Kommission tagte unter Vorsitz von Kardinal Ratzinger, der ebd. 3-8 ein restriktives Vorwort schrieb, demzufolge die Christologie „den Deutungsschlüssel“ für das Verständnis der alttestamentlichen Texte liefert (ebd. 5). Zu einer angemessenen Lesehilfe des Dokumentes vgl. Dohmen, Christoph (Hg.): In Gottes Volk eingebunden. Christlich-jüdische Blickpunkte zum Dokument der Päpstlichen Bibelkommission „Das jüdische Volk und seine Heilige Schrift in der christlichen Bibel“", Stuttgart: Kath. Bibelwerk 2003; zu einem Verständnis der Christologie, die den Glauben der Juden bejaht, vgl. ebd. 37-50 meinen Beitrag „Die heiligen Schriften der Juden und die Christologie“; ausführlicher ders.: Jesus Christus/Christologie. A. Bibeltheologisch, in: NHbthG 2 (2005) 254-272.

II Zenger, Erich: Das Nein heutiger Juden zu Jesus als ihrem Retter ernst nehmen, in: Homolka / Zenger (Hg.): „... damit sie Jesus Christus erkennen“, 205-22I, 216. Zu seinen 
Hermeneutisch gilt allgemein: Historisch-kritische Exegeten stellen mit Recht seit langem fest, dass Menschen im Lichte neuer Erfahrungen neue Bekenntnisse formulieren, wie dies bei der ständigen Aktualisierung der biblischen Texte bereits der Fall ist. Es gibt nicht nur eine ständige Bibelauslegung innerhalb der Bibel, ${ }^{12}$ sondern auch ganz neue Erfahrungen im Glauben an Gottes Wirken.

Im Grunde wurde diese Hermeneutik von jüdischen Theologen zur Zeit des Neuen Testaments gemäß dem Grundsatz nach Ps 62,I2 („Eines hat Gott gesagt, zweierlei habe ich gehört") und der These von den vielfältigen Bedeutungen der Schrift (4-, I2- oder 72fach) in der rabbinischen Auslegung von Jer 23,29 (b. Sanhedrin 34a: „So kann auch ein einziger Schriftvers viele verschiedene Lehren vermitteln") erkannt. ${ }^{13}$ Der Text wurde immer als vieldeutig verstanden, erst der rezipierende Leser/die rezipierende Leserin - allein und als Glaubensgemeinschaft - eröffnet verschiedene, begründete Leseweisen. ${ }^{14}$

Meine Wahrnehmungen zu wissenschaftlichen Aspekten im christlich-jüdischen Dialog blieben unvollständig, wenn nicht auf die elementare Bedeutung des Griechisch sprechenden und schreibenden Judentums seit dem 4./3. Jahrhundert v. Chr. hingewiesen wird. Seine Schriften sind nicht ein „Betriebsunfall“, wie mir mit allem Nachdruck jüdischerseits bei einem Podiumsgespräch 1986 beim Katholikentag in Aachen gesagt wurde. Im Lichte der oben angedeuteten Hermeneutik kann nur „in der rückschauenden Wahrnehmung “ jüdische Bibel mit Hebräischer Bibel identifiziert werden, wie im christlich-jüdischen Dialog engagierte Alttestamentler/ innen bis heute formulieren. Fakt ist: In der Diaspora, aber auch im Mutterland, wurde für die dort lebenden Jüdinnen und Juden die griechische Übersetzung biblischer Bücher aus dem Hebräischen/Aramäischen erforderlich, ebenso die Abfassung original griechischer Schriften durch hellenistische Juden, da dort und im Mutterland Griechisch gesprochen wurde. Im Judentum gibt es - verkürzt gesprochen - einen doppelten Ausgang der frühen Glaubenserfahrungen: in Hebräisch/ Aramäisch, rezipiert und tradiert durch Jesus von Nazaret sowie durch die rabbinischen Theologen und - religionsgeschichtlich gleichberechtigt - in Griechisch, rezipiert und transformiert durch Paulus und die anderen Verfasser neutestamentlicher Schriften und durch die Kirchenväter. Alle Verfasser der neutestamentlichen

zahlreichen Veröffentlichungen vgl. seine Homepage. 2009 wurde Erich Zenger mit der Buber-Rosenzweig-Medaille geehrt.

Vgl. Reventlow, Henning Graf: Epochen der Bibelauslegung. I: Vom Alten Testament bis Origenes, München: C. H. Beck 1990, II-23.

I3 Vgl. Petuchowski, Jakob J.: Wie unsere Meister die Schrift erklären. Beispielhafte Bibelauslegung aus dem Judentum, Freiburg: Herder 1982.

Zur Begründung vgl. Dohmen / Stemberger: Hermeneutik. 
Schriften stehen in dieser Sprachtradition des hellenistischen Judentums. Ohne deren Bekenntnisse zum Gottesbild oder etwa zur Schöpfung und zur Auferweckung sind die neutestamentlichen Texte nicht zu verstehen. ${ }^{15}$ Ein angemessener christlich-jüdischer Dialog ist nur unter Anerkennung dieser Voraussetzungen zu führen, auch wenn die Überzeugungen der jüdischen und nichtjüdischen Anhänger/innen Jesu Christi für andere Jüdinnen und Juden nicht übernommen werden können.

Hier gibt es natürlich Schwierigkeiten bei jüdischen und christlichen Partnerinnen und Partnern, bei Christinnen und Christen, vor allem bei jenen, die Mitglieder von Kirchen sind, die aus der Reformation hervorgegangen sind. Wissenschaftler/innen, auch Alttestamentler/innen, sind davon nicht auszunehmen. Aus der Situation im I6. Jahrhundert ist die damalige Entscheidung, zu den Quellen zu gehen, einsichtig. Jedoch: „Die Reduzierung des Alten Testaments auf den Umfang der ,Hebräischen Schriften ' durch einige Reformationskirchen ist eine kirchlich-theologische Fehlentscheidung, die auf das Wissenschaftsideal der Reformationszeit zurückgeht. "16 Natürlich sind beim Gespräch zwischen Judentum und Christentum über hebräische/aramäische Texte des ersten Teils der gemeinsamen Bibel die Verständnisschwierigkeiten geringer (zu Fragen des Friedens, der Ethik, der Deutung von Geschichte, zum Messias/Christos, ...). Ein wirklich christlich-jüdisches Gespräch heute über den jeweiligen Glauben des Anderen und seine biblischen Wurzeln ist dies nicht. Hier gibt es nach meinen Erfahrungen noch reichlich Bedarf, historisch und hermeneutisch Erkanntes in den Dialog einzubringen. Natürlich ist er nicht auf allen Ebenen durchzuführen, schon gar nicht auf Ortsebene. Das Gespräch auf Ortsebene zwischen jüdischen und christlichen Gemeindemitgliedern sehe ich durchaus nüchtern.

Die Voraussetzungen und Möglichkeiten an der Universität sind anders gelagert. Die gute Zusammenarbeit zwischen den Dozent/inn/en in den Instituten der evangelischen und katholischen Theologie an der Universität in Paderborn ermöglichte nicht nur eine christlich-ökumenische Theologie, sondern ist auch die Voraussetzung für Vorlesungs- und Seminarangebote in Judaistik, jüdischer und muslimischer Theologie, parallel dazu aber auch für ein interreligiöses Seminar zu Christentum, Judentum und Islam im jeweiligen Wintersemester. Die theo-

I5 Zu sprach- und theologiegeschichtlichen Entwicklungen vgl. Frankemölle, Hubert: Frühjudentum und Urchristentum. Vorgeschichte - Verlauf - Auswirkungen (4. Jahrhundert v. Chr. bis 4. Jahrhundert n. Chr.) (Kohlhammer Studienbücher Theologie 5), Stuttgart: Kohlhammer 2006; zu den oben genannten Themen ebd. I28-221.

I6 So als evangelischer Theologe zu Recht Walter, Nikolaus: Zum Problem einer „Biblischen Theologie“, in: Dohmen, Christoph / Söding, Thomas (Hg.): Eine Bibel - zwei Testamente. Positionen biblischer Theologie, Paderborn: Schöningh 1995, 307-317, 309. 
logische Begründung dieser Trennung war die Identität der jüdischen mit der christlichen Bibel im Alten Testament (bei unterschiedlicher Leseweise), folglich das exzeptionelle Verhältnis von Neuem und Altem Testament, von Christentum und Judentum, während im Koran biblische Motive in das eigene, in sich geschlossene theologische Konzept integriert wurden. Die Vertreterinnen und Vertreter monotheistischer Religionen können Gespräche zum gegenseitigen Kennenlernen führen, ob dies ein „abrahamischer Dialog“, das heißt, ein wirklicher Dialog ,auf Augenhöhe" genannt werden kann, sei dahingestellt. Der Monotheismus und der Glaube Abrahams verbinden und verpflichten zur Zusammenarbeit (allein schon aufgrund der vier Millionen Muslime in Deutschland), das eigene, in sich geschlossene muslimische Offenbarungsverständnis sollte Grund dafür sein, zwischen jüdisch-christlichem und jüdisch/christlichem und muslimischem Dialog zu unterscheiden.

\section{Erfahrungen auf Ortsebene}

Auf Ortsebene spricht man zu Recht von „Gesellschaften für christlich-jüdische Zusammenarbeit", so auch in Paderborn. Die Motivation zur Gründung im Jahre 1987 lieferten einwöchige Fortbildungskurse für Priester aller Weihejahrgänge der Diözese (deren Leiter nahmen nicht teil) zum Thema Christologie und Eschatologie anhand des neuen Katechismus. ${ }^{17}$ Das elementare Nichtwissen hinsichtlich der jüdischen Wurzeln des christlichen Glaubens motivierte zur Gründung einer „Gesellschaft für christlich-jüdische Zusammenarbeit“. Ziel war die konkrete Zusammenarbeit mit der jüdischen Gemeinde (Gedenkstunden am 9. November und 27. Januar, Unterstützung bei liturgischen Feiern in der Synagoge, christlich-jüdische Gemeinschaftsfeiern in christlichen Kirchen, Einladung an ehemalige jüdische Mitbürger ...) sowie das gemeinsame Engagement für deutsch-jüdische Erinnerungsarbeit (Vorträge, Nahost-Gesprächskreis, Straßenbenennungen, Stelen, Mahnmal, Dokumentationen, Ausstellungen, musikalische Angebote, Rundgänge auf jüdischen Spuren, Tagesfahrten oder mehrtägige Fahrten nach Israel, in das Baltikum, die Niederlande, Belgien, nach Auschwitz ...) und gemeinsames Eintreten gegen rassistische und antijüdische Tendenzen (u. a. Verhinderung von Nazi-Aufmärschen, Anzeigen). Eine Schwerpunktbildung waren Vortragsreihen zu deutsch-jüdischen und christlich-jüdischen Themen. ${ }^{18}$ Wer je eine derartige Ge-

I7 Deutsche Bischofskonferenz (Hg.): Katholischer Erwachsenen-Katechismus. Das Glaubensbekenntnis der Kirche, Kevelaer: Butzon \& Bercker ${ }^{3}$ I985.

I8 Zu den Veröffentlichungen in Buchform vgl. die Homepage der Gesellschaft unter: http:// 
sellschaft gegründet und als geschäftsführender Vorsitzender 25 Jahre geleitet hat, wird neben der zeitintensiven Arbeit dankbar die unendlichen Bereicherungen bestätigen. Aus dem früheren Engagement Einzelner wurde eine gesellschaftliche Kraft, die das Gesicht der Stadt veränderte, nicht erst durch die bundesweite Ausrichtung der „Woche der Brüderlichkeit“ im Jahre 1997. Die Reaktionen vonseiten der Kirche und der bürgerlichen Gesellschaft waren sehr gemischt; im Vorfeld der Diskussionen um die Errichtung eines repräsentativen Mahnmals I993 gab es heftige öffentliche Kontroversen, sogar eine Morddrohung. Blieb die jüdische Gemeinde vorher unter sich, so wurde sie jetzt verstärkt wahrgenommen. Nach 25 Jahren kann die Gesellschaft „eine eindrucksvolle Bilanz vorweisen“ ${ }^{19}$ Der damalige Vorsitzende der kleinsten jüdischen Gemeinde in NRW, Erwin Angreß, ein Überlebender von Auschwitz, war zugleich jüdischer Vorsitzender im Verein, dazu waren zeitweilig zwei weitere jüdische Mitglieder im Beirat. Die Zusammenarbeit kann man schlicht harmonisch nennen.

Seit den 1990er-Jahren, nach dem Fall der Berliner Mauer und durch die $\mathrm{Zu}$ wanderung von jüdischen Migrant/inn/en aus den GUS-Staaten, vorher schon durch Kontingentflüchtlinge, änderte sich wie in anderen Städten (Gespräche bei zahlreichen Vorträgen bestätigten dieses Faktum) mit einiger Verzögerung auch die Struktur der Paderborner jüdischen Gemeinde. Für das Überleben der jüdischen Gemeinden war diese Entwicklung wie ein Wunder, stieg doch die Mitgliederzahl im wiedervereinigten Deutschland von ca. 25.000 auf über Ioo.00o. Neben der Einheitsgemeinde bildeten sich vielfach unter Geburtswehen liberale neben orthodoxen Gemeinden. Wo dies zahlenmäßig nicht möglich war, verstand man sich orthodox (so auch in Paderborn). Die mit der Immigration einhergehenden Probleme (unverschuldet fehlendes Glaubenswissen, verschiedene religiöse Richtungen) bestehen bis heute. Neben den deutschen Jüdinnen und Juden (und einigen aus Israel) waren es in Paderborn vermehrt russische Jüdinnen und Juden, die in der Folgezeit auch das Leben in der jüdischen Gemeinde bestimmten, so dass etwa im Vorstand der jüdischen Gemeinde zeitweilig russisch gesprochen wurde; von nun an wurde jüdisch-christliche Zusammenarbeit als Sache der Christinnen und Christen bezeichnet, und folglich wurde Anfang 2008 die Mitarbeit im Vorstand eingestellt. Ein zaghafter Neuanfang der Zusammenarbeit zeichnet sich nur mühsam ab. Diese Veränderung im christlich-jüdischen bzw. deutsch-russischen

www.gcjz-paderborn.de/ueber-uns/veroffentlichungen/ [abgerufen am 3.6.20I4].

I9 So Bürgermeister Heinz Paus in seinem Grußwort zu „Für ein erneuertes Verhältnis von Christen und Juden. 25 Jahre Gesellschaft für Christlich-Jüdische Zusammenarbeit Paderborn e. V.“, Paderborn: Gesellschaft für Christlich-Jüdische Zusammenarbeit 2oI2, 9. 
Verhältnis habe ich nüchtern wahrgenommen; die Motive dazu sind mannigfach, am wenigsten meiner Meinung nach dem christlich-jüdischen Glauben im engeren Sinn zu verdanken.

\section{Erfahrungen auf nationaler Ebene}

Eigene Vortragstätigkeit und Teilnahme an christlich-jüdischen Tagungen ${ }^{20}$ und Konferenzen, etwa der Gesellschaften für christlich-jüdische Zusammenarbeit, erweiterten seit Ende der I970er-Jahre ständig den Radius meiner Wahrnehmungen in unterschiedlicher Weise.

\section{I Erfahrungen im Gesprächskreis „Juden und Christen“ "beim Zentralkomitee der deutschen Katholiken ( $Z d K)$}

Diesem Gesprächskreis gehörte ich von 1997 bis 2013 an. Gegründet wurde er 197I, zehn Jahre nach der Gründung der Arbeitsgemeinschaft „Juden und Christen“ beim Deutschen Evangelischen Kirchentag. Er hat wie diese primär die Aufgabe, das christlich-jüdische Programm der Katholiken- bzw. Kirchentage vorzubereiten, beide Kreise wollen aber auch Fragen des christlich-jüdischen Verhältnisses öffentlich machen, auch durch Stellungnahmen und Fachtagungen sowie durch Reisen Kontakte zu jüdischen Gemeinden in anderen Ländern pflegen. Ohne die Erklärung Nostra Aetate des Zweiten Vatikanischen Konzils von 1965 wäre der Gesprächskreis nicht gegründet worden, konnte aber wie auf evangelischer Seite an vielfältige christlich-jüdische Initiativen Einzelner und von kleinen Gruppen anknüpfen. ${ }^{21}$ Das Besondere am Gesprächskreis

20 Lebhaft in Erinnerung ist mir noch die christlich-jüdische Tagung in Morschach/Schweiz vom 3.-7.II.I982, in der ich erstmalig international wichtige jüdische Gesprächspartner kennenlernen konnte, u. a. den unvergesslichen Jakob J. Petuchowski (I925-I99I), mit dem ich später etliche Tagungen gemeinsam bestritt und freundschaftlich verbunden war; zu den Tagungsvorträgen vgl. Falaturi, Abdoldjavad / Strolz, Walter / Talmon, Shemaryahu (Hg.): Zukunftshoffnung und Heilserwartung in den monotheistischen Religionen (Veröffentlichungen der Stiftung Oratio Dominica 9), Freiburg: Herder 1983; zu einem eigenen Beitrag siehe Frankemölle, Hubert: Der Glaube an die Wiederkunft Christi als Vollendung des Gottesreiches. Überlegungen zum Grund christlicher Hoffnung, in: ebd., 8I-I2O.

2I Vgl. etwa Erler, Hans / Koschel, Ansgar (Hg.): Der Dialog zwischen Juden und Christen. Versuche des Gesprächs nach Auschwitz, Frankfurt: Campus 1999; Sirsch, Rudolf (Hg.): Bilanz und Perspektiven des christlich-jüdischen Dialogs (epd Dokumentation), Frankfurt: Gemeinschaftswerk der evangelischen Publizistik 2005; zu einer kurzen Skizze des Gesprächskreises von mir vgl. ebd. 25-29, sowie zu einem Überblick: Zum jüdisch-christlichen Dialog in Deutschland nach dem Holocaust bis zu Papst Johannes Paul II, in: Ders. 
beim ZdK umschreibt Hanspeter Heinz, der seit 1974 dessen Vorsitzender ist, so: „Nirgends sonst in der Welt hat das höchste Laiengremium eines Landes [gemeint ist das ZdK: H.F.] ein Dialogorgan von Juden und Christen mit dem Ziel gegründet, die gegenseitigen Beziehungen zu fördern. Einzig ist der Gesprächskreis auch deshalb, weil er von Anfang an das Wagnis eines theologischen Gespräches unternommen hat", dessen Ergebnisse nach intensiven Diskussionen - auch jeweils in einer zweitägigen Klausurtagung - als eigene Stellungnahmen mit Zustimmung des ZdK-Präsidiums veröffentlicht werden. ${ }^{22}$ Dies ist ein Alleinstellungsmerkmal dieses Kreises weltweit, da alle anderen Kommissionen im Auftrag und mit Zustimmung der „Amtskirche“ arbeiten. Bei den Veröffentlichungen zählen nur das eigene Bekenntnis und die vorgetragenen Argumente. Dem Kreis gehören in der Regel je ca. Is jüdische und katholische Personen aus vielfältigen Berufen an, ${ }^{23}$ natürlich auch Professorinnen und Professoren verschiedener Fachgebiete und Rabbinen der allgemeinen Rabbinerkonferenz (so fast seit Beginn deren Vorsitzender Dr. Henry Brandt, jetzt Augsburg, seit Jahrzehnten ein wahrer Brückenbauer auf allen Ebenen und in zahlreichen Funktionen), aber seit 2005 auch Rabbiner der Orthodoxen Rabbinerkonferenz (Julien-Chaim Soussan, jetzt Frankfurt; zu den zeitlichen Gründen siehe unten 4.3). In großem Vertrauen redet man face to face über schwierigste theologische Themen so lange, bis der Eine den Anderen versteht. In diesem Gremium wird das christlich-jüdische Gespräch wirklich zum Dialog. Die Erfahrungen, die ich in diesem Gremium gemacht habe, wird man kaum anderswo so machen können; dafür bin ich sehr dankbar.

(Hg.): Juden und Christen im Gespräch über „Dabru emet - Redet Wahrheit“, Paderborn: Bonifatius 2005, 9-37.

$22 \mathrm{Zu}$ ihrer Dokumentation und einigen Statements vgl. Heinz, Hanspeter (Hg.): Um Gottes willen miteinander verbunden. Der Gesprächskreis „Juden und Christen“ beim Zentralkomitee der deutschen Katholiken (Forum Christen und Juden I), Münster: LIT 2004; zum Zitat ebd. 8.

23 Vgl. die Homepage des Gesprächskreises. - Unvergesslich in Erinnerung bleiben wird nicht nur mir Ernst Ludwig Ehrlich (I92I-2007), der uns allen zu wesentlichen Einsichten verholfen hat und Freundschaften initiieren konnte; zu diesem bedeutenden jüdisch-christlichen Brückenbauer und seinen gesammelten Beiträgen vgl. Heinz, Hanspeter / Henrix, Hans Hermann (Hg.): „Was uns trennt, ist die Geschichte“. Ernst Ludwig Ehrlich - Vermittler zwischen Juden und Christen, München: Neue Stadt 2008. Unvergesslich bleiben wird allen auch der prophetisch-kämpferische Erich Zenger. Informative Berichte aus der Orts- und Weltkirche lieferte bestens informiert kontinuierlich Hans Hermann Henrix, der all die Jahre auch Mitglied der Unterkommission für die religiösen Beziehungen zum Judentum der Deutschen Bischofskonferenz (DBK) und der gleichnamigen vatikanischen Kommission war und als Berater von Bischof Heinrich Mussinghoff sowie von Walter Kardinal Kasper gelten darf. 
In der Zeit meiner Mitgliedschaft konnten, wie bereits die Titel andeuten, als Antworten auf vatikanische Erklärungen von Benedikt XVI., Papst seit April 2005, u. a. die folgenden Texte veröffentlicht werden:

- am 6. Juli 1998: Nachdenken über die Shoah. Mitschuld und Verantwortung der katholischen Kirche. Zur Erklärung der „Vatikanischen Kommission für die religiösen Beziehungen zu den Juden“" vom I6. März 1998, ${ }^{24}$

- am 2r. Juli 2000: Papst Pius IX. und die Juden, ${ }^{25}$

- am I3. April 2005: Juden und Christen in Deutschland. Verantwortete Zeitgenossenschaft in einer pluralen Gesellschaft,

- am 29. Februar 2008: Neue Belastung der christlich-jüdischen Beziehungen - Zur Karfreitagsfürbitte „Für die Juden“ in der Fassung des außerordentlichen Ritus von 2008,

- am 9. März 2009: Nein zur Judenmission - Ja zum Dialog zwischen Christen und Juden. ${ }^{26}$

Von allen Erklärungen des Gesprächskreises seit seinem Entstehen erregte vor allem die letzte zu der Frage, ob Jüdinnen und Juden, wenn sie ins Heil kommen wollen, zunächst Christinnen bzw. Christen werden müssen, die größte Breitenwirkung, erntete aber auch Kritik, so auch von Kardinal Kasper und dem Vorsitzenden der Deutschen Bischofskonferenz, Karl Kardinal Lehmann. Die Erklärung konkretisiert die allgemein anerkannten hermeneutischen Prinzipien, die oben skizziert wurden ( $\mathrm{I}-2)$, und spricht sie in aller Offenheit und Öffentlichkeit aus. Indirekt ging es bei der Kritik nach meiner Wahrnehmung um das Faktum, dass in aller Öffentlichkeit päpstliche Positionen kritisiert und päpstliche Autorität in Frage gestellt wurden. Direkt wurden dem Text theologische Schwächen vorgeworfen, aber nicht argumentativ vertieft. Die Hermeneutik der Unbedingtheit, die Einbindung der Thesen in die Theologie des Zweiten Vatikanischen Konzils und vor allem die biblische Begründung, bei der zum ersten Mal bei einer christlich-jüdischen Erklärung des ZdK zur Bedeutung Jesu Christi auch die Vorstellungen des griechischsprachigen Judentums, ohne die die Bekenntnisse des Neuen Testaments nicht gedacht werden können, einbezogen und von den jüdischen, auch von den orthodoxen Teilnehmern und Teilnehmerinnen, anerkannt wurden, sind bis heute fraglos gültig. Ein solches dialogisches Einverständnis konnte nur im jahrelang ge-

$24 \mathrm{Zu}$ den Texten vgl. Henrix / Kraus (Hg.): Die Kirchen und das Judentum, IIO-II9 und 392-399; zur Zdk-Erklärung vgl. Heinz (Hg.): Um Gottes willen, 90-99.

25 Vgl. Heinz (Hg.): Um Gottes willen, I38-I4I.

26 Die letzten Erklärungen erschienen als Broschüren, hg. vom Präsidium des ZdK und im Internet; vgl. Henrix / Boschki (Hg.): Die Kirchen und das Judentum. Zu Stellungnahmen aus dem Gesprächskreis vgl. die in Anm. 3 genannten Bücher. 
wachsenen Vertrauen, dass die katholischen Mitglieder nicht noch einen „Joker im Ärmel hätten “, wie formuliert wurde, heranreifen. In diesem Kreis, das ist meine Erfahrung, kann man offen zentrale Themen des jüdischen und christlichen Glaubens gegenseitig bekennen und sie in Aktualisierung der heiligen Schriften diskutieren und für die Öffentlichkeit formulieren. Das macht seine Einzigartigkeit aus.

Mit Recht werden der Gesprächskreis und sein Vorsitzender Hanspeter Heinz im Jahre 2015 mit der Buber-Rosenzweig-Medaille geehrt. Mitglieder des Gesprächskreises führten das Gespräch über die „Judenmission“ in einem voluminösen Sammelband weiter, zu dem jüdische und evangelische Theologinnen und Theologen bereitwillig beitrugen, ${ }^{27}$ sind doch die Themen keineswegs auf die katholische Kirche beschränkt, sondern vielfach in den evangelischen Kirchen viel früher und klarer, aber auch kontroverser beantwortet worden. Die hierarchische Struktur der römisch-katholischen Kirche bedingt aber meine subjektive Sicht und auch meine unmittelbaren Wahrnehmungen und Stellungnahmen, auch wenn man als Bibeltheologe gelernt hat, davon frei historisch-kritisch (also unbestimmt durch kirchliche Dogmen) Texte, auch kirchenamtlicher Art, auszulegen.

\subsection{Wahrnehmungen im Vorstand des DKR}

Der Deutsche Koordinierungsrat der Gesellschaften für Christlich-Jüdische Zusammenarbeit wurde 1949 gegründet als bundesweiter Zusammenschluss von damals fünf (im Jahr 20I4 88) Gesellschaften vor Ort. Die Ziele sind politisch und gesellschaftlich orientiert, schließen aber auch theologische und kirchenpolitische Aspekte ein. Ihre Mitglieder stammen aus den Gesellschaften vor Ort; die drei Vorsitzenden müssen, die anderen Mitglieder im Beirat sollen möglichst paritätisch jüdisch und christlich, evangelisch und katholisch, sein. Auf den jährlichen Vollversammlungen geht es entsprechend den Vertretern und Vertreterinnen der örtlichen Gesellschaften auch schon mal etwas chaotischer zu - zumal beim Thema Frieden zwischen Israel und den Palästinenser/inne/n. Das Spektrum der Arbeit gleicht in Begegnungen und Vorträgen generell dem auf Ortsebene (s. o. 3), ist aber dabei natürlich weit hochrangiger. Vor allem die seit 195I veranstaltete „Woche der Brüderlichkeit" (die Eröffnungsveranstaltung wird jeweils im Fernsehen übertragen) und die seit 1968 praktizierte Verleihung der „Buber-Rosenzweig-Medaille“ an Einzelne und Institutionen, die sich besonders um die Verständigung zwischen Christen und Juden verdient gemacht haben, können den erweiterten Horizont

27 Unter Mitarbeit von weiteren Autorinnen und Autoren, dankenswerter Weise auch von Kardinal Lehmann: Frankemölle / Wohlmuth (Hg.): Das Heil der Anderen, I42-I70. 
der anfallenden Arbeiten, aber auch den meiner Erfahrungen andeuten. Als einzigem katholischen Fachtheologen oblag es mir, während meiner Arbeit in seinem Vorstand von 2000 bis 20I0, vor allem seit 2005, zahlreiche Entwürfe für Briefe an den Vatikan zu verfassen.

Der DKR ist in seiner gesellschaftspolitischen Bedeutung aus Deutschland nicht mehr wegzudenken und wurde im Verlauf der Jahre auch immer stärker gewürdigt. ${ }^{28}$ Das bestärkte auch die Mitglieder im Vorstand, in ihrem Engagement nicht nachzulassen. Er arbeitet nicht isoliert. Angeregt wurde er nach der nationalsozialistischen Zeit in seiner Gründung durch Nationale Räte für Christlich-Jüdische Zusammenarbeit in den USA, in Großbritannien, Frankreich und der Schweiz, nicht weniger durch andere europäische Initiativen und Institutionen, auch der Kirchen (etwa des Vatikans oder im Ökumenischen Rat der Kirchen). Von nachhaltiger Wirkung waren die „IO Seelisberger Thesen“, bereits im August 1947 von einer internationalen Konferenz von Christen beider Konfessionen und Juden veröffentlicht. Die zwölf Thesen „Zeit zur Neu-Verpflichtung“ von Berlin im Juli 2009 verstehen sich als ihre Aktualisierung (auch unter Mitwirkung des DKR); in einem feierlichen Akt wurden sie von Vertretern und Vertreterinnen von 22 Nationen unterschrieben. ${ }^{29}$ Wie stark die internationalen Verflechtungen sind, zeigt auch die Mitarbeit von Michael A. Signer (1945-2009), einem der im jüdisch-christlichen Dialog in den USA profiliertesten Rabbiner, der einer der vier Verfasser der weltweit beachteten jüdischen Erklärung „Dabru Emet. Eine jüdische Stellungnahme zu Christen und Christentum" vom II. September 2000 war $^{30}$ - zugleich langjähriges Mitglied im Gesprächskreis „Juden und Christen“ beim ZdK.

28 Vgl. Münz, Christoph / Sirsch, Rudolf W. (Hg.): „Wenn nicht ich, wer? Wenn nicht jetzt, wann?" Zur gesellschaftspolitischen Bedeutung des Deutschen Koordinierungsrates der Gesellschaften für Christlich-Jüdische Zusammenarbeit (DKR), Münster: LIT 2004; Dies. (Hg.): „Denk an die Tage der Vergangenheit - Lerne aus der Geschichte“. 40 Jahre Buber-Rosenzweig-Medaille (Forum Christen und Juden 7), Münster: LIT 2009 (mit Vorstellung der Preisträger); Dies. (Hg.): „... damit es anders anfängt zwischen uns allen.“ 60 Jahre Woche der Brüderlichkeit, Münster: LIT 20 I2.

29 Zu den Seelisberger Thesen vgl. Rendtorff / Henrix (Hg.): Die Kirchen und das Judentum, 646f.; zu den Berliner Thesen vgl. Konrad-Adenauer-Stiftung (Hg.): Zeit zur Neu-Verpflichtung. Christlich-Jüdischer Dialog 70 Jahre nach Kriegsbeginn und Shoah, St. Augustin: Konrad-Adenauer-Stiftung 2009 (deutsch und englisch).

30 Vgl. Frankemölle, Hubert (Hg.): Juden und Christen im Gespräch über „Dabru emet Redet Wahrheit“, Paderborn: Bonifatius 2005; vgl. auch als Ergebnis einer Klausurtagung des Gesprächskreises ,Juden und Christen“ beim ZdK: Dirscherl, Erwin / Trutwin, Werner (Hg.): Redet Wahrheit - Dabru Emet. Jüdisch-christliches Gespräch über Gott, Messias und Dekalog (Forum Christen und Juden 4), Münster: LIT 2004. 
Die Mitarbeit im DKR und die bundesweit beachteten Veranstaltungen mit hohen kirchlichen und politischen Repräsentanten weiteten den eigenen Blick, auch wenn ich mich aufgrund der eigenen „Ressourcen“ international nicht engagieren wollte und konnte. Meinen Schwerpunkt sah ich in der Arbeit vor Ort, zeitweilig in nationalen Gremien, vor allem in der wissenschaftlichen Beschäftigung, die Schriften des Neuen Testaments als Bekenntnisse jüdischer und nichtjüdischer Anhänger Jesu Christi zu verstehen. ${ }^{31}$ In dieser Perspektive legen immer noch viel zu wenige christliche Exegetinnen und Exegeten die Schriften des Alten und Neuen Testaments aus.

$\mathrm{Zu}$ den Aufgaben im Vorstand des DKR gehört es auch, Tagungen vorzubereiten. So war es auch zum 40. Jahrestag der Veröffentlichung der epochalen „Erklärung über das Verhältnis der Kirche zu den nichtchristlichen Religionen“ / „Nostra Aetate" vom 28. Oktober 1965 mit dem wichtigen Artikel 4 zum neuen Verhältnis der römisch-katholischen Kirche zum Judentum wie auch zum 25. Jahrestag der Verabschiedung der ebenso epochalen Erklärung „Zur Erneuerung des Verhältnisses von Christen und Juden" der Evangelischen Kirche im Rheinland von I980. Eine große, repräsentative Tagung für den Herbst 2005 plante auch der DKR, was aber an den vielfach vorgesehenen Tagungen zum Thema etwa durch Bildungshäuser scheiterte. Ebenso misslang zunächst eine Zusage zu einer DKR-Tagung von Kardinal Kasper, der seit 200I Vorsitzender der vatikanischen „Kommission für die religiösen Beziehungen zum Judentum“ war. Die verwegene Idee, ihn zu einem internen Gespräch mit katholischen und evangelischen Amtsbrüdern und allen Rabbinern einzuladen, wurde zunächst etwas belächelt, konnte aber nach langer Vorarbeit in der „Woche der Brüderlichkeit“ (WdB) am 9. März 2006 in Berlin realisiert werden. Dieses Treffen gehört seither zum festen Bestand der WdB - unter Teilnahme auch von orthodoxen Rabbinern, die im Kontext der Vorbereitungen auch zur Mitarbeit im Gesprächskreis „Juden und Christen“ beim ZdK gewonnen werden konnten (neben Rabbiner Soussan seit 2005 ab 2010 auch Rabbiner Jaron Engelmayer, Köln). ${ }^{32}$ Insgesamt nahmen 27 Rabbiner und Rabbinerinnen am Berliner

3I Vgl. neben Kommentaren zum Matthäusevangelium und Jakobusbrief meine Sammelbände „Jüdische Wurzeln christlicher Theologie. Studien zum biblischen Kontext neutestamentlicher Texte“ (BBB II6), Bodenheim: Philo-Verl.-Ges. 1998, ders.: „Studien zum jüdischen Kontext neutestamentlicher Theologien“ (SBA 37), Stuttgart: Kath. Bibelwerk 2005, ders.: „Das Evangelium des Neuen Testaments“; außerdem die Monographien ders.: „Der Jude Jesus und die Ursprünge des Christentums“, Kevelaer: Topos plus 2003, ders.: „Das jüdische Neue Testament und der christliche Glaube. Grundlagenwissen für den jüdisch-christlichen Dialog“, Stuttgart: Kohlhammer 2009, ders.: „Vater unser - Awinu. Das Gebet der Juden und Christen“, Paderborn: Bonifatius 2012. 
Treffen teil. Es bedurfte wohl der Initiative einer Nicht-Kirchen-Organisation wie des DKR, dass dieses Gespräch realisiert (wer hätte einladen sollen und wer wäre welcher Einladung gefolgt?) und dass es strukturell auf Dauer (mit internem Gespräch und öffentlichen Vorträgen) dank der Offenheit der Evangelischen Kirche in Deutschland und der Deutschen Bischofskonferenz angelegt wurde; dankbar zu nennen sind Präses Nikolaus Schneider und die Bischöfe Karl Lehmann und Heinrich Mussinghoff. Der DKR organisierte die Treffen und übernahm es, sie angemessen mit Texten und Fotos zu dokumentieren. Das erste Treffen in Berlin wurde in den Medien vielfach als „bedeutender Schritt im Dialog“ und als „historisches Treffen“ bezeichnet, es wurde von einer „neuen Ebene im Verhältnis von Christen und Juden" gesprochen, was in der Tat für Deutschland zutreffend ist. Dies sieht man schon allein daran, dass bis 2005 für den Vatikan als Gesprächspartner der Zentralrat der Juden zuständig war, jetzt aber endlich Theolog/inn/en mit Theolog/ inn/en sprachen. Dass strittige Themen, wie beim zweiten Treffen in Mannheim im Jahre 2007 die "Judenmission“, nicht ausgeklammert wurden, belegt die Belastbarkeit im ökumenischen Miteinander, zeigt aber auch deren Grenzen, da die Durchführung ,auf des Messers Schneide“ stand, wie der Bericht belegt. Aktueller Grund waren Äußerungen deutscher katholischer Bischöfe bei einem Besuch in Israel, während das Folgetreffen in Düsseldorf 2008 durch die alte/neue Karfreitagsfürbitte durch Papst Benedikt XVI. belastet war.

Insgesamt konnte ich bei allen Irritationen wahrnehmen, dass zwischen den Vertretern der Deutschen Bischofskonferenz (an ihrer Spitze die Bischöfe Lehmann und Mussinghoff) und des Rates der Evangelischen Kirche Deutschlands (angeführt von Präses Schneider) in Begleitung von Beratern und Mitarbeitern und den Mitgliedern der Allgemeinen Rabbinerkonferenz und der Orthodoxen Rabbinerkonferenz Deutschlands das Verhältnis zwar störanfällig blieb, aber sich ein stetig wachsendes Vertrauensverhältnis entwickelte, das vor dem ersten Treffen 2006 niemand für möglich gehalten hätte.

\subsection{Mitglied in der Unterkommission für die religiösen Beziehungen zum Judentum}

Die Aufgabe dieser Unterkommission der Ökumene-Kommission der Deutschen Bischofskonferenz (DBK), deren Name in Anlehnung an die wichtige vatikanische

schöfe treffen Rabbiner - auch in Deutschland. Eine bemerkenswerte Initiative des DKR im christlich-jüdischen Dialog, in: Münz / Sirsch (Hg): 6o Jahre Woche der Brüderlichkeit, I73-202. Zu den folgenden Treffen ab 2012 vgl. die Homepage des DKR: http://www. deutscher-koordinierungsrat.de/ [abgerufen am 3.6.20I4]. 
Kommission vom Ursprung her auf ein distanziertes Verhältnis zu den „Juden“ hindeutet, besteht in der Beratung der DBK in Fragen des „Judentums“, wozu im Laufe der Zeit aber auch jährliche Besuche in jüdischen Gemeinden gehörten. Jüdische Mitglieder oder Berater sind nicht vorgesehen. In den fünf Jahren meiner Mitgliedschaft (2007-20II) waren es nicht zuletzt die Gespräche vor Ort, die neben den seit 2006 jährlich stattfindenden Bischöfe-Rabbiner-Treffen (s. o. 4.2) das Gespräch über „das Judentum“ zum Gespräch mit Jüdinnen und Juden, d. h. mit jeweiligen Gemeindeleiter/inne/n machten. Dabei ging es um allgemeine, aktuelle Aspekte der jeweiligen Gemeinde, nicht zuletzt um das gegenseitige Kennenlernen. Theologische Grundlagengespräche, ein christlich-jüdischer Dialog, waren nicht möglich (vgl. oben 3).

Gemäß ihrem Auftrag ging es in den ein- oder zweitägigen Klausurtagungen unter Leitung von Bischof Mussinghoff um Berichte und Stellungnahmen zu aktuellen Fragen des christlich-jüdischen Verhältnisses (auch international), um Irritationen desselben (Oberammergauer Passionsfestspiele; etwa durch die Pius-Brüder und die Aufhebung ihrer Exkommunikation; um eine mögliche Seligsprechung von Papst Pius XII.; um die alte/neue Karfreitagsfürbitte), um vorgesehene Erklärungen oder Aktionen der Kirche (etwa Israel-Besuche der deutschen Bischöfe und des Papstes im Kontext der israelisch-palästinensischen Konflikte, Bischöfe-Rabbiner-Treffen, die Konferenz des International Council of Christians and Jews 2009 in Berlin). Zeitintensiv war die Überprüfung der Lieder im neuen „Gotteslob“ auf ajüdische bzw. antijüdische Akzente (etwa im „Tantum ergo“), die Diskussionen zum Projekt einer Website der DBK zum Judentum, ${ }^{33}$ zu einem Unterrichtsdossier im Internet (rpp-katholisch.de) zu Themen des jüdisch-christlichen Dialogs.

Die Gespräche waren offen, vertrauensvoll und konstruktiv. Leider gab es auf unsere Stellungnahmen keine Reaktionen auf mögliche Rezeptionen seitens der DBK oder des Vatikans (was aber für beratende Gremien üblich ist). Ohne ein Geheimnis auszuplaudern, stand die Verlautbarung „Nachsynodales Apostolisches Schreiben ,Verbum Domini' von Papst Benedikt XVI. über das Wort Gottes im Leben und in der Sendung der Kirche" vom 30 . September 2010 nicht nur in deutlichem Widerspruch zu unseren Vorschlägen, sondern auch zum Bekenntnis vom ungekündigten Bund Gottes mit dem Judentum, wie es vor allem Papst Johannes Paul II. nicht müde wurde zu betonen, und wie es im Großen Schuldbekenntnis in St. Peter in Rom am Ersten Fastensonntag 2000 offiziell formuliert wurde. Jetzt

33 Eingerichtet wurde die Website „Nostra aetate - Dialog und Erinnerung“ der Universität Bonn unter Federführung von Reinhold Boschki am 27.I.20I2. Vgl. http://www.nostra-aetate.uni-bonn.de/ [abgerufen am 3.6.20I4]. 
heißt es in Nr. 43: „Papst Johannes Paul II. hat zu den Juden gesagt: Ihr seid ,unsere 'bevorzugten Brüder' im Glauben Abrahams, unseres Patriarchen'. Natürlich bedeuten diese Worte keine Absage an den Bruch, von dem das Neue Testament in Bezug auf die Institutionen des Alten Testaments spricht, und erst recht nicht an die Erfüllung der Schriften im Geheimnis Jesu Christi, der als Messias und Sohn Gottes erkannt wird. Dieser tiefe und radikale Unterschied beinhaltet jedoch keineswegs eine gegenseitige Feindschaft. “34 - Dazu bedarf es keines Kommentars, macht aber die Möglichkeiten und Grenzen hierarchischer Strukturen im Vergleich der letzten Päpste deutlich, in deren Kontext der katholisch-jüdische Dialog vor Ort, in der Wissenschaft und auf nationaler Ebene geführt wird. Während vorher die Päpste im christlich-jüdischen Dialog, allen voran Johannes Paul II., den Gläubigen und zum Teil den Wissenschaftlerinnen und Wissenschaftlern vorangingen, kamen von 2005 bis 2012 Störungen im Dialog nicht zuletzt von Papst Benedikt XVI.

Derlei Konsequenzen zentralistischer Autorität sollten orthodoxe Rabbiner, die ein Oberrabbinat aus Jerusalem als zentrale Autorität anstreben, bedenken. ${ }^{35}$

\section{Christlich-jüdischer Dialog im vatikanischen Kontext}

Dieser päpstliche Widerspruch kennzeichnet das grundlegende Dilemma, von dem das katholisch-jüdische Gespräch und die jüdische Wahrnehmung seit 2005 belastet sind und ipso facto jedes christlich-jüdische Gespräch örtlich, national, international, aber auch im wissenschaftlichen Raum, primär im katholischen Bereich, tangiert wurde. Seit einem Jahr knüpft Papst Franziskus an die Erklärungen des Zweiten Vatikanischen Konzils sowie an seine Vorgänger Johannes XXIII. und Johannes Paul II. deutlich an. Deren Offenheit im christlich-jüdischen Verhältnis prägt ihn, wie sein Dialog als Erzbischof von Buenos Aires mit dem Rabbiner Abraham Skorka, ${ }^{36}$ sein Brief an die jüdische Gemeinde in Rom, den er gleich an seinem ersten Arbeitstag schrieb, und nicht zuletzt sein Apostolisches Schreiben Evangelii gaudium von 2013 (zum Judentum vgl. ebd. 247-249) bestätigen. ${ }^{37}$ In

34 Henrix / Boschki (Hg.): Die Kirchen und das Judentum, K I.33; der gedruckte Text wurde herausgegeben von: Sekretariat der Deutschen Bischofskonferenz, Bonn 20Io; ebd. 72.

35 Vgl. die Pro- und Contra-Diskussion zwischen dem orthodoxen Rabbiner Jaron Engelmayer, Köln, und dem „allgemeinen“ Rabbiner Henry Brandt, Augsburg: in: Jüdische Allgemeine vom 13.5.20I4 - beide Mitglied im Gesprächskreis „Juden und Christen“ beim ZdK.

36 Bergoglio, Jorge (Papst Franziskus) / Skorka, Abraham: Über Himmel und Erde. Jorge Bergoglio im Gespräch mit dem Rabbiner Abraham Skorka, hg. von Diego F. Rosemberg, München: Riemann 20I3.

Die Verdienste seiner Vorgänger sind hier nicht aufzuzählen; zu meiner Wahrnehmung vgl. 
Nr. 247 heißt es auf der gemeinsamen Basis der Hebräischen Bibel: „Die Kirche, die mit dem Judentum einen wichtigen Teil der Heiligen Schrift gemeinsam hat, betrachtet das Volk des Bundes und seinen Glauben als eine heilige Wurzel der eigenen christlichen Identität (vgl. Röm II,I6-I8). Als Christen können wir das Judentum nicht als eine fremde Religion ansehen, noch rechnen wir die Juden zu denen, die berufen sind, sich von den Götzen abzuwenden und sich zum wahren Gott zu bekehren (vgl. I Thess I,9). Wir glauben gemeinsam mit ihnen an den einen Gott, der in der Geschichte handelt und nehmen mit ihnen das gemeinsame offenbarte Wort an." Der Papst ist bei allem Bekenntnis zu Jesus Christus davon überzeugt: „Gott wirkt weiterhin im Volk des Alten Bundes“, der Glaube im Neuen Bund an Jesus Christus ist eine „reiche Komplementarität" zum jüdischen Glauben (Nr. 249).

Auch der dreitägige Besuch in Israel Ende Mai 2014 zusammen mit dem seit seiner Zeit in Argentinien mit ihm befreundeten Rabbiner Abraham Skorka und dem Imam Omar Abboud deutet neue, weiterführende Akzente im ökumenischen Verhältnis der drei monotheistischen Religionen an (vgl. auch Evangelii gaudium $\mathrm{Nr}$. 250-254). Dem Dialog wird es guttun, wenn nicht ständig richtungsweisende neue inhaltliche Festlegungen wie unter seinem Vorgänger aus Rom kommen, stattdessen das gemeinsam Verbindende im Glauben der drei monotheistischen Religionen bei gleichzeitigem Festhalten des unbedingt eigenen Glaubens betont wird.

Bei Papst Benedikt XVI. gab es im Kontext seiner Vätertheologie als systematischer Theologe seit Beginn seiner Veröffentlichungen eine grundsätzliche Skepsis gegen die historisch-kritische Bibelwissenschaft, deren Ergebnisse er nicht als theologische, das heißt, geschichtlich geronnene Bekenntnisse ihrer Zeit anzuerkennen bereit war. ${ }^{38}$ Bedingt war dies aufgrund seines hermeneutischen Ansatzes einer systemisch-platonischen Hermeneutik in der Theologie, die sich in all seinen

„Zum jüdisch-christlichen Dialog in Deutschland nach dem Holocaust bis zu Papst Johannes Paul II.“, in: Ders.: Juden und Christen, 9-37; ders.: Studien zum jüdischen Kontext neutestamentlicher Theologien 292-302; zur weiteren Entwicklung vgl. ders.: Schwerpunkte und Schwachpunkte im jüdisch-christlichen Dialog, in: Compass-Infodienst für christlich-jüdische und deutsch-israelische Tagesthemen im Web. Online-Extra Nr. 29, April 2006, in: http://www.compass-infodienst.de/Hubert_Frankemölle_Schwerpunkte_ und_Schwachpunkte_im_juedisch-christlichen_Dia.967.o.html [abgerufen am 3.6.20I4]; ders.: Das Evangelium des Neuen Testaments 45-I2I, 275-302.

38 Vgl. meine kritische Rezension „Schriftauslegung im Widerstreit“, in: BiKi 45 (1990) 200204 zu dem Beitrag von Ratzinger, Joseph Cardinal: Schriftauslegung im Widerstreit. Zu Frage nach Grundlagen und Weg der Exegese heute, in: Ders.: (Hg.): Schriftauslegung im Widerstreit (QD II7), Freiburg: Herder 1989, I5-44. 
Schriften durchträgt. ${ }^{39}$ Seine drei Bücher zum geschichtlichen, historischen Jesus bestätigen diesen Ansatz. Unbedingtheit identifiziert er mit Absolutheit, Mission mit Zeugnis und Rechenschaft. Als privater Glaube mag dies noch hinnehmbar sein, als kirchenamtliche Theologie geht sie hinter die Erklärungen des Zweiten Vatikanischen Konzils zurück. Mit Recht haben die katholischen Bibelwissenschaftlerinnen und Bibelwissenschaftler in der Regel die durch die Konzilserklärungen gewährte Freiheit des Forschens bestätigt, ohne die spätere christologische und spirituelle Erfüllungstheologie der Kirchenväter als neue Transformationen, die sich an der Schrift zu bewähren haben, zu negieren.

Bedenkt man, welche Veröffentlichungen und Handlungen des Präfekten der Glaubenskongregation, Kardinal Josef Ratzinger, und seit 2005 als Papst Benedikt XVI., jüdische Empfindungen und den jüdisch-christlichen Dialog vor Ort und in nationalen sowie internationalen Gremien am stärksten belastet haben, bleiben in meiner Erinnerung die schon oben angesprochenen:

- Die Erklärung der Glaubenskongregation „Dominus Jesus“von 2000,

- das veränderte Weltgebetstreffen in Assisi von 2002,

- „Antworten auf Fragen zu einigen Aspekten bezüglich der Lehre von der Kirche" von 2007 ,

- die Aufhebung der Exkommunikation der Bischöfe der Priesterbruderschaft Pius X.,

- Vorbereitungen zur Seligsprechung von Papst Pius XII.,

- die alte/neue Karfreitagsliturgie mit der Bitte um Bekehrung der Juden von 2008.

Es gab nicht nur Stolpersteine, sondern auch Fort-Schritte, die auf das durch das Zweite Vatikanische Konzil erneuerte positive Verhältnis des Christentums zum Judentum auf allen Ebenen eingewirkt haben. ${ }^{40}$ An Veröffentlichungen der Bibelkommission sind zu nennen:

- „Die Interpretation der Bibel in der Kirche“ von 1993,

- „Das jüdische Volk und seine Heilige Schrift in der christlichen Bibel“ von 200I,

39 Vgl. zuletzt Frankemölle: Das Evangelium des Neuen Testaments, 45-49, 82-98.

40 Vgl. im Themenheft „40 Jahre Dei Verbum“ meinen Bericht: Fort-Schritte seit der Offenbarungskonstitution Dei Verbum des Zweiten Vatikanischen Konzils (1965), in: BiKi 60 (2005) 173-177; außerdem: Schwerpunkte und Schwachpunkte im jüdisch-christlichen Dialog, in: Compass-Infodienst für christlich-jüdische und deutsch-israelische Tagesthemen im Web. Online-Extra Nr. 29, April 2006, in: http://www.compass-infodienst.de/ Hubert_Frankemölle_Schwerpunkte_und_Schwachpunkte_im_juedisch-christlichen_ Dia.967.o.html [abgerufen am 3.6.2014]. 
- Predigten, Erklärungen und vor allem symbolische Gesten von Johannes Paul II.

Das Schibboleth für das erneuerte Verhältnis des Christentums zum Judentum auf allen Ebenen (örtlich, national und international) bleibt die Frage nach der Judenmission. Sind gläubige Jüdinnen und Juden im von Gott nie gekündigten Bund, das heißt: Sind sie trotz ihres Neins zu Jesus Christus im Heil oder müssen sie über den Glauben an Jesus Christus erst zum Heil kommen? ${ }^{41}$ In Fortschreibung von Nostra Aetate von 1965 erklärte Papst Johannes Paul II. anlässlich des ersten Besuches eines Papstes in einer Synagoge im April 1986 gegen jegliche „zweideutige Vereinnahmungen“: „Niemandem entgeht, dass der anfängliche Unterschied in der Zustimmung der Katholiken zur Person und Lehre Jesu von Nazaret besteht, der ein Sohn eures Volkes ist. [...] Aber diese Zustimmung gehört dem Bereich des Glaubens an, das heißt, der freien Zustimmung der Vernunft und des Herzens, die vom Geist geleitet werden. Sie darf niemals in dem einen oder anderen Sinn zum Gegenstand von äußerem Druck werden. Das ist der Grund, warum wir bereit sind, den Dialog unter uns in Loyalität und Freundschaft sowie in der Achtung der inneren Überzeugungen der einen und anderen zu vertiefen, indem wir die Elemente der Offenbarung, die wir als, großes geistiges Erbe' gemeinsam haben (vgl. Nostra Aetate Nr. 4), als wesentliche Grundlage nehmen. “"

Auf diesem Weg ist beständig weiterzugehen:

- trotz der nicht erst heute allzu geringen Zahl von wissenschaftlichen Theologinnen und Theologen, von Pfarrern und Bischöfen, die ihren Glauben aus der jüdischen Wurzel artikulieren und in konkreter Zusammenarbeit mit Jüdinnen und Juden und im Dialog mit ihnen in Wort und Tat praktizieren,

- trotz der ebenfalls allzu geringen Zahl der Bibelwissenschaftler/innen, die auf der Basis der Akzeptanz der Heiligen Schriften in Hebräisch und Griechisch durch Juden ab dem 4. Jahrhundert v. Chr. den damaligen Glauben des jüdischen Volkes als Wurzel der eigenen christlichen Identität anerkennen und in den jüdisch-christlichen Dialog einzubringen gewillt sind. Dies schließt den aktuellen Dialog mit jüdischen Menschen über deren Hebräische Bibel nicht aus, er ist vielmehr Voraussetzung zum gegenseitigen Verstehen,

4I Die Erklärungen des Gesprächskreises „Juden und Christen“ beim ZdK von 2005 und 2009 zogen hier parallel zu evangelischen Erklärungen klare Folgerungen aus den hermeneutischen Erkenntnissen der Wissenschaften und vatikanischer Erklärungen. Diese Konkretisierung war es wohl, die Kritik hervorrief.

Rendtorff / Henrix (Hg.): Die Kirchen und das Judentum, IO6-II, ebd. IIO. 
- trotz der immer älter und an Zahl geringer werdenden Mitglieder in den Gesellschaften für Christlich-Jüdische Zusammenarbeit vor Ort,

- trotz des zunehmenden Desinteresses der Mitglieder der jüdischen und christlichen Gemeinden an christlich-jüdischen Themen,

- trotz der aktuell in Deutschland drängenden gesellschaftlichen und glaubensmäßigen christlich-muslimischen Aspekte der Zusammenarbeit, die komplementär anzugehen sind. Darüber ist das glaubensmäßig einzigartige Verhältnis des Christentums zum Judentum nicht zu verdrängen.

Ich kann bestätigen: Meine Erfahrungen im christlich-jüdischen Dialog und in der Zusammenarbeit von jüdischen und christlichen Menschen wie im christlich-jüdisch-muslimischen Gespräch veränderten meine Theologie und mein Leben, da es nicht nur um theologische Erkenntnisse ging, sondern auch um das gegenseitige persönliche Kennenlernen. Mein Glaube wurde nicht relativiert, sondern gewann erst so seine eigene „katholische“ Identität, die ich etwa zusammen mit den anderen katholischen Mitgliedern im Gesprächskreis „Juden und Christen“ beim ZdK gemäß I Petr 3,15 ,in Rede und Antwort“, d. h. im Dialog vor Jüdinnen und Juden vertreten und als meinen Glauben bekennen konnte. Verkündigung heute setzt mit Papst Johannes Paul II. den Dialog mit den Wurzeln der eigenen Vergangenheit voraus, ${ }^{43}$ erst so hat der Dialog in der Begegnung zwischen Christinnen/Christen und Jüdinnen/Juden eine tragfähige Zukunft. Papst Franziskus scheint diesen Weg bewusst weitergehen zu wollen. 


\title{
Der eine Gott der Bibel als Subjekt und Adressat

\author{
christlicher Liturgie
}

\author{
Zur Neuformatierung der Feiern des Glaubens und ihrer Theologie \\ durch den jüdisch-christlichen Dialog
}

\section{Peter Ebenbauer}

Die Konzilserklärung des Zweiten Vatikanums über das Verhältnis der Kirche zu den nichtchristlichen Religionen, Nostra Aetate, spricht im Rückgriff auf Röm 9,4f. unter anderem vom jüdischen Gottesdienst als einer Vorzugsgabe des Gottes Israels an sein ersterwähltes Bundesvolk: ,... daß ,ihnen die Annahme an Sohnes Statt und die Herrlichkeit, der Bund und das Gesetz, der Gottesdienst und die Verheißungen gehören wie auch die Väter und daß aus ihnen Christus dem Fleische nach stammt' (Röm 9,4-5)“ (Nostra Aetate 4). Schon aus dieser kurzen Passage könnte man schlussfolgern, dass jüdische Liturgie - bis in ihre zeitgenössischen Gestalten hinein - ein substantiell wertvolles Gegenüber für die christliche Liturgie bildet, und dass sie ein Lernpotential, möglicherweise auch ein Korrekturpotential für den christlichen Gottesdienst bereithält, analog zum exegetischen und bibeltheologischen Lernpotential, das dem christlichen Glauben und der christlichen Theologie aus der Hebräischen Bibel und ihren jüdischen Auslegungstraditionen zuwächst.

\section{Nostra Aetate und ihre Folgewirkungen für den Gottesdienst und die Liturgiewissenschaft}

Der Artikel vier von Nostra Aetate über das Verhältnis der Kirche zum Judentum und seine Folgewirkungen blieben auch im Kontext der konziliaren Liturgiereform nicht wirkungslos. Die hier in Gang gekommenen Transformationsprozesse sind nicht abgeschlossen und zielen im Sinn der konziliaren Reformdynamik auch nicht auf einen Abschluss, sondern auf ständige Erneuerung. Sie sind auch nicht auf die römisch-katholische Kirche und ihre Liturgien beschränkt. Reformatorische Gottesdienstpraxis hat in manchen Punkten stärker auf die Umkehr im Verhältnis der Kirchen zum Judentum reagiert als katholische; die Welt der orthodoxen Liturgien bisher noch am wenigsten.

Einen ersten liturgischen Meilenstein für die israeltheologische Neuformatierung der römisch-katholischen Liturgie bildete die neue Fassung der Karfreitagsfürbitte für die Juden: 
Oremus et pro Iudaeis, ut, ad quos prius locutus est Dominus Deus noster, eis tribuat in sui nominis amore et in sui foederis fidelitate proficere.

[Flectamus genus - Levate]

Omnipotens sempiterne Deus, qui promissiones tuas Abrahae eiusque semini contulisti, Ecclesiae tuae preces clementer exaudi, E ut populus acquisitionis prioris ad redemptionis mereatur plenitudinem pervenire.

Per Christum Dominum nostrum. ${ }^{1}$
Lasst uns auch beten für die Juden,

zu denen Gott, unser Herr, zuerst gesprochen hat: Er bewahre sie in der Treue zu seinem Bund und in der Liebe zu seinem Namen, damit sie das Ziel erreichen, zu dem sein Ratschluss sie führen will. [Beuget die Knie. - Stille - Erhebet euch.] Allmächtiger, ewiger Gott, du hast Abraham und seinen Kindern deine Verheißung gegeben.

Erhöre das Gebet deiner Kirche für das Volk, das du als erstes zu deinem Eigentum erwählt hast:

Gib, dass es zur Fülle der Erlösung gelangt.

Darum bitten wir durch Christus, unseren Herrn. $^{2}$

Diese Fürbitte liegt klar auf einer Linie mit Nostra Aetate und setzt die neue Hermeneutik des Verhältnisses der Kirche zum Judentum an einer bedeutenden Stelle christlicher Liturgie, nämlich in dem großen und maßstäblichen Gebetsformular für das fürbittende Gebet der römisch-katholischen Kirche überhaupt, nicht zufällig innerhalb der Liturgie des Oster-Triduums und in unmittelbarer Nähe zum Gedenken des Heilstodes Jesu, in beeindruckender Weise um.

Das Gebet anerkennt den unwiderruflich bleibenden Bund Gottes mit seinem ersterwählten Bundesvolk. In allen Generationen und bis heute gilt Gottes Bund für Israel, und dieser Bund wird als Weg Israels mit seinem Gott geachtet, ja explizit erbeten: „Er bewahre sie in der Treue zu seinem Bund ...“, unmittelbar verbunden mit einer zentralen Kategorie genuin jüdischen Glaubens: „... und in der Liebe zu seinem Namen."

Wenn Art. 4 von Nostra Aetate brennpunktartig für die durch Umkehr und Erneuerung gekennzeichnete lehramtliche Neupositionierung der katholischen Kirche gegenüber dem Judentum steht, dann repräsentiert diese Fürbitte den konkreten

I Missale Romanum ex decreto sacrosancti Oecumenici Concilii Vaticani II, Editio typica tertia, Città del Vaticano: Libreria editrice vaticana 2002, 319; gleichlautend bereits in den ersten beiden Ausgaben 1970 und 1975.

2 Die Feier der heiligen Messe. Messbuch für die Bistümer des deutschen Sprachgebietes. Authentische Ausgabe für den liturgischen Gebrauch, Teil I, Freiburg: Herder 1975, [48]. 
gottesdienstlichen Maßstab für die Neuformatierung ihrer liturgischen Theologie und Praxis im Hinblick auf Gottes Bundesvolk Israel und den jüdischen Glauben.

Dieses Gebet markiert eine Veränderung der Israeltheologie der Kirche, deren liturgische Reichweite vermutlich erst mit der von Papst Benedikt XVI. ausgelösten Debatte um die von ihm behauptete bruchlose Kohärenz zwischen dem alten Ritus im Gefolge des Trienter Konzils (bis 1962) und dem erneuerten Ritus der römischen Liturgie (seit 1970) voll ins Bewusstsein getreten ist, ${ }^{3}$ und mit seiner umstrittenen Neuformulierung der Karfreitagsfürbitte für den Gebrauch jenes alten, außerordentlichen Ritus der Osterliturgie. ${ }^{4}$

In den letzten Jahrzehnten hat sich im Bereich christlicher Israeltheologie liturgiepraktisch und liturgietheologisch einiges verändert, nicht zuletzt im Diskurs zwischen christlichen und jüdischen Forscher/inne/n, Theolog/inn/en und Praktiker/inne/n auf dem Gebiet der Liturgie; 5 und durchaus auch mit Auswirkungen

3 Vgl. dazu die von Papst Benedikt in seinem Motu Proprio aus dem Jahr 2007 gefällte Entscheidung über den parallelen Gebrauch des alten und des erneuerten römischen Ritus: Summorum Pontificum. Über den Gebrauch der Römischen Liturgie in der Gestalt vor der Reform von 1970, gegeben zu Rom bei Sankt Peter am 7. Juli im Jahr des Herrn 2007, dem dritten Jahr Unseres Pontifikats, Benedictus PP. XVI. Dort heißt es in Nr. I: „Diese zwei Ausdrucksformen der ,Lex orandi' der Kirche werden aber keineswegs zu einer Spaltung der ,Lex credendi ' der Kirche führen; denn sie sind zwei Anwendungsformen des einen Römischen Ritus."Vgl. http://www.vatican.va/holy_father/benedict_xvi/motu_proprio/ documents/hf_ben-xvi_motu-proprio_20070707_summorum-pontificum_ge.html [abgerufen am 26.6.20I4].

4 Vgl. Homolka, Walter / Zenger, Erich (Hg.): „... damit sie Jesus Christus erkennen“. Die neue Karfreitagsfürbitte für die Juden (Theologie kontrovers) Freiburg: Herder 2008.

5 Ich weise hier exemplarisch auf einige Forschungsinitiativen mit einschlägigen Publikationen hin: Unter der Leitung von Albert Gerhards (Bonn) wurde ab 1999 ein breit angelegtes internationales Projekt zur Erforschung liturgiehistorischer und liturgietheologischer Interdependenzen zwischen Judentum und Christentum bearbeitet, aus dem zahlreiche Publikationen hervorgegangen sind. Vgl. dazu Gerhards, Albert / Henrix, Hans Hermann (Hg.): Dialog oder Monolog? Zur liturgischen Beziehung zwischen Judentum und Christentum (QD 208) Freiburg: Herder 2004; Boschki, Reinhold / Gerhards, Albert (Hg.): Erinnerungskultur in der pluralen Gesellschaft. Neue Perspektiven für den christlich-jüdischen Dialog (Studien zu Judentum und Christentum) Paderborn: Schöningh 2oro. Clemens Leonhard (Münster) leitet verwandte Projekte unter intensiver Einbindung jüdischer Forscher/innen; vgl. die informative Website http://www.uni-muenster.de/FB2/personen/ liturgie/leonhard.html [abgerufen am 23.6.20I4] und folgende aktuelle Publikationen: Leonhard, Clemens: The Jewish Pesach and the Origins of the Christian Easter. Open Questions in Current Research, Berlin: de Gruyter 2006; Leonhard, Clemens / Gerhards, Albert (Hg.): Jewish and Christian Liturgy and Worship. New Insights into its History and Interaction, Leiden: Brill 2007. 
auf liturgiewissenschaftliche und theologische Standards. Allerdings ist immer mit zu bedenken, dass die Etablierung eines neuen Standards unterschieden werden muss von der konkreten Rezeption auf den unterschiedlichen Ebenen kirchlicher Reflexion und Praxis. Das gilt für die neuen Standards des Zweiten Vatikanischen Konzils ebenso wie für jene der Liturgie und ihrer Theologie.

In diesem Zusammenhang ist es bemerkenswert, dass der zuletzt erschienene Band 2/2 des Handbuchs der Liturgiewissenschaft unter der Großüberschrift Theologie des Gottesdienstes eine eigene Abhandlung zum Thema "Christliche und jüdische Liturgie" beinhaltet, deren Absicht und Ziel genau darin besteht, die in einigen Punkten doch grundlegend veränderte Forschungslage darzustellen und einen neuen liturgiehistorischen sowie theologischen Standard zu etablieren. Diesbezüglich heißt es im Vorwort des genannten Handbuchs:

[...] vor allem durch die Konzilserklärung, Nostra aetate und die nachfolgende Diskussion, [ist] die Fragestellung nach dem Verhältnis der christlichen Liturgie zum jüdischen Gottesdienst auf eine völlig neue Basis gestellt worden. Das betrifft auch die Gestalt des christlichen Gottesdienstes sowie sein theologisches Selbstverständnis. ${ }^{6}$

Die Abhandlung selbst hat Gerard Rouwhorst verfasst, der sich durch seine Arbeiten zur Frühgeschichte der christlichen Liturgie und ihren Interdependenzen mit dem Gottesdienst Israels bzw. mit der Entwicklung jüdisch-rabbinischer Liturgie international einen Namen gemacht hat.

Bevor in diesem Beitrag drei konkrete und aktuelle Fragenkreise im Kontext einer Neuformatierung christlicher Liturgie durch den jüdischen-christlichen Dialog erörtert werden, seien an dieser Stelle stichwortartig die zentralen Aspekte zusammengefasst, die in diesem Handbuchbeitrag den in den vergangenen Jahrzehnten neu errungenen Standard liturgiegeschichtlicher und liturgietheologischer Art bezeichnen:

Zur Erforschung der historischen Zusammenhänge zwischen jüdischer und christlicher Liturgie werden die folgenden methodischen und inhaltlichen Prinzipien festgehalten:

a) Weder die liturgischen Traditionen des frühen Christentums noch diejenigen des frühen Judentums dürfen von ihrer antiken, d. h. hellenistisch-römischen Umwelt isoliert werden. [...]

6 Klöckener, Martin / Häußling, Angelus A. / Meßner, Reinhard (Hg.): Gottesdienst der Kirche. Handbuch der Liturgiewissenschaft. Theologie des Gottesdienstes 2/2, Regensburg: Pustet 2008, II. 
b) Rekonstruktionen der frühüdischen Liturgie, die in Hypothesen über die frühchristliche Liturgiegeschichte eine Rolle spielen, müssen auf einer gediegenen Kenntnis der jüdischen Quellen und auf einem kritischen Umgang mit ihnen basieren. [...]

c) Die Komplexität sowohl des frühen Christentums als auch des frühen Judentums, namentlich in den ersten Jahrhunderten der christlichen Zeitrechnung, muss sehr ernst genommen werden. [...]

d) Anstatt von einem einfachen Modell der Übernahme einzelner Riten oder ritueller Elemente der einen Tradition durch die andere sollte von einem dynamischen Interaktionsmodell ausgegangen werden. [...]

e) Es könnte hilfreich sein, zwischen verschiedenen Formen der Beeinflussung [...] zu unterscheiden. ${ }^{7}$

Im Hinblick auf liturgietheologische und liturgiepraktische Neuformatierungen resümiert Rouwhorst:

Ausgehend von den zwei Hauptprinzipien, die in Nostra aetate und in anderen kirchlichen Dokumenten formuliert worden sind, nämlich der Verbundenheit mit dem jüdischen Erbe und der Abweisung des Antijudaismus und der Substitutionstheologie, sollten folgende Punkte in der Theologie der Liturgie weiter reflektiert und ausgearbeitet werden, besonders auch im Hinblick auf die liturgische Praxis. ${ }^{8}$

Die Verwurzelung besonders der frühchristlichen Liturgie in jüdischen gottesdienstlichen Traditionen sollte theologisch weiter reflektiert werden und auch im Gottesdienst heute sichtbar sein. Lesung und Auslegung des Alten Testaments verdienen besondere Beachtung, dürfen auf keinen Fall der obsolet gewordenen Substitutionstheologie folgen. Weitere in jüdischen Traditionen wurzelnde Elemente

7 Rouwhorst, Gerard: Christlicher Gottesdienst und der Gottesdienst Israels. Forschungsgeschichte, historische Interaktionen, Theologie, in: Klöckener, Martin / Häußling, Angelus A. / Meßner, Reinhard (Hg.): Gottesdienst der Kirche. Handbuch der Liturgiewissenschaft 2/2, Regensburg: Pustet 2008, 49I-572, 5IIf. Die zuletzt genannten unterschiedlichen Formen der Beeinflussung werden weiter ausdifferenziert: „tiefgehende Beeinflussung durch die Übernahme, Aneignung und Transformation jüdischer Riten und ritueller Elemente in der formativen Phase des Christentums " (in den ersten drei Jahrhunderten); ab dem 4. Jh. „Beeinflussung durch Interaktion mit jüdischen liturgischen Traditionen“; weiters „die Beeinflussung durch das Alte Testament" in Form von Rezeptionsprozessen innerhalb der Kirchen und ihrer Liturgien; sowie die Beeinflussung von Ritualen durch (neue) Vorstellungen, Bilder, Motive unterschiedlicher Herkunft. Rouwhorst: Christlicher Gottesdienst, 5I2f.

8 Ebd., 57I. 
sollten wieder eine prominente Stellung in der Theologie und Praxis christlicher Liturgie erhalten, so etwa der durchgängige „Gemeinschaftscharakter der gottesdienstlichen Feiern und die zentrale Rolle des Lobpreises und der Danksagung in den Gebeten." Schließlich wird mit Nachdruck die „Bekämpfung zählebiger Formen von Antijudaismus in der Liturgie“ eingefordert. Dies betrifft sowohl biblische Lesungen mit ihren Auslegungstraditionen als auch liturgische Gebete und gottesdienstliche Gesänge. ${ }^{9}$

Besonderes Augenmerk sei schließlich auf die jeweils eigenen Wege und die Differenzen zu legen, die jüdische und christliche Liturgie kennzeichnen. Rouwhorst konstatiert abschließend dazu: „Dies kann nämlich für Christen und Juden eine Herausforderung bedeuten, die Traditionen der anderen Religion gerade in ihrem Anderssein kennenzulernen, zu schätzen, sich mit ihnen selbstkritisch auseinanderzusetzen und möglichst von ihnen zu lernen. ${ }^{\text {"10 }}$ Damit ist auch evident, dass sich die Liturgiewissenschaft nicht mehr einfach isoliert innerhalb christlicher Forschungs- und Lernkontexte bewegen darf, um ihrem Gegenstand und ihrer theologischen Aufgabe gerecht zu werden. Gespräch und Zusammenarbeit mit jüdischen Gelehrten und Liturgieexpert/inn/en sind essentiell geworden.

Ausgehend von diesem letzten Punkt möchte ich drei konkrete Fragenkreise thematisieren, die für die Neuformatierung christlicher Liturgie und ihrer Theologie - angesichts der fundamentalen Neubesinnung auf den bleibenden Bund Gottes mit seinem ersterwählten Volk Israel und auf die "geistliche Verbundenheit" (vgl. NA 4) der Kirche mit dem Judentum - bedeutsam erscheinen. ${ }^{11}$

\section{2. Überwindung liturgischer Substitutionstheologie}

Aus der gesamtkirchlich und ökumenisch geteilten Neupositionierung gegenüber dem Judentum, wie sie in Nostra Aetate exemplarisch vorliegt, ergibt sich die Notwendigkeit, dass alle Formen christlicher Abwertung oder Herabsetzung von alttestamentlichen und jüdischen Gotteszeugnissen strikt zu vermeiden sind; das gilt selbstverständlich auch für die Liturgie.

Dieser Grundsatz gerät nun allerdings in Konflikt mit typologischen Überbietungsschemata, wie wir sie seit der Schriftwerdung des Neuen Testaments in den

\footnotetext{
9 Ebd., 57If.

IO Ebd., 572.

II Vgl. dazu auch Ebenbauer, Peter: Mehr als ein Gespräch. Zur Dialogik von Gebet und Offenbarung in jüdischer und christlicher Liturgie (Studien zu Judentum und Christentum) Paderborn: Schöningh 20I0; ich greife im Folgenden Einzelaspekte aus meiner Habilitationsschrift auf und entwickle sie weiter.
} 
kanonischen Texten sowie in den Traditionen der christlichen Kirchen finden. Sie wurzeln in der fundamentalen christlichen Überzeugung von der endzeitlichen und endgültig ergangenen Offenbarung Gottes in Jesus Christus und der fortdauernden Repräsentation dieser Offenbarung durch die Kirche. Die für unser Thema entscheidende Frage lautet: Wie ist es möglich, diese Überzeugung zu wahren, ohne das alttestamentliche und jüdische Gegenüber in seiner theologischen und glaubensgeschichtlichen Dignität zu verletzen? - Die Bearbeitung dieses Problems erfordert auf liturgischer Ebene die Untersuchung und gegebenenfalls die Revision konkreter Texte, Gesänge und weiterer Rituselemente, die eine solche Abwertung oder Ausblendung zum Ausdruck bringen. Beispielhaft ist dies ja wie bereits erwähnt an der Karfreitagsfürbitte für die Juden durchgeführt worden.

Dafür liegen seitens der Liturgiewissenschaft bereits einige detaillierte Analysen und Vorschläge vor. So etwa Entwürfe für die explizite Erwähnung des Gottesbundes mit Israel anstelle der unspezifischen Rede von den Bundesangeboten Gottes an die Menschen im Vierten Hochgebet des Missale Romanum. Georg Braulik hat diesbezüglich einen konkreten Vorstoß gemacht. ${ }^{12}$ Ähnlich Heinzgerd Brakmann, der innerhalb der Interzessionen dieses Hochgebetes die Einfügung ,... für das Volk, das du als erstes zu deinem Eigentum erwählt hast" vorschlägt und darüber hinaus die Schaffung eines eigenen, neuen Hochgebetes einfordert, das speziell die Heilsfunktion Israels thematisiert. ${ }^{13}$

Ein anderes Beispiel betrifft ein Detail der Leseordnung biblischer Schriften in der römisch-katholischen Liturgie, das hier Pars pro Toto für die umfangreiche und komplexe Diskussion um die Zuordnung von Altem und Neuem Testament im Gottesdienst der Kirche kurz beschrieben wird.

In der neuen Leseordnung des Pfingstfestes, genauer: im Kontext der vorabendlichen Pfingst-Vigil, findet sich nun sinnvollerweise auch die Sinaiperikope Ex I9 im Kanon der alttestamentlichen Lesungen. Damit ist ein alter Konnex wieder hergestellt, nämlich der Zusammenhang zwischen dem jüdischen Wochenfest (Schavuot) und dem christlichen Pfingstfest. Die damit zugleich fällig gewordene theologische Zuordnung der Offenbarung der Tora am Sinai zum neutestamentlichen Pfingstwunder kommt in der Oration nach der Lesung Ex 19,3-8a.I6-20 zum Ausdruck. Allerdings muss dieser Gebetstext als Rückfall in eine nicht mehr tragbare Form abwertender Typologie bezeichnet werden. ${ }^{14}$

I2 Vgl. Braulik, Georg: Gott für Israel preisen. Zur Heilsprärogative Israels und zum 4. Hochgebet, in: Gerhards / Henrix (Hg.): Dialog oder Monolog?, 223-253.

I3 Vgl. Brakmann, Heinzgerd: Foedera pluries hominibus. Anmerkungen zur Revision des Eucharistischen Hochgebets IV, in: LJ 50 (2000) 2II-234.

I4 Vgl. Kranemann, Daniela: Teilhabe an der Würde Israels. Anmerkungen zur Israeltheologie 


\begin{abstract}
Allmächtiger Gott,
im Feuer des Sinai hast du dem Mose das alte Gesetz gegeben

und am Pfingstfest im Feuer des Geistes den Neuen Bund kundgetan.

Erfülle uns mit der Glut des Heiligen Geistes,

den du am heutigen Tag den Aposteln gesandt hast.

Schenke dem neuen Volk Israel, das du aus allen Völkern zusammenführst,

Freude an deinem ewigen Gebot der Liebe.

Darum bitten wir [...]. ${ }^{15}$
\end{abstract}

Im anamnetischen Teil dieses Gebetes werden das Sinaigeschehen und die Ausgießung des Geistes Gottes gemäß der Pfingsterzählung des Lukas als zwei Offenbarungsereignisse dargestellt, von denen das Sinaigeschehen als Stiftungsereignis des „alten Gesetzes“" und das neutestamentliche Pfingstwunder als Offenbarung des „neuen Bundes" gedeutet wird: Gott hat „... im Feuer des Sinai [...] dem Mose das alte Gesetz gegeben und am Pfingstfest im Feuer des Geistes den Neuen Bund kundgetan". Im bittenden Passus des Gebetes wird dann in einer Zuspitzung dieser Relation das Volk des neuen Bundes als „neues Volk Israel“ bezeichnet. Diesem neuen Volk Israel, also der Kirche, wird „Freude am ewigen Gebot der Liebe“ zugedacht, womit eine letzte Gegenüberstellung - „altes Gesetz“ versus „ewiges Gebot der Liebe“ - konstruiert wird, die weder bibeltheologisch noch lehramtlich vertretbar erscheint: „Schenke dem neuen Volk Israel, das du aus allen Völkern zusammenführst, Freude an deinem ewigen Gebot der Liebe.“

$\mathrm{Zu}$ Recht hält Daniela Kranemann dazu fest: „Nicht nur vor dem Hintergrund der Karfreitagsfürbitte für die Juden, sondern auch im Hinblick auf die konstitutive Bedeutung der Tora für jüdische Identität ist eine solche Gebetstheologie nicht haltbar." ${ }^{16}$ Daniela Kranemann hat auch auf mögliche Auswege aus einer enterbungstheologischen bzw. das Judentum abwertenden Typologie innerhalb der Liturgie hingewiesen, ohne auf die typologische Methodik gänzlich verzichten zu müssen. ${ }^{17}$ Die typologischen Zuordnungen müssten nach folgendem Struktursche-

in den Gebetstexten des Messbuches, in: Gerhards / Henrix (Hg.): Dialog oder Monolog?, 284-305, 298-302; dies.: „Unsere Väter, die Söhne Israels ...“. Zeitgenossenschaft von Israel und Kirche in der christlichen Liturgie - Chancen und Desiderate, in: HID 58 (2004) $45-58,5$ of.

I5 Ad Missam in Vigilia Pentecostes, in: Notitiae 24 (1988) I56-I59.

I6 Kranemann: Teilhabe an der Würde Israels, 298. Zum selben Gebet vgl. Steins, Georg: Gegen die Bibel beten? Kritische Auseinandersetzung mit dem Wortlaut und Inhalt liturgischen Betens anhand eines Beispiels, in: Gottesdienst 30 (1996) I53-155.

I7 Vgl. Kranemann: Teilhabe an der Würde Israels, 300-302. 
ma gestaltet sein: „wie einst - so auch heute“; bzw. „wie an ihnen - so auch an uns“. ${ }^{18}$ Dafür gibt es übrigens sowohl biblische als auch liturgische Vorbilder aus jüdischen wie christlichen Kontexten. Ich füge einen konkreten Vorschlag für eine Revision des Gebetstextes an:
Allmächtiger Gott,
wie du im Feuer des Sinai dem Mose die Tora
für dein Volk Israel gegeben hast,
so hast du am Pfingstfest im Feuer des Geistes
deinen Bund besiegelt.
Erfülle uns mit der Glut des Heiligen Geistes,
den du am heutigen Tag den Jüngerinnen und Jüngern gesandt hast,
und schenke auch uns die Freude am ewigen Gebot der Liebe.
Darum bitten wir [...].

Liturgische Gesänge und Gebete, die weiterhin entweder explizit oder in ihren bestimmenden Rezeptionssträngen eine den jüdischen Glaubensweg diskriminierende Konnotation aufweisen, ${ }^{19}$ sollten u. a. mit Hilfe dieses Schemas konsequent revidiert werden.

Auf diesem Weg ist es möglich, Partnerschaft und Zeitgenossenschaft zwischen Christ/inn/en und Juden/Jüdinnen auf ihren Bundes-Wegen zu signalisieren, und dabei gleichzeitig das jeweilige Proprium der beiden Wege zu achten, ohne vereinnahmend oder verletzend sprechen bzw. handeln zu müssen.

I8 Vgl. den Hinweis von Angelus Häußling, dass eine solche Redeweise in liturgischen Orationen der lateinischen Tradition bereits vertreten ist: „sicut [...] ita et nos/wie diese [...] so auch wir“. Häußling, Angelus A.: Gemeinschaft aus Identität der Erfahrung, in: Klöckener, Martin / Kranemann, Benedikt / Merz, Michael B. (Hg.): Christliche Identität aus der Liturgie. Theologische und historische Studien zum Gottesdienst der Kirche (LQF 79) Münster: Aschendorff 1997, 334-344, 339.

19 Viel diskutiert sind die so genannten „Improperien“ zur Kreuzverehrung am Karfreitag oder auch der Fronleichnamshymnus „Pange lingua“ des Thomas von Aquin mit seinen Übertragungen ins Deutsche. Zu diesen und anderen Gesängen/Kirchenliedern vgl. Praßl, Franz Karl: Political correctness in der Liturgie? Vom Umgang mit schwierigen Perikopen und Gesängen, in: HID 58 (2004) 59-75; vgl. auch Gerhards, Albert: Theologische und sozio-kulturelle Bedingungen religiöser Konflikte mit dem Judentum. Beispiele aus der katholischen Liturgie und ihrer Wirkungsgeschichte, in: Gerhards, Albert / Wahle, Stephan (Hg.): Kontinuität und Unterbrechung. Gottesdienst und Gebet in Judentum und Christentum (Studien zu Judentum und Christentum) Paderborn: Schöningh 2005, 269-285. 
Übrigens stellt sich die Frage textlicher Revisionen akut auch im Blick auf antijüdische Texte in orthodoxen Liturgien, vor allem im Kontext der Großen und Heiligen Woche. ${ }^{20}$ Dasselbe gilt für Bildtraditionen und ikonographische Programme in Kirchenräumen und liturgischen Kontexten. Es ist dringend erforderlich, diese kritisch sehen zu lernen, sie nicht unkommentiert wirken zu lassen und auch neue Bilder innerhalb und außerhalb von Sakralräumen für das grundlegend erneuerte Verhältnis zwischen Kirche und Judentum zu suchen bzw. anzuregen. ${ }^{21}$

\section{Liturgischer Umgang mit dem Namen und der Einzigkeit/Einheit Gottes}

Wie wir eingangs gesehen haben, wird die „Liebe zum Namen Gottes“, die das Bundesvolk Israel durch die Geschichte hindurch auszeichnet, in der neuen Fürbitte für die Juden speziell herausgestrichen. Zu dieser Liebe gehören auch die spezifischen Erinnerungsformen, die in Schrift, Wort und Geste mit der Offenbarung des Namens Gottes und mit der Überlieferung dieses Namens in Bibel und Liturgie verbunden sind. Der ehrfurchtsvolle Umgang mit dem Tetragramm erweist sich als Zeugnis jenes Glaubens, der von der Einheit, Einzigkeit, Souveränität und Transzendenz Gottes auf der einen Seite, von seiner Nähe, Zugewandtheit, Wirk- und Geschichtsmächtigkeit andererseits getragen ist. Das Tetragramm zu schreiben, gehört in der jüdischen Religion zu den am stärksten mit Ehrfurcht, Gebet und religiöser Intensität verbundenen Handlungen; ebenso die Begegnung mit dem Gottesnamen in der Lektüre und im Studium der Bibel.

Liturgisch wird diese Liebe zum Namen Gottes in mehrschichtiger Weise intensiviert: durch den Verzicht bzw. das Verbot, ihn direkt auszusprechen; durch die Verwendung ganz bestimmter Ersatz-Namen als Chiffren oder Platzhalter für das Tetragramm, vor allem schem/haschem: Name und adon/adonai: Herr, aber auch melek: König, makom: Ort oder ha-olam: der Ewige; durch spezielle Akte der „Heiligung des Namens Gottes“ im Kontext zentraler liturgischer Gebete, ich verweise nur auf die dritte Benediktion der Amida, die keduschat ha-schem; schließlich durch ein lobpreisendes Innehalten in der liturgischen Begegnung mit dem Wort und Namen Gottes.

20 Vgl. Groen, Bert: Anti-Judaism in the Present-Day Byzantine Liturgy, in: The Journal of Eastern Christian Studies 6o (2008) 369-387.

2I Vgl. dazu den Bericht einer Tagung des Grazer Instituts für Liturgiewissenschaft zusammen mit dem Komitee für christlich-jüdische Zusammenarbeit in Graz aus dem Jahr 20I2: Gerzabek, Daphne Maria: Das Judentum in der christlichen Bildwelt, in: Dialog DuSiach 89 (Oktober 20I2) II-24 und http://www.christenundjuden.org/berichte/4I9-das-judentum-in-der-christlichen-bildwelt [abgerufen am 23.6.20I4]. 
Die griechische Übersetzung der Hebräischen Bibel, die Septuaginta, überträgt das Tetragramm in der Regel mit Kyrios: Herr/Herrscher und führt auf diese Weise den Verzicht auf die direkte Verwendung des Gottesnamens weiter. Diese Tradition wurde christlicherseits beibehalten, wobei Kyrios/Herr als Ersatzname des Gottes Israels bereits im Neuen Testament zugleich Würdetitel Jesu Christi und Anzeiger seiner göttlichen Macht oder Gottessohnschaft werden konnte. Im Philipperhymnus heißt es: „,... damit vor dem Namen Jesu alle Knie sich beugen und jede Zunge bekennt: Jesus Christus ist der Herr (Kyrios)" (Phil 2,rof.); und Thomas redet im Johannesevangelium den Auferstandenen an mit „Mein Herr (Kyrios) und mein Gott" (Joh 20,28). Unbeschadet dieser christologischen Spitzentöne steht allerdings das neutestamentliche Gottesbekenntnis ganz klar auf dem Fundament des Gottesglaubens Israels. Der Herr, der Gott Israels, der eine und einzige Gott, ist der Vater Jesu Christi. Sein Name ist heilig und wird von Jesus und seinen Gefährt/inn/en geheiligt, wie es im Vater Unser pointiert zum Ausdruck kommt.

Hierin liegen mehrere Aufträge für das liturgische Beten, die Heiligung des Namens Gottes und die trinitarische Gebetsrede christlicher Liturgie:

\section{I Ehrfurcht und besondere Sorgfalt im Umgang mit dem Namen Gottes und mit liturgischen Gottesanreden}

Diesbezüglich findet sich ein interessanter Hinweis in der römischen Instruktion „Liturgiam authenticam“ über Fragen der Übersetzung liturgischer Bücher in die Volkssprachen. ${ }^{22}$

Nach der seit unvordenklicher Zeit überlieferten Tradition, die ja schon in der genannten Septuaginta-Übersetzung sichtbar ist, soll der Name des allmächtigen Gottes - hebräisch das heilige Tetragramm, lateinisch Dominus - in jeder Volkssprache durch ein Wort derselben Bedeutung [also mit Dominus/Herr] wiedergegeben werden. $^{23}$

Die Kongregation für den Gottesdienst und die Sakramentenordnung hat dazu im Jahr 2008 auch einen Brief an alle Bischofskonferenzen gerichtet, in dem diese Regel erläutert und mit Nachdruck eingemahnt wird, und zwar nicht nur für bib-

22 Kongregation für den Gottesdienst und die Sakramentenordnung (Hg.): Liturgiam authenticam. Der Gebrauch der Volkssprachen bei der Herausgabe der Bücher der römischen Liturgie, Fünfte Instruktion zur ordnungsgemäßen Ausführung der Konstitution des Zweiten Vatikanischen Konzils über die heilige Liturgie, Rom 200 . 
lische Texte, sondern auch für Gebets- und Gesangstexte. Die erste der drei Richtlinien am Ende des Briefes lautet: „In liturgischen Feiern, in Liedern und Gebeten ist der Name Gottes in der Form des Tetragramms JHWH weder zu verwenden noch auszusprechen." ${ }^{24}$

In der liturgischen Praxis ist die konsequente Vermeidung des Tetragramms jedoch erst ganz selten anzutreffen. So wird beispielsweise in der zentralen alttestamentlichen Lesung der Osternachtliturgie (Ex I4) und dem unmittelbar darauf gesungenen Befreiungslied nach dem Durchzug der Israelit/inn/en durch das Rote Meer (Ex I5) das Tetragramm sowohl in der Lesung gesprochen (Ex I4,25) als auch im darauf folgenden Responsorial-Gesang gesungen (Ex I5,3); dies ist auch noch der Fall im neuen Münchener Kantorale, das für das jüngst erschienene Gebetund Gesangbuch Gotteslob (2013) erstellt wurde bzw. gerade im Entstehen ist. ${ }^{25}$ Es ist ein fälliger Lernschritt für die christliche Liturgie, so wie in der jüdischen Praxis auf das Aussprechen des Tetragramms zu verzichten. Ob es aber exklusiv mit Dominus/Herr umschrieben werden soll, wie dies auch im genannten Brief herausgestrichen wird ${ }^{26}$ sei hier ausdrücklich in Frage gestellt.

\subsection{Pflege des Bewusstseins und jener Sprachformen, die das trinitarische Beten der Kirche und ihrer Liturgie ohne jede Verunklärung innerhalb des Fundaments des „einen Gottes der Bibel“ verankern}

Auch hierzu ein Beispiel im Blick auf die abschließende Doxologie des Tagesgebetes, eine täglich wiederkehrende prominente Stelle trinitarischen Betens in der römisch-katholischen Liturgie. Die Formel lautet im Lateinischen:

24 Eine Kopie des Schreibens findet sich auf http://de.scribd.com/doc/471923I/On-the-Name-of-God [abgerufen am 23.6.20I4]. Ich danke Hans Hermann Henrix für den Hinweis auf diesen Link. Er verfasste auch die deutsche Übersetzung, zu finden auf http:// www.nostra-aetate.uni-bonn.de/kirchliche-dokumente/online-publikation-die-kirchen-und-das-judentum/i.-katholische-verlautbarungen-I/dokumente/brief-an-die-bischofskonferenzen-zum-2orenamen-gottes2orc [abgerufen am 23.6.20I4].

25 Vgl. dort den zweiten Vorsängervers auf Seite 202 der Internetversion des Münchener Kantorales für das Lesejahr A: http://www.gotteslob.de/fileadmin/Redaktion/PDF/MueKao_33_ONa.pdf [abgerufen am 23.6.20I4]. Die Printversion des Buches ist in Arbeit. Im Freiburger Kantorenbuch ist das Tetragramm konsequent durch die Bezeichnung HERR ersetzt. Vgl. Amt für Kirchenmusik der Erzdiözese Freiburg (Hg.): Freiburger Kantorenbuch zum Gotteslob. Antwortpsalmen im Kirchenjahr, Stuttgart: Carus 2013, 91 u. ö.

26 Vgl. die zweite Richtlinie am Ende des Schreibens, http://de.scribd.com/doc/471923I/Onthe-Name-of-God [abgerufen am 23.6.20I4]. 
Per Dominum nostrum Iesum Christum Filium tuum, qui tecum vivit et regnat in unitate Spiritus Sancti,

Deus, per omnia saecula saeculorum. Amen.

Die Übersetzung im Messbuch für das deutsche Sprachgebiet lautet gegenwärtig:

Darum bitten wir durch (ihn,)

Jesus Christus, deinen Sohn, unseren Herrn und Gott, der in der Einheit des Heiligen Geistes mit dir lebt und herrscht in alle Ewigkeit. Amen. ${ }^{27}$

Durch diese Übersetzung wird Christus unvermittelt als Gott tituliert, während das Wort Deus in der lateinischen Vorlage den einen bzw. drei-einen Gott am Ende der Doxologie noch einmal explizit bezeichnet und damit eine Brücke zur Gottesanrede am Beginn der Oration schlägt.

Am stärksten irritiert es, wenn - wie es leider nicht selten in der liturgischen Praxis geschieht - die Formel nur verkürzt gebetet wird, und man dann mitunter folgende Variante hören kann: „Darum bitten wir durch Jesus Christus, deinen Sohn, unseren Herrn und Gott. Amen." Gegen solche Verkürzungen gilt es, von der Ehrfurcht und Sorgfalt jüdischer Gottesrede im liturgischen Gebet zu lernen.

Es geht hierbei auch um die Pflege des Bewusstseins und jener Sprachformen, die deutlich machen, dass kein Wort aus Menschenmund Gott dingfest machen oder abschließend benennen, geschweige denn begreifen kann. Vielmehr ist es umgekehrt: Die Versuche des Menschen, die Erfahrung Gottes, seiner Nähe und seiner Entzogenheit, in Worten und Gesten zum Ausdruck zu bringen, sind Zeugnisse für das unverfügbare Wort Gottes, das den Menschen trifft, bewegt und ihm allererst eine Sprache verleiht, um durch seine Geschöpflichkeit und seine Sprachfähigkeit den anzuzeigen, der über allen Namen ist, und ohne den es keinen Namen gäbe. Das Benennen und Beim-Namen-Rufen Gottes ist - gerade auch innerhalb der Liturgie - nicht Ausdruck einer eindeutigen, objektiven sprachlich fassbaren Gegebenheit oder Wahrheit, sondern Zeugnis einer Beziehung zwischen Gott und Mensch, die sprachlich niemals vollständig und objektiv eingeholt werden kann.

27 Allgemeine Einführung ins Messbuch (AEM), in: Die Feier der Heiligen Messe, Teil I, $19^{*}-69^{*}$, Nr. 32 . 
4. Vertiefung des dialogischen Grundprinzips christlicher Liturgie durch das Studium jüdischer Liturgie

Liturgisches Gottes-Gedenken ist, biblisch verstanden, wesentlich mehr als menschliche Erinnerung: Es ist zunächst ein Handeln Gottes. In der lobpreisenden und bekennenden Aktualisierung des Gedenkens Gottes antworten Israel und die christlichen Kirchen dem Wunder der Erwählung, der Befreiung und der Erlösung durch Gott und lassen so jeweils neu das erbarmende Gedenken Gottes in der konkreten Lebenswelt und Lebenszeit der Glaubensgemeinschaft aufscheinen und wirksam werden. So werden im Gebet Synagoge und Kirche erfüllt mit dem Gedächtnis Gottes, und sie bringen sich bei Gott ins Gedächtnis, damit sein Gedenken an ihnen auch heute und morgen fruchtbar wird. ${ }^{28}$

Den Reformprinzipien der Liturgiekonstitution des Zweiten Vatikanums liegt dieses dialogische und heilsgeschichtliche Verständnis des Gottesdienstes als gemeinschaftliche Gedächtnisfeier der Geschichte Gottes mit seinem Volk und als lebendiges und fortdauerndes Gespräch zwischen Gott und Mensch zugrunde. Besonders hervorzuheben ist, dass - ganz analog zur Tora-Liturgie in der Synagoge - nun die rituelle Inszenierung des Wortes Gottes, also der feierliche Vortrag biblischer Lesungen, die Prozession mit dem Evangeliar bzw. mit der Bibel, die Akklamationen/Huldigungsrufe zu den Lesungen, der Psalm, der Ruf vor dem Evangelium, die Predigt, der Ambo als eigens ausgewiesener Ort der Präsenz Gottes in seinem Wort - dass also die rituelle Inszenierung des Wortes Gottes in ihrer Verflechtung von Gebet, Gesang und Lesung Liturgie im Vollsinn des Wortes konstituiert, also Ereignis der Nähe Gottes, Offenbarungsgeschehen in der Gestalt symbolisch-rituellen Handelns, und Begegnung zwischen Gott und Mensch im Mysterium seines Wortes ist.

Hier lässt sich die gemeinsame biblische und liturgietheologische Basis jüdischer (Tora-Liturgie) und christlicher (Wort-Gottes-) Liturgie besonders gut erkennen. Beide sind geprägt durch das Zusammenspiel von Verkündigung des Wortes Gottes mit lobpreisendem und bekennendem Gestus, Bekenntnis, Gebet und Doxologie/Verherrlichung. Und in beiden wird die nicht auflösbare Spannung zwischen der gnadenhaft gewährten Gegenwart Gottes in seinem Wort und seiner nicht fassbaren Transzendenz zur Grundlage des feierlich inszenierten gottesdienstlichen Wort- und Zeichengeschehens.

28 Vgl. hierzu die umfangreiche Studie: Wahle, Stephan: Gottes-Gedenken. Untersuchungen zum anamnetischen Gehalt christlicher und jüdischer Liturgie (Innsbrucker theologische Studien 73) Innsbruck: Tyrolia 2006. 
Von außen betrachtet scheint allerdings zunächst eine unüberbrückbare Differenz in der formalen Grundanlage synagogaler Liturgie und christlicher Wort-Gottes-Feier vorzuliegen:

In der Synagoge wird zuerst das Bekenntnis vollzogen (Sch'ma Israel mit Begleitgebeten) - dann folgt das Gebet in Lobpreis, Bitten und Dank (Amida) - und schließlich die Verkündigung des Wortes Gottes (Tora; z. B. im Sabbatmorgengottesdienst).

In der christlichen Wort-Gottes-Feier ist es gerade umgekehrt. Hier geht die Verkündigung voran (Lesungen, Evangelium, Auslegung des Wortes Gottes) dann folgt das Gebet (Allgemeines Gebet der Gläubigen, Antwort der Gemeinde) - und schließlich das Bekenntnis (Glaubensbekenntnis).

Doch diese Differenz relativiert sich, sobald die da wie dort vorhandene Mehrschichtigkeit innerhalb der einzelnen Rituselemente erkannt wird: Sowohl die Gebetsakte als auch die Verkündigungsakte der Liturgie repräsentieren eine Dialogik von Gotteswort und Menschenwort, von erbetener und ergehender Offenbarung, und zwar so, dass im Gebet stärker die Expressivität der Gottesdienstversammlung zur Repräsentationsfigur dieser Dialogik wird, während in den Verkündigungsakten stärker die Expressivität kanonischer Objektivierungsgestalten diese Dialogik repräsentiert. Bedeutsam ist allerdings, dass in beiden Repräsentationsgestalten das jeweils andere Moment nicht fehlt: Die Gebets- und Bekenntnisakte sind durchzogen von biblischen Referenzen; die Verkündigungsakte sind durchzogen von Elementen „subjektiver Expressivität" durch die Stimmen der Vorleser/innen, die Begleitgebete, die Huldigungsrufe sowie das Predigtwort.

Vor allem diese Verschränkungen sind charakteristisch für das gemeinsame liturgietheologische Profil des Gottesdienstes in Synagoge und Kirche. Hier gibt es viel voneinander zu lernen, ohne die Spezifika der jeweils anderen Liturgie in Frage stellen oder ausblenden zu müssen.

\section{Schluss}

Erich Zenger hat in einem seiner letzten Zeitschriftenbeiträge prägnant formuliert, was in den Lern- und Veränderungsschritten der christlichen Theologie in erster Linie notwendig ist: der Verzicht auf das Pathos christlicher Überlegenheit und Überbietung; stattdessen, sagt er, gilt es ein Pathos der Dankbarkeit gegenüber dem Judentum und der Verbundenheit mit ihm zu pflegen, auch wenn diese Verbundenheit in wichtigen Fragen Differenz und Nicht-Übereinstimmung bedeutet. ${ }^{29}$

29 Vgl. Zenger, Erich: Die Bibel Israels. Grundlage des christlich-jüdischen Dialogs, in: KuI 
In der Welt der christlichen Liturgien ist ein Prozess in Gang gekommen, in dem realisiert wird, dass jüdischer Glaube und jüdischer Gottesdienst unmittelbar mit christlicher, kirchlicher Identität zu tun haben, weil eben jüdischer Glaube und Gottesdienst unwiderruflich Entscheidendes mit dem einen Gott der Bibel, dem ganz Anderen und doch unerhört Nahen zu tun haben. Dieser Prozess hat die Liturgiewissenschaft und die Liturgien vieler christlicher Kirchen in den letzten Jahrzehnten ein Stück weit verändert, und er wird sie - so ist zu hoffen - weiter verändern.

24 (2009) $25-38,35$. 


\title{
Das neue „Gotteslob“ (2013) und die Hebräische Bibel
}

\author{
Ein kritischer Durchblick
}

Albert Gerhards

In den 38 Jahren zwischen den beiden Ausgaben des katholischen Gebet- und Gesangbuchs "Gotteslob“, also zwischen 1975 und 2013, hat sich in Bezug auf das Verhältnis von Kirche und Theologie zum Alten Testament und zum Judentum in Geschichte und Gegenwart ein riesiger Erkenntnisgewinn eingestellt, der als Paradigmenwechsel einzustufen ist und deshalb nicht ohne Auswirkungen auf die zweite Ausgabe des gemeinsamen Gebet- und Gesangbuchs geblieben sein kann. Im Folgenden geht es darum, schlaglichtartig zu überprüfen, ob das neue Buch dem in der theologischen Forschung und kirchlichen Dokumenten erreichten Standard entspricht.

Dieser kann hier nur in Bezug auf die Liturgiewissenschaft kurz skizziert werden. Zum einen hat der interdisziplinäre Austausch zwischen alttestamentlicher Exegese und Liturgiewissenschaft zu Konvergenzen in der Wahrnehmung und Einschätzung des Verständnisses und des Gebrauchs alttestamentlicher Texte in biblischer und christlicher Zeit geführt. Dabei wuchs zunehmend die Anerkennung des Eigenwerts alttestamentlicher Texte unabhängig von ihrer neutestamentlichen und kirchlichen Rezeption. Dies äußerte sich z. B. in der Erarbeitung alternativer Leseordnungen sowie in der Neubewertung der so genannten Feindpsalmen. Zum anderen regte der christlich-jüdische Dialog zu einer neuen Sicht auf die jüdische Liturgie an, die nicht mehr als bloße Vorläuferin und Zulieferin christlicher Liturgie angesehen wird, sondern im Sinne des dynamischen Interaktionsmodells als Partnerin auf Augenhöhe. ${ }^{1}$ Die Grundlage für die Neubewertung war zwar schon mit der Konzilserklärung Nostra Aetate gelegt und mit der Neuformulierung der Judenfürbitte am Karfreitag liturgisch ratifiziert worden, deren theologische, näher hin soteriologische und ekklesiologische Implikationen 1975 gleichwohl noch längst nicht eingeholt. Das sollte, so die logische Schlussfolgerung, fast vier Jahrzehnte später wohl der Fall sein.

I Vgl. Rouwhorst, Gerard: Christlicher Gottesdienst und der Gottesdienst Israels. Forschungsgeschichte, historische Interaktionen, Theologie, in: Klöckener, Martin / Häußling, Angelus A. / Meßner, Reinhard (Hg.): Gottesdienst der Kirche. Handbuch der Liturgiewissenschaft 2/2, Regensburg: Pustet 2008, 49I-572. 
Im Folgenden werden Stichproben entsprechend den literarischen Gattungen vorgenommen: I. Einführungstexte, 2. Biblische Texte sowie 3. Gebete und Gesänge.

\section{$\mathrm{Zu} \mathrm{I.:} \mathrm{Einführungstexte}$}

Die neuen Einführungstexte werden gegenüber denen in GL 1975 gelobt als gelungene katechetische Unterweisungen, die dem Anspruch von GL 2013 als christliches Hausbuch gerecht werden. ${ }^{2}$ Im benutzerfreundlichen Stichwortverzeichnis zu Beginn sucht man freilich Altes Testament und Judentum vergeblich. Zweifellos wird der Heiligen Schrift ein hoher Stellenwert eingeräumt: Das Hören auf Gottes Wort steht vor dem Antworten in Gesang und Gebet. ${ }^{3}$ Die Einführung ${ }^{4}$ interpretiert die Bibel jedoch sogleich christozentrisch ${ }^{5}$ und ekklesiozentrisch, ohne zu erwähnen, dass die Kirche ihre heiligen Schriften zunächst dem Judentum, zu dem Gott zuerst gesprochen hat ${ }^{6}$, verdankt.

Bei der Abhandlung über das Gebet (GL 2) wird die Bibel als „gottgeschenktes Gebetbuch" bezeichnet, unter anderem werden die Psalmen erwähnt, nicht aber deren Herkunft vom und die Gemeinsamkeit ihrer Verwendung mit dem Judentum. Wer solches in der Einführung zum Psalmteil (GL 30) erwartet, sieht sich wieder enttäuscht. Der Einleitungsabschnitt beginnt:

Die Psalmen des Alten Testaments haben ihre eigene Art, uns vor die Frage zu stellen, ob wir richtig und erfüllt leben. Das ist eine uralte Frage. Darum sollten wir uns nicht wundern, dass sie uns auch in alter, bisweilen sogar altertümlicher Sprache, in manchmal uns fremden Bildern und mit überraschenden Blickrichtungen begegnet.

Nach einem Blick auf Ps I, „Selig der Mensch“, wird festgestellt, dass seit fast 3000 Jahren „Juden wie Christen“ die Psalmen in Gebet und Liturgie ganz unterschied-

2 Vgl. Gassmann, Michael: Sympathien für die Tradition. Das neue Gotteslob, in: Stimmen der Zeit 23I (20I3) 78I-784, 782.

3 Vgl. Meßner, Herbert: Eine Schule des Betens. Zum Gebetsteil im künftigen „Gotteslob”, in: Gottesdienst 6 (2013) 49-5I, 49.

4 (Erz-)Bischöfe Deutschlands und Österreichs und der Bischof von Bozen-Brixen (Hg.): Gotteslob. Katholisches Gebet- und Gesangbuch, Stuttgart: Verl. Katholisches Bibelwerk 2013, Nr. I. Weitere Aufzählungen erfolgen im Fließtext.

5 Unter Bezug auf Sacrosanctum Concilium Nr. 7.

6 Vgl. die Fürbitte für die Juden am Karfreitag, dazu: Homolka, Walter / Zenger, Erich (Hg.): „... damit sie Jesus Christus erkennen“. Die neue Karfreitagsfürbitte für die Juden (Theologie kontrovers), Freiburg: Herder 2008. 
lich gelesen und gedeutet hätten. Immerhin wird die kanonische Psalterexegese erwähnt, ansonsten aber der Christologisierung des Psalters breiter Raum gewährt, ohne auf die Legitimität unterschiedlicher Zugänge zu verweisen. Das Monopol der typologischen Psalmenrezeption wird nicht infrage gestellt. ${ }^{7}$

In Bezug auf die einleitenden Texte zum Kirchenjahr sollen der Sonntag und der Osterfestkreis in den Blick genommen werden. Der kurze Abschnitt über den Sonntag (GL 217/I) spricht nur vom „ersten Tag der Woche“, nicht aber vom Tag nach dem Sabbat. Dass die Deutung des Sonntags als Auferstehungstag nur aus dem in der Sabbatruhe fokussierenden Triduum Paschale ableitbar ist, kommt nicht zur Sprache, auch nicht im Zusammenhang mit den Einleitungen zu Ostern (GL 217/2). Das Wort „Sabbat" begegnet im 3. Gebot des Dekalogs (GL 29/6), wird aber nicht kontextualisiert. Bei der Einleitung in die österliche Bußzeit werden zwar die 40-jährige Wüstenwanderung Israels erwähnt sowie das 40-tägige Verweilen Moses auf dem Sinai und die gleichlange Wanderung Elias zum Horeb, aber doch nur, um das 40-tägige Fasten Jesu zu begründen. Bei der Einführung in das Triduum Sacrum (GL 303f.) begegnet nur die typologische Deutung der alttestamentlichen Begebenheiten, die alttestamentlichen Texte haben hier nur vorbereitende Funktion. ${ }^{8}$ Am Karsamstag (GL 309) findet der Deszensus, nicht aber der Sabbat - das Ruhen im Grab - Erwähnung. In der Einleitung zum Ostersonntag wird die „Befreiung des Volkes Gottes (welchen Volkes?) aus dem Sklavenhaus Ägypten" erwähnt (GL 3II); dass dieses Fest aber etwas mit dem jüdischen Pessach zu tun hat, wurde keiner Erwähnung wert befunden. Folglich fehlt bei der Osterzeit (GL 317) der Hinweis auf Schawuot. Man muss beim Hören der Pfingsterzählung wohl den Eindruck gewinnen, an Pfingsten sei Jerusalem nur deshalb voller jüdischer Pilgerinnen und Pilger gewesen, weil sie alle den Heiligen Geist hätten kommen sehen ...

Ein letzter Blick gilt der Einleitung in die Tagzeitenliturgie. Diese besteht ja vorwiegend aus alttestamentlichen Texten und erklärt sich letztlich aus dem Judentum. Im GL wird es aber nur als Gebet der Kirche in Anschluss an I Thess 5,I7 („Betet ohne Unterlass!“) eingeführt (GL 6r3/I), der Zusammenhang mit dem jüdi-

7 Vgl. Gerhards, Albert: Die Psalmen in der römischen Liturgie. Eine Bestandsaufnahme des Psalmengebrauchs in Stundengebet und Meßfeier, in: Zenger, Erich (Hg.): Der Psalter in Judentum und Christentum (HBS I8), Freiburg: Herder 1998, 355-379.

8 Vgl. die Gegenüberstellung einst - jetzt: Gründonnerstag (GL 303, 304), Trauermette am Karfreitag (GL 307); vgl. dazu: Gerhards, Albert: Ego exaltavi te magna virtute. Die latente Präsenz des Anderen in jüdischer und christlicher Liturgie, in: Frankemölle, Hubert / Wohlmuth, Josef (Hg.): Das Heil der Anderen. Problemfeld Judenmission (QD 238), Freiburg: Herder 20I0, 542-555. 
schen Beten in Tempel, Synagoge und Haus ist mit keinem Wort erwähnt.

Fazit: In den einleitenden Texten kommen das Alte Testament als eigenständige und das Judentum als geschichtliche und gegenwärtige Größe praktisch nicht vor. Das Alte Testament ist Vorläufer und Materiallieferant, das Judentum erscheint nur als Vorspiel ohne Gegenwartsrelevanz.

\section{Zu 2.: Biblische Texte}

In Bezug auf die biblischen Texte beschränke ich mich auf einige Fragen der Auswahl und der Übersetzung der Psalmen. Das GL 20I3 enthält mit ca. 70 Psalmen nur unwesentlich mehr an Material als sein Vorgänger. ${ }^{9}$ Allerdings konnte mit einer der heutigen Psalterexegese entsprechenden Auswahl - hier waren die Alttestamentler Erich Zenger und Frank-Lothar Hossfeld maßgeblich beteiligt - ein repräsentativer Auszug aus dem Psalter vorgelegt werden. Zu bemängeln ist allerdings, dass die Auswahl der Verse nicht als solche kenntlich gemacht worden ist, was bei vielen zu der irrigen Annahme führt, die Verse im GL gäben den ganzen Psalm wieder. Das gilt keineswegs nur für die Feindpsalmen bzw. Fluchverse. ${ }^{10}$

Ein nicht weniger gravierendes Problem stellt die Psalmenübersetzung dar. ${ }^{11} \mathrm{Ei}-$ ner der Beweggründe für die Neufassung des GL 1975 war die liturgische Gesetzgebung, insbesondere die $200 \mathrm{I}$ erschienene Übersetzerinstruktion „Liturgiam authenticam. " Der zufolge müssen sämtliche liturgischen Texte sämtlicher Sprachfamilien neu übersetzt werden, darunter also auch die biblischen Texte. ${ }^{12}$ Bekanntlich führte dies zur Aufkündigung des ökumenischen Projekts Einheitsübersetzung; doch nutzten die beteiligten Bibelwissenschaftler die Gelegenheit, den in vieler Hinsicht revisionsbedürftigen Text der Einheitsübersetzung nach exegetischen, sprachlichen und musikalischen Kriterien so zu erneuern, dass er durchaus auch ökumenisch Akzeptanz finden könnte. Der Unterschied beider Fassungen soll am Beispiel des für die Abendliturgie in Ost und West bedeutenden Psalmes I4I (GL I40 $)^{13}$ kurz erläutert werden.

9 Vgl. Praßl, Franz K.: Gotteslob ante portas. Was das neue Gebet- und Gesangbuch bringt, in: HerKorr Spezial I (2013) 20-25, 24.

io Vgl. dazu Ps iıo,6.

II Vgl. Praßl: Gotteslob, 22.

I2 Vgl. Gerhards, Albert: Tradition versus Schrift? Die Übersetzerinstruktion „Liturgiam authenticam " und die deutsche Einheitsübersetzung, in: Ders.: Erneuerung kirchlichen Lebens aus dem Gottesdienst. Beiträge zur Reform der Liturgie (Praktische Theologie heute I20), Stuttgart: Kohlhammer 20I2, I2O-I26.

I3 Vgl. Gerhards, Albert: Art. Stundengebet. I. Geschichte, in: TRE 32 (2000) 268-276. 
Psalm I4I (I40)

\section{Einheitsübersetzung} I4I,I [Ein Psalm Davids.] Herr, ich rufe zu Dir. Eile mir zu Hilfe; höre auf meine Stimme, wenn ich zu dir rufe.

2 Wie ein Rauchopfer steige mein Gebet vor Dir auf; als Abendopfer gelte vor dir, wenn ich meine Hände erhebe.

3 Herr, stell eine Wache vor meinen Mund, eine Wehr vor das Tor meiner Lippen!

4 Gib, daß mein Herz sich bösen Worten nicht zuneigt, daß ich nichts tue, was schändlich ist, zusammen mit Menschen, die Unrecht tun. Von ihren Leckerbissen will ich nicht kosten.

5 Der Gerechte mag mich schlagen aus Güte: Wenn er mich bessert, ist es Salböl für mein Haupt; da wird sich mein Haupt nicht sträuben. Ist er in Not, will ich stets für ihn beten.

6 Haben ihre Richter sich auch die Felsen hinabgestürzt, sie sollen hören, daß mein Wort für sie freundlich ist.

7 Wie wenn man Furchen zieht und das Erdreich aufreißt, so sind unsre Glieder hingestreut an den Rand der Unterwelt.

\section{Neuübersetzung GL}

I [...] Ein Psalm Davids. [...]

HERR, ich habe dich gerufen, eile mir zu Hilfe!* Höre auf meine Stimme, wenn ich zu dir rufe!

2 Mein Bittgebet sei ein Räucheropfer vor deinem Angesicht, ${ }^{*}$ ein Abendopfer das Erheben meiner Hände.

3 HERR, stelle eine Wache vor meinen Mund,* behüte das Tor meiner Lippen!

4 Neige mein Herz nicht zum bösen Wort, ${ }^{*}$ damit ich nicht frevlerische Taten verübe zusammen mit Männern, die Unrecht tun, ${ }^{*}$ damit ich nicht koste von ihren Genüssen.

5 Schlägt mich ein Gerechter, ist es Liebe, / weist er mich zurecht, ist es Salböl, das mein Haupt nicht verweigert.* Ja, immer noch bete ich für sie trotz ihrer Bosheit.

6 Sind ihre Richter auf Felsen hinabgestürzt, ${ }^{*}$ dann werden die Frevler meine Worte hören, denn diese waren freundlich.

7 Wie beim Aufhacken und Pflügen der Er$\mathrm{de},{ }^{*}$ so sind unsere Knochen hingestreut an den Rand der Totenwelt. 
8 Mein Herr und Gott, meine Augen richten sich auf dich; bei dir berge ich mich. Gieß mein Leben nicht aus!

9 Vor der Schlinge, die sie mir legten, bewahre mich, vor den Fallen derer, die Unrecht tun!

Io Die Frevler sollen sich in ihren eigenen Netzen fangen, während ich heil entkomme.
8 Doch auf dich, HERR, mein Herr, richten sich meine Augen, ${ }^{*}$ bei dir berge ich mich, gieße nicht aus mein Leben!

9 Behüte mich vor dem Zugriff der Falle, die sie mir stellten, ${ }^{*}$ und vor dem Fangholz derer, die Unrecht tun!

Io In ihre eigenen Netze werden die Frevler fallen -* sie alle miteinander, ich aber entkomme.

In V. 2 ist die Endbetonung bei „auf“ nicht sinngemäß. Sachlich geht es darum, dass das private Gebet an die Stelle des Räucheropfers tritt sowie das Erheben der Hände an die des Abendopfers. Dabei ist weniger an die Substitution des Tempelopfers zu denken als an eine Harmonie von Privatgebet und Tempelkult. ${ }^{14} \mathrm{~V}$. 5, 6 und 7, die Mitte des Psalms, „zeigen die Verführbarkeit des Beters an, wie er auf die ,correctio fraterna' durch den Gerechten angewiesen bleibt, damit er sich nicht mit den Frevlern verbündet und seinem Lebenskonzept untreu wird. "15 Mit dem Gattungscharakter des weisheitlichen Klage- und Bittgebets aus nachexilischer Zeit korrespondiert die Neufassung von V. 5, wo nun die Bosheit der Feinde der weisheitlichen „correctio fraterna“ entgegengesetzt wird. Und doch: Der Gerechte betet auch für seine Feinde. Diesen wird in V. 6 immer noch die Möglichkeit der Bekehrung zugestanden, wenngleich ihre Bosheit weiterhin droht (V. 7 und 9). ${ }^{16}$

Der Fortschritt gegenüber dem alten Einheitstext wird allein schon an diesem Beispiel evident. Man hat ihn aber nicht für so erheblich angesehen, dass man deswegen das Erscheinen des Buchs noch herausgezögert hätte, um die römische Approbation abzuwarten oder - da man wohl vertraglich an Produktionszeiten gebunden war - dass man den neuen Text im „vorauseilenden Gehorsam“ ohne formelle Approbation abgedruckt hätte. Der dadurch in Kauf genommene Schaden für die wünschenswerte größere Akzeptanz der Psalmen in Spiritualität und Liturgie ist gewaltig. Bekanntlich ist es der Liturgiereform im deutschen Sprach-

I4 Vgl. Hossfeld, Frank-Lothar / Zenger, Erich: Psalmen IOI-I50 (HThKAT), Freiburg: Herder 2008, 747.

I5 Ebd. 746.

I6 Vgl. ebd., 748-750. 
gebiet nicht gelungen, die alttestamentliche Lesung und den Antwortpsalm in den Sonntagsgottesdienst zu integrieren, vom gemeindlich vollzogenen Stundengebet ganz zu schweigen. ${ }^{17}$ Eine in Sprachduktus und Textverständnis verbesserte Version der Psalmen wäre hier am Platz gewesen.

\title{
$\mathrm{Zu}$ 3.: Gebete und Gesänge
}

Auch hier nur wenige Bemerkungen: Die Unterkommission für die religiösen Beziehungen zum Judentum der Deutschen Bischofskonferenz (DBK) war in die Arbeiten am neuen GL involviert, insofern ihr die Texte zur kritischen Durchsicht vorgelegt wurden ${ }^{18}$. Bei den Verbesserungsvorschlägen wurde öfter angeregt, in einer Anmerkung auf den alttestamentlichen bzw. jüdischen Zusammenhang bestimmter Texte hinzuweisen. Diese wie auch die meisten anderen Vorschläge ${ }^{19}$ wurden nicht berücksichtigt. Besondere Emphase wurde auf eine Revision der Neuübersetzung des „Tantum ergo“, der beim eucharistischen Segen verwendeten 5. Strophe des Hymnus „Pange lingu““, ${ }^{20}$ gelegt. Dazu gibt es eine große Zahl von Varianten, die mit Ausnahme der ganz freien Übertragungen sämtlich substitutionstheoretisch verstanden werden. Folgende Varianten sind bekannt:

\section{Hymnus „Pange lingua“, Str. s}

\author{
Tantum ergo sacramentum / veneremur cernui, \\ et antiquum documentum / novo cedat ritui. \\ praestet fides supplementum / sensuum defectui. \\ (Thomas von Aquin I263/64) \\ Lasst uns tiefgebeugt verehren / dies erhab'ne Sakrament, \\ und der Brauch der alten Lehren / weich' dem neuen Testament. \\ Frommer Glaube wird gewähren, / was der Sinn hier nicht erkennt. \\ (Wikipedia 20II, Internet passim)
}

I7 Vgl. Budde, Achim: Gemeinsame Tagzeiten. Motivation - Organisation - Gestaltung (Praktische Theologie Heute 96), Stuttgart: Kohlhammer 2013.

I8 Insbesondere Prof. Dr. Hans Hermann Henrix erarbeitete zahlreiche Modi.

I9 Darunter eine Einleitung von Erich Zenger zu den Psalmen.

20 Vgl. Tück, Jan-Heiner: Gabe der Gegenwart. Theologie und Dichtung der Eucharistie bei Thomas von Aquin. Überarbeitete Neuauflage, Freiburg: Herder 2014. 
Darum lasst uns tief verehren / Ein so großes Sakrament

Dieser Bund wird ewig währen / Und der alte hat ein End.

Unser Glaube soll uns lehren, / Was das Auge nicht erkennt.

(Heinrich Bone 1847)

Gott ist nah in diesem Zeichen: / Knieet hin und betet an.

Das Gesetz der Furcht muss weichen, / da der neue Bund begann;

Mahl der Liebe ohnegleichen: / Nehmt im Glauben teil daran.

(Maria Luise Thurmair 1969 = GL 1975, 544)

Sakrament der Liebe Gottes: / Leib des Herrn, sei hoch verehrt, Mahl, das uns mit Gott vereinigt, / Brot, das unsre Seele nährt, Blut, in dem uns Gott besiegelt / Seinen Bund, der ewig währt.

(Friedrich Dörr I970 = GL I975, 542)

Lasst uns dieses große Zeichen / tiefgebeugt nun beten an.

Altes Zeugnis möge weichen, / da der neue Brauch begann.

Was die Sinne nicht erreichen, / nehme doch der Glaube an.

(Liborius Lumma 2008 = GL 20I3, 493)

Lasst uns dieses große Zeichen / tiefgebeugt nun beten an.

Altes Zeugnis konnte weichen, / da ein neuer Dienst begann.

Was die Sinne nicht erreichen, / nehme doch der Glaube an.

(Vorschlag Zenger/Gerhards 2009)

Die letzte Version wurde von der Unterkommission für die religiösen Beziehungen zum Judentum der Ökumenekommission der Deutschen Bischofskonferenz als Verbesserungsvorschlag eingereicht. Dem Kommissionstext war folgende Begründung angefügt: „Ein substitutionstheologisches (Miss-)Verständnis muss in jedem Fall ausgeschlossen sein. " ${ }^{21}$ In der Sache geht es im lateinischen Text des Thomas von Aquin um die heilsgeschichtliche bzw. rituelle Abfolge von Tieropfer und Eucharistie. Die Textkorrektur wurde von Bischof Heinrich Mussinghoff eingebracht, jedoch ohne Erfolg, da sie als interpretierende Übersetzung formal nicht mit der erwähnten Übersetzerinstruktion übereinstimmt. Eines der Probleme einer theologisch ausgewogenen Textfassung ist der Reimzwang, dem auch die Fassung von Lumma erliegt. Sinnvoll wäre eine Nachdichtung mit größerer formaler wie

2I Archiv Albert Gerhards. 
inhaltlicher Freiheit wie bei Dörr gewesen. So bleibt das Ärgernis des substitutionstheoretischen Verständnisses dieses häufig verwendeten Gesangs bestehen.

\section{Gesamtbewertung}

Die hier vorgebrachte Kritik am neuen "Gotteslob“ könnte leicht den Eindruck erwecken, es sei darin in Bezug auf AT und Judentum nur Negatives zu sehen. Dies ist keineswegs der Fall. In vieler Hinsicht handelt es sich bei der Neuauflage nicht nur um einen graduellen, sondern um einen substantiellen Fortschritt. Generell hat man aber die Chance vertan, die einmaligen Beziehungen der Kirche zum Judentum, ihre Verwurzelung in der Hebräischen Bibel, also das unlösbare Band zwischen Judentum und Christentum, ${ }^{22}$ herauszuarbeiten. Das fast vollständige Fehlen dieser Bezüge ist ein fatales Signal. So wird bei der Theologie des Segens (GL I3) mit keinem Wort erwähnt, dass die Wiederentdeckung der eulogischen Dimension, etwa in den neuen Begleitgebeten zur Gabenbereitung, aber auch in allen Segensgebeten der Sakramente und Sakramentalien, auf der Rezeption der jüdischen Berakha fußt. ${ }^{23}$ Der fast völlige Ausfall der Erwähnung der alttestamentlichen-jüdischen Bezüge der Liturgie des Tages, der Woche und des Jahres wurde bereits ausführlich kritisiert. Israeltheologie, Bundestheologie haben nirgendwo einen Ort. Selbst eine Jerusalemtheologie sucht man vergebens, andeutungsweise ist davon lediglich in einem eingeschobenen Text über die Wallfahrt (GL 22/4) die Rede, wenn von der Wallfahrt zum Jerusalemer Tempel („Bereits im Leben des Volkes Israel war [...]“) sowie von der endzeitlichen Völkerwallfahrt (Jes 2) die Rede ist. Aber auch hier ist die Perspektive christomonistisch und ekklesiozentrisch. Zwar ist ein nicht weiter spezifiziertes „Jüdisches Friedensgebet“ (GL 20/5) aufgenommen, es steht aber unter anderen Texten in der Rubrik „Dialog zwischen den Religionen“. Dass der jüdisch-christliche Dialog ein ganz besonderer ist, wird nicht erwähnt, und speziell für die Jüdinnen und Juden wird weder im Kontext der Religionen noch im Kontext der christlichen Ökumene gebetet. Im Übrigen kommt auch diese im neuen GL kaum zur Sprache, aber das ist ein anderes Thema. So bleibt nur zu hoffen, dass die bereits ins Auge gefasste Revision des GL 20I3 im Hinblick auf AT und Judentum zu besseren Ergebnissen kommt als der erste Durchgang.

22 Vgl. Nostra Aetate Nr. 4.

23 Vgl. Gerhards, Albert: Art. Berakha, in: $\mathrm{LThK}^{3} 2$ (1994) $238 \mathrm{f}$. 


\title{
Hat infolge des Christlich-Jüdischen Dialogs ein Paradigmen- wechsel in Kirche und Theologie stattgefunden?
}

\author{
Bertold Klappert
}

\author{
Karl-Josef Kuschel, \\ dem Tübinger Religionsdialogiker und Welt-Ethos-Promotor, \\ ist dieser Beitrag als Zeichen der Dankbarkeit \\ für langjährige und vertrauensvolle Weggemeinschaft \\ und gemeinsames ökumenisches Leben und Lernen zugeeignet.
}

Als Paradigmenwechsel wird zunächst die Absage an ein traditionell heidenchristliches Denkmodell bezeichnet, das das Judentum als zum Inneren der christlichen Religion gehörend bestimmt und im Sinne eines inklusiven dogmatischen Denkens das Judentum ohne das ökumenische Christentum der Völker als defizitär versteht. Paradigmenwechsel meint die Abkehr und Umkehr von allem inklusiv-christomonistischen Denken, das das Judentum im Rahmen der Ekklesiologie oder der Ökumene christlich zu- und einordnet, indem es das Judentum inklusiv zur Ökumene der Völker rechnet und in diesem Sinne nicht nur - gesamtbiblisch zu Recht - die Ökumene ohne das Judentum, sondern auch umgekehrt das Judentum ohne die Ökumene als defizitär bestimmt. Dieses traditionelle und auch heute noch weithin das ekklesiologische und dogmatische Denken und Handeln von Kirche und Theologie bestimmende Integrations- und Inklusionsmodell ist das Gegenmodell zu einem gesamtbiblisch fundierten und heute anzustrebenden Paradigmenwechsel.

Paradigmenwechsel in einem positiven Verständnis meint sodann, dass die Kirche als das ökumenische Gottesvolk aus allen Völkern ihre eigene Sendung an die Völker innerbalb der bleibenden Erwählung und Sendung Israels und seiner von JHWH gesetzten Bestimmung, das Licht für die Völker zu sein (Jes 42,6; 49,6; Lk 2,32), versteht. Von daher ist das Judentum nicht mehr, wie es in Umkehrung der gesamtbiblischen Inklusion bis heute geschieht, als „das alte Gottesvolk des alten Bundes“, dem die Kirche als „das neue Gottesvolk des neuen Bundes“ gegenübersteht, zu bestimmen, weil das Judentum selbst bereits anfangend innerhalb des Israel verheißenen neuen Bundes (Jer 31,3I-34) lebt und seinen Weg zum Ziel der Vollendung des verheißenen neuen Bundes in der neuen Welt Gottes entgegengeht (Röm II,27 ), wie Norbert Lohfink in seinem Buch „Der niemals gekündigte Bund“"1 (1989) gezeigt hat.

I Lohfink, Norbert: Der niemals gekündigte Bund. Exegetische Gedanken zum christlich-jüdischen Dialog, Freiburg: Herder 1989. 


\section{Der Passacharakter des letzten Mahles des Messias Jesus}

Karl-Joseph Kuschels Buch „Festmahl am Himmelstisch. Wie Mahl feiern Juden, Christen und Muslime verbindet ${ }^{\text {"2 }}$ hat uns von katholischer Seite her begründet Mut gemacht, bei der Feier der Eucharistie die Passamahltradition des Judentums für die Deutung des letzten Mahles Jesu wieder in den Blick zu nehmen, wie es mein Lehrer Joachim Jeremias in seinem Abendmahlsbuch im Jahre 1960 überzeugend getan hat. ${ }^{3}$

Kuschel wendet sich zu Recht unter den Überschriften „Jesu letztes Mahl: Kein Pessachmahl“ bzw. „Die Konsequenz: Entjudaisierung des Abendmahles“ ${ }^{\text { gegen }}$ die Ausführungen von Benedikt XVI. und dessen Plädoyer für die johanneische Tradition in seinem Jesus-Buch (Bd. II 20II). ${ }^{5}$ Diese Tradition ist aber doch nichts anderes als eine Vertiefung der synoptischen Passatradition, weil Johannes Jesu Kreuzigung am Passarüsttag des I4. Nisan zur Zeit der Schlachtung der Passalämmer stattfinden lässt (Joh I8,28; 19,I4), um damit zum Ausdruck zu bringen, dass der messianische Menschensohn das wahre Passalamm ist (Joh I,29). Trotz der differenzierter gewordenen historischen und exegetischen Diskussionslage, die Günter Stemberger umsichtig erörtert hat, ${ }^{6}$ stehe ich, wie mein Göttinger Kollege Berndt

2 Kuschel, Karl-Josef: Festmahl am Himmelstisch. Wie Mahl feiern Juden, Christen und Muslime verbindet, Ostfildern: Patmos 2013.

3 Jeremias, Joachim: Die Abendmahlsworte Jesu, Göttingen: Vandenhoeck \& Ruprecht ${ }^{3}$ I960.

4 Kuschel: Himmelstisch, 79-85.

5 Ratzinger, Josef/Benedikt XVI.: Jesus von Nazareth. Zweiter Teil: Vom Einzug in Jerusalem bis zur Auferstehung, Freiburg: Herder 2oII.

6 Stemberger, Günter: Pesachhaggada und Abendmahlsberichte des Neuen Testaments, in: Kairos 29 (1987) I47-158; wiederabgedruckt in: Ders.: Studien zum rabbinischen Judentum, Stuttgart: Kath. Bibelwerk 1990, 357-374. Dabei bestätigt Stemberger ausdrücklich „das Verständnis der synoptischen Abendmahlsberichte, die auf jeden Fall an ein Pesachmahl denken“ (359). Auch Philo überliefert, dass es „ein festliches Mahl mit dem Osterlamm und ungesäuerten Broten, begleitet von Gebeten mit Gesängen “ zur Zeit des Neuen Testamentes gegeben hat (372). Und „natürlich [war] der Tempel das Zentrum der Feier [...] und ein Pesachlamm [durfte] im eigentlichen Sinn nur in Jerusalem gegessen werden“ (ebd.). Wahrscheinlich ist „das Neue Testament als [älteste] Quelle für die frühe Entwicklung des Pesachseders zu verwenden“ (373), wie auch Flusser und Safrai mir gegenüber mündlich geäußert haben. - Michael Theobald hat in kritischer Weiterführung von Günter Stembergers mit Recht zurückhaltender Quellenanalyse auf die von Lukas gezielt verstärkte Passakontur des letzten Mahles Jesu hingewiesen und darüber hinaus wertvolle Hinweise auf den Zusammenhang von Passamahl und Eucharistiefeier gegeben. Vgl. Theobald, Michael: Paschamahl und Eucharistiefeier. Zur heilsgeschichtlichen Relevanz 
Schaller und der Mußner-Schüler Michael Theobald, ganz zu schweigen von den jüdischen Gelehrten wie David Flusser, Shmuel Safrai, Yehuda Aschkenazy, Shalom ben Chorin und Chana Safrai auch weiterhin zur These von der Passa-Kontur des letzten Mahles Jesu meines Göttinger Lehrers Joachim Jeremias.

Denn Deuteworte kommen bei der erstmaligen Erwähnung des Passafestes im josianischen Festkalender vor: „Du sollst [...] ungesäuerte Mazzen essen“, „[das ist] Brot des Elends" (Dtn I6,3). Und das jüdische Passamahl wurde und wird im Unterschied zu den anderen Mahltypen nur „in der Nacht“ (I Kor II,23), als „Nachtmahl“ (Martin Luther) gefeiert. Hinzu kommt, dass es schwer zu begründen ist, warum man nach Ostern ein Abschiedsmahl Jesu vor seinem Sterben, das wegen des fehlenden Passakontextes als „ein schlichtes Essen“ und „Ersatz“-Mahl gegen die jüdische Passaliturgie und den Tempelkult gefeiert worden sein soll, ${ }^{7}$ nachträglich in ein Passamahl verwandelt hätte. Die Ableitung des Herrenmahles von hellenistischen Mahltypen liegt der Forschung und ökumenischen Praxis heute historisch-exegetisch und dogmatisch-liturgisch wieder näher, „als wäre nichts geschehen“! Und auch unser protestantisches „Abendmahl“, das wir - obwohl sich kaum jemand über den Terminus „Abendmahl“ Gedanken macht -, sonntäglich am Morgen feiern, wird liturgisch nach wie vor begangen, ,als wäre nichts geschehen!“ ${ }^{8}$ Denn außer dem Rückgriff auf ein jüdisches Mahlgebet aus der Didache (EG 218) hat sich in unserer protestantischen Abendmahlsliturgie kaum etwas geändert.

Im Gegenteil: Nicht einmal der eschatologische Ausblick der messianischen Hoffnung von Mk I4,25 wird bei den Spendeworten mitzitiert. Hinzu kommt: Die Einsetzungsworte sind im Evangelischen Gesangbuch (EG I89) zum Teil falsch wiedergegeben: Jesus wird nach I Kor II, 23 „dahingegeben“. Das schließt zwar auch das „er wurde verraten" (EG I89) ein, ist aber in seiner theologischen Bedeutung tiefer und bedeutungsvoller. Hinzu kommt: Die Deuteworte Jesu zu den zerbrochenen

der Abendmahlsszenerie bei Lukas (Lk 22,I4-38), in: „Für alle Zeiten zur Erinnerung“ (Jos 4,7). Beispiele zu einer biblischen Gedächtniskultur, FS Franz Mußner zum 90. Geburtstag (SBS 209), Stuttgart: Kath. Bibelwerk 2006, I33-180, I57. Die Thesen von Haarmann und Theobald sind von Kuschel, Himmelstisch, 54ff., 65ff. aufgenommen worden.

7 So Theissen, Gerd / Merz Annette: Der historische Jesus. Ein Lehrbuch, Göttingen: Vandenhoeck \& Ruprecht ${ }^{4}$ 20II, 359-386, 382.

8 Vgl. Klappert, Bertold: Gedenken, Ertrag und Auftrag des Rheinischen Synodalbeschlusses von 1980, in: Kreuzer, Siegfried / Ueberschär, Frank (Hg.): Gemeinsame Bibel - Gemeinsame Sendung. 25 Jahre Rheinischer Synodalbeschluss zur Erneuerung des Verhältnisses von Christen und Juden (Veröffentlichungen der Kirchl. Hochschule Wuppertal 9), Neukirchen-Vluyn: Neukirchener 2006, 236-255. 
Mazzen „das ist mein Leib“ (Mk I4,22) verweisen nicht auf eine Opferterminologie (Fleisch und Blut Christi als Elemente des Opfertieres; so leider auch noch Joachim Jeremias), sondern meinen eine Ganzheitsaussage in dem Sinn: „Das (diese zerbrochene Mazze) bin ich selbst“. Und die Deuteworte Jesu zum roten Pessach-Wein meinen die durch Jesus in seinem Leiden vollbrachte Lebenshingabe für die vielen (Mk I4,24), d. h. für alle beide, für das Judentum und die Völker. Und sie erzählen von der durch den Messias Jesus bekräftigten Öffnung des in Jeremia 3I nur für Israel verheißenen „neuen Bundes“ auch für die Völker, d. h. für alle Menschen aus den Völkern (J. Jeremias, Fr. Mußner), sie beziehen sich aber nicht auf „das Neue Testament in meinem Blut" (EG I89), wie das Evangelische Gesangbuch fälschlich sagt.

Und die zwölf Jünger, die voller Hoffnung für ganz Israel das eschatologische Zwölf-Stämmevolk Israel repräsentieren, erwähnen wir nicht mehr, z. T. wegen der an anderen Stellen nötigen und richtigen Verwendung der inklusiven Sprache. Weiter: Aus „einem Becher“ (nicht: Kelch!), wie Jesus es ausdrücklich befohlen hat, trinken wir schon gar nicht, sondern mit stets wechselnden faulen, aber behebbaren Begründungen aus kleinen ,Pinnchen'. War doch das Herrenmahl und das Trinken aus einem Becher der Testfall für die Gemeinschaft zwischen Menschen jüdischer und hellenischer Provenienz in der entstehenden urchristlichen Gemeinde (Gal 3,28), dann dort ebenfalls zwischen Armen und Reichen (Gal 3,24-26). ${ }^{9}$

Weiters fehlen der rote Wein, das Symbol für die ganzheitliche Lebenshingabe des Messias Jesus, und der Opferteller, der in den reformierten Gemeinden bis heute auf dem Abendmahlstisch (nicht auf dem Altar!) steht, weil Paulus die ChristInnen aus den Völkern zum ökumenisch-diakonischen Gedenken der „Armen

9 In Japan zwischen der unterdrückten und verarmten Urbevölkerung der Ainu und den über Südkorea eingewanderten, diese schließlich beherrschenden Stämmen; in Indien zwischen den kastenlosen Dalith, die von dem verheerenden Tsunami 2004 am meisten getroffen wurden, und der Oberschicht; während des so genannten „Dritten Reiches“ zwischen Deutschen und den an Jesus als Messias glaubenden Jüdinnen und Juden z. B. in Berlin-Dahlem unter den Pastoren Martin Niemöller und Helmut Gollwitzer; schließlich auch zwischen Schwarz und Weiß in Südafrika. Denn, so hat der Ökumeniker Ulrich Duchrow geurteilt, „wenn irgendetwas $[. .$.$] von dem häretischen Charakter der weißen und aller Apartheidchristen und$ -kirchen überzeugt hat, so war und ist es der Bruch der Abendmahlsgemeinschaft selbst bei gleichem Bekenntnis“ (vgl. Duchrow, Ulrich: Bekennende Kirche werden - 1934 und 1984 - Barmen III, in: Moltmann, Jürgen [Hg.]: Bekennende Kirche wagen [KT 83], München: Kaiser 1984, I26-I90). Aus einem Becher tranken auch die Drogenabhängigen und die „Bürgerlichen" in dem von mir bis zu meinem Weggang nach Göttingen geleiteten Drogenhaus des „Christlichen Vereins Junger Menschen“ (CVJM) Bonn in der Kaiserstraße, und schließlich trinken auch aus einem Becher die „Gesunden“ und Aidskranken in Gemeinden, die diese durch den Fundamentalismus in Amerika Stigmatisierten sammeln. 
in Jerusalem“ im Abendmahl (I Kor I6,I) und zur Rücksicht der reichen „Freien“ auf die sozial verarmten „Sklaven“ (Gal 3,28; I Kor II,I7-34) auffordert. Duchrow hat in seiner ökumenischen Deutung von Barmen Art. III Entsprechendes im Zusammenhang seiner Analyse „des massenmordenden Weltwirtschaftssystems“ ${ }^{\text {"10 }}$ auch für Luthers Abendmahlsverständnis nachgewiesen: „Bereits Luther hat die unlösliche Einheit von Abendmahl und universaler Gerechtigkeit und Solidarität im einen Leibe Christi herausgestellt". ${ }^{11}$ Diese sozial-ethische Dimension, der Armen beim Mahl zu gedenken, ist wiederum abkünftig vom jüdischen Passamahl als einem Mahl der Befreiung der Versklavten aus Ägypten und aus jeder sich auf der Welt findenden Sklaverei und Ausbeutung der Elenden (Victor Hugo), der weltweit Marginalisierten. Mein jüngst verstorbener Kollege und Barth-Schüler Jürgen Fangmeier hat sich zu Gründonnerstag (und nur für Gründonnerstag) von der Synagoge in Wuppertal Mazzen und Pessach-Wein zum Gedenken an das Letzte Pessach-Mahl des messianischen Menschensohnes Jesus besorgt und dies am Sonntag vor Karfreitag der Gemeinde in Schöller-Wuppertal ausführlich liturgisch erläutert.

Auch im Hinblick auf die gemeindliche, reale Utopie von Gal 3,28, anfangend realisiert in einer heidenchristlichen Gemeinde mit einer jüdischen Minorität in Galatien, die zwar nicht das Passamahl feiert, aber dessen gedenkt, ist die unumkehrbare Reihenfolge im Paulustext zu beachten: I. die Versöhnung zwischen Jüdinnen/Juden und Hellenen, den Menschen aus den Völkern, wie sie durch die Kollekte „für die Armen in Jerusalem“ (I Kor I6,I) praktisch wird, 2. die Überwindung der Ausbeutung der Versklavten durch die Herren, wie sie durch den Exodus anfänglich geschehen ist und in der Pessach-Feier auf neue Befreiung hin erinnert wird, und 3. die Versöhnung zwischen „männlich und weiblich“ (vgl. I Kor 7,II), die ihrerseits nicht von der Befreiung der durch die Herren aller Zeiten versklavten und dadurch sich selbst entfremdeten „Männer" und auch nicht von der Befreiungsgeschichte des jüdischen Volkes durch die Jahrtausende zu trennen ist. ${ }^{12}$

Könnte nicht, so möchte ich fragen, die Überwindung des Passaverschweigens und die Wiederentdeckung der Passa-Kontur von Abendmabl und Eucharistie helfen, den evangelisch-katholischen - wahrscheinlich bis auf Weiteres nicht aufhebbaren - Gegensatz in der Abendmahlsfrage zu überbrücken?!

IO Ebd., I44.

II Ebd., I49.

I2 Vgl. die von mir betreute Dissertation von Haarmann, Michael: „Dies tut zu meinem Gedenken!“ Gedenken beim Passa- und Abendmahl. Ein Beitrag zur Theologie des Abendmahls im Rahmen des christlich-jüdischen Dialogs, Neukirchen-Vluyn: Neukirchener 2004, worauf sich Kuschel neben der Analyse von Michael Theobald in seiner Analyse der Mahltradition im Koran zu Recht weitgehend stützt, und auch Bieler, Andrea / Schottroff, Luise: Das Abendmahl. Essen, um zu leben, Gütersloh: Gütersloher Verlagshaus 2007. 


\section{Die Tauf- und Abendmahlslehre des späten Karl Barth}

Der späte Karl Barth hat noch im hohen Alter mehrere Seminare zu Abendmahl und Eucharistie in Basel gehalten und eine Entsakramentalisierung des Abendmables wie schon zuvor der Taufe vorgeschlagen: Wie die Geisttanfe (durch Jesus Christus im Geist, der hier allein handelt und das alleinige Sakrament der Vermittlung ist) von der Wassertaufe (in welchem Akt die Gemeinde handelt) zu unterscheiden ist (KD IV/4), so ist nach Barth auch das HERRENMAHL (in welchem nicht der katholische Priester oder der lutherische Pastor als Mittler, sondern der Messias Jesus allein sakramental vermittelnd als HerR verheißend und befreiend handelt) von der Eucharistie zu unterscheiden. Einer Eucharistie, in welcher die Gemeinde ihrerseits für das Geschenk der Versöhnung und Befreiung (KD IV/I-3; 1953/1956/1959) in $\varepsilon \dot{z} \chi \alpha \rho ı \tau i ́ \alpha$, d. h. in Dankbarkeit antwortet. Dabei sind die beiden Aspekte sowohl des Herrenmahles als auch der Eucharistie untrennbar aufeinander zu beziehen. Das alles hat Barth freilich schon in reformiert Barmen (Januar 1934; Thesen IV/I-3; V/I-3) und dann auch in uniert Barmen (Mai 1934; Thesen III/IV) angesprochen. Barth hat im Vorwort zu KD IV/4 dazu ausführlich Stellung bezogen: Die Taufe und das Abendmahl gehören als Geisttaufe und als messianisches Abendmahl nicht in die Ethik, wohl aber die von der Gemeinde zu vollziehende Wassertaufe und „die auf die Präsenz [d. h. Selbstvermittlung] Jesu Christi in seinem Selbstopfer [d. h. in seiner Selbsthingabe] antwortende und seiner Zukunft entgegenblickende Danksagung". 13

Barths Tauflehre (KD IV/4, 1967) und die geplante Abendmahlslehre ist deshalb vor dem Hintergrund seiner Lehre von Versöhnung und Befreiung (KD IV I-3) zu verstehen und darf von diesem befreiungstheologischen Hintergrund nicht getrennt werden..$^{14}$ Deshalb kommt der französische Pfarrer der Bekennenden Kirche, Mitkämpfer in der Resistance in Frankreich und Schwiegersohn Karl Barths, Georges Casalis, mit den folgenden Thesen zum Abendmahl inhaltlich in die Nähe des von Barth avisierten Neuentwurfs: „I. Die Gemeinde Christi wird permanent durch die Sakramente Christi in der Welt angesprochen. - 2. Die Sakramente Christi in der Gemeinde erinnern ständig daran, dass Christus nicht außerhalb der Welt zu begegnen sei. - 3. Die um das Wort und die Sakramente versammelte Gemeinde selbst wird in ihrem Gehorsam zum Sakrament der neuen Welt Christi. ${ }^{\text {"15 }}$

I3 Barth, Karl: Die Kirchliche Dogmatik IV/4, Zürich: Evangel. Verl. I967, IX.

I4 Vgl. Klappert, Bertold: Versöhnung und Befreiung. Versuche, Karl Barth kontextuell zu verstehen (NBST I4), Neukirchen-Vluyn: Neukirchener 1994.

I5 Casalis, Georges: Die Zeichen der Hingabe Christi an die Welt, in: Herbert, Karl (Hg.): Christliche Freiheit im Dienst am Menschen. Deutungen der kirchlichen Aufgabe heute. 
Barth hätte freilich die durch Casalis vorgeschlagene Ausdehnung des Sakramentsbegriffs über Christus hinaus auch auf die Gemeinde und die Welt der Armen und Entrechteten nicht mitvollzogen, denn Christus ist nach Barth das einzige Sakrament. Aber warum sollte nicht im Blick auf die Identifizierung des messianischen Menschensohnes mit den Hungernden, Kranken und Gefangenen (Mt 25,3I-46) und von Bonhoeffers ekklesiologischem Grundsatz „Christus als Gemeinde existierend" her darüber im Sinne der lehrreichen Ausführen von Casalis nachgedacht werden!?

Casalis hat in seinem Vortrag zur Tauf- und Abendmahlslehre noch einen weiteren grundlegenden Hinweis gegeben: „Im Alten Testament“, sagt er, „werden die Heiden aufgefordert, auf Israel zu blicken, auf das Volk, das auf seine Weise Sakrament Gottes in der Geschichte ist. [...] Ich möchte hier gleich bemerken, daß es kein echtes Denken über Sakramente gibt, wenn man nicht entschieden im Sinne dieser Antwort jeglichem Antisemitismus bzw. jeglichem Rassismus den Rücken kehrt, auf die Juden hört und sich solidarisch zu ihnen bekennt ". ${ }^{16}$ Wenn Casalis dann allerdings meint, dass im Neuen Testament im Unterschied zum Alten Christus alleine und nicht zugleich Israel Sakrament der Vermittlung ist, dann übersieht er: Die Formel Bonhoeffers „Christus als Gemeinde existierend“ hat als axiomatischen und exzentrischen Grundsatz zur Voraussetzung „Christus, der Jude, als Israel-Judentum existierend“" ${ }^{17}$

Ich habe die bisher nicht publizierten, inhaltlich und theologisch-liturgisch hochinteressanten schriftlichen Ausführungen Barths im Barth-Archiv in Basel eingesehen und ausgewertet. Mein Schüler Michael Haarmann hat sie in seiner Dissertation ${ }^{18}$ zum Teil ausgewertet. Weil er dies übersehen hat, hat der von mir hochgeschätzte Clemens Thoma, in dessen Festschrift ich gerne mitgeschrieben habe, ${ }^{19}$ in einer Rezension zu Haarmanns Buch diesem und damit auch mir doch wohl zu Unrecht einen antikatholischen Unterton aus eng reformierter Perspektive vorgeworfen. ${ }^{20}$ Denn Barths späte Tauf- und Abendmahlslehre ist nicht ein-

Zum 8o. Geburtstag von Martin Niemöller, Frankfurt a. M.: Lembeck I972, 79-95.

I6 Ebd., 84.

I7 Vgl. dazu Marquardt, Friedrich-Wilhelm: Die Gegenwart des Auferstandenen bei seinem Volk Israel. Ein dogmatisches Experiment (Abhandlungen zum christlich-jüdischen Dialog I5), München: Kaiser 1983.

I8 Vgl. Haarmann: „Dies tut zu meinem Gedenken!“, 215-243.

I9 Klappert, Bertold: Israel und die Kirche. Zeugen Gottes vor der Welt und voreinander, in: Käppeli, Silvia (Hg): Lesarten des jüdisch-christlichen Dialoges: Festschrift zum 70. Geburtstag von Clemens Thoma (Judaica et Christiana 20), Bern: Lang 2002, 97-IO7. Vgl. Thoma, Clemens: Rez. „Michael Haarmann: ,Dies tut zu meinem Gedenken!' Passa- 
fach reformiert im Sinne Zwinglis oder Calvins. Allerdings hat auch Barth nicht den Passacharakter des Herrenmahles/der Eucharistie für deren inhaltliche Interpretation beachtet. Das hat sein Sohn Markus Barth in einem grundlegenden Aufsatz ${ }^{21}$ und dann ausführlich in seinem Buch mit dem überaus charakteristischen Titel: „Das Mahl des Herrn. Gemeinschaft mit Israel, mit Christus und unter den Gästen “22 getan, nunmehr aber unter lebhafter Zustimmung auch seines zeitlebens lernfähigen Vaters Karl Barth.

Kuschels überraschender Nachweis unter der Fragestellung „Das Abendmahl Jesu im Koran? Zu Sure 5,II2-II ${ }^{\text {“232 }}$, dass auch im Koran, und zwar mit Bedacht in der letzten Sure des Koran 5,II2-II5, auf diese Passamahltradition des Judentums und des Messias Jesus angespielt wird, war mir und meinem früheren Assistenten Haarmann völlig neu. Gefragt werde ich gelegentlich, welche Bedeutung die Passamahltradition des Judentums und des Messias Jesus im Koran über die Anspielung auf dieselbe hinaus für den Islam selbst hat, weil es doch kein dieser Tradition entsprechendes Mahl im Islam gibt. Weitere Forschungen über die Wirkungsgeschichte dieser Sure in der islamischen Tradition jenseits des Koran werden darüber Auskunft geben können.

Kuschels Buch über Theodor Heuss ${ }^{24}$ legt erstmalig eine bisher vergessene Dimension von dessen Leben und Wirken, nämlich sein enges und von „Umkehr und Neuanfang" geprägtes Verhältnis zum Judentum und zu vielen jüdischen Zeitgenossen umfassend frei. Kuschel zeichnet eindrücklich den Weg von Heuss (I884I963) durch die Zeit des „Rassenantisemitismus und seiner tödlichen Folgen“25, den "Judenboykott ${ }^{\text {“26, }}$, die Gefährdung seiner Freunde ${ }^{27}$ und das Überleben der NS-Zeit ${ }^{28}$ bis in die Zeit nach der Schoah, in der Heuss eine umfassende Umkehr zum Judentum und Selbstreinigung im Hinblick auf seine Zeit vor und nach 1933

mahl und Abendmahl. Ein Beitrag zur Theologie des Abendmahls im Rahmen des christlich-jüdischen Dialogs“, Neukirchen-Vluyn: Neukirchener 2004“, in: FrRu NF I (2006) $56-58$.

2I Barth, Markus: Das Abendmahl. Passamahl, Bundesmahl und Messiasmahl (Theologische Studien I8), Zürich: Evangel. Verl. 1945.

22 Barth, Markus: Das Mahl des Herrn. Gemeinschaft mit Israel, mit Christus und unter den Gästen, Neukirchen-Vluyn: Neukirchener 1987.

23 Kuschel: Himmelstisch, I2I-I47.

24 Kuschel, Karl-Josef: Theodor Heuss, die Schoah, das Judentum, Israel. Ein Versuch, Tübingen: Klöpfer \& Meyer 20I4.

25 Ebd., 6Iff.

26 Ebd., 77ff.

27 Ebd., I65ff.

28 Ebd., 96ff., I25ff. 
vollzieht, indem er im Hinblick auf die Schoah das Wort der „Kollektivscham“ prägt. Heuss ermuntert Adenauer zu einer israeloffenen Politik der Entschädigung der Opfer im Sinne der Wiedergutmachung nationalsozialistischen Unrechts innerhalb und außerhalb des Staates Israel und unternimmt schließlich, nur wenige Jahre vor seinem Sterben, 1960 eine Reise nach Israel, ${ }^{29}$ die mit dem Vortrag an der Hebräischen Universität in Jerusalem, der durch Buber eingeführt wird, und in den Begegnungen mit Buber und Shalom Ben Chorin u. a. ihren Höhepunkt erfährt. Demgegenüber behandelt das später erschienene Buch von Joachim Radkau, "Theodor Heuss" ${ }^{30}$ die Modernisierung Deutschlands von der Kaiserzeit durch das Dunkel der NS-Zeit hin zur Demokratie. Besonders eindrucksvoll ist die Würdigung, die Heuss zum 80. Geburtstag Leo Baecks im Jahre 1953 geschrieben hat: „Es darf nicht beim Abbruch des Gesprächs mit Israel bleiben. Und wenn gerade der furchtbare Ausbruch [...] in Hass, in Verachtung und Schändung zu unserer Zeit geschehen ist und auch an Leo Baeck, dem stillen, alten Mann, nicht vorüberging, sondern ihm furchtbare Wunden schlug, so ist sein 8o. Geburtstag ein erschütternder Weckruf für die christliche Kirche“. Bewegend sind dabei die Dokumentation der Einladung, die Heuss an Baeck 195I schreibt, und die Begegnung, die dann am 22. August in Bonn zustande kommt, dazu die Ausführungen Kuschels über die Begegnung zwischen Heuss und Leo Baeck drei Jahre später 1954 im Landtag in Düsseldorf. ${ }^{31}$ Dort hält Leo Baeck seine Rede über Maimonides. ${ }^{32}$ Leider ist das Tonband der von Baeck völlig frei gehaltenen Rede über Maimonides, der Heuss beiwohnte, bis heute in den Archiven des Düsseldorfer Landtages nicht aufgefunden worden. Kuschels Ausführungen über Baeck sollten aber unbedingt der Leo-Baeck-Gesellschaft und dem Leo Baeck-College in London und New York bekannt gemacht werden, da diese das nicht in Kuschels informativem Heuss-Buch vermuten werden. Kuschel sollte ermutigt werden, ein entsprechendes Buch über Gustav Heinemann und sein Verhältnis zum Judentum und Israel nach der Schoah zu schreiben.

29 Ebd., 35 ff.

30 Radkau, Joachim: Theodor Heuss, München: Hansen 2014.

3I Kuschel: Heuss 17, 45ff., 29Iff.

32 Vgl. Baeck, Leo: Maimonides - der Mann und seine Wirkung, in: Friedlander, Albert H. / Klappert, Bertold (Hg.): Leo Baeck Werke. 5: Nach der Schoa - Warum sind die Juden in der Welt? Schriften aus der Nachkriegszeit Gütersloh: Gütersloher Verlagshaus 2002, I39-I57. 
3. Hat der christlich-jüdisch-islamische Dialog einen Paradigmenwechsel in der Theologie zur Folge gehabt?

Das von der katholisch-theologischen Fakultät in Graz organisierte Symposion zur Geschichte des christlich-jüdischen Dialogs steht unter der Leitfrage, ob es nach I945 durch den christlich-jüdischen Dialog einen Paradigmenwechsel in den christlich-jüdischen Beziehungen sowie in Theologie und Kirche gegeben hat. Leider kann ich diese Frage für die Evangelische Theologie nur teilweise positiv beantworten, weil man in Theologie und Kirche weiterhin dem ekklesiozentrisch-christologischen Denkmodell verpflichtet ist. In diesem Zusammenhang habe ich nochmals in Kuschels Opus Grande über „Juden, Christen und Muslime ${ }^{\text {“33 }}$ zu seiner Analyse des Status der NichtchristInnen im II. Vatikanum gegriffen. Dort zeigt Kuschel die doppelte Argumentationsrichtung zu dieser Frage einmal von innen nach außen in Lumen Gentium (LG) und andermal von außen nach innen in Nostra Aetate (NA) auf. Dabei bleibt, wenn ich richtig verstanden habe, trotz aller vorher in katholischer Theologie und Kirche unbekannten „revolutionären“ Öffnungen, wie Karl Rahner diese kommentierte, die ekklesiozentrische Sicht der antijüdischen und antiislamischen Tradition der Kirche weiterhin unangetastet, sodass man besser von einer Inklusion und Integration als von einer wirklichen dialogischen Öffnung reden sollte.

Ein wirklicher Dialog im Sinne auch der Selbstinfragestellung im Lichte der „Wahrheit der Anderen“ findet nach Kuschel aber nicht statt. Dennoch ist die Öffnung gegenüber der bisherigen antijüdischen und antiislamischen Tradition der katholischen Kirche beträchtlich, weil nunmehr anerkannt wird, dass es in den Religionen „Wahres und Heiliges" gibt, das die katholische Kirche nicht verwirft, und dass es ethische Werte gibt, die man mit anderen teilt und die man als Kirche „wahren und fördern“ will (NA 2). Vor allem ist die Kategorie des „gegenseitigen Verstehens" (NA 3) als Ziel aller Dialogbemühungen nach Kuschel ein kostbares Vermächtnis des Konzils. Denn das schließt ein, dass das Ziel des Dialogs nicht das „Verschwinden“ der Unwahrheit des je Anderen, wie es in der alten Missionstheologie verstanden wurde, sondern ein letzter Respekt vor der Andersheit des Anderen ist. ${ }^{34}$

33 Kuschel, Karl-Josef: Juden, Christen, Muslime. Herkunft und Zukunft, Düsseldorf: Patmos 2007.

34 Vgl. auch Kuschel, Karl-Josef: Leben ist Brückenschlagen. Vordenker des interreligiösen Dialogs, Düsseldorf: Patmos 2oII; vgl. zur Theologie der Mission weiter Kollbrunner, Fritz: Art. „Vaticanum II“, in: Müller, Karl W. / Sundermeier, Theo (Hg.): Lexikon missionstheologischer Grundbegriffe, Berlin: Reimer 1987, 520-525. 
Die Ökumene der Evangelischen Kirchen in Deutschland und weltweit steht freilich noch weit hinter dieser partiellen Öffnung zum Islam im II. Vatikanum zurück! Davon ist auszunehmen das missionstheologische und religionsdialogische Konzept des mit mir freundschaftlich verbundenen Theo Sundermeier (Heidelberg ${ }^{35}$, dessen Dialogmodell - ganz im Sinne des Rheinischen Synodalbeschlusses von 1980 mit der These 4,6: „Wir glauben, daß Juden und Christen je in ihrer Berufung Zeugen Gottes vor der Welt und voreinander sind“ - „das Zeugnis als integralen Teil des Dialogs" versteht, dessen Konzept aber bisher leider nur in der Erklärung „Religionen, Religiosität und christlicher Glaube“ der VELKD und der Arnoldshainer Konferenz eine kirchliche Rezeption erfahren hat. Im Anschluss an Karl Barth hat Robert Brandau in der von mir betreuten Dissertation den ,innerbiblischen Dialog“ mit dem Judentum von der „dialogischen Mission“ mit den Religionen unterschieden. ${ }^{36}$

Nun hat Karl Barth 1967 aufgrund einer Audienz bei Papst Paul VI., nachdem dieser sich lobend über das epochale Werk der Kirchlichen Dogmatik geäußert hatte, schmunzelnd gemeint, es könne an dem Dogma der päpstlichen Unfehlbarkeit doch etwas dran sein. Nach diesem Besuch in Rom, um Klarstellungen über zentrale Themen des II. Vatikanums zu suchen, und nach seinem Bericht darüber in „Ad Limina Apostolorum“ (1966) ${ }^{37}$ hat Barth in mehreren Gesprächen von einem von ihm geplanten religionsdialogischen Neuentwurf in Sachen des Dialogs mit den Religionen gesprochen. Es gehe ihm darum, nach dem innerkonfessionellen Dialog zwischen der evangelischen und der katholischen Kirche zunächst in einem ersten Kreis den grundlegenden Dialog mit dem Judentum und sodann in einem zweiten Kreis diesen mit dem Islam zu führen. Weiter in einem dritten Kreis mit den östlichen Religionen (Buddhismus und Hinduismus) und schließlich in einem äußersten Kreis mit der Weisheit (Philosophie) und dem Atheismus.

Barths Bildersprache von den konzentrischen Kreisen und sein Dialog-Weg von innen nach außen haben dabei, wie Kuschel gesehen hat, eine auffällige Parallele zu der zwei Jahre vor Barths Rom-Besuch publizierten Enzyklika Pauls VI. „Ecclesiam

35 Vgl. Sundermeier, Theo: Art. „Religion, Religionen“ und Art. „Theologie der Mission“, in: Lexikon missionstheologischer Grundbegriffe, 4II-422, 470-495; ders.: Was ist Religion? Religionswissenschaft im theologischen Kontext. Ein Studienbuch (Theologische Bücherei 96), Gütersloh: Kaiser 1999; ders.: Mission - Geschenk der Freiheit. Bausteine für eine Theologie der Mission, Frankfurt a. M.: Lembeck 2005.

36 Vgl. Brandau, Robert: Innerbiblischer Dialog und dialogische Mission. Die Judenmission als theologisches Problem, Neukirchen-Vluyn: Neukirchener 2006.

37 Vgl. Busch, Eberhard: Meine Zeit mit Karl Barth. Tagebuch 1965-1968, Göttingen: Vandenhoeck \& Ruprecht 20II, 82-9I, 209ff., 216ff. 
suam" vom 6. August 1964, in der das Lehramt erstmals die Welt der Religionen in verschiedene konzentrische Kreise je nach Nähe und Ferne zur Kirche einteilt (Abschnitt 107). Dabei müsse die Kirche mit allen „Kreisen“ in je verschiedener Weise den Dialog führen.

Markus Barth hat mir von diesem Konzept einer „ökumenischen Theologie des Heiligen Geistes", d. h. einer Ausgießung der Geisteskraft JHWHs auf alles Fleisch, erzählt: zuerst zu Pfingsten auf das Volk Israel und die jüdische Diaspora (Acta 2), dann in der Samaritaner-Mission durch Philippus auf die Samaritaner (Acta 8); schließlich in der anfangenden Ausgießung der Geisteskraft JHWHs gemäß der Verheißung von Joël 3 auch auf die Völker von Antiochien über Athen bis nach Rom (Acta IO-28) und in weitere ethnische und kosmische Horizonte hinein. In diesem Zusammenhang hat mein Schüler, Prof. Dr. Bernd Wander (Heidelberg), zu Recht von einem „zerdehnten [vielleicht besser: entschränkten] Pfingsten“ gesprochen. Ich selbst würde das "von Gott selbst geöffneteloffene Pfingsten" aufgrund der universalen Verheißung von Joël 3 mit Barth auf die Ausgießung der Geisteskraft JHWHs auch auf den Propheten und die Prophetie Muhammads und die Entstehung der weltweiten islamischen Umma ausweiten. Davon haben mich die $60 \%$ der toleranten Muslime meiner indonesischen Heimat ${ }^{38}$ und meine islamischen Lehrer, der Bosniake Smail Balic ${ }^{39}$ und der aus dem Iran stammende islamische Theologe Abdoldjavad Falaturi4o überzeugt.

Kuschel hat die Entstehung des Islam zu Recht ein „Zeichen des Geistes Gottes ${ }^{\text {"41 } 1}$ genannt und sie damit terminologisch und theologisch hilfreich wie Barth in KD IV $3 \$ 69$ als Teil der fortschreitenden Offenbarungsgeschichte des Messias und des Fortschreitens der Geisteskraft JHWHs im Sinne des entschränkten Pfingsten

38 Vgl. dazu Schumann, Olaf: Der Christus der Muslime. Christologische Aspekte in der arabisch-islamischen Literatur, Gütersloh: Gütersloher Verlagshaus Mohn 1975, mit dem ich zusammen in Pematang-Siantar (Sumatra/Indonesien) Vorlesungen gehalten habe und dem die tolerante Mehrheit der Muslime Indonesiens so vertraute, dass er seinerzeit als einer von wenigen Staatspräsident Abdul Rachman Wahid im Krankenhaus in Djakarta besuchen durfte.

39 Vgl. Balić, Smail: Ruf vom Minarett. Weltislam heute - Renaissance oder Rückfall? Eine Selbstdarstellung, Hamburg: EB-Verl. Rissen ${ }^{3}$ I984.

40 Vgl. Falaturi, Abdoldjavad: Der Islam im Dialog. Aufsätze, Köln: Islam. Wissen. Akademie ${ }^{4}$ I992; Ders.: Dialog zwischen Christentum und Islam, Köln: Islam. Akad. Deutschland 22002; vgl. Tworuschka, Udo: Gottes ist der Orient - Gottes ist der Okzident, FS für Abdoldjavad Falaturi zum 65. Geburtstag (Kölner Veröffentlichungen zur Religionsgeschichte 2I), Köln: Böhlau I99I.

4I Kuschel: Juden, Christen, Muslime, 6I8ff. 
beschrieben. ${ }^{42}$ Dabei handelt es sich in der Prophetie Muhammads und der Entstehung der islamischen Ökumene nur um ein Zeichen der Geschichte der Prophetie des Messias Jesus und der dynamischen Geisteskraft im Sinne der Verheißung von Joël 3 der Geisteskraft JHWHs, wie Kuschel christologisch ganz im Sinne von Barmen Art. I formuliert, weil ,alle Geschichte nach Christus eine Geschichte mit und durch Christus " ${ }^{43}$ und mit und durch die Heilige Geisteskraft JHWHs ist. Kuschel formuliert dies sowohl in Abgrenzung von allen exklusiven, eine solche Öffnung dogmatistisch verweigernden als auch in Abgrenzung von allen religionsund universalgeschichtlichen Konzepten einer fortschreitenden Offenbarung in der Geschichte in der Nachfolge der Theologie meines Lehrers Wolfhart Pannenberg, die in dieser Ausweitung und Öffnung auf den Islam und weitere Religionen hin eine Etappe der fortschreitenden Offenbarung Gottes in der Weltgeschichte sehen möchten.

Karl Barth hat also um das Jahr 1967 herum nach dem II. Vatikanum (19621965) und kurz vor seinem Sterben (1968) von diesem dogmatisch-religionsdialogischen Konzept einer ökumenischen Theologie des Heiligen Geistes gesprochen, von dem mir sein Sohn, Markus Barth, Neutestamentler in Chicago/USA, erzählt hat. Dabei ging es Barth um ein ernsthaft dialogisches Konzept auf Augenhöhe und nicht um den Aufweis der „Absolutheit des Christentums“ im Sinne von Ernst Troeltsch bis zu dem diesen fortschreibenden universalgeschichtlichen Programm „Offenbarung als Geschichte" in der Nachfolge Hegels von Wolfhart Pannenberg. Ich habe diesen Bericht von Markus Barth verschriftlicht und mir von ihm wie auch von dem Barth-Biographen Eberhard Busch bestätigen lassen. Daraufhin

42 Vgl. dazu die Dissertation meines indonesischen Schülers Sihombing, Fridz P.: Versöhnung, Wahrheit und Gerechtigkeit. Die ökumenische Bedeutung der Barmer Theologischen Erklärung für den Weg der Kirchen in Indonesien, Neukirchen-Vluyn: Neukirchener 2007, besonders Kp. I „Barmen Artikel I/II und der Kampf um die Wahrheiten der Pancasila“, d. h. die in der Staatsverfassung Indonesiens verankerte Religionsfreiheit, Demokratie, soziale Gerechtigkeit u. a., 3I-80, und Kp. IV „Barmen Artikel VI und der Dialog mit dem Islam“, 203-243. Vgl. weiter Klappert, Bertold: Barmen I und der Dialog mit dem Islam aus christlicher Sicht, in: Evangelische Kirche im Rheinland (Hg.): Jesus Christus, das eine Wort Gottes - Barmen I und der Dialog mit dem Islam, Tagung vom 2I./22. Januar 2005 unter der Schirmherrschaft des rheinischen Präses Manfred Kock 16-26; vgl. weiter das dort gehaltene Referat der Juristin und islamischen Theologin Mohagheghi, Hamideh: Die Barmer Theologische Erklärung aus islamischer Sicht, 9-I6, auch zugänglich in: Siedler, Dirk Chr. / Fallois, Annette de / Klußmann, Jürgen (Hg.): (K)eine Chance für den Dialog. Christen und Muslime in der pluralen Gesellschaft. Beiträge zu kontroversen Themen, Berlin: Alektor-Verl. 2007, 89-100.

Kuschel: Juden, Christen, Muslime, 619. 
habe ich diesen Hinweis, in welchen Barth seine bereits 1959 entfaltete und christologisch begründete Lehre von den wahren Worten im Weltgeschehen und Lichtern in der Schöpfung (KD IV 3, I959, \$69,I-4) im Jahre 1967 fortschreibt, veröffentlicht. ${ }^{44}$

In konsequenter Weiterführung seines theozentrisch-christologischen Ansatzes, dazu unter Zitierung von Barmen Art. I als Leitsatz des ganzen $\$ 69$, - was in der ganzen $\mathrm{KD}$ einmalig ist - hat sich Barth für einen interreligiösen Dialog geöffnet, und zwar im Sinne seines sich an der Lebendigkeit JHWHs im Messias Jesus orientierenden Leitwortes, „man müsse theologisch immer mit dem Anfang wieder neu anfangen". Von den Barthkritikern, die ihm eine Unfähigkeit zum Dialog immer vorgeworfen haben, wie auch von der Barth-Orthodoxie, die ihm darin bisher kaum gefolgt ist, ist diese ökumenische Öffnung Barths bisher nicht ernst genommen worden. Wohl aber hat der schon genannte Linkssozialist, Widerstandskämpfer in der französischen Resistance, Dozent für reformierte Theologie an der Kirchlichen Hochschule Berlin und danach Pfarrer in Straßburg, Georges Casalis, bekannt geworden durch sein Buch „Les idées justes ne tombent pas du ciel“" ${ }^{45}$ in welchem er eine „kontextuelle Theologie“ im Sinne der Befreiungstheologie Lateinamerikas vertritt, mir gegenüber im Barmen-Gedenkjahr 1984 zurecht die große Kirchliche Dogmatik als einen spannenden "Kommentar zur Zeitgeschichte" und also als durch und durch kontextuelle Theologie bezeichnet. ${ }^{46}$

Schaut man sich aber dieses weiterführende Konzept Barths genauer an, so ist

44 Vgl. Klappert, Bertold: Versöhnung und Befreiung, 42-50. Ich muss hier nicht eigens betonen, dass Barth zwar im Blick auf sein religionsdialogisches Modell von konzentrischen Kreisen und insofern h i e r christologisch-ekklesiozentrisch spricht, dass Barths Dogmatik als ganze aber in keiner Weise einem ekklesiozentrisch-inklusiven Denken folgt. Vielmehr zeigt nicht zuletzt die Struktur der großen Versöhnungslehre (KD IV I-IV 4), dass Barth theozentrisch-christologisch denkt und im Rahmen der universalen Prophetie des messianischen Menschensohnes Christus von den wahren Worten im Weltgeschehen und Lichtern in der Schöpfung spricht. In diesem Rahmen schreibt er auch von den Religionen und dem Dialog mit diesen auf Augenhöhe (vgl. dazu Klappert: Versöhnung und Befreiung, 3-52, bes. 4off.). Vgl. Casalis, Georges: Les idées justes ne tombent pas du ciel. Éléments de „théologie inductive“, Paris: Ed. du Cerf 1977.

46 Vgl. dazu Barth, Karl: Briefe 196I-1968, hg. v. Jürgen Fangmeier, Zürich: Theolog. Verl. 1975; ders.: Offene Briefe 1945-1968, hg. v. Diether Koch, Zürich: Theolog. Verl. 1984; vgl. weiter die unter meiner Betreuung entstandenen Dissertationen von dem jetzigen japanischen Professor und Übersetzer der politischen Aufsätze Karl Barths, Amano, Yu: Karl Barths Ethik der Versöhnungslehre. Ihre theologische Rezeption in Japan und ihre Bedeutung für die kirchlich-gesellschaftliche Situation in Japan, Frankfurt a. M.: Lang 1994, und von Hoffmann, Klaus: Die große ökumenische Wegweisung. Die Bedeutung der Versöhnungsethik Karl Barths für die ökumenische Bewegung im konziliaren Prozess für Gerechtigkeit, Frieden und Bewahrung der Schöpfung heute, Frankfurt a. M.: Lang 2004. 
freilich auch dieses wie das des II. Vatikanums noch weithin christologisch-pneumatologisch-ekklesiozentrisch zentriert und orientiert. Das zeigt sich daran, dass der Dialog mit dem Judentum nicht grundlegend vor anderen Themen, sondern erst nach einer innerkonfessionellen katholisch-evangelischen Verständigung, wenn auch bereits in dem ersten Kreis, zur Sprache kommen soll. Wahrscheinlich ist dieses Konzept, wie mir Eberhard Busch einmal sagte, unmittelbar am II. Vatikanum orientiert, und zwar an Lumen Gentium (LG) mit seiner Argumentationsrichtung von innen nach außen, wie Kuschel ${ }^{47}$ gezeigt hat.

\section{Die große ökumenische Frage oder der Paradigmenwechsel}

Für ein anderes Konzept des Dialogs als das des II. Vatikanums hat Manuel Goldmann plädiert. ${ }^{48}$ Dort gehört der christlich-jüdische Dialog zum Basisdialog, in welchem die Kirche sich der grundlegenden Bezogenheit auf das Judentum, ihrer Wurzel und ihres Stammes (Röm II,I7f.), bewusst bleibt. Goldmann entwickelt einen anderen, und zwar einen dialogischen Wahrheitsbegriff, demzufolge das Ich vom Du her verstanden wird (Martin Buber) und Theologie nicht erst im Nachbinein auf das Du des jüdischen Dialogpartners zu sprechen kommt, sodass das Judentum das bleibende externe Fundament unserer ökumenischen Kirche aus allen Völkern ist. So wird sich das Ich vom Du her verstehen, sich also nicht, wie in der abendländischen kirchlichen wie philosophischen Tradition, in einem Akt des selbstbezüglichen Bewusstseins konstituieren, sondern vom Angesicht des Anderen her lernen und vor dem Angesicht des Anderen sich handelnd ver-antworten (Emmanuel Lévinas).

Neuere Arbeiten wie die von Peter Schäfer ${ }^{49}$ zeigen demgegenüber, wohin die Reise wieder gehen soll: in die Richtung der Umkehrung des unumkehrbaren Begründungszusammenhangs zwischen Judentum und Christentum. Ich bin mir durchaus bewusst, dass die babylonische Diaspora nicht solchen Verfolgungen aus-

47 Kuschel: Juden, Christen, Muslime, $56 \mathrm{ff}$.

48 Goldmann, Manuel: „Die große ökumenische Frage ...“. Zur Strukturverschiedenheit christlicher und jüdischer Tradition und ihrer Relevanz für die Begegnung der Kirche mit Israel (NBST 22), Neukirchen-Vluyn: Neukirchener 1997. Ders.: Umkehr und Erneuerung 2.o. Zur Differenzerfahrung in der christlich-jüdischen Begegnung, in: KuI I (2013) 47-5I.

49 Schäfer, Peter: Die Geburt des Judentums aus dem Geist des Christentums. Fünf Vorlesungen zur Entstehung des rabbinischen Judentums (TrC 6), Tübingen: Mohr Siebeck 2010. - Obwohl Schäfer in der englischen Fassung seines Buches auf diesen provokanten Titel verzichtet hat, relativiere man den Titel der deutschen Fassung nicht zu schnell. Auch das inzwischen überholte Sprechen vom „Spätjudentum“ hatte seine antijüdischen Konnotationen und Implikationen: „Deine Sprache verrät dich!“ 
gesetzt war wie die im Römischen Reich lebenden jüdischen Gemeinden, und ich weiß auch um die korrelativ sich entwickelnden, wenn auch asymmetrisch verlaufenden Wechselbeziehungen zwischen Christentum und Judentum durch die Jahrhunderte. ${ }^{50}$ Dennoch habe ich für mich dem Buch von Peter Schäfer einen anderen Titel gegeben und auf dem Cover des Buches eingetragen: „Die Antwort des verfolgten Judentums auf den antijüdischen Ungeist des seit Konstantin etablierten und sich antijüdisch verstehenden und auch handelnden Christentums". Obwohl in der Tat einige Diskussionen der Rabbinen nur kontextuell aus der kritischen Abgrenzung gegenüber der das Judentum verfolgenden Frühen Kirche und als Polemik gegen deren problematische antijüdische Lehren zu verstehen sind, wie schon Leo Baeck zur Pessach-Haggadah beobachtet hat, würde ich nicht einmal von einer nur partiellen Geburt des Judentums aus dem Geist des Christentums sprechen können.

Und gilt nicht Entsprechendes auch für den Konsens in Augsburg zwischen Evangelischer und Katholischer Kirche in der Rechtfertigungslehre, wo wiederum übersehen wurde, dass nicht die das Heidenchristentum betreffende Rechtfertigungslehre, die gesamtbiblisch erst an zweiter Stelle zu stehen kommt, die Basis ist, aus der die Erwählung Israels ihre Wahrheit bezieht? Denn umgekehrt ist JHWHs, des einen GOTTes, freies Erwählen des jüdischen Volkes die Basis unserer, der Heidenchristen, Hinzu-Erwählung. In diesem Zusammenhang hat Hans-Joachim Kraus öfters mündlich darauf hingewiesen, dass das Judentum als das erste extra nos der Kirche noch vor der Rechtfertigungsverkündigung als dem zweiten extra nos zu thematisieren sei. ${ }^{51}$ Das ist trotz der berechtigten Kritik von Eberhard Jüngel, die der reformatorischen Linie meines Göttinger Lehrers E. Wolf folgt, an der "Gemeinsamen Erklärung der Rechtfertigungslehre" von Augsburg (1996) auch im Hinblick auf seine eigene Darstellung der reformatorischen Rechtfertigungslehre ${ }^{52}$ zu sagen: Sie kommt ohne den Rekurs auf das Ältere Testament und erst recht ohne Rekurs auf das Judentum, d. h. ohne das erste extra nos des christlichen Glaubens

50 Vgl. dazu die Konzepte von Hilton, Michael: „Wie es sich christelt, so jüdelt es sich“. 2000 Jahre christlicher Einfluss auf das jüdische Leben, Berlin: JVB 2000; von Juval, Israel: Zwei Völker in deinem Leib. Gegenseitige Wahrnehmung von Juden und Christen in Spätantike und Mittelalter, Göttingen: Vandenhoeck \& Ruprecht 2007 und von Boyarin, Daniel: The Jewish Gospels. The Story of the Jewish Christ, New York: New Press 20I2; vgl. weiter die überzeugende Kritik von Peter Schäfer an Boyarins Buch in: KuI 2 (20I2) IoO-IO9.

5I Vgl. Kraus, Hans-Joachim: Rückkehr zu Israel. Beiträge zum christlich-jüdischen Dialog, Neukirchen-Vluyn: Neukirchener 1991.

52 Jüngel, Eberhard: Das Evangelium von der Rechtfertigung des Gottlosen als Zentrum des christlichen Glaubens. Eine theologische Studie in ökumenischer Absicht, Tübingen: Mohr Siebeck 1998. 
und ohne die Begründung der Rechtfertigungslehre in der Erwählung des Volkes Israels sola gratia (Dtn 7,6f.) aus. Sie steht deshalb noch vor einem nötigen Paradigmenwechsel in der Systematischen Theologie und ist von daher, - um mit Barth zu reden - „abstrakt, billig und bedeutungslos in dem Maß“, als Jüngel „das für eine beiläufige und zufällige [ich ergänze: und zu vernachlässigende] Bestimmung zu halten " 53 gedenkt.

Jüngel, der als ein führender Interpret der Theologie Barths gilt, hat jedenfalls von der für die Dogmatik im Sinne des ersten und grundlegenden extra nos zentralen Israeltheologie Barths und dessen Verhältnis zum Judentum nichts verlauten lassen. Auch Jüngels Versuch einer Paraphrase der Gotteslehre Karl Barths in seiner Schrift "Gottes Sein ist im Werden "54 kommt ohne irgendeinen Rekurs auf das Ältere Testament und erst recht ohne eine Bezugnahme auf das Gottesverständnis und das Gotteserleiden des Judentums aus, sondern ist eine dogmatische Existentialisierung Gottes. ${ }^{55}$ Würde Jüngel sich am „Vaterunser" orientiert haben, so würde er nicht ontologisierend von „Gottes Sein ist im Werden“, sondern wie Barth verheißungsgeschichtlich von „Gottes Reich ist im Kommen“ (Hans-Joachim Kraus, Jürgen Moltmann) sprechen. Sollte sich Jüngels Titel auf Ex 3,I4 „ICH werde dasein als der ICH dasein werde" beziehen, was dieser freilich an keiner Stelle andeutet, dann wäre daran zu erinnern, dass das Gottes-Prädikat von Ex 3,I4 auf den JHWH-NAMEN zielt: „Und weiter sprach GOTT zu Mose: So sollst du zu den Israeliten sprechen: Der GOTT eurer Vorfahren, der GOTT Abrahams, der GOTT Isaaks, der GOTT Jakobs hat mich zu euch gesandt. Das ist mein NAME für immer, und so soll man mich anrufen von Generation zu Generation" (Ex 3,15). Das GOTTes-Prädikat von Ex 3,I4 zielt also, was so geflissentlich in der Nachfolge des metaphysisch-ontologisierenden Verständnisses von Ex 3,14 in der Septuaginta übersehen wird, entscheidend auf den JHWH-NAMEN. Es legt diesen NAMEN mittels der Geschichte seiner heilvollen und rechtsetzenden Taten aus (Walther Zimmerli56), es kann und darf aber diesen Heiligen NAMEN nicht ersetzen, wie es in einer in den Fesseln der antiken Metaphysik gefangenen Theologie dann erfolgt

53 Vgl. Barth, Karl: Die Kirchliche Dogmatik IV/I, Zürich: Evangel. Verl. 1967, 182.

54 Jüngel, Eberhard: Gottes Sein ist im Werden. Verantwortliche Rede vom Sein Gottes bei Karl Barth, eine Paraphrase, Tübingen: Mohr ${ }^{2} 1967$.

55 Vgl. ebd., 69ff.

56 Vgl. Zimmerli, Walther: Grundriß der alttestamentlichen Theologie (Theologische Wissenschaft 3), Stuttgart: Kohlhammer 1972, ${ }^{6}$ I989, Teil I $\$ \$$ I-6; Motte, Jochen: Biblische Theologie nach Walther Zimmerli. Darstellung und Würdigung der alttestamentlichen Theologie Walther Zimmerlis und der sich aus ihr ergebenden Perspektive zum Neuen Testament in systematisch-theologischer Sicht, Frankfurt a. M.: Lang 1995, 4-35. 
ist und bis heute erfolgt. Der Gottes-NAME spielt aber in der ganzen Theologie Jüngels keine Rolle.

Das hier aufgezeigte Defizit zeigte sich im gleichen Jahr, im Oktober 1967, auch auf der „Parrhesia“-Tagung, einem Zusammensein Karl Barths mit den Autoren seiner Festschrift zum 8o. Geburtstag, besonders aber in dem Streitgespräch zwischen Jüngel und dem holländischen Alttestamentler Frans Breukelman. Im Blick auf das Verständnis des Älteren Testamentes und das Israel der Gegenwart hatte „Jüngel hervorgehoben, dass nach dem Erscheinen Jesu ein besonderes Verhältnis Gottes zu Israel aufgehoben sei. Ein Verständnis des Alten Testamentes sei ausgeschlossen, außer dass es im Licht der neutestamentlichen Christusverkündigung erfolge“. Dieser antijüdischen These widersprach Breukelman entschieden mit der Gegenthese „dass Christus vielmehr nur in dem im ,Tenach' dokumentierten höchst besonderen Verhältnis Gottes zu Israel recht zu verstehen sei“. Barth hatte die Diskussion schweigend verfolgt, äußerte sich aber dann später „vehement dazu: Er stehe in dieser Sache grundsätzlich auf der Seite des [...] Herrn Breukelman. " ${ }^{\text {"57 }}$

Deshalb frage ich: Wie sähe es aus, wenn wir auch den Dialog mit dem Islam, der im Unterschied zum christlich-jüdischen Dialog zwar nicht zum Basisdialog zu rechnen ist, weil der Koran nicht Teil der "ganzen Heiligen Schrift“ ist, nicht nur im Sinne einer sekundären Integration bzw. Inklusion, wie man heute gerne sagt, und parallelen Bestätigung unseres etablierten Christentums, sondern im Sinne einer dialogischen Partnerschaft und eines in seinem Du, der uns viel zu sagen hätte, unauflösbaren und nicht ekklesiologisch-christologisch integrierbaren Partners führen würden? Der Islam wäre dann, wie Kuschel formuliert hat, als ein „Zeichen des Geistes“ GOTTes eine echte Herausforderung von außen, analog zu dem, wie es Manuel Goldmann für die Begegnung mit dem Judentum vorbildlich beschrieben hat. Wir würden dann katholischer- wie evangelischerseits endlich auch Positives zu Muhammads Prophetie und zur anfangenden Realisierung der Abraham-Ismael-Verheißungen im Islam seit dem 7. Jahrhundert bis heute theologisch und ökumenisch sagen. Wir würden dann endlich ernst nehmen, was der Philosoph und orthodoxe Theologe, Michael Wyschogrod, in seinem Buch „Abraham's Promise " ${ }^{\text {58 }}$ zu den aus der Abraham-Verheißung heraus entstandenen und einander von der universalen Abraham-Verheißung her begegnenden Religionen Judentum, Christentum und Islam geschrieben hat. Wir würden dann endlich das

57 Busch: Meine Zeit mit Karl Barth, 485; vgl. ders.: Unter dem Bogen des einen Bundes. Karl Barth und die Juden 1933-1945, Neukirchen-Vluyn: Neukirchener 1996.

58 Wyschogrod, Michael: Abraham's Promise. Judaism and Jewish-Christian Relations, hg. v. R. Kendall Soulen, Grand Rapids: Eerdmans 2004. 
sagen können, was wir bis heute evangelischer- und katholischerseits in offiziellen Dokumenten zu dem Propheten Muhammad und seiner Prophetie nicht sagen, was aber Leo Baeck 1956 noch kurz vor seinem Tode geschrieben hat: „Mohammed war einer der [...] kühnsten Menschen, die es je gegeben hat, ein Mann von einer Kraft des Glaubens, welcher [...] Berge versetzen kann. [...] Was trennt Islam und Judentum? Es ist weniges [...]. Für Juden ist Mohammed nicht der letzte und entscheidende der Propheten [...], sondern nur Prophet, aber der Glaube an den einen Gott eint, und der Islam hat auch das Gebot aufgenommen: er fordert Wohltun“.59

\section{Hat in der Systematischen Theologie ein Paradigmenwechsel stattgefunden?}

Was besagt der hier verwendete Terminus „Paradigmenwechsel“ inhaltlich? Paradigmenwechsel meint die unzweideutige Absage an das traditionelle heidenchristliche Konzept der "Judenmission“ auch in ihrer eschatologischen Variante und die positive Erkenntnis, dass Israel und die Kirche, „daß Juden und Christen je in ihrer Berufung Zeugen Gottes vor der Welt und voreinander sind" (Rh Sy B These 4,6). Paradigmenwechsel meint die Umkehr von allem inklusiven, ekklesiologisch-christologisch enggeführten dogmatischen Denken, das das Judentum im Rahmen der Ekklesiologie, der Soteriologie oder der Ökumene christlich einordnet und damit das Alte Testament und das Judentum als das allem vorgeordnete erste extra nos des Glaubens $\left(\mathrm{Kraus}^{60}\right.$ ) überspringt. Paradigmenwechsel beschreibt die in allen dog-

59 Baeck, Leo: Judentum, Christentum und Islam (1956), in: Friedlander, Albert H. / Klappert, Bertold (Hg.): Leo Baeck Werke. 5: Nach der Schoa - Warum sind die Juden in der Welt? Schriften aus der Nachkriegszeit Gütersloh: Gütersloher Verlagshaus 2002, 472-492, 486f. Vgl. Kuschel: Juden, Christen, Muslime, 63.

60 Vgl. Kraus, Hans-Joachim: Systematische Theologie im Kontext biblischer Geschichte und Eschatologie, Neukirchen-Vluyn: Neukirchener 1983, 488, 327. Im Nachlass von Kraus fand sich jüngst der Plan für ein auf ca. 360 Seiten angelegtes Buch mit dem Titel: „Jüdische Beiträge zur christlichen Dogmatik“. Dort wollte Kraus „die Bedeutung der jüdischen Tradition für die Dogmatik der Kirche“ unter folgenden Themen entfalten: „I. Die Schrift: Überlieferung - Auslegung und Lehre der Tora - Dogma und Ketzer -- 2. Das Wort Gottes: Tora und Propheten, ,Gott spricht - der Mensch antwortet'. Die Prophetie des Mose; -- 3. Der Gott Israels: Name - Offenbarung - Einzigkeit Gottes - Erkenntnis Gottes. -- 4. Gott der Schöpfer: Schöpfung - Erhaltung - Weisheit - Theodizee - Kabbala und Zimzum. -- 5. Der Mensch: Sünde - Glaube - Gehorsam - Furcht Gottes - Frau und Ehe - Geburt und Tod - Eltern und Kinder - Der Nächste - Krankheit und Leiden. -- 6. Erlösung und Versöhnung -- 7. Der Messias -- 8. Gottes Geist -- 9. Gerechtigkeit - Liebe - Wahrheit und Lüge - der Nächste -- Io. Das Volk Gottes und die Völker: Exodus - Wüste - Got- 
matischen Lehrinhalten zu berücksichtigende „Mit-Struktur“ im Sinne der Formel von Hans Joachim Iwand: „Vergeßt das MIT (mit Israel-Judentum) nicht!" ${ }^{\text {"61 }}$ Der Paradigmenwechsel meint eine Ortsanweisung, nämlich den Ort des primären Hörens und Lernens vom Judentum als dem uns von JHWH vorgegebenen Anderen (Lévinas ${ }^{62}$ ) nicht zu verlassen und so die immer neu durch Konvivenz, Zeugnis und Dialog zu suchende Begegnung auf Augenhöhe ${ }^{6_{3}}$ nicht zu verspielen. Nicht eigentlich um „Umkehr und Erneuerung“ geht es dabei, denn „Erneuerung' kann sich mit Reparatur begnügen“, wie der Alttestamentler, Kraus-Schüler und langjährige Vorsitzende des Rheinischen Ausschusses „Christen und Juden“ der Evangelischen Kirche im Rheinland (EKiR), Johann Michael Schmidt, zu Recht schreibt. Er spricht demgegenüber von „dem gebotenen Weg zu,Umkehr und Neuanfang'“, womit er den Paradigmenwechsel eindeutig beschreibt. ${ }^{64}$

Die systematischen Entwürfe von Wolfhart Pannenberg, Walter Kreck, Wilfried Joest, Wilfried Härle, Hans-Martin Barth u. a. haben den Paradigmenwechsel nicht vollzogen und folgen nach wie vor einem israelvergessenen dogmatischen Schema im Dreischritt von Schöpfung Versöhnung und Erlösung: - Sowohl in der Ethik $^{65}$ als auch in der Ekklesiologie ${ }^{66}$ (ein Jahr nach dem Rheinischen Synodalbeschluss von 1980 publiziert) meines Doktorvaters Walter Kreck, dem ich persönlich viel und wissenschaftlich die präzise, zum eigenständigen Denken anleitende Einführung in das Opus Grande der Kirchlichen Dogmatik Barths und in die

tesdienst - Tempel - Proselyten - Schabbat - Feste. -- II. Verheißung der neuen Welt: Land Israel. -- I2. Auferstehung“. Hier erfolgt erstmalig keine in der christlichen Dogmatik so beliebte Integration und Funktionalisierung jüdischer Traditionen im Dienst einseitig christlich-dogmatischer Interessen, sondern hier vollzieht sich visionär ein, wenn auch leider noch nicht ausgeführter, wirklicher Paradigmenwechsel aus Umkehr, Erneuerung und Neuanfang - ein Paradigmenwechsel, der Israel als das erste extra nos des christlichen Glaubens versteht. Vgl. Kraus-Archiv bei B. Klappert, Gartenstraße 54, 42107 Wuppertal.

6I Iwand, Hans-Joachim: Meditation zu Eph 2,19-22, in: Ders.: Predigt-Meditationen, Göttingen: Vandenhoeck \& Ruprecht ${ }^{2} 1964,20-23,23$.

62 Vgl. Wohlmuth, Josef: Begegnung mit Emmanuel Lévinas, in: Haarmann, Michael (Hg.): Momente der Begegnung. Impulse für das christlich-jüdische Gespräch. Bertold Klappert zum 65. Geburtstag, Neukirchen-Vluyn: Neukirchener 2004, 217-220.

63 Vgl. Sundermeier, Theo: Konvivenz als Grundstruktur ökumenischer Existenz heute, in: Huber, Wolfgang / Ritschl, Dietrich / Sundermeier, Theo: Ökumenische Existenz heute, München: Kaiser 1986, 49-100.

64 Vgl. Schmidt, Johann Michael: 2010 - Ein Jahr mehrerer runder Gedenkdaten, in: Brocke, Edna / Seim, Jürgen (Hg.): Helmut Starck: Festgabe zum 80. Geburtstag, Düsseldorf: Evang. Kirche im Rheinland 20I0, 37-39, 37.

65 Kreck, Walter: Grundfragen christlicher Ethik, München: Kaiser 1975.

66 Ders.: Grundfragen der Ekklesiologie, München: Kaiser 198I. 
Theologie Hans-Joachim Iwands verdanke, als auch in dessen Dogmatik, ${ }^{67}$ die sich zwischen der Reformation Luthers und Calvins einerseits und zwischen Bultmann und Barth andererseits positioniert, fehlt die Israel- und Judentums-Dimension ganz. - Mein Wuppertaler Lehrer in der Systematik, Wolfhart Pannenberg, dem ich wie später meinem Göttinger Mentor bei der Habilitation, dem Wolfgang Cramer-Schüler sowie ausgewiesenen Adorno- und Horkheimer-Kenner, Hans-Georg Geyer, die Einführung in die Philosophie des Deutschen Idealismus verdanke, kommt erst im Bd. 3 seiner materialreichen und universalgeschichtlich orientierten Systematischen Theologie im Rahmen der Ekklesiologie und in der Reihenfolge „Kirche und Israel“, d. h. im Sinne der ekklesiologisch-christologischen Integration und Inklusion, auf das Judentum zu sprechen. ${ }^{68}$

Die Dogmatik von Wilfried Härle bezieht sich im Rahmen der Christologie auf nur eineinhalb Seiten unter der vielsagenden Überschrift „Die Möglichkeit und Wirklichkeit anderer Gottesoffenbarung" auf das Ältere Testament, wobei die dort erzählte Gottesoffenbarung "nicht den Weg zum Leben erschlie $\beta t^{\prime \prime}$, ${ }^{69}$ was Paulus geschrieben haben soll. Vom Judentum und seiner Geschichte bis heute ist dabei nichts zu hören, vermutlich, weil dort erst recht der Weg zum Leben verschlossen ist. - Die „Dogmatik im Kontext der Weltreligionen“ von Hans-Martin Barth sucht auf dem Boden einer intakten, lutherisch orientierten Tradition nach Analogien in außerchristlichen Religionen. Dabei kommen das Judentum an erster und der Islam an zweiter, schließlich der Hinduismus an dritter und der Buddhismus an vierter Stelle im Rahmen von ,außerchristlichen Entsprechungen“ (!) zur christlichen Theologie vor. Das II. Vatikanum mit seinem kirchenzentrierten Weg von innen nach außen in Lumen Gentium ist hier zum Vorbild genommen. ${ }^{70}$ - Die informative Dogmatik von Wilfried Joest positioniert sich zwischen Luther und Barth und entfaltet im traditionellen, an Luthers „disputatio de homine“ (I536) orientierten Schema vom geschaffenen, versöhnten/gerechtfertigten und auf Hoffnung angelegten Menschen im Bd. I „Die Wirklichkeit Gottes“ und im Bd. 2 den „Weg Gottes mit dem Menschen“71, wobei der Geschichte Israels im Alten Testa-

67 Ders.: Grundfragen der Dogmatik, München: Kaiser 1970.

68 Pannenberg, Wolfhart: Systematische Theologie. 3, Göttingen: Vandenhoeck \& Ruprecht I993, 509-517.

69 Härle, Wilfried: Dogmatik, Berlin: de Gruyter I995, $98 \mathrm{f}$.

70 Barth, Hans-Martin: Dogmatik. Evangelischer Glaube im Kontext der Weltreligionen. Ein Lehrbuch, Gütersloh: Kaiser 200I, 85-IO4.

7I Joest, Wilfried: Dogmatik I: Die Wirklichkeit Gottes, Göttingen: Vandenhoeck \& Ruprecht 1984; 2: Der Weg Gottes mit den Menschen, Göttingen: Vandenhoeck \& Ruprecht 1986. 
ment die Bedeutung einer „Vorgeschichte“ zukommt. Die Dogmatik von Joest, der mir gegenüber mündlich das Defizit in der Behandlung des Alten Testaments und das völlige Fehlen des Dialogs mit dem Judentum zum Ausdruck gebracht hat, hat in der durch meinen Wuppertaler Kollegen Johannes von Lüpke völlig neu bearbeiteten Auflage ${ }^{72}$ im Hinblick auf diesen alttestamentlich-jüdischen Fragenkreis eine anfängliche Ergänzung erfahren. Denn das Alte Testament zählt hier nicht mehr wie noch bei Joest zur „Vorgeschichte“ des Neuen Testaments, sondern wird zu allen dogmatischen Hauptabschnitten zur Sprache gebracht.

Demgegenüber haben die Entwürfe a) meines väterlichen Freundes Helmut Gollwitzer ${ }^{73}$ und b) die nur fragmentarisch überlieferte, aber inspirative Dogmatik von Hans Joachim Iwand ${ }^{74}$ mit seiner Formel „Vergeßt das Mit (mit dem Volk Israel) nicht!" den Weg eines Paradigmenwechsels beschritten. Dieser ist dann entscheidend weitergegangen worden: c) in dem Lebenswerk von Eberhard Bethge, der uns die fragmentarisch gebliebene Ethik und Theologie Dietrich Bonhoeffers vermittelt hat. ${ }^{75}$ Seine Person hat als Mittler des Erbes seines zum Märtyrer gewordenen Freundes, aber auch als eigenständiger Vermittler der amerikanischen Holocaust-Theologie entscheidend dazu beigetragen, dass der Rheinische Synodalbeschluss 1980 von der Synode angenommen wurde. Bethge, den ich regelmäßig zu meinen Seminaren und Vorlesungen nach Wuppertal eingeladen habe, hat dann über Bonhoeffer hinaus, ja sogar in vorsichtiger Kritik sowohl an dem antijüdischen Pharisäerbild Bonhoeffers in der Tradition seines Lehrers Adolf von Harnack als auch an der hohen Christologie mit ihren Vergottungstendenzen das erste Gebot als theologisches Axiom in das Zentrum seiner Bemühungen gestellt. ${ }^{76}$

72 Joest, Wilfried / Lüpke, Johannes von: Dogmatik I: Die Wirklichkeit Gottes, Göttingen: Vandenhoeck \& Ruprecht '2oro und Dogmatik II: Der Weg Gottes mit den Menschen, Göttingen: Vandenhoeck \& Ruprecht `20I2.

73 Gollwitzer, Helmut: Befreiung zur Solidarität. Einführung in die evangelische Theologie, München: Kaiser 1978.

74 Vgl. Iwand, Hans Joachim: Christologie: Die Umkehrung des Menschen zur Menschlichkeit. Nachgelassene Werke Neue Folge 2, bearbeitet, kommentiert und mit einem Nachwort versehen von Eberhard Lempp und Edgar Thaidigsmann, Gütersloh: Kaiser 1999. Ders.: Göttinger Predigt-Meditationen 1963/64, Göttingen: Vandenhoeck \& Ruprecht 1964. Vgl. dazu Seim, Jürgen: Hans Joachim Iwand. Eine Biographie, Gütersloh: Kaiser 1999.

75 Bethge, Eberhard: Dietrich Bonhoeffer. Theologe, Christ, Zeitgenosse, München: Kaiser I967; zu Bethge vgl. Gruchy, John W. de: Eberhard Bethge - Freund Dietrich Bonhoeffers. Eine Lebensgeschichte, Gütersloh: Gütersloher Verl.-Haus 2007.

76 Bethge, Eberhard: Jesus Christus - Christologie und das Erste Gebot, in: Edna Brocke / Jürgen Seim (Hg.): Gottes Augapfel. Beiträge zur Erneuerung des Verhältnisses von Christen und Juden, Neukirchen-Vluyn: Neukirchener 1986, 47-58; vgl. dazu Klappert, Bertold: 
- d) Zeitlich parallel sind hier mit Berufung auf Bonhoeffer die Entwürfe einer nicht-antijüdischen Christologie von Heinz Kremers zu nennen, der schon früh einen lebendigen Dialog in Jerusalem, Nes Ammim und Duisburg mit David Flusser, Shalom Safrai, Yehuda Aschkenasy u. a. geführt und die christliche Siedlung Nes Ammim in Israel mitbegründet hat. Er hat sich engagiert für die diplomatische Anerkennung des Staates Israel eingesetzt und mit seinen vielseitigen Aktivitäten entscheidend zum Rheinischen Synodalbeschluss und zum EKD-Ausschuss bzw. den EKD-Studien „Kirche und Israel I-III“ beigetragen. ${ }^{77}$ Sein fragmentarisches Lebenswerk ist in dem Aufsatzband „Liebe und Gerechtigkeit“ (1990) erschienen.

e) Vollzogen wurde der Paradigmenwechsel in der Systematischen Theologie von Hans-Joachim Kraus ${ }^{78}$ mit seinem Neuentwurf einer „messianischen Geist-Christologie im Kontext alttestamentlich-jüdischer Tradition" und seiner an dem einen NAMEN JHWH und seinem Kommen orientierten Trinitätslehre, sodann f) in dem Entwurf des Heidelberger Systematikers Dietrich Ritschl „Zur Logik der Theologie ${ }^{\text {" } 79}$ mit seiner erhellenden Unterscheidung zwischen dem Jerusalemer und Athener anthropologischen Modell und von dem Bochumer Systematiker Christian Link mit seiner eindrucksvollen Rede von der "Spur des Namens" und seinem Hinweis auf die für eine gesamtbiblische Theologie grundlegende „Bedeutung des biblischen Gottesnamens" ${ }^{80}{ }^{80}$ weiter g) in den Arbeiten von Martin Stöhr, ${ }^{81}$ der als Mitbegründer des Studienprogramms „Studium in Israel“, an dem auch ich lange Jahre beteiligt war, sich öfters die Frage gefallen lassen musste, ob stattdessen ein „Studium in Athen" nicht viel angemessener sei, und der mit der Israelthematik immer auch betont die Islam-Frage und die Palästinenser-Problematik verbunden hat.

Bonhoeffer und die Juden, in: Tietz, Christiane (Hg.): Bonhoeffer-Handbuch, Tübingen: Mohr Siebeck, in Vorbereitung.

77 Vgl. Kremers, Heinz: Liebe und Gerechtigkeit. Gesammelte Beiträge, Neukirchen-Vluyn: Neukirchener 1990. Ein weiterer Aufsatzband ist geplant: Kremers, Heinz: Vom Judentum lernen - Impulse für eine nichtantijüdische Christologie, hg. v. Klappert, Bertold / Kremers, Thomas, Neukirchen-Vluyn: Neukirchener 2015 (in Vorbereitung).

78 Vgl. Kraus, Hans-Joachim: Systematische Theologie im Kontext biblischer Geschichte und Eschatologie, Neukirchen-Vluyn: Neukirchener 1983.

79 Ritschl, Dietrich: Zur Logik der Theologie. Kurze Darstellung der Zusammenhänge theologischer Grundgedanken, München: Kaiser 1984. Vgl. weiter ders. / Hailer, Martin: Diesseits und jenseits der Worte. Grundkurs christliche Theologie, Neukirchen-Vluyn: Neukirchener 2006.

80 Link, Christian: Die Spur des Namens. Wege zur Erkenntnis Gottes und zur Erfahrung der Schöpfung, Neukirchen-Vluyn: Neukirchener 1997, 37-66.

8I Stöhr, Martin: Dreinreden. Essays, Vorträge, Thesen, Meditationen, hg. v. Klaus Müller und Alfred Wittstock, Wuppertal: Foedus 1997. 
h) Weiter ist hier die siebenbändige Dogmatik von Friedrich-Wilhelm Marquardt zu nennen. ${ }^{82}$ Seine Dogmatik stellt sich von Anfang bis Ende der Israel- und Judentum-Problematik im Sinne des ersten extra nos und versteht dieses grundlegende extra nos des christlichen Glaubens als Anfrage an das Elend und die Heimsuchung von Theologie und Kirche durch die Schoah. Ich bin nach dem jeweiligen Erscheinen der Bände regelmäßig an die Akademie Berlin-Brandenburg zum kritischen Referat eingeladen worden und habe aus der Beschäftigung mit den nach und nach publizierten Bänden viel gelernt, wobei Marquardt mündlich wie schriftlich auf meine Rezensionen immer ausführlich geantwortet hat. ${ }^{83}$ Marquardt nahm Thesen spontan zurück und war im Dialog flexibler, als es die Dogmatik-Bände vermuten lassen. Gegenüber viel Kritik an Marquardt aus der dogmatischen Zunft steht das Urteil des unvergessenen Landesrabbiners von Baden und Kraus-Freundes Robert Raphael Geis: In den beiden Barth-Büchern Marquardts, „Israel im Denken Karl Barths" und „Theologie und Sozialismus“ wird, so schreibt er am I5. April 1972 an Hans-Joachim Kraus, „der Versuch unternommen, die tiefe Kluft zum Judentum abzubauen. Imponierend ist das, schon gar, wenn man bedenkt, daß das Judentum für die christliche Theologie bis heute nicht existiert. Ich kenne kaum einen, der als Lernender ohne christliche Arroganz so tief in Wesentliches des Judentums vorgedrungen ist wie Marquardt. Mehr noch, Marquardt wird bei Betrachtung des Judentums von seinem Christentum nicht gestört, sondern angetrieben". 84

82 Marquardt, Friedrich-Wilhelm: Von Elend und Heimsuchung der Theologie. Prolegomena zur Dogmatik, München: Kaiser 1988; ders.: Das christliche Bekenntnis zu Jesus, dem Juden. Eine Christologie, Bd. I-2, München: Kaiser 1990/I99I; ders.: Was dürfen wir hoffen, wenn wir hoffen dürften? Eine Eschatologie, Bd. I-3, Gütersloh: Kaiser 1993/1994/1996; ders.: Eia, wärn wir da. Eine theologische Utopie, Gütersloh: Kaiser 1997.

83 Vgl. Klappert, Bertold: Jesus als König, Priester und Prophet. Eine Wiederholung der Wege und des Berufs Israels. Versuch einer Würdigung der Christologie Friedrich-Wilhelm Marquardts, in: BThZ II (1994) 25-4I; ders.: Tora und Eschatologie. Auf dem Schulweg der Tora. Mosetora - Christustora - noachidische Völkertora und die Neue Welt Gottes. Friedrich-Wilhelm Marquardt zum Gedenken, in: Licharz, Werner / Zademach, Wieland (Hg.): Treue zur Tradition als Aufbruch in die Moderne. Visionäre und mahnende Stimmen aus Judentum und Christentum, Waltrop: Spenner 2005, I88-263; ders.: Der Gott Israels in seinem Reich und Ort. Plädoyer für eine ortsorientierte Utopie, in: Frettlöh, Magdalene L. / Döhling, Jan-Dirk (Hg.): Die Welt als Ort Gottes - Gott als Ort der Welt. Friedrich-Wilhelm Marquardts Theologie der Utopie im Gespräch, Gütersloh: Kaiser 20oI, 36-85 u. ö.

84 Geis, Robert Raphael: Leiden an der Unerlöstheit der Welt. Reden, Aufsätze, Briefe, hg. v. Dietrich Goldschmidt und Ingrid Ueberschär, München: Kaiser 1984, 363 f. 
Freilich lässt Marquardt aus der nur zu berechtigten Sorge heraus, das Bekenntnis zu Jesus als dem verheißenen Messias Israels könne wieder judenmissionarisch missbraucht werden, leider eine klare Antwort auf die Frage der Messianität Jesu, des verheißenen Messias aus und für Israel und der Völker vermissen, eine Antwort, die $\mathrm{m}$. E. vom Neuen Testament her nicht umgangen werden kann. In einem sieben Seiten langen Brief an mich kurz vor seinem Sterben im Jahre 200I, nachdem ich ihn zuvor brieflich auf die messianische Menschensohntradition und ganz elementar auf I Joh 5,I u. a. hingewiesen hatte, hat Marquardt mir auf meine Fragen ausführlich geantwortet und sich, wenn auch nur zögerlich, dann doch zur Messianität Jesu positiv geäußert, die er aber in seiner Dogmatik leider durchgängig offen gelassen hat. Bei Marquardt fehlt weiter die Berücksichtigung der innovativen Werke von Jürgen Moltmann und Hans-Joachim Kraus und deren am Alten Testament, am Judentum und an der Reformation geschulten systematischen Einsichten, zuletzt dokumentiert bei Kraus in seinen „Beiträgen zum christlich-jüdischen Dialog ${ }^{\text {"85 }}$. Erst kurz vor dem Sterben von Kraus habe ich beide im Hause Marquardt noch miteinander persönlich bekannt gemacht. Marquardt hat mir gegenüber das Fehlen eines innerevangelischen Dialogs mit anderen systematischen Entwürfen damit entschuldigt, dass er einen völligen „Neuanfang“"zunächst alleine gehen musste. Das mag stimmen. Wir sollten aber, um eine Terminologie Barths abzuwandeln, in Abgrenzung von einer antijüdischen "hohen Christologie im Exzess" nicht dem Gegenteil einer „israelorientierten Christologie im Defekt “verfallen, sondern den Weg einer im Dialog erst noch zu gewinnenden "Christologie im Prozess" $z$ u gehen versuchen.

i) Die Ablehnung des urchristlichen Bekenntnisses zu Jesus, dem verheißenen Messias aus und für Israel und die Völker, vollzieht auch der amerikanische Systematiker Paul M. van Buren in seiner dreibändigen Dogmatik. ${ }^{86}$ Darin kritisiert van Buren wie Marquardt den Rheinischen Synodalbeschluss mit seinem Bekenntnis zu Jesus, dem verheißenen Messias Israels aus und für Israel und bestreitet damit wie Marquardt die Legitimität des Messiastitels für Jesus nach Auschwitz. Van Buren will stattdessen nur noch von „Christus als dem Herrn der Kirche“ sprechen, der

85 Vgl. Kraus: Rückkehr zu Israel.

86 Buren, Paul M. van: A Theology of the Jewish Christian Reality, Part I: Discerning the Way, New York: Seabury Press 1980, Part II: A Christian Theology of the People of Israel, New York: Seabury Press 1983, Part III: Christ in Context, New York: Seabury Press 1988. Vgl. dazu Klappert, Bertold: Mitverantwortung aus messianischer Hoffnung. Paul van Burens Theologie im christlich-jüdischen Kontext, in: Schweitzer, Wolfgang (Hg.): Der Jude Jesus und die Völker der Welt. Ein Gespräch mit Paul M. van Buren (Institut Kirche und Judentum 19), Berlin: Institut Kirche und Judentum 1993, I9I-2I4. 
„ein Licht für die Heiden“ sei. - j) Dazu hat der holländische Ökumeniker und Systematiker Simon Schoon, der lange Jahre nach Heinz Kremers als Leiter in Nes Ammim/Israel gearbeitet hat, eine Christologie aus den Erfahrungen der christlich-jüdischen Begegnungen in Europa und Israel ${ }^{87}$ entworfen und diese Erfahrungen auch für den christlich-islamischen Dialog fruchtbar gemacht hat, auf der Nes Ammim-Tagung 1986 zu Recht gesagt, man müsse diese wichtigen Positionen ernst nehmen, die einen christlichen Triumphalismus bekämpfen möchten. „Aber ich möchte doch fragen: Ist es dafür [...] wirklich nötig, auf den Messias-Titel zu verzichten? Wird dieses ,Opfer' [...] im Dialog von den Juden uns gegenüber verlangt? Ich meine, dass die Herausforderung tiefer geht als nur den messianischen Titel für Jesus zu vermeiden. Es geht darum, (im Sinne von Heinz Kremers) eine nicht antijüdische und nicht-triumphalistische Christologie aus den vielen Christologien des Neuen Testaments zusammenzudenken "88. - k) Innerhalb der der Systematischen Theologie benachbarten Religionswissenschaft hat der mit mir befreundete Heidelberger Missionswissenschaftler Theo Sundermeier als Schüler von Hans-Werner Gensichen $^{89}$ mit einer in der ökumenischen Missionstheologie heute nur selten zu findenden Absage an die "Judenmission" diesen Paradigmenwechsel ebenfalls vollzogen. Erschüttert, wie er mir brieflich berichtet hat, von dem hautnahen Erlebnis eines judenfeindlichen Wutausbruchs von James Cone auf einer Konferenz und als großer Kenner der nicht-antijüdischen, erst durch die Theologie der Missionare antijüdisch „erzogenen“ afrikanischen so genannten „Primärreligionen“ hat er in das von ihm und Karl Müller herausgegebene „Lexikon Missionstheologischer Begriffe " ${ }^{\text {“90 }}$ einen höchst informativen Artikel „Judentum“ von Kriestlieb Adloff ${ }^{91}$ aufgenommen. Darin spricht dieser von der „primäre[n] prophetischen Sendung

87 Schoon, Simon: De weg van Jezus. Een christologische heroriëntatie vanuit de joods-christelijke ontmoeting, Kampen: Kok 1991.

88 Schoon, Simon: Nes Ammim Tagung 1986, in: Kremers, Heinz: Vom Judentum lernen - Impulse für eine nichtantijüdische Christologie, hg. v. Klappert, Bertold / Kremers, Thomas, Neukirchen-Vluyn: Neukirchener 20I5 (in Vorbereitung); vgl. Kremers: Liebe und Gerechtigkeit, 93-I52; vgl. weiter Klappert, Bertold: Jesus, der messianische Prophet und prophetische Messias. Die Versuche zu einer nicht-antijüdischen Christologie von Heinz Kremers, in: Kremers, Heinz: Vom Judentum lernen - Impulse für eine nichtantijüdische Christologie, hg. v. Klappert, Bertold / Kremers, Thomas, Neukirchen-Vluyn: Neukirchener 2015 (in Vorbereitung).

89 Vgl. Gensichen, Hans-Werner: Glaube für die Welt. Theologische Aspekte der Mission, Gütersloh: Mohn I97I.

90 Müller, Karl / Sundermeier, Theo (Hg.): Lexikon missionstheologischer Grundbegriffe, Berlin: Reimer 1987.

9I Adloff, Kristlieb: Art. Judentum, in: Müller / Sundermeier (Hg.): Lexikon, 200-204. 
Israels, auf dem Wege zur Aufrichtung der Königsherrschaft Gottes durch seine Existenz in der nicht endenden Tat der Treue zur Tora, inmitten der Weltvölker den Einen zu verkündigen" ${ }^{\text {" }}$.

1) Ein epochaler Paradigmenwechsel ist aber insbesondere in dem großen eschatologischen Entwurf einer ökumenischen Hoffnungs- und Befreiungstheologie meines Wuppertaler Lehrers Jürgen Moltmann zur Ausführung gelangt. Von der in Wuppertal geschriebenen „Theologie der Hoffnung “933 über die Theologie des Kreuzes („Der gekreuzigte Gott“), ${ }^{94}$ die ich als Vorlesung während meiner Bonner Zeit als Assistent bei Walter Kreck hören konnte, über „Der Weg Jesu Chris$\mathrm{ti}^{\text {“"95 }}$ bis hin zur abschließenden Fassung der „Theologie der Hoffnung“ im Buch „Das Kommen Gottes “96 spannt sich ein weiter faszinierender Bogen, und darin finden sich bisher unentdeckte Einsichten.

Freilich gibt es einige Thesen, die mit einem Paradigmenwechsel noch nicht kompatibel sind: Die Konflikte Jesu mit den Pharisäern um das Gesetz seien eine Causa crucis. ${ }^{97}$ Das ist die Fortschreibung der These Ernst Käsemanns, der zufolge sich Jesus in souveräner Vollmacht über die Autorität des Mose hinweggesetzt habe, was letztlich seinen Tod zur Folge hatte, eine von Käsemann zwar leidenschaftlich vertretene, aber historisch falsche These, weil die sadduzäische Hierarchie im Bündnis mit Pilatus diese Causa crucis darstellt. Weiter: Die Epheser- und Kolosser-Hymnen mit dem „kosmischen Christus“ sollen gegenüber dem verheißenen Messias Israels einen diesem gegenüber "größeren Christus“ repräsentieren, ${ }^{98}$ obwohl der verheißene Messias Israels schon in den messianischen Verheißungen des Älteren Testaments (Jes II,I-IO; Ps 2 u. ö.), aber auch im Neuen Testament (Mk $\mathrm{I}, \mathrm{I3}$ ) immer eine kosmische Dimension impliziert. Schließlich ist in „Das Kommen Gottes“, das hoffnungstheologisch zu Recht auf eine kosmische Weltstadt zielt, ${ }^{99}$ nicht mehr klar, inwieweit die zwölf Stämme Israels und die zwölf Apostel als deren Repräsentanten die Fundamente des „neuen Jerusalem“ (Offb 2I) sind - eine

92 Ebd., 201.

93 Moltmann, Jürgen: Theologie der Hoffnung. Untersuchungen zur Begründung und zu den Konsequenzen einer christlichen Eschatologie (BEvTh 38), München: Kaiser 1964.

94 Ders.: Der gekreuzigte Gott. Das Kreuz Christi als Grund und Kritik christlicher Theologie, München: Kaiser 1972.

95 Ders.: Der Weg Jesu Christi. Christologie in messianischen (und apokalyptischen) Dimensionen, München: Kaiser 1989 .

96 Ders.: Das Kommen Gottes. Christliche Eschatologie, München: Kaiser 1995.

97 Ders.: Der gekreuzigte Gott, I2Iff.

98 Ders.: Der Weg Jesu Christi, 297ff.

99 Moltmann: Das Kommen Gottes, $338 \mathrm{ff}$. 
Frage, die im Hinblick auf das „Kairos- und Wahrheitsdokument“ ${ }^{\text {“100 }}$ der palästinensischen Christinnen und Christen von 2009 und deren These von einer kosmischen Weltstadt Jerusalem, die der Menschheit, d. h. allen Menschen, zugänglich ist, nicht offen gelassen werden kann. Hans-Joachim Kraus hat in seiner Systematischen Theologie im Kapitel „Die Weltvollendung“ diese Frage präzis beantwortet: „Die Stätte der universalen Gemeinschaft mit Gott ist [...] die Stadt, in der der Gott Israels seinem erwählten Volk zuerst gegenwärtig war" ${ }^{101}$

Aber auch Moltmann will in seinem Brief an mich vom 23. Februar 2014 im Blick auf Offb 2I diese Frage nicht unbeantwortet lassen: „Zum ,himmlischen Jerusalem' fällt mir ein [...], daß die Tore und Mauern nach den I2 Stämmen Israels und den I2 Aposteln genannt werden und damit wäre die göttliche Stadt aus Israel und der Christenheit? gebaut und für alle Völker offen und nach ihren Maßen eine [kosmische] Verbindung von Himmel und Erde“. All das einem Paradigmenwechsel noch nicht Entsprechende ändert aber nichts an dem grundsätzlich vollzogenen Paradigmenwechsel, der in allen Werken Moltmanns erstmalig bahnbrechend erfolgt ist. So ist für den christologischen Entwurf Moltmanns charakteristisch, dass er eine "Christologie in messianischen und apokalyptisch-kosmischen Dimensionen“ entwirft, die die messianische Sendung Christi zu Israel und den Völkern in das Zentrum der Überlegungen stellt. ${ }^{102}$ In seinem abschließenden Entwurf einer messianisch orientierten Eschatologie hat Moltmann für einen eschatologischen Entwurf einmalig vor aller Entfaltung der christlichen Gotteslehre das erste extra nos, $d$. h. die Externität der Israel- und Judentums-Begründung jeder Gotteslehre nach Auschwitz darin ernstgenommen, dass er zuerst nach "der Wiedergeburt des messianischen Denkens im Judentum " des 20. Jahrhunderts (Ernst Bloch, Franz Rosenzweig, Gershom Scholem, Walter Benjamin und Jacob Taubes) fragt. ${ }^{103}$ Hat Jürgen Moltmann in der

IO० Vgl. die deutschsprachige Übersetzung des Dokuments „Die Stunde der Wahrheit: Ein Wort des Glaubens, der Hoffnung und der Liebe aus der Mitte des Leidens der Palästinenser und Palästinenserinnen“, in: http://www.jai-pal.org/images/campaigns/international/ German.pdf [zuletzt abgerufen am 30.9.20I4].

IOI Kraus: Systematische Theologie, $553 \mathrm{ff} ., 562 \mathrm{f}$.

IO2 Vgl. Moltmann: Der Weg Jesu Christi, 92ff., I72ff.

I03 Moltmann: Das Kommen Gottes, 47-64. Vgl. folgende Besprechungen der Bände Moltmanns: Klappert, Bertold: Die Gottverlassenheit Jesu und der gekreuzigte Gott. Beobachtungen zum Problem einer theologia crucis in der Christologie der Gegenwart, in: Welker, Michael (Hg.): Diskussion über Jürgen Moltmanns Buch „Der gekreuzigte Gott“, München: Kaiser 1979, 57-73; ders.: Worauf wir hoffen. Das Kommen Gottes und der Weg Jesu Christi, München: Kaiser 1997, mit einer Antwort Jürgen Moltmanns; ders.: Adventliche Hoffnung und kosmische Verwandlung. „Die ganze Erde - die Fülle Seiner Herrlichkeit“ (Jes 6,3), in: $\operatorname{ThLZ}_{4}$ (1997) 313-322 u. ö. 
„Theologie der Hoffnung“ das Ältere Testament entdeckt und eine in den alttestamentlichen Verheißungen verwurzelte Eschatologie entworfen, so hat er im „Kommen Gottes" darüber hinaus eine auch am Judentum und seiner messianischen Hoffnung orientierte Hoffnungslehre entfaltet. ${ }^{104}$

IO4 Wie Moltmann seine ganze Theologie, so hat soeben der im jüdisch-christlichen Dialog im Sinne des hier präzisierten Paradigmenwechsels zuvorderst engagierte Berliner Neutestamentler und Träger der Buber-Rosenzweig-Medaille, Peter von der Osten-Sacken, seine „Gesammelten Aufsätze zur Theologie des Paulus“ mit dem Hinweis auf Jürgen Moltmanns epochalen Entwurf unter dem Titel „Der Gott der Hoffnung“ veröffentlicht (Leipzig: Evangel. Verlagsanstalt 2014). 


\title{
Kirche ohne Judentum?
}

\author{
Eine Vergewisserung zur Präsenz des Jüdischen in der ökumenischen \\ Theologie
}

Hans Hermann Henrix

Einleitung: „Eine wahre Ökumene ohne Israel ist nicht möglich“

(Walter Kardinal Kasper)

In einem Beitrag für eine Publikation zur Fortsetzung der Rezeption der Konzilserklärung über die Haltung der katholischen Kirche zu den nichtchristlichen Religionen Nostra Aetate bedachte Walter Kardinal Kasper die Beziehung von Judentum und Christentum als ein Verhältnis der Verschiedenheit, das jedoch kein Nebeneinander und noch weniger ein Gegeneinander sei. Zur Klärung dieser Beziehung diente ihm das paulinische Bild vom Wurzelstock und von den eingepfropften Zweigen (Röm II,I6-20). Er meinte, dieses Bild bringe die Zusammengehörigkeit und die Unterschiedenheit zwischen beiden gleichermaßen zum Ausdruck und erläuterte dies:

\begin{abstract}
„Ohne die eingepfropften Zweige bleibt die Wurzel ein unfruchtbarer Wurzelstumpf. Die eingepfropften Zweige haben dem Wurzelstock neue Lebenskraft und Fruchtbarkeit gegeben. So hat die Kirche den Monotheismus Israels und die Zehn Gebote als den Kern des mosaischen Gesetzes weltweit unter die Völker gebracht und damit dazu beigetragen, dass die Abraham gegebene Verheißung, er werde ein Segen für alle Völker sein (Gen I2,3; I8,I8 u. a.), wahr wurde. Israel ohne die Kirche ist in der Gefahr, partikularistisch und eigenbrötlerisch zu werden, die Kirche ohne Israel dagegen ist $[\ldots]$ in der Gefahr, das historische Fundament zu verlieren, geschichtslos und gnostisch zu werden. Israel und die Kirchen brauchen einander und sind deshalb aufeinander angewiesen. Eine wahre Ökumene ohne Israel ist nicht möglich."
\end{abstract}

I Kasper, Walter Cardinal: Foreword, in: Cunningham, Philip A. u. a. (Hg.): Christ Jesus and the Jewish People Today. New Explorations of Theological Interrelationships, Cambridge: Grand Rapids 20II, XVI. Vgl. auch Kasper, Walter Kardinal: Juden und Christen - das eine Volk Gottes, in: IkaZ Communio 39 (2010) 418-427. 
Kaspers Nachfolger im Amt des Präsidenten der „Vatikanischen Kommission für die religiösen Beziehungen zum Judentum“, Kardinal Kurt Koch, las das paulinische Bild ähnlich, als er es dahingehend ernst nahm, „dass die Kirche nur lebensfähig ist, wenn sie ihre Nahrung und Kraft aus der Wurzel Israels bezieht und dass die aufgepfropften Zweige welk oder gar absterben würden, wenn sie von der Wurzel Israels abgeschnitten werden. "2 In einer früheren Reflexion hatte Kardinal Koch diese Beziehung als „zur innerchristlichen Ökumene selbst“ gehörend qualifiziert, da diese „keine Vollendung finden (kann) ohne Versöhnung zwischen Juden und Christen“. Er sah gar den „Ernstfall der christlichen Ökumene“ darin begründet, dass - und hier folgt zum Judentum eine Aussage, die der Position von Kardinal Kasper gegenläufig ist und dem mehrheitlichen Selbstverständnis im Judentum eher entspricht - „das Judentum zwar ohne das Christentum, das Christentum aber auf keinen Fall ohne das Judentum leben kann". ${ }^{3}$ Gerne zitiert Kurt Koch in seinen Äußerungen zum Verhältnis von Kirche und Israel den Theologen Erich Przywara, der in der Festschrift für Karl Rahner von 1964 die Trennung zwischen der Synagoge und der frühen Kirche als „Ur-Riss“ bezeichnete, aus dem die nachfolgenden Schismen der Kirche abzuleiten seien. ${ }^{4}$

2 Koch, Kurt Kardinal: Wie treu stehen wir zum Erbe Abrahams? Vortrag in Stuttgart vom 9. November 20II, in: http://www.erzdioezese-freiburg.de/lib/download.php?key=32088722a633\&file=/dynamic/datei/20II_II_09_vortrag_kardinal_koch.pdf\&name=vortrag_kardinal_koch_9.II.20II_[abgerufen am 7.5.20I4].

3 Koch, Kurt: Was bedeutet die Hinwendung der Kirchen zu ihren jüdischen Quellen für die christliche Ökumene heute?, in: IkaZ Communio 23 (2000) I60-I74, I62. Zum jüdischen Selbstverständnis, dass das Judentum ohne das Christentum leben kann, ist in den zurückliegenden Jahrzehnten gerne die Aussage von Ernst Ludwig Ehrlich aus seinem Beitrag „Eine jüdische Auffassung von Jesus", in: Eckert, Willehad Paul / Henrix, Hans Hermann (Hg.): Jesu Jude-Sein als Zugang zum Judentum (Aachener Beiträge zu Pastoral- und Bildungsfragen 6), Aachen: Einhard-Verl. 1976, 35-49, 36 zitiert worden: „So besteht hier eine grundsätzlich andere Situation zwischen Christen und Juden: Wollen jene die Religion des Volkes Israel ignorieren, schneiden sie sich selbst die Wurzeln ab, von denen sie theologisch leben; der Jude hingegen kann ein vollgültiges religiöses Leben führen, ohne je etwas von Jesus und dem Evangelium gehört zu haben." Die aktuelle und auch beim Forschungskolloquium angesprochene Diskussion um die Frage, ob das Judentum ganz ohne das Christentum zu verstehen ist oder nicht, hat einen Kristallisationspunkt in der Publikation von Schäfer, Peter: Die Geburt des Judentums aus dem Geist des Christentums. Fünf Vorlesungen zur Entstehung des rabbinischen Judentums (Tria corda 6), Tübingen: Mohr Siebeck 20 Io.

4 So Koch: Was bedeutet die Hinwendung?, 162 oder: Theologische Fragen und Perspektiven im christlich-jüdischen Dialog. Vorlesung vom 30. Oktober 20II in South Orange, in: http://www.nostra-aetate.uni-bonn.de/kirchliche-dokumente/online-publikation-die-kirchen-und-das-judentum/i.-katholische-verlautbarungen-I/dokumente/theologische-fra- 
Wenn man sich von diesen ökumenischen Verortungen der Beziehung von Kirche und Judentum durch lehramtlich Verantwortliche dem theologischen Diskurs zuwendet, dann kann man dort auf eine „Einführung in die ökumenische Theologie" ohne jeden Hinweis auf die Beziehung der Kirche zum Judentum stoßen. ${ }^{5}$ Oder es begegnen aktuelle Konzilsgeschichten zum Zweiten Vatikanum, ohne dass dort die Konzilserklärung Nostra Aetate eine eigene oder ausgeführte Würdigung erfährt. ${ }^{6}$ Das lässt fragen: Bleibt in der geschichtlichen Rekonstruktion des Konzilsgeschehens Nostra Aetate bzw. die Beziehung Kirche - Judentum eher ausgeblendet? Ist an der Rezeption von Nostra Aetate die ökumenische Theologie nicht beteiligt? Wie steht es um die Präsenz des Jüdischen in der ökumenischen Theologie?

Eine solche Frage an die ökumenische Theologie zu stellen, kann ein Doppeltes bedeuten: Im ersten Fall kann die tatbestandliche Frage gestellt sein, ob und wie das Judentum in den Äußerungen der ökumenischen Theologie überhaupt vorkommt. Eine entsprechende Erhebung des Tatbestands, ob das Jüdische in der ökumenischen Theologie präsent ist, würde noch nicht aus sich heraus klären, ob eine Nichtpräsenz Israels auch den Makel eines Versäumnisses habe und daraus ein Verschweigen, Verdrängen und Marginalisieren Israels zu konstatieren sei. Eine solche Qualifizierung ist erst aus der Antwort auf den zweiten Fall bzw. auf die andere Frage begründbar, nämlich: Gehört es denn überhaupt zum Auftrag der christlichen ökumenischen Theologie, die Haltung der Kirche zum Judentum zu thematisieren und auf das Judentum im ökumenischen Kontext einzugehen? Welche theologischen Gründe lassen sich für eine Präsenz des Jüdischen in der ökumenischen Theologie benennen? Die folgenden Erwägungen stellen sich der Aufgabe, das Judentum und die Beziehung der Kirche dazu als eine quaestio iuris und quaestio facti ökumenischer Theologie zu bedenken.

gen-und-perspektiven-im-christlich-juedischen-dialog [abgerufen am 7.5.20I4] oder: Gemeinsam Volk Gottes sein. Perspektiven des jüdisch-katholischen Dialogs von Nostra aetate bis Papst Benedikt XVI. Vortrag an der Universität Luzern am 25. Oktober 20II, in: http://www.unilu.ch/files/Koch---Luzern-IJCF,-20II.pdf [abgerufen am 7.5.20I4].

5 Nüssel, Friederike / Sattler, Dorothea: Einführung in die ökumenische Theologie, Darmstadt: Wissenschaftliche Buchgesellschaft 2008.

6 Delgado, Mariano / Sievernich, Michael (Hg.): Die großen Metaphern des Zweiten Vatikanischen Konzils. Ihre Bedeutung für heute, Freiburg: Herder 2013 oder Böttigheimer, Christoph (Hg.): Zweites Vatikanisches Konzil. Programmatik - Rezeption - Vision (QD 26I), Freiburg: Herder 2014. 


\section{I. Ökumene als binnenchristliches Phänomen - Kirche abseits vom Judentum}

Die christliche ökumenische Theologie ist Teil der neuzeitlichen Ökumene, die aus mehreren Wurzeln und unterschiedlichen Motiven hervorgegangen ist. Es sind Fortschritte erzielt worden. Und doch sind Äußerungen der Stagnation und Resignation darüber nicht zu leugnen, dass theologisch Kontroversen als nicht kirchentrennend analysiert wurden, ohne dass die Kirchen daraus die möglichen Konsequenzen gezogen hätten. ${ }^{7}$ Insgesamt jedoch ist die Ökumene als ein Lichtblick der zurückliegenden Jahrzehnte zu würdigen. ${ }^{8}$ Die christliche Welt ist bei allen bleibenden internen Spannungen zusammengewachsen.

Das sowohl dem Begriff wie der Sache nach immer wieder diskutierte Wort "Ökumene" ist im Laufe einer langen Begriffsgeschichte zum Begriff der religiösen Sprache geworden. Es kommt mit seinem Sinn als die „bewohnte Welt“ im neutestamentlichen Sprachgebrauch positiv und negativ vor und erfährt eine Theologisierung. ${ }^{9}$ Sobald das Römische Reich christlich geworden ist, werden Ökumene und Kirche deckungsgleich. „Katholizität und Ökumenizität werden zu sich gegenseitig erklärenden Begriffen [...] Die Kirche ist, katholisch', weil sie über die ganze Ökumene hin verbreitet ist“ ${ }^{10}$ Der über die ganze bewohnte Welt verbreiteten „Ökumene" stehen jedoch die Nationen und Heiden gegenüber, welche der christlichen „Ökumene“ nicht angehören. Das Wort ist damit in den Dienst einer Definitionsgewalt getreten, die in Gegenüberstellung und Abgrenzung, ja Zurückweisung und Ablehnung denkt und auch innerchristlich greifen kann, sodass „Ökumene“ schließlich zum Synonym für die gesamte rechtgläubige Kirche in Ost und West

7 Neuner, Peter: Ökumenische Theologie. Die Suche nach der Einheit der christlichen Kirchen, Darmstadt: Wissenschaftliche Buchgesellschaft 1997, I8; ders. / Kleinschwärzer-Meister, Birgitta: Kleines Handbuch der Ökumene, Düsseldorf: Patmos 2002, 23-26; Baumann, Urs: Art. Ökumene, in: Eicher, Peter (Hg.): Neues Handbuch theologischer Grundbegriffe. 3. Neuausgabe 2005, München: Kösel 2005, 26I-283, 275. Koslowski, Jutta: Die Einheit der Kirche in der ökumenischen Diskussion. Zielvorstellungen kirchlicher Einheit im katholisch-evangelischen Dialog (Studien zur systematischen Theologie und Ethik 52), Münster: LIT 2008 vertritt die nüchterne These: „Die Einheit der Christenheit ist nicht verwirklicht, weil sie nicht genügend gewollt wird.“ Ebd., 523.

8 So mit Kasper, Walter Kardinal: Konfessionelle Identität - Reichtum und Herausforderung, in: Bolzenius, Theodor u. a. (Hg.): Ihr sollt ein Segen sein. Ökumenischer Kirchentag 28. Mai - I. Juni 2003 in Berlin, Dokumentation, Gütersloh: Gütersloher Verlagshaus 2004, 428-442, 429 .

9 Vgl. Neuner: Ökumenische Theologie, If.

IO Ebd., 2-9; Neuner / Kleinschwärzer-Meister: Kleines Handbuch, II. 
werden kann. Der Begriff „Ökumene“ bzw. „ökumenisch“ erfährt im I9. Jahrhundert mit dem neu erwachten Sinn für die weltweite Zusammengehörigkeit der Christen und Christinnen eine Renaissance, in deren Folge „Ökumene“ besonders in den Kirchen der Reformation stark mit „Mission“ zusammengedacht wird. Aus der „Ökumene“ als theologischer Begriff wird ein Handlungsmovens.

Das aber verschärft ein Dilemma. Als die Kirchen in ihren konfessionellen Identitäten missionarisch auf die nichtchristliche Welt zugingen, erfuhren sie ihr Nebeneinander als eine Konkurrenzsituation. Diese schlug ihnen zum einen von den Adressaten und Adressatinnen ihrer missionarischen Bemühungen her, also von außen, als Reaktion des Irritiert-Seins zurück. Zum anderen nahmen sie in ihrem Binnenverhältnis ihr Getrenntsein als ein Gegenzeugnis wahr, welches die Glaubwürdigkeit des Zeugnisses beschädigte und beeinträchtigte. Die Zuwendung der Kirchen nach außen erforderte eine Klärung ihres zwischenkirchlichen Binnen bzw. der binnenkirchlichen Situation. Der Begriff „Ökumene“ und „ökumenisch“ wurde damit verstärkt auf diese zwischenkirchlichen Bemühungen der Klärung bezogen. Es waren parallel laufende, einander gegenläufige und schließlich konvergierende Klärungsprozesse, die nach dem Zweiten Weltkrieg 1948 zur Gründung des Ökumenischen Rates der Kirchen in Amsterdam führten. ${ }^{11}$ Ihm gehören die übergroße Mehrzahl der Kirchen der Reformation und die Familie der orthodoxen Kirche, nicht aber die katholische Kirche an. Erst Papst Johannes XXIII. gründete im Juni 1960 das Sekretariat zur Förderung der Einheit der Christen, mit dessen Leitung er Augustin Bea beauftragte, welcher der „Kardinal des Ökumenismus und des Dialogs" genannt wurde. Für Kardinal Koch ist es Johannes XXIII. selbst, den man „als geistlichen Vater der ökumenischen Bewegung in der katholischen Kirche würdigen" darf. ${ }^{12}$ Das von Johannes XXIII. einberufene Zweite Vatikanischen Konzil (1962-1965) kommt zur Bejahung der ökumenischen Bewegung und spricht besonders mit seinem Dekret über den Ökumenismus Unitatis redintegratio „eine klare Option für die ökumenische Bewegung“ aus. ${ }^{13}$ Der Begriff „Ökume-

II Vgl. nur ebd., 82-88 oder Ritschl, Dietrich / Ustorf, Werner: Ökumenische Theologie Missionswissenschaft, Stuttgart: Kohlhammer 1994, 67-75.

I2 Koch, Kurt Kardinal: Ökumene auf dem Weg. Situationsvergewisserung der ökumenischen Bewegung heute, in: Catholica 65 (20II) I-26, I.

I3 Kasper: Konfessionelle Identität, 43I; zur Entwicklung der katholischen Option für die ökumenische Bewegung siehe: Stobbe, Heinz-Günther: Lernprozeß einer Kirche. Notwendige Erinnerung an die fast vergessene Vorgeschichte des Ökumenismus-Dekrets, in: Lengsfeld, Peter (Hg.): Ökumenische Theologie. Ein Arbeitsbuch, Stuttgart: Kohlhammer 1980, 7I-I23 oder Petri, Heinrich: Die römisch-katholische Kirche und die Ökumene, in: Urban, Hans Jörg / Wagner, Harald (Hg.): Handbuch der Ökumenik. 2, Paderborn: Boni- 
ne“ und „ökumenisch“ hat damit aus katholischer Sicht eine grundsätzlich positive Färbung, auch wenn er mit unterschiedlichen Akzentuierungen versehen wird.

Ökumene meint also im herrschenden Sprachgebrauch die Überwindung des Skandals der Spaltung der Kirchen, die gemäß dem neutestamentlichen Leitwort der Ökumene „Alle sollen eins sein“ (Joh 17,2I) unter dem Gebot der Einheit stehen. Ökumene ist das „dramatische“ Ringen der Kirchen um Einheit und Gemeinschaft. Es beteiligen sich an diesem Ringen die großen Kirchen, d. h. die Kirchen der Reformation, die katholische Kirche und die Familie der orthodoxen Kirche, während sich die Kirchen oder kirchlichen Gemeinschaften der pfingstlichen und evangelikalen Tradition zurückhalten bzw. erst allmählich zur Ökumene finden. Das Wort „Ökumene“ ist der binnenchristlichen Realität vorbehalten. So konnte der Befund in den I970er-Jahren lauten: „Das Judentum kommt darin nicht vor“ ${ }^{\text {“ }}{ }^{4}$ Die Ökumene als ein binnenchristliches Phänomen verstand die Kirchen abseits des Judentums.

\section{Erste Voten für die Präsenz des Jüdischen in der ökumenischen Theologie}

Die „Ökumenische Theologie“ - ihr Begriff hat sich erst nach dem Zweiten Vatikanischen Konzil durchgesetzt - will der sichtbaren Einheit der Kirche den Weg bereiten: Sie ist damit strategisch-funktional ausgerichtet. Zugleich ist die ökumenische Theologie kritisch. Denn sie hält präsent, dass die Ökumene „in einen Schulddiskurs eingeschrieben “ ist. ${ }^{15}$ Ökumenische Theologie versteht sich als „die methodisch gesicherte Kenntnisnahme, kritische Beurteilung und theoretische Verarbeitung des gegenwärtigen Zustands der Christenheit, sofern sie in verschiedene Kirchen und Konfessionen geteilt und zugleich, zur Erfüllung ihres Auftrages, auf Verständigung und Einheit in der Wahrheit angewiesen ist “. ${ }^{16}$ Die ökumenische Theologie blickt ausdrücklich über die Grenzen der jeweiligen einzelkirchlichen

fatius 1986 , 95-168.

I4 Henrix, Hans Hermann: Ökumene aus Juden und Christen. Ein theologischer Versuch (1978), in: Ders.: Gottes Ja zu Israel. Ökumenische Studien christlicher Theologie (SKI 23), Berlin: Inst. Kirche und Judentum 2005, 7-64, 8; vgl. auch ders.: Der Dialog mit dem Judentum als Aufgabe ökumenischer Theologie. Eine Problemanzeige, in: Una Sancta 3I (1976) I36-I45 und die dort genannte Literatur zum damals herrschenden Selbstverständnis ökumenischer Theologie.

I5 Hoff, Gregor Maria: Ökumenische Passagen - zwischen Identität und Differenz. Fundamentaltheologische Überlegungen zum Stand des Gesprächs zwischen römisch-katholischer und evangelisch-lutherischer Kirche (SThSt 25), Innsbruck: Tyrolia 2005, 26.

I6 Lengsfeld, Peter / Stobbe, Heinz-Günther: Studium Ökumenische Theologie im theologischen Studium, in: Lengsfeld (Hg.): Ökumenische Theologie, 379-388, 382. 
Tradition hinaus und vollzieht sich als Gespräch mit den anderen kirchlichen Traditionen. Sie tut es in einer doppelten Weise, insofern sie gemäß anerkanntem Standard in jedem theologischen Fach die anderskonfessionelle Theologie berücksichtigt und es zugleich Strukturen einer eigenen ökumenischen Projektdisziplin gibt.

Trotz einer dispositionellen Offenheit für Andere oder für Aufstörungen durch das Andere gab es unter ökumenischen Theolog/innen lange Zeit „einen breiten Konsens, der alle sonstigen Unterschiede und Gegensätze überbrückte und die Überzeugung zum Inhalt hatte, dass das jüdisch-christliche Gespräch nicht zur Aufgabe ökumenischer Theologie im engeren und eigentlichen Sinne gehöre." ${ }^{17}$ Und doch hatte es wenige Jahre nach der Schoa erste Aufstörungen durch das jüdisch Andere gegeben. Sie bestanden in der kritischen Einrede gegen das breite Einvernehmen, Ökumene sei eine rein christliche Angelegenheit. Einzelne Stimmen - zunächst aus der französischen Theologie - meinten, man dürfe theologisch nicht verkennen, dass den geschichtlichen Spaltungen der Christenheit ein „Initialkonflikt“ im Volk Gottes vorausging. Dieses könne man ebenso wenig wie das zeitgenössische Judentum aus der Ökumene der Kirchen ausklammern. Paul Démann, Mitglied des Ordens Unserer Lieben Frau von Sion, sprach 1953 von einem Ur-Schisma „im Innern Israels“, als ein Teil des alten Gottesvolkes an den Auferstandenen glaubte und die Mehrheit des Volkes sich diesem Glauben versagte: Israel und die Kirche seien nicht zwei einander fremde Religionsgemeinschaften, sondern zwei getrennte Zweige eines und desselben Gottesvolkes. Die Haltung der Christen zu Juden und Judentum könne nicht eine missionarische sein, die auf individuelle Konversionen setzt, sondern nur eine ökumenische Haltung, in der die gemeinsamen Grundelemente des Glaubens durch Läuterung und Vertiefung wieder gefunden werden müssten. Die Erwägungen, die der Wiedererrichtung der Einheit der Kirchen gelten, ließen sich ,auf die Wiedereingliederung Israels in die Kirche (sic) anwenden“. Und: „Die Existenz Israels ist nicht ,außerhalb’ der Kirche“. ${ }^{18}$ Paul Démanns Formulierung einer „Wiedereingliederung Israels in die Kirche" fand keinen Nachhall. Aber die Grundüberzeugung, die Beziehung der Kirche(n) zueinander sei ohne die Beziehung zum Judentum nicht zu klären und die

I7 Stobbe, Heinz-Günther: Dialog mit dem Judentum als Paradigma ökumenischer Theologie. Eine Skizze, unveröffentlichtes Manuskript 1986, I9 Seiten, 2.

I8 Démann, Paul: Israël et l'Unité de l'Église, in: Cahiers Sioniens 7 / 3 (1953) I7-24, teilweise in Deutsch veröffentlicht in: Gollwitzer, Helmut / Sterling, Eleonore (Hg.): Das gespaltene Gottesvolk, Stuttgart: Kreuz-Verl. 1970, 256-260; ders.: Kirche und Israel in ökumenischer Sicht, in: Marsch, Wolf-Dieter / Thieme, Karl (Hg.): Christen und Juden. Ihr Gegenüber vom Apostelkonzil bis heute, Mainz: Grünewald 1961, 270-283. 
Wiederversöhnung der Kirchen habe ihre Analogie in einem Näherkommen von Kirche und Israel, wurde in der Theologie vielfach aufgegriffen. Mit Kardinal Koch wurde bereits an die Formulierung von Erich Przywara von 1964 vom „Ur-Riss“ zwischen der Synagoge und der frühen Kirche erinnert. Den stärksten Widerhall erfuhr das Votum, welches Karl Barth bei seinem Besuch in Rom 1966 den Mitgliedern des Vatikanischen Einheitssekretariates als sein Vermächtnis hinterließ: „Die ökumenische Bewegung wird deutlich vom Geiste des Herrn getrieben. Aber wir sollen nicht vergessen, dass es schließlich nur eine tatsächlich große ökumenische Frage gibt: unsere Beziehungen zum Judentum. ${ }^{\text {19 }}$

3. Konturen einer Präsenz des Jüdischen in der ökumenischen Theologie

a. Ein Konsens in der quaestio iuris

Immer wieder wurde auf das Wort von Karl Barth Bezug genommen. Aber was sind die theologischen Argumente, welche zur Begründung des Barthschen Aphorismus ausgeführt werden? Der Bogen spannt sich von exegetischen über ekklesiologische bis zu pneumatologischen Aspekten. So interpretiert der Exeget und Judaist Karlheinz Müller die neutestamentlichen Befunde als „unabweisbar“ für eine notwendige ,jüdisch-christliche Ökumene“. Die Jesusüberlieferungen erlauben keinen Zweifel daran, „dass es Jesus von Nazaret um die Wahrheit des jüdischen Gottesglaubens ging, dass der Nazarener zur Erkenntnis der Wahrheit des jüdischen Bekenntnisses, zum Gott Israels also, aufrief". Die jüdisch-christliche Ökumene könne ,an den Koordinaten der Willensrichtung Jesu direkt abgelesen werden“. Die Besonderheit des Christentums ist „eben die Gestalt des Nazareners“. Ohne die Schriften des Judentums wüssten wir Christinnen und Christen heute nicht, wer Jesus war: „alle Christologie des Anfangs verdankt sich jüdischer Authentie [...] Die Achse des Christentums kann sich niemals ohne Identitätsverluste ihrer in der Mitte nach wie vor jüdischen Veranlagung entschlagen“. ${ }^{20}$

Für Wilhelm Breuning war es - hier zitiert er den evangelischen Kollegen Michael Weinrich und hätte zahlreiche Hinweise von Bertold Klappert an die Seite

I9 Überliefert vom damaligen Sekretär des Vatikanischen Büros für die Beziehungen zu den Juden: Rijk, Cornelius A.: Das gemeinsame Band. Die Bedeutung der jüdisch-christlichen Beziehungen für die Einheit der Christen, in: BiKi 29 (1974) 42-44, 44.

20

Müller, Karlheinz: Rückbesinnung auf die Zukunft. Von der Notwendigkeit einer jüdisch-christlichen Ökumene, in: Schreiner, Josef / Wittstadt, Klaus (Hg.): Communio Sanctorum. Einheit der Christen - Einheit der Kirche. FS Bischof Paul-Werner Scheele, Würzburg: Echter 1988, 23I-245, 234f., 238. 
stellen können - „Karl Barth, der den Begriff der Ökumene auf das Verhältnis zwischen Kirche und Israel ausweitete“. Die Bejahung dieser Ausweitung verband Breuning mit der nüchternen Einschätzung, dass „am Ende eines ökumenischen Prozesses, der auch die Juden mitbeteiligte," sich nicht „so etwas wie Einheit herausstellen würde“. Und er mahnte, dass „das Judentum als besondere ökumenische Frage [...] zwar in die Grundlagen ökumenischer Verhaltensweisen (gehört), deren allererste Umkehr und Zuwendungsbereitschaft sind, aber es darf [...] nicht zu gleichsinnig in eine Ökumene vereinnahmt werden. “21 So hält er bewusst: Bei aller Zuwendung der christlichen Theologie zum Judentum hat sich ihr das christliche Versagen, Unrecht und Unheil „wie ein Brandmal eingeprägt". ${ }^{22}$

Franz Mußner, dem Theologie und Dialog grundlegende exegetische und bibeltheologische Einsichten zum Verhältnis Kirche - Judentum verdanken und der - fast hundertjährig - nach wie vor eine erfreuliche Präsenz zeigt, beschäftigte sich ebenfalls mit der Frage: „Was haben die Juden mit der christlichen Ökumene zu tun?" ${ }^{23}$ Nach der Feststellung, dass es gerade die Schoa war, welche die christliche Ökumene nach ihrem Verhältnis zum Judentum fragen ließ, meint er, die ökumenische Theologie „kann sich der durch die Schoah mit Vehemenz aufgebrochenen Frage nach Gott, nach dem ,Gottesbild' nicht entziehen“ und müsse ihre Antwort zusammen mit den Juden suchen. Defizite sieht er auch in einer Ekklesiologie „ohne Besinnung auf die ,Wurzel' Israel“. Er hatte schon früher in seinem „Traktat" gefordert, zu den Kirchenattributen der Einheit, Heiligkeit, Katholizität und

2I Breuning, Wilhelm: Was erbringt der jüdisch-christliche Dialog für das katholisch-evangelische Gespräch?, in: Hahn, Ferdinand u. a. (Hg.): Zion - Ort der Begegnung. Festschrift für Laurentius Klein zur Vollendung des 65. Lebensjahres (BBB 90), Bodenheim: Athenäum Hain Hanstein 1993, 347-369, 354f. Vgl. Weinrich, Michael: Jüdisch-christlicher Dialog, in: Neues Handbuch theologischer Grundbegriffe. 3, München: Kösel I99I, 54 und aus den Wortmeldungen von Klappert, Bertold: Die Öffnung des Israelbundes für die Völker. Karl Barths Israeltheologie und die Bundestheologie der reformierten Reformation, in: Wengst, Klaus u. a. (Hg.): Ja und Nein. Christliche Theologie im Angesicht Israels. FS für Wolfgang Schrage zum 70. Geburtstag, Neukirchen: Neukirchen-Vluyn 1998, 33I-348; Folgen der Israelvergessenheit in Mission und Ökumene vor und nach Auschwitz, in: Lilienthal, Ulrich / Stiehm, Lothar (Hg.): Den Menschen zugewandt leben. FS für Werner Licharz, Osnabrück: Secolo-Verl. 1999, 57-80. Breuning: Was erbringt der jüdisch-christliche Dialog?, 353.

23 Mußner, Franz: Was haben die Juden mit der christlichen Ökumene zu tun?, in: Una Santa 50 (1995) 33I-339; vgl. seine Werke: Traktat über die Juden, München: Kösel 1979 bzw. überarbeitete Neuauflage Göttingen: Vandenhoeck \& Ruprecht 2009; Die Kraft der Wurzel. Judentum - Jesus - Kirche, Freiburg: Herder ${ }^{2}$ I989; Dieses Geschlecht wird nicht vergehen. Judentum und Kirche, Freiburg: Herder I99I. 
Apostolizität müsse auch „die unlösbare Verwurzelung der Kirche in Israel“ gezählt werden. ${ }^{24}$

Das einzigartige Verhältnis der Kirche zum Judentum wurde für Erwin Dirscherl nach dem Zweiten Vatikanischen Konzil „mehr und mehr in Richtung Ökumene gerückt“. Es sei - so sagt Dirscherl in pneumatologischer Diktion - „derselbe Atem Gottes, der beide das Wort Gottes auf je eigene Weise verkünden lässt. Beide leben aus derselben Inspiration, aus dem Geist Gottes, der sie dazu befähigt, dem Wort Gottes auf je andere Weise zu antworten." Und Dirscherl zieht aus dieser "Zuordnung im ökumenischen Kontext“ die Folgerung, dass „das Judentum nicht Gegenstand einer Missionierung sein“ kann. ${ }^{25}$ So kennzeichnet er das „singuläre Phänomen der Bezogenheit von Kirche und Israel“ als ein solches „von wahrhaft ökumenischer Tragweite“. ${ }^{26}$

In eigenen Wortmeldungen hatte ich in den I970er-Jahren versucht, dem Jüdischen eine Präsenz in der ökumenischen Theologie zu erstreiten. Der Versuch war durch die erste Rezeptionsphase von Nostra Aetate angeregt und setzte bei einem Thema ein, das auf den ersten Blick nur das Moment des Geschiedenseins von Kirche und Judentum hervortreten lässt: beim christologisch-inkarnationstheologischen Aspekt. Das Bekenntnis zu Jesus Christus als Fleisch gewordenem Wort Gottes sei von Karl Barth dahingehend bedacht worden, dass Gottes Sohn in Jesus Christus „,nicht allgemein und neutral Mensch' geworden [ist]. Vielmehr ist er ,jüdisches Fleisch', Jude, Sohn einer jüdischen Mutter und als solcher konkret Mensch geworden. Menschwerdung (des Sohnes) Gottes geschah als Judewerdung. Das ist alles andere als ,eine beiläufige und zufällige Bestimmung' " In der Judewerdung liege für die ökumenische Theologie die theologische Begründung, ,über die Trennung durch den Christusglauben hinauszufragen und Wege der Verständigung und Einheit in der Wahrheit mit dem Judentum zu erkunden." Auch der ekklesiologische Aspekt als zweiter Begründungsgang der damaligen Wortmeldung bezog sich auf kirchliche Selbstauslegung, um das Jüdische präsent zu machen, so auf den Eröffnungssatz von Nostra Aetate, Artikel 4: „Bei ihrer Besinnung auf das Geheimnis der Kirche gedenkt die Heilige Synode des Bandes, wodurch das Volk des Neuen Bundes mit dem Stamme Abrahams geistlich verbunden ist". Hier werden in einem „Akt der Selbstvergewisserung [...] Israel und Judentum thematisiert.

24 Mußner: Traktat, 175.

25 Dirscherl, Erwin: Gottes Wort als Fülle der Zeit - Die Heilsbedeutung des jüdischen Glaubens in der Zeit post Christum natum, in: Frankemölle, Hubert / Wohlmuth, Josef (Hg.): Das Heil der Anderen. Problemfeld „Judenmission“ (QD 238), Freiburg: Herder 20IO, 395-419, 398. 
Das gehört zur Selbstbesinnung der Kirche", was die vatikanischen Richtlinien und Hinweise für die Durchführung der Konzilserklärung von 1975 bekräftigten: „Das Problem der Beziehungen zwischen Juden und Christen ist ein Anliegen der Kirche als solcher, denn sie begegnet dem Mysterium Israels bei ihrer ,Besinnung auf ihr eigenes Geheimnis'“ "Der damalige Kommentar: „In solcher Definition von Kirche ist das Judentum quasi mitgesetzt. Und in ihr ist die Teilung von Kirche und Synagoge hintangesetzt zugunsten der Zusammengehörigkeit beider". Und der dritte Begründungsansatz bestand in einem heilsökonomischen Aspekt. Als Deutung konziliarer und paulinischer Aussagen wurde vorgetragen: „Wem die Gnadengaben Gottes gehören und wer von Gott geliebt ist nach dem Zeugnis der christlichen Bibel und des Konzils, dem kann christliche Theologie das spezifische Licht, die besondere Würde und den eigenen Wert, vor allem aber das Heil vor Gott nicht streitig machen wollen." Die damals gezogene Folgerung für die Kirche lautete: „Das bedeutet jedoch, dass es nur ein Volk Gottes gibt - in der Zweigestalt von Israel und Kirche", womit unübersehbar das Judentum bzw. die Beziehung der Kirche(n) zum Judentum als Thema ökumenischer Theologie reklamiert wurde. ${ }^{27}$

Einige Zuspitzungen dieser fast vier Jahrzehnte zurückliegenden Erwägungen erscheinen heute zu pointiert, als dass sie ohne Einschränkung wiederholt werden könnten; etwa die dezidierte Rede von einer „Einheit“ zwischen Judentum und Kirche oder die doch wohl zu exklusive These eines von Gott gesegneten Unterwegsseins nur der Kirche und des Judentums. In der Zwischenzeit ist - ganz in Analogie zur Betonung der bleibenden Bedeutung der Differenz in der ökumenischen Theologie in Beiträgen etwa von Gregor Maria Hoff, Ulrich H. J. Körtner oder Thomas Fornet-Ponse ${ }^{28}$ - das theologisch bedeutsame Gewicht der Andersheit des Anderen besonders in der Rezeption des Denkens von Emmanuel Levinas $^{29}$ sehr viel klarer vor Augen. Die eigene frühere Wortmeldung fügt sich

27 Zitate aus: Henrix: Der Dialog, I4I-I43. Diese Argumente lagen auch einer weiteren Wortmeldung des Autors zu Grunde: Ökumenische Theologie und Judentum. Gedanken zur Nichtexistenz, Notwendigkeit und Zukunft eines Dialogs, in: Freiburger Rundbrief XXVIII (1976) i6-27.

28 Vgl. hierzu nur ihre Beiträge zur ökumenischen Theologie: Hoff: Passagen; Körtner, Ulrich H. J.: Wohin steuert die Ökumene? Vom Konsens- zum Dissensmodell, Göttingen: Vandenhoeck \& Ruprecht 2005; Fornet-Ponse, Thomas: Ökumene in drei Dimensionen. Jüdische Anstöße für die innerchristliche Ökumene, Münster: Aschendorff 2oII.

29 Hierzu nur: Henrix, Hans Hermann (Hg.): Verantwortung für den Anderen - und die Frage nach Gott. Zum Werk von Emmanuel Levinas (Aachener Beiträge zu Pastoral- und Bildungsfragen 13), Aachen: Einhard-Verl. 1984; Wohlmuth, Josef (Hg.): Emmanuel Levinas - eine Herausforderung für die christliche Theologie, Paderborn: Schöningh I999; Henrix, Hans Hermann: Gott und der Andere bei Emmanuel Levinas, in: ThPh 8I (2006) 48I-502. 
unabhängig von einigen Überpointierungen in den Konsens einer positiven Beantwortung der quaestio iuris ein, der zufolge es recht getan ist, wenn die ökumenische Theologie sich als Sachwalterin für einen Ort des Jüdischen in der christlichen Theologie versteht. Es gibt heute keine ernsthafte, ausdrückliche Bestreitung, dass die Klärung der einmaligen Beziehung der Kirche/n zum Judentum und jüdischen Volk zu den Aufgaben einer ökumenischen Theologie gehört. Hier kann man einen Konsens etwa zwischen katholischen und evangelischen Theolog/innen konstatieren.

\section{b. Die Präsenz des Jüdischen in der ökumenischen Theologie als Projektdisziplin. Zur quaestio facti}

Wie steht es aber mit der quaestio facti? Setzt die Ökumene bzw. die ökumenische Theologie die theologische Erkenntnis auch tatsächlich um? Es bietet sich ein vielfältiger, manchmal ambivalenter, insgesamt aber positiv zu würdigender Befund.

Bei den kirchlichen Trägern der Ökumene ist eine strukturelle Folgerung aus der theologischen Einsicht greifbar. So approbierte Papst Paul VI. bereits 1966 die Gründung eines Büros für katholisch-jüdische Beziehungen im damaligen Sekretariat für die Förderung der Einheit der Christen. Aus dem Büro ging 1974 die Vatikanische Kommission für die religiösen Beziehungen zum Judentum hervor und blieb dem Sekretariat bzw. ab 1988 dem Päpstlichen Rat zur Förderung der Einheit der Christen zugeordnet. ${ }^{30}$ Als 1970 Vertreter des Vatikans und des Internationalen Jüdischen Komitees für Interreligiöse Konsultationen (IJCIC) das Internationale katholisch-jüdische Verbindungskomitee (ILC) als Forum des offiziellen Dialogs und Austausches schufen, gab es auf jüdischer Seite zunächst einen Argwohn wegen der Zuordnung des katholisch-jüdischen Austauschs zum Anliegen der Einheit der Christen/innen. Beim Pariser Treffen des Internationalen Verbindungskomitees vom Frühjahr 20II zum 40. Jahrestag seiner ersten Zusammenkunft 197I in Paris äußerten jüdische Delegationsmitglieder jedoch ihre Freude über den ökumenischen Charakter der Beratungen in einem Klima freundschaftlicher Kollegialität. ${ }^{31}$ Dem vatikanischen Vorbild folgen Bischofskonferenzen, welche ihr

30 Fumagalli, Pier Francesco: The International Catholic-Jewish Liaison Committee: Historical Note, in: International Catholic-Jewish Liaison Committee (Hg.): Fifteen Years of Catholic-Jewish Dialogue 1970-1985. Selected Papers, Rom: Libreria Editrice Vaticana I988, XV-XIX, XV.

3I Siehe zum Treffen selbst: Joint Declaration of the 2Ist International Catholic-Jewish Liaison Committee Meeting - Paris, 27 February - 2 March 20II, in: The Pontifical Council for Promoting Christian Unity, Information Service N. 136 (20II/I) 22. 
offizielles Gremium für die katholisch-jüdischen Beziehungen der jeweiligen Ökumene-Kommission zuordnen. So ist in der Deutschen Bischofskonferenz die Unterkommission für die religiösen Beziehungen zum Judentum der Ökumene-Kommission zugeordnet. Anders hat man in der Österreichischen Bischofskonferenz entschieden; dort sind die vom Referat „Ökumene“ getrennten Einrichtungen des Referates „Weltreligionen“ und der Kontaktstelle „Weltreligionen“ auch zuständig für Fragen des Verhältnisses der Kirche zum Judentum. Das hindert aber nicht, dass z. B. aus Anlass des 75. Jahrestags der Reichspogromnacht die Österreichische Bischofskonferenz als ganze für eine sehr respektable Erklärung vom 9. November 2013 verantwortlich zeichnete. ${ }^{32}$ Die Tradition des jährlichen „Tags des Judentums", der in den Kirchen von Italien, Österreich, Polen, den Niederlanden und der Schweiz begangen wird, hat ihre ökumenische Kontur darin, dass der Tag - mit Ausnahme der Schweiz - einen Tag vor Beginn der Gebetswoche für die Einheit der Christ/innen vom I8. bis 25. Januar begangen wird. ${ }^{33}$ Dieser zeitliche Ort ist ein Symbol der ökumenischen Qualität der Beziehung der Kirchen zum Judentum.

In der Theologie bietet sich ein breites Spektrum der Erörterung der einzigartigen Beziehung der Kirche(n) zum Judentum und jüdischen Volk als eine ökumenische Aufgabe. Die deutschen ökumenischen Fachzeitschriften wie „Ökumenische Rundschau“, „Una Sancta“ oder „Catholica“ haben sich gegenüber einem anders gerichteten Befund aus den 1970er-Jahren ${ }^{34}$ deutlich für das Anliegen geöffnet. Sie bieten immer wieder Beiträge zum christlich-jüdischen Verhältnis und flankieren gleichsam die Spezial-Zeitschriften zur christlich-jüdischen Agenda wie den „Freiburger Rundbrief. Zeitschrift für christlich-jüdische Begegnung“ oder „Kirche und Israel“ ${ }^{35}$ Die amerikanische ökumenische Zeitschrift „Journal of Ecumenical Studies ${ }^{\text {“36 }}$ ist mit der dortigen Präsenz des Jüdischen geradezu ein Vorbild. Die genannten ökumenischen Zeitschriften stehen für die ökumenische Theologie als Projektdisziplin oder Traktattheologie. Diese hat ihren näheren Kontext in der Fundamentalttheologie und deren ekklesiologischen Erwägungen. Das Jüdische ist

32 Österreichische Bischofskonferenz: Erklärung zum 75. Jahrestag der Reichspogromnacht vom 9. November 2013, in: http://www.jcrelations.net/75_Jahre_nach_dem_Novemberpogrom_1938.4455.o.html? $\mathrm{L}=2$ [abgerufen am 8.5.2014].

33 Batlogg, Andreas R.: Tag des Judentums, in: Stimmen der Zeit I36 (20II) If.

34 Henrix: Der Dialog, I39 und ders.: Gottes Ja, 8f.

35 Eigene Websites geben Einblick in die Autor/innen, Themen und Entwicklungen der beiden Zeitschriften: http://www.freiburger-rundbrief.de/de/ und http://www.kirche-und-israel.de/ [beide abgerufen am 8.5.20I4].

36 The Journal of Ecumenical Studies, in: http://journal.jesdialogue.org/home/ [abgerufen am 8.5.20I4]. 
in der ökumenischen Theologie als Projektdisziplin über die Zeitschriften hinaus zunehmend präsent, was an einigen Beispielen vergegenwärtigt sei.

So teilt etwa Peter Neuner, ökumenischer Theologe und Systematiker, mit seinem evangelischen Kollegen Dietrich Ritschl die Überzeugung, die Trennung von Juden und Christen sei „das ökumenische Problem par excellence“ bzw. der Christenheit „kardinales ökumenisches Problem“. Deshalb kann die Beziehung zwischen Judentum und Christentum nicht lediglich „ein Spezialfall der Beziehungen zu den nichtchristlichen Religionen sein“. Aber er hat in seinem Handbuch der ökumenischen Theologie bei aller Bejahung, dass das Verhältnis der Kirche zum Judentum „in die ökumenische Thematik“ gehört, die Fragestellung dennoch nicht aufgenommen, weil sie „eine eigenständige Methodik“ verlange. ${ }^{37}$ Dorothea Sattler, ökumenische Theologin und Dogmatikerin, hat in ihrer Einführung in die Ekklesiologie unter dem Titel „Kirche(n)“ an die Traditionen der Rede von der Kirche erinnert und eigens auf die Mehrzahl der Kirchen geachtet. Sie ist dabei ausdrücklich auf die Grundbeziehung von Kirche und Judentum eingegangen und nimmt die biblische Fundierung der Kirche nicht nur neutestamentlich vor. Denn die neutestamentliche Kirche übernehme „Merkmale der alttestamentlich bezeugten jüdischen Tradition auch auf der institutionellen Ebene" ${ }^{38}$ So betrachtet die Pfingsterzählung in Apg 2 die frühe christliche Gemeinde „im Horizont der bleibenden göttlichen Verheißungen für Israel“ (30). Die Autorin geht Strukturmerkmalen zur Nähe von Kirche und Israel nach, etwa: „Israel ist wie die Kirche eine Gedächtnisgemeinschaft." Viele Feste im Kirchenjahr sind ohne ihren Bezug zum jüdischen Kalender nicht verständlich. Und die Sorge um die „Armen und Entrechteten“ ist „ein Erkennungszeichen Israels“, das in der jungen christlichen Gemeinde seine Entsprechung findet. Ihre Reflexion zu den Bildern von der Kirche nennt als erstes dieser Bilder das „Volk Gottes“, das der Leitbegriff des zweiten Kapitels in der Kirchenkonstitution des Zweiten Vatikanischen Konzils ist und vom Konzil her „im Kontext des jüdisch-christlichen Dialogs zu verstehen“ sei (88). Auch das Bild des Tempels des Heiligen Geistes erinnert heutige Christ/innen an den apostolischen Ursprung der Kirche und an die jüdische Tradition (9of).

Während Dorothea Sattler die Verbundenheit der Kirche mit Israel besonders als Kontinuität zum Alten Testament bzw. zum apostolischen Ursprung betont, ist Gregor Maria Hoff in seinem ekklesiologischen Programm die Verbundenheit der

37 Neuner: Ökumenische Theologie, 9 und 13.

38 Sattler, Dorothea: Kirche(n) (Grundwissen Theologie), Paderborn: Schöningh 2013, 23 (Die Fundorte der weiteren Zitate sind im fortlaufenden Text in Klammern angegeben.) Die Öffnung der Autorin für die Präsenz des Jüdischen in der Kirche gegenüber ihrer Einführung in die ökumenische Theologie von 2008 ist bemerkenswert. 
Kirche mit Israel als eine der Gegenwart wichtig. Voraussetzung ist ihm die Heilige Schrift, die er besonders von ihrem „Schnittpunkt von unaufgebbarer Israelverwiesenheit und normativem Christusbezug" her liest. ${ }^{39}$ Im genannten Schnittpunkt meldet sich ein „Zueinander von fremden Perspektiven und eigenen Interpretationen" ( $\mathrm{I} 7)$. In der Auseinandersetzung mit anderen Überzeugungen klärt die Kirche ihre Identität. Dies gilt besonders für die „Ursprungsdifferenz zu Israel“ (48). Die Kirche entdeckt in der Heilsgeschichte Gottes mit Israel „den Ort der eigenen Erwählung [...] Israel und Kirche haben beide ihren Ort im einen Heilsplan Gottes (NA 4)“ (49). Das ist dem Autor nicht lediglich eine Aussage über den historischen Ursprung, sondern „Israel bleibt Erwählungsweg zu Gott.“ Es ist an einem „theologischen Dauerbezug zu Israel“ für die Kirche festzuhalten. Die Kirche kann Israel „nicht als überholten Aspekt der eigenen Geschichte begreifen.“ Hoff erinnert an Franz Mußners Forderung, der zufolge die bleibende Verwurzelung der Kirche in Israel zu den „notae ecclesiae“ zu rechnen ist. Das Bleiben der Erwählung Israels auch nach Christus lässt einen „Heilszugang über die Kirche hinaus israeltheologisch“ bejahen und bekräftigen. „Mit Israel wird in der Kirche ein Ort außerhalb ihrer erfasst. Die Kirche kann ohne Israel nicht verstehen, was sie ist, weil sie sich selbst und ihre theologische Grammatik in Israel verorten muss - auch in dem Maße, in dem sie diese transformiert und überschreitet" (5I). Wenn die Kirche Gottes Liebe zu den Menschen und zur Welt bezeugt und ihr einen Raum gibt, dann ist diesem Zeugnis und dieser Raumgabe die Verbundenheit mit Israel eingestiftet. Die erst im 5. Jahrhundert definitiv vollzogene Trennung der Kirche vom Judentum - hier rezipiert Hoff die aktuellen Einsichten des ,parting of the ways" - hat ihren Grund in der Transformation des jüdischen Verständnisses von Gottes Handeln und seiner Wirklichkeit: „Das Handeln Gottes in Jesus Christus, die durchbrechende Theologie der Inkarnation, die Deutung der bleibenden Gegenwart Jesu Christi nach seiner Auferweckung von den Toten führte zu einer Anerkennung der singulären Bedeutung Jesu in der mit Juden geteilten Gottesbestimmung. Die christologische Differenz ist insofern historisch wie systematisch als Entstehungsmoment des Christentums wie seiner Identität als Kirche zu begreifen. [...] Sie ist von ihrem bleibenden Bezug auf das Judentum her zu verstehen und zugleich christologisch zu profilieren" (IO2). Dieser Doppelklang von der unaufgebbaren Israelverwiesenheit und vom normativen Christusbezug bestimmt Hoffs Ekklesiologie. Der Doppelklang gehört zur Identität der Kirche und begegnet in Hoffs Hauptkapiteln zur Gegenwart (17-75) und zur Geschichte (77-215), schließ-

39 Hoff, Gregor Maria: Ekklesiologie (Gegenwärtig Glauben Denken / Systematische Theologie 6), Paderborn: Schöningh 20II, I4. 
lich aber auch im Kapitel zur Heiligen Schrift (217-295). Die Heiligen Schriften Israels sind „aus der Sicht der Kirche immer mit dem ersten Auge der jüdischen Perspektive mitzulesen. Das gilt auch für die anhaltende Geschichte Israels, für die fortlaufende Auslegung der Schrift“. Was die Bibel Israels ,über das Volk und die Gemeinde Gottes sagt“, ist „offenbarungstheologisch“ bleibend wichtig (224). Wenn das Geheimnis der Kirche in der Exodusgeschichte Israels vorgebildet ist, dann gilt für die Kirche auch „eine entsprechende Exodusidentität“. Die Kirche ist dann auch als „die Ekklesia (zu) verstehen, die ,Herausgerufene““. In dieser Qualität als Herausgerufene hat die Kirche ,sich von den überraschenden, umwegigen Initiativen Gottes leiten zu lassen“ (226).

Gregor Hoffs Ekklesiologie ist in Gestalt und Gehalt weniger ein klassisches Lehrbuch, sondern unter mehrfacher Hinsicht innovatorisch. Sie ist durch eine Hermeneutik der Differenz grundiert und geht den Spannungen ekklesialer Wirklichkeit in einer Tiefendimension nach, welche darin ökumenisch ist, dass sie den Schnittpunkt zwischen einer unaufgebbaren Israelverwiesenheit und einem normativem Christusbezug aufsucht. So vollzieht sie eine Treue zum Ursprung und dient der je heutigen Verbundenheit der Kirche mit Israel. Sie ist darin scharfsinnig und zugleich lehrreiches Exempel einer fortlaufenden Präsenz des Jüdischen in der ökumenischen Theologie. Sie steht damit für den neuen Grundzug in der Theologie, der Gott sein Ja zu Israel nicht zurücknehmen lässt, sondern die Kirche bleibend in ein positives Grundverhältnis zu Israel bzw. zum Judentum und jüdischen Volk gesetzt hat. Das Element einer Antistruktur, die lange die christliche Theologie bis in ihre Verästelungen hinein bestimmt hat, ist ihr fremd. Zugleich ist sie ein lehrreiches Gegenbeispiel zu einer ajüdischen Entfaltung von Glaube und Theologie, welche sich zwar der antijüdischen Polemik enthält, zugleich aber einem Schweigen oder Verschweigen Israels anheimfällt.

Immer stärker setzt sich die Überzeugung von der Bindung der Kirche(n) bzw. des Christentums an das Judentum als so grundlegend durch, dass sie durchgehend zu bedenken bleibt. Für Karl-Heinz Menke bedeutet dies eine „Reformulierung aller Inhalte der christlichen Theologie im Lichte der von außen, von der Schoah, angestoßenen Erinnerung an die jüdischen Wurzeln des Christentums “. ${ }^{40}$ Die Anstrengungen, die christliche Identität weder zu Lasten des Judentums noch zum Preis seines Verschweigens zu artikulieren, wollen nicht nur dem Judentum gegenüber gerecht sein. Sie geschehen auch um der Integrität christlicher Theologie und Existenz willen. Die theologischen Bemühungen weisen dem Judentum nicht

40 Menke, Karl-Heinz: Rechtfertigung: Gottes Handeln an uns ohne uns? Jüdisch perspektivierte Anfragen an einen binnenchristlichen Konsens, in: Catholica 63 (2009) 58-72, 58. 
lediglich einen sektoralen Ort im Gebäude christlicher Theologie zu. In der stets mitlaufenden Offenheit für eine Vergegenwärtigung des Jüdischen ist es zu unterschiedlichen Graden der Aufmerksamkeit in den theologischen Fächern gekommen. Die dafür verantwortlichen Theolog/innen bilden in der Zunft der Theologie gewiss eine Minderheit, und manche berichten von Ausgrenzungserfahrungen; aber dennoch ist ihre Wirkung in der theologischen Landschaft deutlich zu greifen. So nimmt die Theologie auf einzelne Fächer oder Traktate bezogen grundlegende kritische Sichtungen coram Israel vor, um Konsequenzen aus der Wiederentdeckung der Nähe zum Judentum zu ziehen..$^{41}$ Dass es in der Theologie einen Reifegrad der durchgehenden und kritischen Selbstreflexion des christlichen Glaubens in seiner Verwiesenheit auf das Judentum gibt, kann man nicht zuletzt daran ablesen, dass ökumenische Lexika zum christlich-jüdischen Verhältnis erarbeitet wurden. ${ }^{42}$

\section{c) Die lutherisch-katholische Rechtfertigungserklärung von Ig99 in ihrem Versäumnis einer Präsenz des Jüdischen}

Die vorgestellten bzw. angedeuteten Fortschritte können jedoch nicht leugnen, dass es noch relativ wenig zu gemeinsamen Äußerungen der getrennten Kirchen

4I Für die katholische Theologie als Ganze vgl. nur: Hünermann, Peter / Söding, Thomas (Hg.): Methodische Erneuerung der Theologie. Konsequenzen der wiederentdeckten jüdisch-christlichen Gemeinsamkeiten (QD 207), Freiburg: Herder 2003 und Langer, Gerhard / Hoff, Gregor Maria (Hg.): Der Ort des Jüdischen in der katholischen Theologie, Göttingen: Vandenhoeck \& Ruprecht 2009; für einzelne Fächer: Grunden, Gertrud: Fremde Freiheit. Jüdische Stimmen als Herausforderung an den Logos christlicher Theologie (Religion, Geschichte, Gesellschaft 5), Münster: LIT 1996; Dirscherl, Erwin (Hg.): Einander zugewandt. Die Rezeption des christlich-jüdischen Dialogs in der Dogmatik, Paderborn: Schöningh 2005; Wohlmuth, Josef: Mysterium der Verwandlung. Eine Eschatologie aus katholischer Perspektive im Gespräch mit jüdischem Denken der Gegenwart, Paderborn: Schöningh 2005; Heinz, Hanspeter / Trutwin, Werner (Hg.): Aktuelle Probleme am Anfang des Lebens. Juden und Christen im Dialog mit Ethik, Recht und Medizin, Bonn 2013 [elektronische Dokumentation zu finden unter: http://www.zdk.de/organisation/gremien/gespraechskreise/gespraechskreis-juden-undchristen-beim-zdk/tagungen, abgerufen am 8.5.20I4].

42 Petuchowski, Jakob J. / Thoma, Clemens: Lexikon der jüdisch-christlichen Begegnung, Freiburg: Herder 1989; Klenicki, Leon / Wigoder, Geoffrey (Hg.): A Dictionary of the Jewish-Christian Dialogue. Expanded Edition, New York: Paulist Press 1995; Kessler, Edward / Wenborn, Neil (Hg.): A Dictionary of Jewish-Christian Relations, Cambridge: Cambridge University Press 2005; Lexikon der Begegnung. Judentum - Christentum - Islam. Für den jüdisch-christlichen Teil: Jakob J. Petuchowski und Clemens Thoma. Bearbeitet von Thomas Fornet-Ponse und Peter Klaiber. Für den islamischen Teil: Ludwig Hagemann und Adel Th. Khoury, Freiburg: Herder 2009. 
zur Beziehung von Kirche und Israel gekommen ist. ${ }^{43}$ Auch wirken die neuen kirchlichen Einsichten und Einschätzungen zur Beziehung der Kirche(n) zum Judentum noch nicht hinreichend genug auf Konsensdokumente der innerchristlichen bzw. zwischenkirchlichen Ökumene ein. Dies zeigt sich exemplarisch an der "Gemeinsamen Erklärung zur Rechtfertigungslehre" des Lutherischen Weltbundes und der katholischen Kirche, die am Reformationstag vom 3I. Oktober 1999 in Augsburg feierlich unterzeichnet wurde. ${ }^{44}$ Zur Vorgeschichte dieser Erklärung gehören theologische Studien aus den I950er-Jahren wie auch zahlreiche lutherisch-katholische Dialoge zu dem Thema ${ }^{45}$, das ein Hauptgrund für die Spaltung der abendländischen Kirche im I6. Jahrhundert war. In deren Zentrum stand die Frage, wie die Rechtfertigung des Menschen durch Gottes Gnade im Glauben an Jesus Christus näher zu verstehen ist. Die Unterzeichnung der Erklärung von 1999 bedeutete die gegenseitige Anerkennung kirchlicher Lehre und Praxis im Verhältnis zwischen der katholischen und der lutherischen Kirche. Es gab gegen die Erklärung einen heftigen innerlutherischen Protest zahlreicher Theolog/innen. Dies verhinderte jedoch weder die Promulgation noch die Rezeption der Erklärung durch die lutherische(n) Kirche(n). Allerdings folgte der Veröffentlichung der Erklärung ein Einspruch, der aus jüdischer Position oder aus Einsichten des christlich-jüdischen Dialogs heraus formuliert wurde. ${ }^{46}$ Die Erklärung sagt in ihrer

43 Wie etwa das Memorandum der Patriarchen und Häupter der kirchlichen Gemeinschaften in Jerusalem „Die Bedeutung Jerusalems für Christen“ von 1994, in: Henrix, Hans Hermann / Wolfgang Kraus (Hg.): Die Kirchen und das Judentum. II: Dokumente von 1986 bis 2000, Paderborn: Bonifatius 200I, 250-255 oder das Dokument „Kirche und Israel. Ein Beitrag der reformatorischen Kirchen Europas zum Verhältnis von Christen und Juden“ vom 24. Juni 200 in: Schwier, Helmut (Hg.): Kirche und Israel. Ein Beitrag der reformatorischen Kirchen Europas zum Verhältnis von Christen und Juden (Leuenberger Texte 6), Frankfurt a. M.: Lembeck 20OI.

44 Der Text findet sich in: Meyer, Harding u. a. (Hg.): Dokumente wachsender Übereinstimmung. Sämtliche Berichte und Konsenstexte interkonfessioneller Gespräche auf Weltebene. 3. 1990-200I, Paderborn: Bonifatius 2003, 419-44I. Die nachfolgend zitierten Nummern 33 und 3I finden sich auf der Seite 428. Eine kritische Auseinandersetzung zum Dokument findet sich auch bei Hoff: Passagen, I40-156.

45 Der Katechismus der Katholischen Kirche von 1992 sagt zur Rechtfertigung knapp: „Die Rechtfertigung hat wie die Bekehrung zwei Seiten. Unter dem Antrieb der Gnade wendet sich der Mensch Gott zu und von der Sünde ab; so empfängt er die Vergebung und die Gerechtigkeit von oben" (Nr. 20I8).

46 Die nun folgenden Stimmen sind zitiert nach Fornet-Ponse, Thomas: Einigung auf Kosten des Judentums? Zur kritischen Funktion des Judentums für die innerchristliche Ökumene am Beispiel der GER, in: Catholica 64 (2010) 309-325, 313f. und 314-316. Fornet-Ponse geht auch in seiner umfangreichen Arbeit: Ökumene in drei Dimensionen, 237-253 auf das kritische Echo aus jüdisch-christlicher Perspektive ein. 
Nr. 33: „Weil das Gesetz als Heilsweg durch das Evangelium erfüllt und überwunden ist, können Katholiken sagen, dass Christus nicht ein Gesetzgeber im Sinne von Mose ist". Dieser Aussage attestierte der jüdische Autor Micha Brumlik ein „triumphalistische[s] Verständnis“, das dem Christentum einen „höherwertigen Glauben“ zuspricht. Jüdischer Glaube fungiere als negativer Hintergrund, sodass die Rechtfertigungserklärung in der Nachwirkung der traditionellen „Lehre der Verachtung" stehe. Eine schärfere Kritik nimmt Friedrich-Wilhelm Marquardt vor. Sein Protest ist doppelgerichtet. Zum einen erwähne die Erklärung Israel nicht und verschweige das Judentum. Zum anderen stelle die Erklärung eine zwischenkirchliche Übereinstimmung ,auf Kosten der Wahrheit des Alten Testaments und des Judentums“ dar: „Im Antijudaismus einigen sich die christlichen Kirchen““ ${ }^{47}$ Hätte die Erklärung ihren Begriff vom "Gesetz" in seinem Bezug zur Tora geklärt oder die Ungekündetheit des Bundes Gottes mit Israel mitbedacht, dann hätte so möchte ich Thomas Fornet-Ponse zustimmend zitieren - die Erklärung möglicherweise „klarer das Wirken der Gnade erfassen“ können und dies „besonders im Blick auf den menschlichen ,Anteil' bzw. seine ,Mitwirkung' an seiner Erlösung (bzw. der Erlösung der Welt) und der Rolle seiner Taten. “48 Das Fehlen der Präsenz des Judentums im Entstehungsprozess und Text der Rechtfertigungserklärung hat sich in einer Kritikanfälligkeit und Blöße dieses Dokumentes niedergeschlagen. Die Präsenz des Jüdischen hätte dem Ziel der Erklärung, eine Gemeinsamkeit im lutherisch-katholischen Verständnis der Grundwahrheit vom Heilshandeln Gottes zu besiegeln, keinen Abbruch getan, sondern ihrer Stimmigkeit und Integrität eher aufgeholfen. ${ }^{49}$

47 Diese Aussage bezieht sich besonders auf Nr. 3 I der Erklärung: „Wir bekennen gemeinsam, dass der Mensch im Glauben an das Evangelium ,unabhängig von Werken des Gesetzes` (Röm 3,28) gerechtfertigt wird. Christus hat das Gesetz erfüllt und es durch seinen Tod und seine Auferstehung als Weg zum Heil überwunden“.

48 Fornet-Ponse: Ökumene in drei Dimensionen, 253.

49 Leider haben die Feierlichkeiten zum ıo-jährigen Jubiläum der Rechtfertigungslehre im Jahr 2009 die Möglichkeit nicht genutzt, den Mangel der Erklärung zu beheben und die Perspektive einer Präsenz des Jüdischen in diese ökumenische Kontroversfrage einzuführen. Vgl. Lutherischer Weltbund / Päpstlicher Rat zur Förderung der Einheit der Christen (Hg.): Io Jahre Gemeinsame Erklärung zur Rechtfertigungslehre; Io Years Joint Declaration on the Doctrine of Justification - Dokumentation der Jubiläumsfeier in Augsburg 2009 / Documentation of the Jubilee Year Celebration in Augsburg 2009, Paderborn: Bonifatius 2oII oder Amt der Vereinigten Evangelisch-Lutherischen Kirche Deutschlands (VELKD) / Johann-Adam-Möhler-Institut: Unter dem Horizont der Gnade. Ökumenische Arbeitshilfe zum Io. Jahrestag der „Gemeinsamen Erklärung zur Rechtfertigungslehre“, Hannover: Hansisches Druck- und Verlagshaus 2009. 
Insgesamt aber ist das Spektrum der offiziellen Texte der Kirchen zur Haltung gegenüber dem Judentum eindrucksvoll. Einige Dokumente enthalten indirekte Hinweise zur Frage nach den Zielen und Perspektiven der Gemeinschaft bzw. Nähe von Kirche und Judentum. ${ }^{50}$ Diese Frage sei abschließend aufgenommen, um den Bezug zwischen der innerchristlichen Ökumene und der einmaligen Beziehung der Kirche(n) zum Judentum weiter zu bedenken.

\section{Perspektiven und Ziele einer jüdisch-christlichen Ökumene ${ }^{51}$}

In den Kirchen und der ökumenischen Theologie hat es ein Auf und Ab in der Näherbestimmung dessen gegeben, was denn Kircheneinheit und Kirchengemeinschaft bedeuten kann. In seinem berühmten Grazer Vortrag von 1976 hat Joseph Ratzinger gemeint: Die Kircheneinheit ist „kein politisches Problem, das auf dem Weg des Kompromisses, der Abwägung des Durchsetzbaren und als eben noch erträglich Angesehenen gelöst wird. Hier geht es um Einheit im Glauben, das heißt, um die Frage der Wahrheit, die nicht Gegenstand eines politischen Spiels werden kann" ${ }^{52}$ Aber er hielt sich in der Frage der Näherbestimmung von konkreten Modellen und Zielvorstellungen zurück. ${ }^{53}$ Wohl ist in theologischen Studien und offiziellen zwischenkirchlichen Konsensdokumenten eine Mehrzahl von Zielvorstellungen und Modellen der kirchlichen Einheit formuliert worden. So dachte man über die ,geistliche Einheit“, Dialoggemeinschaft, Aktionsgemeinschaft oder Interkommunion als Modelle partieller Einheit nach. Ihnen wurden als Modelle umfassender Einheit die organische Union, die korporative Vereinigung, die Kirchengemeinschaft durch Konkordie, die konziliare Gemeinschaft oder Einheit in

so Päpstliche Bibelkommission: Das jüdische Volk und seine Heilige Schrift in der christlichen Bibel vom 24. Mai 200I. Siehe dazu den Band: Dohmen, Christoph (Hg.): In Gottes Volk eingebunden. Jüdisch-christliche Blickpunkte zum Dokument der Päpstlichen Bibelkommission „Das jüdische Volk und seine Heilige Schrift in der christlichen Bibel“, Stuttgart: Katholisches Bibelwerk 2003.

5I Der Begriff der Ökumene ist hier für die Beziehung von Israel und Kirche, von Judentum und Christentum in einem analogen Sinn zur zwischenkirchlichen Ökumene gebraucht und soll den besonderen Charakter der Nähe der Kirchen zum Judentum als getrennt bleibende Entitäten anzeigen.

52 Ratzinger, Joseph: Prognosen für die Zukunft des Ökumenismus, in: PRO ORIENTE (Hg.): Ökumene - Konzil - Unfehlbarkeit, Innsbruck: Tyrolia 1979, 208-2I5, 2II (auch zugänglich unter: http://www.oekumenischesforum.at/upload/file/Ratzinger_Oekumene-Prognose_1976(I).pdf [abgerufen am 8.5.20I4]).

53 Vgl. dazu Maaßen, Thorsten: Das Ökumeneverständnis Joseph Ratzingers, Göttingen: V\&R unipress 20II, 23f. u. ö. 
versöhnter Verschiedenheit gegenübergestellt. ${ }^{54}$ Den Modellen der umfassenden Einheit ist gemeinsam die Voraussetzung, dass sie eine „Einheit in der Verschiedenheit" anzielen. Die Verschiedenheit kann u. a. hier als Differenz von ekklesialen Typen und dort als Unterschied von Schwesterkirchen gedacht sein. ${ }^{55}$ Angesichts des offenen Befundes zu den Zielvorstellungen der Einheit der Kirchen kann man festhalten, dass die Vorstellung einer uniformen Einheit ausgeschlossen ist und man die ökumenische Kirchengemeinschaft als eine Balance zwischen Einheit und Differenz erwartet. ${ }^{56}$

Hält man am ökumenischen Charakter der Beziehung der Kirche(n) zum Judentum fest und fragt nach möglichen Zielvorstellungen der Pflege dieser Beziehung, so meldet sich das Element der Differenz ungleich gewichtiger als im binnenchristlichen Kontext. Die Schranke besteht in der vieldimensionalen Asymmetrie zwischen den Kirchen und dem Judentum - sei es die Asymmetrie der historischen Last zwischen Christentum und Judentum, sei es die Asymmetrie in der Identität zwischen dem Sein der Kirche und dem Sein des Judentums. Die Last der Geschichte ist ein so tiefes Trauma, vor dem der Gedanke einer korporativen Einheit zwischen Kirche und Israel, zwischen Christentum und Judentum nur erodieren kann. Die Asymmetrie in der Identität besagt: Das Judentum ist mehr als Synagoge und Religion, nämlich auch Volk und Zentrierung um das Land Israel; der Kirche fehlt die dem Judentum eigene ethnische Dimension. Diese mehrdimensionale Identität des Jüdischen bedeutet eine tiefe Differenz zur christlichen Identität als confessio und Glaube. Die Beziehung kann nur als Verhältnis zwischen Getrennten gedacht werden. Ihre Beziehung als eine Einheit oder ein organisatorisches, in Institutionen und deren Lebensvollzügen zum Ausdruck kommendes Zusammensein von Christentum und Judentum ist ausgeschlossen. Man muss eine „ökumenische Idee der sichtbaren Einheit des Gottesvolkes“ aus Israel und Kirche, aus Judentum und Christentum theologisch „in den Bereich des Utopischen ver-

54 Bericht der Gemeinsamen Römisch-katholischen / Evangelisch-lutherischen Kommission: „Einheit vor uns“ - 1984, in: Meyer, Harding u. a. (Hg.): Dokumente wachsender Übereinstimmung. Sämtliche Berichte und Konsenstexte interkonfessioneller Gespräche auf Weltebene. 2: 1982-1990, Paderborn: Bonifatius 1992, 45I-506, 453-465.

55 Für Kardinal Walter Kasper ist der „Mangel einer gemeinsamen Zielvorstellung [...] das wohl schwerwiegendste Problem der gegenwärtigen ökumenischen Situation“, siehe: Kasper, Walter Kardinal: Ökumene im Wandel. Einführung bei der Vollversammlung des Päpstlichen Einheitsrates am I3. November 2006, in: Stimmen der Zeit I32 (2007) 3-I8, I0.

56 Den aktuellen Diskussionsstand präsentieren z. B. Koslowski: Einheit der Kirche und Fornet-Ponse, Thomas: Komplementarität und differenzierter Konsens. Perspektiven einer ökumenischen Hermeneutik aus katholischer Sicht, in: Catholica 66 (20I2) 254-272. 
weisen [...] die sichtbare Einheit von Kirche und Synagoge [ist] keine realistische Perspektive“. ${ }^{57}$

Das Nachdenken über die Perspektive und das Ziel einer jüdisch-christlichen Ökumene wird seine Anregungen nicht aus den Modellen einer umfassenden Einheit von Kirchengemeinschaft nehmen können. Es hat die Differenz zwischen Judentum und Christentum und die bleibende Andersheit des Judentums zu achten. Wo in der zwischenkirchlichen Ökumene vom Ziel der „Gemeinschaft“, der koinonia gesprochen werden muss, kann in der jüdisch-christlichen oder christlich-jüdischen Ökumene bescheidener vom Ziel einer „Mitgemeinschaft“, einer synkoinonia gesprochen werden..$^{58}$ Den Begriff hat Franz Mußner der neutestamentlichen „Mitteilhaberschaft" (sygkoinonos) der Kirche an der „Wurzel“ Israel (Röm II,I7) nachgebildet. „Mitgemeinschaft“ kann sowohl jene Nähe, in welche für den christlichen Glauben die Kirchen zu Israel und dem jüdischen Volk durch Gott gesetzt sind, als auch das bleibende Gegenüber, die Andersheit und Fremdheit des Judentums zum Ausdruck bringen. „Mitgemeinschaft“ besagt eine Nähe der Differenten, der getrennt Bleibenden. Aber es wäre eine von Respekt, Wohlwollen, ja Liebe getragene Nähe.

Die Nähe von Getrennten kann verschiedene Formen des Ausdrucks haben. Sie wird als offizieller Dialog zwischen Kirchen und Judentum praktiziert. Sie ist präsent im Gespräch zwischen einzelnen als persönliche Begegnung, als Überwindung von Vorurteilen und als Austausch von Gehalten, Ideen oder Bezeugungen. Sie hat vielfältige Veranlassung für den theologischen Austausch, bei dem das Zeugnis des Anderen als Fremdprophetie und Wahrheitsanspruch wahrzunehmen ist. Über den theoretischen Austausch hinaus ist solche Nähe als gelebtes Vertrauen eingefordert, wenn die Andersheit sich als Fremdheit erweist. Das Theologische entlässt aus sich heraus ein Ethos. So ist die „Mitgemeinschaft“ zwischen den Kirchen und dem Judentum besonders in Situationen der Bedrängnis und Bedrohung als Solidarität zu bewähren. Sie gibt Raum für eine gemeinsame Bezeugung ihrer Verantwortung für die Völker, und zwar nicht im Sinne einer Bevorzugung, sondern als Inpflichtnahme durch den Gott Israels, der der Schöpfer und Herr der

57 Körtner: Wohin steuert die Ökumene?, 34.

58 Franz Mußner hat in diesem Begriff seine Sicht zusammengefasst gesehen, dass die Kirchen „für immer unlösbar mit Israel verbunden sind“: Ders.: Ökumene, 333f. Sachlich nahe zu diesem Verständnis steht der von Bertold Klappert oft erinnerte (so z. B. in: „Geheiligt werde Dein NAME! Dein Wille werde getan!“ Gedenken, Ertrag und Auftrag des Rheinischen Synodalbeschlusses von I980, in: http://ekir.de/ekir/dokumente/ekir2005-OI-09lsvortrag-klappert3.pdf [abgerufen am 8.5.20I4) Ruf von Hans Joachim Iwand: „Vergesst das Mit nicht!“ 
Welt ist. Die jüdisch-christliche Ökumene ist Vision und Wirklichkeit zugleich. Ihre Wirklichkeit bedeutet die Erfahrung eines Reichtums, an der die Träger/innen der ökumenischen Theologie teilhaben, wenn sie sich theologisch an der Gemeinschaft zwischen den Kirchen und an der Mitgemeinschaft zwischen den Kirchen und dem Judentum abarbeiten. Und nicht selten wird sich ihnen zeigen, dass die jüdisch-christliche Ökumene ein neues Licht auf die innerchristliche Ökumene wirft. 


\title{
Von Julius Wellhausen bis Joseph Ratzinger
}

\author{
Simon Lauer
}

\section{Vorbemerkung}

Vor gut fünfzig Jahren erzählte mir Dr. Eugen Messinger, damals Rabbiner in Bern, bei einer Synagogenführung für etwa fünfzehnjährige Schülerinnen und Schüler habe er (wie immer) darauf hingewiesen, dass Jesus Jude war. Eine Schülerin war perplex; sie fiel in tiefes Nachdenken. Aber nach einer Weile hellte sich ihr Gesicht auf, und sie sagte: „Aber, nicht wahr, Herr Rabbiner, jetzt ist er's nicht mehr.“

Im „Freiburger Rundbrief" ${ }^{\prime 1}$ legt Franz Mußner dar, dass und warum er weiterhin vom Juden Jesus spreche, obwohl ihm ein deutscher Bischof nahegelegt habe, dies nicht mehr zu tun.

\section{Bibelkritik}

Bibel-Philologie hat es ja schon im Humanismus des I6. Jahrhunderts gegeben, „Kritik“ am religiösen Verständnis der Bibel im I7. Jahrhundert. Kritik als philologische Disziplin, seit dem Hellenismus bekannt, ist wohl erst im I9. Jahrhundert, zusammen mit einem neuen Aufbruch der Historiographie, zu einer Herrscherrolle gekommen. Leitend war dabei die Altertumswissenschaft, in der Meinung, die Antike sei abgeschlossen und könne deshalb untersucht werden wie ein Leichnam in der Anatomie.

Es ist verständlich, dass diese Einstellung nicht von allen geschätzt wurde; Goethe klagte im Xenion „Der Wolfische Homer“ darüber, dass „der Wolf ihn [Homer] zerriß[en] “ hätte. ${ }^{2}$ (Eine Anspielung auf den ersten großen Homer-Philologen Friedrich August Wolf, Halle I795.) Das Bild vom Leichnam wurde von manchem Begründer der Wissenschaft des Judentums aufgenommen; das Wort des großen Bibliographen Moritz Steinschneider, ${ }^{3}$ es gelte jetzt nur noch, dem Judentum einen

I Mußner, Franz: Der Jude Jesus, in: Freiburger Rundbrief N. F. 2I / I (20I4) 55-59.

2 Vgl. Goethe, Johann Wolfgang: Sämtliche Gedichte. Zweiter Teil: Ausgabe letzter Hand (Gedenkausgabe der Werke, Briefe und Gespräche), Zürich 1953, 478.

3 Moritz Steinschneider, Prossnitz I816 - Berlin 1907. Zeitungskorrespondent, Lehrer an der Veitel Heine Ephraimschen Lehranstalt, Beamter für die Abnahme des Judeneides (I86oI869), bis I89o Direktor der jüdischen Mädchenschule. Steinschneider ist der „Vater der hebräischen Bibliographie“. 
schönen Grabstein zu gestalten, ist oft zitiert worden (etwa von Gerschom Scho$\mathrm{lem}^{4}$ in seiner scharfen Kritik dieser Wissenschaft).

Während sich die jüdische Orthodoxie der historisch-kritischen Bibelwissenschaft gegenüber immer ablehnend verhielt, neigten reform-orientierte Männer dazu, sie zu akzeptieren; 5 im Liberalismus fand sie jedoch auch scharfe Gegnerschaft. So hat einer der führenden Männer der Reform in Nordamerika, Isaac Mayer Wise (gestorben 1900), ein antikritisches Buch, „Pronaos to Holy Writ“, 6 verfasst; es steht mittlerweile im "Giftschrank" des von ihm gegründeten Hebrew Union College in Cincinnati. ${ }^{7}$ Wenn ein Student der Lehranstalt für die Wissenschaft des Judentums etwas Bibelkritisches einfließen ließ, konnte er von Sigmund Maybaum, der ab I888 Homiletik dozierte, hören: „Verschonen Sie uns mit dem protestantischen Unsinn! “8 Mit besonderer Energie hat Benno Jacob in mehreren Publikationen, besonders aber in „Das erste Buch der Tora. Genesis" (Berlin 1934) nicht die mosaische Autorschaft, aber die Einheit des Pentateuchs verteidigt. ${ }^{10} \mathrm{Im}$ gleichen Jahr ist in Florenz „La Questione della Genesi "11 von Umberto (Moshe David) Cassuto erschienen. Cassuto hat die „Documentary Hypothesis“ zeitlebens bekämpft. ${ }^{12}$

4 „Wir haben nur noch die Aufgabe, den Überresten des Judentums ein ehrenvolles Begräbnis zu bereiten." Die Quelle ist Gotthold Weils Nachruf auf Steinschneider, in: Jüdische Rundschau XII / 6 (8. Februar 1907). Zitiert in: Scholem, Gershom: Judaica 6: Die Wissenschaft vom Judentum, Frankfurt a. M.: Suhrkamp 1997, 29, Fußnote 62. Vgl. Auch Scholem, Gershom: Von Berlin nach Jerusalem. Erweiterte Fassung, Frankfurt a. M.: Jüdischer Verlag im Suhrkamp Verlag 1982, I47. - Zu Gotthold Weil: Berlin I882 - Jerusalem 1960. Arabist und Turkologe, 1906 Bibliothekar der Preußischen Staatsbibliothek, 193I Professor in Frankfurt a. M., I935 Chefbibliothekar der National- und Universitätsbibliothek Jerusalem. Vgl. Kopf, Lothar: Art. „Weil, Gotthold“, in: Encyclopaedia Judaica, Bd. 20 ('2007) 7II.

5 Bechtoldt, Hans-Joachim: Die jüdische Bibelkritik im I9. Jahrhundert, Stuttgart: Kohlhammer 1995 .

6 Mayer Wise, Isaac: Pronaos to Holy Writ. Establishing on Documentary Evidence, the Authorship, Date, Form, and Contents of Each of its Books, and the Authenticity of the Pentateuch, Cincinnati: R. Clark I89ı.

7 Mündliche Mitteilung von Jakob J. Petuchowski.

8 Mündliche Mitteilung von Rabbiner Dr. Georg Salzberger (Frankfurt-London).

9 Jacob, Benno: Das erste Buch der Tora: Genesis, Berlin: Schocken I934.

IO Meines Erinnerns hat der damalige Leiter des Päpstlichen Bibelinstituts, Augustin Bea SJ, das Buch ausführlich besprochen. Meine Nachfrage beim Kardinal Bea-Archiv an der Gregoriana ist ohne Ergebnis geblieben.

II Cassuto, Umberto: La Questione della Genesi, Florenz: Le Monnier I934.

I2 Eine Zusammenfassung ad usum magistrorum ist auf Hebräisch 194I erschienen (Nach- 


\section{Kritik der Kritik von jüdischer Seite}

Schon Moses Mendelssohn hat am Umgang von Zeitgenossen mit dem überlieferten Bibeltext Kritik geübt. Besonders sei auf seine beiden Briefe an einen Bibelforscher (dessen Name nicht bekannt ist) verwiesen: Im ersten (I6. Februar 1773) beklagt Mendelssohn die Leichtfertigkeit, mit der Konjekturen zum Text vorgeschlagen werden. Der zweite Brief an den gleichen Adressaten (8. Februar 1774) gilt der Auseinandersetzung mit Benjamin Kennicotts monumentalem Unternehmen. ${ }^{13}$

Im 19. und 20. Jahrhundert geht es nicht mehr so sehr um die Frage, ob die Bibel göttlichen oder menschlichen Ursprungs sei, wie um ihre Einordnung in die Geschichte. ${ }^{14}$ Bei Julius Wellhausen ist klar, dass das Spätere das Schlechtere ist: Vom Jahwisten (9. Jahrhundert) zur Priesterschrift (6./5. Jahrhundert) sinkt das religiöse Niveau zur Gesetzlichkeit ab. Damit hört dann bald das biblische „Israel“ auf; die Frage, ob das nachbiblische - und gar das nachchristliche - ,Judentum“ in irgendeiner Kontinuität dazu stehe, stellt sich nicht. Neutestamentliche Zeitgeschichte (damals und noch lange „Spätjudentum“ genannt) wird quasi ein Fach für sich. ${ }^{15}$ Dass Wellhausen die Geschichte der christlichen Religion nicht viel anders betrachtet hat, ist wohl ein eher schwacher Trost.

Scharfe Kritik an Wellhausen und seiner Schule ist schon 1906 zu lesen, und zwar bei Moritz Güdemann, schon in der Einleitung zu seinem Werk, ${ }^{16}$ und be-

drucke 1953 und 1959) und in englischer Übersetzung in Jerusalem 196r: The Documentary Hypothesis and the Composition of the Pentateuch: Eight Lectures (Magnes Print).

I3 Die Briefe: Mendelssohn, Moses: Gesammelte Schriften. Jubiläumsausgabe 12,2, Berlin: Akad.-Verl. 1976, 33f. und 4I-43. Zum Thema: Altmann, Alexander: Moses Mendelssohn. A Biographical Study, Alabama: Univ. of Alabama Press 1973, 286f. und Bourel, Dominique: Moses Mendelssohn. La naissance du judaïsme moderne, Paris: Gallimard 2004, 374f. Eine Auseinandersetzung mit jüdischer und christlicher Bibelkritik, besonders mit jüdischen Gegenpositionen, freilich ohne die Entwicklung innerhalb der römisch-katholischen Kirche, bietet Solomon, Norman: Torah from Heaven. The Reconstruction of Faith, Oxford: The Littman Library of Jewish Civilization, 20I2. Der Rahmen ist ein breit angelegter Versuch über eine mögliche jüdische Theologie in der Gegenwart, vielleicht sogar für eine voraussehbare Zukunft.

I4 Von scharfsinns-philologischen Exzessen wie Harry Torczyners Ijob-Kommentar (I920), der durchaus Parallelen in der Klassischen Philologie hat, sei hier abgesehen.

I5 $\mathrm{Zu}$ Wellhausens geschichtsphilosophischem Hintergrund siehe Bechtoldt: Die jüdische Bibelkritik, 4I4f.

I6 Güdemann, Moritz: Jüdische Apologetik (Schriften herausgegeben von der Gesellschaft zur Förderung der Wissenschaft des Judentums. Grundriß der Gesamtwissenschaft des Judentums), Glogau: Flemming 1906, xiif. und öfter. 
sonders im siebten und letzten Kapitel „Die jüdische Religion und die Zukunft der Menschheit oder der Messianismus“. ${ }^{17}$

Während Hermann Cohen seinem Marburger Kollegen Wellhausen völlige Freiheit von Antisemitismus bezeugt, ${ }^{18}$ scheint mir dies für den achtzehn Jahre jüngeren Hermann Gunkel nicht mehr ohne weiteres zu gelten. Was hat es zu bedeuten, wenn Gunkel in einer Vorlesung sagt: „Wenn ich in lobendem Sinn von Israel spreche, denken Sie ja nicht an das heutige Israel“; auch gehe es darum, „Israel seinen Nimbus zu nehmen“. ${ }^{19}$ Cohen hat Gunkels wissenschaftliche Bedeutung durchaus anerkannt und sich mit ihm ernsthaft auseinandergesetzt. ${ }^{20}$ Während Gunkel zwischen Heilspropheten und Unheilspropheten unterscheidet, hält Cohen an dem „einheitlichen Geist der Propheten“ fest und ebenso an der „Einheit des Monotheismus mit dem Messianismus“. Ohne auf die fundamentale Frage nach dem „Verhältnis von Messias zu Christus“ eine Antwort zu geben, stellt Cohen eine Reihe von Fragen an Gunkel, die wohl noch zu bedenken wären. „Der Prophetismus ist Messianismus. Und der zugestandene Universalismus hat nur einen halben Sinn, wenn er nicht ergänzt wird durch den Messianismus. [...] Das Heil der Menschheit allein ist im Prophetismus der letzte Sinn des Messias, den das ,Licht der Völker` seinen Gott verheissen lässt“. ${ }^{21}$

Auf eine neue Ebene hat wohl Ernst Troeltsch die Auseinandersetzung geführt. Dieser hat einen Vortrag vor der Religionswissenschaftlichen Gesellschaft, an dem ihm Cohens Schüler Benzion Kellermann opponiert hatte, in der Zeitschrift Logos veröffentlicht, die ihrerseits einer Gegenschrift Kellermanns die Publikation verweigerte. Diese erschien darauf als selbständige Schrift, die nun Cohen referiert

I7 Ebd., 203-233.

I8 Cohen, Hermann: Werke I7 = Kleinere Schriften VI. I916-I918, Hildesheim: Olms 2002, 615-622.

I9 Mündliche Mitteilung von Rabbiner Dr. Arthur Weil, Basel, bestätigt von Wiese, Christian: Wissenschaft des Judentums und protestantische Theologie im wilhelminischen Deutschland. Ein Schrei ins Leere? (Schriftenreihe wissenschaftlicher Abhandlungen des Leo Baeck Instituts 6r), Tübingen: Mohr Siebeck 1999, 198. Siehe auch daselbst 190-198 und 339f. - Die kürzlich erschienene Biographie: Hammann, Konrad: Hermann Gunkel. Eine Biographie, Tübingen: Mohr Siebeck 2014 ist mir noch nicht zugänglich. Gunkels Schüler Walter Baumgartner geht in seinem Nachruf auf Gunkels Stellung zum nachbiblischen Judentum nicht ein („Neue Zürcher Zeitung“ vom I6. und 17.3.1932). Ich danke dem Archiv der „Neuen Zürcher Zeitung“ für Kopien.

20 Gunkel, Hermann: Die Religion der Propheten, in: Preußische Jahrbücher 166 (November I916) I88-214. Cohen: Werke I7 = Kleinere Schriften VI, 355-363.

2I Vgl. ebd. 363. 
und kommentiert. ${ }^{22}$ Kurz gesagt, will Troeltsch den Gott des Alten Testaments so weit wie möglich auf den Gott einer „bäuerlichen Sippe“ reduzieren, ihm also universale Geltung verweigern.

Von einer solchen Position aus ist es wohl nicht mehr weit zu einem völkisch geprägten Antisemitismus in theologischem Gewand. Einen kleinen Einblick gewährt Bechtoldt. ${ }^{23}$

\section{Ein Gegenstoß}

I898 erschien „Die Grundlagen des 19. Jahrhunderts“24 von Houston Stewart Chamberlain, I899 fand in Hamburg ein Antisemitentag statt. Rund zwanzig Jahre später kam es zu Publikationen wie „Die Sünde wider das Blut ${ }^{\text {“25 }}$ u. Ä. Sie alle forderten unter anderem die Ausschaltung des Alten Testaments. 1932 wurde an einer Tagung in Eisenach die öffentlich-rechtliche Anerkennung einer „nordisch-germanischen Religion“ verlangt. „Da kann der Bischof nicht schweigen“, sagte dazu der Münchner Erzbischof Kardinal Michael von Faulhaber (von Hause aus Alttestamentler) und hielt vier Predigten im Advent und eine weitere an Silvester I933. ${ }^{26}$ Diese Predigten müssen wie ein Paukenschlag gewirkt haben: Zwei Kirchen mussten mit Lautsprechern an St. Michael angeschlossen werden, die fortlaufend gedruckten Predigten fanden reißenden Absatz. ${ }^{27}$ Die drei ersten Predigten galten

22 Troeltsch, Ernst: Das Ethos der hebräischen Propheten, in: Logos. Internationale Zeitschrift für Philosophie der Kultur 6 (1916/17) I-28. Kellermann, Benzion: Der ethische Monotheismus der Propheten und seine soziologische Würdigung, Berlin: Schwetschke 1917. Cohen, Hermann: Der ethische Monotheismus und seine soziologische Würdigung, in: Allgemeine Zeitung des Judentums 8I (I9I7) 373f. (Werke I7 = Kleinere Schriften VI, 495-50I). Dazu gehört auch: Cohen, Hermann: Der Prophetismus und die Soziologie, in: Neue Jüdische Monatshefte I (I9I6/I7) 652-655 (Werke I7 = Kleinere Schriften VI, 505-510).

23 Bechtoldt: Die jüdische Bibelkritik, 4I6f.

24 Chamberlain, Houston Stewart: Die Grundlagen des 19. Jahrhunderts, München: Bruckmann 1898.

25 Dinter, Artur: Die Sünde wider das Blut. Ein Zeitroman, Leipzig: Wolfverlag I9I8 [Erstauflage im Eigenverlag 1917].

26 Faulhaber, Michael von: Judentum, Christentum, Germanentum. Adventspredigten gehalten in St. Michael zu München 1933, München: Graph. Kunstanst. 1934. Ich danke Frau Dr. Esther Schmid Heer, Bibliothekarin der Schweizer Provinz der Jesuiten, Zürich, für eine Photokopie des sehr schwer greifbaren Buches.

27 Ich erinnere mich gut daran, wie bewegt mein Vater, damals Klaus-Rabbiner in Mannheim, davon sprach. Laut einer Meldung von Jakob Wetzel in der „Süddeutsche(n) Zeitung" vom I5. Oktober 2013 erschließen derzeit Forscher des Münchner Instituts für Zeitgeschichte und der Westfälischen Wilhelms-Universität Münster zusammen mit dem 
den religiösen, sittlichen und sozialen Werten des Alten Testaments und ihrer Erfüllung im Evangelium, die vierte thematisierte Jesus Christus als den „Eckstein zwischen Judentum und Christentum“; die Silvesterpredigt stellte Christentum und Germanentum einander gegenüber. Faulhaber macht klar, dass es ihm nur um das vorchristliche Judentum geht, genauer um das Alte Testament, weil dieses - anders als das nachbiblische jüdische Schrifttum - inspiriert und somit integraler Bestandteil der christlichen Heiligen Schrift ist. Mahnend verweist er auf Mt 5,I7f. und hebt hervor, dass nicht etwa Blutsbeziehungen entscheidend sind, sondern Glaubensbeziehungen (Lk 8,20f.; Gal 3,28). ${ }^{28}$ Spr 31,IO-3I ist ihm „ein ewiger Beichtspiegel [...] für die Frauenwelt aller Zeiten ", ${ }^{29}$ das Gegenstück für die Männer: Ijob 3r. Auch die Speisegesetze sind Faulhaber eine Würdigung wert als „Wegweiser der sittlichen Ordnung: Abstand halten von allem, was Staub und Schlange ist. “30 Judit lügt zwar; aber sie liebt ihr Vaterland und lobt Gott. „Wollt ihr Judith sittlich tiefer stellen als die germanische Kriemhild mit ihrem Hassgesang?" ${ }^{31}$ Schließlich: „Los von dem Pharisäismus, der so wenig von den vielen Lichtern des Alten Bundes spricht und so viel von seinen wenigen Schatten! “32 Die Predigt über „die sozialen Werte des Alten Testamentes“ schließt: „Entweder glauben wir an die Inspiration der Heiligen Bücher oder wir müssen dem jüdischen Volke sagen: Du bist die genialste Rasse der Weltgeschichte. "33 Gegen Rassenforschung an sich hat Faulhaber nichts einzuwenden, stellt ihr jedoch drei Bedingungen: Sie darf nicht zum Hass gegen andere Völker führen, nicht von den sittlichen Pflichten entbinden, nicht durch Ablehnung des Alten Testaments gegen das Christentum auftreten ${ }^{34}$ Rasse ist Naturordnung, Christentum übernatürliche Ordnung, und „wir

Erzbischöflichen Archiv in München die privaten Tagebücher von Kardinal von Faulhaber. „Die kleinen schwarzen Notizbücher, die in seine Soutane passten, [...] enthalten Aufzeichnungen zu etwa 52.000 Besuchen und Gesprächen “ in Gabelsberger-Stenographie, die kaum noch jemand lesen kann. Das Projekt wird von der Deutschen Forschungs-Gemeinschaft unterstützt.

28 Faulhaber: Judentum, 22f.

29 Am Rande mag erwähnt werden, dass traditionell praktizierende jüdische Männer im aschkenasischen Raum diese Verse vor dem Freitagabendmahl zu singen pflegen, um ihre Frau zu preisen. Der Brauch scheint aus einem kabbalistischen Kreis des I6. Jahrhunderts zu stammen; seine ursprüngliche Intention dürfte weithin vergessen sein.

30 Faulhaber: Judentum, 37.

3I Ebd., $48 f$.

32 Ebd., 5 If.

33 Ebd., 76.

34 Ebd., II6-II8. 
sind nicht mit deutschem Blut erlöst “" ${ }^{35}$ Der Unterschied zwischen Germanentum und Christentum muss klar sein: Es geht um die Unterscheidung von heidnischem Aberglauben und christlichem Brauch: „Der Marienkult ist nicht getaufter Freiakult. Der Erzengel Michael ist nicht Amtsnachfolger Wotans für die christlich gewordenen Germanen. ${ }^{\text {"36 }}$

\section{Stimmen aus Rom}

Vierzig Jahre vor Kardinal Faulhabers Adventspredigten, nicht lange nach Otto von Bismarcks „Kulturkampf“, promulgierte Papst Leo XIII. die Enzyklika Providentissimus Deus, an die Papst Pius XII. nach fünfzig Jahren mit der Enzyklika Divino afflante Spiritu ${ }^{37}$ ausdrücklich und mehrfach anknüpfte. ${ }^{38}$ Es geht darin um eine Stellungnahme gegen Stimmen, welche die göttliche Herkunft der Heiligen Schriften in Frage stellen oder deren Wahrheit nur in Sachen des Glaubens und der Moral, nicht aber für ihre historischen und physikalischen Aussagen gelten lassen. Gegen solche Tendenzen ergeht die feierliche Erklärung der Kirche, dass alle Bücher der Heiligen Schrift göttliche Autorität genießen und irrtumslos sind. Es sei überhaupt frevelhaft (nefas omnino), „die Inspiration auf einige Teile der Heiligen Schrift einzuschränken oder einen Irrtum des heiligen Autors zuzugestehen ". 39

Was die Wissenschaft angeht, so ist die Lage 1943 freilich anders als fünfzig Jahre zuvor: Das Studium der orientalischen Sprachen und die archäologischen Forschungen haben gewaltige Fortschritte gemacht; an ihren Ergebnissen kommt man nicht mehr vorbei. All dies hebt der Papst ausdrücklich hervor und ermutigt die Bibelwissenschafter zur Teilnahme an solchen Forschungen. Die Anforderungen an die Forschenden hat schon Papst Pius XI. festgeschrieben. ${ }^{40}$ Überhaupt habe ,jede menschliche Erkenntnis, auch wenn sie nicht das Heilige betrifft, ihre eigene Würde und Erhabenheit - sie ist ja eine begrenzte Teilhabe an der unbegrenzten Erkenntnis Gottes: So erhält sie eine neue und höhere Würde und Hei-

35 Ebd. II7.

36 Ebd., I2I.

37 http://www.vatican.va/holy_father/pius_xii/encyclicals/documents/hf_p-xii_ enc_19430930_divino-afflante-spiritu_lt.html [abgerufen am 28.7.20I4]. Die Zitation erfolgt nach Kapiteln (in lateinischen Ziffern) und Absätzen des jeweiligen Kapitels (in arabischen Ziffern) anhand der Online-Publikation. Die Übersetzungen aus dem Lateinischen stammen vom Verfasser.

38 Ich danke Frau Mag. ${ }^{a}$ Edith Petschnigg für den Wink zum Link.

39 Divino afflante Spiritu, I, Abs. I.

40 Ebd., I, Abs. 6 v. u. 
ligung, wenn sie dazu dient, das Göttliche in helleres Licht zu rücken. “41 Bemerkenswert ist, dass unter allen anderen Disziplinen auch die Textkritik ausdrücklich empfohlen wird, wofür sich der Papst auf Augustinus beruft. ${ }^{42}$ Allerdings dürfen sich die Exegeten nicht auf historisch-philologische und ähnliche Ausführungen beschränken, wie es bedauerlicherweise ${ }^{43}$ bisweilen geschieht. Vielmehr sei herauszuarbeiten, was die Glaubens- und Morallehre der Texte ist, damit die Priester allen Gläubigen zu einem eines Christen würdigen Leben helfen können. Damit sollen auch diejenigen zurückgewiesen werden, denen die Kommentare zu wenig davon bieten, was man heute etwa Spiritualität nennen würde. ${ }^{44}$ Einen ,sensus spiritualis“ hat die Heilige Schrift nämlich: „Was im Alten Testament gesagt und getan ist, hat Gott so weislich geordnet und angeführt, dass das Vergangene geistlich vorbildet, was im Neuen Bund der Gnade sein wird." ${ }^{45}$ Dass der Exeget bisweilen auf unüberwindliche Schwierigkeiten des Textes stößt, entgeht dem Schreiben nicht. Es beruft sich auf nicht weniger als vier Stellen bei Augustinus, nach dem Gott Schwierigkeiten in den inspirierten Heiligen Büchern verteilt habe, um uns anzuspornen, die Grenzen unseres Verstandes zu erfahren (was heilsam ist) und uns in der Demut zu schulen, die wir schulden. ${ }^{46}$ Schließlich bleibe genügend Spielraum für freie Forschung, weil nur weniges - vor allem das, was Glaubensund Sittenlehre betrifft - von der kirchlichen Autorität oder dem Konsens der Väter festgeschrieben ist. ${ }^{47}$

\section{Historischer Kontext}

Es ist unnötig zu sagen, dass eine Enzyklika nicht in wenigen Wochen entsteht. Der eigentliche Schluss des päpstlichen Schreibens ${ }^{48}$ geht auf den tobenden Krieg ein, ohne die Opfer oder die Täter spezifisch zu nennen. Was Papst Pius XII. zu dieser Zurückhaltung bewogen haben mag, wird uns die vollständige Öffnung der Archive vielleicht enthüllen. Es möge dem Schreibenden lediglich gestattet werden, zwei Daten zu nennen, um die Brisanz der Lage zu illustrieren: Die Promulgation

4I Ebd., II, Abs. 2 v. u.

42 Ebd., II, Abs. 2 und 3; Augustinus, De doct. christ. 2,2I = Migne PL 34 col. 46.

43 Ebd., II, Abs. 5: ,id quod in quibusdam commentariis fieri dolemus“.

44 Ebd., II, Abs. 6: spiritualis quaedam et mystica, ut aiunt, interpretatio [im Original: spiritualem quamdam et mysticam, ut aiunt, interpretationem].

45 Ebd., II, Abs. 6.

46 Ebd., II, Abs. I5.

47 Ebd., II, Abs. I5.

48 Ebd., II, Abs. I8. 
ist etwa sieben Monate nach dem Fall von Stalingrad und zwei Wochen vor der Deportation der Jüdinnen und Juden Roms erfolgt.

\section{Dei Verbum}

Liegen zwischen den Promulgationen von Providentissimus Deus und Divino afflante Spiritu fünfzig Jahre, so ist die Promulgation der Dogmatischen Konstitution Dei Verbum nur zweiundzwanzig Jahre später erfolgt. Es sind wohl eher die Geschehnisse seit den so weitgehend ungehört verhallten Mahnungen Papst Pius‘ XI. von $1937^{49}$ als ein rasender Fortschritt der Bibelwissenschaften. Die drei ersten Kapitel handeln von der Offenbarung, ihrer Überlieferung und Interpretation. Das Alte Testament wird als praeparatio evangelica gewertet. Die Erkenntnis des einzigen, lebenden und wahren Gottes, des fürsorglichen Vaters und gerechten Richters, sowie die Erwartung des verheißenen Erlösers werden auf Moses und die Propheten zurückgeführt. ${ }^{50}$ Die Heilige Schrift ist Gottes Rede, insofern sie unter dem Anhauch des göttlichen Geistes schriftlich aufgezeichnet wird; die Heilige Überlieferung aber gibt das Wort Gottes unversehrt an deren (der Apostel) Nachfolger weiter.5I Zur Interpretation der Heiligen Schrift heißt es weiter: Gott hat in der Heiligen Schrift durch Menschen nach Menschenart gesprochen. ${ }^{52}$ Dem Alten Testament gelten die zwei Seiten des vierten Kapitels. Mit Augustinus hält Dei Verbum fest, dass das Neue Testament im Alten verborgen, das Alte im Neuen offen liegt. ${ }^{53}$ Im sechsten (letzten) Kapitel über die Heilige Schrift im Leben der Kirche wird bestätigt, dass das Studium der Heiligen Schrift „gleichsam die Seele der Heiligen Theologie" sein soll. ${ }^{54}$

49 Die Enzyklika „Mit brennender Sorge“ vom März 1937 wird etwa in DV IV 15,I (377) erwähnt. - Ich zitiere nach Hünermann, Peter: Die Dokumente des Zweiten Vatikanischen Konzils. Konstitutionen, Dekrete, Erklärungen. Lateinisch-deutsche Studienausgabe, Freiburg: Herder 20I2, folgendermaßen: Kapitel, Absatz (Seite). - Es sei hier ein für alle Mal auf die Arbeiten zu Dei Verbum in Tück, Jan-Heiner (Hg.): Erinnerung an die Zukunft: Das Zweite Vatikanische Konzil, Freiburg: Herder 2012 verwiesen, besonders 423-490. Die überaus reichhaltigen Bibliographien auszuwerten war dem Schreibenden physisch unmöglich.

50 I 3,I (365). Ist hier nicht implizite anerkannt, dass die messianische Idee bei den Propheten mehr als nur national ist? (s. o. Hermann Cohens Kritik an Gunkel und Troeltsch.)

SI II 9,I (370).

52 III I2,I (373). - Das gleiche hermeneutische Prinzip hat schon Rabbi Yishma'el im 2. Jahrhundert n. Chr. formuliert (SifBem II2).

53 IV i6,I (377).

54 VI 24,I (383), unter Berufung auf Leo XIII. und Benedikt XV. 


\section{Joseph Ratzinger/Benedikt XVI.}

In seinem Vorwort zum Dokument der Päpstlichen Bibelkommission „Das jüdische Volk und seine Heiligen Schriften in der christlichen Bibel ${ }^{\text {“55 }}$ skizziert Ratzinger zunächst den Weg von Origenes über Ambrosius zu Augustinus und Adolf von Harnacks Forderung nach der marcionitischen Entfernung des Alten Testaments aus dem Kanon der christlichen Bibel. Diese Forderung wäre verständlich, wenn das Alte - aber ebenso das Neue - Testament nur Gegenstand historisch-philologischer und keiner anderen Forschung wäre. Dem kann das Christentum jedoch nicht zustimmen; vielmehr ist es so, wie das Dokument zu Beginn seiner Schlussfolgerungen festhält, dass das Neue Testament ohne das Alte nicht könnte entziffert werden und so einer entwurzelten Pflanze gliche. ${ }^{56}$ Die Erkenntnis, dass die menschliche Sprache mehr als nur eine Dimension hat und auch in die Zukunft weisen kann, führt dazu, dass man den alttestamentlichen Texten einen potentiell zukünftigen Sinn vindizieren kann. ${ }^{57}$ Die Päpstliche Kommission geht über die bisher in der christlichen Hermeneutik vorgestellten Dokumente in einem wesentlichen Punkt hinaus: Nrn. $\mathrm{I}_{2}-\mathrm{I} 4^{58}$ bieten einen gedrängten Überblick über Methoden jüdischer Exegese und ihre Rezeption im Neuen Testament ${ }^{59}$ sowie eine knappe und - in diesem Rahmen - differenzierte Übersicht über das nachexilische Judentum.6o Darauf folgt eine detaillierte Untersuchung der Darstellung der Juden in den einzelnen Schriften des Neuen Testaments, aus der nur ein Passus herausgehoben sei: I Thess 2,16 wird mit Jer 7 und 2 Chr 36,16 zusammengestellt und dazu bemerkt, dass die Katastrophe von 587 nicht das völlige Ende war; denn danach hat sich Gott seines Volkes erbarmt. Paulus`schreckliche Voraussage hat

55 Das jüdische Volk und seine Heilige Schrift in der christlichen Bibel, 24. Mai 200I (Verlautbarungen des Apostolischen Stuhls 152), Bonn: Sekretariat der Dt. Bischofskonferenz 200I.

56 Vgl. ebd., Nr. 84, I6I.

57 Vgl. ebd., Nr. 64, II8f. Dazu - apropos DV IIf. - Schwienhorst-Schönberger, Ludger: Zwei antagonistische Modelle der Schriftauslegung in Dei Verbum? in: Tück (Hg.): Erinnerung an die Zukunft, 449-46I, 454-457. Die bekannte Lehrerfrage „was will der Dichter damit sagen?" ist kaum je schlüssig zu beantworten (Prof. Karl Pestalozzi, Basel, mündlich).

58 Vgl. Das jüdische Volk und seine Heilige Schrift, 28-3I.

59 Es fällt auf, dass die Targumim überhaupt nicht erwähnt werden. Die Arbeiten von Roger Le Déaut und anderen wären doch sehr wichtig für das Verständnis des Neuen Testaments. Genannt seien nur Le Déaut, Roger: La Nuit Pascale. Essai sur la signification de la Pâque juive à partir du Targum d'Exode XII, Rom: Inst. Bibl. Pont. 1963; ders.: Liturgie Juive et Nouveau Testament. Le témoignage des versions araméennes, Rom: Inst. Bibl. Pont. 1965.

6o Vgl. Das jüdische Volk und seine Heilige Schrift, Nrn. 66-69, I23-I30. 
sich zwar bewahrheitet; aber sie schließt die spätere Versöhnung nicht aus. Die „pastoralen Wegweisungen"61 schließlich knüpfen explizit an Nostra Aetate 4 und die Homilie Papst Pauls VI. bei der Promulgation an: „ut erga eos reverentia et amor adhibeatur spesque in iis collocetur." ${ }^{\text {"62 }}$ Dass auch Papst Johannes Pauls II. Einsatz gewürdigt wird, versteht sich wohl von selbst. Als Hauptbedingung gilt, dass weder das Alte noch das Neue Testament einseitig gelesen werde; denn beide durchwalte eine Gesamt-Dynamik, und diese ist eine Dynamik der Liebe. „So bringt das Neue Testament zugleich seine Zustimmung zur Offenbarung des Alten Testaments und seine mangelnde Übereinstimmung mit der Synagoge zum Ausdruck. [...] So tief die Uneinigkeit auch reichen mag, so rechtfertigt sie doch in keiner Weise wechselseitige Feindschaft. ${ }^{63}$ Man müsse eben anerkennen, dass die Offenbarung ein langsamer geschichtlicher Prozess auf „Vereinigung mit Gott und sittliche Lauterkeit“ hin sei, „von dem unsere moderne Gesellschaft im Übrigen noch weit entfernt ist. " ${ }^{\text {"64 }}$ So vermeidet man zwei gegensätzliche Gefahren: Die Annahme, alte Vorschriften ${ }^{65}$ seien noch gültig, oder die pauschale Verwerfung des Alten Testaments. Was die im engeren Sinn rituellen Vorschriften des Alten Testaments (z. B. Reinheitsgesetze) betrifft, so müsse man sich deren symbolische und anthropologische Bedeutung und ihre soziale und religiöse Funktion bewusst machen. ${ }^{66}$ Dass Institutionen wie Beschneidung, Speisegesetze und Kalender „Kennzeichen der jüdischen Identität" sind, wird deutlich festgehalten (Nr. 44: über die paulinische Gesetzestheologie). ${ }^{67}$

\section{Verbum Domini}

Dieses Nachsynodale Schreiben Papst Benedikts XVI. fasst im Wesentlichen die Ergebnisse der „XII. Ordentlichen Generalversammlung der Bischofssynode über das Wort Gottes" zusammen; es ist mit 30. September 20I0 datiert. ${ }^{68}$ Leicht ver-

6I Vgl. ebd., Nrn. 86f., I63-167.

62 Ebd., Nr. 86, 164.

63 Ebd., Nr. 87, 167.

64 Ebd., Nr. 87, 165.

65 Merkwürdigerweise führt das Dokument die Ablehnung der Bluttransfusion als Beispiel an. M. W. denken und handeln nur die Zeugen Jehovas so. Nach geltender jüdischer Lehre muss eine medizinisch indizierte Bluttransfusion durchgeführt werden, weil die Erhaltung von Gesundheit und Leben höchste Werte sind.

66 Vgl. Das jüdische Volk und seine Heilige Schrift, Nr. 87, I66.

67 Vgl. ebd., Nr. 44, 83-85.

68 Vgl. Nachsynodales Apostolisches Schreiben „Verbum Domini“ von Papst Benedikt XVI. über das Wort im Leben und in der Sendung der Kirche (Verlautbarungen des Apostoli- 
allgemeinernd kann man wohl sagen, dass damit die Ergebnisse der oben vorgestellten Studie der Päpstlichen Bibelkommission von 20or bestätigt und bekräftigt werden. Einige grundsätzliche Aussagen sollen hier doch erwähnt werden.

Der methodischen Trennung von historisch-philologischer Forschung und Theologie unbeschadet, ist ein eigentlicher Dualismus zu vermeiden, damit auch eine säkularisierte Hermeneutik ebenso wie ein - bereits von Papst Johannes Paul II. in seiner Enzyklika Fides et ratio abgelehnter - Fideismus, der zum Fundamentalismus führt. ${ }^{69}$ Ein bekanntes Problem vieler - ungeübter - BibelleserInnen sind deren „dunkle“ Stellen, deren Deutung spezifischer Fachkenntnisse bedarf. Dazu gilt es, zum einen die tiefe Verwurzelung der Bibel in der Geschichte zu bedenken, in deren Verlauf sich der Plan Gottes erst allmählich offenbart. Zum andern darf die Bibellektüre nicht vergessen machen, dass es die dunklen Seiten menschlichen Verhaltens sehr wohl auch heute noch gibt. Als hermeneutischer Schlüssel gilt „das Evangelium und das neue Gebot Jesu Christi “ ${ }^{70}$

Einen besonderen Abschnitt widmet Papst Benedikt XVI. dem Thema „Christen und Juden im Hinblick auf die Heiligen Schriften" (Nr. 43): Der tiefe und radikale Unterschied zwischen Altem und Neuen Testament (vgl. das Dokument der Bibelkommission, Nr. 44, s. o.) und die Erfüllung der Schriften im Geheimnis Jesu Christi „beinhaltet keineswegs eine gegenseitige Feindschaft“ ${ }^{\text {" }}$ " Der Papst bekräftigt ausdrücklich, „wie wertvoll für die Kirche der Dialog mit den Juden ist" ${ }^{\text {“72 }}$ (Hervorhebung im Text). Dazu passt genau Benedikts XVI. Wiederholung seines am I2. Mai 2009 in Jerusalem ergangenen Aufrufs, ${ }^{73}$ die ChristInnen im Heiligen Land sollen „Sauerteig der Eintracht, der Weisheit und des Gleichgewichts im Leben einer Gesellschaft sein, die traditionell stets pluralistisch, multiethnisch und multireligiös war und dies auch weiterhin ist" ${ }^{\text {" }}{ }^{74}$ Was Dialog überhaupt angeht, so gilt, dass ,jede wahre Kultur [...], um wirklich dem Menschen zu dienen, offen sein [muss] für die Transzendenz ${ }^{\text {" }}{ }^{75}$ Dafür ist freilich volle Religionsfreiheit unabdingbar. ${ }^{76}$

schen Stuhls 187), Bonn: Sekretariat der Dt. Bischofskonferenz 20 Iо.

69 Vgl. ebd., Nr. 36, 6r.

70 Ebd., Nr. 42, 72.

7I Ebd.

72 Ebd., Nr. 43, 73.

73 AAS IOI (2009) 473.

74 Verbum Domini, Nr. 89, 135 .

75 Ebd., Nr. I09, I59.

76 Vgl. ebd., Nr. I20, I70. 


\section{Io. Nachbemerkungen}

In der christlichen (vorwiegend liberal-protestantischen) ${ }^{77}$ Bibelkritik des I9. Jahrhunderts geht es um die Anwendung der zeitgenössischen historisch-philologischen Kritik auf beide Testamente und die Frage nach Jesus Christus und Israel; das immer noch bestehende - und im Laufe des Jahrhunderts bürgerrechtlich gleichgestellte - Judentum bleibt im besten Fall unberücksichtigt. Danach setzt eine Rückgewinnung des Alten Testaments für das Christentum ein. Wie soll man auch die „Erfüllung“" ohne hinreichende Kenntnis der „Verheißung“"verstehen?

Die Besorgnis erregenden Vorfälle und Erscheinungen der letzten hundert Jah$\mathrm{re}^{78}$ führen zu einer Rückbesinnung auf die Tradition der Kirchenväter und Kirchenlehrer, im Laufe der Zeit mit einer (impliziten) Neubewertung der adversus Iudaeos-Texte. Es ist ein nicht hoch genug zu schätzendes Verdienst der Päpstlichen Bibelkommission und des nachkonziliaren Schreibens Verbum Domini, die Differenzen zwischen Judentum und Christentum klar und vor allem ohne jede Feindseligkeit herausgearbeitet und den Weg zu einem besseren Verständnis des fortbestehenden Judentums gewiesen zu haben. ${ }^{79}$

Intellektuelle Redlichkeit zwingt wohl dazu, anzuerkennen, dass die Formel „christlicher (bzw. jüdischer) Humanismus “80 nicht restlos aufgeht. Verwirklichen

77 Einen groß angelegten Gegenentwurf bietet der eigenständige Zwinglianer Johann Caspar Lavater in seinem „Pontius Pilatus“ (1782-1785). Lavater, Johann Caspar: Ausgewählte Werke in historisch-kritischer Ausgabe. VI/I, hg. v. Christina Reuter, Zürich: Verl. Neue Zürcher Zeitung 2013.

78 Man denke etwa an die infame „Judenzählung“ von 19ı6. Diese hat von November 1916 bis Februar 1917 stattgefunden; das Kriegsministerium hat die Ergebnisse nicht veröffentlicht. Dazu: Friedländer, Saul: Die politischen Veränderungen der Kriegszeit und ihre Auswirkungen auf die Judenfrage, in: Mosse, Werner E. / Paucker, Arnold (Hg.): Deutsches Judentum in Krieg und Revolution 1916-1923 (Schriftenreihe wissenschaftlicher Abhandlungen des Leo Baeck Instituts 25), Tübingen: Mohr (Siebeck) 197I, 37f. sowie: Jochmann, Werner: Die Ausbreitung des Antisemitismus, in: ebd., 409-510, bes. 425-427. Auch der Artikel der Wikipedia (deutsch) s. v. Judenzählung ist sehr gut und bietet auch die neuere Literatur. Vgl. http://de.wikipedia.org/wiki/Judenz\%C3\%A4hlung [zuletzt abgerufen am 18.9.2014].

79 Dazu Stemberger, Günter: Das rabbinische Judentum als bleibende Basis jüdischer Kultur, in: Lenzen, Verena (Hg.): Das Studium des Judentums und die jüdisch-christliche Begegnung, Göttingen: V \& R Unipress 2013, 79-90. - Es fällt mir auf, dass weder die vatikanischen Dokumente noch Stemberger die Kabbala überhaupt erwähnen, deren Einfluss auf die europäische Geistesgeschichte - von Pico della Mirandola über Leibniz zum Pietismus - doch nicht unbedeutend ist.

80 Der Humanismus des 15./16. Jahrhunderts hat südlich der Alpen zu schöner Zusammenar- 
muss dieses Ideal jeder und jede Einzelne „in tiefem geistlichem Leben“81, in der „pia et docta eloquentia ${ }^{\text {“82 }}$, verbunden mit gläubig fundierter humanitas.

beit von Christen und Juden geführt; im Norden war das deutlich weniger der Fall, wie der scharfe Antijudaismus des Erasmus von Rotterdam zeigt.

8I Vgl. Verbum Domini, Nr. 47.

82 Als Beispiel diene das Verslein in Meyer, Conrad Ferdinand: Huttens letzte Tage, Kapitel 2, Absatz VII, Verse 9-I2, in: http://gutenberg.spiegel.de/buch/I873/2 [abgerufen am I.8.20I4]: „Es ist antik, und christlich ist's gedacht“. 


\section{Kirche und Judentum \\ Von Papst Benedikt XVI. zu Papst Franziskus}

JosefWohlmuth

Mein Beitrag betrifft zwei Pontifikate und fragt, ob die Weichenstellungen des Zweiten Vatikanischen Konzils in Nostra Aetate 4 bei Papst Benedikt XVI. ihre entschiedene Weiterführung gefunden haben und ob sich schon abzeichnet, in welche Richtung Papst Franziskus die Beziehung von Kirche und Judentum vertiefen will. Wie Papst Benedikt selbst berichtet, hat er eine erste Anregung zwar schon bei seinem Lehrer Gottlieb Söhngen 1947/48 in München erhalten, wo es in einer Vorlesung über die Offenbarung u. a. um das Verhältnis der beiden Testamente und ihre innere Einheit ging. Doch in den jüdisch-christlichen Dialog sei er erst eingetreten, als diese Fragen an ihn als Präfekt der Glaubenskongregation herangetragen wurden. Dabei sei ihm immer bewusster geworden: Wenn Jesus nur irgendein jüdischer Rabbi gewesen wäre, könnte nicht plausibel gemacht werden, dass er den Gott Israels zu den Völkern gebracht hat. ${ }^{1}$

Von Papst Franziskus liegen bisher nicht annähernd vergleichbare theologische Texte zum Verhältnis von Judentum und Christentum vor. Umso erstaunlicher war es aber, dass gleich nach seiner Wahl seine Freundschaft mit dem jüdischen Rabbiner Abraham Skorka bekannt wurde, mit dem er über Jahre hinweg intensive Gespräche führte, die inzwischen auch in deutscher Übersetzung vorliegen. ${ }^{2}$

I Vgl. Ratzinger, Joseph Kardinal: Die Vielfalt der Religionen und der Eine Bund (Urfelder Reihe I), Hagen: Verlag Urfeld 1998, I4f.. Vergleicht man diesen Band mit einem frühen Beitrag, der während der Konzilszeit in der Festschrift für Karl Rahner erschienen ist, dann erahnt man, wie sich Ratzinger als Präfekt der Glaubenskongregation dem jüdischchristlichen Dialog stellen musste. Vgl. Ratzinger, Joseph: Der christliche Glaube und die Weltreligionen, in: Metz, Johannes Baptist u. a. (Hg.): Gott in Welt. 2. Zur Theologie von Christus und Kirche, Freiburg: Herder 1964, 287-305. Ratzinger ist hier noch der fundamentaltheologisch-religionsphilosophischen Frage verpflichtet, die sich von Karl Barth her gestellt hatte.

2 Vgl. Bergoglio, Jorge (Papst Franziskus) / Skorka, Abraham: Über Himmel und Erde. Jorge Bergoglio im Gespräch mit dem Rabbiner Abraham Skorka, hg. v. Diego F. Rosemberg, München: Riemann 2013. 


\section{Die Jesusinterpretation Joseph Ratzingers in „Jesus von Nazareth“} $(\mathrm{I} \text { und II })^{3}$

\section{I.I Hermeneutische Grundlagendiskussion}

Bekanntlich hat Joseph Ratzinger/Papst Benedikt XVI. schon in seinem ersten Band Jesus von Nazareth einen inzwischen berühmt gewordenen Dialog mit dem jüdischen Gelehrten Jacob Neusner geführt (134-I55). Dieser hatte schon 1993 das Buch Ein Rabbi spricht mit Jesus vorgelegt. Darin bestätigte Jacob Neusner dem matthäischen Jesus, dass er die Tora des Mose ganz hervorragend verstand, nichts davon weglassend, jedoch in einem einzigen, allerdings entscheidenden Punkt sich selbst hinzufügend. ${ }^{4}$ Papst Benedikt hält aber gerade diesen Befund Neusners, dass Jesus sich selbst göttliche Autorität der Torainterpretation zugeschrieben habe, für das authentische Jesusbild der Evangelien. Ob Joseph Ratzinger damit in die Gefahr geraten ist, das Neue Testament nur unter dem hermeneutischen Modell „Verheißung-Erfüllung " zu lesen, ${ }^{5}$ möchte ich eher bezweifeln. ${ }^{6}$

Jacob Neusner hat nach dem Erscheinen des zweiten Bandes Jesus von Nazareth erneut die Stimme erhoben und sich dabei vor allem mit der hermeneutischen Frage befasst, wie Theologie und Geschichtswissenschaften zueinander stehen. ${ }^{7}$ Man liest also gleichsam ein Stück jüdisch-christlichen Disputs über den allseits bekannten Streit um historische und kanonische Bibellesung. Die Frage betrifft die Jesusinterpretation Ratzingers insofern zentral, als dieser die These vertritt, dass eine Schriftaus-

3 Vgl. Ratzinger, Joseph/Papst Benedikt XVI: Jesus von Nazareth. Erster Teil: Von der Taufe im Jordan bis zur Verklärung, Freiburg: Herder 2007; ders.: Jesus von Nazareth. Zweiter Teil: Vom Einzug in Jerusalem bis zur Auferstehung, Freiburg: Herder 2011.

4 Vgl. Neusner, Jacob: Ein Rabbi spricht mit Jesus. Ein jüdisch-christlicher Dialog, Freiburg: Herder 20II, hier bes. IIzf.

5 Vgl. Standhartinger, Angela: Der Papst und der Rabbi. Anmerkungen zum christlich-jüdischen Dialog im Jesusbuch von Benedikt XVI., in: Söding, Thomas (Hg.): Das Jesus-Buch des Papstes. Die Antwort der Neutestamentler, Freiburg: Herder 2007, I47-156, I48.

6 Als kurze Bemerkung zum gegenwärtigen Trend jüdischer Forschung möchte ich nur an das Buch von Daniel Boyarin mit dem Titel The Jewish Gospels. The Story of the Jewish Christ (New York 20I2) erinnern. Seiner Grundthese wird Jacob Neusner mit seinem ebenfalls enormen Forschungswerk kaum zustimmen. Neusner liest Jesus von der Tora des Mose her, während Boyarin die jüdische Apokalyptik in den Mittelpunkt stellt und dabei zu erstaunlichen Ergebnissen kommt.

7 Neusner, Jacob: Rabbi Jesus im Spannungsfeld von Theologie und Geschichtswissenschaft, in: Tück, Jan-Heiner (Hg.): Passion aus Liebe. Das Jesus-Buch des Papstes in der Diskussion, Ostfildern: Matthias Grünewald 20II, IIO-I25. 
legung, die immer neue Hypothesen hervorbringt, schließlich theologisch belanglos werde und deshalb ergänzt werden müsse durch einen „methodisch neuen Schritt“, der gewährleistet, dass sich eine historische Hermeneutik neu als theologische Disziplin versteht, „ohne auf ihren historischen Charakter zu verzichten“. So verbinde sie sich mit einer Hermeneutik des Glaubens „zu einem methodischen Ganzen“.8 Neusner seinerseits bezweifelt in seinem Beitrag bei den Arbeiten über den historischen Jesus von John P. Meier und John D. Crossan, ob ihre methodischen Vorentscheidungen überhaupt etwas übrig lassen von dem, was Jesus zum Christus, was ihn „einzigartig, zu einem wahren Menschen und einem wahren Gott, zum inkarnierten Gott und all den anderen Dingen macht, die Christus für das Christentum ausmachen [...]“ (I2I). Wenngleich Neusner, wie oben gezeigt, dies als Jude von Jesus nicht bekennen kann, ist er doch davon überzeugt, dass eine unvoreingenommene Lesung der neutestamentlichen Schriften von all dem Aufgezählten keine Abstriche zulasse. ${ }^{9}$

Im zweiten Band wird zum Verhältnis von Judentum und Christentum hermeneutisch Grundlegendes gesagt, und zwar in Verbindung mit der Zerstörung des Zweiten Tempels im Jahre $70 \mathrm{n}$. Chr. Ratzinger leitet davon eine grundlegende hermeneutische Überlegung ab, die für die Zeit nach der Zerstörung des Tempels Folgendes besagt: „Die Bibel - das Alte Testament - musste neu gelesen werden. Das sadduzäische, ganz an den Tempel gebundene Judentum hat diese Katastrophe nicht überlebt, und auch Qumran [...] ist aus der Geschichte verschwunden.“ Daraus ergeben sich „zwei Antworten auf diese Situation - zwei Weisen, das Alte Testament nach 70 neu [kursiv: J. W.] zu lesen: die Lektüre mit Christus, von den Propheten her, und die rabbinische Lektüre" (49). Es sei der Pharisäismus gewesen, „der [...] seine besondere Weise erarbeitet, in der Zeit ohne Tempel das Alte Testament von der Tora als Zentrum her zu lesen und zu deuten. Erst von da an sprechen wir von ,Judentum' im eigentlichen Sinn als einer Weise, den Kanon der biblischen Schriften als Offenbarung Gottes anzusehen und zu lesen ohne die konkrete Welt des Tempelkultes. Diesen Kult gibt es nicht mehr. Insofern hat auch der Glaube Israels nach 70 eine neue [kursiv: J. W.] Gestalt angenommen“ (49).

Mit der einen Lektüre, die sich in der neutestamentlichen Literatur niedergeschlagen hat, beginnen die Jesusgemeinden, mit der anderen fängt das ,Judentum

8 Ebd., II2.

9 Deshalb schreibt Neusner über die historisch-kritische Interpretation: „Kein historisches Forschungsunternehmen spricht über sich selbst so unaufrichtig wie die Erforschung des historischen Jesus. [...]“. Vgl. Neusners These im Schlusssatz: „Denn der religiöse Glaube spricht in der Gegenwart über die Ewigkeit - wie die Dinge sind und immer sein müssen, während historische Tatsachen uns nicht mehr als das berichten, was vor langer Zeit einmal war" (I25). 
der nachbiblischen Zeit an, die eine Zeit ohne Tempel ist und in der der Glaube Israels bezeichnenderweise ebenfalls eine „neue Gestalt“ erhält. ${ }^{10}$ Dabei ist m. E. erstaunlich, dass die Literatur, die wir ,Neues Testament nennen, bereits um das Jahr Ioo $\mathrm{n}$. Chr. fast fertig vorlag, während die rabbinische Literatur um diese Zeit erst ihren Anfang nahm und insofern nicht von ungefähr in manchen Punkten auch bereits eine Reaktion auf die neutestamentliche Lektüre des Alten Testaments (in der Gestalt der Septuaginta) darstellt. Für Joseph Ratzinger ist folgende Konsequenz wichtig: „Wir erkennen es nach Jahrhunderten des Gegeneinanders als unsere Aufgabe, dass diese beiden Weisen der neuen Lektüre der biblischen Schriften - die christliche und die jüdische - miteinander in Dialog treten müssen, um Gottes Willen und Wort recht zu verstehen“(49). Papst Benedikt vertritt hier wohl die These, welche sich in der Erklärung der Päpstlichen Bibelkommission „Das jüdische Volk und seine Heilige Schrift in der christlichen Bibel“" (200I) findet und die mit Recht als Meilenstein für das Gelingen eines neuen Verhältnisses von Judentum und Christentum angesehen wird. ${ }^{11}$

Im Kontext der hermeneutischen Weichenstellung des zweiten Bandes vertritt Joseph Ratzinger ferner die Meinung, dass schon Jesus selbst „das Ende des Tempels - und zwar sein theologisches, heilsgeschichtliches Ende - vorausgesagt hat" (50). Darüber hinaus sei offenkundig, ,dass alle wesentlichen Elemente der neuen Synthese" (5I), die in Reaktion auf die Zerstörung des Zweiten Tempels in die neutestamentliche Literatur eingegangen sind, von Paulus bereits vorweggenommen worden waren, als der Tempel noch stand. Papst Benedikt verweist mit Recht besonders auf Röm 3,23-25. Dies ist jedenfalls die literarisch älteste Quelle des Neuen Testaments, der zufolge Paulus „die Aufhebung des Tempels und seiner Opfertheologie in die Christologie hinein bereits vollständig vollzogen hat" (56). ${ }^{12}$ Papst Benedikt interpretiert die entsprechenden paulinischen Texte folglich

Io Vgl. Groß, Walter: Der doppelte Ausgang der Bibel Israels und die doppelte Leseweise des christlichen Alten Testaments, in: Ders. (Hg.): Das Judentum - Eine bleibende Herausforderung christlicher Identität, Mainz: Matthias Grünewald 200I, 9-25.

II Vgl. Das jüdische Volk und seine Heilige Schrift in der christlichen Bibel: 24. Mai 200 I Päpstliche Bibelkommission (Verlautbarungen des Apostolischen Stuhls I52), hg. v. Sekretariat der Deutschen Bischofskonferenz, Bonn: Sekretariat der Deutschen Bischofskonferenz 200I, Nr. 22. Vgl.: Nachsynodales Apostolisches Schreiben Verbum Domini von Papst Benedikt XVI. über das Wort Gottes im Leben und in der Sendung der Kirche: 3o. September 20IO, hg. v. Sekretariat der Deutschen Bischofskonferenz, Bonn: Sekretariat der Deutschen Bischofskonferenz 2010 (Verlautbarungen des Apostolischen Stuhls 187). Ebd. 20I0, Nr. 43.

I2 Diese These wäre zu differenzieren. Vgl. Stökl, Daniel Ben Esra: The Impact of Yom Kippur on Early Christianity. The Day of Atonement from Second Temple Judaism to the Fifth Century, Tübingen: Mohr Siebeck 2003, bes. 197-205. 
als eine neue Theologie des Jom ha-Kippurim (Lev I6), die sich im Hebräerbrief und im Hohepriesterlichen Gebet der johanneischen Abschiedsreden (Joh 17,I-26) in vertiefter Form wiederfänden (vgl. 54-56; 95-II9). Aus meinen eigenen Studien der vergangenen Jahre und der Beobachtung der Forschungslage auf jüdischer und christlicher Seite neige ich dazu, zu sagen, dass der oben dargestellte Zusammenhang von historischer Tempelzerstörung und den Konsequenzen einer zweigeteilten rückschauenden Bibelinterpretation sehr plausibel erscheint. Dies trägt dazu bei, die Entstehung von Christentum und Judentum (im angezeigten Sinn) nicht allein auf Boshaftigkeit von beiden Seiten zu reduzieren. Im zweiten Band erhält die Kategorie des Neuen im hermeneutischen Gefüge m. E. eine zunehmende Bedeutung.

Wenn hier vermieden werden soll, dass das ,Neue' das ,Alte' auf das Abstellgleis der Geschichte im Sinn des Überholten stellt, dann muss jeweils deutlich gemacht werden, dass der Rückbezug auf die Bibel Israels (sei es in der hebräisch/aramäischen Tradition, sei es in der griechischen Septuaginta-Übersetzung) sich zwar auf die zeitlich frühere Literatur beruft, damit aber nicht ein abwertendes Urteil verbunden wird. Im Gegensatz dazu scheint das Selbstverständnis der neutestamentlichen Autoren (und wohl auch Jesu selbst) das biblische Offenbarungswort des einen Gottes so zu verstehen, dass das Spätere durch das Frühere jeweils in das Licht der Offenbarung gehalten wird. Als die rabbinische Tradition in ihren nach der Zerstörung des Zweiten Tempels entstehenden Schriften neu zu klären hatte, welche Autorität ihrem neuen Schrifttum zukommt, entstand zwar kein jüdisches ,Neues Testament', wohl aber eine Literatur, die zur überkommenen schriftlichen Tora hinzukam. Dabei entzündete sich über kurz oder lang ein Streit, ob nicht dem Späteren, d. h. dem rabbinischen Schrifttum, eine ebenbürtige Autorität zukomme wie dem Früheren, ja sogar - als mündliche Tora - die zum Kanon gewordenen Schriften der Sinaioffenbarung an Autorität übertreffe.

Sobald die Schriften des Neuen Testaments in den christlichen Gemeinden unter die Kategorie des Neuen gestellt wurden, ließ der innerchristliche Streit, wie es um die Autorität der beiden Schriftcorpora bestellt sei, nicht lange auf sich warten. Unter dem Namen Markion wurde dieser Streit bekanntlich kirchlich durchgefochten und für die Rezeption beider Testamente als der einen Offenbarungsquelle entschieden. Vergleicht man in der Rückschau diesen Vorgang mit der rabbinischen Theoriebildung, könnte man sagen, dass der innerchristliche Streit um die Wertigkeit beider Testamente mit dem innerjüdischen Streit um die Valenz der mündlichen und schriftlichen Tora verglichen werden könnte. ${ }^{13} \mathrm{Wie}$ ordnet sich

I3 Vgl. Das jüdische Volk und seine Heilige Schrift, Nr. 9-II. 
hier der zweite Jesusband Joseph Ratzingers ein? Ich will es kurz an zwei Themen zeigen.

\section{I.2 Das neue Pascha ${ }^{I 4}$}

Joseph Ratzingers Hermeneutik bestätigt m. E., dass Altes und Neues Testament nicht gegeneinander ausgespielt werden dürfen. So wird bei Papst Benedikt aus dem Pascha des frühen Israel Jesu Pascha. Die theologische Neuheit des Paschas relativiert bei Joseph Ratzinger nur die Frage, ob das Letzte Abendmahl ein Sedermahl war oder in einem anderen jüdischen Mahlritus vollzogen wurde. Doch das Neue kann nur durch den Rückgriff auf das Alte verstanden werden. Weder auf Ex I2,I-I2 kann verzichtet werden noch auf die Schlachtung der Lämmer zur Zeit des Zweiten Tempels. Doch an deren Stelle tritt nun Jesus als das getötete Osterlamm. Demnach ist Joseph Ratzinger zufolge der Abschied Jesu als solcher bedeutsam, „in dem er Neues gab, sich selbst als das wahre Lamm schenkte und damit sein Pascha stiftete“ (133; kursiv: J. W.). Gleichwohl spielt antik-jüdische Mahltradition (etwa mit der Gestik des Brotbrechens) eine zentrale Rolle. Im Abendmahl Jesu wird „das Wesen des neuen Kultes sichtbar“, in dem „der alte Tempelkult aufgehoben und zugleich zu seiner Erfüllung gebracht“ wird (I5O). Deshalb ist auch für die Kelchgestik die Kategorie des Neuen bei Joseph Ratzinger wichtig, wenn er schreibt: „Er [Jesus] schenkt den ,Neuen Bund in seinem Blut'. ,Sein Blut " - das ist die vollständige Gabe seiner selbst [...]. “ So entsteht der „neue Kult“, in dem die „Menschheit in seinen stellvertretenden Gehorsam" hineingezogen wird (I54).

Wenn in diesem Zusammenhang von der Aufhebung des alten Tempelkultes und zugleich von dessen Erfüllung die Rede ist, wird das heutige Judentum in diesem Wort Papst Benedikts eher die Aufhebung vernehmen als die Erfüllung. Aufgehoben wurde durch die Zerstörung des Tempels aber auch das Opferwesen des Zweiten Tempels. Gibt es also neben der Erfüllung im christlichen Sinn auch eine Erfüllung im jüdisch-rabbinischen Sinn? Hier wird das Gespräch mit dem nachbiblischen Judentum und seinen Liturgien durch die Jahrhunderte notwendig, soll das Wort ,Erfüllung nicht den Unterton der Enterbung wachrufen. Denn die zweifache Lesart der vorchristlichen Bibel kennt nicht nur, wie oben gezeigt, die neue Lesart der Jesusgemeinden, sondern auch die neue Lesart des sich neu formierenden Judentums nach dem Jahre 7o. Insofern könnten aufs Ganze gesehen nicht

I4 Vgl. zum Folgenden: Wohlmuth, Josef: Die Sicht auf das Judentum im zweiten Band des Jesusbuches, in: Häring, Hermann (Hg.): Der Jesus des Papstes. Passion, Tod und Auferstehung im Disput, Münster: LIT 20II, I79-I93. 
,alt' (= vorchristlich) und ,neu' (= neutestamentlich) gegenüber gestellt werden, sondern es müssen beide Lesarten der gemeinsamen Bibel in ihrer Neuheit erfasst werden (vgl. zum alttestamentlichen Hintergrund I2I-I64).

Es fällt auf, dass Papst Benedikt bezüglich der Datierung des Letzten Abendmahls eine sehr dezidierte historisch-kritische These voranstellt. Das Johannesevangelium dürfe mit seiner von den Synoptikern abweichenden Datierung nicht von vorneherein als unzutreffend angesehen werden. Dies aber verschiebt die Frage, ob das Letzte Abendmahl ein im jüdischen Sinn verstandenes Sedermahl sein musste. Da inzwischen weitgehend Konsens darüber besteht, dass die synoptischen und paulinischen Abendmahls- bzw. Eucharistietexte keine historischen Schilderungen des liturgischen Ablaufes eines möglichen letzten Mahles oder gar Sedermahles darstellen, zumal alle nachbiblischen jüdischen Pessachtraditionen, auf denen das Sedermahl basiert, nach heutigem Forschungsstand zeitlich später als die neutestamentlichen Texte anzusetzen sind, ${ }^{15}$ erhält Joseph Ratzingers Auslegung einen gewissen neuen Freiraum für seine theologische Interpretation. Es sei nur wichtig für uns, „ob die Grundüberzeugungen des Glaubens auch bei vollem Ernst heutiger exegetischer Erkenntnisse historisch möglich und glaubwürdig sind" (I23). Diese beiden Aspekte, „historisch möglich und glaubwürdig“, liegen gewiss auf verschiedenen erkenntnistheoretischen Ebenen, müssen sich aber gegenseitig stützen, wenn der Kritik standgehalten werden soll. Auf Glaubwürdigkeit ist für Papst Benedikt aber nicht nur der Rückblick auf die Abendmahlstexte angewiesen, sondern vor allem auch die Entwicklung von den neutestamentlichen Mahltexten zur frühkirchlichen Eucharistiefeier, d. h. der „Übergang vom Abendmahl zum ,Morgenopfer“", von dem Augustinus geschrieben hat (vgl. I25).

Nun fragt sich also, was das Abendmahl Jesu eigentlich war und wie es „zu der gewiss sehr frühen Auffassung von seinem Pascha-Charakter" kam (133). Die Beantwortung dieser Fragen sei verblüffend einfach und zugleich überzeugend: „Jesus wusste um seinen bevorstehenden Tod. Er wusste, dass er das Pascha nicht mehr werde essen können. In diesem vollen Wissen lud er die Seinen zu einem letzten Mahl ganz besonderer Art ein, das keinem bestimmten jüdischen Ritus zugehörte, sondern sein Abschied war, in dem er Neues [kursiv: J. W.] gab, sich selbst als das wahre Lamm schenkte und damit sein Pascha stiftete“ (I33). Daraus folgt: „Das Wesentliche dieses Abschiedsmahles war nicht das alte Pascha, sondern das Neue, das Jesus in diesem Zusammenhang vollzog" (I33). Unter der Voraussetzung, dass der johanneische Kalender nicht aus der Luft gegriffen ist, also Abschiedsmahl und

I5 Vgl. Stemberger, Günter: Pesachhaggada und Abendmahlsberichte des Neuen Testaments, in: Kairos 29 (1987) I47-I58. 
Sedermahl historisch voneinander unterschieden werden können, schreibt Joseph Ratzinger: „Und in diesem Sinn hat er [Jesus] Pascha gefeiert und nicht gefeiert: Die alten Riten konnten nicht begangen werden; als ihre Stunde kam, war Jesus schon gestorben. Aber er hatte sich selbst gegeben und so wirklich gerade Pascha mit ihnen gefeiert. Das Alte war so nicht abgetan, sondern erst zu seinem vollen Sinn gebracht" (134). Papst Benedikt begründet die Paschatradition, die Altes und Neues zusammenfügt, mit dem Verweis auf den frühesten literarischen Nachweis dafür bei Paulus in I Kor 5,7: „Das früheste Zeugnis für dieses Zusammenschauen des Neuen und des Alten, das die neue paschatische Auslegung von Jesu Mahl im Zusammenhang von Tod und Auferstehung vollzieht, findet sich bei Paulus in I Kor 5,7 [...]; denn unser Pascha wurde getötet, Christus . "Dies ist die theologische Brücke, die dafür steht, dass auch ein Abendmahl Jesu, das kein Sedermahl gewesen sein muss, mit der jüdischen Pessachtradition verwoben bleibt und zugleich das Abendmahl zu Jesu Pascha macht, in dem Tod und Auferstehung Jesu bereits miteinander verbunden sind. So werden denn auch die Einsetzungstexte im Kontext jüdischer Mahlpraxis als „menschliche Urgeste des Gebens, des Teilens und Einens" (I49) verstanden, um nur diesen Aspekt kurz zu erwähnen. ${ }^{16}$ Die Forschung ist heute jedenfalls zurückhaltender, wenn es darum geht, die neutestamentlichen Abendmahlstraditionen mit der Feier des jüdischen Pesach zu vergleichen.

Walter Homolka, der Kenner jüdischer und christlicher Tradition, meint in Der Jesus des Papstes, ${ }^{17}$ Joseph Ratzinger habe in seinem 5. Kapitel über das Abendmahl das Jüdische bei Jesus ,auf einen bloßen kulturellen Hintergrund reduziert, vor dem jedoch etwas völlig Neues anbricht." Hier werde das Jüdische „epochal“ umgedeutet. Jesus aber sei sehr viel jüdischer gewesen, als ihn die nachfolgende Generation gezeichnet habe. Man müsse deshalb „Jesus ganz und gar in seinem jüdischen Kontext verstehen, aus dem er zeitlebens nicht heraustrat". Die genaue Bestimmung dessen, was zur Zeit Jesu in der jüdischen Pessachtradition liturgisch und theologisch galt, dürfte jedoch gar nicht so eindeutig sein. Ich frage deshalb zurück, ob die Bereitschaft Jesu, sein Leben hinzugeben und so an die Stelle des Paschalammes

I6 Papst Benedikt hält die These, die Eucharistie könne erst in der „Gemeinde“ entstanden sein, für „historisch völlig absurd“ (I44); die Eucharistie konnte nur „aus dem Eigenen des Bewusstseins Jesu“ (I45) kommen. Nach meiner Kenntnis der Abendmahlstraditionen spricht viel dafür, dass die Einsetzungstexte mitsamt dem eschatologischen Ausblick den Tod Jesu vor Augen haben. Eine andere Frage ist es, ob damit im streng historischen Sinn auch schon das Todesbewusstsein Jesu erwiesen ist.

I7 Vgl. Homolka, Walter: Jesu letztes Abendmahl. Abschied vom Judentum und Aufbruch ins Neue?, in: Häring, Hermann (Hg.): Der Jesus des Papstes. Passion, Tod und Auferstehung im Disput, Münster: LIT 20II, 195-199. 
zu treten, nicht ebenso noch ganz jüdisch verstanden werden muss. Mit jüdischen Ohren scheint Papst Benedikt so verstanden werden zu können, als behandle er das Judentum nur als durch das Christentum radikal überholte Vorform der Vergangenheit. Homolka fordert mit Recht ein, dass das Judentum auch nachbiblisch und bis in die Gegenwart eine Wirklichkeit darstellt, die um Gottes und der Menschen willen ernst genommen werden muss. Gleichwohl führt m. E. die neutestamentliche Eucharistietradition nicht aus dem Judentum hinaus, macht Jesus nicht zu einem marginalen Juden, sondern stellt ihn als das ,geschlachtete Lamm“ in die Mitte der Pessachtradition und damit auch in die Mitte des Judentums.

\section{I.3 Der Neue Kult als Feier der Versöhnung}

Die Rede von der Neuheit des Kultes wird im zweiten Band unter der Überschrift "Jesu Tod als Versöhnung (Sühne) und Heil“ (254-264) weiterverfolgt. Wenn zutrifft, dass die Zerstörung des Zweiten Tempels für die entstehenden Jesusgemeinden und für das verbleibende Judentum gleichermaßen von einschneidender Bedeutung war, dann treffen sich - sonderbarerweise - beide Traditionen in der gemeinsamen These, dass mit dem Ende des Zweiten Tempels auch das Ende der Tieropfer (und somit aller Opfer) gekommen war. Früh reifte auch schon im Judentum die Einsicht, dass an die Stelle der Opfer die Berakah/Eucharistia trete. Joseph Ratzinger schreibt: „Mit dem Kreuz Christi waren die alten Tempelopfer endgültig überholt. Neues war geschehen. [...] Das ,Lamm Gottes' hatte die Sünde der Welt auf sich genommen und weggetragen. Das durch die Schuld der Menschen gestörte Verhältnis Gottes zur Welt war erneuert. Versöhnung war geschehen“" (254; kursiv: J. W.). Die paulinische „Rede von Jesus als ,Hilasterion“ [Sühneort]" (Röm 3,25) verweist Papst Benedikt zufolge nicht auf den zürnenden und beleidigten Gott, sondern genau auf das Gegenteil: „Gott selbst richtet sich als Ort der Versöhnung auf und nimmt das Leid in seinem Sohn auf sich. Gott selbst schenkt seine unendliche Reinheit in die Welt hinein. Gott selbst ,trinkt den Kelch alles Schrecklichen aus und stellt so das Recht wieder her durch die Größe seiner Liebe, die im Leid das Dunkle verwandelt“ (256). ${ }^{18}$ Dann legt Ratzinger Hebr 9,5ff. mit Ps 40,7ff. aus und zeigt damit die existentielle Dimension „des neuen Begriffs von Kult und Opfer" (260), weil die Glaubenden in diesen Gehorsam leibhaftig einbezogen werden, wie Paulus in Röm I2,I ausgelegt habe.

I8 Das dreimalige emphatische „Gott selbst“ ist religiöse Bekenntnissprache, die einerseits christologisch begründet und metaphorisch verstanden werden muss, soll sie - zumal für jüdische Ohren - nicht anstößig wirken. 
Aber Papst Benedikt geht schon im ersten Abschnitt von Kapitel 4 (95-99) einen Schritt weiter, indem er das Hohepriesterliche Gebet in Joh 17 vom jüdischen Jom Kippur her deutet. Die These lautet: „Was dort in Riten dargestellt war, geschieht nun real, und es geschieht endgültig“ (95). „Das Hohepriesterliche Gebet Jesu ist Vollzug des Versöhnungstages, das gleichsam für immer zugängliche Versöhnungsfest Gottes mit den Menschen [...]. In Jesu Reden mit dem Vater wird das Ritual des Versöhnungstages in Gebet umgewandelt [...]“ (97). ${ }^{19}$ Die Kritik dieser Auslegung ließ nicht lange auf sich warten. ${ }^{20}$

Ich selbst bin auch davon überzeugt, dass der zweite Band der Jesus-Interpretation Ratzingers in seiner hermeneutischen Grundausrichtung bei allem Disput über Einzelfragen den Lesenden die tiefe Einwurzelung des christlichen Glaubens im Judentum vor und nach der Zeitenwende nahebringen kann. Auf dieser Basis kann die Erkenntnis reifen, dass Judentum und Christentum unter dem Aspekt des Neuen nicht nur auseinandergetrieben wurden, sondern in einem einmaligen Beziehungsverhältnis auch eine innere Nähe bewahrten und deshalb einander bleibend zugehören. In Verbum Domini (Nr. 43) schreibt Papst Benedikt: „Ich möchte noch einmal bekräftigen, wie wertvoll für die Kirche der Dialog mit den Juden ist. Dort, wo die Möglichkeit besteht, sollten auch öffentliche Gelegenheiten zur Begegnung und Diskussion geschaffen werden, die das gegenseitige Kennenlernen, die Wertschätzung und die Zusammenarbeit fördern, auch beim Studium der Heiligen Schrift."

Wie aber steht es, so muss nun gefragt werden, um die Irritation, die Papst Benedikt mit der neuen Karfreitagsfürbitte von 2008 für den katholischen Ritus extraordinarius ausgelöst hat? Im folgenden Abschnitt versuche ich den neuen Text $\mathrm{zu}$ interpretieren, und setze mich damit einer weiteren Auseinandersetzung aus,

I9 Dabei denkt der Papst zugleich an den fürbittenden Mose, der sein Leben für die Rettung Israels anbot. Darauf hat bekanntlich Jacob Taubes seine Paulusinterpretation aufgebaut. Vgl. Taubes, Jacob: Die politische Theologie des Paulus. Vorträge, gehalten an der Forschungsstätte der evangelischen Studiengemeinschaft in Heidelberg, 23.-27. Februar 1987, München: Wilhelm Fink 1993. Darauf nimmt Joseph Ratzinger freilich keinen Bezug. Vgl. Theobald, Michael: Das „hohepriesterliche“ Gebet Jesu (Joh I7). Ein Eckpfeiler in der sazerdotal-kultischen Wahrnehmung der Passion Jesu durch Joseph Ratzinger, in: Tück, Jan-Heiner (Hg.): Passion aus Liebe. Das Jesus-Buch des Papstes in der Diskussion, Ostfildern: Matthias Grünewald 20II, 77-IO9. Theobalds Hauptkritik: Dem Text entsprechend bitte Jesus nicht für sich selbst, sondern um die Verherrlichung des Sohnes durch den Vater und des Vaters durch den Sohn. Das klassische Gliederungsmodell (Fürbitte Jesu für sich selbst, für die Apostel und für die Nachgeborenen) entspreche nicht dem Text. Ratzingers Rückbezug auf Lev I6 erscheine problematisch. Joh I7 sei keine „Konsekrationsbitte“ für die Apostel und das nachfolgende Priestertum. 
die durch diesen Text aufgebrochen ist. Die zentrale Frage lautet, ob der neue Text hinter Nostra Aetate 4 zurückfällt oder für die Judenmission plädiert. Hier geht es nicht nur um Pragmatik, sondern um eine theologische Argumentation, um die weiterhin zu ringen sein wird.

\section{Rückkehr zur Judenmission in der Karfreitagsfürbitte von 2008?}

Auf einen synoptischen Vergleich der verschiedenen Karfreitagsfürbitten seit 1570 muss hier verzichtet werden. ${ }^{21}$ Der Text der Fürbitte von 2008 lautet in Übersetzung:

Lasset uns beten auch für die Juden, dass Gott, unser Herr, ihre Herzen erleuchte, damit sie Jesus Christus als den Heiland aller Menschen erkennen (agnoscant). Allmächtiger, ewiger Gott, der du willst, dass alle Menschen gerettet werden und zur Erkenntnis der Wahrheit gelangen, gewähre gnädig, dass, indem [= während, in der Zeit, da] die Fülle der Heidenvölker in deine Kirche eintritt [plenitudine gentium in ecclesiam tuam intrante], ganz Israel gerettet werde: Durch Christus unsern Herrn. Amen.

Schwierigkeiten bereitet im Gebetsaufruf bereits das lateinische Wortfeld agnoscerelagnitio. ${ }^{22}$ Meinem Interpretationsvorschlag zufolge besteht das Gebetsanliegen nicht darin, die Jüdinnen und Juden sollten an Jesus glauben (hebr. Wurzel אמן [aman]), sondern darin, dass sich ihnen das Geheimnis Jesu Christi als Retter der Welt innerlich, intellektuell erschließt.

Die Oration selbst ist eine Neugestaltung gegenüber den bisherigen Vorlagen. Der Text beginnt theozentrisch und bleibt $\mathrm{m}$. E. auch insgesamt theozentrisch. Dabei bezieht er sich auf zwei kanonische Texte aus dem Neuen Testament, die ohne ih-

2I Vgl. Wohlmuth, Josef: Die Karfreitagsfürbitte für die Juden als Indikator des Grundverhältnisses von Juden und Christen, in: Homolka, Walter / Zenger, Erich (Hg.): „... damit sie Jesus Christus erkennen. Die neue Karfreitagsfürbitte für die Juden, Freiburg: Herder 2008, 19I-204.

22 Lexikalisch hat agnoscere mehrere Bedeutungen, die von ,anerkennen', über ,genau erkennen' bis zu ,erkennen' oder ,verstehen' reichen. Vgl. die Übersetzungstradition, die über das Griechische bis in das Hebräische zurückreicht. Agnoscerel agnitio entspricht den griechi-

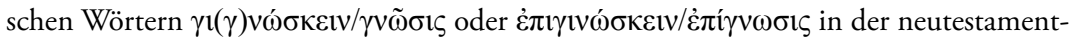

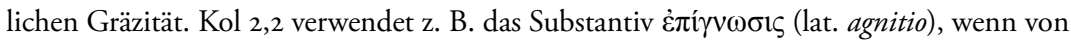
der (tiefen) Erkenntnis des Geheimnisses Gottes und Christi gesprochen wird. Vgl. hebr. die Wurzel ידע [jada] mit der Grundbedeutung „erkennen“. 
ren frühjüdischen Hintergrund bzw. ohne das Grundproblem der Verhältnisbestimmung von Judentum und Christentum gar nicht verstanden werden könnten. In beiden Rückbezügen auf das Neue Testament werden auch deren nähere und weitere Kontexte angedeutet. So nimmt die Oration zunächst auf den Ersten Timotheusbrief Bezug, aus dessen näherem Kontext im ersten Kapitel hervorgeht, dass die Gemeinde zum Gebet "für alle Menschen“ aufgefordert wird. Es sei gut, so zu dem zu beten, der will, „dass alle Menschen gerettet werden und zur Erkenntnis der Wahrheit gelangen" (I Tim 2,4). Dem lat. Ausdruck ad agnitionem veritatis venire geht gleichsam eine Umschreibung des Gottesnamens voraus: qui omnes homines vult salvos fieri. Somit ist vom Gott des universalen Heiles die Rede, der sich der „verstehende[n] Aneignung“ darbieten möge. ${ }^{23}$ Vom „Rettergott“, der das Heil aller Menschen will - ein weichenstellender Grundsatz auch des Zweiten Vatikanums insgesamt - wird in I Tim 2,5 der Gemeinde in einem bereits bekannten hymnischen Zusatz der jüdische Monotheismus nahegebracht. Der Text besteht $\mathrm{m}$. E. darauf, dass die christologische Ergänzung den jüdischen Monotheismus nicht zerstört. Es ist der eine Gott, der zugunsten der einen Menschheit handelt, indem der (jüdische) Mensch Christus Jesus zum Lösegeld für alle wird. In diesem Text kommt somit zum Ausdruck, dass das Christentum zur Zeit der Abfassung dieses Briefes bereits ganz und gar auf dem Weg ist, zur Völkerkirche zu werden und sich auch mit der Intellektualität jener Zeit auseinandersetzt. Wer also das heimliche Grunddogma des Zweiten Vatikanums, die Lehre vom universalen Heilswillen vertritt, muss sich bewusst sein, dass es der universale Heilswille des Gottes Israels durch die Vermittlung des Menschen Christus Jesus ist. Insofern schließt die Bekehrung eines Heiden zum Christentum immer auch die Bekehrung zum einen Gott Israels ein. Freilich wurde vor allem von jüdischer Seite befürchtet, dass die neue Oration für die Judenmission plädiere, weil der universale Heilswille Gottes auch auf das Judentum angewendet werden könnte.

Der zweite Teil der Oration ist nach allgemeiner Auslegung eine weiterführende Interpretation von Röm II,25-27. Dabei fällt auf, dass die Oration von 2008 über den paulinischen Text hinaus eine Ergänzung vornimmt: Das intrare betrifft das Eintreten der Heiden in die Kirche. In Röm II,25 hat hingegen, wie Heinrich Schlier zur Stelle bemerkt, die Kirche keinen Ort. ${ }^{24}$ Entweder, so meint er, denke

23 „Quelle der Wahrheitserkenntnis ist die ,gesunde Lehre', deren erstehende Aneignung erwartet wird." Roloff, Jürgen: Der erste Brief an Timotheus (EKK XV), Zürich: Benziger 1988, I20, vgl. I07-I25. Wie Roloff ausführt, tritt die Erkenntnis an die Stelle des paulinischen Glaubensbegriffes, weshalb hier die „noetische Komponente des Heilsweges“ (I2O) deutlicher zum Ausdruck komme.

Vgl. Schlier, Heinrich: Der Römerbrief (HThK NT 6), Freiburg: Herder 1977, 339. 
Paulus an das Eingehen in das Gottesreich oder - wahrscheinlicher - ins ewige Leben (vgl. Röm II,I5). Die crux interpretationis bleibt die folgende Klausel: plenitudine gentium in ecclesiam tuam intrante. Die grammatische Konstruktion (Ablativus absolutus) verweist nach meinem Verständnis auf einen noch andauernden Prozess, in dem die Heidenvölker (bis zu der von Gott bestimmten Vollzahl ${ }^{25}$ kraft der Evangeliumsverkündigung in die Kirche eintreten. Daraus ergibt sich die gravierende Schlussfolgerung: Während dieses Wachstumsprozesses der Kirche unter den Völkern wird ganz Israel gerettet. Die Rettung Israels geschieht somit unabhängig vom Vorgang der Völkermission der Kirche allein durch Gott. Von Judenmission kann deshalb nicht die Rede sein.

Ich ziehe daraus die gravierende Konsequenz: Die Oration von 2008 ist das erste offizielle Gebet der katholischen Kirche, in dem von der Rettung ganz Israels gesprochen wird, und zwar nicht nur rückblickend auf das vorchristliche Israel, sondern auf das Israel aller Zeiten. Gleichzeitig wird der Vorgang der Völkermission enteschatologisiert. ${ }^{26}$ Die Verkündigung des Evangeliums an die Heidenvölker stellt eine Aufgabe der Kirche dar. Daraus folgt weiter: Die Rettung ganz Israels und die Rettung der Völkerwelt dürfen nicht gegeneinander ausgespielt werden. Die Oration eröffnet somit auf diese Weise für die gesamte Menschheit den einen Heilsweg in zwei Versionen, die Rettung der Völker durch deren Gewinnung für das Evangelium, das sie zugleich mit dem Gott Israels und seinem ersterwählten Volk verbindet, und die Rettung ganz Israels durch die unverbrüchliche Treue des einen Gottes, durch den auch die Heidenvölker gerettet werden. Die Karfreitagsfürbitte von 2008 macht also aus der paulinischen Überzeugung der Rettung ganz Israels am Jüngsten Tag eine Geschichtsaussage: Während das Heil durch Jesus Christus der gesamten Völkerwelt via Kirche vermittelt wird, geschieht durch Gott die Rettung Israels in seiner Gesamtheit. Die Rettung ganz Israels durch Gott und die Rettung der Völkerwelt durch

25 Ich gebe der Kritik Michael Theobalds in seinem unten behandelten Beitrag recht, dass meine Übersetzung des Ausdrucks plenitudine gentium mit „Heidenvölker“ zu schwach wirkt.

Zum Verständnis des paulinischen Textes vgl. auch Schöttler, Heinz-Günther: Röm II,2527 und die Wahrheitsfrage im christlich-jüdischen Dialog, in: Bruckmann, Florian / Dausner, René (Hg.): Im Angesicht der Anderen. Gespräche zwischen christlicher Theologie und jüdischem Denken. Festschrift für Josef Wohlmuth zum 75. Geburtstag (Studien zu Judentum und Christentum 25), Paderborn: Schöningh 20I3, I4I-I66, hier bes. I44-I48.

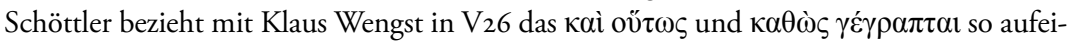
nander, dass das Wort aus Jesaja zur offenbarungsbedingten Begründung der Rettung ganz Israels wird. Dadurch werden das Eingehen der Völker und das Kommen des Retters aus Zion zum Ausdruck des eschatologischen Handelns Gottes. Die Erreichung der Vollzahl der Völker sei aber nicht Vorbedingung für das Kommen des Retters. 
die Verkündigung der Kirche gehören zusammen. Dies möge, so lässt die Oration von 2008 beten, das Judentum aus den eigenen Vorgaben der Offenbarung, die es mit dem Christentum teilt, selbst erkennen. Der Paulus zufolge „dem Fleische nach" aus dem Judentum stammende Jesus-Messias ist als der Auferstandene erkennbar das Heil aller Menschen. Diese Rettung ist für Paulus schon im Gang und betrifft - in eschatologischer Perspektive - Israel in seiner Gesamtheit, und zwar allein durch Gottes Treue, der auch die Völker ihre Rettung verdanken.

Michael Theobald hat sich mit meiner Lesart kritisch auseinandergesetzt, ${ }^{27}$ was ich als der Sache sehr dienlich betrachte. Wenn ich recht sehe, betrifft seine Auslegung der neuen Fürbitte vor allem die Frage, ob sie in ihrem Anklang auf Paulus auch wirklich der Paulusexegese entspricht. In meiner Interpretation drängt sich vor allem der Aspekt des Prozesshaften auf, worin mir freilich Theobald am wenigsten folgt, weil sie auch gewiss aus Röm II,25-27 nicht ableitbar erscheint. Gleichwohl treffen wir uns überraschenderweise in der These, dass es für das geschichtliche Israel aller Zeiten keine heilsfreie und somit heil-lose Zeit gibt. ${ }^{28}$ Einig sind wir uns auch, dass aus der Oration kein Plädoyer für die Judenmission abgeleitet werden kann. Somit kann ganz Israel auf Rettung hoffen, weil Gott zu seinen Verheißungen steht. Die Kirche ist für die Rettung Israels nicht die zuständige Instanz. ${ }^{29}$ Heinz-Günther Schöttler hat als Fazit der bisherigen Diskussion über

27 Vgl. Theobald, Michael: Zur Paulus-Rezeption in der Karfreitagsfürbitte für die Juden von 2008, in: Frankemölle, Hubert / Wohlmuth, Josef (Hg.): Das Heil der Anderen - Problemfeld ,Judenmission' (QD 238), Freiburg: Herder 20I0, 507-54I. - Für Theobald zeigt intrante Gleichzeitigkeit an, bezieht diese aber nicht auf den Prozess der Völkermission und deren Vollmaß (5I7). Immerhin konzediert Theobald, dass der Wachstumsgedanke in der Ablativformulierung entrante nicht ganz auszuschließen sei. Vor allem der Ausdruck in Ecclesiam tuam lege ihn nahe. Damit sei allerdings eine Umgestaltung des paulinischen Gedankens vorgenommen. Das Ende der Zeiten droht aus dem Blick zu geraten, was für Paulus natürlich nicht tragbar sei. Dem stimme ich zu. Die Fürbitte beansprucht nicht, auf Paulus begrenzt zu werden.

28 Theobald: Zur Paulus-Rezeption, 529, macht mit Recht darauf aufmerksam, dass sich in Röm II,28-32 Zeitangaben finden, die u. a. besagen, dass die Juden, die jetzt (vṽv) ungehorsam geworden sind, während die Heiden gerettet werden, jetzt auch Barmherzigkeit erfahren.

29 Angesichts dieser grundlegenden Übereinstimmungen habe ich die kritische Auseinandersetzung Michael Theobalds mit meiner Auslegung als einen Freundschaftsdienst verstanden, der darauf aufmerksam macht, dass der Systematiker gut daran tut, mit der Paulusinterpretation nicht zu schnell fertig zu sein. Nicht folgen kann ich Theobald jedoch, wenn er die Oration in ihrer Auslegung vom Katechismus der Katholischen Kirche abhängig macht, weil ich nicht erkennen kann, dass Ratzinger in den zitierten Aufsätzen der I990er-Jahre den Thesen des Katechismus folgt. 
Paulus Röm II,25-27 den Satz formuliert: „Christen müssen sich um die Rettung Israels keine ,Sorgen' machen. “"30

Hat Papst Benedikt die Kritik an der Fürbitte von 2008 zur Kenntnis genommen? In Verbum Domini (Nr. 43) zitiert er Röm II,28f. und verweist auf Röm II,I7-24, um dann festzuhalten: „Wir nähren uns also aus denselben spirituellen Wurzeln. Wir begegnen einander als Brüder - Brüder, die in gewissen Augenblicken ihrer Geschichte ein gespanntes Verhältnis zueinander hatten, sich aber jetzt fest entschlossen darum bemühen, Brücken beständiger Freundschaft zu bauen.“

\section{Weichenstellende Äußerungen von Papst Franziskus zum Verhältnis von Judentum und Christentum}

Im eingangs angeführten Gesprächsband Über Himmel und Erde kommen beide Gesprächspartner in Kapitel 24 „Über den Holocaust“ auf Papst Benedikt XVI. zu sprechen (187-199). Abraham Skorka erinnert an die Irritation, die die Karfreitagsfürbitte von Papst Benedikt im Judentum ausgelöst hat (194). Sie habe gestattet, wieder für die Bekehrung der Jüdinnen und Juden zu beten. Kardinal Bergoglio wendet ein, die ursprüngliche Fürbitte [sc. von I570] sei viel drastischer gewesen. Sie habe bereits Johannes XXIII. „mit einem Federstrich“ verändert. Dabei bleibe es. Als Skorka davon spricht, wir müssten „eine gemeinsame Botschaft vertreten, die sich an alle richtet, nicht um den jeweils anderen zu bekehren, sondern um uns einander anzunähern" (197), verweist der Kardinal auf das Zweite Vatikanische Konzil, indem er ausführt: „Es gibt einen Schlüsselsatz des Zweiten Vatikanischen Konzils, [d]er besagt, dass Gott sich allen Menschen kundgetan hat, und an erster Stelle nennt er das Volk, das Träger der Verheißung ist." Und da Gott seine Versprechen hält, wurde es nicht verstoßen. Die Kirche erkennt offiziell an, dass das Volk Israel weiterhin Träger der Verheißungen ist. In keinem Moment sagt sie: ,Ihr habt das Spiel verloren, jetzt sind wir an der Reihe“" (297f.). Das ist mit einfachsten Worten die Absage an jede Form von Enterbungstheorie. Der Ausdruck ,in keinem Moment" muss eher auf die Kirche des Zweiten Vatikanischen Konzils bezogen werden; denn auf die gesamte Kirchengeschichte trifft dies nicht zu. In seinem Apostolischen Schreiben Evangelii Gaudium ${ }^{31}$ hat Papst Franziskus die Be-

30 Schöttler: Röm II,25-27, I54.

3I Vgl. Apostolisches Schreiben EVANGELII GAUDIUM des Heiligen Vaters Papst Franziskus an die Bischöfe, an die Priester und Diakone, an die Personen geweihten Lebens und an die christgläubigen Laien über die Verkündigung des Evangeliums in der Welt von heute: 24. November 2013 (Verlautbarungen des Apostolischen Stuhls 194), hg. v. Sekretariat der Deutschen Bischofskonferenz, Bonn: Sekretariat der Deutschen Bischofskonferenz 2013. 
ziehung zwischen Judentum und Kirche nun auch in sein ,Regierungsprogramm aufgenommen und für sein Pontifikat Folgendes festgehalten:

247. Ein ganz besonderer Blick ist auf das jüdische Volk gerichtet, dessen Bund mit Gott niemals aufgehoben wurde, denn , unwiderruflich sind Gnade und Berufung, die Gott gewährt' (Röm II,29). Die Kirche, die mit dem Judentum einen wichtigen Teil der Heiligen Schrift gemeinsam hat, betrachtet das Volk des Bundes und seinen Glauben als eine heilige Wurzel der eigenen christlichen Identität (vgl. Röm II,I6-I8). Als Christen können wir das Judentum nicht als eine fremde Religion ansehen, noch rechnen wir die Juden zu denen, die berufen sind, sich von den Götzen abzuwenden und sich zum wahren Gott zu bekehren (vgl. I Thess I,9). Wir glauben gemeinsam mit ihnen an den einen Gott, der in der Geschichte handelt, und nehmen mit ihnen das gemeinsame offenbarte Wort an.

248. Der Dialog und die Freundschaft mit den Kindern Israels gehören zum Leben der Jünger Jesu. Die Zuneigung, die sich entwickelt hat, lässt uns die schrecklichen Verfolgungen, denen die Juden ausgesetzt waren und sind, aufrichtig und bitter bedauern, besonders, wenn Christen darin verwickelt waren und sind.

249. Gott wirkt weiterhin im Volk des Alten Bundes und lässt einen Weisheitsschatz entstehen, der aus der Begegnung mit dem göttlichen Wort entspringt. Darum ist es auch für die Kirche eine Bereicherung, wenn sie die Werte des Judentums aufnimmt. Obwohl einige christliche Überzeugungen für das Judentum unannehmbar sind und die Kirche nicht darauf verzichten kann, Jesus als den Herrn und Messias zu verkünden, besteht eine reiche Komplementarität, die uns erlaubt, die Texte der hebräischen Bibel gemeinsam zu lesen und uns gegenseitig zu helfen, die Reichtümer des Wortes Gottes zu ergründen sowie viele ethische Überzeugungen und die gemeinsame Sorge um die Gerechtigkeit und die Entwicklung der Völker miteinander zu teilen.

Diese programmatischen Formulierungen sind ein klares Zeugnis dafür, dass Papst Franziskus weiterhin auf Nostra Aetate 4 setzt und die gesamte Kirche dafür gewinnen will, sich selbst in engster Verbindung mit dem ersterwählten Volk verstehen soll.

\section{Kurze Schlussfolgerungen}

I. Am weichenstellenden Charakter der Erklärung des Zweiten Vatikanischen Konzils Nostra Aetate 4 kann bezüglich des neuen Verhältnisses von Judentum und Christentum im Pontifikat von Papst Benedikt trotz einiger Irritationen kein 
Zweifel gehegt werden. Papst Franziskus hat sich seinerseits diesbezüglich bereits eindeutig festgelegt.

2. Die These vom exzeptionellen Verhältnis von Judentum und Christentum entspricht dem derzeitigen Stand des jüdisch-katholischen Dialogs nach der Schoah und begründet sich vor allem aus der Interpretation von Röm 9-II. Dem folgt auch Papst Franziskus. Nachdem wir als Christinnen und Christen dieses exzeptionelle Verhältnis des Christentums zum Judentum tiefer zu verstehen beginnen, ohne - wie beide Pontifikate betonen - die Christologie zur Disposition stellen zu können, wirbt die christliche Theologie darum, dass auf längere Sicht auch das Judentum sein exzeptionelles Verhältnis zum Christentum neu entdecken möge, ohne dass der Glaube an Jesus Christus dafür zur Voraussetzung gemacht wird.

3. Für Judenmission gibt es keine stichhaltigen theologischen Gründe mehr. Gerettet wird „ganz Israel“ allein durch die Bundestreue Gottes, die wir als Christinnen und Christen in Tod und Auferstehung Jesu bekräftigt sehen und die auf das universale Heil der Menschheit ausgerichtet ist. Die Kirche der Zukunft kann aufgrund der Offenbarung des Gottes der Treue ohne engste innere Zusammengehörigkeit mit dem Judentum nicht Kirche Jesu Christi sein und bleiben. 


\section{Verzeichnis der Autorinnen und Autoren}

\section{Apl. Prof. Dr. Gerlinde Baumann}

Fachgebiet Altes Testament, Fachbereich Evangelische Theologie, Philipps-Universität Marburg

\section{Prof. Dr. Erhard Blum}

Altes Testament I, Evangelisch-Theologische Fakultät, Eberhard Karls Universität Tübingen

\section{Ao. Univ.-Prof. Mag. Dr. Peter Ebenbauer}

Institut für Liturgiewissenschaft, Christliche Kunst und Hymnologie, Katholisch-Theologische Fakultät, Karl-Franzens-Universität Graz

Univ.-Prof. Mag. Dr. Irmtraud Fischer

Institut für Alttestamentliche Bibelwissenschaft, Katholisch-Theologische Fakultät, Karl-Franzens-Universität Graz

\section{Em. Prof. Dr. Hubert Frankemölle}

Institut für Katholische Theologie, Fakultät für Kulturwissenschaften, Universität Paderborn

\section{Prof. Dr. Albert Gerhards}

Seminar für Liturgiewissenschaft, Katholisch-Theologische Fakultät, Rheinische Friedrich-Wilhelms-Universität Bonn

\section{Prof. Dr. phil. h. c. Hans Hermann Henrix}

Akademiedirektor a. D./Bischöfliche Akademie Aachen, Honorarprofessor

\section{Em. Prof. Dr. Bertold Klappert}

Systematische Theologie, Kirchliche Hochschule Wuppertal/Bethel

Univ.-Prof. Mag. Dr. Gerhard Langer

Institut für Judaistik, Universität Wien

\section{Em. Prof. Dr. Simon Lauer}

Altphilologe und Judaist, Institut für Jüdisch-Christliche Forschung, Universität Luzern 


\section{Em. Univ.-Prof. DDr. Johann Maier}

Martin-Buber-Institut für Judaistik, Universität Köln

Em. Univ.-Prof. Dr. Johannes Marböck

Institut für Alttestamentliche Bibelwissenschaft, Katholisch-Theologische Fakultät, Karl-Franzens-Universität Graz

\section{MMag. Dr. Edith Petschnigg}

Institut für Alttestamentliche Bibelwissenschaft, Katholisch-Theologische Fakultät, Karl-Franzens-Universität Graz

\section{Em. o. Univ.-Prof. Dr. Günter Stemberger}

Institut für Judaistik, Universität Wien

\section{Prof. Dr. Marie-Theres Wacker}

Seminar für Exegese des Alten Testaments, Katholisch-Theologische Fakultät, Westfälische Wilhelms-Universität Münster

\section{Em. Prof. Dr. Klaus Wengst}

Neues Testament und Judentumskunde, Evangelisch-Theologische Fakultät, Ruhr-Universität Bochum

\section{Em. Prof. Dr. Dr. h. c. Josef Wohlmuth}

Dogmatik, Katholisch-Theologische Fakultät, Rheinische Friedrich-Wilhelms-Universität Bonn 


\section{Literaturverzeichnis}

Adelman, Rachel: The Return of the Repressed. Pirqe de-Rabbi Eliezer and the Pseudepigrapha (JSJ.S I4O), Leiden: Brill 2009.

Adloff, Kristlieb: Art. Judentum, in: Müller, Karl / Sundermeier, Theo (Hg.): Lexikon missionstheologischer Grundbegriffe, Berlin: Reimer 1987, 200-204.

Altmann, Alexander: Moses Mendelssohn. A Biographical Study, Alabama: Univ. of Alabama Press 1973.

Amano, Yu: Karl Barths Ethik der Versöhnungslehre. Ihre theologische Rezeption in Japan und ihre Bedeutung für die kirchlich-gesellschaftliche Situation in Japan, Frankfurt a. M.: Lang 1994 .

Amt der Vereinigten Evangelisch-Lutherischen Kirche Deutschlands (VELKD) / Johann-Adam-Möhler-Institut: Unter dem Horizont der Gnade. Ökumenische Arbeitshilfe zum Io. Jahrestag der „Gemeinsamen Erklärung zur Rechtfertigungslehre“, Hannover: Hansisches Druck- und Verlagshaus 2009.

Amt für Kirchenmusik der Erzdiözese Freiburg (Hg.): Freiburger Kantorenbuch zum Gotteslob. Antwortpsalmen im Kirchenjahr, Stuttgart: Carus 2013.

Apostolisches Schreiben EVANGELII GAUDIUM des Heiligen Vaters Papst Franziskus an die Bischöfe, an die Priester und Diakone, an die Personen geweihten Lebens und an die christgläubigen Laien über die Verkündigung des Evangeliums in der Welt von heute: 24. November 2013 (Verlautbarungen des Apostolischen Stuhls 194), hg. v. Sekretariat der Deutschen Bischofskonferenz, Bonn: Sekretariat der Deutschen Bischofskonferenz 20I3.

Avery Peck, Alan J.: The Church Fathers and Rabbinic Midrash: A Supplementary Bibliography, 1985-2005, in: RRJ 9 (2006) 190-196.

Baeck, Leo: Der Glaube des Paulus, in: Friedlander, Albert H. / Klappert, Bertold (Hg.): Nach der Schoa - warum sind Juden in der Welt? Schriften aus der Nachkriegszeit (Leo Baeck Werke 5), Gütersloh: Gütersloher Verlagshaus 2002, 420-466.

- Judentum, Christentum und Islam (1956), in: Friedlander, Albert H. / Klappert, Bertold (Hg.): Leo Baeck Werke. 5: Nach der Schoa - Warum sind die Juden in der Welt? Schriften aus der Nachkriegszeit, Gütersloh: Gütersloher Verlagshaus 2002, 472-492.

- Maimonides - der Mann und seine Wirkung, in: Friedlander, Albert H. / Klappert, Bertold (Hg.): Leo Baeck Werke. 5: Nach der Schoa - Warum sind die Juden in der Welt? Schriften aus der Nachkriegszeit Gütersloh: Gütersloher Verlagshaus 2002, I39I57.

Bail, Ulrike u. a. (Hg.): Bibel in gerechter Sprache, Gütersloh: Gütersloher Verlagshaus 2006; ${ }^{4} 201$. 
Balić, Smail: Ruf vom Minarett. Weltislam heute - Renaissance oder Rückfall? Eine Selbstdarstellung, Hamburg: EB-Verl. Rissen ${ }^{3}$ I984.

Bar-Asher Siegal, Michal: Early Christian Monastic Literature and the Babylonian Talmud, Cambridge: Cambridge University Press 2013.

Barth, Hans-Martin: Dogmatik. Evangelischer Glaube im Kontext der Weltreligionen. Ein Lehrbuch, Gütersloh: Kaiser 200I.

Barth, Karl: Briefe 196I-I968, hg. v. Jürgen Fangmeier, Zürich: Theolog. Verl. I975.

- Die Kirchliche Dogmatik IV/ı, Zürich: Evangel. Verl. 1967.

- Die Kirchliche Dogmatik IV/4, Zürich: Evangel. Verl. 1967.

- Offene Briefe 1945-1968, hg. v. Diether Koch, Zürich: Theolog. Verl. I984.

Barth, Markus: Das Abendmahl. Passamahl, Bundesmahl und Messiasmahl (Theologische Studien I8), Zürich: Evangel. Verl. I945.

- Das Mahl des Herrn. Gemeinschaft mit Israel, mit Christus und unter den Gästen, Neukirchen-Vluyn: Neukirchener 1987.

Barthélemy, Dominique: Est-ce Hoshaya Rabba qui censura le "Commentaire allégorique"?, in: Colloques Nationaux du CNRS: "Philon d'Alexandrie”, Lyon 1966, Paris: Centre National de la Recherche Scientifique 1967, 45-78; Nachdruck in: Ders.: Études d'histoire du texte de l'Ancien Testament (OBO 2I), Fribourg: Universitätsverlag 1978, I40-I73.

Baskin, Judith: Rabbinic-Patristic Exegetical Contacts in Late Antiquity: A Bibliographical Reappraisal, in: Green, William Scott (Hg.): Approaches to Ancient Judaism. 5. Studies in Judaism in Its Greco-Roman Context (Brown Judaic Studies 32), Chico: Scholars Press 1985, 53-80.

Batlogg, Andreas R.: Tag des Judentums, in: Stimmen der Zeit I36 (20II), If.

Baumann, Gerlinde: „Zukunft feministischer Spiritualität“ oder „Werbefigur des Patriarchats"? Die Bedeutung der Weisheitsgestalt in Prov I-9 für die feministisch-theologische Diskussion, in: Marie-Theres Wacker / Luise Schottroff (Hg.): Von der Wurzel getragen. Christlich-feministische Exegese in Auseinandersetzung mit Antijudaismus (BIS I7), Leiden: Brill I996, I35-152.

- Die Bibel. Wissen was stimmt (Herder spektrum 5955), Freiburg: Herder 2008.

- Gottesbilder der Gewalt im Alten Testament verstehen, Darmstadt: Wissenschaftliche Buchgesellschaft 2006.

Baumann; Urs: Art. Ökumene, in: Eicher, Peter (Hg.): Neues Handbuch theologischer Grundbegriffe. 3. Neuausgabe 2005, München: Kösel 2005, 26I-283.

Bechtoldt, Hans-Joachim: Die jüdische Bibelkritik im 19. Jahrhundert, Stuttgart: Kohlhammer 1995 .

Beckmann, Klaus: Die fremde Wurzel. Altes Testament und Judentum in der evangelischen Theologie des i9. Jahrhunderts (FKDG 85), Göttingen: Vandenhoeck \& Ruprecht 2002. 
Ben-Chorin, Schalom: Jüdischer Glaube. Strukturen einer Theologie des Judentums anhand des Maimonidischen Credo. Tübinger Vorlesungen, Tübingen: Mohr Siebeck I975.

Bergoglio, Jorge (Papst Franziskus) / Skorka, Abraham: Über Himmel und Erde. Jorge Bergoglio im Gespräch mit dem Rabbiner Abraham Skorka, hg. von Diego F. Rosemberg, München: Riemann 2013.

Berlin, Adele / Brettler, Marc Z. (Hg.): The Jewish Study Bible. Oxford: Oxford University Press 2004; Liss, Hanna, in Zusammenarbeit mit Annette M. Böckler und Bruno Landthaler: TANACH. Lehrbuch der jüdischen Bibel (Schriften der Hochschule für Jüdische Studien Heidelberg 8), Heidelberg: Universitätsverlag Winter ${ }^{3}$ 2oII.

Berndt, Rainer: The School of St. Victor in Paris, in: Sæbø, Magne (Hg.): Hebrew Bible / Old Testament. The History of Its Interpretation. I: From the Beginnings to the Middle Ages (Until I300), Göttingen: Vandenhoeck \& Ruprecht 2000, 467-495.

Bernstein, Moshe J.: The Contribution of Qumran Discoveries to the History of Early Biblical Interpretation, in: Najman, Hindy / Newman, Judith H. (Hg.): The Idea of Biblical Interpretation: Essays in Honor of James L. Kugel (JSJ 83) Leiden: Brill 2004, 215-238.

Bethge, Eberhard: Dietrich Bonhoeffer. Theologe, Christ, Zeitgenosse, München: Kaiser 1967.

Jesus Christus - Christologie und das Erste Gebot, in: Edna Brocke / Jürgen Seim (Hg.): Gottes Augapfel. Beiträge zur Erneuerung des Verhältnisses von Christen und Juden, Neukirchen-Vluyn: Neukirchener 1986, 47-58.

Bieler, Andrea / Schottroff, Luise: Das Abendmahl. Essen, um zu leben, Gütersloh: Gütersloher Verlagshaus 2007.

Blum, Erhard: Volk oder Kultgemeinde? Zum Bild des nachexilischen Judentums in der alttestamentlichen Wissenschaft, in: KuI ro (1995) 24-42.

Boschki, Reinhold / Gerhards, Albert (Hg.): Erinnerungskultur in der pluralen Gesellschaft. Neue Perspektiven für den christlich-jüdischen Dialog (Studien zu Judentum und Christentum) Paderborn: Schöningh 2010.

Böttigheimer, Christoph (Hg.): Zweites Vatikanisches Konzil. Programmatik - Rezeption - Vision (QD 26I), Freiburg: Herder 2014.

Bourel, Dominique: Moses Mendelssohn. La naissance du judaïsme moderne, Paris: Gallimard 2004.

Bousset, Wilhelm: Die Religion des Judentums im neutestamentlichen Zeitalter, Berlin: Reuther \& Reichard 1903.

Boyarin, Daniel: A Radical Jew: Paul and the Politics of Identity (Contraversions: Critical Studies in Jewish Literature, Culture and Society I), Berkeley: University of California Press 1994 . 
- Border Lines: The Partition of Judaeo-Christianity (Divinations), Philadelphia: University of Pennsylvania Press 2004. Deutsch: Abgrenzungen: Die Aufspaltung des Judäo-Christentums (ANTZ ıo), Berlin: Institut Kirche und Judentum 2009.

- Dying for God. Martyrdom and the Making of Christianity and Judaism (Figurae: Reading Medieval Culture), Stanford: Stanford Univ. Press I999.

- The Jewish Gospels. The Story of the Jewish Christ, New York: New Press 2012.

Brakmann, Heinzgerd: Foedera pluries hominibus. Anmerkungen zur Revision des Eucharistischen Hochgebets IV, in: LJ 50 (2000) 2II-234.

Brandau, Robert: Innerbiblischer Dialog und dialogische Mission. Die Judenmission als theologisches Problem, Neukirchen-Vluyn: Neukirchener 2006.

Braulik, Georg: Gott für Israel preisen. Zur Heilsprärogative Israels und zum 4. Hochgebet, in: Gerhards, Albert / Henrix, Hans Hermann (Hg.): Dialog oder Monolog? Zur liturgischen Beziehung zwischen Judentum und Christentum (QD 208) Freiburg: Herder 2004, 223-253.

Brenner, Athalya (Hg.): A Feminist Companion to the Bible, Sheffield: Sheffield Academic Press bzw. T\&T Clark 1993-200I.

Breuning, Wilhelm: Was erbringt der jüdisch-christliche Dialog für das katholisch-evangelische Gespräch?, in: Hahn, Ferdinand u. a. (Hg.): Zion - Ort der Begegnung. Festschrift für Laurentius Klein zur Vollendung des 65. Lebensjahres (BBB 90), Bodenheim: Athenäum Hain Hanstein 1993, 347-369.

Brumlik, Micha: Kritik des Zionismus, Hamburg: Europ. Verlagsanstalt 2007; Aloni, Udi: What Does a Jew Want? On Binationalism and Other Specters, New York: Columbia University Press 20II.

Buber, Martin: Werke. 2. Schriften zur Bibel, München: Kösel I964.

Buber, Salomon (Hg.): Midrasch Tanchuma. Ein aggadischer Commentar zum Pentateuch. Zum ersten Male nach Handschriften aus den Bibliotheken zu Oxford, Rom, Parma und München herausgegeben. 2, Wilna: Romm I885 (Nachdruck Jerusalem 1964).

Budde, Achim: Gemeinsame Tagzeiten. Motivation - Organisation - Gestaltung (Praktische Theologie heute 96), Stuttgart: Kohlhammer 2013.

Bunte, Wolfgang: Rabbinische Traditionen bei Nikolaus von Lyra: Ein Beitrag zur Schriftauslegung des Spätmittelalters (JudUm 58), Frankfurt: Lang 1994.

Buren, Paul M. van: A Theology of the Jewish Christian Reality, Part I: Discerning the Way, New York: Seabury Press 1980, Part II: A Christian Theology of the People of Israel, New York: Seabury Press 1983, Part III: Christ in Context, New York: Seabury Press 1988.

Busch, Eberhard: Meine Zeit mit Karl Barth. Tagebuch 1965-1968, Göttingen: Vandenhoeck \& Ruprecht 20 II. 
- Unter dem Bogen des einen Bundes. Karl Barth und die Juden I933-1945, Neukirchen-Vluyn: Neukirchener 1996.

Butler, Judith: Parting Ways. Jewishness and the Critique of Zionism, New York: Columbia University Press 2013.

Campanini, Saverio (Hg.): The Book of Bahir. Flavius Mithridates' Latin Translation, the Hebrew Text, and an English Version (The Kabbalistic Library of Giovanni Pico della Mirandola 2), Turin: Aragno 2005.

Carlebach, Elisheva / Schacter, Jacob J. (Hg.): New Perspectives on Jewish-Christian Relations: In Honor of David Berger (The Brill Reference Library of Judaism 33), Leiden: Brill 2012.

Casalis, Georges: Die Zeichen der Hingabe Christi an die Welt, in: Herbert, Karl (Hg.): Christliche Freiheit im Dienst am Menschen. Deutungen der kirchlichen Aufgabe heute. Zum 80. Geburtstag von Martin Niemöller, Frankfurt a. M.: Lembeck 1972, 79-95.

- Les idées justes ne tombent pas du ciel. Éléments de „théologie inductive“, Paris: Ed. du Cerf 1977.

Cassuto, Umberto: La Questione della Genesi, Florenz: Le Monnier 1934.

- The Documentary Hypothesis and the Composition of the Pentateuch: Eight Lectures, Jerusalem: Magnes Print 196r.

Chamberlain, Houston Stewart: Die Grundlagen des 19. Jahrhunderts, München: Bruckmann 1898 .

Chazan, Robert / Friedman, John / Hoff, Jean C.: The Trial of the Talmud: Paris, I24O (Mediaeval Sources in Translation 53), Toronto: Pontifical Institute of Mediaeval Studies 2012.

Barcelona and Beyond. The Disputation of 1263 and Its Aftermath, Berkeley, Calif.: Univ. of California Press 1992.

Cohen, Hermann: Der ethische Monotheismus und seine soziologische Würdigung, in: Allgemeine Zeitung des Judentums 8I (I9I7) $373 \mathrm{f}$.

- Der Prophetismus und die Soziologie, in: Neue Jüdische Monatshefte I (1916/17) 652-655.

- Werke I7 = Kleinere Schriften VI. I916-I918, Hildesheim: Olms 2002.

Cohen, Jeremy: The "Persecutions of I096". From Martyrdom to Martyrology: The Sociocultural Context of the Hebrew Crusade Chronicles (Hebr.), in: Zion 59 (1994) I69-208.

Cohen, Shaye J. D.: The Beginnings of Jewishness: Boundaries, Varieties, Uncertainties, Berkeley: University of California Press 1999.

Corazzol, Giacomo: Menahem Recanati, Commentary on the Daily Prayers. Flavius Mithridates' Latin Translation, the Hebrew Text, and an English Version (The Kabbalistic Library of Giovanni Pico della Mirandola 3), Turin: Aragno 2008. 
Crüsemann, Frank: Das Alte Testament als Wahrheitsraum des Neuen. Die neue Sicht der christlichen Bibel, Gütersloh: Gütersloher Verlagshaus 20 II.

- Israel in der Perserzeit. Eine Skizze in Auseinandersetzung mit Max Weber, in: Schluchter, Wolfgang (Hg.): Max Webers Sicht des Christentums. Interpretation und Kritik (stw 548), Frankfurt a. M.: Suhrkamp 1985, 205-232 = in: Ders.: Kanon und Sozialgeschichte. Beiträge zum Alten Testament, Gütersloh: Kaiser 2003, 210226.

Cytrin, Yitzhak: Ha-pôlîţîqah ha-qarqa ît šäl ha-t nû ah ha-şijjônît bi-š’ elat ge' ûllat ha-'aräş bi-šnôt ha-20, in: Shaanan 4 (1997/8) I55-I70.

Das jüdische Volk und seine Heilige Schrift in der christlichen Bibel: 24. Mai 200I / Päpstliche Bibelkommission (Verlautbarungen des Apostolischen Stuhls 152), hg. v. Sekretariat der Deutschen Bischofskonferenz, Bonn: Sekretariat der Deutschen Bischofskonferenz 200I.

Dávid, Nóra u. a. (Hg.): The Hebrew Bible in Light of the Dead Sea Scrolls (FRLANT 239), Göttingen: Vandenhoeck \& Ruprecht 2012.

Delgado, Mariano / Sievernich, Michael (Hg.): Die großen Metaphern des Zweiten Vatikanischen Konzils. Ihre Bedeutung für heute, Freiburg: Herder 2013.

Démann, Paul: Israël et l'Unité de l'Église, in: Cahiers Sioniens 7 / 3 (I953) 17-24, teilweise in Deutsch veröffentlicht in: Gollwitzer, Helmut / Sterling, Eleonore (Hg.): Das gespaltene Gottesvolk, Stuttgart: Kreuz-Verl. 1970, 256-260.

- Kirche und Israel in ökumenischer Sicht, in: Marsch, Wolf-Dieter / Thieme, Karl (Hg.): Christen und Juden. Ihr Gegenüber vom Apostelkonzil bis heute, Mainz: Grünewald 1961, 270-283.

Deutsche Bischofskonferenz (Hg.): Katholischer Erwachsenen-Katechismus. Das Glaubensbekenntnis der Kirche, Kevelaer: Butzon \& Bercker ${ }^{3}$ I985.

Die Feier der heiligen Messe. Messbuch für die Bistümer des deutschen Sprachgebietes. Authentische Ausgabe für den liturgischen Gebrauch, Teil I, Freiburg: Herder 1975.

Dimant, Devorah: Jerûšat ha-'aräş `al pî tefîsatah šäl ‘adat mº̣̂llôt Qûmra'n. The Inheritance of the Land of Israel According to the Ideology of the Qumran Community, in: Meghillot 8-9 (2010) II3-I33.

Dinter, Artur: Die Sünde wider das Blut. Ein Zeitroman, Leipzig: Wolfverlag I9I8 [Erstauflage im Eigenverlag 1917].

Dirscherl, Erwin (Hg.): Einander zugewandt. Die Rezeption des christlich-jüdischen Dialogs in der Dogmatik, Paderborn: Schöningh 2005.

- Gottes Wort als Fülle der Zeit - Die Heilsbedeutung des jüdischen Glaubens in der Zeit post Christum natum, in: Frankemölle, Hubert / Wohlmuth, Josef (Hg.): Das Heil der Anderen. Problemfeld „Judenmission“ (QD 238), Freiburg: Herder 2010, 395-419. 
- I Trutwin, Werner (Hg.): Redet Wahrheit - Dabru Emet. Jüdisch-christliches Gespräch über Gott, Messias und Dekalog (Forum Christen und Juden 4), Münster: LIT 2004.

Dohmen, Christoph (Hg.): In Gottes Volk eingebunden. Christlich-jüdische Blickpunkte zum Dokument der Päpstlichen Bibelkommission „Das jüdische Volk und seine Heilige Schrift in der christlichen Bibel“, Stuttgart: Kath. Bibelwerk 2003.

- „Nicht wegen deines Bundes...“ (Ez 16,6I). Warum es für Christen keinen Bund mit Gott ohne Israel gibt, in: Dohmen, Christoph / Frevel, Christian (Hg.): Für immer verbündet. Studien zur Bundestheologie der Bibel (SBS 2II), Stuttgart: Katholisches Bibelwerk 2007, 43-48.

- Das Alte Testament als Altes Testament verstehen, in: Dohmen, Christoph / Stemberger, Günter: Hermeneutik der Jüdischen Bibel und des Alten Testaments (Kohlhammer Studienbücher Theologie I,2), Stuttgart: Kohlhammer 1996, 192-209.

- I Stemberger, Günter: Hermeneutik der Jüdischen Bibel und des Alten Testaments, Stuttgart (Kohlhammer Studienbücher Theologie I,2), Stuttgart: Kohlhammer 1996.

Donner, Herbert: Geschichte des Volkes Israel und seiner Nachbarn in Grundzügen. Teil 2: Von der Königszeit bis zu Alexander dem Großen. Mit einem Ausblick auf die Geschichte des Judentums bis Bar Kochba, Grundrisse zum Alten Testament (ATD.E 4/2), Göttingen: Vandenhoeck \& Ruprecht 1986, ${ }^{4} 2008$.

Duchrow, Ulrich: Bekennende Kirche werden - 1934 und I984 - Barmen III, in: Moltmann, Jürgen (Hg.): Bekennende Kirche wagen (KT 83), München: Kaiser I984, I26-I90.

Dunn, James D. G.: The Theology of Paul the Apostle, Edinburgh: Clark 1998.

Ebach, Jürgen: Hören auf das, was Israel gesagt ist - hören auf das, was in Israel gesagt ist. Perspektiven einer "Theologie des Alten Testaments“ im Angesicht Israels, in: EvTh 62 (2002) 37-53.

Ebenbauer, Peter: Mehr als ein Gespräch. Zur Dialogik von Gebet und Offenbarung in jüdischer und christlicher Liturgie (Studien zu Judentum und Christentum) Paderborn: Schöningh 2010.

Ehrlich, Ernst Ludwig: Eine jüdische Auffassung von Jesus, in: Eckert, Willehad Paul / Henrix, Hans Hermann (Hg.): Jesu Jude-Sein als Zugang zum Judentum (Aachener Beiträge zu Pastoral- und Bildungsfragen 6), Aachen: Einhard-Verl. 1976, 35-49.

Erler, Hans / Koschel, Ansgar (Hg.): Der Dialog zwischen Juden und Christen. Versuche des Gesprächs nach Auschwitz, Frankfurt: Campus I999.

Ernst, Hanspeter: Rabbinische Traditionen über Gottes Nähe und Gottes Leid, in: Thoma, Clemens / Wyschogrod, Michael (Hg.): Das Reden vom einen Gott bei Juden und Christen (JudChr 7), Bern: Peter Lang 1984, I57-I77.

(Erz-)Bischöfe Deutschlands und Österreichs und der Bischof von Bozen-Brixen (Hg.): 
Gotteslob. Katholisches Gebet- und Gesangbuch, Stuttgart: Verl. Katholisches Bibelwerk 2013 .

Evangelische Kirche in Deutschland Kirchenamt (Hg.): Gelobtes Land? Land und Staat Israel in der Diskussion. Eine Orientierungshilfe, Gütersloh: Gütersloher Verlagshaus 2012.

Falaturi, Abdoldjavad: Der Islam im Dialog. Aufsätze, Köln: Islam. Wissen. Akademie ${ }^{4} 1992$.

- Dialog zwischen Christentum und Islam, Köln: Islam. Akad. Deutschland ${ }^{2} 2002$.

- / Strolz, Walter / Talmon, Shemaryahu (Hg.): Zukunftshoffnung und Heilserwartung in den monotheistischen Religionen (Veröffentlichungen der Stiftung Oratio Dominica 9), Freiburg: Herder 1983.

Faulhaber, Michael von: Judentum, Christentum, Germanentum. Adventspredigten gehalten in St. Michael zu München 1933, München: Graph. Kunstanst. I934.

Finkelstein, Louis (Hg.): Siphre ad Deuteronomium, H. S. Horovitzii schedis usus cum variis lectionibus et adnotationibus (Corpus Tannaiticum), Berlin: Jüdischer Kulturbund in Deutschland E.V. 1939 / New York: Jewish Theological Seminary of America 1969.

Fishbane, Michael: Biblical Interpretation in Ancient Israel, Oxford: Clarendon 1985.

Inner-Biblical Exegesis, in: Sæbø, Magne u. a. (Hg.): Hebrew Bible/Old Testament. The History of Its Interpretation. I: From the Beginnings to the Middle Ages (Until I300). Teil I: Antiquity, Göttingen: Vandenhoeck \& Ruprecht 1996, 33-48.

Inner-Biblical Exegesis. Types and Strategies of Interpretation in Ancient Israel, in: Ders.: The Garments of Torah. Essays in Biblical Hermeneutics, Bloomington: Indiana University Press 1989, 3-I8.

Flusser, David: Jesus, Reinbek bei Hamburg: Rowohlt-Taschenbuch-Verl. ${ }^{22} 2000$ (1968). Fornet-Ponse, Thomas: Einigung auf Kosten des Judentums? Zur kritischen Funktion des Judentums für die innerchristliche Ökumene am Beispiel der GER, in: Catholica 64 (2010) 309-325.

- Komplementarität und differenzierter Konsens. Perspektiven einer ökumenischen Hermeneutik aus katholischer Sicht, in: Catholica 66 (2012) 254-272.

- Ökumene in drei Dimensionen. Jüdische Anstöße für die innerchristliche Ökumene, Münster: Aschendorff 2011.

Frankemölle, Hubert (Hg.): Juden und Christen im Gespräch über „Dabru emet - Redet Wahrheit“, Paderborn: Bonifatius 2005.

- Biblische Handlungsanweisungen. Beispiele pragmatischer Exegese, Mainz: Matthias Grünewald 1983 .

- Bischöfe treffen Rabbiner - auch in Deutschland. Eine bemerkenswerte Initiative des DKR im christlich-jüdischen Dialog, in: Münz / Sirsch (Hg): 6o Jahre Woche der Brüderlichkeit, $173-202$. 
- Das Evangelium des Neuen Testaments als Evangelium aus den heiligen Schriften der Juden (Forum Christen und Juden Io), Münster: LIT 2013.

- Das jüdische Neue Testament und der christliche Glaube. Grundlagenwissen für den jüdisch-christlichen Dialog, Stuttgart: Kohlhammer 2009.

- Der Glaube an die Wiederkunft Christi als Vollendung des Gottesreiches. Überlegungen zum Grund christlicher Hoffnung, in: Falaturi, Abdoldjavad / Strolz, Walter / Talmon, Shemaryahu (Hg.): Zukunftshoffnung und Heilserwartung in den monotheistischen Religionen (Veröffentlichungen der Stiftung Oratio Dominica 9), Freiburg: Herder 1983, 8I-I2O.

- Der Jude Jesus und die Ursprünge des Christentums, Kevelaer: Topos plus 2003.

- Die heiligen Schriften der Juden und die Christologie, in: Dohmen, Christoph (Hg.): In Gottes Volk eingebunden. Christlich-jüdische Blickpunkte zum Dokument der Päpstlichen Bibelkommission „Das jüdische Volk und seine Heilige Schrift in der christlichen Bibel“, Stuttgart: Kath. Bibelwerk 2003, 37-50.

- Fort-Schritte seit der Offenbarungskonstitution Dei Verbum des Zweiten Vatikanischen Konzils (1965), in: BiKi 60 (2005) I73-177.

- Frühjudentum und Urchristentum. Vorgeschichte - Verlauf - Auswirkungen (4. Jahrhundert v. Chr. bis 4. Jahrhundert n. Chr.) (Kohlhammer Studienbücher Theologie 5), Stuttgart: Kohlhammer 2006.

- Jahwe-Bund und Kirche Christi. Studien zur Form- und Traditionsgeschichte des „Evangeliums“ nach Matthäus (NTA Io), Münster: Aschendorff I974, ${ }^{2}$ I984.

- Jesus Christus/Christologie. A. Bibeltheologisch, in: NHbthG 2 (2005) 254-272.

- Jüdische Wurzeln christlicher Theologie. Studien zum biblischen Kontext neutestamentlicher Texte“ (BBB II6), Bodenheim: Philo-Verl.-Ges. 1998.

- Rez. „Schriftauslegung im Widerstreit“, in: BiKi 45 (I990) 200-204.

- Studien zum jüdischen Kontext neutestamentlicher Theologien (SBA 37), Stuttgart: Kath. Bibelwerk 2005.

- Vater unser - Awinu. Das Gebet der Juden und Christen, Paderborn: Bonifatius 2012.

- Vielfalt von Anfang an. Option für den katholisch-evangelisch-jüdischen Dialog, in: Ders.: Das Evangelium des Neuen Testaments als Evangelium aus den heiligen Schriften der Juden (Forum Christen und Juden Io), Münster: LIT 20I3, 99-I2I.

- Zum jüdisch-christlichen Dialog in Deutschland nach dem Holocaust bis zu Papst Johannes Paul II, in: Ders. (Hg.): Juden und Christen im Gespräch über „Dabru emet - Redet Wahrheit“, Paderborn: Bonifatius 2005, 9-37.

- / Wohlmuth, Josef (Hg.): Das Heil der Anderen. Problemfeld „Judenmission“ (QD 238), Freiburg: Herder 2010.

Franz, Matthias: Der barmherzige und gnädige Gott. Die Gnadenrede vom Sinai (Ex- 
odus 34,6-7) und ihre Parallelen im Alten Testament und seiner Umwelt (BWANT I60), Stuttgart: Kohlhammer 2003.

Frey, Jörg: Neutestamentliche Wissenschaft und Antikes Judentum: Probleme - Wahrnehmungen - Perspektiven, in: ZThK Io9 (20I2) 445-47I.

Friedländer, Saul: Die politischen Veränderungen der Kriegszeit und ihre Auswirkungen auf die Judenfrage, in: Mosse, Werner E. / Paucker, Arnold (Hg.): Deutsches Judentum in Krieg und Revolution 1916-1923 (Schriftenreihe wissenschaftlicher Abhandlungen des Leo Baeck Instituts 25), Tübingen: Mohr (Siebeck) I97I, $37 \mathrm{f}$.

Fruhstorfer, Karl: Der Ruf: Fort mit dem Alten Testament!, in: ThPQ 86 (I933) 280290.

Fumagalli, Pier Francesco: The International Catholic-Jewish Liaison Committee: Historical Note, in: International Catholic-Jewish Liaison Committee (Hg.): Fifteen Years of Catholic-Jewish Dialogue 1970-1985. Selected Papers, Rom: Libreria Editrice Vaticana I988, XV-XIX.

Für ein erneuertes Verhältnis von Christen und Juden. 25 Jahre Gesellschaft für Christlich-Jüdische Zusammenarbeit Paderborn e.V., Paderborn: Gesellschaft für Christlich-Jüdische Zusammenarbeit 2012.

Gassmann, Michael: Sympathien für die Tradition. Das neue Gotteslob, in: Stimmen der Zeit 23I (2013) 78I-784.

Geis, Robert Raphael: Leiden an der Unerlöstheit der Welt. Reden, Aufsätze, Briefe, hg. v. Dietrich Goldschmidt und Ingrid Ueberschär, München: Kaiser 1984.

Gensichen, Hans-Werner: Glaube für die Welt. Theologische Aspekte der Mission, Gütersloh: Mohn i97I.

Gerhards, Albert: Art. Berakha, in: $\mathrm{LThK}^{3} 2$ (1994) $238 \mathrm{f}$.

- Art. Stundengebet. I. Geschichte, in: TRE 32 (2000) 268-276.

- Die Psalmen in der römischen Liturgie. Eine Bestandsaufnahme des Psalmengebrauchs in Stundengebet und Meßfeier, in: Zenger, Erich (Hg.): Der Psalter in Judentum und Christentum (HBS i8), Freiburg: Herder I998, 355-379.

- Ego exaltavi te magna virtute. Die latente Präsenz des Anderen in jüdischer und christlicher Liturgie, in: Frankemölle, Hubert / Wohlmuth, Josef (Hg.): Das Heil der Anderen. Problemfeld Judenmission (QD 238), Freiburg: Herder 20IO, 542-555.

- Theologische und sozio-kulturelle Bedingungen religiöser Konflikte mit dem Judentum. Beispiele aus der katholischen Liturgie und ihrer Wirkungsgeschichte, in: Gerhards, Albert / Wahle, Stephan (Hg.): Kontinuität und Unterbrechung. Gottesdienst und Gebet in Judentum und Christentum (Studien zu Judentum und Christentum) Paderborn: Schöningh 2005, 269-285.

- Tradition versus Schrift? Die Übersetzerinstruktion „Liturgiam authenticam“ und die deutsche Einheitsübersetzung, in: Ders.: Erneuerung kirchlichen Lebens aus dem 
Gottesdienst. Beiträge zur Reform der Liturgie (Praktische Theologie heute I2O), Stuttgart: Kohlhammer 20I2, I20-I26.

- / Henrix, Hans Hermann (Hg.): Dialog oder Monolog? Zur liturgischen Beziehung zwischen Judentum und Christentum (QD 208), Freiburg: Herder 2004.

Gerzabek, Daphne Maria: Das Judentum in der christlichen Bildwelt, in: Dialog DuSiach 89 (Oktober 20I2) II-24.

Gesundheit, Shimon: Das Land Israels als Mitte einer jüdischen Theologie der Tora: Synchrone und diachrone Perspektiven, in: ZAW I23 (20II) 325-335.

Goethe, Johann Wolfgang: Sämtliche Gedichte. Zweiter Teil: Ausgabe letzter Hand (Gedenkausgabe der Werke, Briefe und Gespräche), Zürich 1953.

Goldin, Simcha: The Ways of Jewish Martyrdom, Turnhout: Brepols 2008.

Goldman, Shalom: Zeal for Zion: Christians, Jews, and the Idea of the Promised Land, Chapel Hill: University of North Carolina Press 20 Io.

Goldmann, Manuel: „Die große ökumenische Frage ...“. Zur Strukturverschiedenheit christlicher und jüdischer Tradition und ihrer Relevanz für die Begegnung der Kirche mit Israel (NBST 22), Neukirchen-Vluyn: Neukirchener 1997.

- Umkehr und Erneuerung 2.o. Zur Differenzerfahrung in der christlich-jüdischen Begegnung, in: $\mathrm{KuI} \mathrm{I} \mathrm{(2OI3)} \mathrm{47-5I.}$

Gollwitzer, Helmut: Befreiung zur Solidarität. Einführung in die evangelische Theologie, München: Kaiser 1978.

Groen, Bert: Anti-Judaism in the Present-Day Byzantine Liturgy, in: The Journal of Eastern Christian Studies 60 (2008) 369-387.

Grohmann, Marianne: Aneignung der Schrift. Wege einer christlichen Rezeption jüdischer Hermeneutik, Neukirchen-Vluyn: Neukirchener 2000.

Groß, Walter: Der doppelte Ausgang der Bibel Israels und die doppelte Leseweise des christlichen Alten Testaments, in: Ders. (Hg.): Das Judentum - Eine bleibende Herausforderung christlicher Identität, Mainz: Matthias Grünewald 200I, 9-25.

Gruchy, John W. de: Eberhard Bethge - Freund Dietrich Bonhoeffers. Eine Lebensgeschichte, Gütersloh: Gütersloher Verlagshaus 2007.

Grunden, Gertrud: Fremde Freiheit. Jüdische Stimmen als Herausforderung an den Logos christlicher Theologie (Religion, Geschichte, Gesellschaft 5), Münster: LIT 1996.

Güdemann, Moritz: Jüdische Apologetik (Schriften herausgegeben von der Gesellschaft zur Förderung der Wissenschaft des Judentums. Grundriß der Gesamtwissenschaft des Judentums), Glogau: Flemming 1906.

Gunkel, Hermann: Die Religion der Propheten, in: Preußische Jahrbücher 166 (November I9I6) I88-2I4.

Haacker, Klaus: Die biblischen Landverheißungen und der jüdisch-palästinensische Konflikt, in: ThBeitr 34 (2003) 294-305. 
Haarmann, Michael von: „Dies tut zu meinem Gedenken!“ Gedenken beim Passa- und Abendmahl. Ein Beitrag zur Theologie des Abendmahls im Rahmen des christlich-jüdischen Dialogs, Neukirchen-Vluyn: Neukirchener 2004.

Haarmann, Volker: JHWH-Verehrer der Völker. Die Hinwendung von Nichtisraeliten zum Gott Israels in alttestamentlichen Überlieferungen (AThANT 9I), Zürich: Theolog. Verl. 2008.

Hammann, Konrad: Hermann Gunkel. Eine Biographie, Tübingen: Mohr Siebeck 2014. Härle, Wilfried: Dogmatik, Berlin: de Gruyter 1995.

Häußling, Angelus A.: Gemeinschaft aus Identität der Erfahrung, in: Klöckener, Martin / Kranemann, Benedikt / Merz, Michael B. (Hg.): Christliche Identität aus der Liturgie. Theologische und historische Studien zum Gottesdienst der Kirche (LQF 79) Münster: Aschendorff I997, 334-344.

Hedwig-Jahnow-Forschungsprojekt: Feministische Hermeneutik und Erstes Testament in: Hedwig Jahnow u. a.: Feministische Hermeneutik und Erstes Testament. Analysen und Interpretationen, Stuttgart: Kohlhammer 1994, 9-25.

Heer, Friedrich: Gottes erste Liebe. 2000 Jahre Judentum und Christentum. Genesis des österreichischen Katholiken Adolf Hitler, München: Bechtle 1967.

Heinz, Hanspeter (Hg.): Um Gottes willen miteinander verbunden. Der Gesprächskreis „Juden und Christen“ beim Zentralkomitee der deutschen Katholiken (Forum Christen und Juden I), Münster: LIT 2004.

- / Henrix, Hans Hermann (Hg.): „Was uns trennt, ist die Geschichte“. Ernst Ludwig Ehrlich - Vermittler zwischen Juden und Christen, München: Neue Stadt 2008.

Henrix, Hans Hermann (Hg.): Verantwortung für den Anderen - und die Frage nach Gott. Zum Werk von Emmanuel Levinas (Aachener Beiträge zu Pastoral- und Bildungsfragen I3), Aachen: Einhard-Verl. I984.

- „Die eigentliche Quelle ist das Herz Johannes' XXIII.“ Entstehung und Wirkung der Konzilskonstitution „Nostra Aetate“, in: ThPQ I6I(20I3) 280-29I.

- Der Dialog mit dem Judentum als Aufgabe ökumenischer Theologie. Eine Problemanzeige, in: Una Sancta 3I (1976) I36-I45.

- Die jüdische Messiashoffnung ist nicht vergeblich. Ein theologischer Versuch von Gewicht, in: Dialog DuSiach 5I(2003) I7-30.

- Gott und der Andere bei Emmanuel Levinas, in: ThPh 8I (2006) 48I-502.

- Ökumene aus Juden und Christen. Ein theologischer Versuch (1978), in: Ders.: Gottes Ja zu Israel. Ökumenische Studien christlicher Theologie (SKI 23), Berlin: Inst. Kirche und Judentum 2005, 7-64.

- Ökumenische Theologie und Judentum. Gedanken zur Nichtexistenz, Notwendigkeit und Zukunft eines Dialogs, in: Freiburger Rundbrief XXVIII (1976) $16-27$. 
- / Kraus, Wolfgang (Hg.): Die Kirchen und das Judentum. Dokumente von 1986 bis 2000, Paderborn: Bonifatius 200I.

Herman, Geoffrey: A Prince without a Kingdom. The Exilarch in the Sasanian Era (TSAJ I5O), Tübingen: Mohr Siebeck 2012.

Herweg, Rachel: Kain blick auf, damit es anders anfängt zwischen uns allen! Jüdisch-feministische Auslegung zu Genesis 4,I-I6, in: Schlangenbrut 77 (Mai 2002) 34-37.

Heschel, Abraham J.: The Prophets. An Introduction. I, New York: Harper \& Row I969.

The Prophets. 2, Harper \& Row 1975.

Hezser, Catherine (Hg.): The Oxford Handbook of Jewish Daily Life in Roman Palestine, Oxford: Oxford University Press 2010.

Hilton, Michael: „Wie es sich christelt, so jüdelt es sich“. 2000 Jahre christlicher Einfluss auf das jüdische Leben, Berlin: JVB 2000.

Hirshman, Marc: Origen and the Rabbis on Leviticus, in: Adamantius II (2005) 93-IOO.

- A Rivalry of Genius. Jewish and Christian Biblical Interpretation in Late Antiquity (SUNY Series in Judaica: Hermeneutics, Mysticism, and Religion), Albany: State University of New York Press 1996.

- The Greek Fathers and the Aggada on Ecclesiastes: Formats of Exegesis in Late Antiquity, in: HUCA 59 (1988), I37-165.

Hoff, Gregor Maria: Ekklesiologie (Gegenwärtig Glauben Denken / Systematische Theologie 6), Paderborn: Schöningh 201 .

- Ökumenische Passagen - zwischen Identität und Differenz. Fundamentaltheologische Überlegungen zum Stand des Gesprächs zwischen römisch-katholischer und evangelisch-lutherischer Kirche (SThSt 25), Innsbruck: Tyrolia 2005.

Hoffmann, Klaus: Die große ökumenische Wegweisung. Die Bedeutung der Versöhnungsethik Karl Barths für die ökumenische Bewegung im konziliaren Prozess für Gerechtigkeit, Frieden und Bewahrung der Schöpfung heute, Frankfurt a. M.: Lang 2004 .

Homolka, Walter: Jesu letztes Abendmahl. Abschied vom Judentum und Aufbruch ins Neue?, in: Häring, Hermann (Hg.): Der Jesus des Papstes. Passion, Tod und Auferstehung im Disput, Münster: LIT 20II, 195-199.

- I Zenger, Erich (Hg.): „... damit sie Jesus Christus erkennen“. Die neue Karfreitagsfürbitte für die Juden (Theologie kontrovers), Freiburg: Herder 2008.

Horovitz, H. S. / Rabin, Israel A. (Hg.): Mechilta d'Rabbi Ismael, Jerusalem: Wahrmann ${ }^{2}$ I970.

Horowitz, Elliot: Medieval Jews Facing the Cross (Hebr.), in: Assis, Yom Tov u. a. (Hg.): Facing the Cross. The Persecutions of 1096 in History and Historiography, Jerusalem: Hebrew University Magnes Press ${ }^{2}$ 200I (Hebr.), II8-I40. 
Hossfeld, Frank-Lothar / Zenger, Erich: Psalmen IOI-I50 (HThKAT), Freiburg: Herder 2008.

Hünermann, Peter: Die Dokumente des Zweiten Vatikanischen Konzils. Konstitutionen, Dekrete, Erklärungen. Lateinisch-deutsche Studienausgabe, Freiburg: Herder 2012.

- / Söding, Thomas (Hg.): Methodische Erneuerung der Theologie. Konsequenzen der wiederentdeckten jüdisch-christlichen Gemeinsamkeiten (QD 207), Freiburg: Herder 2003.

Iwand, Hans Joachim: Christologie: Die Umkehrung des Menschen zur Menschlichkeit. Nachgelassene Werke Neue Folge 2, bearbeitet, kommentiert und mit einem Nachwort versehen von Eberhard Lempp und Edgar Thaidigsmann, Gütersloh: Kaiser 1999 .

- Göttinger Predigt-Meditationen 1963/64, Göttingen: Vandenhoeck \& Ruprecht I964.

- Meditation zu Eph 2,19-22, in: Ders.: Predigt-Meditationen, Göttingen: Vandenhoeck \& Ruprecht ${ }^{2} 1964,20-23$.

Jacob, Benno: Das erste Buch der Tora: Genesis, Berlin: Schocken I934.

Janowski, Bernd: Gottes Weisheit in Jerusalem. Sirach 24 und die biblische Schekina-Theologie, in: Lichtenberger, Hermann / Mittmann-Reichert, Ulrike (Hg.): Biblical Figures in Deuterocanonical and Cognate Literature (DCLY 2008) Berlin: de Gruyter 2009, I-29.

Jeremias, Joachim: Die Abendmahlsworte Jesu, Göttingen: Vandenhoeck \& Ruprecht ${ }^{3}$ I960.

Jochmann, Werner: Die Ausbreitung des Antisemitismus, in: Mosse, Werner E. / Paucker, Arnold (Hg.): Deutsches Judentum in Krieg und Revolution 1916-1923 (Schriftenreihe wissenschaftlicher Abhandlungen des Leo Baeck Instituts 25), Tübingen: Mohr (Siebeck) I97I, 409-5IO.

Joest, Wilfried: Dogmatik I: Die Wirklichkeit Gottes, Göttingen: Vandenhoeck \& Ruprecht 1984; 2: Der Weg Gottes mit den Menschen, Göttingen: Vandenhoeck \& Ruprecht 1986.

- / Lüpke, Johannes von: Dogmatik I: Die Wirklichkeit Gottes, Göttingen: Vandenhoeck \& Ruprecht ${ }^{5}$ 2oro und Dogmatik II: Der Weg Gottes mit den Menschen, Göttingen: Vandenhoeck \& Ruprecht ${ }^{5} 2012$.

Joint Declaration of the 2Ist International Catholic-Jewish Liaison Committee Meeting - Paris, 27 February - 2 March 20II, in: The Pontifical Council For Promoting Christian Unity, Information Service N. 136 (20II/I) 22.

Jörg Bremer im Gespräch mit Marie-Theres Wacker. Zeitdiagnose: Heiliges Land. Zum Umgang mit dem Land im heutigen Israel/Palästina, in: JBTh 23 (2008) 275-294. 
Jüngel, Eberhard: Das Evangelium von der Rechtfertigung des Gottlosen als Zentrum des christlichen Glaubens. Eine theologische Studie in ökumenischer Absicht, Tübingen: Mohr Siebeck 1998.

- Gottes Sein ist im Werden. Verantwortliche Rede vom Sein Gottes bei Karl Barth, eine Paraphrase, Tübingen: Mohr ${ }^{2} 1967$.

Juval, Israel: Zwei Völker in deinem Leib. Gegenseitige Wahrnehmung von Juden und Christen in Spätantike und Mittelalter, Göttingen: Vandenhoeck \& Ruprecht 2007.

Kamesar, Adam: The Church Fathers and Rabbinic Midrash, in: Neusner, Jacob / Avery Peck, Alan J. (Hg.): Encyclopedia of Midrash. Biblical Interpretation in Formative Judaism. I. Leiden: Brill 2005, 20-40.

Kasper, Walter Cardinal: Foreword, in: Cunningham Philip A. u. a. (Hg.): Christ Jesus and the Jewish People Today. New Explorations of Theological Interrelationships, Cambridge: Grand Rapids 20II, XVI.

Kasper, Walter Kardinal: Juden und Christen - das eine Volk Gottes, in: IkaZ Communio 39 (2010) 418-427.

- Konfessionelle Identität - Reichtum und Herausforderung, in: Bolzenius, Theodor u. a. (Hg.): Ihr sollt ein Segen sein. Ökumenischer Kirchentag 28. Mai - I. Juni 2003 in Berlin, Dokumentation, Gütersloh: Gütersloher Verlagshaus 2004, 428-442.

- Ökumene im Wandel. Einführung bei der Vollversammlung des Päpstlichen Einheitsrates am 13. November 2006, in: Stimmen der Zeit 132 (2007) 3-18.

Kellermann, Benzion: Der ethische Monotheismus der Propheten und seine soziologische Würdigung, Berlin: Schwetschke I917.

Kessler, Edward / Wenborn, Neil (Hg.): A Dictionary of Jewish-Christian Relations, Cambridge: Cambridge University Press 2005; Lexikon der Begegnung. Judentum - Christentum - Islam. Für den jüdisch-christlichen Teil: Jakob J. Petuchowski und Clemens Thoma. Bearbeitet von Thomas Fornet-Ponse und Peter Klaiber. Für den islamischen Teil: Ludwig Hagemann und Adel Th. Khoury, Freiburg: Herder 2009.

Klappert, Bertold: Adventliche Hoffnung und kosmische Verwandlung. „Die ganze Erde - die Fülle Seiner Herrlichkeit" (Jes 6,3), in: ThLZ 4 (1997) 313-322.

- Bonhoeffer und die Juden, in: Tietz, Christiane (Hg.): Bonhoeffer-Handbuch, Tübingen: Mohr Siebeck, in Vorbereitung.

- Der Gott Israels in seinem Reich und Ort. Plädoyer für eine ortsorientierte Utopie, in: Frettlöh, Magdalene L. / Döhling, Jan-Dirk (Hg.): Die Welt als Ort Gottes Gott als Ort der Welt. Friedrich-Wilhelm Marquardts Theologie der Utopie im Gespräch, Gütersloh: Kaiser 200I, 36-85.

- Die Gottverlassenheit Jesu und der gekreuzigte Gott. Beobachtungen zum Problem einer theologia crucis in der Christologie der Gegenwart, in: Welker, Michael (Hg.): Diskussion über Jürgen Moltmanns Buch „Der gekreuzigte Gott“, München: Kaiser 1979, 57-73. 
- Die Öffnung des Israelbundes für die Völker. Karl Barths Israeltheologie und die Bundestheologie der reformierten Reformation, in: Wengst, Klaus u. a. (Hg.): Ja und Nein. Christliche Theologie im Angesicht Israels. FS für Wolfgang Schrage zum 70. Geburtstag, Neukirchen-Vluyn: Neukirchener 1998, 33I-348.

- Folgen der Israelvergessenheit in Mission und Ökumene vor und nach Auschwitz, in: Lilienthal, Ulrich / Stiehm, Lothar (Hg.): Den Menschen zugewandt leben. FS für Werner Licharz, Osnabrück: Secolo-Verl. 1999, 57-80.

- Gedenken, Ertrag und Auftrag des Rheinischen Synodalbeschlusses von 1980, in: Kreuzer, Siegfried / Ueberschär, Frank (Hg.): Gemeinsame Bibel - Gemeinsame Sendung. 25 Jahre Rheinischer Synodalbeschluss zur Erneuerung des Verhältnisses von Christen und Juden (Veröffentlichungen der Kirchl. Hochschule Wuppertal 9), Neukirchen-Vluyn: Neukirchener 2006, 236-255.

- Israel und die Kirche. Zeugen Gottes vor der Welt und voreinander, in: Käppeli, Silvia $(\mathrm{Hg})$ : Lesarten des jüdisch-christlichen Dialoges. Festschrift zum 70. Geburtstag von Clemens Thoma (Judaica et Christiana 20), Bern: Lang 2002, 97-I07.

- Jesus als König, Priester und Prophet. Eine Wiederholung der Wege und des Berufs Israels. Versuch einer Würdigung der Christologie Friedrich-Wilhelm Marquardts, in: BThZ II (I994) 25-4I.

- Jesus, der messianische Prophet und prophetische Messias. Die Versuche zu einer nicht-antijüdischen Christologie von Heinz Kremers, in: Kremers, Heinz: Vom Judentum lernen - Impulse für eine nichtantijüdische Christologie, hg. v. Klappert, Bertold / Kremers, Thomas, Neukirchen-Vluyn: Neukirchener, in Vorbereitung.

- Mitverantwortung aus messianischer Hoffnung. Paul van Burens Theologie im christlich-jüdischen Kontext, in: Schweitzer, Wolfgang (Hg.): Der Jude Jesus und die Völker der Welt. Ein Gespräch mit Paul M. van Buren (Institut Kirche und Judentum 19), Berlin: Institut Kirche und Judentum 1993, I9I-2I4.

- Tora und Eschatologie. Auf dem Schulweg der Tora. Mosetora - Christustora - noachidische Völkertora und die Neue Welt Gottes. Friedrich-Wilhelm Marquardt zum Gedenken, in: Licharz, Werner / Zademach, Wieland (Hg.): Treue zur Tradition als Aufbruch in die Moderne. Visionäre und mahnende Stimmen aus Judentum und Christentum, Waltrop: Spenner 2005, 188-263.

- Versöhnung und Befreiung. Versuche, Karl Barth kontextuell zu verstehen (NBST I4), Neukirchen-Vluyn: Neukirchener 1994.

- Worauf wir hoffen. Das Kommen Gottes und der Weg Jesu Christi, München: Kaiser 1997 .

Klenicki, Leon / Wigoder, Geoffrey (Hg.): A Dictionary of the Jewish-Christian Dialogue. Expanded Edition, New York: Paulist Press 1995.

Klöckener, Martin / Häußling, Angelus A. / Meßner, Reinhard (Hg.): Gottesdienst der 
Kirche. Handbuch der Liturgiewissenschaft. Theologie des Gottesdienstes 2/2, Regensburg: Pustet 2008.

Koch, Kurt Kardinal: Ökumene auf dem Weg. Situationsvergewisserung der ökumenischen Bewegung heute, in: Catholica 65 (20II) I-26.

- Was bedeutet die Hinwendung der Kirchen zu ihren jüdischen Quellen für die christliche Ökumene heute?, in: IkaZ Communio 23 (2000) I60-I74.

Koerrenz, Ralf / Wacker, Marie-Theres (Hg.): Heiliges Land (JBTh 23), Neukirchen-Vluyn: Neukirchener 2008.

Kollbrunner, Fritz: Art. „Vaticanum II“, in: Müller, Karl W. / Sundermeier, Theo (Hg.): Lexikon missionstheologischer Grundbegriffe, Berlin: Reimer 1987, 520-525.

Kongregation für den Gottesdienst und die Sakramentenordnung (Hg.): Liturgiam authenticam. Der Gebrauch der Volkssprachen bei der Herausgabe der Bücher der römischen Liturgie, Fünfte Instruktion zur ordnungsgemäßen Ausführung der Konstitution des Zweiten Vatikanischen Konzils über die heilige Liturgie, Rom 200I.

Konrad-Adenauer-Stiftung (Hg.): Zeit zur Neu-Verpflichtung. Christlich-Jüdischer Dialog 70 Jahre nach Kriegsbeginn und Shoah, St. Augustin: Konrad-Adenauer-Stiftung 2009.

Kopf, Lothar: Art. „Weil, Gotthold“, in: Encyclopaedia Judaica, Bd. 20 (²007) 7II.

Körtner, Ulrich H. J.: Wohin steuert die Ökumene? Vom Konsens- zum Dissensmodell, Göttingen: Vandenhoeck \& Ruprecht 2005.

Koslowski, Jutta: Die Einheit der Kirche in der ökumenischen Diskussion. Zielvorstellungen kirchlicher Einheit im katholisch-evangelischen Dialog (Studien zur systematischen Theologie und Ethik 52), Münster: LIT 2008.

Kranemann, Daniela: „Unsere Väter, die Söhne Israels ....”. Zeitgenossenschaft von Israel und Kirche in der christlichen Liturgie - Chancen und Desiderate, in: HID 58 (2004) 45-58.

- Teilhabe an der Würde Israels. Anmerkungen zur Israeltheologie in den Gebetstexten des Messbuches, in: Gerhards, Albert / Henrix, Hans Hermann (Hg.): Dialog oder Monolog? Zur liturgischen Beziehung zwischen Judentum und Christentum (QD 208) Freiburg: Herder 2004, 284-305, 298-302.

Kratz, Reinhard Gregor: Das Judentum im Zeitalter des Zweiten Tempels. Kleine Schriften I (FAT 42), Tübingen: Mohr Siebeck ${ }^{2} 2013$.

Kraus, Hans-Joachim: Rückkehr zu Israel. Beiträge zum christlich-jüdischen Dialog, Neukirchen-Vluyn: Neukirchener I99I.

- Systematische Theologie im Kontext biblischer Geschichte und Eschatologie, Neukirchen-Vluyn: Neukirchener 1983.

- Systematische Theologie im Kontext biblischer Geschichte und Eschatologie, Neukirchen-Vluyn: Neukirchener 1983.

Kreck, Walter: Grundfragen christlicher Ethik, München: Kaiser 1975. 
- Grundfragen der Dogmatik, München: Kaiser 1970.

- Grundfragen der Ekklesiologie, München: Kaiser I98I.

Kremers, Heinz: Liebe und Gerechtigkeit. Gesammelte Beiträge, Neukirchen-Vluyn: Neukirchener 1990.

- Vom Judentum lernen - Impulse für eine nichtantijüdische Christologie, hg. v. Klappert, Bertold / Kremers, Thomas, Neukirchen-Vluyn: Neukirchener, in Vorbereitung.

Kriener, Tobias: „Glauben an Jesus“ - ein Verstoß gegen das zweite Gebot? Die johanneische Christologie und der jüdische Vorwurf des Götzendienstes, Neukirchen-Vluyn: Neukirchener 200 .

Kugel, James L.: How to Read the Bible. A Guide to Scripture, Then and Now, New York: Free Press 2008.

Kuschel, Karl-Josef: Festmahl am Himmelstisch. Wie Mahl feiern Juden, Christen und Muslime verbindet, Ostfildern: Patmos 20I3.

- Juden, Christen, Muslime. Herkunft und Zukunft, Düsseldorf: Patmos 2007.

- Leben ist Brückenschlagen. Vordenker des interreligiösen Dialogs, Düsseldorf: Patmos $201 \mathrm{I}$.

- Theodor Heuss, die Schoah, das Judentum, Israel. Ein Versuch, Tübingen: Klöpfer \& Meyer 20I4.

Labendz, Jenny R.: Socratic Torah. Non-Jews in Rabbinic Intellectual Culture, Oxford: Oxford University Press 20I3.

Lang, Bernhard: Die Bibel. Eine kritische Einführung, Paderborn: Schöningh ${ }^{2}$ I994. Lange, Armin: Handbuch der Textfunde vom Toten Meer. I. Die Handschriften biblischer Bücher von Qumran und den anderen Fundorten, Tübingen: Mohr Siebeck 2009.

- / Dávid, Nóra (Hg.): Qumran and the Bible. Studying the Jewish and Christian Scriptures in Light of the Dead Sea Scrolls (Contributions to Biblical Exegesis \& Theology 57), Leuven: Peeters 2010.

Lange, Nicholas R. M. de: Origen and the Jews. Studies in Jewish-Christian Relations in Third-Century Palestine, Cambridge: Cambridge University Press, 1976.

Langer, Gerhard (Hg.): Esau - Bruder und Feind, Göttingen: Vandenhoeck \& Ruprecht 2009.

- / Hoff, Gregor Maria (Hg.): Der Ort des Jüdischen in der katholischen Theologie, Göttingen: Vandenhoeck \& Ruprecht 2009.

Lapide, Pinchas: Juden und Christen. Verleitung zum Dialog, Zürich: Benziger 1976.

Lavater, Johann Caspar: Ausgewählte Werke in historisch-kritischer Ausgabe. VI/I, hg. v. Christina Reuter, Zürich: Verl. Neue Zürcher Zeitung 2013.

Le Déaut, Roger: La Nuit Pascale. Essai sur la signification de la Pâque juive à partir du Targum d'Exode XII, Rom: Inst. Bibl. Pont. I963. 
- Liturgie Juive et Nouveau Testament. Le témoignage des versions araméennes, Rom: Inst. Bibl. Pont. 1965.

Lengsfeld, Peter / Stobbe, Heinz-Günther: Studium Ökumenische Theologie im theologischen Studium, in: Lengsfeld, Peter (Hg.): Ökumenische Theologie. Ein Arbeitsbuch, Stuttgart: Kohlhammer 1980, 379-388.

Lenzen, Verena: Der jüdisch-christliche Dialog heute, in: ZMR 97 (2013) 203-2IO.

Leonhard, Clemens: The Jewish Pesach and the Origins of the Christian Easter. Open Questions in Current Research, Berlin: de Gruyter 2006.

- I Gerhards, Albert (Hg.): Jewish and Christian Liturgy and Worship. New Insights into its History and Interaction, Leiden: Brill 2007.

Lieu, Judith: Image and Reality: The Jews in the World of the Christians in the Second Century, Edinburg: T \& T Clark 1996.

Link, Christian: Die Spur des Namens. Wege zur Erkenntnis Gottes und zur Erfahrung der Schöpfung, Neukirchen-Vluyn: Neukirchener 1997.

Lohfink, Norbert: Der niemals gekündigte Bund. Exegetische Gedanken zum christlich-jüdischen Dialog, Freiburg: Herder 1989.

Lutherischer Weltbund / Päpstlicher Rat zur Förderung der Einheit der Christen (Hg.): Io Jahre Gemeinsame Erklärung zur Rechtfertigungslehre; Io Years Joint Declaration on the Doctrine of Justification - Dokumentation der Jubiläumsfeier in Augsburg 2009 / Documentation of the Jubilee Year Celebration in Augsburg 2009, Paderborn: Bonifatius 20II.

Maaßen, Thorsten: Das Ökumeneverständnis Joseph Ratzingers, Göttingen: V\&R unipress $201 \mathrm{II}$.

Maier, Johann: Jesus von Nazareth in der talmudischen Überlieferung (EdF 82), Darmstadt: Wissenschaftliche Buchgesellschaft ${ }^{2} \mathrm{I} 992$.

- Jüdische Auseinandersetzung mit dem Christentum in der Antike (EdF I77), Darmstadt: Wissenschaftliche Buchgesellschaft 1982.

- / Schreiner, Josef (Hg.): Literatur und Religion des Frühjudentums. Eine Einführung, Würzburg: Echter 1973.

Marböck, Johann: Weisheit im Wandel. Untersuchungen zur Weisheitstheologie bei Ben Sira. Mit Nachwort und Bibliographie zur Neuauflage (BZAW 272), Berlin: de Gruyter 1999; Erstveröffentlichung in: BBB 37, Bonn: Peter Hanstein 197I.

- Die römisch-katholische Kirche und das Judentum. Perspektiven eines Neubeginns, in: Kogler, Franz / Fischer, Irmtraud / Hubmann, Franz (Hg.): Johannes Marböck: Faszination Bibel (Theologie im kulturellen Dialog 27), Innsbruck: Tyrolia 20I4, 239-258.

Marcus, Ivan G.: Rituals of Childhood. Jewish Acculturation in Medieval Europe, New Haven: Yale University Press 1996. 
- Marquardt, Friedrich-Wilhelm: Die Bedeutung der biblischen Landverheißungen für die Christen, München: Kaiser I964.

- Das christliche Bekenntnis zu Jesus, dem Juden. Eine Christologie, Bd. I-2, München: Kaiser 1990/ı99I.

- Die Gegenwart des Auferstandenen bei seinem Volk Israel. Ein dogmatisches Experiment (Abhandlungen zum christlich-jüdischen Dialog 15), München: Kaiser 1983.

- Eia, wärn wir da. Eine theologische Utopie, Gütersloh: Kaiser 1997.

- Von Elend und Heimsuchung der Theologie. Prolegomena zur Dogmatik, München: Kaiser 1988.

- Was dürfen wir hoffen, wenn wir hoffen dürften? Eine Eschatologie, Bd. I-3, Gütersloh: Kaiser 1993/1994/1996.

Mayer Wise, Isaac: Pronaos to Holy Writ. Establishing on Documentary Evidence, the Authorship, Date, Form, and Contents of Each of Its Books, and the Authenticity of the Pentateuch, Cincinnati: R. Clark I89i.

Mendelssohn, Moses: Gesammelte Schriften. Jubiläumsausgabe ı2,2, Berlin: Akad.-Verl. 1976.

Menke, Karl-Heinz: Rechtfertigung: Gottes Handeln an uns ohne uns? Jüdisch perspektivierte Anfragen an einen binnenchristlichen Konsens, in: Catholica 63 (2009) 58-72.

Meßner, Herbert: Eine Schule des Betens. Zum Gebetsteil im künftigen „Gotteslob”, in: Gottesdienst 6 (2013) 49-5I.

Meyer, Harding u. a. (Hg.): Dokumente wachsender Übereinstimmung. Sämtliche Berichte und Konsenstexte interkonfessioneller Gespräche auf Weltebene. 3. 1990-200I, Paderborn: Bonifatius 2003.

Miletto, Gianfranco (Hg.): Die Heldenschilde / Abraham ben David Portaleone (JudUm 74), Frankfurt: Lang 2002.

- Glauben und Wissen im Zeitalter der Reformation. Der salomonische Tempel bei Abraham ben David Portaleone (I542-I6I2) (SJ 27), Berlin: de Gruyter 2004.

Missale Romanum ex decreto sacrosancti Oecumenici Concilii Vaticani II, Editio typica tertia, Città del Vaticano: Libreria editrice vaticana ${ }^{3} 2002$.

Missam in Vigilia Pentecostes, in: Notitiae 24 (1988) I56-I59.

Mohagheghi, Hamideh: Die Barmer Theologische Erklärung aus islamischer Sicht, in: Siedler, Dirk Chr. / Fallois, Annette de / Klußmann, Jürgen (Hg.): (K)eine Chance für den Dialog. Christen und Muslime in der pluralen Gesellschaft. Beiträge zu kontroversen Themen, Berlin: Alektor-Verl. 2007, 89-100.

Moltmann, Jürgen: Das Kommen Gottes. Christliche Eschatologie, München: Kaiser 1995 .

- Der gekreuzigte Gott. Das Kreuz Christi als Grund und Kritik christlicher Theologie, München: Kaiser 1972. 
- Der Weg Jesu Christi. Christologie in messianischen (und apokalyptischen) Dimensionen, München: Kaiser 1989.

- Theologie der Hoffnung. Untersuchungen zur Begründung und zu den Konsequenzen einer christlichen Eschatologie (BEvTh 38), München: Kaiser 1964.

Mosse, Werner E. (Hg.): Juden im Wilhelminischen Deutschland I890-19I4. Ein Sammelband (Schriftenreihe wissenschaftlicher Abhandlungen des Leo Baeck Instituts 33), Tübingen: Mohr Siebeck ${ }^{2}$ I998.

Motte, Jochen: Biblische Theologie nach Walther Zimmerli. Darstellung und Würdigung der alttestamentlichen Theologie Walther Zimmerlis und der sich aus ihr ergebenden Perspektive zum Neuen Testament in systematisch-theologischer Sicht, Frankfurt a. M.: Lang 1995 .

Müller, Karl / Sundermeier, Theo (Hg.): Lexikon missionstheologischer Grundbegriffe, Berlin: Reimer 1987.

Müller, Karlheinz: Rückbesinnung auf die Zukunft. Von der Notwendigkeit einer jüdisch-christlichen Ökumene, in: Schreiner, Josef / Wittstadt, Klaus (Hg.): Communio Sanctorum. Einheit der Christen - Einheit der Kirche. FS Bischof Paul-Werner Scheele, Würzburg: Echter 1988, 23I-245.

Munayer, Salim J. / Loden, Lisa (Hg.): The Land Cries Out. Theology of the Land in the Israeli-Palestinian Context, Eugene, OR: Cascade Books 2012.

Münz, Christoph / Sirsch, Rudolf W. (Hg.): „... damit es anders anfängt zwischen uns allen." 6o Jahre Woche der Brüderlichkeit, Münster: LIT 2012.

- „Denk an die Tage der Vergangenheit - Lerne aus der Geschichte“. 40 Jahre Buber-Rosenzweig-Medaille (Forum Christen und Juden 7), Münster: LIT 2009.

- „Wenn nicht ich, wer? Wenn nicht jetzt, wann?“ Zur gesellschaftspolitischen Bedeutung des Deutschen Koordinierungsrates der Gesellschaften für Christlich-Jüdische Zusammenarbeit (DKR), Münster: LIT 2004.

Mußner, Franz: Der Jude Jesus, in: Freiburger Rundbrief N. F. 2I / I (20I4) 55-59.

- Die Kraft der Wurzel. Judentum - Jesus - Kirche, Freiburg: Herder ${ }^{2}$ I989.

- Dieses Geschlecht wird nicht vergehen. Judentum und Kirche, Freiburg: Herder I99I.

- Traktat über die Juden, München: Kösel 1979, überarbeitete Neuauflage Göttingen: Vandenhoeck \& Ruprecht 2009.

- Was haben die Juden mit der christlichen Ökumene zu tun?, in: Una Santa 50 (I995) 33I-339.

Nachsynodales Apostolisches Schreiben „Verbum Domini“ von Papst Benedikt XVI. über das Wort im Leben und in der Sendung der Kirche (Verlautbarungen des Apostolischen Stuhls 187), Bonn: Sekretariat der Dt. Bischofskonferenz 20 oro. 
Najman, Hindy: The Vitality of Scripture Within and Beyond the "Canon", in: JSJ 43 (2OI2) 497-5I8.

Neuner, Peter / Kleinschwärzer-Meister, Birgitta: Kleines Handbuch der Ökumene, Düsseldorf: Patmos 2002.

- Ökumenische Theologie. Die Suche nach der Einheit der christlichen Kirchen, Darmstadt: Wissenschaftliche Buchgesellschaft 1997.

Neusner, Jacob: Ein Rabbi spricht mit Jesus. Ein jüdisch-christlicher Dialog, Freiburg: Herder 20II.

- Eliezer ben Hyrcanus. The Tradition and the Man, Leiden: Brill 1973.

- Rabbi Jesus im Spannungsfeld von Theologie und Geschichtswissenschaft, in: Tück, Jan-Heiner (Hg.): Passion aus Liebe. Das Jesus-Buch des Papstes in der Diskussion, Ostfildern: Matthias Grünewald 20II, IIO-I25.

Noth, Martin: Die Gesetze im Pentateuch. Ihre Voraussetzungen und ihr Sinn, Halle: Niemeyer 1940; wiederabgedruckt in: Ders.: Gesammelte Studien zum AT (TB 6), München: Kaiser 1960, 9-I4I.

- Geschichte Israels, Göttingen: Vandenhoeck \& Ruprecht ${ }^{6}$ I966.

- Überlieferungsgeschichtliche Studien. Die sammelnden und bearbeitenden Geschichtswerke im Alten Testament, Halle: Niemeyer 1943, Tübingen: Niemeyer ${ }^{3} 1967$.

Novak, David: Land and People, in: Walzer, Michael (Hg.): Law, Politics, and Morality in Judaism, Princeton, NJ: Princeton University Press 2006, 57-82.

Novikoff, Alex J.: The Medieval Culture of Disputation. Pedagogy, Practice, and Performance (The Middle Ages Series), Philadelphia: Univ. of Pennsylvania Press 2013.

Nüssel, Friederike / Sattler, Dorothea: Einführung in die ökumenische Theologie, Darmstadt: Wissenschaftliche Buchgesellschaft 2008.

Ochs, Christoph: Matthaeus Adversus Christianos. The Use of the Gospel of Matthew in Jewish Polemics Against the Divinity of Jesus (WUNT 2/350), Tübingen: Mohr Siebeck 20I3.

Oesch, Josef M.: Die gemeinsame Bibel von Juden und Christen. Der steinige Ausstieg aus dem katholischen Antijudaismus, in: Guggenberger, Wilhelm / Steinmair-Pösel, Petra (Hg.): Religionen - Miteinander oder Gegeneinander? Vorträge der sechsten Innsbrucker Theologischen Sommertage, Frankfurt a. M.: Peter Lang 2006, 45-60.

Osten-Sacken, Peter von der: Der Gott der Hoffnung. Gesammelte Aufsätze zur Theologie des Paulus (SKI.NF 3), Leipzig: Evangel. Verlagsanstalt 2014.

Pannenberg, Wolfhart: Systematische Theologie. 3, Göttingen: Vandenhoeck \& Ruprecht 1993.

Papst Franziskus: Die Freude des Evangeliums. Das Apostolische Schreiben „Evangelii gaudium “ über die Verkündigung des Evangeliums in der Welt von heute, Freiburg: Herder 20I3. 
Petri, Heinrich: Die römisch-katholische Kirche und die Ökumene, in: Urban, Hans Jörg / Wagner, Harald (Hg.): Handbuch der Ökumenik. 2, Paderborn: Bonifatius I986, 95-I68.

Petuchowski, Jakob J.: Wie unsere Meister die Schrift erklären. Beispielhafte Bibelauslegung aus dem Judentum, Freiburg: Herder 1982.

- I Thoma, Clemens: Lexikon der jüdisch-christlichen Begegnung, Freiburg: Herder I989.

Plaskow, Judith: Und wieder stehen wir am Sinai. Eine jüdisch-feministische Theologie, Luzern: Exodus 1992.

Praßl, Franz K.: Gotteslob ante portas. Was das neue Gebet- und Gesangbuch bringt, in: HerKorr Spezial I (2013) 20-25.

- Political correctness in der Liturgie? Vom Umgang mit schwierigen Perikopen und Gesängen, in: HID 58 (2004) 59-75.

Rabkin, Yakov M.: A Threat from Within. A Century of Jewish Opposition to Zionism, Winnipeg: Zed Books 2006.

Rad, Gerhard von: Das erste Buch Mose. Genesis Kap. I-I2 (ATD 2/2) Göttingen: Vandenhoeck \& Ruprecht ${ }^{9}$ I972.

- Theologie des Alten Testaments. 2. Die Theologie der prophetischen Überlieferungen Israels (Einführung in die evangelische Theologie I,2), München: Kaiser ${ }^{4}$ I965.

Radkau, Joachim: Theodor Heuss, München: Hansen 2014.

Ragacs, Ursula: Die zweite Talmuddisputation von Paris I269 (JudUm 7I), Frankfurt: Lang 200I.

Raheb, Mitri: Faith in the Face of Empire. The Bible through Palestinian Eyes, Maryknoll/NY: Orbis Books 2014.

Ratzinger, Joseph Kardinal: Die Vielfalt der Religionen und der Eine Bund (Urfelder Reihe I), Hagen: Verlag Urfeld 1998.

- Der christliche Glaube und die Weltreligionen, in: Metz, Johannes Baptist u. a. (Hg.): Gott in Welt. 2. Zur Theologie von Christus und Kirche, Freiburg: Herder 1964, 287-305.

- Prognosen für die Zukunft des Ökumenismus, in: PRO ORIENTE (Hg.): Ökumene - Konzil - Unfehlbarkeit, Innsbruck: Tyrolia 1979, 208-215.

- Schriftauslegung im Widerstreit. Zur Frage nach Grundlagen und Weg der Exegese heute, in: Ders.: (Hg.): Schriftauslegung im Widerstreit (QD II7), Freiburg: Herder I989, I5-44.

Ratzinger, Joseph/Papst Benedikt XVI: Jesus von Nazareth. Erster Teil: Von der Taufe im Jordan bis zur Verklärung, Freiburg: Herder 2007.

- Jesus von Nazareth. Zweiter Teil: Vom Einzug in Jerusalem bis zur Auferstehung, Freiburg: Herder 20II. 
Rendtorff, Rolf: Das „Ende“ der Geschichte Israels, in: Ders.: Gesammelte Studien zum Alten Testament (TB 57), München: Kaiser 1975, 267-276.

- Kontinuität im Widerspruch. Autobiographische Reflexionen, Göttingen: Vandenhoeck \& Ruprecht 2007.

- / Henrix, Hans Hermann (Hg.): Die Kirchen und das Judentum. I. Dokumente von I945-1985, Paderborn: Bonifatius ${ }^{2}$ I989.

- Die Kirchen und das Judentum. Dokumente von 1945 bis 1985, Paderborn: Bonifatius 1988.

Renz, Andreas: Die katholische Kirche und der interreligiöse Dialog. 50 Jahre „Nostra Aetate“ - Vorgeschichte, Kommentar, Rezeption, Stuttgart: Kohlhammer 2014.

Reventlow, Henning Graf: Epochen der Bibelauslegung. I: Vom Alten Testament bis Origenes, München: C. H. Beck 1990.

Rijk, Cornelius A.: Das gemeinsame Band. Die Bedeutung der jüdisch-christlichen Beziehungen für die Einheit der Christen, in: BiKi 29 (1974) 42-44.

Ritschl, Dietrich: Zur Logik der Theologie. Kurze Darstellung der Zusammenhänge theologischer Grundgedanken, München: Kaiser 1984.

- / Hailer, Martin: Diesseits und jenseits der Worte. Grundkurs christliche Theologie, Neukirchen-Vluyn: Neukirchener 2006.

- / Ustorf, Werner: Ökumenische Theologie - Missionswissenschaft, Stuttgart: Kohlhammer 1994.

Rokéah, David: Justin Martyr and the Jews (JCP 5), Leiden: Brill 2002.

Roloff, Jürgen: Der erste Brief an Timotheus (EKK XV), Zürich: Benziger 1988.

Rouwhorst, Gerard: Christlicher Gottesdienst und der Gottesdienst Israels. Forschungsgeschichte, historische Interaktionen, Theologie, in: Klöckener, Martin / Häußling, Angelus A. / Meßner, Reinhard (Hg.): Gottesdienst der Kirche. Handbuch der Liturgiewissenschaft 2/2, Regensburg: Pustet 2008, 49I-572.

Sanders, Ed P.: Paulus und das palästinische Judentum. Ein Vergleich zweier Religionsstrukturen, Göttingen: Vandenhoeck \& Ruprecht 1985; amerikanisches Original: Paul and Palestinian Judaism. A Comparison of Patterns of Religion, London: SCM Press 1977.

Sattler, Dorothea: Kirche(n) (Grundwissen Theologie), Paderborn: Schöningh 2013.

Schäfer, Peter: Die Geburt des Christentums aus dem Geist des Judentums. Fünf Vorlesungen zur Entstehung des rabbinischen Judentums (Tria Corda: Jenaer Vorlesungen zu Judentum, Antike und Christentum 6), Tübingen: Mohr Siebeck 20 Io.

- Jesus im Talmud, Tübingen: Mohr Siebeck ${ }^{2} 20$ o.

- The Jewish Jesus. How Judaism and Christianity Shaped Each Other, Princeton: Princeton University Press 2012.

Schedl, Claus: Die Sehnsucht der ewigen Hügel. Christus im Alten Testament, Graz: Anton Pustet 1947. 
- Geschichte des Alten Testaments. I-5, Innsbruck: Tyrolia 1952-I964.

- Sieben Thesen wider des Alten Testaments Verächter, Wien: Herder 1947.

- Talmud. Evangelium. Synagoge, Innsbruck: Tyrolia 1969.

Schlier, Heinrich: Der Römerbrief (HThK NT 6), Freiburg: Herder 1977.

Schmidt, Johann Michael: 2010 - Ein Jahr mehrerer runder Gedenkdaten, in: Brocke, Edna / Seim, Jürgen (Hg.): Helmut Starck: Festgabe zum 8o. Geburtstag, Düsseldorf: Evang. Kirche im Rheinland 20I0, 37-39.

Schmidt, Stjepan: Augustin Bea. Der Kardinal der Einheit, Graz: Styria 1989.

Schoeps, Hans Joachim: Jüdisch-christliches Religionsgespräch in neunzehn Jahrhunderten. Mit einem Nachwort von Edna Brocke, Königstein: Jüd. Verl. Athenäum 1984 [Nachdruck der 3. Aufl. München: Ner-Tamid-Verl. 196I; Erstauflage Berlin: Vortrupp-Verl. 1937].

Scholem, Gershom: Judaica 6: Die Wissenschaft vom Judentum, Frankfurt a. M.: Suhrkamp I997.

- Von Berlin nach Jerusalem. Erweiterte Fassung, Frankfurt a. M.: Jüdischer Verlag im Suhrkamp Verlag 1982.

Schoon, Simon: De weg van Jezus. Een christologische heroriëntatie vanuit de joods-christelijke ontmoeting, Kampen: Kok I99I.

Schoon, Simon: Nes Ammim Tagung 1986, in: Kremers, Heinz: Vom Judentum lernen - Impulse für eine nichtantijüdische Christologie, hg. v. Klappert, Bertold / Kremers, Thomas, Neukirchen-Vluyn: Neukirchener, in Vorbereitung.

Schöttler, Heinz-Günther: Röm II,25-27 und die Wahrheitsfrage im christlich-jüdischen Dialog, in: Bruckmann, Florian / Dausner, René (Hg.): Im Angesicht der Anderen. Gespräche zwischen christlicher Theologie und jüdischem Denken. Festschrift für Josef Wohlmuth zum 75. Geburtstag (Studien zu Judentum und Christentum 25), Paderborn: Schöningh 20I3, I4I-I66.

Schottroff, Luise / Wacker, Marie-Theres (Hg.): Kompendium feministische Bibelauslegung, Gütersloh: Gütersloher Verlagshaus 1998; ${ }^{2}$ I999; ${ }^{3} 2007$; amerikanische Übersetzung: Feminist Biblical Interpretation. A Compendium, Grand Rapids/MI: Eerdmans 20I2.

- Von der Wurzel getragen. Christliche feministische Exegese in Auseinandersetzung mit Antijudaismus (Biblical Interpretation Series I7), Leiden: Brill 1996.

Schreckenberg, Heinz: Die christlichen Adversus-Judaeos-Texte und ihr literarisches und historisches Umfeld (I.-II. Jh.) (EHS.T 172), Frankfurt: Lang ${ }^{3}$ I995.

- Die christlichen Adversus-Judaeos-Texte und ihr literarisches und historisches Umfeld (II.-I3. Jh.) mit einer Ikonographie des Judenthemas bis zum 4. Laterankonzil (EHS.T 335), Frankfurt: Lang ${ }^{3} 1997$.

- Die christlichen Adversus-Judaeos-Texte und ihr literarisches und historisches Umfeld (13.-20. Jh.) (EHS.T 497), Frankfurt: Lang 1994. 
Schremer, Adiel: Brothers Estranged. Heresy, Christianity, and Jewish Identity in Late Antiquity, Oxford: Oxford University Press 2010.

Schuller, Eileen: The Dead Sea Scrolls and Jewish-Christian Dialogue, in: Walters, Patricia (Hg.): From Judaism to Christianity. Tradition and Transition. A Festschrift for Thomas H. Tobin, S.J., on the Occasion of His Sixty-Fifth Birthday (NT Supplements 136), Leiden: Brill 20I0, 43-58.

Schumann, Olaf: Der Christus der Muslime. Christologische Aspekte in der arabisch-islamischen Literatur, Gütersloh: Gütersloher Verlagshaus Mohn 1975.

Schwartz, Daniel / Weiss, Zeev (Hg.): Was 7o CE a Watershed in Jewish History? On Jews and Judaism before and after the Destruction of the Second Temple (Ancient Judaism and Early Christianity 78), Leiden: Brill 2012.

Schwienhorst-Schönberger, Ludger: Zwei antagonistische Modelle der Schriftauslegung in Dei Verbum? in: Tück, Jan-Heiner (Hg.): Erinnerung an die Zukunft: Das Zweite Vatikanische Konzil, Freiburg: Herder 20I2, 449-46I.

Schwier, Helmut (Hg.): Kirche und Israel. Ein Beitrag der reformatorischen Kirchen Europas zum Verhältnis von Christen und Juden (Leuenberger Texte 6), Frankfurt a. M.: Lembeck $200 I$.

Secunda, Shai: The Iranian Talmud. Reading the Bavli in Its Sasanian Context (Divinations: Rereading Late Ancient Religion), Philadelphia: University of Pennsylvania Press 20I4.

Segal, Alan F.: Paul the Convert. The Apostolate and Apostasy of Saul the Pharisee, New Haven: Yale University Press I990.

Seim, Jürgen: Hans Joachim Iwand. Eine Biographie, Gütersloh: Kaiser 1999.

Shavit, Yaacov / Eran, Mordechai: The Hebrew Bible Reborn: From Holy Scripture to the Book of Books. A History of Biblical Culture and the Battles over the Bible in Modern Judaism (Studia Judaica 38), Berlin: de Gruyter 2007.

Siebenrock, Roman: Theologischer Kommentar zur Erklärung über die Haltung der Kirche zu den nichtchristlichen Religionen: Nostra Aetate, in: Hünermann, Peter / Hilberath, Bernd Jochen (Hg.): Herders Theologischer Kommentar zum Zweiten Vatikanischen Konzil. 3, Freiburg: Herder 2005, 59I-693.

- / Tück, Jan-Heiner (Hg.): Selig, die Frieden stiften. Assisi - Zeichen gegen Gewalt (Theologie kontrovers), Freiburg: Herder 2012.

Siegele-Wenschkewitz, Leonore (Hg.): Verdrängte Vergangenheit, die uns bedrängt. Feministische Theologie in der Verantwortung für die Geschichte (Kaiser Taschenbücher 29), München: Kaiser I988.

Signer, Michael A.: Auf der Suche nach der Schrift. Juden, Christen und das Buch, in: Ders.: Brücken bauen. Aufsätze und Vorträge zum jüdisch-christlichen Verhältnis, hg. von Rainer Kampling / Hans Hermann Henrix / Peter von der Osten-Sacken (SKI 29), Berlin: Institut Kirche und Judentum 2013, I3-27. 
- Die Erneuerung der Erzählung. Jüdische und christliche Exegese im I2. Jahrhundert, 29-45; Polemik und Exegese. Spielarten der Hebraistik im I2. Jahrhundert, in: Ders.: Brücken bauen. Aufsätze und Vorträge zum jüdisch-christlichen Verhältnis, hg. von Rainer Kampling / Hans Hermann Henrix / Peter von der Osten-Sacken (SKI 29), Berlin: Institut Kirche und Judentum 2013, 47-59;

- Die gemeinsame Bibel lesen? Juden und Christen 25 Jahre nach der Erklärung der Rheinischen Synode von I980. Auf dem Weg zu einem neuen Verhältnis zwischen Juden und Christen, in: Ders.: Brücken bauen. Aufsätze und Vorträge zum jüdisch-christlichen Verhältnis, hg. von Rainer Kampling / Hans Hermann Henrix / Peter von der Osten-Sacken (SKI 29), Berlin: Institut Kirche und Judentum 20I3, 397-407.

- Rabbi und Magister. Überschneidungen zwischen Denkmodellen in der „Renaissance des I2. Jahrhunderts“, in: Ders.: Brücken bauen. Aufsätze und Vorträge zum jüdisch-christlichen Verhältnis, hg. von Rainer Kampling / Hans Hermann Henrix / Peter von der Osten-Sacken (SKI 29), Berlin: Institut Kirche und Judentum 20I3, 6I-85;

- Tröstung und Streit. Jüdische und christliche Auslegungen der Prophetenbücher, in: Ders.: Brücken bauen. Aufsätze und Vorträge zum jüdisch-christlichen Verhältnis, hg. von Rainer Kampling / Hans Hermann Henrix / Peter von der Osten-Sacken (SKI 29), Berlin: Institut Kirche und Judentum 20I3, I27-I44.

Sihombing, Fridz P.: Versöhnung, Wahrheit und Gerechtigkeit. Die ökumenische Bedeutung der Barmer Theologischen Erklärung für den Weg der Kirchen in Indonesien, Neukirchen-Vluyn: Neukirchener 2007.

Siquans, Agnethe: Die alttestamentlichen Prophetinnen in der patristischen Rezeption. Texte - Kontext - Hermeneutik (HBS 65), Freiburg i. B.: Herder 2011.

Sirsch, Rudolf (Hg.): Bilanz und Perspektiven des christlich-jüdischen Dialogs (epd-Dokumentation 9/Io), Frankfurt a. M.: Gemeinschaftswerk der evangelischen Publizistik 2005 .

Sivertsev, Alexei M.: Judaism and Imperial Ideology in Late Antiquity, Cambridge: Cambridge University Press 2011.

Söding, Thomas: Einheit der Heiligen Schrift? Zur Theologie des biblischen Kanons (QD 2II), Freiburg: Herder 2005.

Solomon, Norman: Torah from Heaven. The Reconstruction of Faith, Oxford: The Littman Library of Jewish Civilization, 2012.

Sommer, Benjamin D. (Hg.): Jewish Concepts of Scripture. A Comparative Introduction, New York: New York University Press 2012.

Spieckermann, Hermann: „Barmherzig und gnädig ist der Herr ...“, in: ZAW IO2 (1990) I-I8; Nachdruck in: Ders.: Gottes Liebe zu Israel. Studien zur Theologie des Alten Testaments (FAT 33), Tübingen: Mohr Siebeck 200I, 3-19. 
Stahl, Neta (Hg.): Jesus Among the Jews. Representation and thought, London: Routledge 2012.

- Other and Brother. Jesus in the 2oth-Century Jewish Literary Landscape, Oxford: University Press 20I3.

Standhartinger, Angela: Der Papst und der Rabbi. Anmerkungen zum christlich-jüdischen Dialog im Jesusbuch von Benedikt XVI., in: Söding, Thomas (Hg.): Das Jesus-Buch des Papstes. Die Antwort der Neutestamentler, Freiburg: Herder 2007, I47-I56.

Steck, Odil Hannes: Gott in der Zeit entdecken. Die Prophetenbücher des Alten Testaments als Vorbild für Theologie und Kirche (BThSt 42), Neukirchen-Vluyn: Neukirchener 200I.

Steins, Georg: Gegen die Bibel beten? Kritische Auseinandersetzung mit dem Wortlaut und Inhalt liturgischen Betens anhand eines Beispiels, in: Gottesdienst 30 (I996) I53-I55.

Stemberger, Günter: Das rabbinische Judentum als bleibende Basis jüdischer Kultur, in: Lenzen, Verena (Hg.): Das Studium des Judentums und die jüdisch-christliche Begegnung, Göttingen: V\&R unipress 2013, 79-90.

- Die Mischna-Übersetzung von Johann Jacob Rabe, in: Ders.: Judaica Minora II, 676-689.

- Hieronymus und die Juden seiner Zeit, in: Ders.: Judaica Minora II. Geschichte und Literatur des rabbinischen Judentums (TSAJ I38), Tübingen: Mohr Siebeck 20IO, 66-8I.

- Pesachhaggada und Abendmahlsberichte des Neuen Testaments, in: Kairos 29 (1987) I47-I58; wiederabgedruckt in: Ders.: Studien zum rabbinischen Judentum, Stuttgart: Kath. Bibelwerk 1990, 357-374.

- Reaktionen auf die Tempelzerstörung in der rabbinischen Literatur, in: Hahn, Johannes (Hg.): Zerstörungen des Jerusalemer Tempels. Geschehen - Wahrnehmung - Bewältigung (WUNT I47), Tübingen: Mohr Siebeck 2002, 207-236.

Stendahl, Krister: The Apostle Paul and the Introspective Conscience of the West, in: Harvard Theological Review 56 (1963) I99-215; in deutscher Übersetzung in: KuI II (1996) I9-33.

Stern, David: The "Alphabet of Ben Sira" and the Early History of Parody in Jewish Literature, in: Najman, Hindy / Newman, Judith H. (Hg.): The Idea of Biblical Interpretation. Essays in Honor of James L. Kugel (JSJ.S 83), Leiden: Brill 2004, 423-448. Stingeder, Franz: Homiletischer Führer durch das Alte Testament. Mit einem Verzeichnis der wichtigsten exegetisch-homiletischen Literatur, der dogmatischen Stellen im A.T., einem Verwendungsregister nebst einem Anhang von Predigt-Dispositionen über alttestamentliche Texte, Linz an der Donau: Preßverein I93I. 
Stobbe, Heinz-Günther: Dialog mit dem Judentum als Paradigma ökumenischer Theologie. Eine Skizze, unveröffentlichtes Manuskript 1986.

- Lernprozeß einer Kirche. Notwendige Erinnerung an die fast vergessene Vorgeschichte des Ökumenismus-Dekrets, in: Lengsfeld, Peter (Hg.): Ökumenische Theologie. Ein Arbeitsbuch, Stuttgart: Kohlhammer 1980, 7I-I23.

Stöhr, Martin: Dreinreden. Essays, Vorträge, Thesen, Meditationen, hg. v. Klaus Müller und Alfred Wittstock, Wuppertal: Foedus 1997.

Stökl, Daniel Ben Esra: The Impact of Yom Kippur on Early Christianity. The Day of Atonement from Second Temple Judaism to the Fifth Century, Tübingen: Mohr Siebeck 2003.

(Strack, Hermann Leberecht /) Billerbeck, Paul: Kommentar zum Neuen Testament aus Talmud und Midrasch, 6 Bände, München: C. H. Beck I922-I96I.

Strack, Hermann Leberecht: Einleitung in den Thalmud, in: Herzog, Johann Jakob / Hauck, Albert / Plitt, Gustav Leopold (Hg.): Real-Encyklopädie für protestantische Theologie und Kirche 18, Leipzig: Hinrichs ${ }^{2}$ I888, 297-368.

Summorum Pontificum. Über den Gebrauch der Römischen Liturgie in der Gestalt vor der Reform von 1970, gegeben zu Rom bei Sankt Peter am 7. Juli im Jahr des Herrn 2007, dem dritten Jahr Unseres Pontifikats, Benedictus PP. XVI.

Sundermeier, Theo: Art. „Religion, Religionen“, in: Müller, Karl / Sundermeier, Theo (Hg.): Lexikon missionstheologischer Grundbegriffe, Berlin: Reimer 1987, 4II-422.

- Art. „Theologie der Mission“, in: Müller, Karl / Sundermeier, Theo (Hg.): Lexikon missionstheologischer Grundbegriffe, Berlin: Reimer 1987, 470-495.

- Konvivenz als Grundstruktur ökumenischer Existenz heute, in: Huber, Wolfgang / Ritschl, Dietrich / Sundermeier, Theo: Ökumenische Existenz heute, München: Kaiser I986, 49-IOO.

- Mission - Geschenk der Freiheit. Bausteine für eine Theologie der Mission, Frankfurt a. M.: Lembeck 2005.

- Was ist Religion? Religionswissenschaft im theologischen Kontext. Ein Studienbuch (Theologische Bücherei 96), Gütersloh: Kaiser 1999.

Taubes, Jacob: Die politische Theologie des Paulus. Vorträge, gehalten an der Forschungsstätte der evangelischen Studiengemeinschaft in Heidelberg, 23.-27. Februar 1987, München: Wilhelm Fink 1993.

Teppler, Yaakov Y.: Birkat haMinim. Jews and Christians in Conflict in the Ancient World (TSAJ 120), Tübingen: Mohr Siebeck 2007.

The Kabbalistic Library of Giovanni Pico della Mirandola. r: Busi, Giulio / Bondoni, Simonetta M. / Campanini, Saverio (Hg.): The Great Parchment. Flavius Mithridates' Latin Translation, the Hebrew Text, and an English Version (The Kabbalistic Library of Giovanni Pico della Mirandola I), Turin: Aragno 2004. 
Theissen, Gerd / Merz Annette: Der historische Jesus. Ein Lehrbuch, Göttingen: Vandenhoeck \& Ruprecht ${ }^{4}$ 20II.

Theobald, Michael: Das „hohepriesterliche“ Gebet Jesu (Joh I7). Ein Eckpfeiler in der sazerdotal-kultischen Wahrnehmung der Passion Jesu durch Joseph Ratzinger, in: Tück, Jan-Heiner (Hg.): Passion aus Liebe. Das Jesus-Buch des Papstes in der Diskussion, Ostfildern: Matthias Grünewald 20II, 77-IO9.

- Paschamahl und Eucharistiefeier. Zur heilsgeschichtlichen Relevanz der Abendmahlsszenerie bei Lukas (Lk 22,I4-38), in: „Für alle Zeiten zur Erinnerung“ (Jos 4,7). Beispiele zu einer biblischen Gedächtniskultur, FS Franz Mußner zum 90. Geburtstag (SBS 209), Stuttgart: Kath. Bibelwerk 2006, I33-I80.

- Zur Paulus-Rezeption in der Karfreitagsfürbitte für die Juden von 2008, in: Frankemölle, Hubert / Wohlmuth, Josef (Hg.): Das Heil der Anderen - Problemfeld ,Judenmission' (QD 238), Freiburg: Herder 20I0, 507-54I.

Thoma, Clemens: Art. Dialog, in: Petuchowski, Jakob. J. / Thoma, Clemens: Lexikon der jüdisch-christlichen Begegnung, Freiburg: Herder 1989, 69-76.

- Rez. „Michael Haarmann: ,Dies tut zu meinem Gedenken!' Passamahl und Abendmahl. Ein Beitrag zur Theologie des Abendmahls im Rahmen des christlich-jüdischen Dialogs“, Neukirchen-Vluyn: Neukirchener 2004“, in: FrRu NF I (2006) $56-58$.

Tov, Emanuel: Samkûtan šäl ha-megillôt ha-miqra'ijôt ha-q'dûmôt. The Authority of Early Hebrew Scripture Scrolls, in: Meghillot Io (2013) 57-7I.

Troeltsch, Ernst: Das Ethos der hebräischen Propheten, in: Logos. Internationale Zeitschrift für Philosophie der Kultur 6 (I916/I7) I-28.

Tück, Jan-Heiner (Hg.): Erinnerung an die Zukunft: Das Zweite Vatikanische Konzil, Freiburg: Herder 2012.

- Gabe der Gegenwart. Theologie und Dichtung der Eucharistie bei Thomas von Aquin. Überarbeitete Neuauflage, Freiburg: Herder 2014.

Tworuschka, Udo: Gottes ist der Orient - Gottes ist der Okzident, FS für Abdoldjavad Falaturi zum 65. Geburtstag (Kölner Veröffentlichungen zur Religionsgeschichte 2I), Köln: Böhlau ı99ı.

Ulmer, Rivka: Psalm 22 in Pesiqta Rabbati: The Suffering of the Jewish Messiah and Jesus, in: Garber, Zev (Hg.): The Jewish Jesus. Revelation, Reflection, Reclamation, West Lafayette: Purdue University Press 20II, I06-I28.

- The Contours of the Messiah in "Pesiqta Rabbati", in: HThR Io6 (2013) II5-I44.

- The Culture of Apocalypticism. Is the Rabbinic Work "Pesiqta Rabbati” Intertextually Related to the New Testament Book "The Revelation to John"?, in: RRJ I4 (2OII) 37-70.

Ulrich, Eugene C.: Clearer Insight into the Development of the Bible - A Gift of the 
Scrolls, in: Roitman, Adolfo D. / Schiffman, Lawrence H. / Tzoref, Shani (Hg.): The Dead Sea Scrolls and Contemporary Culture: Proceedings of the International Conference Held at the Israel Museum, Jerusalem (July 6-8, 2008) (STJD 93) Leiden: Brill 20II, II9-I37.

Ulrich, Jörg: Euseb von Caesarea und die Juden. Studien zur Rolle der Juden in der Theologie des Eusebius von Caesarea (PTS 49), Berlin: de Gruyter 1999.

Urbach, Ephraim Elimelech: Rabbinic Exegesis and Origenes. Commentaries on the Song of Songs and Jewish-Christian Polemics, in: Studia Hierosolymitana 22 (1971) 247-275; Nachdruck in: Ders.: Collected Writings in Jewish Studies, hg. v. Raphael Brody und Moshe David Herr, Jerusalem: The Hebrew University Magnes Press 1999, 318-345.

Valerio, Karolina de: Altes Testament und Judentum im Frühwerk Rudolf Bultmanns (BZNW 7I), Berlin: de Gruyter 1994.

Visotzky, Burton L.: Anti-Christian Polemic in Leviticus Rabbah, in: PAAJR 56 (1990), 83-IOo.

Fathers of the World: Essays in Rabbinic and Patristic Literature (WUNT 8o), Tübingen: Mohr Siebeck 1995.

Jots and Tittles: On Scriptural Interpretation in Rabbinic and Patristic Literatures, in: Prooftexts 8 (1988), 257-269.

Vos, Cornelis Jacobus de: Heiliges Land und Nähe Gottes. Wandlungen alttestamentlicher Landvorstellungen in frühjüdischen und neutestamentlichen Schriften. The Holy Land and Nearness to God. How Old Testament Concepts of Land Changed in Early Jewish and New Testaments Writings (FRLANT 244), Göttingen: Vandenhoeck \& Ruprecht 2012.

Wacker, Bernd / Lauer, Rolf (Hg.): Der Kölner Dom und „die Juden“. Fachtagung der Karl Rahner Akademie Köln in Zusammenarbeit mit der Dombauverwaltung Köln vom I8. bis zum 19. November 2006 (Kölner Domblatt 73), Köln: Verlag Kölner Dom 2008.

Wacker, Bernd / Wacker, Marie-Theres: ... verfolgt, verjagt, deportiert. Juden in Salzkotten 1933-1942. Eine Dokumentation aus Anlaß des 50. Jahrestages der „Reichskristallnacht“ vom 9./IO.II.I938, Salzkotten: Selbstverlag 1988.

- Abschied von Ratisbonne. Ein Exkurs zum katholischen Antijudaismus, in: Faber, Richard (Hg.): Katholizismus in Geschichte und Gegenwart, Würzburg: Königshausen \& Neumann 2005, 29-32.

- Ausgelöscht. Erinnerung an die jüdische Gemeinde Salzkotten, Salzkotten: Selbstverlag 2002.

Wacker, Marie-Theres: „... ein großes Blutbad“: Ester 8-9 und die Frage nach der Gewalt im Ester-Buch, in: Bibel heute 42 / I67 (2006) I4-I6. 
- „Jüdischer Feminismus ist eine Notwendigkeit!“ Zum Tode von Marianne Wallach-Faller, in: Schlangenbrut 57 (Mai 1997) 2.

- „Monotheismus“ als Kategorie der alttestamentlichen Wissenschaft. Erkenntnisse und Interessen, in: Manemann, Jürgen (Hg.): Monotheismus (JPTh 4), Münster: LIT 2002, 50-67.

- Das biblische Estherbuch zwischen Palästina und Israel. Zum Film „Esther“ von Amos Gitai (1985) und seiner Kontextualisierung, in: Zwick, Reinhold (Hg.): Religion und Gewalt im Bibelfilm (Film und Theologie 20), Marburg: Schüren 20I2, 39-59.

- Das Buch Ester, in: Zenger, Erich (Hg.): Stuttgarter Altes Testament. Einheitsübersetzung mit Kommentar und Lexikon, Stuttgart: Kath. Bibelanstalt 2004, 86I-882.

- Das Patriarchat in uns austreiben. Antijudaismus als Testfall, in: Schlangenbrut I8 (August 1987) 36-38.

- Der Fall Eva(s). Christlich-feministische Theologie und die Paradiesgeschichte, in: Schöning-Kalender, Claudia / Neusel, Aylâ / Jansen, Mechtild M. (Hg.): Feminismus-Islam-Nation. Frauenbewegungen im Maghreb, in Zentralasien und in der Türkei, Frankfurt: Campus 1997, 24I-247.

- Die „Bibel in gerechter Sprache“. Vorstellung und Würdigung eines Projektes, in: BiKi 62 / I (2007) 54-59.

- Die Göttin kehrt zurück. Kritische Sichtung neuerer Entwürfe, in: Dies. (Hg): Der Gott der Männer und die Frauen (Theologie zur Zeit 2), Düsseldorf: Patmos I987, II-37 (= dies.: Von Göttinnen, Göttern und dem einzigen Gott. Studien zum biblischen Monotheismus aus feministisch-theologischer Sicht [Theologische Frauenforschung in Europa I4], Münster: LIT 2004, I3-32).

- Die Wurzel trägt auch uns. Feministische Theologie angesichts des Antijudaismusvorwurfs, in: RU I8 / 3 (I988) II2-II7.

- Ester. Jüdin - Königin - Retterin (Kleine Frauen-Reihe), Stuttgart: Kath. Bibelwerk 2006.

- Feldherr und Löwensohn. Das Buch Josua - angeeignet durch David Ben-Gurion, in: Noort, Ed (Hg.): The Book of Joshua (BETL 250), Leuven: Peeters 2012, 609-647.

- Feminist Theology and Anti-Judaism: The Status of the Discussion and the Context of the Problem in the FRG, in: JFSR 7 / 2 [I99I] I09-II7).

- Feministische Theologie und Antijudaismus. Diskussionsstand und Problemlage in der BRD, in: KuI $5 / 2$ (1990) I68-I76 (= Theologie féministe et anti-judaisme. Mise à jour et évaluation de la situation en R.F.A., in: Recherches féministes [Quebec, Canada 3 / 2 [1990] 155-165).

- Feministische Theologie und das Judentum, in: Deutscher Koordinierungsrat der Gesellschaften für Christlich-Jüdische Zusammenarbeit (Hg.): 1949-2009: Soviel Aufbruch war nie. Themenheft 2009, Bad Nauheim 2009, 24-26. 
- Gottes erste Liebe. Christliche Wahrnehmungen des Judentums in Münster, in: Sattler, Dorothea (Hg.): Gedenken und gestalten. I200 Jahre Bistum Münster, Münster: Aschendorff 2005, 48-86.

- Innensichten und Außensichten des Judentums im septuagintagriechischen Estherbuch (EstLXX), in: Reiterer, Friedrich u. a. (Hg.): Gesellschaft und Religion in der spätbiblischen und deuterokanonischen Literatur (Deuterocanonical and Cognate Literature Studies 20), Berlin: de Gruyter 2014, 55-92.

- Kain und die Macht der Sünde. Eine feministisch-gendersensible Lektüre von Gen 4,I-I7, in: Weibel, Nadine (Hg.): Weiblicher Blick - Männerglaube / Religions d'hommes - regards de femmes. Beiträge zur Gender-Perspektive in den Religionen, Münster: Waxmann 2008, 45-54.

- Matriarchalische Bibelkritik - ein antijudaistisches Konzept?, in: Siegele-Wenschkewitz, Leonore (Hg.): Verdrängte Vergangenheit, die uns bedrängt. Feministische Theologie in der Verantwortung für die Geschichte (Kaiser Taschenbücher 29), München: Kaiser 1988, I8I-242.

- Miriam - Doppelschriftauslegung mit Marianne Wallach-Faller, in: Leicht, Irene / Rakel, Claudia / Rieger-Goertz, Stefanie (Hg.): Arbeitsbuch feministische Theologie. Inhalte, Methoden und Materialien für Hochschule, Erwachsenenbildung und Gemeinde, Gütersloh: Gütersloher Verlagshaus 2003, Seminareinheit 5.I: Mirjam und ihre Bedeutung für christliche und jüdische Frauen, II8-I2I.

- Mit Toratreue und Todesmut dem einen Gott anhangen. Zum Esther-Bild der Septuaginta, in: Crüsemann, Frank u. a. (Hg.): Dem Tod nicht glauben. Sozialgeschichte der Bibel. Festschrift für Luise Schottroff zum 70. Geburtstag, Gütersloh: Gütersloher Verlagshaus 2004, 312-332.

- Seresch, in: Duncker, Christina / Keita, Katrin (Hg.): Lieblingsfrauen der Bibel und der Welt. Ausgewählt für Luise Metzler zum 6o. Geburtstag, Norderstedt: Books on Demand 2009, I40-I5I.

- Tödliche Gewalt des Judenhasses - mit tödlicher Gewalt gegen Judenhass? Hermeneutische Überlegungen zu Est 9, in: Hossfeld, Frank-Lothar / Schwienhorst-Schönberger, Ludger (Hg.): Das Manna fällt auch heute noch. Beiträge zur Geschichte und Theologie des Alten, Ersten Testaments. Festschrift für Erich Zenger (HBS 44), Freiburg i. Br.: Herder 2004, 609-637.

- Was ist neu am Neuen Bund? (Jer 3I,3I-34), in: Junge Kirche 55 / 4 (I994) 224-226.

- Widerstand - Rache - verkehrte Welt, in: Butting, Klara / Minnaard, Gerard / Wacker, Marie-Theres (Hg.): Ester. Mit Beiträgen aus Judentum, Christentum, Islam, Literatur, Kunst, Wittingen: Erev Rav 2005, 35-44.

- I Schottroff, Luise (Hg.): Von der Wurzel getragen. Christlich-feministische Exegese in Auseinandersetzung mit Antijudaismus (BIS 17), Leiden: Brill 1996. 
- / Wainwright, Elaine (Hg.): Landkonflikte - Landutopien. Themenheft Concilium $43 / 2$ (2007).

Wahle, Stephan: Gottes-Gedenken. Untersuchungen zum anamnetischen Gehalt christlicher und jüdischer Liturgie (Innsbrucker theologische Studien 73), Innsbruck: Tyrolia 2006.

Wallach-Faller, Marianne: Miriam - Schwester unter Brüdern, in: Brodbeck, Doris / Domhardt, Yvonne (Hg.): Marianne Wallach Faller: Die Frau im Tallit. Judentum feministisch gelesen, Zürich: Chronos 2000, I77-I9I.

Wallas, Armin: Rabbi Jeschua ben Josseph. Jüdische Jesus-Interpretation im 20. Jahrhundert, in: Das jüdische Echo 46 (I997) 2I-38.

Walter, Nikolaus: Zum Problem einer „Biblischen Theologie“, in: Dohmen, Christoph / Söding, Thomas (Hg.): Eine Bibel - zwei Testamente. Positionen biblischer Theologie, Paderborn: Schöningh 1995, 307-317.

Weingart, Kristin: Stämmevolk - Staatsvolk - Gottesvolk? Studien zur Verwendung des Israel-Namens im Alten Testament (FAT II/68), Tübingen: Mohr Siebeck 2014.

Weinrich, Michael: Jüdisch-christlicher Dialog, in: Neues Handbuch theologischer Grundbegriffe. 3, München: Kösel I99I.

Wellhausen, Julius: Prolegomena zur Geschichte Israels, Berlin: de Gruyter (I878) ${ }^{6}$ I927. Weltsch, Robert: Die schleichende Krise der jüdischen Identität - Ein Nachwort, in: Mosse, Werner E. (Hg.): Juden im Wilhelminischen Deutschland I890-I9I4. Ein Sammelband (Schriftenreihe wissenschaftlicher Abhandlungen des Leo Baeck Instituts 33), Tübingen: Mohr Siebeck ${ }^{2}$ I998, 689-702.

Wengst, Klaus: „Freut euch, ihr Völker, mit Gottes Volk!“ Israel und die Völker als Thema des Paulus - ein Gang durch den Römerbrief, Stuttgart: Kohlhammer 2008.

- Das Johannesevangelium. I. Teilband: Kapitel I-Io (ThKNT 4,I), Stuttgart: Kohlhammer ${ }^{2}$ 2004; 2. Teilband: Kapitel II-2I (ThKNT 4,2), Stuttgart: Kohlhammer ${ }^{2} 2007$.

- Das Regierungsprogramm des Himmelreichs. Eine Auslegung der Bergpredigt in ihrem jüdischen Kontext, Stuttgart: Kohlhammer 20 o.

- Neues Testament und dreieiniger Gott. Trinitarisch von Gott reden im Angesicht Israels, in: Ders.: Christsein mit Tora und Evangelium. Beiträge zum Umbau christlicher Theologie im Angesicht Israels, Stuttgart: Kohlhammer 20I4, 77-96.

Wiese, Christian: Wissenschaft des Judentums und protestantische Theologie im wilhelminischen Deutschland. Ein Schrei ins Leere? (Schriftenreihe wissenschaftlicher Abhandlungen des Leo Baeck Instituts 6I), Tübingen: Mohr Siebeck 1999.

Wohlmuth, Josef (Hg.): Emmanuel Levinas - eine Herausforderung für die christliche Theologie, Paderborn: Schöningh 1999.

- Begegnung mit Emmanuel Lévinas, in: Haarmann, Michael (Hg.): Momente der Begegnung. Impulse für das christlich-jüdische Gespräch. Bertold Klappert zum 65 . Geburtstag, Neukirchen-Vluyn: Neukirchener 2004, 217-220. 
- Die Karfreitagsfürbitte für die Juden als Indikator des Grundverhältnisses von Juden und Christen, in: Homolka, Walter / Zenger, Erich (Hg.): „... damit sie Jesus Christus erkennen. Die neue Karfreitagsfürbitte für die Juden, Freiburg: Herder 2008, I9I-204.

- Die Sicht auf das Judentum im zweiten Band des Jesusbuches, in: Häring, Hermann (Hg.): Der Jesus des Papstes. Passion, Tod und Auferstehung im Disput, Münster: LIT 201 .

- Mysterium der Verwandlung. Eine Eschatologie aus katholischer Perspektive im Gespräch mit jüdischem Denken der Gegenwart, Paderborn: Schöningh 2005.

Worthen, Jeremy: Praying the Psalms and the Challenges of Christian-Jewish Relations: Dietrich Bonhoeffer and Thomas Merton, in: Studies in Jewish-Christian Relations 9 (2014) I-22.

Wyschogrod, Michael: Abraham's Promise. Judaism and Jewish-Christian Relations, hg. v. R. Kendall Soulen, Grand Rapids: Eerdmans 2004.

- Inkarnation aus jüdischer Sicht, in: EvTh 55 / I(I995) I3-28.

Yuval, Israel: Zwei Völker in deinem Leib. Gegenseitige Wahrnehmung von Juden und Christen in Spätantike und Mittelalter (Jüdische Religion, Geschichte und Kultur 4), Göttingen: Vandenhoeck \& Ruprecht 2007.

Zellentin, Holger Michael: Rabbinic Parodies of Jewish and Christian Literature (Texts and Studies in Ancient Judaism I39), Tübingen: Mohr Siebeck 20Ir.

Zenger, Erich: Das Buch Esther, in: Ders. u. a.: Einleitung in das Alte Testament, Stuttgart: Kohlhammer ${ }^{7}$ 2008, 302-3II.

- Das Erste Testament. Die jüdische Bibel und die Christen, Düsseldorf I99I.

- Das Nein heutiger Juden zu Jesus als ihrem Retter ernst nehmen, in: Homolka, Walter / Zenger, Erich (Hg.): „... damit sie Jesus Christus erkennen“. Die neue Karfreitagsfürbitte für die Juden, Freiburg: Herder 2008, 205-22I.

- Die Bibel Israels. Grundlage des christlich-jüdischen Dialogs, in: KuI 24 (2009) 2538.

- Eigenart und Bedeutung der Prophetie Israels, in: Ders. u. a.: Einleitung in das Alte Testament (Kohlhammer Studienbücher Theologie I,I), 8. Aufl. hg. v. Christian Frevel, Stuttgart: Kohlhammer ${ }^{8} 2012$, 509-520.

- Einleitung in das Alte Testament, Stuttgart: Kohlhammer ${ }^{3}$ I995.

- Heilige Schrift der Juden und der Christen, in: Ders. u. a.: Einleitung in das Alte Testament, Stuttgart: Kohlhammer ${ }^{5} 2004$.

- Heilige Schrift der Juden und der Christen, in: Ders. u. a.: Einleitung in das Alte Testament (Kohlhammer Studienbücher Theologie I,I), 8. Aufl. hg. v. Christian Frevel, Stuttgart: Kohlhammer ${ }^{8}$ 20I2, II-36.

Zimmerli, Walther: Grundriß der alttestamentlichen Theologie (Theologische Wissenschaft 3), Stuttgart: Kohlhammer 1972, ${ }^{6}$ I989. 


\section{Internetdokumente}

Ansprache von Johannes Paul II., I3. April 1986, in: http:/www.vatican.va/holy_father/ john_paul_ii/speeches/1986/april/documents/hf_jp-ii_spe_I98604I3_sinagoga-roma_ge.html [abgerufen am 9.5.20I4].

Apostolisches Schreiben „Evangelii gaudium“ des Heiligen Vaters Papst Franziskus, in: http://w2.vatican.va/content/francesco/de/apost_exhortations/documents/papa-francesco_esortazione-ap_20I3II24_evangelii-gaudium.html\#Die_Beziehungen_ zum_Judentum [abgerufen am 9.5.20I4].

Brief an die Bischofskonferenzen zum „Namen Gottes“, Kongregation für den Gottesdienst und die Sakramentenordnung vom 29. Juni 2008, in: http://www. nostra-aetate.uni-bonn.de/kirchliche-dokumente/online-publikation-die-kirchen-und-das-judentum/i.-katholische-verlautbarungen-I/dokumente/ brief-an-die-bischofskonferenzen-zum-2orenamen-gottes2orc [abgerufen am 23.6.20I4].

Deutscher Koordinierungsrat der Gesellschaften für Christlich-Jüdische Zusammenarbeit (DKR), in: http://www.deutscher-koordinierungsrat.de/ [abgerufen am 3.6.20I4].

Die Osterzeit. Hochfest der Auferstehung des Herrn - Ostersonntag, in: http://www. gotteslob.de/fileadmin/Redaktion/PDF/MueKao_33_ONa.pdf [abgerufen am 23.6.20I4].

Die Stunde der Wahrheit: Ein Wort des Glaubens, der Hoffnung und der Liebe aus der Mitte des Leidens der Palästinenser und Palästinenserinnen, in: http://www.jai-pal. org/images/campaigns/international/German.pdf [zuletzt abgerufen am 30.9.2014].

Dokumentation Jüdischer Friedhof Münster, in: http://www.juedischer-friedhof-muenster.de/ [abgerufen am 6.5.20I4].

Frankemölle, Hubert: Schwerpunkte und Schwachpunkte im jüdisch-christlichen Dialog, in: Compass-Infodienst für christlich-jüdische und deutsch-israelische Tagesthemen im Web. Online-Extra Nr. 29, April 2006, in: http://www.compass-infodienst. de/Hubert_Frankemölle_Schwerpunkte_und_Schwachpunkte_im_juedisch-christlichen_Dia.967.o.html [abgerufen am 3.6.2014].

Freiburger Rundbrief. Zeitschrift für christlich-jüdische Begegnung, in: http://www.freiburger-rundbrief.de/de/ [abgerufen am 8.5.20I4].

Heinz, Hanspeter / Trutwin, Werner (Hg.): Aktuelle Probleme am Anfang des Lebens. Juden und Christen im Dialog mit Ethik, Recht und Medizin, Bonn, in: http:// www.zdk.de/organisation/gremien/gespraechskreise/gespraechskreis-juden-undchristen-beim-zdk/tagungen, abgerufen am 8.5.20I4].

Henrix, Hans Hermann / Boschki, Reinhold (Hg.): Die Kirchen und das Judentum. 
Dokumente von 2000 bis heute (Band 3. Digitale Version), in: http://www.nostra-aetate.uni-bonn.de/kirchliche-dokumente/online-publikation-die-kirchen-und-das-judentum/online-publikation-die-kirchen-und-das-judentum [abgerufen am 3.6.20I4]. Judenzählung, in: http://de.wikipedia.org/wiki/Judenz\%C3\%A4hlung [zuletzt abgerufen am I8.9.20I4].

Kirche und Israel - Neukirchener Theologische Zeitschrift, in: http://www.kirche-und-israel.de/ [abgerufen am 8.5.20I4].

Klappert, Bertold: „Geheiligt werde Dein NAME! Dein Wille werde getan!“ Gedenken, Ertrag und Auftrag des Rheinischen Synodalbeschlusses von I980, in: http://ekir.de/ ekir/dokumente/ekir2005-OI-o9ls-vortrag-klappert3.pdf [abgerufen am 8.5.20I4].

Klappert, Bertold: Barmen I und der Dialog mit dem Islam aus christlicher Sicht, in: Evangelische Kirche im Rheinland (Hg.): Jesus Christus, das eine Wort Gottes Barmen I und der Dialog mit dem Islam, Tagung vom 21./22. Januar 2005 unter der Schirmherrschaft des rheinischen Präses Manfred Kock, in: http://www.reformiert-info.de/3063-0-8-I.html [abgerufen am 2.I2.20I4].

Koch, Kurt Kardinal: Wie treu stehen wir zum Erbe Abrahams? Vortrag in Stuttgart vom 9. November 20II, in: http://www.erzdioezese-freiburg.de/lib/download.php?key=32088722a633\&file=/dynamic/datei/20II_II_o9_vortrag_kardinal_koch.pdf\&name=vortrag_kardinal_koch_9.II.2OII_[abgerufen am 7.5.20I4].

Koch, Kurt: Gemeinsam Volk Gottes sein. Perspektiven des jüdisch-katholischen Dialogs von Nostra aetate bis Papst Benedikt XVI. Vortrag an der Universität Luzern am 25. Oktober 20II, in: http://www.unilu.ch/files/Koch---Luzern-IJCF,-20II.pdf [abgerufen am 7.5.20I4].

Koch, Kurt: Theologische Fragen und Perspektiven im christlich-jüdischen Dialog. Vorlesung vom 30. Oktober 201 in South Orange, in: http://www.nostra-aetate. uni-bonn.de/kirchliche-dokumente/online-publikation-die-kirchen-und-das-judentum/i.-katholische-verlautbarungen-I/dokumente/theologische-fragen-und-perspektiven-im-christlich-juedischen-dialog [abgerufen am 7.5.20I4].

Meyer, Conrad Ferdinand: Huttens letzte Tage, in: http://gutenberg.spiegel.de/ buch/1873/2 [abgerufen am I.8.20I4]

Mohagheghi, Hamideh: Die Barmer Theologische Erklärung aus islamischer Sicht, in: Evangelische Kirche im Rheinland (Hg.): Jesus Christus, das eine Wort Gottes Barmen I und der Dialog mit dem Islam, Tagung vom 21./22. Januar 2005 unter der Schirmherrschaft des rheinischen Präses Manfred Kock, in: http://www.reformiert-info.de/I853-0-8-I.html [abgerufen am 2.I2.20I4].

Nostra Aetate - Dialog und Erinnerung, in: http://www.nostra-aetate.uni-bonn.de/ [abgerufen am 3.6.20I4]. 
On the ,Name of God', in: http://de.scribd.com/doc/471923I/On-the-Name-of-God [abgerufen am 23.6.20I4].

Österreichische Bischofskonferenz: Erklärung zum 75. Jahrestag der Reichspogromnacht vom 9. November 2013, in: http://www.jcrelations.net/75_Jahre_nach_dem_Novemberpogrom_1938.4455.0.html?L=2 [abgerufen am 8.5.20I4].

Pius XII., Enzyklika „Divinio afflante spiritu“, in: http://www.vatican.va/holy_father/ pius_xii/encyclicals/documents/hf_p-xii_enc_19430930_divino-afflante-spiritu_lt.ht$\mathrm{ml}$ [abgerufen am 28.7.2014].

Prof. Dr. Clemens Leonhard, in: http://www.uni-muenster.de/FB2/personen/liturgie/ leonhard.html [abgerufen am 23.6.20I4].

Quo vadis, Benedicte? Theologische Prinzipien des Papstes und ihre kirchlichen Folgen, in: Compass-Infodienst für christlich-jüdische und deutsch-israelische Tagesthemen im Web. Online-Extra Nr. 57 vom 28.9.2007, in: http://www.compass-infodienst. de/Hubert_Frankemölle__uo_vadis__Benedicte.3872.o.html [abgerufen am 3.6.2014].

Salzburger Arbeitskreis „Rabbinen und Kirchenväter“, in: http://www.uni-salzburg.at/ fileadmin/multimedia/Zentrum\%2ofuer\%20Juedische\%20Kulturgeschichte/documents/SalzburgerArbeitskreis2.pdf [abgerufen am 9.5.20I4].

Scholz, Susanne (Hg.): Feminist Commentary upon Feminist Commentary. A Report from the Feminist Biblical Trenches, in: Lectio difficilior I (20I4), in: http://www. lectio.unibe.ch/I4_I/pdf/scholz_susanne.pdf [abgerufen am I.8.20I4].

Summorum Pontificium über den Gebrauch der Römischen Liturgie in der Gestalt vor der Reform von 1970, Apostolisches Schreiben von Papst Benedikt XVI., in:http://www.vatican.va/holy_father/benedict_xvi/motu_proprio/documents/hf_benxvi_motu-proprio_20070707_summorum-pontificum_ge.html [abgerufen am 26.6.20I4].

The Journal of Ecumenical Studies, in: http://journal.jesdialogue.org/home/ [abgerufen am 8.5.20I4].

Veröffentlichungen der Gesellschaft für christlich-jüdische Zusammenarbeit Paderborn e. V., in: http://www.gcjz-paderborn.de/ueber-uns/veroffentlichungen/ [abgerufen am 3.6.20I4].

Wacker, Marie-Theres: The New Inclusive Bible Translation in the Context of (Post) Modern Germany, in: SBL Forum 6.4. (2008), http://www.sbl-site.org/publications/ article.aspx?ArticleId=764 [abgerufen am 6.5.2014]. 


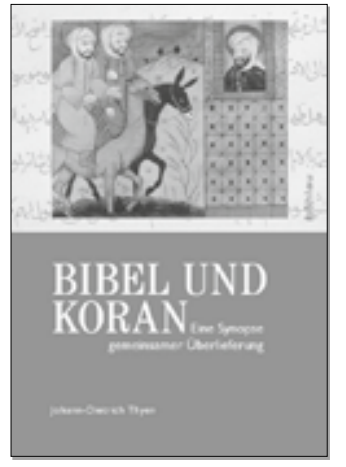

JOHANN-DIETRICH THYEN

\section{BIBEL UND KORAN}

EINE SYNOPSE GEMEINSAMER ÜBERLIEFERUNG

Bibel, Talmud und Koran sind die Schlüsseltexte der großen monotheistischen Weltreligionen. Dass sich in ihnen neben vielen Unterschieden zahlreiche Entsprechungen und Querverbindungen finden, belegt Johann-Dietrich Thyen (1934-1994) in diesem Buch. Seine synoptische Darstellung setzt parallele Textpassagen aus jüdisch-christlicher und koranischer Verkündigung nebeneinander. Dabei geht es ihm vor allem um die Entdeckung gleichklingender, einander entsprechender Aussagen sowie um die Verdeutlichung der unterschiedlichen Intention biblischer und koranischer Glaubenszeugnisse. Die Synopse bildet für jeden, der sich um ein tieferes Verstehen der Beziehungen zwischen Bibel und Koran bemüht, ein unersetzliches Arbeitsinstrument.

4. UNV. AUFLAGE 2015. XXXII, 397 S. 14 S/W-ABB. BR. $145 \times 210$ MM.

ISBN 978-3-412-50211-9

BÖHLAU VERLAG, URSULAPLATZ I, D-50668 KÖLN, T:+49 22I 9I3 90-O INFO@BOEHLAU-VERLAG.COM, WWW.BOEHLAU-VERLAG.COM | WIEN KÖLN WEIMAR 
Veränderte der „jüdisch-christliche“ Dialog die Theologie? Die in diesem Band versammelten Beiträge belegen eindeutig einen theologischen Paradigmenwechsel in den Jahrzehnten nach dem Zweiten Weltkrieg. Evangelische, katholische und jüdische Expertinnen und Experten aus unterschiedlichen theologischen Fachrichtungen wie der alt- und neutestamentlichen Bibelwissenschaft, der Liturgiewissenschaft, der feministischen und systematischen Theologie sowie der Judaistik zeichnen den Wandel von antijüdischer Polemik hin zu einem respektvollen Dialog mit dem Judentum facettenreich nach. Der vorliegende Band gibt zudem Einblick in die biografische Entwicklung der involvierten Forschenden und bietet damit ein Stück reflektierter Theologiegeschichte.

Edith Petschnigg ist wissenschaftliche Mitarbeiterin, Irmtraud Fischer Professorin am Institut für Alttestamentliche Bibelwissenschaft der Universität Graz. 